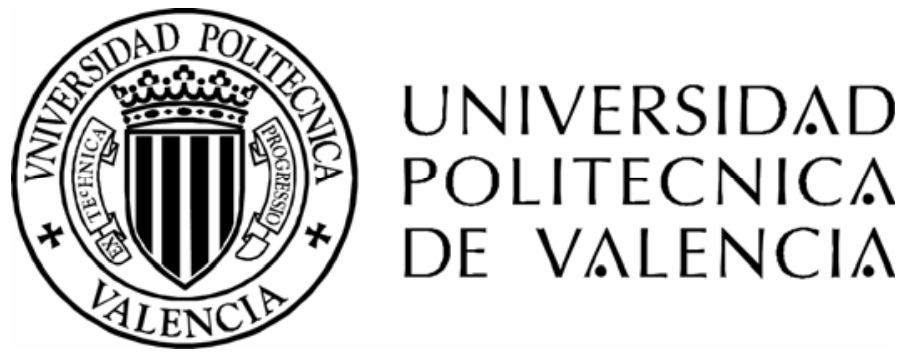

FACULTAD DE BELLAS ARTES DE SAN CARLOS

DEPARTAMENTO DE CONSERVACIÓN Y RESTAURACIÓN DE BIENES CULTURALES

\title{
INVESTIGACIÓN Y ANÁLISIS DE LAS MASILLAS DE RELLENO PARA LA REINTEGRACIÓN DE LAGUNAS CERÁMICAS ARQUEOLÓGICAS
}

Doctoranda:

MONTSERRAT LASTRAS PÉREZ

Directores:

Dra. $D^{a}$ Begoña Carrascosa Moliner Dr. D. Enrique Parra Crego

Valencia 2007 



\section{RESUMEN}

Una de las características más comunes en los objetos cerámicos arqueológicos recuperados son las lagunas o faltantes matéricos, debido a las condiciones en las que han estado expuestos o a la historia misma de los materiales. Es por ello que de entre las distintas fases que intervienen en la restauración de cerámica arqueológica, la reintegración formal tiene una doble función: aportar estabilidad a la pieza y proporcionarle una correcta legibilidad.

A lo largo de la historia y en la actualidad se han venido empleando variados materiales en la elaboración de masillas para la reposición de faltantes en cerámica arqueológica. En la actualidad la investigación de nuevos materiales ofrece al campo de la restauración innumerables productos, siendo los tradicionales poco a poco sustituidos. La elección de estos productos se basa en la mayoría de las ocasiones en su fácil trabajabilidad o en la comodidad que ofrece un material ya preparado, sin investigar qué efectos a largo plazo presentará este tipo de masillas o si afectará al material original.

La tesis se divide en tres partes muy diferenciadas a la vez que complementarias entre sí: un primer bloque donde se realiza una revisión histórica sobre los tratamientos de conservación de cerámica arqueológica. Un segundo bloque donde se ahonda en los criterios, procesos y materiales empleados a lo largo de la historia en los tratamientos de restauración, en concreto el tratamiento de lagunas. Y un tercer bloque experimental donde se expone la metodología de la investigación y los resultados obtenidos tras los diversos ensayos de envejecimientos a los que se han expuesto las distintas masillas experimentadas. 



\section{RESUM}

Una de les característiques més comunes en els objectes ceràmics arqueològics recuperats són les llacunes o mancances matèriques, a causa de les condicions en què han estat exposats $\mathrm{o}$ a la història mateixa dels materials. És per això que entre les distintes fases que intervenen en la restauració de ceràmica arqueològica, la reintegració formal té una doble funció: aportar estabilitat a la peça i proporcionarli una correcta llegibilitat.

Al llarg de la història i en l'actualitat s'han emprat variats materials en l'elaboració de massilles per a la reposició de mancances en ceràmica arqueològica. En l'actualitat la investigació de nous materials ofereix al camp de la restauració innumerables productes, sent els tradicionals a poc a poc substituïts. L'elecció d'aquests productes es basa en la majoria de les ocasions en la fàcil treballabilitat o en la comoditat que ofereix un material ja preparat, sense investigar quins efectes a llarg termini presentarà aquest tipus de massilles o si afectarà el material original.

La tesi es divideix en tres parts molt diferenciades alhora que complementàries entre si: un primer bloc on es realitza una revisió històrica sobre els tractaments de conservació de ceràmica arqueològica. Un segon bloc on s'aprofundeix en els criteris, processos i materials emprats al llarg de la història en els tractaments de restauració, en concret el tractament de llacunes. I un tercer bloc experimental on s'exposa la metodologia de la investigació i els resultats obtinguts després dels diversos assajos d'envelliments a què s'han exposat les distintes massilles experimentades. 

One of the most common characteristics of recovered archaeological ceramic objects are gaps or missing parts, due to the conditions they have been exposed to, or to the history of materials. This is the reason why, of the different stages involved in the restoration process of archaeological ceramics, formal reintegration fulfils a double function: to provide both stability to the artefact and a correct legibility.

Throughout history, just as at present, various materials have been used in the production of clays for the reconstruction of missing parts in archaeological ceramics. Nowadays, research on new materials has brought countless products to the field of restoration, so traditional ones are progressively being replaced. The choice of these products is most of the times based on their easier workability, or on the comfort offered by an already prepared material.

The thesis is divided into three different parts which, at the same time, complement each other: An initial section where a historical review of the conservation treatments for archaeological ceramics is carried out. A second section, where there is an in-depth study of the criteria, processes and materials used in restoration works throughout history, particularly with regard to gap treatments. Finally, there is a third section in which the research methodology is explained, as well as the results obtained after the different ageing tests performed on the various fillers analysed. 

Varios de los resultados obtenidos en la presente Tesis Doctoral han sido alcanzados gracias a una beca de investigación en el Proyecto "Investigación y desarrollo de estucos aplicados a la restauración y creación de nuevos soportes para piezas de azulejería” dentro del Programa de incentivo a la Investigación de la Universidad Politécnica de Valencia. Siendo presentado en:

- CARRASCOSA, B., LASTRAS, M., "Restauro di ceramiche. Quale stucco scegliere?. Congresso Nazionale IGIIC "Lo Stato dell'Arte III”. Palermo, 2005. 

A mis padres, por regalarme todo su tiempo, y su apoyo constante. 



\section{Agradecimientos}

Quisiera expresar mi más sincero y afectuoso agradecimiento a todas aquellas personas que me han ayudado y alentado durante todos estos años de trabajo.

Gracias, especialmente, a mi directora, la Dra. Begoña Carrascosa Moliner, a la que nunca podré agradecer suficientemente toda la confianza que ha depositado en mi durante tantos años. Gracias a su formación, su apoyo incondicional, su ánimo en momentos bajos, sus sabios consejos y su amistad, esta Tesis se ha hecho realidad.

Gracias a mi director, el Dr. Enrique Parra Crego por su paciencia y asesoramiento desinteresado.

Gracias al Departamento de Conservación y Restauración de Bienes Culturales, al Instituto de Restauración del Patrimonio de la Universidad Politécnica de Valencia y a la Universidad Alfonso X el Sabio de Madrid.

Gracias a la Dra. $\mathrm{M}^{\mathrm{a}}$ Teresa Doménech, a la Dra. Ma Luisa Martínez Bazán, y a la Dra. Dolores Yusá Marco, por su apoyo, comprensión y ayuda técnica en parte de los procesos realizados, y a la Dra. Pilar Roig Picazo, por su aliento y confianza en mi.

Gracias a mis compañeros del Departamento por su apoyo, en especial a José Madrid, Diego Seara, Vicente Guerola y Laura Fuster por ofrecerme su ayuda desinteresadamente.

Gracias al personal técnico y administrativo del Departamento, Juana, Ester, Maite, Álex y Santiago.

Por último agradecer de todo corazón a mis padres toda la confianza que han depositado en mi, a mis hijas Paula y Lucia que en breve espero recompensar, a mis hermanos Marta y Patrice por su apoyo incondicional, a Concha y Fernando por sus ánimos y especialmente a mi marido Remi, sin el cual esta Tesis Doctoral nunca se habría llevado a cabo, gracias por su ayuda, ánimo y comprensión de estos últimos años. 

La vida no es una cuestión de velocidad, es una carrera de fondo.

Requiere fortaleza y coraje. Saber aguantar.

Amar y valorar cada paso que das, no lo que te falta.

Pepe Struch. 



\section{LA CONSERVACIÓN EN LA CERÁMICA ARQUEOLÓGICA}

I.1. RESTAURACIÓN ARQUEOLÓGICA A LO LARGO DE LA HISTORIA 31

I.2. EVOLUCIÓN DE LA CONSERVACIÓN CERÁMICA ARQUEOLÓGICA .

I.3. LA CONSERVACIÓN EN CERÁMICA ARQUEOLÓGICA DESDE LA ANTIGÜEDAD HASTA NUESTROS DÍAS . . . . . . . . . . . . . 49

I.3.1.INTRODUCCIÓN . . . . . . . . . . . . . . . . . . 51

I.3.2. ACTUACIONES IN-SITU . . . . . . . . . . . . . . . 56

I.3.3. ESTUDIOS PREVIOS . . . . . . . . . . . . . . . . 59

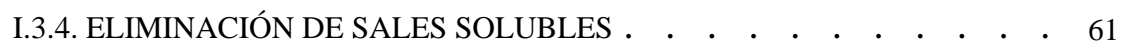

I.3.5. LIMPIEZA . . . . . . . . . . . . . . . . . . . 64

I.3.6.CONSOLIDACIÓN . . . . . . . . . . . . . . . . . 67

I.3.7. MONTAJE . . . . . . . . . . . . . . . . . . . 69

I.3.8. DOCUMENTACIÓN Y REGISTRO DE LAS INTERVENCIONES • 78

II. REINTEGRACIÓN FORMAL EN LA CERÁMICA ARQUEOLÓGICA

II.1. INTRODUCCIÓN . . . . . . . . . . . . . . . . . . . 83

II.2. REINTEGRACIÓN FORMAL ¿ÉTICA O ESTÉTICA? . . . . . . . 85

II.3. MASILLAS Y MATERIALES DE RELLENO . . . . . . . . . . 97

II.3.1. INTRODUCCIÓN. • . • . . . . . . . . . . . . . 99 
II.3.2. MASILLAS Y MATERIALES EN DESUSO UTILIZADOS A LO LARGO DE LA HISTORIA. . . . . . . . . . . . . . . . . 101

II.3.3. MASILLAS UTILIZADAS EN LA ACTUALIDAD. . . . . . . . 109 I.4. TIPOLOGÍA DE LAS LAGUNAS. . . . . . . . . . . . . . 121 II.4.1. INTRODUCCIÓN. . . . . . . . . . . . . . . . . 123

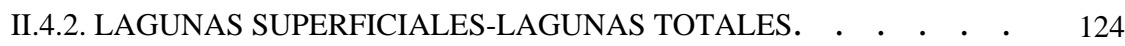

II.5. APLICACIÓN DE LAS MASILLAS DE RELLENO. . . . . . . . . . 129

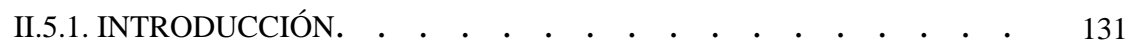
II.5.2. TRATAMIENTOS PREVIOS. . . . . . . . . . . . . . 132

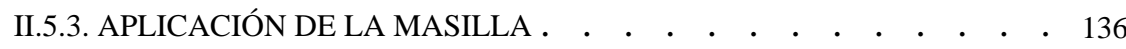
I.5.3.1. Moldes y soportes sustentantes. . . . . . . . . . . 136

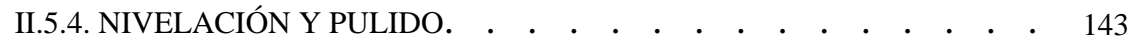
II.5.5. REINTEGRACIONES DESMONTABLES. • . . . . . . . . 146

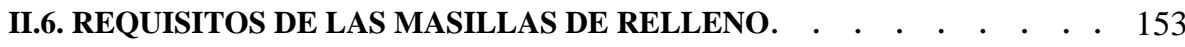

\section{ESTUDIO EXPERIMENTAL}

III.1. OBJETIVOS. . . . . . . . . . . . . . . . . . . . . 159

III.2. FUNDAMENTO TEÓRICO DE LAS TÉCNICAS DE ANÁLISIS E INSTRUMENTACIÓN. . . . . . . . . . . . . . . . . . . 163

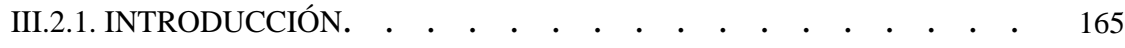
III.2.2. MÉTODOS DE ANÁLISIS. . . . . . . . . . . . . . 167 III.2.2.1. Colorimetría. . . . . . . . . . . . . . . . 167 


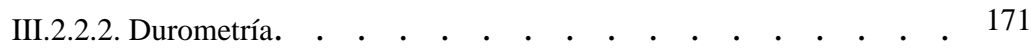

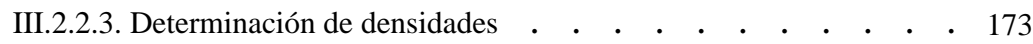

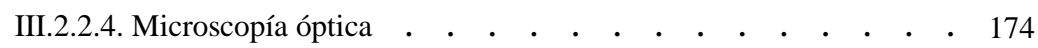

III.2.2.5. Espectroscopia Infrarroja por Transformada de Fourier (FT-IR) 176

III.2.3. ENSAYOS DE ENVEJECIMIENTO. • • • • • • • • • • 178

III.2.3.1. Envejecimiento acelerado de humidificación y secado • • • • 178

III.2.3.2. Envejecimiento acelerado por irradiación con luz ultravioleta 180

III.2.3.3. Envejecimiento acelerado en atmósfera saturada con $\mathrm{SO}_{2} \quad \cdot \quad \cdot \quad 181$

III.3. MASILLAS. MATERIAS PRIMAS Y PREPARACIÓN 183

III.3.1. MATERIALES EMPLEADOS EN LA ELABORACIÓN DE LAS

MASILLAS • • • • • • • • • • • • • • • • • • • 185

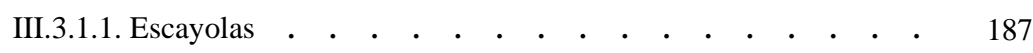

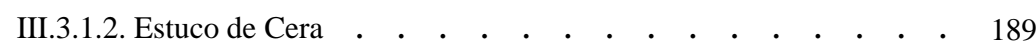

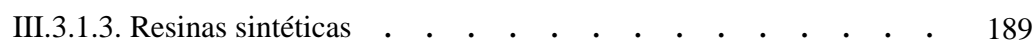

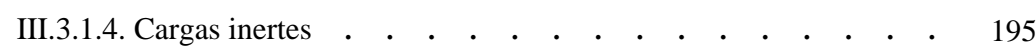

III.3.1.5. Masillas comerciales • • • • • . • • • • • • . 198

III.3.2. PREPARACIÓN DE MASILLAS. ESTUDIOS PREVIOS • • • • • 206

III.3.2.1. Elaboración del molde para el estudio previo de las masillas 206

III.3.2.2. Elaboración de masillas

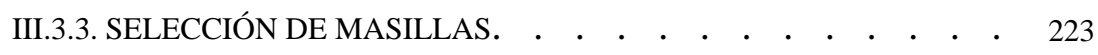

III.3.3.1.Introducción • • • • • • • • • • • • • • • • . 223 
III.3.3.2. Elaboración del molde para las probetas . • . • . • . 225

III.3.3.3. Elaboración de las probetas . • . • • • • • • • . 226

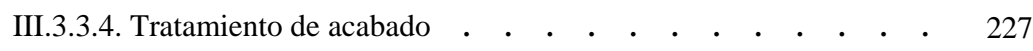

III.3.4. SELECCIÓN DE CERÁMICA. • • • • • • • • • • • • • • 228

III.3.4.1. Introducción • • • • • • • • • • • • • • • • 228

III.3.4.2. Cerámica seleccionada • • • • • • • • • . • 228

III.3.4.3. Preparación de las muestras cerámicas • • • • • • • 231

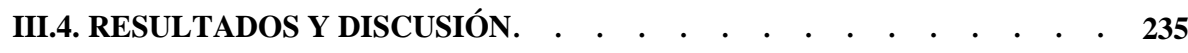

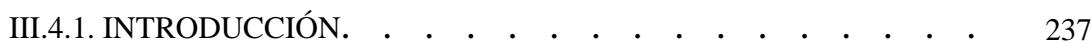

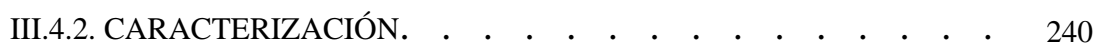

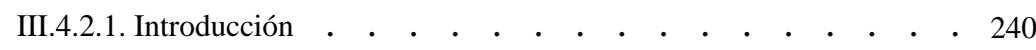

III.4.2.2. Determinación de la velocidad de evaporación • • • • 243

III.4.2.3. Durometría • • • • • • • • • • • • • • • • 249

III.4.3. ESTABILIDAD FRENTE A AGENTES DEGRADANTES FÍSICO-

QUÍMICOS. • • • • • • • • • • • • • • • • • • • 254

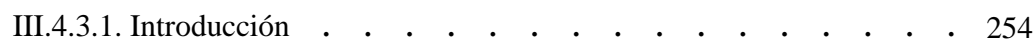

III.4.3.2. Ensayo de envejecimiento acelerado de humidificación y secado 257

III.4.3.3. Ensayo de envejecimiento acelerado por irradiación con luz

ultravioleta . . . . . . . . . . . . • . . . . 268

III.4.3.3. Ensayo de envejecimiento acelerado en atmósfera saturada con

$\mathrm{SO}_{2}$. . . . . . . . . . . . . . . . . . . . . 278

III.4.5. CONCLUSIONES. • • . . . . . . . . . . . . . . . 291 
BIBLIOGRAFÍA. . . . . . . . . . . . 303

ANEXO I.

ANEXO II. 



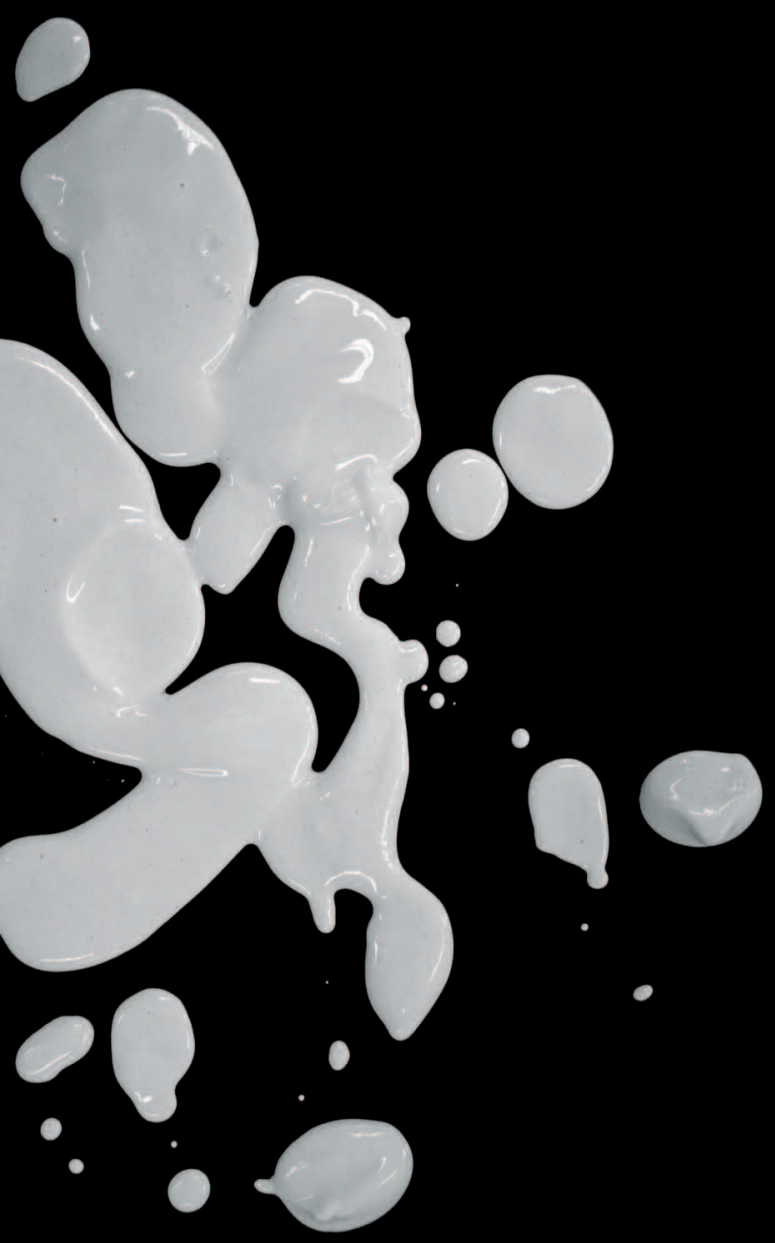

INTRODUCCIÓN 

La elección del tema vino suscitada por mi Directora de Tesis, siempre preocupada en el modo de intervenir los objetos cerámicos arqueológicos y más concretamente en los materiales que tan a menudo se incorporan a éstos bienes culturales. Quizá los productos que más se han empleado indiscriminadamente a lo largo de la historia han sido y son las masillas de relleno, también llamadas estucos, destinadas principalmente al relleno de lagunas o faltantes matéricos.

Los estucos utilizados en la restauración cerámica, así como su técnica de aplicación, han sido múltiples, tanto en el pasado como en la actualidad. Gracias a las publicaciones especializadas basadas en este tipo de materiales, así como nuestra propia experiencia en este campo tan específico, hemos catalogado las diferentes masillas empleadas a lo largo de la historia, siendo uno de los resultados de esta tesis.

Hasta hace unas décadas, lo concerniente a la conservación y restauración de cerámica arqueológica, en especial en nuestro país, no ha sido tan ampliamente investigada si lo comparamos con otros ámbitos de restauración de bienes culturales. Los motivos pueden ser varios, como la no valoración de la cerámica como bien cultural sino 
más bien como bienes destinados a investigaciones arqueológicas, y la no especialización en el campo de la restauración entre muchos. Hoy en día con el resurgimiento de los Museos Arqueológicos y las nuevas leyes de protección de patrimonio arqueológico, la especialización en la restauración de estos bienes está en auge, pretendiendo con esta tesis aportar más datos en su investigación.

Somos conscientes de cómo responden los estucos tradicionales, no hay más que asomarse a cualquier vitrina de nuestros museos, pero ¿qué efectos tendrán los estucos que hoy en día se utilizan? ¿cómo responderán a cambios climáticos o a vitrinas poco acondicionadas? ¿Repercutirán de alguna manera en las piezas? ¿Son tan reversibles como nos aseguran los fabricantes? ¿Qué deterioros por si mismos experimentan con el paso del tiempo? Estas cuestiones son las que nos planteamos día a día, cada vez que nos enfrentamos a una restauración y más en concreto a la hora de abordar la Restitución formal o Reintegración volumétrica de piezas cerámicas de tipo arqueológico o etnográfico en el Taller de materiales arqueológicos y etnográficos del Instituto Universitario de Restauración del Patrimonio así como cuando realizamos nuestra labor docente en la especialidad de materiales arqueológicos en el Dpto. de Conservación y Restauración de Bienes Culturales de la Facultad de Bellas Artes de San Carlos, ambos pertenecientes a la Universidad Politécnica de Valencia.

Hoy en día los restauradores especializados en este campo, no tienen un criterio estético definido en las actuaciones, siendo el de la reintegración tanto volumétrica como cromática uno de los más 
conflictivos. Por ello es normal ver distintas actuaciones, desde la más purista en la que la reintegración de lagunas es inexistente, hasta la más extremista como es la reintegración ilusionista.

La reintegración cromática que a veces va de la mano con la reintegración volumétrica, es uno de los más controvertidos en nuestro campo, donde la verdad no la tiene un grupo de profesionales o taller específico, pero que debería ser tema de debate, con el fin de llegar a unas conclusiones y unos criterios comunes. Todos nos hemos preguntado o hemos sido testigos de espectadores que se preguntaban ante una pieza "restaurada” qué parte era original y cuál no.

De las distintas fases que intervienen en la restauración de cerámicas, todas importantes, la reintegración formal tiene una doble función, la de aportar estabilidad, dependiendo de las lagunas existentes en la pieza, y la de legibilidad. La gran mayoría de profesionales de bienes culturales, nos planteamos hasta que punto es necesaria esta intervención y sí ésta es vital para la pervivencia de los bienes culturales. En todos los casos la función estética es la predominante, mientras que la función de estabilidad se cumple en determinados objetos donde la morfología de las lagunas impide el montaje de la pieza.

Constatamos que la inmensa mayoría de material cerámico arqueológico recuperado se encuentra fragmentado y con faltantes de materia, dadas las condiciones en las que han estado expuestas. 
Por tanto con esta tesis se pretende profundizar en los criterios, productos y técnicas a utilizar en la reposición de faltantes en piezas cerámicas de tipo arqueológico, teniendo como fin catalogar los materiales más idóneos que permitan la recuperación de la obra de arte desde su concepción estética compatible con su historicidad y su reversibilidad.

La finalidad de la presente investigación es la elaboración de una guía de masillas de relleno destinadas a la reintegración de lagunas en cerámica arqueológica e histórica, describiendo las ventajas e inconvenientes de cada una de ellas, con el fin de esclarecer cuales son más afines a los distintos tipos de cerámicas que se encuentran en los Museos o en sus fondos; asegurando la preservación de las colecciones para generaciones futuras.

En la actualidad la investigación de nuevos materiales ofrece al campo de la restauración innumerables productos, siendo los tradicionales, en el caso de la cerámica, poco a poco sustituidos. La utilización de estos productos se basa en la mayoría de las ocasiones en su fácil trabajabilidad o fraguado, siendo el tiempo de ejecución de la restauración más corto, sin investigar qué efectos a largo plazo presentará este tipo de masillas o si afectará al material original. Conscientes de estos hechos, es necesario que cada producto sea investigado y que cada tipo de pieza sea intervenida no sólo con unos criterios sino con unos materiales acordes a su estructura, estado de conservación y condiciones de exposición. 

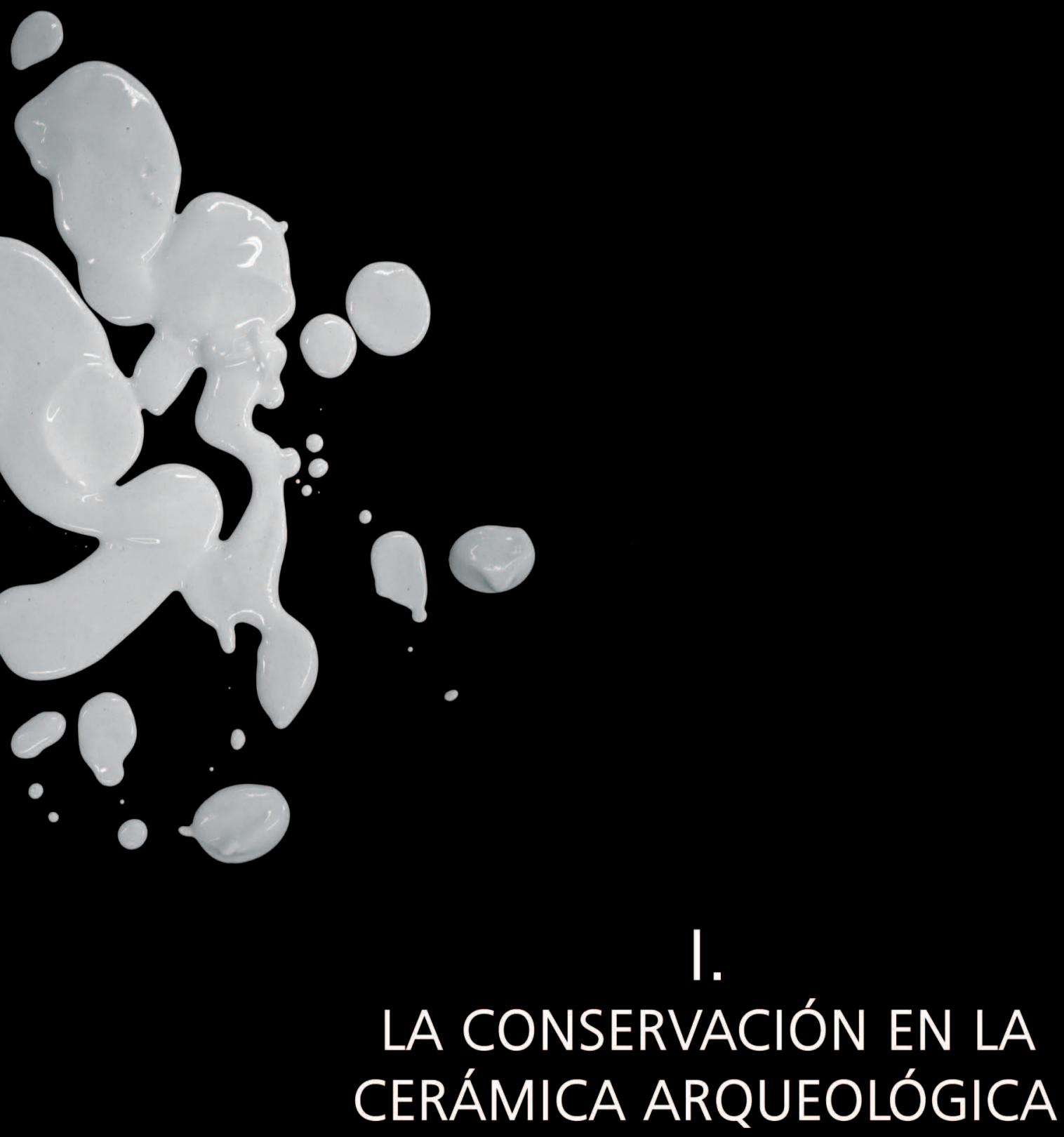



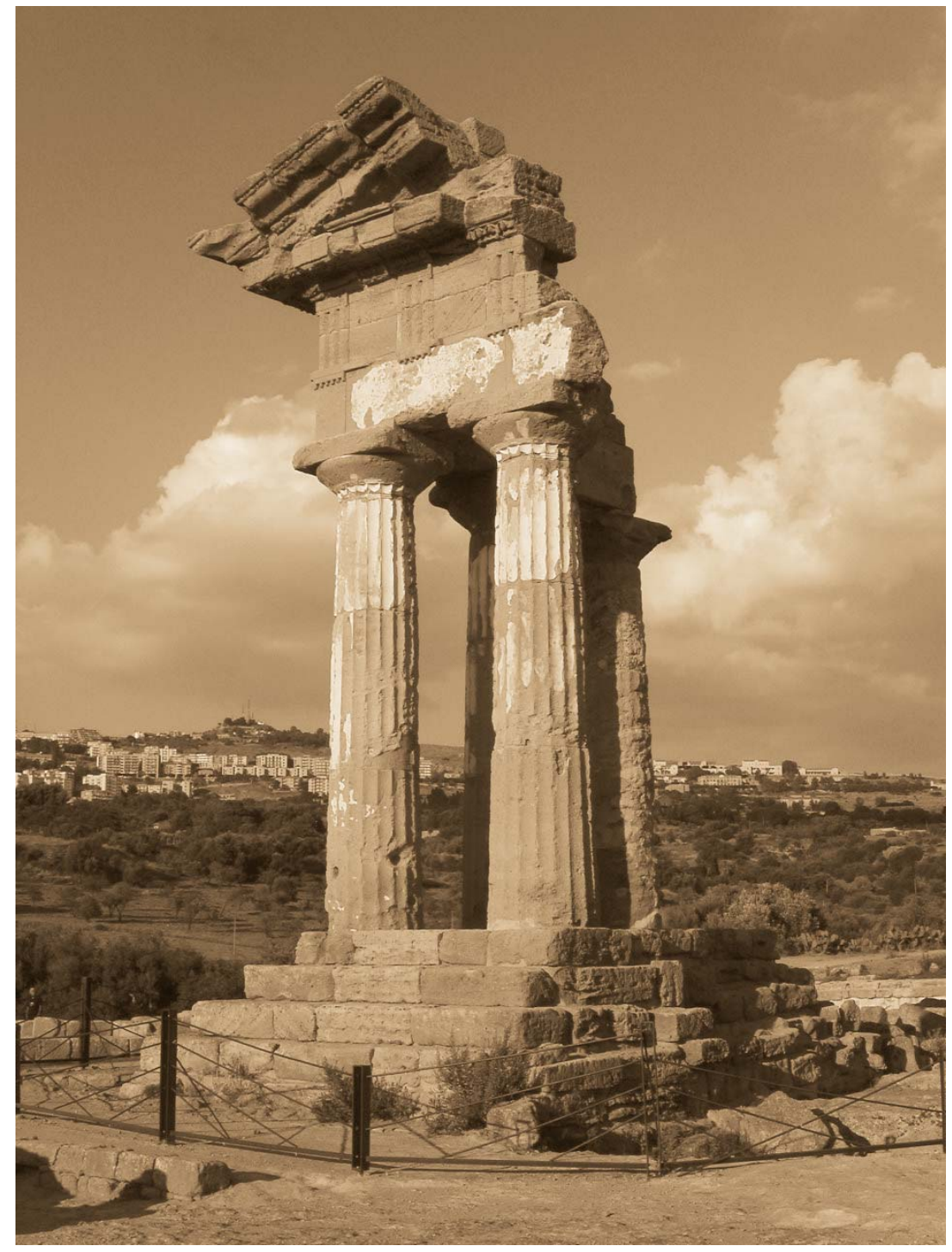

I.1. RESTAURACIÓN ARQUEOLÓGICA A LO LARGO DE LA HISTORIA 
Valle de los Templos. Agrigento, Palermo. 


\section{I.1. RESTAURACIÓN ARQUEOLÓGICA A LO LARGO DE LA HISTORIA}

El modo de entender y realizar una restauración, en nuestro caso la cerámica, ha variado a lo largo de la historia. Las sociedades en sus diferentes épocas han establecido diversas soluciones de restauración, estando directamente relacionadas con los significados atribuidos a los bienes, así como a sus ideas políticas, religiosas, estéticas y económicas del momento.

El interés por conservar objetos considerados valiosos se remonta a épocas antiguas, existiendo la evidencia de este hecho desde la prehistoria, a partir del hallazgo de objetos pertenecientes a épocas diferentes en el mismo estrato de un yacimiento ${ }^{1}$. Desde entonces, el concepto de restauración ha evolucionado adquiriendo diversos significados.

Durante la antigüedad clásica y la Edad Media, restaurar significaba volver a un estado anterior, no existiendo una diferenciación esencial

\footnotetext{
${ }^{1}$ Macarrón, A.M., Historia de la conservación y la restauración desde la antigüedad hasta finales del siglo XIX. Ed. Tecnos, Madrid, 1995, p.252.
} 
entre restaurar, reparar, reconstruir o readaptar. En este sentido, el concepto de restauración aún no estaba vinculado con la idea de autenticidad.

El periodo renacentista, se caracterizó por la convivencia de dos formas diferentes de entender la restauración. Por un lado el concepto todavía se encontraba impregnado de su antigua connotación de volver a un estado anterior, y por el otro, empezaba a incorporarse de manera incipiente algunas ideas sobre antigüedad y autenticidad, ligadas a la revalorización del arte clásico. Por su parte, Macarrón, a propósito del coleccionismo de antigüedades ${ }^{2}$, considera que en la restauración de esta etapa prevalece la instancia estética sobre la histórica, en donde las intervenciones oscilan entre una visión respetuosa, pero también fetichista del significado iconográfico e histórico de las obras. El campo de acción de la restauración en esta época se limitó a las obras de arte, en particular aquellas de la antigüedad clásica.

A finales del siglo XVII y durante el siglo XVIII, empezó a gestionarse una conciencia más crítica hacia la restauración en aras de desarrollar una práctica más científica. Se comienza a valorar la importancia del conocimiento estilístico, iconográfico e histórico de la obra y se aprovechan algunos avances científicos de la época, para experimentar con nuevos materiales y métodos de restauración. El interés hacia los vestigios del pasado ya no se limita a las obras de

${ }^{2}$ Macarrón, A.M., op. cit., 1995, p.47 
arte, sino a cualquier objeto que tenga o haya tenido que ver con el hombre en épocas pasadas, en donde los vestigios se conciben como material científico. Los criterios ilustrados de finales del siglo XVIII, darán origen a un nuevo sentimiento de patrimonio cultural colectivo que se traducirá en la creación de museos y academias de carácter público. Esta nueva percepción favorecerá el control estatal de los vestigios del pasado, así como el control y supervisión de las intervenciones de restauración ${ }^{3}$. Sin embargo, la asimilación y puesta en práctica de estas nuevas ideas no se dio de manera automática y generalizada.

Los descubrimientos de las ciudades de Herculano en 1711 y Pompeya en 1748 motivan el interés por la conservación de restos arqueológicos. Evidentemente la arqueología será el motor en el desarrollo de la ciencia de la restauración de objetos arqueológicos, debido a su interés por conocer la historia de nuestros antecesores. El siglo XVIII marca así el nacimiento de la restauración arqueológica como disciplina, paralelamente al surgimiento de la arqueología y de la historia del arte.

La restauración tiende a consolidarse en el transcurso del siglo XIX como una disciplina científica. Es aquí donde se establecen realmente las bases de la restauración contemporánea. Este siglo se caracterizará por su enorme interés en la historia; no obstante, la recuperación de este pasado aun se concebía de diferentes maneras. Las diferencias de

\footnotetext{
${ }^{3}$ Macarrón, A.M., op. cit., 1995, p.73-144
} 
criterios de restauración parten de los diversos intereses hacia la obra. Los coleccionistas y comerciantes se inclinaban hacia un criterio que pretendía enmascarar las alteraciones que con el tiempo ha adquirido la obra, ya que consideraban que ello la devaluaba. En contraposición, la postura de los museos partía de una concepción historicista de la pieza, en donde se valoraban sus datos auténticos y originales ${ }^{4}$. En este aspecto hemos de comentar que estos criterios no difieren en absoluto con la realidad actual.

En varios países europeos, se desarrolló un gran interés por proteger y restaurar los monumentos, en particular los edificios medievales. Éstas actuaciones buscaban completar y recrear un todo arquitectónico de acuerdo con las intenciones originales o con los periodos más significativos, utilizando para ello documentaciones históricas y analogías con otros edificios de la misma época como referencia. En contraposición a este tipo de restauraciones, se desarrolló un movimiento anti-restauración, alcanzando su mayor definición en John Ruskin. Este autor enfatizó la importancia del tiempo histórico y la autenticidad, en relación con el objeto original y la imposibilidad de reproducir un objeto con el mismo significado en otro contexto histórico-cultural sin caer en falsificaciones. Como consecuencia de este movimiento surgen las bases del concepto de la mínima intervención, la discernibilidad y la reversibilidad, como requisito de cualquier intervención.

\footnotetext{
${ }^{4}$ Macarrón, A.M., op. cit., 1995, p.148-164
} 
En el ámbito científico, surgen las primeras investigaciones sistemáticas que pretendían identificar los materiales constitutivos y las técnicas de manufactura de los distintos artefactos, así como los procesos de alteración. Uno de los mayores precursores fue sin duda Camillo Boito, quién intentó poner orden en las actuaciones sobre los monumentos antiguos, orientando hacia el equilibrio las teorías que llegaban desde Francia e Inglaterra, capitaneadas por Viollet.le-Duc y Ruskin, respectivamente.

Sus propuestas son consideradas como un anticipo de lo que después llegaría a ser la "Carta del Restauro”. Sin embargo la personalidad más destacada y quien puede considerarse como el verdadero creador de un documento de esta naturaleza fue Gustavo Giovannoni. Además de publicar en 1913 "La tutela delle Opere d'Arte in Italia", desarrolló una ingente labor docente y teórica para lograr definir un concepto de restauración más moderno y científico. Su contribución fue decisiva en la redacción de la "Carta de Atenas" de 1931, en la que se ofrecía una serie de normas técnicas y jurídicas que pretendían delimitar lo que se entendía por conservación, tanto en el sentido de salvaguardia como en el de la prevención, de lo que era una actuación restauradora. Si bien el documento se dedicaba al campo de la arquitectura, resultaba fácil extrapolar sus normas a cualquier otro bien del patrimonio cultural ${ }^{5}$.

\footnotetext{
${ }^{5}$ Morales, A., Patrimonio histórico-artístico. Historia 16, Madrid, 1996. p.34
} 
El siglo XX contemplará un desarrollo extraordinario y se caracterizará por la institucionalización, el apoyo científico y la profesionalización de la disciplina en muchas partes del mundo. Surgen los primeros intentos para unificar criterios y normar a la restauración a escala internacional.

Algunos de los grandes museos tales como el Royal Berlín Museum, el British Museum y el Metropolitan Museum de Nueva York generan departamentos que se dedican específicamente a la conservación de sus colecciones, contratando especialistas capacitados para ello. Todo ello permitió un seguimiento y control de las intervenciones más objetivo y científico.

A pesar de todo, se sucedían las intervenciones carentes de rigor sobre los bienes culturales. Poner fin a esta situación, concretamente en Italia, fue una de las razones por las que en 1938 se creó el "Istituto Centrale del Restauro", cuya labor formativa y normalizadora fue en buena medida responsabilidad del crítico e historiador del arte Cesare Brandi. Brandi desarrolló todo un sistema teórico, en el que resultaban actualizadas y desarrolladas muchas de las ideas de Giovannoni. La creación del "Istituto", la aparición durante el mismo año de las “Instrucciones para la Restauración de monumentos” y la”Carta del Restauro de Venecia”, de 1960, fueron elementos claves para que en 1972 surgiera la primera "Carta del Restauro”. En ella, el Ministerio de Educación Italiano intentó establecer unos criterios uniformes en la labor desarrollada por la administración en materia de conservación del patrimonio. Dicho documento, que en buena medida recoge el 
pensamiento del propio Brandi, supone un considerable avance en la metodología de la restauración. El texto se dirigía a los responsables de los centros de restauración y a los propios restauradores, teniendo la consideración de norma de obligado cumplimiento en todo el territorio italiano.

La "Carta del Restauro" se organiza con un texto de presentación y desarrollo de sus fines, más doce artículos sobre salvaguardia y restauración, completándose con cuatro anexos o documentos, que son parte consustancial de la propia "Carta”. Siendo el primer anexo, Anexo A, Instrucciones para la salvaguarda y restauración de objetos arqueológicos.

La "Carta del Restauro" ha servido de base para el desarrollo de la llamada "restauración crítica", superando al poco tiempo de su publicación los límites geográficos italianos, para convertirse en un documento reconocido internacionalmente y constituyendo el punto de partida de las reflexiones modernas.

En la actualidad numerosas son las instituciones de restauración que trabajan en todo el mundo en pro de la conservación del patrimonio cultural, así como en la formación de especialistas. La investigación se ha profundizado y diversificado adquiriendo un carácter interdisciplinario. Todo lo cual ha dado lugar a que hoy la restauración sea una disciplina profesional. 



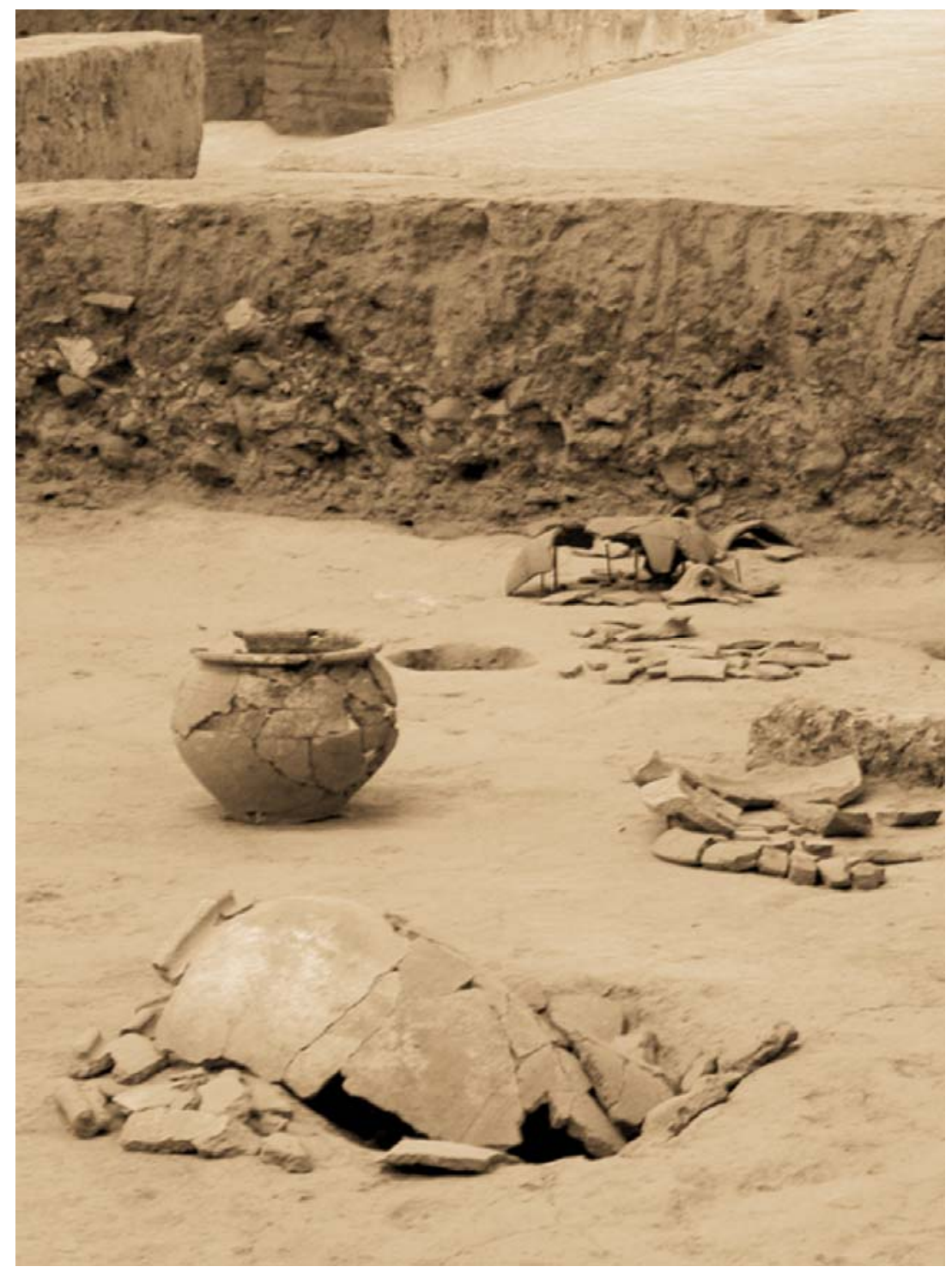

I.2.

\section{EVOLUCIÓN DE LA CONSERVACIÓN CERÁMICA ARQUEOLÓGICA}





\section{I.2. EVOLUCIÓN DE LA CONSERVACIÓN EN LA CERÁMICA ARQUEOLÓGICA}

La elaboración de objetos de cerámica es una de las manufacturas más antiguas. La cerámica, por su naturaleza, es un material altamente estable, constituyendo uno de los restos de la cultura material más abundantes en los yacimientos arqueológicos. A lo largo de la historia las distintas culturas han producido una amplia gama de objetos cerámicos, siendo éstos la prueba de la evolución y huella de las épocas que nos precedieron, formando los cimientos de nuestra cultura.

Siendo para la ciencia de la arqueología un instrumento clave en la datación de sus excavaciones.

Gracias a las labores de investigación y rescate de los equipos de arqueología, podemos ser testigos del desarrollo de nuestra historia. Pero la conservación y perdurabilidad de las piezas rescatadas por el arqueólogo, dependen sin lugar a dudas de la figura especializada del restaurador de objetos arqueológicos. El gran avance en la conservación y restauración de objetos arqueológicos que se está desarrollando en las últimas décadas, se debe a la aceptación del Restaurador como una parte más de la labor de equipo, junto a los arqueólogos, historiadores, químicos, físicos, biólogos, geólogos, arquitectos, etc. 
La idea de que la conservación de los objetos arqueológicos comienza en el laboratorio, tras los estudios de los arqueólogos, comienza poco a poco a ser desestimada, siendo aceptada nuestra labor a pie de yacimiento, justo en el momento inicial de la aparición y extracción. La metodología de los tratamientos ha de ser muy rigurosa y se debe contar siempre con el apoyo, la colaboración y el auxilio de otras disciplinas ${ }^{6}$. De esta participación conjunta nace el concepto actual de Conservación-Restauración de objetos arqueológicos que, acepta como premisa de todo tratamiento el respeto por el objeto, aunque carezca del valor estético que pudo poseer en su origen. Se considera la Conservación-Restauración como una labor multidisciplinar encaminada a un objetivo común, conservar los Bienes Culturales con el mínimo riesgo para su integridad, para lograr este objetivo la conservación y restauración de piezas arqueológicas se apoyará en los resultados del resto de ciencias experimentales relacionadas con esta materia.

Las primeras restauraciones datadas se sitúan en el Neolítico y responden, por lo general, a una necesidad de reparar el daño sufrido en las piezas, fundamentalmente roturas; el objetivo era recuperar de nuevo la funcionalidad de los mismos. Evidentemente también existían otros motivos, bien de tipo religioso o simplemente conservar ciertos objetos con un valor singular, al igual que sucede hoy en día.

\footnotetext{
${ }^{6}$ Carrascosa, B., Iniciación a la conservación y restauración de objetos cerámicos. Ed. Universidad Politécnica de Valencia, Valencia, 2006, p.10.
} 
Los orígenes, a nivel institucional, de la Conservación-Restauración de tipo arqueológico, se sitúan a finales del siglo XVIII, cuando los conocimientos químicos y físicos más recientes, se aplicaron al estudio de las técnicas y de los materiales. A principios del siglo XIX (1833), se abrió el primer laboratorio de un museo, en el entonces Staatliche Museen, de Berlín, hoy en día desaparecido. La tendencia en pro de la instalación de laboratorios en los museos se inició, en realidad, tras la primera guerra mundial, al abrirse un pequeño laboratorio en el British Museum de Londres. En principio, y como medida temporal, se trató de restaurar los deterioros sufridos por las colecciones del museo, que habían estado almacenadas en el sistema de subterráneos de la ciudad, para salvaguardarlas del peligro de las bombas alemanas. Este laboratorio, fue creciendo en tamaño e importancia y hoy en día ocupa un edificio completo. Otros museos y galerías siguieron pronto su ejemplo. El Louvre abrió su laboratorio en 1925; el museo de Bellas Artes de Boston, en 1927, y el Metropolitan Art Museum de Nueva York, en 1930. Desde entonces fueron apareciendo laboratorios independientes, dedicados a la conservación y restauración de obras de arte, pero no asociados necesariamente a un museo o galería concreta ${ }^{7}$.

En lo referente a España, el Museo Arqueológico Nacional fue creado por el R.D. de fundación de Museos Arqueológicos de 18 de Marzo de 1867, en tiempos de la reina Isabel II. Su primera ubicación,

\footnotetext{
7 Aura, E., Desarrollo de procedimientos metodológicos para la caracterización, restauración y conservación de piezas cerámicas medievales (siglos XIII-XV) de Paterna y Manises. Tesis doctoral. Universidad Politécnica de Valencia, 1996, p.16.
} 
provisional, se encontraba en el palacio denominado Casino de la reina, donde se inauguró el 9 de Julio de 1871. Los fondos se trasladaron en 1894-95 a su local definitivo, el Palacio de la Biblioteca y Museos Estatales, construido al efecto. El Museo fue inaugurado en su nueva sede de la calle Serrano, el 5 de Julio de 1895. Por lo que se refiere a la actividad restauradora, existen datos desde fecha muy temprana, coincidiendo con la apertura del Casino de la Reina: en 1871, se "llamó al ingenioso restaurador del Museo, D. Ceferino Díaz” para arrancar el "Mosaico de las Estaciones”, de Palencia ${ }^{8}$, lo que indica que ya había restauradores en el M.A.N. Es a partir de 1932, cuando se convocan las dos primeras plazas de restauradores fijos por oposición, cuando se comienza a diferenciar al auténtico profesional de los que eran artesanos o simples auxiliares sin cualificar. A partir de 1875, la lista de restauradores se sucede de forma prácticamente ininterrumpida hasta la actualidad ${ }^{9}$.

En la actualidad los criterios sobre restauración en materiales cerámicos plantean una problemática parecida a la de épocas pasadas, en la que destacan de modo generalizado las intervenciones de extracción in-situ, consolidación, limpieza, eliminación de sales solubles, unión de fragmentos y reintegración de lagunas, siendo ésta

\footnotetext{
${ }^{8}$ Memoria de Rada y Delgado,J., Malibran,J., que presentan al Excmo. Sr. Ministro de Fomento, dando cuenta de los trabajos practicados y adquisiciones hechas para el Museo Arqueológico Nacional, cumpliendo con la comisión que para ello les fue concedida. Madrid. 1871, en Moreno, M ${ }^{\mathrm{a}}$., Davila, C., "Estudio de antiguas intervenciones de restauración en los diferentes tipos de objetos, llevadas a cabo en el Museo Arqueológico Nacional desde su fundación. Evolución de los criterios y productos empleados”.X Congreso de Conservación y Restauración de Bienes Culturales. Cuenca, 1994, pp.337-348.

${ }^{9}$ Moreno, M${ }^{\mathrm{a}}$., Davila., op. Cit., 1994, p.338.
} 
última intervención la más controvertida entre los investigadores y profesionales, como veremos a lo largo de esta Tesis, si bien, el respeto a la obra original, es una norma admitida hoy por todos y a de presidir los trabajos de cualquier tipo.

En cerámica, al igual que en otros bienes culturales, la mayor polémica aparece en la elección de los materiales y criterios estéticos a seguir en la reintegración volumétrica y colorimétrica de faltantes. No todas las piezas se restauran según unos criterios claros de discernibilidad con los fragmentos originales, de hecho cada vez son más los talleres que proponen a sus clientes realizar reintegraciones caracterizadas por su gran ilusionismo e imitación con respecto a la pieza original, amparándose en la documentación de los procesos y la reversibilidad de los materiales empleados.

Pero antes de adentrarnos en esta discutible percepción de restauración veremos qué se entiende por laguna o faltante matérico, la reposición de éstos y las distintas metodologías y materiales utilizados al efecto. Todo ello constituye el desarrollo del segundo capítulo de esta tesis. Aún así, hemos creído conveniente y necesario para su comprensión, exponer brevemente la metodología y tratamientos empleados en la conservación y restauración de la cerámica arqueológica. 



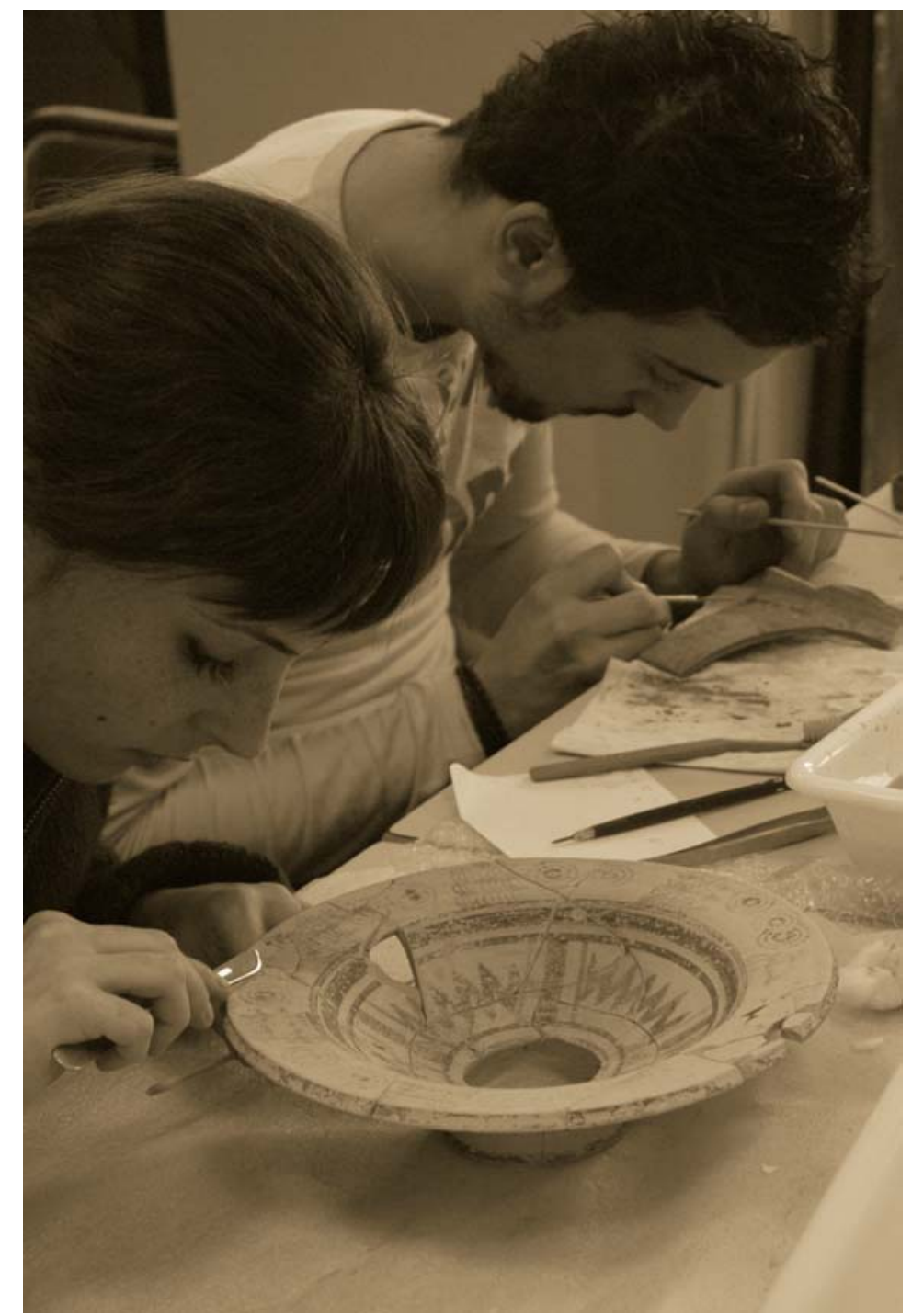

I.3. LA CONSERVACIÓN EN CERÁMICA ARQUEOLÓGICA DESDE LA ANTIGÜEDAD HASTA NUESTROS DÍAS 



\section{I.3. LA CONSERVACIÓN EN CERÁMICA ARQUEOLÓGICA DESDE LA ANTIGÜEDAD HASTA NUESTROS DÍAS}

\section{I.3.1. INTRODUCCIÓN}

No pretendemos en esta tesis la elaboración de un decálogo de restauración cerámica, en la actualidad disponemos de amplia bibliografía al respecto que día a día va renovándose gracias al trabajo e investigación de los profesionales. No obstante, creemos que para la comprensión de la misma es necesario "pasar de puntillas" por las intervenciones que se han llevado a cabo a lo largo de la historia.

Por todos es conocido que la materia prima de la cerámica es la arcilla y que dependiendo de los aditivos añadidos a ésta (desgrasantes, fundentes), de los revestimientos (engobes, vidriados), y su técnica de preparación (preparación de la arcilla, modelado, decoración, secado o endurecimiento, el proceso de cocción) el producto final que llega a nuestras manos puede ser diferente en cuanto a estética o características físico-químicas, pero todo el conjunto de objetos cerámicos tiene en común de una manera u otra su naturaleza, tecnología y manufactura.

Se desconoce exactamente a partir de cuando surge el interés por restaurar objetos de cerámica. El British Museum posee ejemplos de materiales cerámicos intervenidos que datan del 7.000 a. C. ${ }^{10}$ Como

\footnotetext{
${ }^{10}$ Buys, S., Oakley, V., The conservation and restoration of ceramics. ButterworthHeinemann series in Conservation and Museology, London, 1993, p.63.
} 
ya ha sido mencionado, la necesidad de restaurar objetos cerámicos se vincula con el valor y significado que la sociedad les ha asignado, el cual puede ser ritual, doméstico, estético-artístico o histórico. Los criterios, tratamientos y materiales a emplear en la intervención también estarán determinados por éste, así como por el tipo de alteraciones que éstos presenten.

Ya en el Neolítico se perforaban platos rotos de cerámica para poder coserlos usando tendones de animales o ramas y de este modo seguir utilizándolos. Estas primeras intervenciones eran muy sencillas y tenían por objeto reparar el daño sufrido por la pieza cerámica con relación a la utilidad y significado de la misma sin tener en cuenta su valor artístico ${ }^{11}$.

En América la cerámica más temprana es la procedente de Valdivia en Ecuador, fechada en 3000 años a. C. Con respecto a la restauración de cerámica en época prehispánica, se han encontrado piezas unidas mediante perforaciones cónicas y fibras naturales (la perforación se hacía en los extremos de las roturas de los fragmentos para luego introducir la fibra y amarrar la pieza) y mediante el empleo de un adhesivo como el copal. También se han encontrados piezas cerámicas en México que presentaban la técnica del “enclavijado”, es decir una unión mediante la utilización de un perno de piedra ${ }^{12}$.

\footnotetext{
${ }^{11}$ Aura, E., op. cit., 1996, p.11

${ }^{12}$ Cruz, L., Magar, V., "Algunos aspectos de la historia de la restauración de los objetos cerámicos en México: materiales, procesos y criterios”. Instituto Nacional de Antropología e Historia. El Correo de Restaurador nº5, p.14.
} 
Los tipos de materiales usados en restauraciones antiguas de objetos cerámicos son incontables, la experiencia nos ha demostrado que no es extraño encontrar materiales aún sin documentar en la restauración de piezas con intervenciones anteriores. Por lo general, los materiales utilizados en antiguas restauraciones eran experimentados en las piezas originales. En el pasado esta información era considerada como una receta secreta del artesano y era celosamente guardada, de ahí la dificultad para conocer cada uno de los materiales utilizados con detalle.

La gran mayoría de objetos eran reparados por el propio usuario o propietario con aquellos materiales que estaban al alcance de su mano, o bien era un "experto" en reparación cerámica conocido como el "lañador", existiendo hasta bien entrada la mitad del siglo XX en España.

En cuanto al tipo de gente que en el pasado llevó a cabo acciones de “restauración” sobre los objetos cerámicos, puede decirse que fue sumamente variada. No obstante, la aparición de los restauradores profesionales es relativamente reciente. Asimismo, puede decirse que la mayoría de las restauraciones anteriores al siglo XIX tuvieron un carácter doméstico, estando más bien vinculadas con el concepto de reparación.

En lo referente a la Comunidad Valenciana, hemos sido testigos de la situación en la que se encontraban distintos "talleres de restauración” de museos arqueológicos, que en muchas ocasiones hacían honor al tipo de museo que los albergaba. La desidia, la falta de recursos 
económicos destinados a restauración, la mínima preocupación por formar o poner al día a su personal en técnicas más avanzadas y nuevos materiales, hicieron que estos talleres se detuvieran en el tiempo.

En la actualidad, los museos arqueológicos van logrando aunar la investigación y la conservación tal y como se entiende hoy en día, todo ello gracias a la concienciación hacia la conservación de los materiales arqueológicos de las nuevas generaciones de restauradores y arqueólogos y la remodelación de los museos tanto en su ámbito expositivo como en el personal que ocupan sus instalaciones,.

Debido a la falta de documentación de las intervenciones, se conoce muy poco en cuanto a técnicas, instrumentos, útiles y materiales. Nuestra experiencia tras haber trabajado en distintos talleres de restauración de museos arqueológicos de la Comunidad Valenciana en la década de los 90 y conocer al personal de estos talleres que ejercieron sus labores como restauradores desde los años 1950-1960, nos dan una idea del gran esfuerzo que realizaron para acometer su labor. Sin preparación, sin bibliografía especializada al respecto, usando como manual recetas que iban consiguiendo o usando la imaginación ante determinados tratamientos o técnicas a base de acierto/error. Ante esta situación que padecieron no sólo en estos museos sino en la mayoría de España, no es de extrañar las técnicas y materiales utilizados en la restauración. Pasados los años y con un cierto bagaje en el mundo de la restauración arqueológica no dejo de sorprenderme y preguntarme sí muchos profesionales de hoy en día 
serían capaces de realizar lo que estas personas hicieron en su día sin apenas presupuesto, sin información de materiales, sin analíticas, sin instrumental específico, etc.

No será hasta bien entrada la segunda mitad del siglo XX cuando se asientan los criterios de la restauración y empiezan a formarse los verdaderos profesionales en el campo de la restauración cerámica.

Gracias a los estudios conducentes a la disciplina de restauración, las publicaciones especializadas, las investigaciones realizadas en cuanto a materiales y técnicas desde las distintas instituciones mundiales y los congresos específicos de restauración, los profesionales tenemos al alcance de nuestras manos una variada bibliografía de consulta que nos ayuda en nuestra labor sin dejar de formarnos y aprender día a día.

También es cierto que la preocupación de las direcciones de los museos arqueológicos han cambiado sustancialmente desde hace unas dos décadas, año tras año venimos comprobando como estos espacios culturales se acercan más al público, intentado que éste comprenda la disciplina arqueológica y la importancia de su investigación, así como los tratamientos de restauración realizados en sus talleres, realizando exposiciones con materiales restaurados desde unos criterios actuales. 


\section{I.3.2. ACTUACIONES IN-SITU.}

La conservación de material arqueológico debe comenzar en la misma excavación, por lo que la planificación de las necesidades de conservación debería iniciarse cuando la excavación es programada. Tanto la arqueología como la conservación deberían considerarse en conjunto si el deber es recuperar el máximo de información y si los hallazgos deben ser preservados y accesibles a las generaciones futuras.

Hasta no hace muchos años la responsabilidad de la conservación se delegaba al restaurador después de que la excavación hubiera terminado, pero todo profesional especializado en este campo conoce que parte del trabajo de conservación realizado después de la excavación sería innecesario si se tomaran medidas adecuadas de conservación preventiva en el sitio mismo.

Durante la excavación, la correcta conservación de sus estructuras, y en nuestro caso de restos cerámicos, se asegura si un restaurador especializado forma parte del equipo de excavación. Sin embargo incluso hoy en día esta afirmación parece una utopía. De hecho pocas excavaciones disponen de un equipo especializado en conservación y restauración arqueológica a no ser que dispongan de un gran presupuesto o formen parte de un proyecto de investigación interdisciplinar en el que el director del proyecto esté sensibilizado con la conservación de los hallazgos. 
Somos conscientes de los bajos presupuestos otorgados a los arqueólogos cuando afrontan una excavación, al igual que somos conocedores de la labor del arqueólogo y la necesidad de conocer la tipología de una cerámica fragmentada cuando es descubierta. Pero un incorrecto levantamiento de una pieza, un lavado indiscriminado, un montaje con un adhesivo poco idóneo o un incorrecto embalaje o almacenamiento, en la mayoría de las ocasiones induce a daños irreversibles. Si además añadimos que el descubrimiento de un objeto enterrado, durante siglos en un ambiente determinado, implica cambiarlo a otro ambiente totalmente diferente (humedad relativa, oxigeno y luz), el objeto entonces acelerará su deterioro natural sufriendo unos cambios aún más traumáticos e iniciará procesos que pueden provocar, también, daños irreversibles.

Hoy en día los restauradores especializados en este campo disponen de los conocimientos necesarios en cuanto a técnicas y materiales para efectuar actuaciones in-situ, minimizando los daños producidos por la salida a la luz de los materiales.

Por otro lado conocemos por transmisión oral y en ocasiones visual, que el material cerámico se sometía a lavados indiscriminados a pie de excavación, no solamente con agua, evidentemente sin desmineralizar, sino en ocasiones utilizando productos químicos como ácidos para eliminar concreciones calcáreas. Estos tipos de limpiezas tan agresivas provocaron la desaparición de numerosas decoraciones, la utilización indiscriminada del ácido clorhídrico sin apenas neutralizar, en combinación con medidas inapropiadas de exposición o almacenaje 
siguen siendo hoy en día el gran caballo de batalla en la mayoría de nuestros museos arqueológicos, ya que las pastas de estas cerámicas se encuentran en un estado avanzado de pulverulencia.

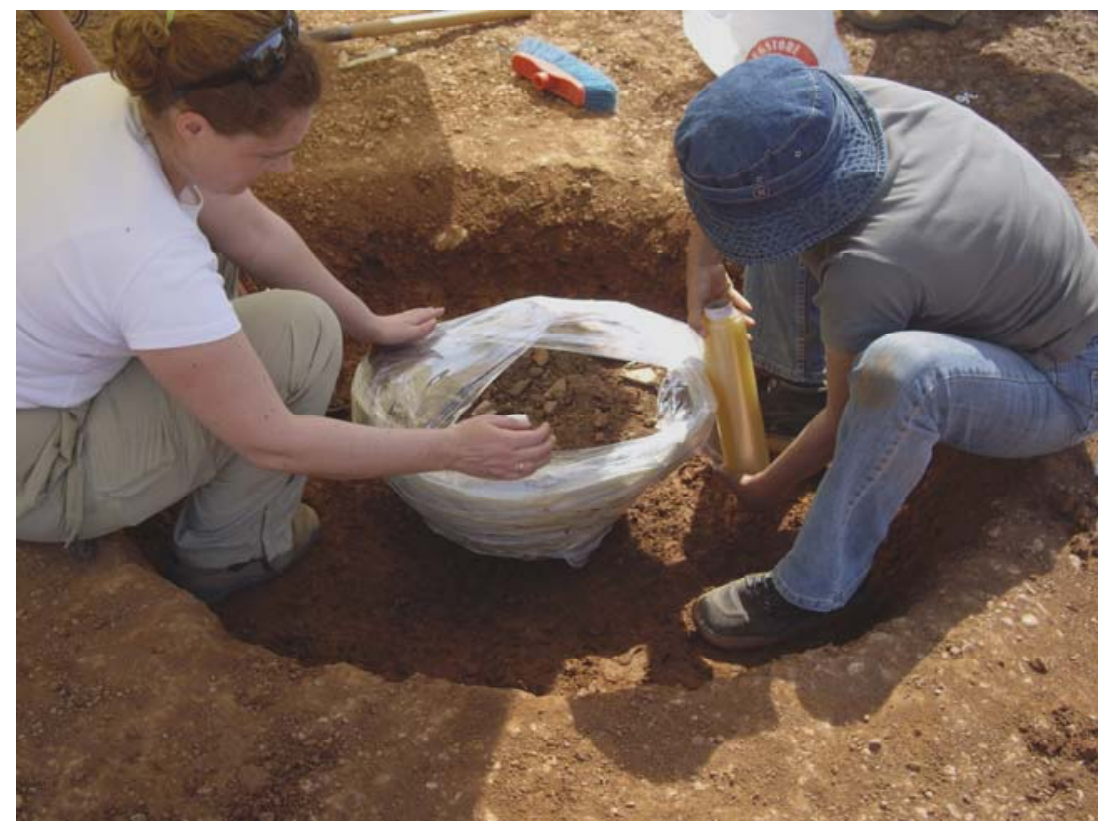

Figura. I.1. Engasado previo a la extracción in-situ de un objeto cerámico. 


\section{I.3.3. ESTUDIOS PREVIOS}

Hoy en día no se entiende una conservación-restauración de cualquier material sin unos estudios previos del estado de conservación. Algunos de estos estudios pueden ser efectuados por los propios restauradores, ya que se tratan de analíticas sencillas, como la determinación de sales solubles, concreciones calcáreas, estado de la pasta cerámica, decoraciones superficiales, etc. Pero en otros casos es necesario recurrir a la colaboración de otras ciencias, como el caso de la química.

Los cambios en los programas de estudio de restauración han hecho posible que viéramos a la figura del químico como un aliado y no como una figura lejana e inaccesible, su lenguaje científico apenas era entendido en otras épocas cuando la restauración sólo era una disciplina artística.

Los análisis de laboratorio encaminados a la conservación y restauración de los objetos cerámicos son capaces de darnos información sobre el estado de conservación o causa de alteración de los materiales: modificaciones microestructurales, alteraciones químicas de la pasta o revestimientos y ataque microbiológico. También son capaces de definir las características tecnológicas de los materiales cerámicos: naturaleza de la pasta, temperatura de cocción y definición de los revestimientos. 
A partir de pequeñas muestras, el químico elabora su propio informe, dándonos datos muy valiosos como la determinación de la composición química y mineralógica de la pasta cerámica, condiciones de elaboración y cocción, porosidad, datación, alteraciones químicas y microbiológicas de la pasta cerámica, etc. así como de los materiales añadidos en intervenciones anteriores: consolidantes, adhesivos, masillas, etc. 


\section{I.3.4. ELIMINACIÓN DE SALES SOLUBLES}

La eliminación de sales solubles es uno de los tratamientos más importantes en la conservación de cerámica, siendo además una de las principales causas de alteración.

Todos los suelos contienen en mayor o menor medida sales solubles. Si el suelo está cerca de la costa o forma parte de un antiguo depósito marino, hay una gran cantidad de cloruro de sodio, la sal se puede introducir artificialmente a través de fertilizantes y depósitos de sal o a través del descongelamiento de caminos en países fríos. Las sales solubles y el agua líquida presentes en el suelo, penetran en la estructura porosa de la cerámica, siendo imperceptible en el momento de la excavación.

La extracción de la cerámica, en la excavación, supondrá exponerla generalmente a un aire más seco. El agua contenida en la estructura porosa va a evaporar y aflorar lentamente a la superficie, llevando con ella las sales solubles. Las sales obviamente no se pueden evaporar por lo que cristalizan.

Todas las sales ejercen una presión dentro de los poros en el momento de la cristalización, llegando a fraccionarlos, dando como resultado, en mayor o menor medida una superficie escamosa en el objeto. 
Mientras una cerámica contenga sales solubles, éstas se desplazarán dentro del cuerpo cerámico de acuerdo a las variaciones de la humedad relativa del aire. Este proceso de disolución, cristalización, redisolución y recristalización, producirá microfisuras en el objeto y una aceleración de su desintegración.

Actualmente la eliminación de sales en cerámicas consistentes se realiza por medio de baños de agua desmineralizada, la cual es sustituida en un periodo de tiempo determinado previa medición de la conductividad del agua con un conductímetro. Una vez terminada la extracción de sales, las piezas son secadas a oreo en espacios sin corrientes de aire o luz directa del sol o bien son desecadas en estufas de aire a no más de $60^{\circ} \mathrm{C}$ durante un periodo de tiempo determinado. Evidentemente existen otros métodos de eliminación de sales solubles e investigaciones realizadas al respecto. ${ }^{13}$

En el pasado, no aún muy lejano, la eliminación de sales o desalación de las piezas indudablemente no se realizaba, constatamos que hasta los años 90 muchos de los talleres de restauración de museos arqueológicos no adquirieron equipos de desmineralización de agua. Las limpiezas generalmente efectuadas a pie de excavación se realizaban con agua no desmineralizada. El secado se efectuaba al aire libre, exponiéndolas a veces a las radiaciones solares para que su desecación fuera más rápida. Las consecuencias de estos tratamientos

${ }^{13}$ Aura, E., op. cit., 1996, p.161-188. 
aún son visibles en muchas vitrinas de museos arqueológicos de nuestro país, con la consiguiente pérdida de decoración, engobes, etc.

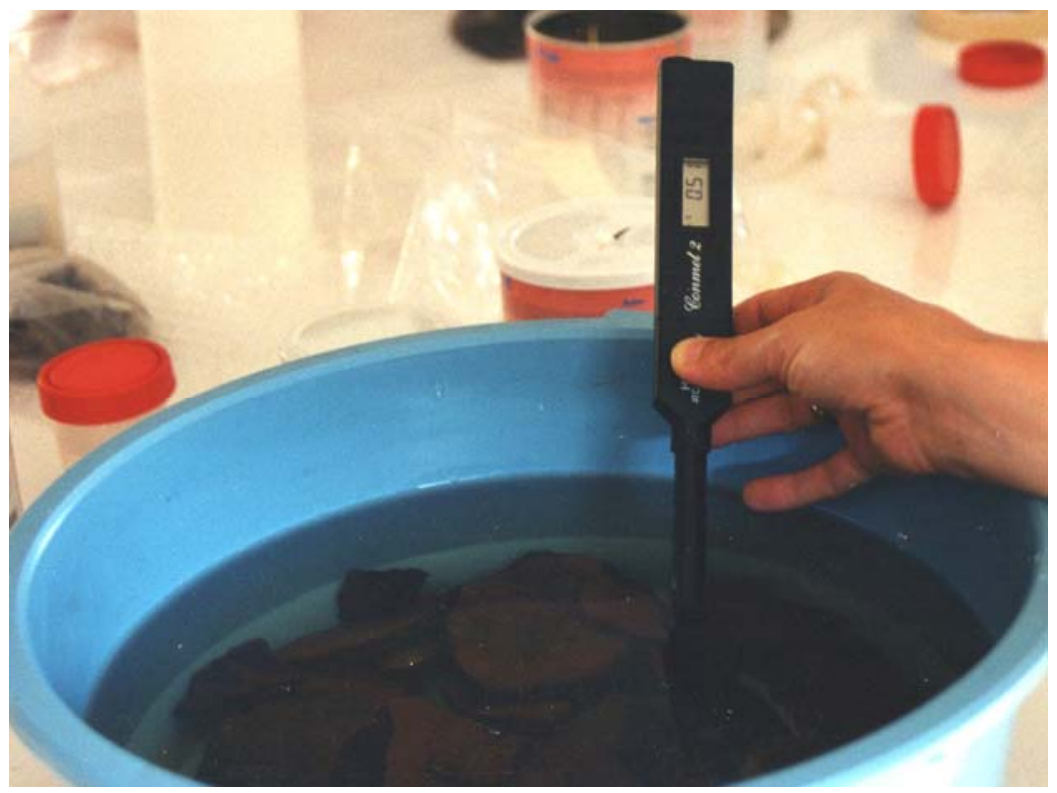

Figura. I.2. Medición de la conductividad del agua en el proceso de eliminación de sales solubles. 


\section{I.3.5. LIMPIEZA}

Las piezas o fragmentos cerámicos desenterrados presentan unas superficies recubiertas generalmente de concreciones terrosas, calcáreas, ataques microbiológicos, etc., que a su vez han desencadenado unos procesos de alteración en los materiales constitutivos de la cerámica. Estos depósitos deben ser eliminados con sumo cuidado de forma controlada, gradual y selectiva, ya que se trata de una operación irreversible. Hoy en día disponemos de numerosos materiales y métodos $^{14}$ para efectuar las limpiezas de cerámica arqueológica.

En la ejecución de las limpiezas de tipo mecánico se dispone de abundante instrumental comenzando por el quirúrgico de tipo dental, micromotores vibroincisores, vibrocinceles, limpiezas por ultrasonidos, láser, etc.

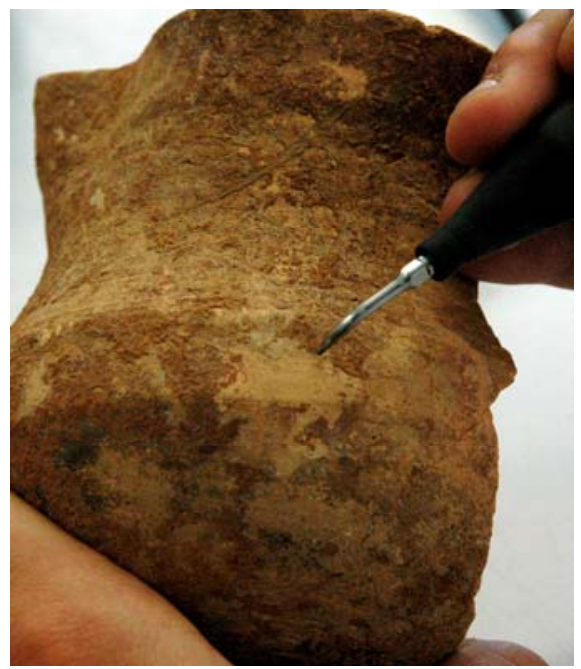

Figura I.3. Eliminación de concreciones mediante ultrasonido.

\footnotetext{
${ }^{14}$ Carrascosa, B., Lastras, M., La Conservación y Restauración de la Azulejería. Ed. Universidad Politécnica de Valencia, Valencia, 2006.
} 
Las limpiezas de tipo físico-químico cada vez más controladas se utilizan en proporciones mínimas, utilizando jabones neutros y disolventes. Los ácidos, cada día más denostados, se utilizan en contadas ocasiones, cambiando con respecto al pasado en su modo de aplicación.

En el pasado las limpiezas en objetos cerámicos se efectuaban de manera indiscriminada dando prioridad a la eliminación de concreciones y manchas de tipo orgánico, originando una pérdida y descohesión en las pastas cerámicas y en sus decoraciones. Estas limpiezas se efectuaban principalmente con ácidos debido a su rápida efectividad. Evidentemente se usaban otros disolventes como el alcohol, acetona, aguarrás, ayudándose con cepillos e instrumental no precisamente quirúrgico, navajas o cuchillos afilados pequeños.

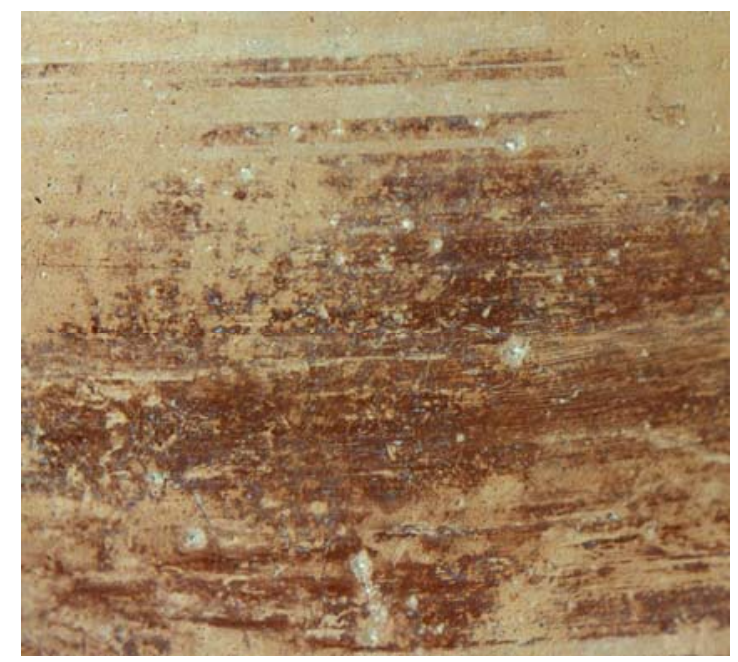

Figura I.4. Pérdida de decoraciones ocasionadas por limpiezas agresivas. 
Otro tipo de limpieza que habitualmente se realiza es la llamada eliminación de tratamientos sobre intervenciones anteriores. A lo largo de la historia las piezas cerámicas han sido "restauradas”. En el mejor de los casos se trata de un simple montaje que el propio arqueólogo realiza para poder estudiar la pieza, pero en ocasiones menos afortunadas se trata de reparaciones antiguas con productos poco estables que han envejecido y que en ocasiones son difícilmente reversibles.

Por lo general se tratan de antiguos encolados de fragmentos, con colas de muy diverso tipo y comportamiento, protecciones superficiales poco estables y reintegraciones volumétricas y cromáticas poco adecuadas. Gracias a los métodos, materiales e investigaciones que se realizan al respecto hoy en día la gran mayoría de estos materiales pueden ser eliminados aunque sus efectos a lo largo de los años han dejado una huella ya irreparable.

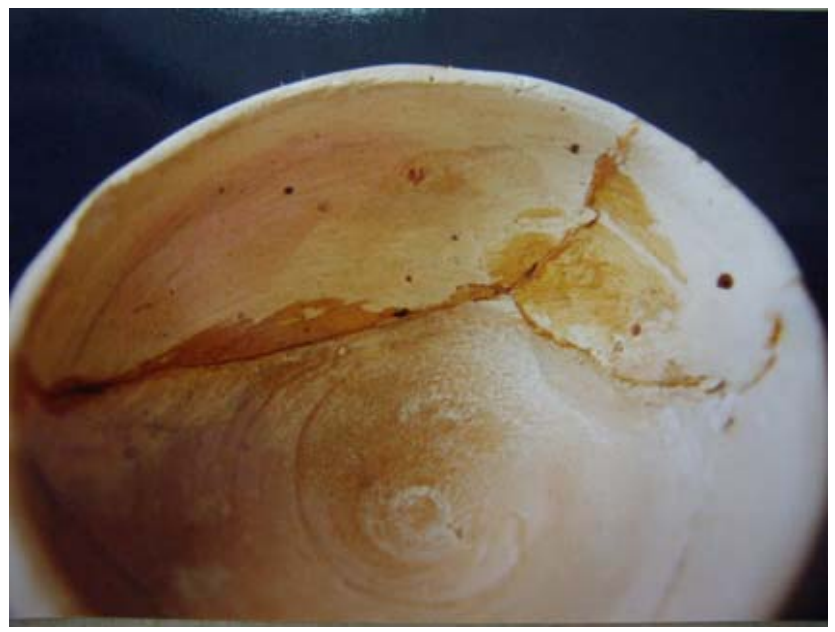

Figura.I.5. Intervenciones anteriores. 


\section{I.3.6. CONSOLIDACIÓN}

Otro de los tratamientos empleados en la conservación de piezas cerámicas es la Consolidación, intervención que puede ser efectuada en el transcurso de la conservación-restauración de una pieza que haya perdido la cohesión de sus materiales y no sea capaz de soportar las posteriores manipulaciones e intervenciones.

La mayoría de las piezas procedentes de excavación han experimentado transformaciones de origen físico y de influencia físico-ambiental, podemos hablar de roturas, exfoliaciones, deformaciones, disgregación, pulverulencia, pérdidas de pasta cerámica y decoraciones, etc. En muchos casos es indispensable realizar una intervención de urgencia con un tratamiento que estabilice su estado y detenga el proceso de desintegración.

Estas consolidaciones se vienen realizando por medio de pulverización, impregnación, inyección, inmersión parcial o completa en baño y mediante aplicación al vacío. Los productos aplicados son variados en cuanto a su composición, siendo actualmente todos ellos productos sintéticos e investigados, como los ésteres de silicio o las resinas sintéticas termoplásticas.

En cuanto a las consolidaciones somos conocedores, bien por transmisión oral de antiguos restauradores, bien por investigaciones realizadas al respecto, de la utilización de ceras, goma lacas, adhesivos disueltos a altas concentraciones, colas animales, etc. todos 
ellos aplicados en superficie mediante pincel o inmersión por baño o incluso ajo ${ }^{15}$ frotado para conseguir brillo en la superficie. En la mayoría de los casos, este tipo indiscriminado de consolidaciones han afectado de manera traumática a las piezas, ocultando los auténtico deterioros de las piezas.

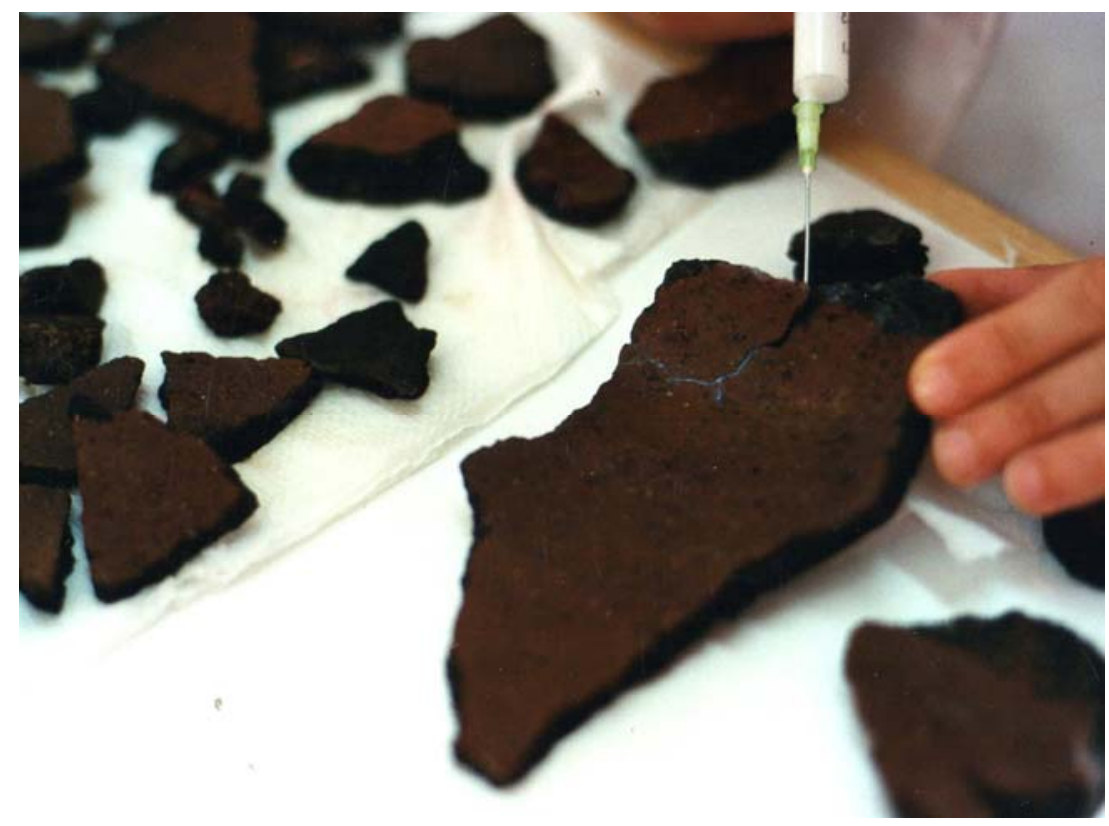

Figura. I.6. Consolidación de fisuras en pastas cerámicas descohesionadas mediante inyección de resina acrílica.

${ }^{15}$ Moreno, M․, Davila, C., op. cit., 1994, p.342. 


\section{I.3.7. MONTAJE}

Otro de los tratamientos importantes y frecuentes en la conservación de cerámica es el montaje de los distintos fragmentos que componen una pieza.

Por todos es sabido que la cerámica aún siendo uno de los materiales que mayor ha resistido a lo largo de la historia, es frágil y se fractura con suma facilidad al recibir un choque mecánico o un impacto, provocándose la fragmentación de las piezas.

Paralelamente a la recuperación del valor arqueológico o patrimonial de la pieza, el propósito de esta fase es la conservación del objeto y su posterior estudio, ya que con la adhesión de fragmentos se elimina el riesgo de pérdida de los mismos, y el deterioro de sus bordes.

Aunque, no solamente con la utilización de una sustancia adhesiva apropiada se consigue una perfecta unión de fragmentos. La elección del adhesivo y la maestría del restaurador son claves en este proceso. Dos fragmentos mal unidos provocan uniones defectuosas en cadena obteniéndose como resultado final un montaje defectuoso.

La adhesión de fragmentos o montaje, es uno de los procesos más atractivos para la gente no instruida en la materia y uno de los que más dificultades conlleva cuando las piezas están compuestas por decenas de fragmentos. Éste proceso en definitiva es complejo ya que necesita 
de unos materiales y metodologías adecuadas ${ }^{16}$.

Actualmente con el fin de evitar montajes defectuosos esta intervención viene precedida por una primera etapa de montaje a la cual denominamos pre-montaje. En muchas ocasiones nos encontramos ante piezas que son un verdadero puzzle siendo necesario y conveniente realizar este paso antes del montaje definitivo de los fragmentos que componen la pieza. El pre-montaje nos permite tener el primer contacto con la verdadera volumetría de la pieza, analizando la ubicación de cada fragmento, así como las características de cortes y fracturas que presentan, de modo que en el montaje definitivo con un adhesivo podamos decidir el orden de colocación de los fragmentos. Este estudio previo nos permitirá a la vez conocer la tipología de las lagunas y su situación en la pieza. El premontaje se suele realizar con materiales reversibles como la cinta adhesiva de papel o bien en el caso de piezas multifragmentadas de gran tamaño mediante la técnica de aplicación de cola caliente aplicada con pistola eléctrica ${ }^{17}$, siendo conveniente en estos casos establecer una numeración correlativa sobre un estrato intermedio o película de resina acrílica.

\footnotetext{
${ }^{16}$ Carrascosa, B., Investigación sobre tratamientos de conservación y restauración de piezas cerámicas y arqueológicas. Tesis doctoral. Universidad Politécnica de Valencia 1995. pp.176-195;Carrascosa, B., Lastras, M., La conservación y restauración de la azulejería. Ed. Universidad Politécnica de Valencia, 2006. pp.8693.

${ }^{17}$ Carrascosa, B., op. cit., 2006, pp. 87-88.
} 


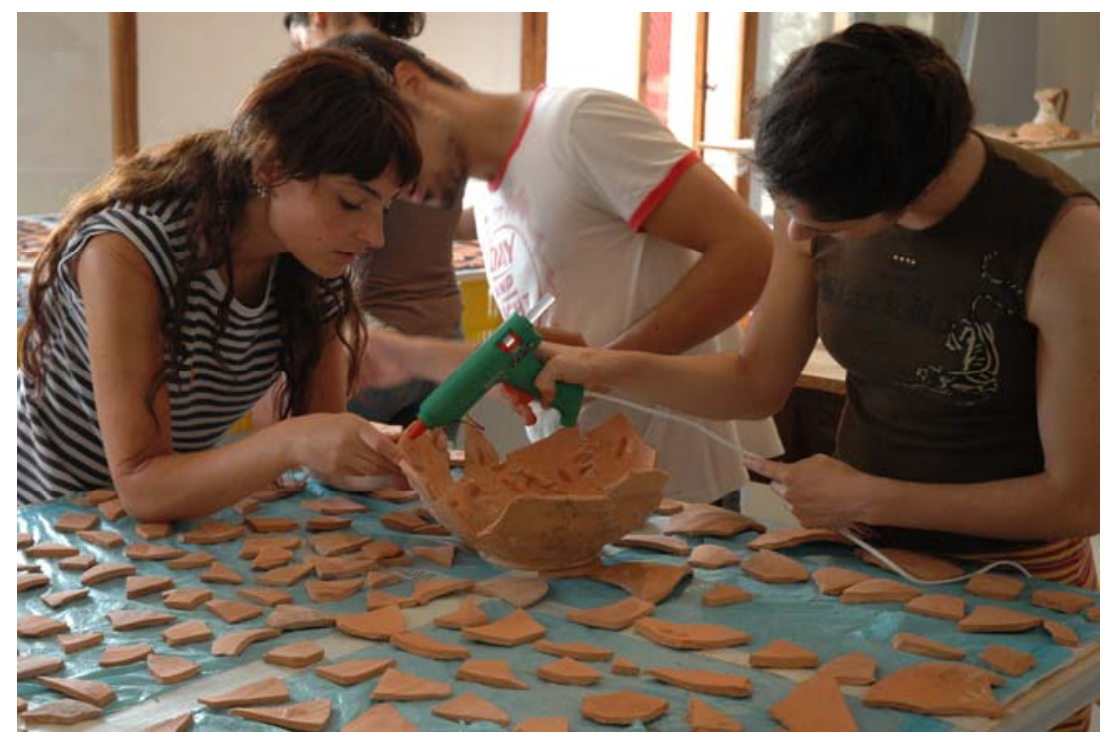

Figura I.7. Clasificación y premontaje de fragmentos correspondientes a ánforas Ibéricas. Museo Municipal de Requena. Valencia.

Los adhesivos utilizados en restauración cerámica han sido y son motivo de estudios e investigaciones ${ }^{18}$. Hoy por hoy gracias a la industria, disponemos de numerosos productos que pueden cumplir su función como adhesivos cerámicos en el campo de la restauración. Muchos de ellos son denostados por su irreversibilidad como los adhesivos epoxídicos, pero que en el caso de piezas grandes y pesadas como las tinajas de contención son a veces los que nos ofrecen mayor garantía junto con otros medios de anclaje como los pernos. En estos casos determinados podemos establecer un estrato intermedio, película a base de un polímero acrílico como el Paraloid-B72 entre la fractura a

18 Aura, E., Domenech, M $M^{\text {a }}$ T., ”Evaluación de adhesivos cerámicos ensayados, estudio comparativo de sus características" XII Congreso de Conservación y Restauración de Bienes Culturales. Alicante, 1998, pp.211-219. 
unir y el adhesivo, de forma que éste no penetre en el poro cerámico. Otro tipo de adhesivo, quizá el más utilizado en este campo, es el nitrato de celulosa, el cual se caracteriza por su alta reversibilidad, facilidad de manejo y tiempo de secado óptimo aunque estudios han demostrado su alto grado de envejecimiento con respecto a otros productos adhesivos ${ }^{19}$. Otro de los adhesivos estudiados ${ }^{20}$ y utilizados hoy en día son los polímeros acrílicos, como el Paraloid B-72, dada su alta estabilidad al envejecimiento con respecto al nitrato de celulosa, aunque también se caracteriza por su dificultad de manejo, tiempo largo de secado y un alto grosor de junta de unión.

Somos conscientes de que la disciplina de restauración se abastece de los productos existentes en el mercado, por lo que la búsqueda del adhesivo idóneo continuará, al igual otros productos como los consolidantes o masillas, mientras la industria siga existiendo. Anotamos también al respecto que día a día la restauración tiende a elaborar sus propias recetas, con el fin de conocer exactamente que productos estamos utilizando y en que proporciones, debido al gran celo guardado de las formulaciones por los fabricantes.

Independientemente de lo descrito con anterioridad, el restaurador es el que realiza la elección final del adhesivo, dependiendo de las características de cada pieza, es decir, porosidad, tamaño, peso y

${ }^{19}$ KOOB, S. P., "Instability of cellulose nitrate adhesives". The Conservator, $\mathrm{n}^{\circ}$ 6, 1982, pp.6:31-3.

${ }^{20}$ KOOB, S. P.,'”The use of Paraloid B-72 as an adhesive: it is application for archaeological ceramics and other materials". Studies in Conservation, $\mathrm{n}^{\circ} 31,1986$. pp. 7-14. 
ubicación final. Con todo esto, debemos tener en cuenta una serie de factores básicos que debe cumplir todo adhesivo destinado a unir fragmentos cerámicos de origen arqueológico: reversibilidad, transparencia, óptimo tiempo de secado, resistencia, grosor de película adhesiva, estabilidad en el tiempo y toxicidad.

No es difícil suponer que en la prehistoria los hombres conocieran sustancias adhesivas, como la arcilla, la cera y las resinas naturales. Más tarde, el hombre hallaría que la sangre, los huevos, la caseína y los restos de huesos y despojos cocidos eran capaces de mantener unidas las distintas piezas componían las armas y las herramientas. ${ }^{21}$.

Según investigaciones realizadas muchos han sido los materiales utilizados como adhesivos cerámicos como el: bitumen o asfalto, colas animales, resinas naturales ${ }^{22}$, y un largo etcétera. Con la llegada de la Revolución Industrial, comienzan a incorporarse nuevos materiales obtenidos mediante tratamiento de productos naturales o completamente sintéticos.

Al igual que en otros tratamientos hemos sido testigos en muchas ocasiones de montajes realizados con muy poca práctica y criterio, donde el adhesivo no solamente recorría toda la junta de unión sino que se encontraba desbordado por toda la pieza, originando manchas irreversibles en la propia cerámica. Otra práctica bastante común era

\footnotetext{
${ }^{21}$ Aura, E., op. cit., 1996, p.190.

${ }^{22}$ KOOB, S., "Obsolete fill materials found on ceramics" en Journal of the American Institute for conservation. Spring 1998, Volume 37, n 1, p. 49.
} 
la de limar fragmentos para obtener un buen encaje en el caso de haber cometido errores previos, originando con ello pérdida de materia original.

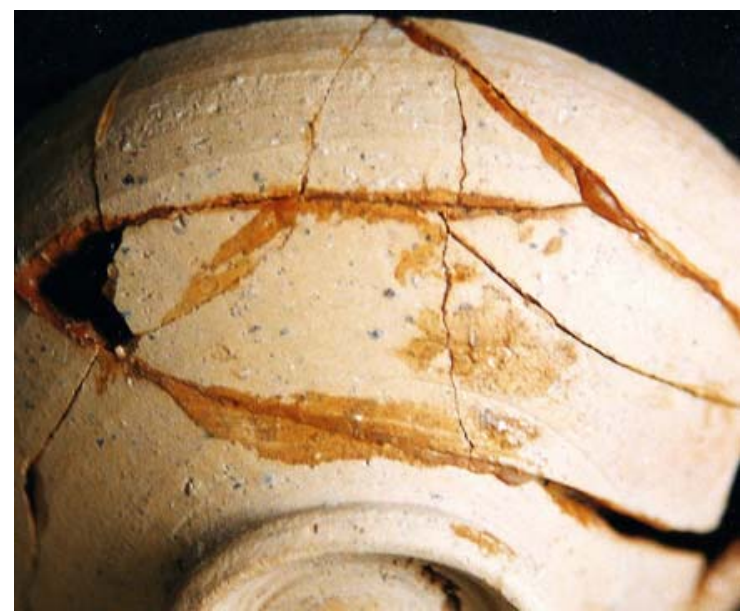

Figura. I.8. Detalle de antiguos encolados.

Muchos de los materiales que nos encontramos cuando efectuamos una restauración cerámica con intervenciones anteriores son adhesivos oxidados que de ningún modo cumplen su función, se trata de colas animales, goma laca o incluso películas fotográficas disueltas en acetona $^{23}$.

En la práctica del montaje de fragmentos cerámicos, no solamente han intervenido las sustancias adhesivas, de hecho hemos encontrado refuerzos internos a base de tela, cartón o periódico.

${ }^{23}$ Conversación privada con D.Rafael Fambuena, antiguo restaurador del S.I.P. Diputación de Valencia. 
Otra de las técnicas empleadas en el montaje de piezas fracturadas o fisuradas es la conocida como "Lañado". El lañado es una operación prácticamente perdida en España. Hasta hace tres o cuatro décadas aún era frecuente encontrar al "lañador" en las plazas de los pueblos o a la entrada de algunas aldeas de Castilla León ${ }^{24}$. El Lañador solía recorrer las casas pregonando sus servicios y dedicándose a la labor de reparar la cerámica:

"En nuestra época consumista cuesta pensar que ollas, lebrillos, fuentes y pucheros de cerámica se repararan uniendo sus partes mediante lañas metálicas y tapando las grietas con cal grasa para redondear la operación. Todavía es frecuente ver, en algunas casas, piezas que pasaron por las manos de uno de estos artesanos que, valiéndose de un rudimentario berbiquí de inercia (bombín), ponían las correspondientes lañas a la loza fracturada o agrietada; eso si, con una técnica envidiable de taladrado oblicuo y lañas de puntas convergentes, que encajaban al primor, revocadas con la ya citada pasta; quedando la vasija como nueva. Su pregón era: El lañaoooor! Se lañan los lebrillooos! El lañaoooor! “25

Desgraciadamente y con posterioridad no solamente reparaba sino que incluso cambiaba los objetos cerámicos por recipientes de plástico, con gran júbilo por parte de sus propietarios, desconocedores del gran valor que hoy en día tienen estas piezas de tipo etnográfico.

\footnotetext{
${ }^{24}$ Transmisión oral.

${ }^{25}$ http://www.todohistoria.com/mipueblo/pregones.htm
} 
El lañado consiste en realizar unos orificios cercanos a las zonas de fractura, sin que se rompa la pieza. Estos orificios permitían el cosido de las fracturas o fisuras. Los orificios de lañado se han venido practicando desde el neolítico hasta nuestros días de forma continua,

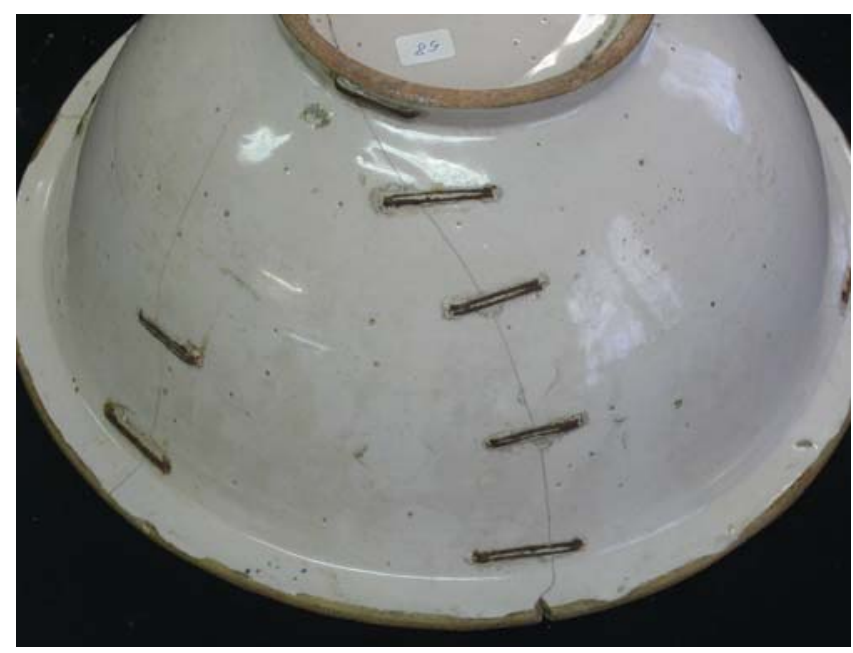

Figura I.9. Fracturas y fisuras reparadas de un lebrillo vidriado reparado con la técnica del lañado.

incluso aún hoy en día se sigue realizando esta práctica en algunas zonas menos desarrolladas. El “cosido" se realizaba mediante diverso material de agarre. Al principio se utilizaban ramas y hierbas, tendones de animales, etc., para después con el avance de la historia utilizar materiales de tipo metálico como las grapas metálicas de cobre, bronce, hierro o plomo.

Evidentemente esta técnica ha provocado una serie de daños irreversibles en las piezas, desde el momento en que se realizaban los orificios y la colocación de las grapas a presión. Hoy en día nos llegan 
muchas piezas con este tipo práctica, pero en nuestra opinión forma parte de la historia de la propia pieza. En estos casos optamos por retirar con sumo cuidado las grapas metálicas, realizando a continuación los tratamientos de conservación-restauración que la pieza requiere. Las grapas o lañas son tratadas como objetos aislados de la pieza y tras su limpieza son protegidas mediante resinas de tipo sintético, ya que al ser de origen metálico pueden volver a ocasionar contaminación en la pasta cerámica por su oxidación. Finalizadas todas estas intervenciones las lañas son devueltas a su lugar original, como testigo de su propia historia.

Otra técnica que podemos encontrar en antiguos encolados es la utilización de "pernos". Esta práctica muy común durante el siglo XIX aún se utiliza hoy en día aunque en casos muy especiales. La práctica consiste en efectuar unos orificios internos en la cerámica, en concreto en el interior de los bordes de las fracturas a unir para a continuación colocar en ellos unos pernos o espigas, que dependiendo de la época han estado constituidos por distintos materiales como la manera, hueso o diversos útiles metálicos, de manera que junto con el adhesivo dieran solidez a la unión. El problema de esta técnica radica en la clase pernos utilizados generalmente madera y metal. El primero, la madera, provoca roturas al hinchar debido a su gran higroscopicidad al hinchar y el segundo, el metal, por lo general hierro, el cual oxida, aumenta de volumen y también produce roturas en la cerámica a la vez que origina manchas de herrumbre. 


\section{I.3.8. DOCUMENTACIÓN $\quad$ Y REGISTRO DE LAS INTERVENCIONES}

La documentación de las intervenciones es “sinónimo” hoy en día de la calidad en los procesos efectuados de cualquier manufactura, basta asomarnos a cualquier empresa de un país desarrollado, donde deben cumplir unas normas determinadas en cuanto a la documentación de sus procesos.

En el caso que nos ocupa, no disponemos de ninguna Norma específica que nos indique como debemos documentar nuestros procesos, pero ello no es excusa ya que disponemos de los medios necesarios para llevar a cabo el registro y documentación exhaustiva de nuestro trabajo. De hecho la restauración se caracteriza desde hace unas décadas por su exhaustiva documentación, registrando fotográficamente e incluso filmando las obras antes, durante y al finalizar cualquier intervención.

En la actualidad cualquier profesional que se precie, taller o empresa de restauración documenta sus trabajos mínimamente. Estos mínimos se traducen en fotografías, cuaderno de campo en los procesos de conservación-restauración, fichas técnicas y memoria técnica o informe al finalizar la intervención.

La fotografía forma parte de la restauración, realizando registros iniciales de la pieza a su entrada en el laboratorio, durante su 
intervención y su estado final, asi como todas aquellas que aporten información y documentación sobre el estado de conservación.

El cuaderno de campo, indispensable para el restaurador, siempre debe estar a mano para anotar todo lo que se realice, desde la entrada de la obra en el taller, el estado de conservación, siglado o anotaciones del arqueólogo, peso de las piezas, el proceso de eliminación de sales solubles, limpiezas detallando tanto el instrumental utilizado como los productos y sus porcentajes, así como los que han sido efectivos como los que no han originado ningún resultado, de igual modo las consolidaciones, reintegraciones volumétricas o formales, y reintegraciones cromáticas o retoque cromático.

La ficha técnica será el documento que siempre acompañe a la pieza, será su historial clínico. No hay ninguna normativa que nos indique que tipo de ficha utilizar aunque cada centro dispone de una propia. La ficha debe de recoger las características de la pieza, el estado de conservación, reflejando todos los procesos incluyendo instrumental, materiales y porcentajes utilizados de manera concisa. Generalmente incorpora como mínimo dos fotografías una inicial y otra final del estado de la obra.

La memoria técnica o informe es un documento mucho más extenso donde se recoge tanto el estudio histórico-artístico, como nuestra intervención, incluyendo documentación fotográfica y analíticas realizadas. 
Por desgracia, todas estas técnicas de documentación tan exhaustivas comenzaron hace apenas unas décadas, en lo que se refiere al campo de la restauración cerámica; apenas existe documentación de las intervenciones realizadas tanto fotográficamente como documentalmente.

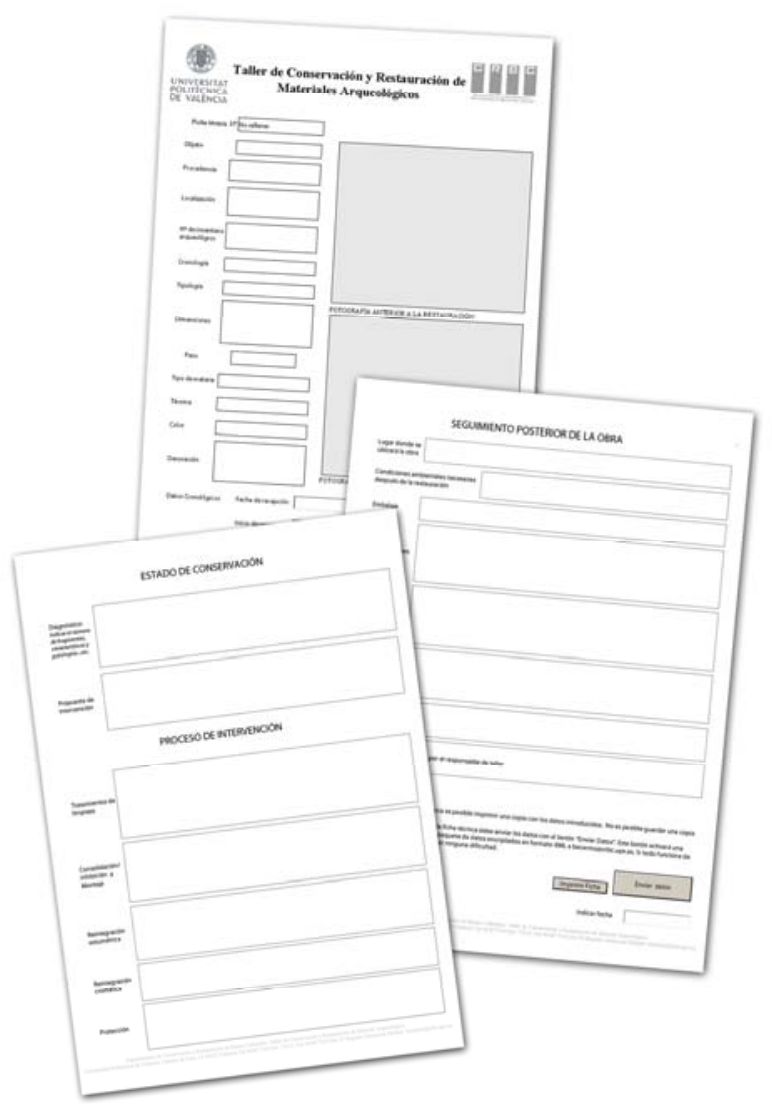

Figura I.10. Modelo de Ficha técnica 



\section{II.1. INTRODUCCIÓN.}

En la primera parte de esta Tesis Doctoral hemos visto los distintos procesos de conservación que se efectúan en las piezas cerámicas de tipo arqueológico, pero raramente una cerámica procedente de excavación llega a nuestras manos “completa”, por lo general nos enfrentamos a piezas con carencias de materia. Llegados a este punto es cuando consideramos que la conservación de la materia, en nuestro caso la cerámica, en si misma ha finalizado, comenzando la restauración.

A lo largo de esta segunda Parte hablaremos de la reintegración formal, donde se agrupa la reintegración volumétrica y cromática de la obra, es decir la restitución de su imagen estética. Muchas han sido y son las metodologías y materiales empleados en esta intervención con el fin de reestablecer la materia perdida, pero de igual modo estas metodologías y materiales han sido utilizados de manera indiscriminada sin detenerse a pensar que reintegración es la más adecuada y sin investigar la idoneidad de los materiales que se manejan ni su posible comportamiento a largo plazo. 



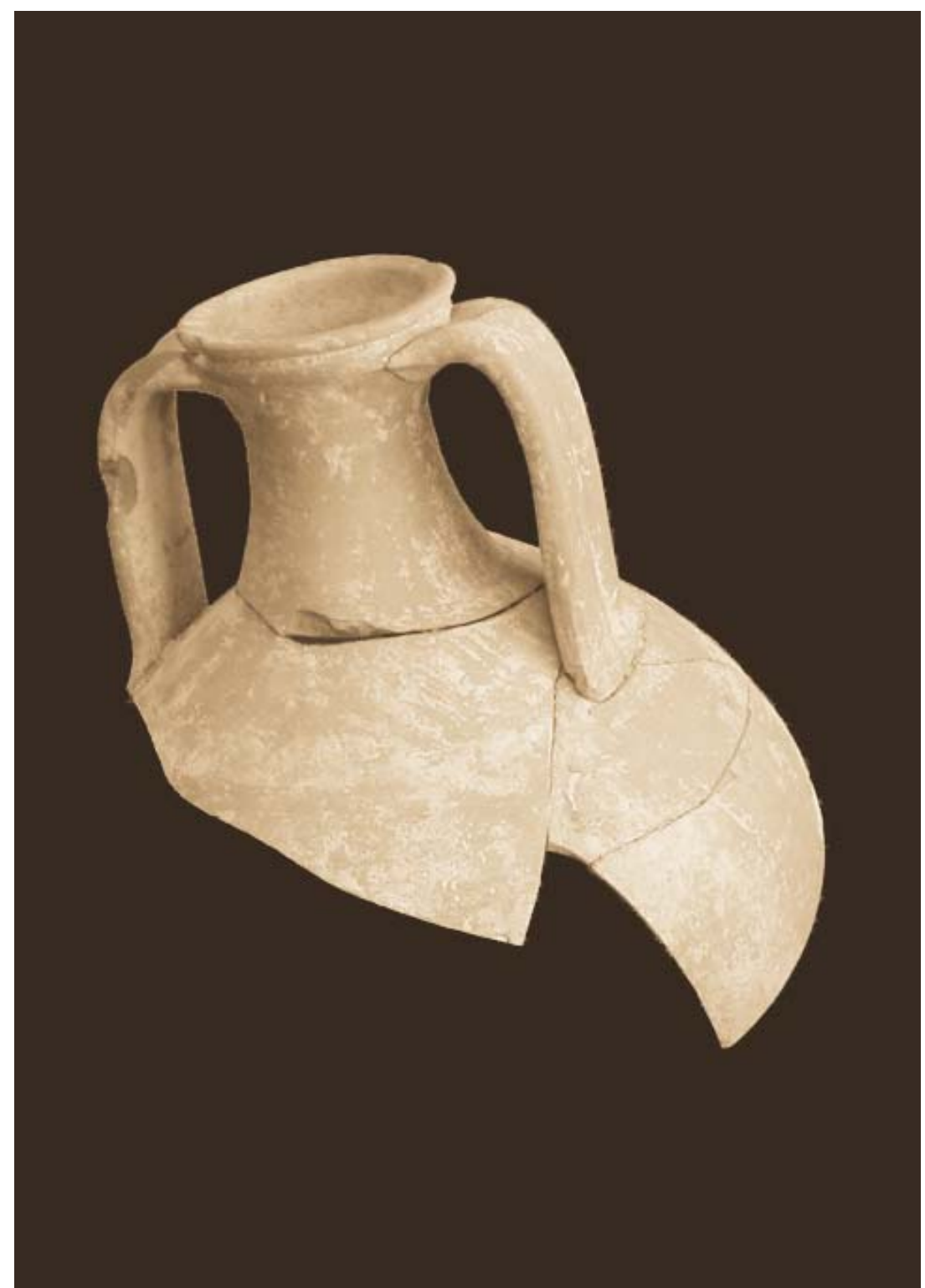

II.2.

REINTEGRACIÓN FORMAL ¿ÉTICA O ESTÉTICA? 



\section{II.2. REINTEGRACIÓN FORMAL ¿ÉTICA O ESTÉTICA?}

La reintegración formal constituye una fase en el proceso de restauración que habitualmente se realiza una vez ha concluido el proceso de unión de fragmentos con un adhesivo, incorporando otros elementos en sustitución de los que se han perdido. Esencialmente radica en rellenar con una masilla o estuco los faltantes originados por la pérdida de materia cerámica original. A estas pérdidas, bastante comunes en las piezas arqueológicas se las denomina lagunas.

La restitución de faltantes o lagunas, no solamente en objetos arqueológicos sino pictóricos o escultóricos, ha estado y está lleno de interrogantes a lo largo de la historia de la restauración moderna ¿Hasta qué punto es ético o incluso necesario restituir zonas carentes de materia en una obra cuya integridad material no peligra? ¿A quién molestan las pérdidas de materia que la historia se ha cobrado? ¿Es preciso para la obra incorporar materiales nuevos que nada tienen que ver con los originales? ¿Dónde empieza la hipótesis de una reconstrucción volumétrica y cuándo debemos dar freno a nuestra imaginación?

El estucado o relleno de lagunas en cerámica arqueológica es una intervención que se ha venido realizando hasta nuestros días, de hecho podemos afirmar que este proceso hasta no hace mucho tiempo ha 
sido imperativo tras el montaje de fragmentos, además de ser el último tratamiento aplicado a una pieza, dejando la reintegración cromática y la protección final para otro tipo de obras de arte.

Como hemos visto la restauración en cerámica arqueológica ha variado sustancialmente tanto en metodología como en materiales. Hemos de reconocer que el relleno de lagunas sigue siendo hoy uno de los aspectos más controvertidos entre arqueólogos y restauradores, y son aún muchos los profesionales de la restauración los que efectúan reintegraciones indiscriminadas, sin atender a la historia de la pieza, rellenando fracturas o fisuras, e incluso incorporando fragmentos cerámicos de otras piezas. Llegados a este punto nos podríamos preguntar ¿por qué reintegramos las lagunas de este tipo de piezas?

Todos estaremos de acuerdo que la presencia de lagunas o faltantes en una cerámica repercute en su percepción visual ya que interrumpe su correcta lectura al igual que en cualquier obra de arte, pero debemos tener en cuenta que en la restauración arqueológica perseguimos recuperar el valor arqueológico frente al estético siendo ésta una afirmación un tanto subjetiva. Muchos son los profesionales que abogan por la reconstrucción de lagunas con el fin de dotar a la pieza de una mayor cohesión, aunque con los sistemas expositivos que hoy en día disponemos esta afirmación quedaría obsoleta.

Hay que tener en cuenta, que no toda la cerámica que se excava es expuesta, motivo por el cual los almacenes de nuestros museos se encuentran hoy en día colapsados. El arqueólogo tras la excavación e 
investigación del material, al cual previamente se le deben haber realizado los pertinentes tratamientos de conservación, valora la idoneidad e importancia de los fragmentos o piezas que puedan ser expuestas. Son estas determinadas piezas, las que serán percibidas por el espectador desde la vitrina de un museo o exposición. Es por ello, que tras el trabajo de investigación y catalogación el arqueólogo desee ver estas piezas lo más completas posibles o incluso como fueron en realidad. Nuestra labor como restauradores, no solamente interviene en la conservación del material en sí mismo, sino en evaluar la necesidad o no de una reintegración formal, y en caso afirmativo qué tipo de reintegración es la más adecuada a cada caso particular.

No es necesario ser un espectador especializado para percibir que cada museo expone unas piezas con un sistema de reintegración distinto, cada laboratorio o taller tiene su manera de trabajar justificando sus actuaciones en pro del valor estético o arqueológico o en ambos a la vez.

Por lo general las piezas destinadas a almacenaje, estudio y publicación son conservadas siguiendo una política de mínima intervención. Solamente en algunos casos determinados somos partidarios de la llamada "reintegración parcial”, es decir el relleno de aquellas lagunas que jueguen un papel únicamente estructural, que junto con el uso de soportes adecuados efectúen una función de prevención física del objeto, con el fin de facilitar una manipulación segura a los investigadores. 
Otro caso bien distinto son las piezas destinadas a exposición. Generalmente se trata de piezas relevantes bien por información que ha aportado a la investigación, bien por ser piezas únicas. En estos casos la reintegración de sus lagunas, es motivo de un profundo estudio, valorando la idoneidad o no de efectuar una reintegración parcial o total.

A nuestro juicio uno de los factores a tener en cuenta es el tanto por cien original de la pieza, generalmente establecido en un $70 \%$. Es decir, si la pieza posee más de un 70\% del original, la reintegración formal de sus lagunas podría ser efectuada, siempre y cuando existan paralelos en la pieza original para reproducir sus lagunas. Los casos pueden ser muy variados. De hecho, muchas piezas pueden poseer el $70 \%$ del original pero sus lagunas pueden estar situadas en todo el perímetro de lo que fue su base o boca, o partes exentas como asas, o en el caso de las cerámicas figuradas, pérdidas de extremidades, rostros, etc. en estos casos específicos la reintegración volumétrica debe ser desestimada.

El caso contrario lo podemos encontrar en piezas excepcionales que sólo posean el 40-50\% del original pero con el 100\% de la información global de su imagen. Además, la complejidad puede ser mucho mayor cuando su original se encuentra a su vez dividido en varios conjuntos de fragmentos correspondientes a zonas superiores, medias e inferiores, pero que no conectan o unen entre sí. En estos casos tan particulares somos partidarios de: 
- Ejecutar una reintegración parcial a bajo nivel de las lagunas existentes en cada conjunto.

- Valorar una exposición global y siempre reversible sobre un soporte inerte, bien con una coloración acorde a la pieza original o bien traslúcido, guardando la forma interna de la pieza, de manera que estos conjuntos se acoplen sobre el soporte creado pudiendo contemplar la pieza en su globalidad.

Otra solución que solemos aportar a los arqueólogos que deseen exponer piezas de bajo porcentaje original y con escaso presupuesto, son los dibujos o paneles explicativos de cómo sería la pieza, reflejando en ellos el original expuesto.

Como hemos comentado, cada centro de restauración o laboratorio aboga por un tipo de intervención, siempre desde la perspectiva de máximo respeto a la obra. Basta asomarse a los museos británicos ${ }^{24}$ para percibir unas intervenciones opuestas en el relleno de lagunas, donde en aras de una correcta lectura de los objetos o piezas cerámicas éstas son reintegradas en su totalidad, independientemente del porcentaje original conservado de los objetos. Este tipo de intervención es justificado basándose en:

- $\quad$ La información recibida por el visitante es visual. Cuando una pieza tiene una pérdida considerable de materia original el

\footnotetext{
${ }^{24}$ Smith, S., "Filling and painting of ceramics for exhibition en the British Museum. Restoration: Is it acceptable?” British Museum Occasional Papers. N ${ }^{\mathrm{a}}$ 99, 1994. London. pp. 159-169.
} 
visitante aficionado puede necesitar asistencia para comprender la relevancia de la misma.

- Los paneles explicativos suelen ser inviables, ya que sólo están destinados a "piezas estrella”. Ocuparían un espacio que podría ser destinado a mostrar más piezas. Además, un alto porcentaje de los visitantes son de países extranjeros y no todos leen o hablan inglés.

Pero, en nuestra opinión, no solamente un panel expositivo puede explicar al visitante una pieza incompleta, siempre que éste sea atractivo, ya que por lo general se encuentran saturados con un exceso de información. Si no que otros sistemas alternativos como un dibujo o fotografía retocada digitalmente pueden exponer claramente al visitante la situación actual de la pieza y la posible imagen que pudo tener en el momento de su creación. Estos recursos pueden ocupar un mínimo espacio junto a la pieza, sin necesidad de recurrir a la reintegración formal de un objeto con un bajo porcentaje de original.

¿En cuantas ocasiones los visitantes de museos arqueológicos salen de sus instalaciones con la falsa creencia de que bajo tierra se encuentran grandes tesoros sin un ápice de daño?.

En otras ocasiones somos testigos de posturas totalmente opuestas. Son museos cuya política de conservación es llevada al extremo, las piezas que aparecen expuestas no presentan ningún tipo de reintegración, de manera que las lagunas prevalecen sobre el resto de 
la pieza, convirtiéndose en figura mientras que el fondo lo conforma la propia pieza.

El tipo de reintegración llevado a su máximo extremo es quizá el relleno de lagunas con función de cohesión entre fragmentos, siendo éstas claramente identificables, ya que generalmente tienen una coloración blanca. Este tipo de reintegraciones al igual que muchas otras realizadas con estucos coloreados "neutros" efectuadas a lo largo del s. XX atienden en cierta medida a la discernibilidad que toda laguna reintegrada debe tener con respecto a su original. Pero nada más lejos de la realidad, estos tipos de reintegraciones interrumpen la correcta lectura de cualquier obra de arte, siendo en la mayoría de los casos un elemento distorsionador. Hay que tener en cuenta que el concepto de neutro es muy subjetivo ya que obedece claramente a la propia percepción visual del restaurador que la ejecuta.

Cada una de las etapas que forman el proceso de conservaciónrestauración de una cerámica arqueológica poseen una serie de dificultades técnicas. Pero, estaremos de acuerdo que es aquí, en la reintegración de lagunas, donde se aúnan mayores dificultades tanto a nivel técnico, como veremos a lo largo del capítulo, como a nivel ético.

Ciertamente, todas estas valoraciones a cerca de la metodología utilizada en la reintegración volumétrica de lagunas son las que separan a unos y otros profesionales de la restauración por una 
delgada línea, (o gruesa, como se quiera ver), siendo un aspecto dentro de la restauración difícil de resolver pero de apasionante discusión.

Como hemos visto, cada profesional se decanta por un tipo de intervención, pero desde nuestra perspectiva la reintegración formal, aunando en ella la reintegración volumétrica y cromática, debería de tener unos mínimos básicos:

- La reintegración de lagunas se debería realizar exclusivamente en las zonas faltantes de materia cerámica sin invadir de ningún modo la materia original. Damos por hecho en este punto la no reintegración de decoraciones erosionadas.

- La reintegración formal debería ser fácilmente discernible de la pieza original sin interrumpir la lectura de la pieza. Esta discernibilidad puede ser evidenciada efectuando un bajo nivel en la masilla de relleno, de manera que podamos efectuar una reintegración cromática de la laguna lo más aproximadamente posible a la colorimetría original de la pieza.

- No se debería ocultar información arqueológica e histórica de la pieza, es decir, no deberíamos reintegrar fisuras, grietas, lascas o lagunas de pequeño formato que, de ninguna forma, interrumpen la lectura de la pieza. 
- No se deberían de reconstruir piezas donde el tanto por ciento del original sea menor del $70 \%$.

- No se debería improvisar zonas faltantes de las que no se disponga de alguna mínima referencia en el original. No es lícito crear o inventarse elementos morfológicos, incluso a pesar de ser supuestamente conocidos. Solamente podrán realizarse aquellos que aparezcan claramente indicados en la pieza.

- Se ha de tener en cuenta al igual que en la etapa de conservación los criterios de respeto al original, fácil reconocimiento de las intervenciones y reversibilidad de los materiales. 



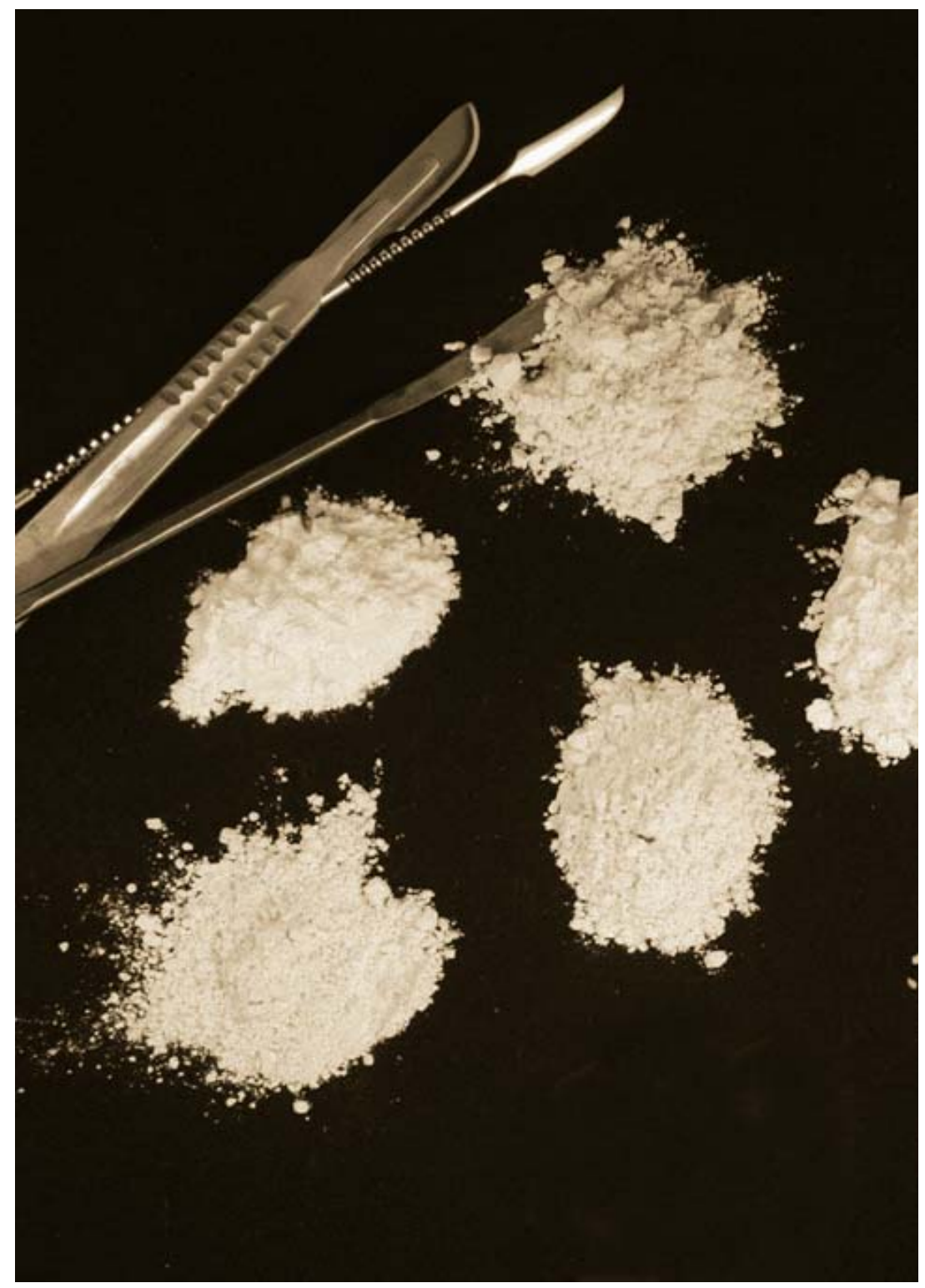

II.3.

MASILLAS Y MATERIALES DE RELLENO 



\section{II.3. MASILLAS Y MATERIALES DE RELLENO}

\section{II.3.1. INTRODUCCIÓN}

El objetivo principal de una masilla de relleno o estuco en un objeto cerámico arqueológico es reponer la materia faltante, logrando su máxima integración en su conjunto, además de actuar de soporte para la estabilidad de la pieza cuando reintegramos lagunas totales de gran extensión.

Resulta muy difícil establecer el momento exacto en el que el hombre se plantea la reposición de lagunas en la cerámica. Así como se han encontrado vestigios de materiales adhesivos en épocas prehistóricas, no ha sido así en el tema de lagunas. Quizá, la razón sea que en el momento en que una pieza cerámica, con una funcionalidad concreta de contención de alimentos o líquidos, perdía parte de su materia, perdía también en sí misma su funcionalidad. Distinto era que se fragmentara, ya que podían unir sus fragmentos y recuperar su funcionalidad, pero hasta el momento no se han encontrado vestigios que atestigüen, en épocas tan antiguas, el uso de un material de relleno para reponer faltantes.

Cuando realmente se tiene conciencia del relleno de lagunas en el tipo de obras que nos ocupa es en el s. XIX con el crecimiento de la demanda de cerámicas antiguas. Los anticuarios de arte deseaban piezas completas por lo que la "restauración” de cerámica comenzó 
hacia la mitad del s. XIX, creándose los primeros talleres de restauración en EE.UU. y Europa ${ }^{25}$.

Existe poca documentación anterior al s. XX en cuanto a recomendaciones y uso de materiales de relleno para cerámicas. Es en este punto o fecha cuando comienza a desarrollarse la restauración como una disciplina seria. A lo largo de este tiempo el número de cerámicas en museos y colecciones privadas fue en aumento creándose una gran necesidad por su restauración.

Entre la mitad y finales del s. XX empezaron a aparecer manuales de restauración. Éstos estaban llenos de recetas, donde se refleja el desarrollo de nuevos adhesivos sintéticos y masillas, desconocidos algunas décadas antes. Muchos de estos materiales de relleno han sido reemplazados por nuevos o incluso mejorados, con una creciente estabilidad, facilidad de aplicación y reversibilidad. Este hecho ha sido acelerado por una mayor comunicación, educación y práctica en los métodos de conservación-restauración, así como en las reformas éticas y estéticas de la restauración.

Como veremos a continuación, son muchos los "materiales" que se han utilizado en el relleno de lagunas en objetos cerámicos. Indicamos "materiales" ya que como veremos no solamente las masillas han sido utilizadas a tal fin, sino que también se han incorporado objetos de muy diverso origen, como madera, metal, etc.

${ }^{25}$ Koob, S., "Obsolete fill materials found on ceramics". En: Journal of the Ameriacan Institute for Conservation, $\mathrm{N}^{\circ}$ 37, 1998. pp.50-51 


\section{II.3.2. MASILLAS $Y$ MATERIALES EN DESUSO UTILIZADOS A LO LARGO DE LA HISTORIA}

Desgraciadamente, como ya hemos comentado, las intervenciones realizadas, en épocas pasadas, en objetos cerámicos arqueológicos, no eran debidamente documentados, por lo que se ha dejado al restaurador la labor de identificar los materiales que fueron utilizados.

La observación visual bajo luz natural o luz ultravioleta, así como el examen al microscopio pueden ser unos de los primeros pasos en la identificación de estos rellenos. Aún así, estos métodos tienen sus limitaciones y deberían venir acompañados de analíticas químicas.

En la mayoría de ocasiones se realizaban restauraciones "invisibles” o miméticas, coloreando las masillas o posteriormente retocándolas con una película de pintura para mimetizar o esconder completamente las masillas utilizadas. Estos “restauradores” eran y son auténticos artistas de la falsificación, siendo muy difícil, en ocasiones, apreciar estas reintegraciones a simple vista. Este tipo de intervenciones, por lo general, invaden el original con el fin de que no se aprecie fractura alguna.

Es difícil conocer cuales fueron las primeras técnicas y materiales, cuando fueron desarrolladas y en que punto dejaron de utilizarse. Sabemos que en la antigüedad se utilizaban morteros de cal y estucos basándose en arcilla para otros menesteres (reconstrucciones 
arquitectónicas), pero no esta claro si fueron utilizados en las reparaciones de cerámica.

Lo que sí es seguro, es que a lo largo de la historia y por lo general, el relleno de lagunas ha estado asociado a la incorporación de masillas, estando éstas siempre asociadas con los adhesivos. Es decir, los materiales utilizados como adhesivos eran espesados con cargas (yeso, cerámica en polvo, serrín, etc.), consiguiéndose así una masilla bien para rellenar la laguna o bien para ocultar un determinado material incluido en ella.

Muchos de estos materiales o masillas que referenciamos a continuación, en desuso en la actualidad, son a menudo encontrados en piezas intervenidas anteriormente.

Según Koob, $\mathrm{S}^{26}$ uno de los primeros materiales de relleno fue el alquitrán. De apariencia oscura y brillante, se vuelve frágil con el tiempo, rompiéndose en escamas. La aplicación de este material cumplía la función de adhesivo y masilla aunque no fuera muy atractivo. Fue utilizado hace más de 6500 años y probablemente usado hasta más tarde del s. XIX, al igual que las resinas de pino u otras resinas de árboles. Estas resinas con adición de cargas inertes fueron utilizadas habitualmente en la reposición de faltantes en Sudamérica.

${ }^{26}$ Koob, S., Op. Cit.1998 pp.53. 
Otra de las masillas de gran profusión a lo largo de la historia ha sido la cola animal, muy popular durante el s. XIX hasta la mitad del s. XX. Esta cola ha sido la base de numerosas masillas adhesivas, cumpliendo una doble función tanto de adhesión como de relleno. Por lo general eran mezcladas con carbonatos de calcio, oxido de zinc, blanco de plomo y polvo de cerámica cocida (para el relleno de fracturas). La mayor desventaja de este relleno, incluida la contracción y su envejecimiento, es la extremada sensibilidad al agua. Estas alteraciones generalmente se presentan en forma de grietas, fisuras y craqueladuras. En ocasiones se añadía aceite de linaza y esencia de trementina, aunque pronto se dejó de usar debido a que la migración de estas sustancias manchaban la cerámica.

Otra de las masillas utilizadas desde tiempos remotos, pero con seguridad desde la época romana hasta la actualidad, ha sido la cera. La cera de abeja adicionada con cera de carnauba consigue masillas fuertes y duraderas. Estas ceras eran pigmentadas para conseguir la tonalidad de la cerámica original. Pero sus pobres propiedades adhesivas y la tendencia a decolorarse ha hecho que su uso decaiga. Como veremos en el punto siguiente, las masillas a base de cera siguen estando vigentes hoy en día, aunque con distintas formulaciones.

La goma laca, utilizada como adhesivo, desde el s. XVI hasta mediados del s. XX, también ha sido utilizada de manera indiscriminada como, barniz de pintura y masilla, tanto para lagunas totales como para ocultar líneas de rotura entre los fragmentos. Al 
igual que con las colas animales, la goma laca era mezclada con distintos inertes para conseguir la densidad apropiada para funcionar como masilla. Pero su debilitamiento y fragilidad hace que las reintegraciones de este tipo, que aún se encuentran en determinadas piezas, estén hoy en día al final de su estabilidad física. Con la llegada de modernas resinas termoplásticas, la goma-laca y la cola animal dejaron de utilizarse en la restauración de cerámica.

La arcilla, sin cocer, es otro de los productos que ha sido utilizado desde la antigüedad hasta el s. XX, generalmente para recubrir reparaciones y superficies dañadas en el interior de numerosos objetos cerámicos. Su uso fue muy frecuente en el s. XIX mezclándola con cola animal y goma-laca.

Los Morteros de cal y el cemento fueron uno de los materiales usados como reintegración de lagunas más antiguo, aunque no se sabe con seguridad cuando comenzó a usarse. Se sabe con certeza que su uso ha sido muy común entre los siglos XVIII y XX. Eran utilizados para anclar armaduras metálicas en las cerámicas, como veremos a continuación. Pero, quizás su uso principal fue el de reforzar internamente las vasijas de contención. Ésta última práctica aún se puede ver en cualquier museo de nuestro país. Si el mortero es tradicional (cal, arena y agua), su eliminación es relativamente sencilla mediante humectación y limpieza mecánica de tipo manual. Aunque su intrusión en los poros cerámicos es imposible de eliminar sin recurrir a determinados ácidos que también pueden dañar la pieza original, si no son utilizados con la debida precaución. 
A partir del s. XX la industria de la construcción comienza a elaborar nuevos tipos de mortero, en especial hablamos de los cementos, de extraordinaria dureza. La eliminación es imposible sin causar daños a las piezas ya que se requiere instrumental más preciso y de mayor potencia que el manual. Siendo imprescindible, con el fin de no causar daños añadidos, el uso de maquinaria más especializada como el ultrasonidos, vibroincisores, etc.

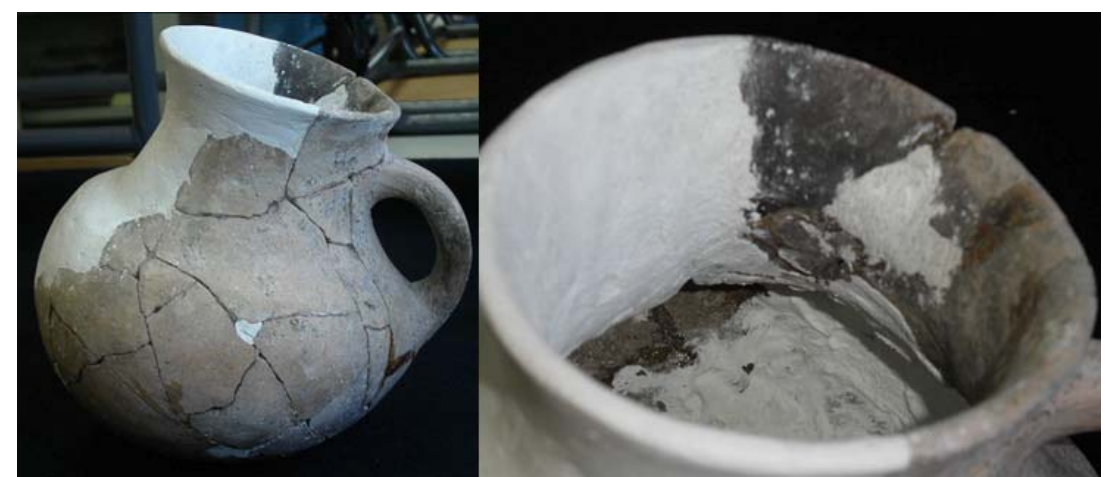

Figura. II.1. Vasija cerámica con antiguas intervenciones, donde se puede apreciar un refuerzo interno con yeso.

Armaduras y objetos metálicos variados han sido utilizados desde la antigüedad. Estos objetos eran introducidos en orificios taladrados en los bordes internos de la cerámica adyacente a la laguna, creando una armadura interna que sirviese a la vez de refuerzo estructural a la cerámica y como soporte de la masilla. Estas estructuras fueron muy utilizadas en el s. XIX, descubriéndolas cuando restauramos cerámica ya intervenida. 
Hasta el s. XX fue común la práctica de utilizar fragmentos cerámicos pertenecientes a otras piezas para completar las pérdidas de un objeto cerámico en cuestión. Por lo general se elegían fragmentos de tipología y color lo más aproximadamente posible, de manera que al cortarlo a la medida de la laguna fuera un fragmento más de la pieza. En otras ocasiones estos fragmentos sólo servían como soporte siendo luego recubiertos con una masilla. Estos fragmentos son muy difíciles de localizar a no ser que la pieza sea restaurada de nuevo. Con esta práctica se han reintegrado todo tipo de lagunas, desde bases, bocas o bordes, asas, etc.

La madera también ha sido encontrada en ocasiones como material interno en reintegraciones de lagunas. Con este material se realizaba la forma de la laguna para luego adherirla a los bordes cerámicos de la misma. Por último, se recubría con una capa de masilla, para ocultar su existencia. Por todos es sabido que la madera se caracteriza por tener movimiento propio, son higroscópicas y con el tiempo este tipo de material con humedades altas se hincha pudiendo originar excesiva presión y rotura en el objeto cerámico, así como grietas en la propia masilla que la recubre.

El serrín de madera también ha sido ampliamente utilizado mezclado con colas animales, goma laca, ceras o resinas para rellenar lagunas.

Desde el s. XVIII ha habido un gran interés en utilizar arcilla cocida, para completar las pérdidas en una cerámica. En los primeros intentos, la fabricación consistía en rellenar la laguna con arcilla húmeda, 
inevitablemente al secar se producía una contracción, y podía ser extraída fácilmente. El nuevo fragmento de arcilla era cocido y una vez seco adherido a la laguna con ayuda de un adhesivo. Este tipo de intervención requería siempre ser retocado con una masilla de relleno, debido a la contracción sufrida, por la arcilla, durante el secado y la cocción. En ocasiones se han encontrado reintegraciones de este tipo incluso firmadas y con la fecha de ejecución.

El papel, papel maché, y otros materiales celulósicos, también han sido utilizados en reintegraciones volumétricas. El papel, troceado y cocido junto con cola, formaba una pasta de papel para estucar grandes lagunas. También se ha utilizado para reforzar internamente vasijas tela o gasas de algodón, bañadas en goma laca o colas, al igual que el papel de periódico, eso sí, éste último nos ofrece la posibilidad de conocer la fecha de la intervención.

La gutapercha, goma natural del látex, fue usada a finales del s. XIX hasta principios del s. XX como material de relleno. Resultaba extremadamente viscosa y difícil de trabajar, de color oscuro pero blanqueada para éste fin. Con el tiempo presenta contracciones y debilitamiento ${ }^{27}$.

Con la aparición de la industria moderna en el s. XIX empiezan a aparecer resinas sintéticas. Una de las más populares fue el nitrato de

${ }^{27}$ Koob, S., Op Cit., 1998. p.61. 
celulosa mezclado con serrín y pigmentos. Con el tiempo esta masilla presentaba una pobre estabilidad.

Desde principios a finales del s. XX otra resina utilizada fue la de poliéster. Eran recomendadas para rellenar lagunas tanto de cerámica como de vidrio. Se caracterizan porque son muy exotérmicas durante su preparación y tienden a ser muy frágiles. Su eliminación es una de sus mayores desventajas, ya que es muy irreversible, ocasionando daños en la pieza original.

La resina de acetato de polivinilo mezclada con arcilla cocida y pigmentos fue otra de las masillas utilizadas durante la primera mitad del s. XX. Resultaba una masilla muy plástica pero excesivamente dura tras su secado. AJB/BJK Dough, usado como masilla desde 1860 hasta $1980^{28}$, consiste en una mezcla de "Alvar" (acetato de polivinilo), jute, kaolin y disolventes. Con esta masilla se realizaban tiras o cordones que una vez secos se adherían a la laguna con adhesivo formando un soporte o armadura. A continuación se rellenaba con esta misma masilla la laguna. Se conseguía una fina superficie bien por medios mecánicos o papeles abrasivos. El mayor inconveniente era su trabajabilidad, ya que debía aplicarse en películas muy finas al presentar una alta contracción durante su secado. Su mayor ventaja la reversibilidad.

${ }^{28}$ Koob, S., Op Cit 1998. p.63 


\section{II.3.3. MASILLAS UTILIZADAS EN LA ACTUALIDAD}

Son muchos los materiales utilizados en la actualidad, tantos como talleres y centros dedicados a la docencia e investigación. Cada día pueden surgir nuevos materiales basados generalmente en productos comerciales ya que éstos son cómodos en cuanto que no hay que prepararlos. Pero, por lo general, podemos dividirlos en 4 grandes grupos: las escayolas de origen inorgánico y las de origen orgánico basados en cera, en resinas sintéticas de tipo acrílico y epoxídico mezcladas con cargas inertes y por último las masillas comerciales tanto en polvo como las preparadas para su uso.

Es difícil pronosticar cuanto tiempo se seguirán aplicando las masillas actuales en el relleno de lagunas, ello depende de los resultados de nuevas investigaciones realizadas a las mismas y de los nuevos materiales que aparezcan en el mercado susceptibles de ser usados para este fin, de manera que se abandonen masillas que hoy en día se utilizan.

Tradicionalmente el material de relleno más utilizado ha sido y es la escayola. Es el material más conocido, usado y referenciado bibliográficamente, y sin lugar a dudas figura en la práctica totalidad de restauraciones efectuadas en nuestro país, Europa y EE.UU.

En las dos últimas décadas hemos asistido a un menosprecio generalizado de este material, no sabemos muy bien si debido a la 
supuesta agresividad de éste hacia la cerámica o a la intencionalidad de utilizar otros materiales, generalmente comerciales.

La mayor desventaja de la escayola es su alta higroscopicidad traspasando sales solubles a la cerámica, al igual que otras masillas a base de sulfato de calcio (Polyfilla) por las que se aboga su sustitución. Otra desventaja es la supuesta reacción que puede ocurrir entre el sulfato de la escayola y el carbonato de calcio que pueden contener las cerámicas. Según Del Francia(1991), un estudio realizado en el Centro de Restauración de la Toscana, en presencia del sulfato el carbonato de calcio es eliminado en forma de dióxido de carbono y oxido de calcio, produciendo un daño estructural en las partes originales en contacto con este tipo de estucos ${ }^{29}$.

En nuestra opinión, en el caso de que este tipo de daño pueda originarse sería mínimo o nulo, si tenemos en cuenta que antes de aplicar cualquier tipo de masilla debemos aislar los bordes cerámicos de la laguna ${ }^{30}$, con el fin de que la masilla no se introduzca en los poros cerámicos y no pueda efectuarse por higroscopicidad la contaminación por sales solubles.

De la escayola se ha hecho un mal uso. La tendencia a pigmentarse en exceso (por lo general con pigmentos de baja calidad) para conseguir

\footnotetext{
${ }^{29}$ Del Francia, P R., "Centro di restauro, Soprintendenza archeologica per la Toscana, Florence, Italy” En: Glass \& ceramics conservation, n 2 2, 1997, pp. 8-11.

${ }^{30}$ Ver punto II.5.2. Tratamientos previos.
} 
una coloración neutra en las reintegraciones ha hecho que la escayola pierda sus propiedades cohesivas.

Las limpiezas deficientes o excesivas, la no eliminación de sales solubles contenidas en la pasta cerámica, el uso de adhesivos poco apropiados, las exposiciones a temperaturas y humedades relativas altas, acompañados casi siempre de retoques cromáticos antiestéticos, hace que estas cerámicas presenten un estado deficiente de conservación, atribuyendo su mala conservación a la escayola.

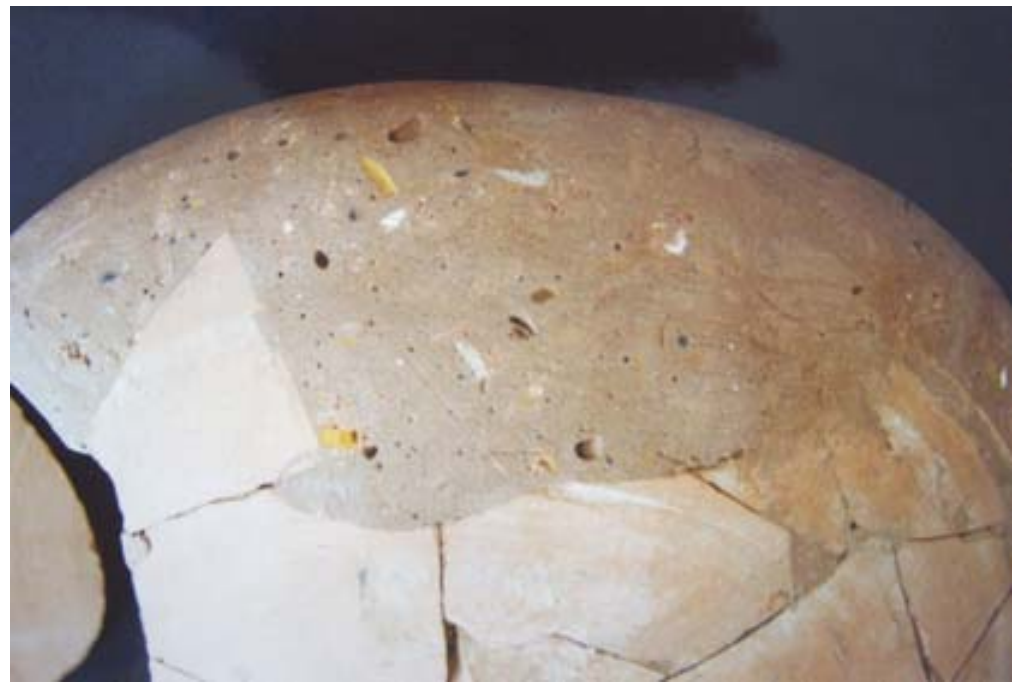

Figura II.2. Antigua reintegración volumétrica con escayola pigmentada.

Hay también que tener en cuenta que, dependiendo de las calidades de la escayola, dependerá su estabilidad a largo plazo. La escayola que se utiliza en la actualidad por todos los laboratorios de restauración es la 
escayola dental, siendo la dureza de ésta variable dependiendo del tamaño de partículas, tiempo de secado, densidad, expansión y color.

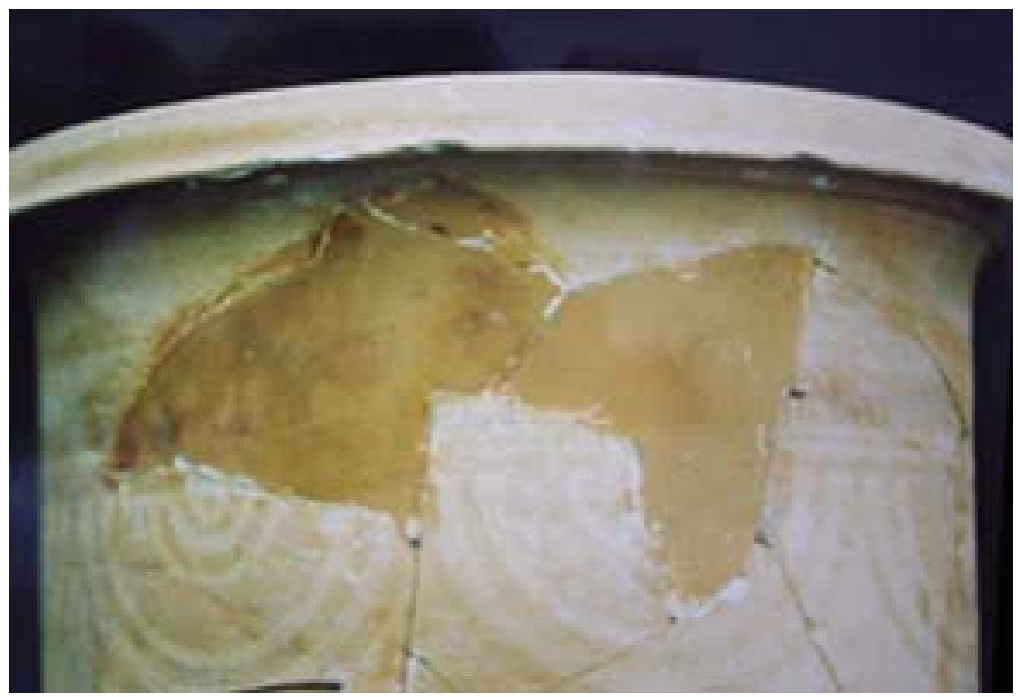

Figura II.3. Retoque cromático de deficiente ejecución sobre escayola.

La escayola es fácil de adquirir, económica, cómoda de usar, puede utilizarse con cualquier tipo de molde o soporte, se puede tallar y lijar sin demasiada dificultad y tiene un tiempo de fraguado rápido. Una vez seca puede retocarse cromáticamente con cualquier tipo de pintura.

Algunos profesionales como Bonetti, S et alt., Koob, S, y algunos restauradores de la Soprintendenza ${ }^{31}$, defienden el uso de la escayola

\footnotetext{
${ }^{31}$ Bonetti, S et alt. "Il restauro dei Bacini ceramici del Duomo di San Miniato in Pisa. Tecniche e metodi di integrazione per la cerámica". En: Rivista dell’Opificio delle Pietre Dure e Laboratori di Restauro di Firenze. 2000 p.62.
} 
como uno de los materiales más óptimos en la reintegración de lagunas en la restauración de cerámicas.

Otros estudios realizados con respecto a la escayola en comparación con otras masillas utilizadas en la actualidad, no revelan que este tipo de material posea malas características. Pantelli, $\mathrm{K}^{32}$, realizó un estudio comparativo de cuatro productos, entre ellos la escayola dental, una resina de poliéster, una masilla comercial preparada a base de resina epoxy y una resina epoxy; éstas fueron sometidas a un estudio experimental de envejecimiento acelerado de luz y calor y un envejecimiento de luz natural y dureza. Las conclusiones de este pequeño estudio fueron que la escayola dental mostró una excelente estabilidad durante los diferentes ensayos de envejecimiento.

Otro de los materiales de relleno utilizado en las últimas décadas como alternativo a la escayola ha sido una receta de cera, I76, ideada por el Centro de Restauración de la Soprintendenza Archeologica per la Toscana en Florencia ${ }^{33}$.a finales del s. XX. El I76 está formado por yeso blanco (40\%), oxido de zinc (32\%), parafina (13\%), cera blanca de abeja (13\%) y resina de colofonia (2\%). A esta receta base se le pueden añadir pigmentos para colorear la mezcla. Según sus estudios este material de relleno presenta una estabilidad química y biológica, reversibilidad y sobre todo repelencia al agua. La fabricación de la

\footnotetext{
${ }^{32}$ Pantelli, K., "A comparative study testing various media used for gap filling glazed ceramics", En: Ceramics and glass section. Conservation News, $\mathrm{N}^{\circ} 70$, 1999. pp.21-25

${ }^{33}$ Del Francia, P R., op cit., 1997. p.8.
} 
masilla se realiza con calor al baño Maria y se aplica por vertido en caliente o derritiendo la mezcla endurecida con espátula caliente.

El uso de materiales básicos garantiza la posibilidad de reproducir la mezcla siempre. El secado es inmediato y el tiempo de trabajo indefinido ya que es sensible al calor y a algunos disolventes como la acetona. También se puede lijar y trabajar mecánicamente con bisturí.

Como inconvenientes presenta su experimentación previa para conseguir la tonalidad deseada, no se debe aplicar excesivamente caliente ya que los componentes de la cera pueden migrar hacia la superficie cerámica provocando oscurecimiento irreversible en esta zona. Se debe controlar la formación de grietas durante el secado y tiene una escasa adhesión a los bordes cerámicos de la laguna. Las quemaduras con este estuco pueden resultar peligrosas. Necesita moldes o soportes especiales de creta o planchas de plomo.

Las resinas sintéticas de tipo acrílico junto con cargas inertes están siendo utilizadas en la actualidad para sustituir los materiales de relleno a base de sulfato de calcio, como la escayola dental y la Polyfilla.

Todas estas resinas son mezcladas por lo general con cargas inertes como carbonato cálcico, microesferas de vidrio, chamota, polvo de mármol, etc. Además pueden ser coloreadas por adición de pigmentos o tintes. En cuanto a su dosificación en la preparación, hay pocas indicaciones, siendo el propio restaurador el que a través de la 
consistencia deseada y la experiencia determina la dosificación. Dependiendo del porcentaje de la resina y la carga añadida, estas masillas tendrán más o menos una consistencia pastosa y por lo tanto una dureza diferente, a excepción de las resinas epoxídicas que se caracterizan por su excesiva dureza e irreversibilidad. Todas estas resinas son en mayor o menor medida toxicas ya que puede resultar peligrosa su ingestión, inhalación o absorción a través de la piel.

Una de las masillas más referenciadas a lo largo de ésta última década es la compuesta por resinas termoplásticas Paraloid B-72, copolímero de etil metacrilato y cargas inertes, como las microesferas de vidrio ${ }^{34}$. Esta masilla está especialmente indicada para cerámicas de deficiente cocción, siendo sus pastas muy delicadas como es el caso de determinadas cerámicas del Neolítico o Edad del Bronce. Se caracteriza por ser una masilla muy ligera, fuerte y fácilmente reversible con acetona. Esta resina también puede mezclarse con polvo de mármol para incrementar su peso y dureza. Como en el resto de masillas requiere un soporte para realizar la reintegración, bien de plastilina, cera dental, etc. como veremos a continuación en el punto de metodología. Una vez seca puede retocarse cromáticamente con pinturas al agua.

\footnotetext{
${ }^{34}$ Smith, S., "British Bronze Age Pottery; an overview of deteriotarion and current techniques of conservation at the British Museum. En: The Conservator, ${ }^{\circ} 22,1989$, p.p. 3-11.; Oakley, V., Jain, K., En: Essential in the Care and Conservation of Historical of Ceramics Objects. Archetype Publications.2002. p. 75
} 
En el grupo de resinas epoxídicas destacamos la utilización de una masilla en pasta indicada para la restauración de madera, existente en muchas marcas comerciales (Araldit Madera, EPO 127 C.T.S., etc.). $\mathrm{Al}$ igual que la resina epoxídica líquida ésta se obtiene por la mezcla de dos componentes en pasta. Es más fácil de tallar y lijar, una vez seca, que el resto de masillas epoxídicas. Puede parecer extraño el uso de esta masilla pero, aunque no hemos encontrado su uso referenciado bibliográficamente, sabemos de su aplicación en la reintegración de lagunas de objetos cerámicos arqueológicos en empresas de restauración existentes en nuestro país.

El uso de masillas a base de resinas epoxídicas más cargas inertes ha sido y es utilizado en la actualidad. Aunque últimamente sólo se encuentra referenciado en la práctica de reintegraciones desmontables ${ }^{35}$.

Estas resinas se caracterizan por su extremada dureza e irreversibilidad. Barov, Z. y Lambert, F. ${ }^{36}$ realizaron un estudio de las propiedades mecánicas de distintas masillas (distintas marcas comerciales de resina epoxídica con y sin carga inerte y una escayola) para determinar su compatibilidad con respecto a la cerámica. Las conclusiones del estudio con respecto a las masillas epoxídicas ensayadas determinaron que presentaban fisuras o grietas tras varios ciclos de calentamiento-enfriamiento. Su comportamiento mejora en

\footnotetext{
${ }^{35}$ Ver pto. II.5.5. Reintegraciones desmontables.

${ }^{36}$ Barov, Z.,Lambert, F., "Mechanical properties of some fill materials for ceramic conservation". En: Preprints $7^{\text {th }}$ Triennial Meeting. ICOM Committee for conservation.Copenhagen, 1984. pp.84.21.1-84.20.4
} 
todos los casos con la adición de microesferas de vidrio, y si bien, aún así no supera la resistencia o propiedades mecánicas de la escayola, la cual se mostró como la más compatible con las cerámicas antiguas.

Por último, el grupo de masillas comerciales tanto en polvo como preparadas para su uso es tan amplio que sería imposible citarlo. De entre las masillas comerciales en polvo, la "Polyfilla Interior" ha sido y es uno de los materiales más profusamente utilizado y referenciado en la bibliografía específica en la última década en sustitución de la escayola. Este material presentado en polvo, del que no se sabe a ciencia cierta sus componentes, es un material de relleno, según sus fabricantes y distribuidores, básicamente formado de celulosa soluble en agua (para aportar ligereza), sulfato de calcio y agentes retardantes del secado.

Esta masilla es útil debido a su estabilidad dimensional, no encoge ni expande, es resistente al calor y tras su aplicación es relativamente insoluble en agua. La Polyfilla es considerada un relleno ideal para cerámicas de tipo arqueológico cocidas a baja temperatura. Es mucho más blanda que la escayola por lo que se recomienda adicionar al agua de la mezcla resinas vinílicas ${ }^{37}$ en dispersión acuosa y prepararla con una consistencia pastosa. Se caracteriza por ser utilizable, al menos, durante media hora y por su buena trabajabilidad después del secado, mediante bisturí y papel abrasivo. Al igual que en la escayola y la cera, en este producto es posible agregar pigmentos para colorear la

${ }^{37}$ Oakley, V., Jain, K., op. cit.,2002, p. 75 
masilla. Una vez seca puede retocarse cromáticamente con cualquier tipo de pintura.

Un aspecto importante a tener en cuenta con el uso de la Polyfilla es que también puede contaminar la pasta cerámica original con sales solubles debido a su alta higroscopicidad y a su contenido en sulfato de calcio. Es por ello necesario aplicar un "estrato intermedio" al igual que en la escayola

En cuanto a las masillas comerciales preparadas para su uso, son cada vez más utilizadas por su comodidad al encontrarse ya preparadas. En ningún caso sus componentes son especificados completamente. Por lo general, son aplicados con espátula, debido a su consistencia pastosa, y en finas capas, ya que la mayoría se caracteriza por su agrietamiento en capa gruesa, ralentizando el trabajo.

Actualmente en el mercado existen multitud de estas masillas, generalmente indicadas para reparación de estucos, muros o trabajos decorativos. De entre todas las masillas disponibles en el mercado hemos seleccionado dos por ser las más referenciadas bibliográficamente: Liquitex Modelling Paste y Modostuc. El uso de la masilla Liquitex Modelling Paste está extendido tanto en Europa como en EE.UU. Según el estudio realizado por Loew, M y Solz ${ }^{38}$, J en 1998. Esta masilla se caracteriza por la contracción experimentada

\footnotetext{
${ }^{38}$ Loew, M., Solz, J., “Commercial vinyl and acrylic fill materials” En: Journal of the American Institute for Conservation. Vol.37. n¹.1998. p.23-24.
} 
durante su secado (alrededor del 20\%). Según sus fabricantes se compone de una resina acrílica en dispersión acuosa, polvo de mármol y agua desionizada; suponemos que también retardantes del secado. Desde nuestra experiencia práctica es una de las masillas más complicadas de aplicar, debido a su viscosidad y a su agrietamiento en capa gruesa, pero que una vez seca presenta una superficie homogénea, sin poros, además de ser dura y pesada.

Conocemos también la utilización de Modostuc, tanto en España como en Italia. Se trata de una masilla lista para su uso, compuesta según los fabricantes y distribuidores por resina en emulsión, carbonato de calcio, sulfato de calcio, aditivos celulósicos, plastificantes y biocidas. Comparada con el Liquitex resulta una masilla de fácil aplicación, aunque también contrae en capas gruesas y es bastante más blanda que el Liquitex.

$\mathrm{Al}$ igual que en el pasado, otro de los materiales que sigue siendo investigado y recomendado, por distintos autores, es la arcilla cocida. En nuestra opinión esta técnica es demasiado laboriosa y no ofrece resultados muy distintos de los conseguidos con la masilla, de hecho esta técnica requiere la utilización de masilla para ajustar los fragmentos nuevos y los originales debido a la contracción que la arcilla cocida experimenta durante el secado ${ }^{39}$.

${ }^{39}$ Ver punto II.5.5. 



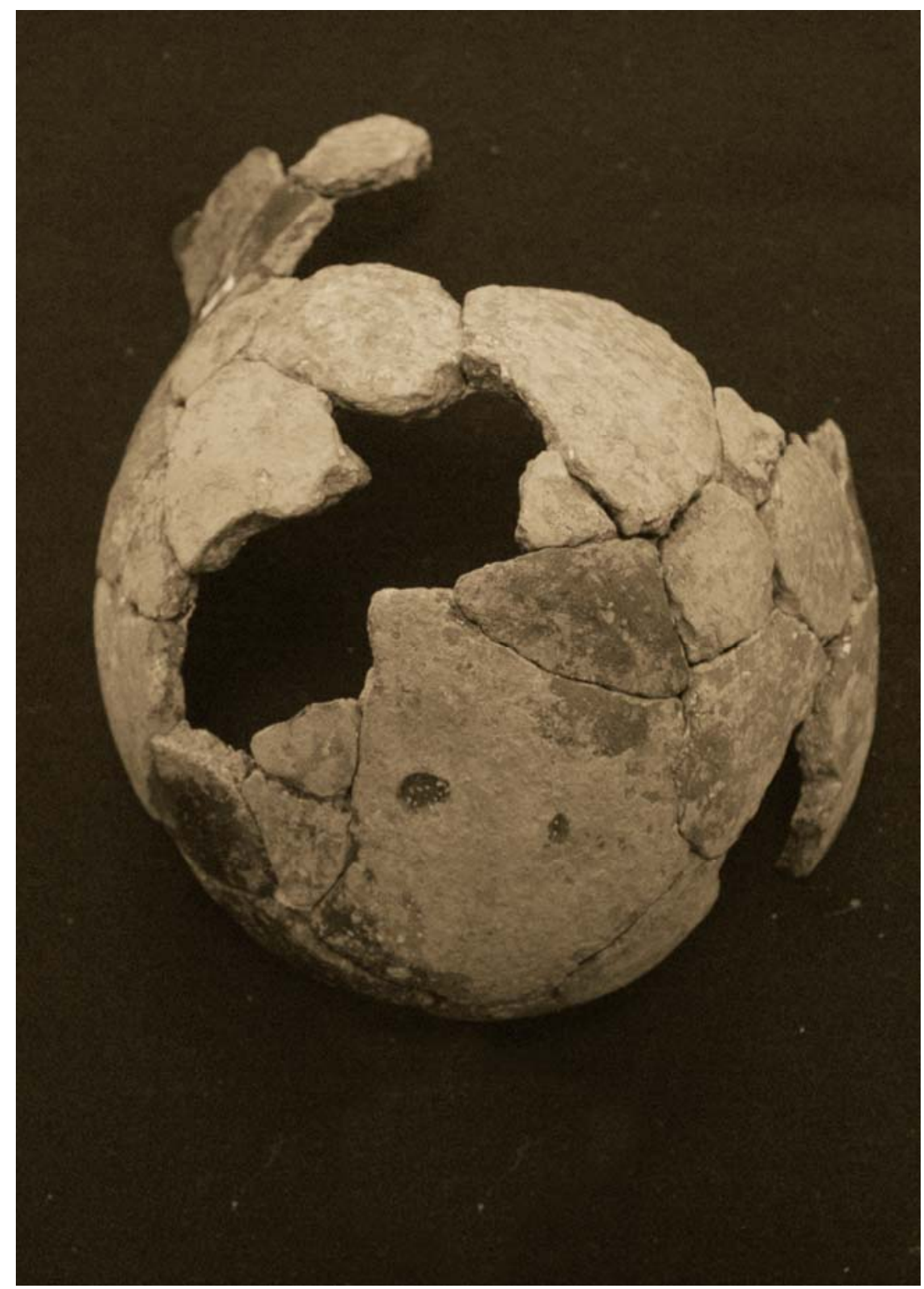

II.4.

TIPOLOGÍA DE LAS LAGUNAS. 



\section{II.4. TIPOLOGÍA DE LAS LAGUNAS.}

\section{II.4.1. INTRODUCCIÓN.}

Como sabemos, las lagunas son ausencias de imagen, que tienen su origen en la pérdida de materia de cualquier objeto o bien cultural. Éstas interrumpen la continuidad de la composición original, destruyendo el verdadero mensaje y perdiéndose parte del testimonio o lectura que la obra puede transmitirnos.

En el ámbito de la cerámica arqueológica, existen tantos tipos de lagunas como piezas y es difícil prever todos los casos. En este sentido, como veremos a continuación, clasificamos las lagunas en la forma en que afectan a la materia misma del objeto y no en cuanto a su posición o extensión, ya que sólo dependiendo de estos criterios la reintegración de éstas se realizará de una manera u otra. 


\section{II.4.2. LAGUNAS SUPERFICIALES-LAGUNAS TOTALES.}

Cuando hablamos de objetos cerámicos arqueológicos no solamente encontramos vasijas o platos sino también cualquier objeto realizado con barro cocido, es por ello que encontremos esculturas, exvotos, pavimentos, etc. Igualmente, cualquier pieza cerámica puede estar decorada, cromáticamente, en su superficie.

Las lagunas o pérdidas en una cerámica pueden variar en su extensión desde unos milímetros a centímetros. La ubicación de las mismas

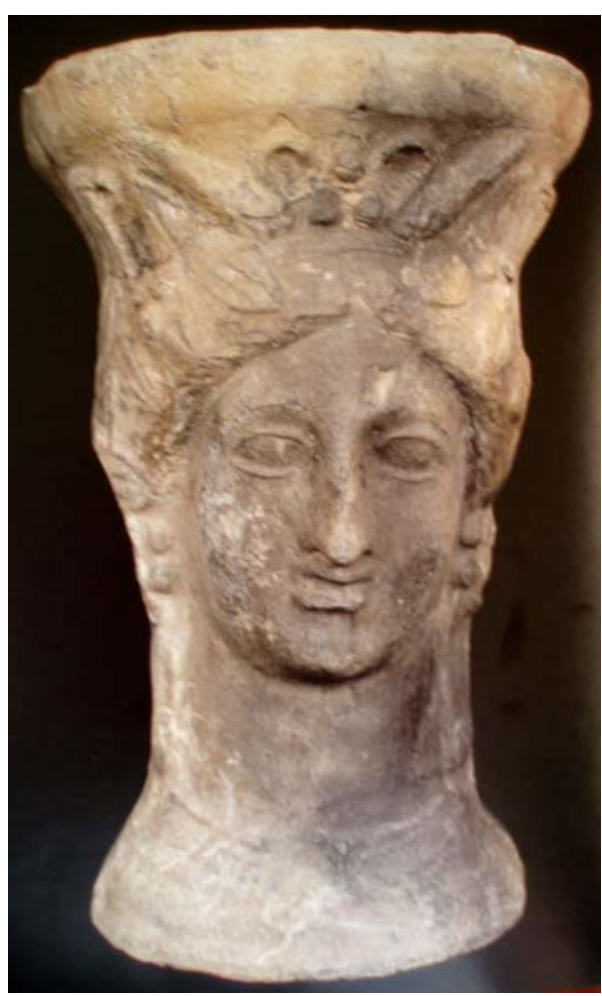
dependerá del tipo de pieza, generalmente pueden definirse en base cuerpo y borde, pero también muchas de estas piezas pueden tener elementos adicionales como asas, flores, etc. En el caso concreto de un exvoto, nos referiremos al cuerpo $\mathrm{y}$ elementos externos, decorativos, etc; así como en una placa cerámica plana serán las coordenadas $\mathrm{X}$ e $\mathrm{Y}$ las que determinen su posición.

Figura II.4. Quemaperfumes de terracota. s. III a. C. Museo de Prehistoria de la Diputación de Valencia. 
Al tratar con objetos tridimensionales, el tipo de laguna vendrá determinada por el grosor y no por su extensión o posición. En este sentido podemos clasificar las lagunas de este modo:

- Lagunas de tipo decorativo: en cerámicas decoradas, puede darse el caso de una pérdida de decoración sin por ello afectar al cuerpo cerámico. Estas pérdidas son bastante frecuentes en cerámicas decoradas de época Ibérica.

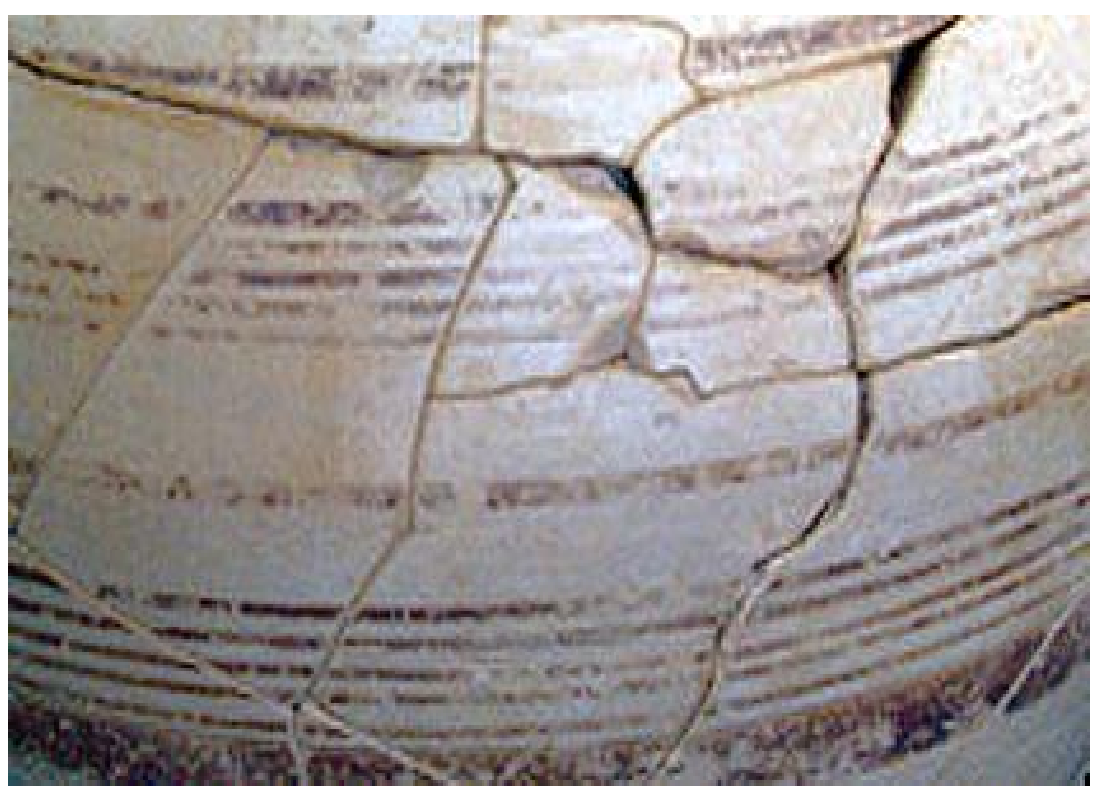

Figura II.5. Lagunas de tipo decorativo. 
- Lagunas superficiales: tanto si son cerámicas decoradas como no, pueden darse pérdidas en la superficie del cuerpo cerámico. Estas lagunas pueden haberse generado por pequeños golpes a las que llamamos lascas (alteraciones de la pasta cerámica por sales solubles o por las pequeñas pérdidas generadas a lo largo de las roturas de los fragmentos).

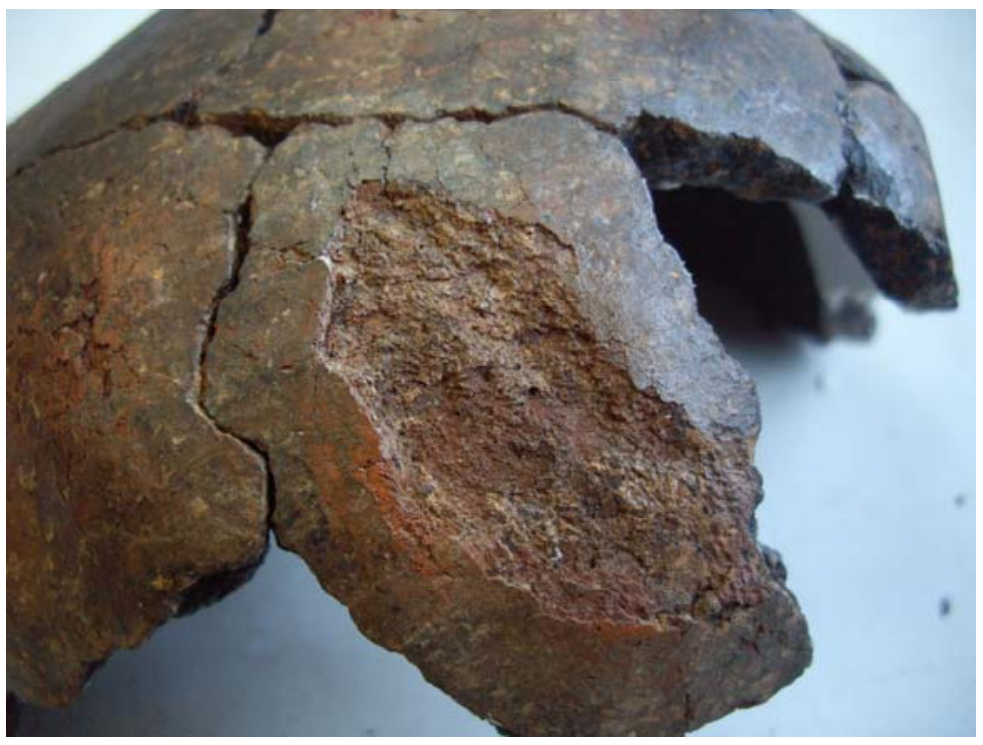

Figura II.6. Laguna superficial y pequeñas pérdidas de pasta cerámica a lo largo de las fracturas. 
- Lagunas totales: son aquellas que afectan tanto a la posible decoración como al grosor del cuerpo cerámico, originándose por tanto una ausencia total de materia.

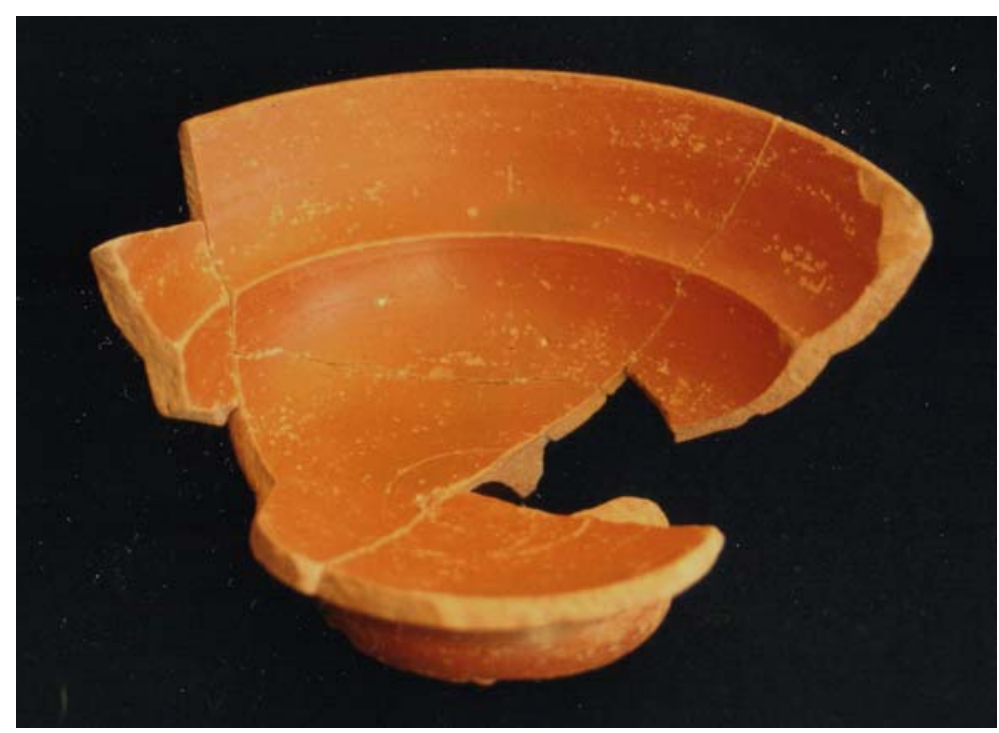

Figura II.7. Vaso de sigil.lata romana perteneciente al MAOVA. Con lagunas totales en más de un $50 \%$ del original.

Todo este tipo de lagunas puede ser variable en cuanto a extensión. Es por ello que, en la gran mayoría de las ocasiones, nos refiramos a ellas en porcentaje con respecto a la pieza original. Dependiendo del tipo de lagunas y del porcentaje de las mismas, en una pieza determinada, se valorará la reintegración de éstas, como vimos en el punto anterior. 



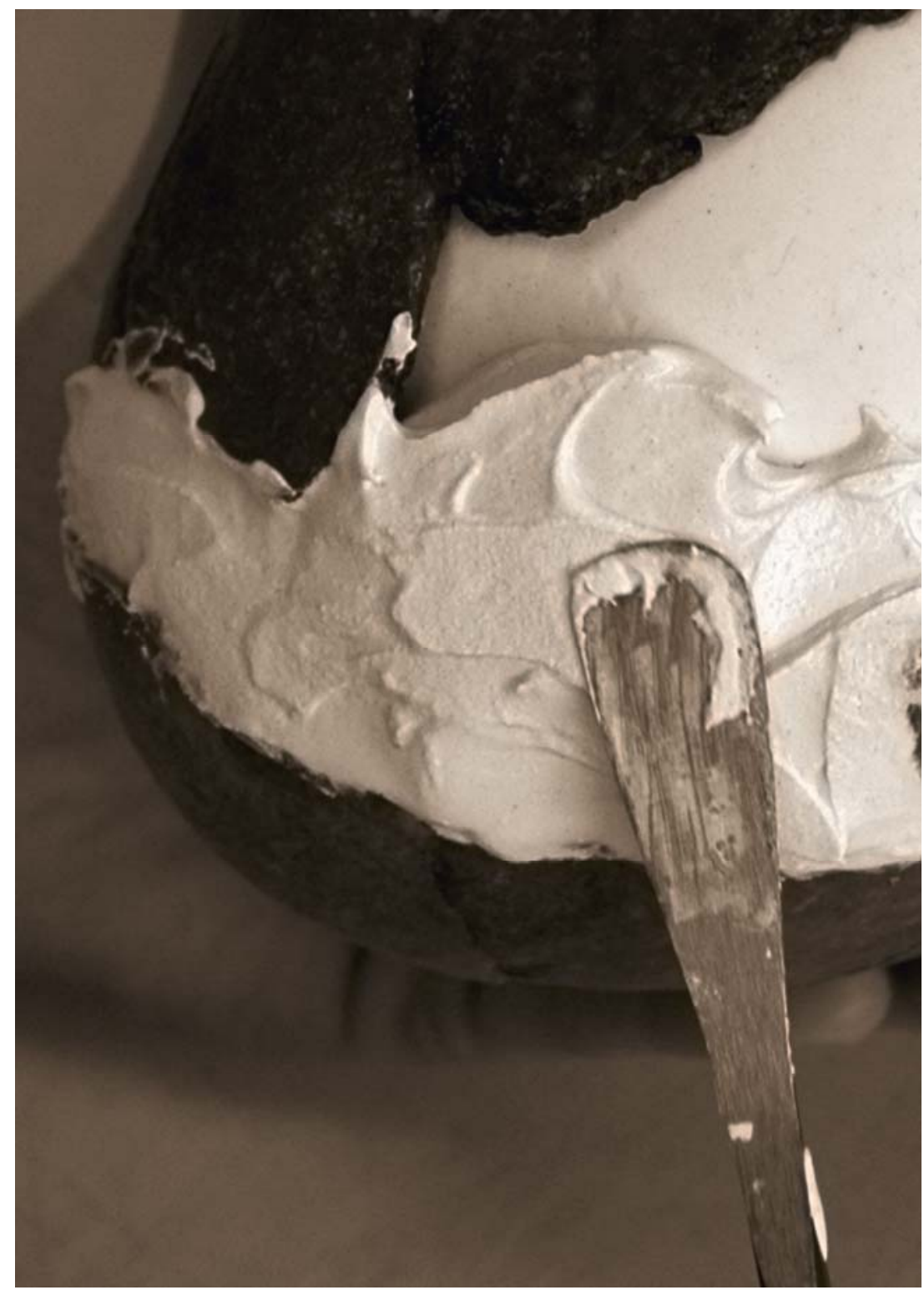

II.5.

APLICACIÓN DE LAS MASILLAS DE RELLENO. 



\section{II.5. APLICACIÓN DE LAS MASILLAS DE RELLENO.}

\section{II.5.1. INTRODUCCIÓN.}

Como ya vimos en el capítulo II.1, la reintegración de lagunas debe limitarse, desde nuestro punto de vista, a la materia cerámica y no a su decoración superficial. Dentro de las pérdidas de materia cerámica como hemos visto en el capítulo II. 4. se encuentran las lagunas totales que son en realidad las que interrumpen la lectura correcta de una pieza al contrario que las pequeñas pérdidas superficiales como lascas o pequeñas pérdidas de material cerámico a lo largo de las fracturas, testimonio del paso del tiempo.

Es por ello que dentro de este capítulo veremos la metodología aplicada en el relleno de lagunas totales: moldes y soportes sustentantes de las masillas, reintegraciones desmontables y soportes expositivos para casos especiales. 


\section{II.5.2. TRATAMIENTOS PREVIOS.}

Todo profesional dedicado a esta especialidad es conocedor que la reintegración volumétrica es una de las operaciones más "sucias" en la restauración de cerámica. Cualquier tipo de relleno o masilla que utilicemos puede manchar la pieza penetrando en los poros de la cerámica. En muchas ocasiones estas masillas son reversibles pero si penetran en los poros son difíciles de eliminar. De igual manera ocurre cuando realizamos las operaciones de acabado de la superficie reintegrada, generalmente utilizando papeles abrasivos (lijas), cuya acción produce gran cantidad de polvo.

Para evitar manchar la pieza cuando vertemos o espatulamos la masilla, al igual que cuando realizamos las operaciones de acabado, es recomendable cuanto menos proteger las zonas cerámicas circundantes a la laguna. Aunque, sin duda, la mejor manera de asegurar su protección es aislar toda la superficie de la pieza, a excepción de los bordes cerámicos de las lagunas a reintegrar. Este aislamiento o protección de la pieza original se puede conseguir a través de varios materiales:

- Cintas de papel adhesivo libres de ácido.

Su aplicación debe de ser de corta duración (días). Si prevemos que la exposición de dicho material se va a prolongar en el tiempo (semanas) optaremos por otro tipo de protección, ya que el adhesivo de estas cintas puede alojarse en el interior de los poros 
cerámicos y ocasionar manchas en la superficie de la pieza siendo muy difícil su eliminación.

- Film de polietileno.

Indicado en la protección de grandes piezas que no requieren manipulación durante la fase de reintegración. Este film plástico se adapta bastante bien a la morfología de la pieza con ayuda de cinta de papel adhesivo.

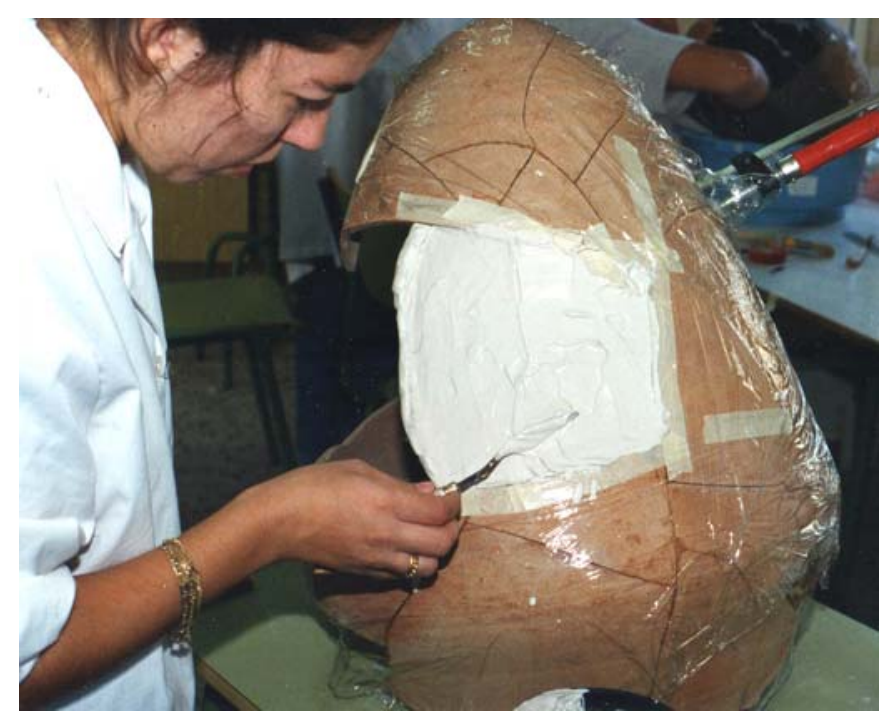

Figura II.8. Protección con film de polietileno y cinta adhesiva durante la fase de reintegración.

- Emulsión de látex amoniacal.

Protección bastante efectiva, aplicada mediante pincel o hisopo. Una vez seca se retira sin ningún problema por pelado. Al contener amoniaco es necesario tomar las oportunas medidas de seguridad. 


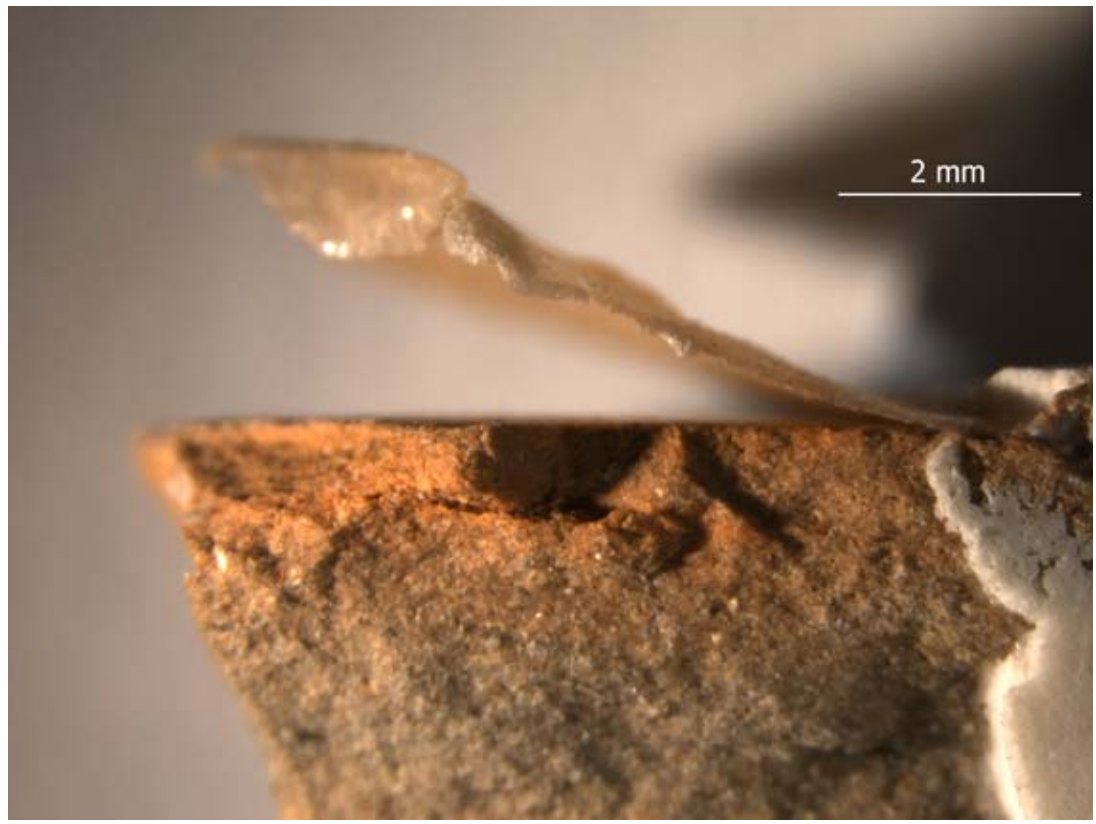

Figura II.9. Macrofotografía realizada mediante Lupa binocular en la que se observa un pequeño fragmento cerámico, el cual ha sido protegido parcialmente con una fina película de látex antes de aplicar una masilla.

Con cualquiera de los productos mencionados, a excepción del film plástico, se debe realizar una prueba, ya que hay que asegurar que no dejan restos de adhesivo sobre piezas porosas, ocasionando manchas irreversibles con el tiempo. Del mismo modo, hay que comprobar que la fuerza de pelado sea débil y no arrastre partículas cerámicas y posibles decoraciones al eliminarlas.

Sea cual sea el tipo de material reintegrante éste penetrará más o menos en los poros de la pasta cerámica cuando realicemos el relleno de la laguna, siendo difícil su completa eliminación. Esta 
problemática se puede evitar aplicando un "estrato intermedio" en los bordes cerámicos de la laguna.

No todos los profesionales de este campo realizan esta operación, siendo a nuestro modo de ver una de las más importantes, ya que de ello depende la estabilidad de una cerámica ante masillas que puedan contaminar la pasta cerámica adyacente.

Muchos de los problemas de contaminación o penetración en exceso de masillas se pueden evitar aplicando este estrato. Consiste básicamente en la aplicación de una película aislante de resina acrílica (Paraloid B-72). 


\section{II.5.3. APLICACIÓN DE LA MASILLA}

Dependiendo de la composición de la masilla y su dosificación ésta tendrá distintas consistencias, distinguiendo entre líquida, espesa o pastosa. En función de ésta consistencia y la ubicación de la laguna elegiremos un tipo de soporte que realice la función sustentante de la masilla durante su fraguado y secado.

Por lo general una masilla líquida es aplicada mediante vertido o inyección, una espesa mediante vertido o espatulado y si es de consistencia pastosa mediante espátula de acero flexible.

No cabe duda que una masilla líquida se adaptará bien a toda la superficie de la laguna y a su soporte o molde. Aunque un restaurador experimentado no debe tener problema en este sentido si aplica masillas densas o pastosas.

\section{II.5.3.1. Moldes y soportes sustentantes.}

En la actualidad disponemos de abundante bibliografía específica relativa a la metodología de realización de moldes, por ello no nos extenderemos demasiado en este capítulo. A continuación revisamos brevemente la metodología de realización de moldes, así como, los tipos y materiales de moldes y soportes principales utilizados para la aplicación de la masilla en lagunas de cerámica arqueológica. 
Todas las masillas requieren un material de soporte durante el fraguado y secado de las mismas. Dependiendo del tamaño y disposición de la laguna, en una cerámica dada, podemos elegir un tipo de molde o soporte.

Éstos moldes o soportes, además de cumplir una función sustentante de la masilla también pueden cumplir la función de replicar la forma de la zona faltante, actuando como un negativo de la laguna, a estos soportes se les denomina moldes.

El proceso es relativamente sencillo, ya que con el material de moldeo se adquiere la impronta de una zona original de la pieza que corresponda a la laguna a intervenir. A continuación el molde obtenido se traslada a la laguna. Los moldes pueden ser simples o dobles y su elección dependerá tanto de la habilidad del restaurador como de la ubicación de la laguna dentro de la pieza.

En el caso de tener una laguna rodeada de cerámica (cuerpo o base de una vasija) el molde será simple, y se podrá disponer encima de la laguna tanto en el exterior como en el interior, dependiendo de la accesibilidad al trabajo. Por lo general, se recomienda efectuar y disponer el molde en el interior de piezas más o menos cerradas o en el reverso, en el caso de tener que reintegrar lagunas en objetos más o menos planos, como un plato.

Este tipo de molde es uno de los más utilizados, ya que generalmente el tipo de masillas que se viene utilizando son de tipo pastoso, 
indudablemente a excepción de las escayolas que si permiten un vertido.

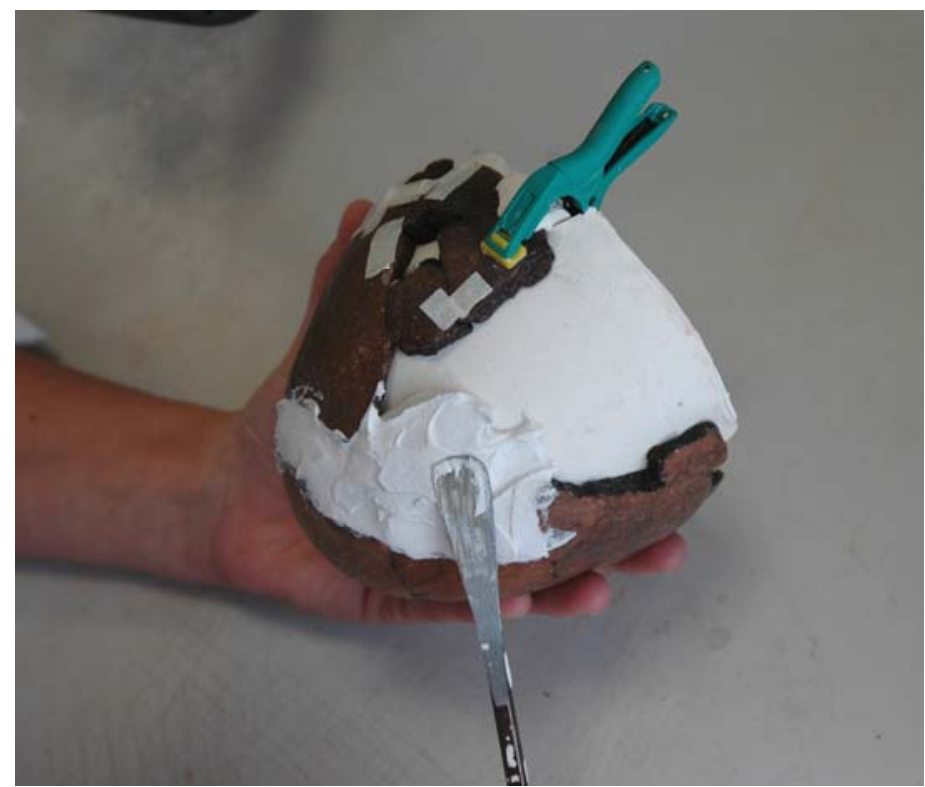

Figura II.10. Molde simple.

Sin embargo, si la laguna está situada en un borde de la pieza (bocas de vasijas, bordes de platos, etc.), podremos realizar un molde doble (molde y contramolde) tanto en el anverso o interior como en el reverso o exterior de la pieza. El molde quedará abierto por uno de sus lados, siendo esta abertura aprovechada para verter o inyectar la masilla preferiblemente líquida o densa.

En piezas cerámicas también se pueden dar otro tipo de lagunas, como las exentas (asas, motivos decorativos, etc.), estas lagunas se pueden reintegrar siempre y cuando dispongamos de un paralelo en la propia 
pieza. Se puede realizar obteniendo un molde simple o doble, dependiendo de las salidas o entradas que tenga el original a replicar. De la misma forma el molde podrá acoplarse en la misma pieza o realizarlo fuera de ella, siendo en este caso más aconsejable realizarlo doble y con un orificio para colar la masilla preferiblemente líquida.

Los materiales más aconsejados para la realización de estos moldes (simples o dobles) son:

- Plastilina blanca.

Se trata de un material blando y moldeable, que al presionarlo sobre el original recoge bastante bien la impronta a reproducir. Es un material fácil de usar, aplicar y de bajo coste. Por el contrario es un material que al desmoldear puede perder la impronta a reproducir. Otro de los inconvenientes que debemos tener en cuenta tanto en la elaboración del molde como en el transcurso en el que éste actúa como soporte de la masilla, es que sus componentes grasos pueden originar manchas en la superficie cerámica original, por lo que se debe aislar la zona en contacto, bien con látex, film plástico o cinta adhesiva de papel a modo de película protectora aislante.

- Placas de cera dental.

Este material debe ser calentado, bien con aire caliente o por inmersión en agua caliente, para adquirir una consistencia blanda y que se ajuste a la zona a reproducir. Su ventaja radica que al enfriar y desmoldear no pierde la impronta reproducida y su desventaja es que al tratarse de un material rígido no se adapta demasiado bien a los 
contornos cerámicos de la laguna. Es importante realizar un tamaño de molde lo más ajustado a la laguna, no sobresaliendo de ésta más de un centímetro, con ayuda de cinta adhesiva de papel y pinzas podremos sujetar el molde a la cerámica.

- Siliconas.

Son elastómeros con buenas propiedades de elasticidad, resistencia a la tracción, estabilidad y antiadherencia. Especialmente indicados para la obtención de moldes de partes exentas. Permiten obtener moldes de una altísima calidad aunque su adquisición puede resultar cara. En la actualidad este producto permite obtener réplicas de materiales como la resina epoxídica.

- Látex.

Indicado para la obtención de pequeños motivos decorativos en relieve. Es un material muy flexible que se aplica por capas, puede reforzarse con serrín, talco, etc. para reducir su considerable tracción y evitar su desgarro. Es incompatible con las resinas epoxídicas.

Aparte de los moldes existen otros tipos de soporte para la sustentación de la masilla en este proceso. Estos métodos están indicados en la ejecución de grandes lagunas o bien en piezas donde su morfología cerrada impide la extracción del molde una vez montada la pieza (jarras o vasijas con boca estrecha). Los métodos más utilizados son: 
- El método del globo.

Es un procedimiento útil en la reconstrucción de lagunas en la que su acceso a su cara interior solo se puede realizar a través de una boca o un cuello muy estrecho. Al introducir e hinchar ${ }^{40}$ un globo por su boca o cuello éste ira aumentando de tamaño y adaptándose a la forma interna de la pieza, obturando la laguna internamente y realizando la función de soporte para reintegrar la laguna.

- El método de la arena.

Consiste en realizar un soporte interno con arena. Obturados externamente los huecos de las lagunas existentes en la pieza mediante unas gasas, la pieza se llena de arena. A través de la gasa humectamos la arena con agua con el fin de compactarla. Se retiran las gasas y se da forma a la arena, constituyendo un molde interno. Se debe aplicar una resina en la superficie con el fin de que la arena quede bien compactada y ejerza de desmoldeante con la masilla que se aplique. Una vez seca la reintegración se retira la tierra por el hueco inicial de entrada.

\footnotetext{
${ }^{40}$ La introducción de aire en el globo debe de realizarse poco a poco, controlando la presión que éste ejerce dentro de la cerámica ya que si se trata de cerámicas de baja cocción, una presión excesiva puede provocar fisuras o roturas.
} 


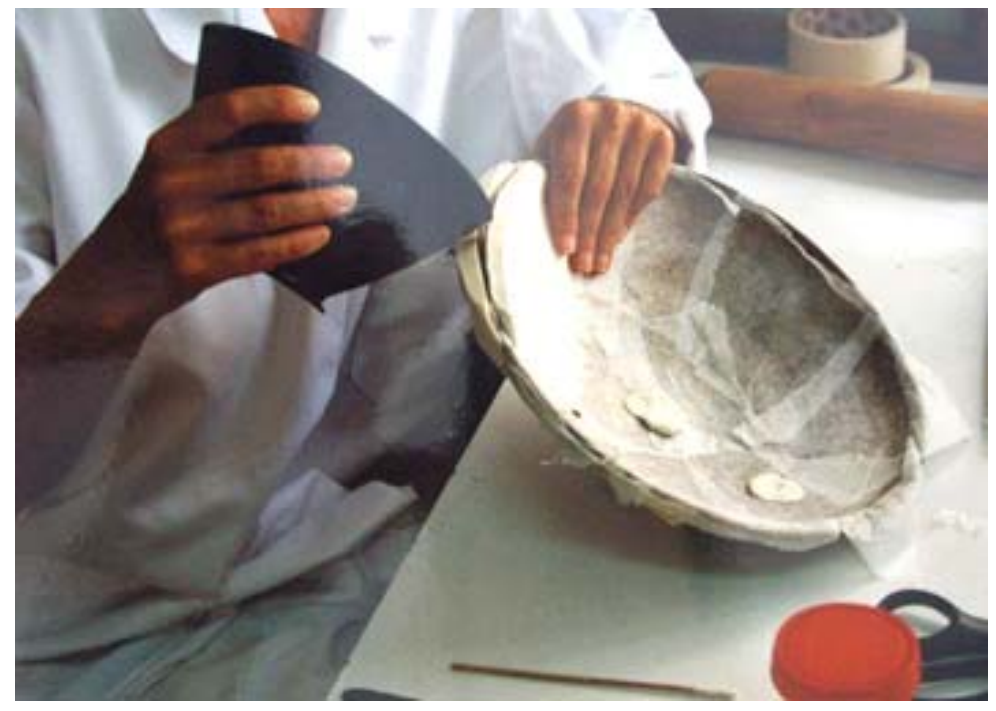

Figura II.11. Molde de plastilina y vertido del producto reintegrante.

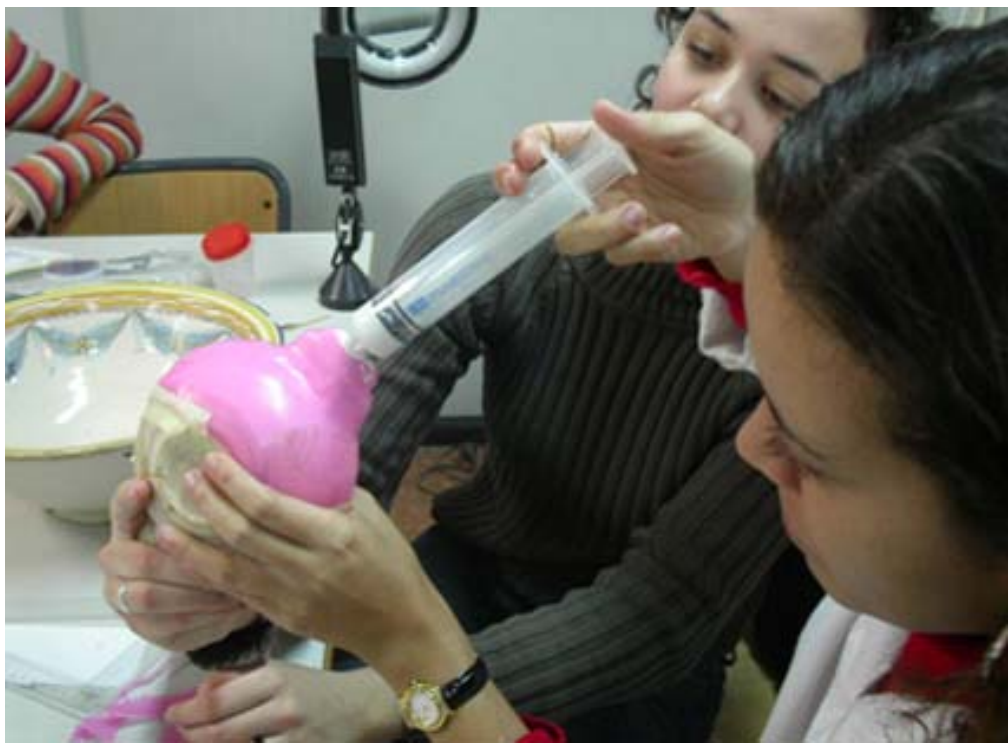

Fig. II.12. Molde doble de cera dental e inyectado del producto reintegrante. 


\section{II.5.4. NIVELACIÓN Y PULIDO.}

Uno de los requisitos en restauración de cualquier bien cultural es la discernibilidad de las actuaciones o intervenciones. En la mayoría de los casos esta discernibilidad se consigue a través del retoque cromático de las reintegraciones volumétricas, efectuado a bajo tono o tinta neutra.

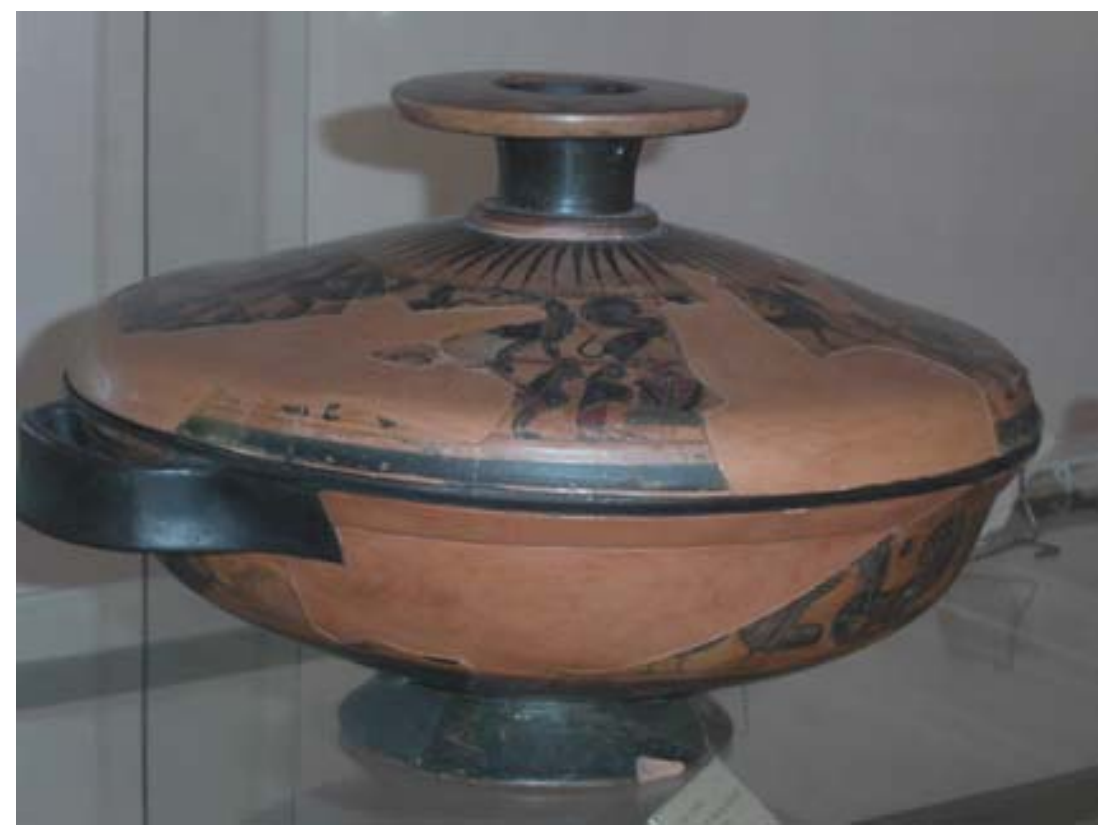

Figura II.13. Lagunas retocadas cromáticamente con tinta neutra. Museo Arqueológico de Palermo, Italia.

En lo referente a la cerámica arqueológica, en el taller de Conservación y Restauración de materiales Arqueológicos y Etnográficos del departamento de Conservación y Restauración de Bienes Culturales de la Universidad Politécnica de Valencia, esta 
discernibilidad la llevamos a cabo en la misma reintegración volumétrica. Para ello se practica un bajo nivel en la laguna reintegrada de unos $2 \mathrm{~mm}$. Éste se puede efectuar, preferiblemente, durante el fraguado de la masilla o estuco, con ayuda de medios mecánicos como bisturí o escalpelo. El pulido de la superficie, en caso de ser necesario, es preferible realizarlo cuando el estuco o masilla se encuentre totalmente seco mediante papeles abrasivos.

El bajo nivel efectuado en las reintegraciones es retocado cromáticamente con pinturas reversibles, preferiblemente al agua, ejecutando la técnica del estarcido mediante aerógrafo, y si procede a pincel.

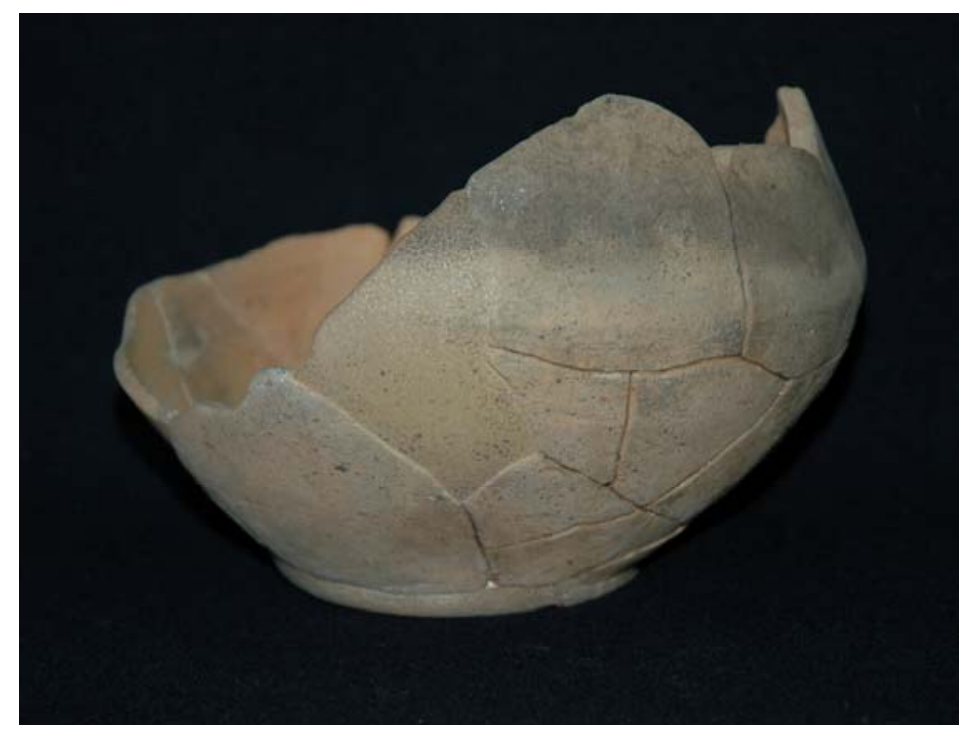

Figura II.14. Reintegración parcial de lagunas a bajo nivel y retoque cromático con la técnica del estarcido mediante aerógrafo y pincel. 


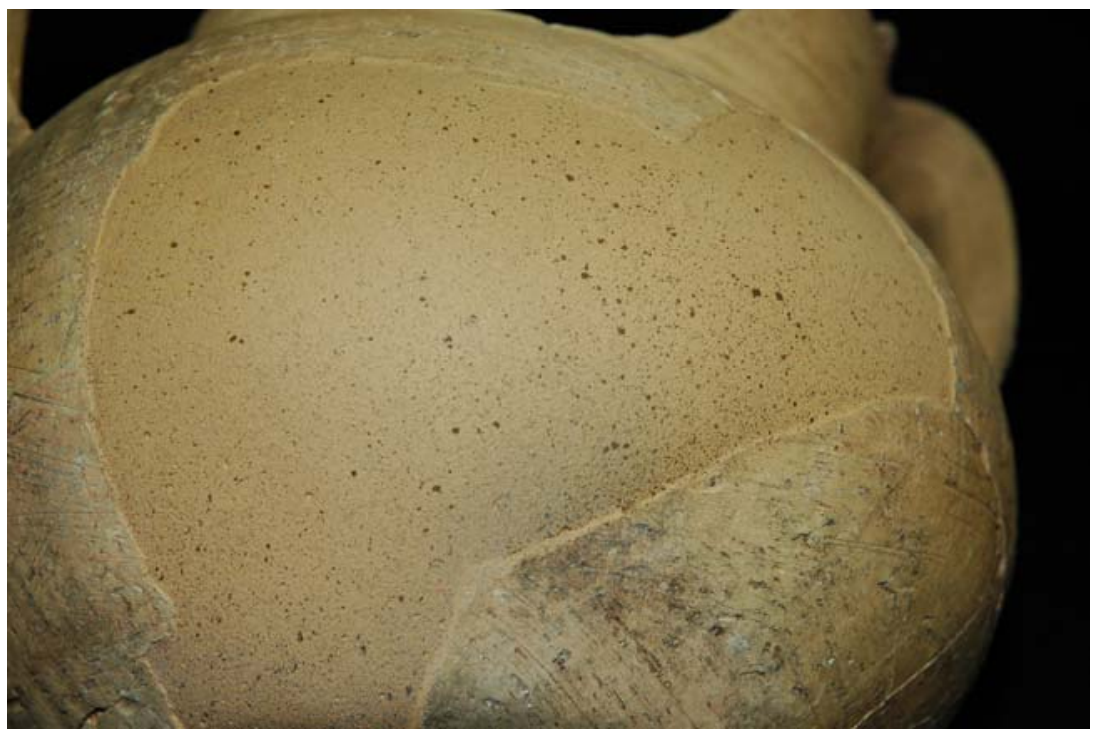

Figura II.15. Detalle de reintegración volumétrica a bajo nivel y retoque cromático con la técnica del estarcido mediante aerógrafo. 


\section{II.5.5. REINTEGRACIONES DESMONTABLES.}

Como su propio nombre indica, son reintegraciones volumétricas que por la metodología de su realización pueden ser separadas de la pieza original, no entrando en contacto directo con el cuerpo cerámico.

Con esta práctica conseguimos dos objetivos principales:

- Que la masilla no penetre en los poros de la cerámica y sea totalmente reversible.

- En caso de encontrar los fragmentos originales en un futuro, poderlos insertar en su lugar original sin provocar excesivos daños a la pieza original al retirar las reintegraciones efectuadas.

Este tipo de reintegración debe realizarse antes de la adhesión completa de los fragmentos, sobre todo cuando se realiza en lagunas cerradas o rodeadas por piezas. Dado que el principal objetivo es conseguir reintegraciones desmontables, éstas deben poder ser separadas sin dificultad de la laguna. Por lo tanto, los fragmentos que se encuentren a su alrededor deben ser retirados una vez finalice la reintegración de la laguna.

Antes de que la laguna reciba el material reintegrante, es necesario aislar los bordes cerámicos de ésta. Son varios los materiales que se 
pueden utilizar como aislante. Koob, S (1987) ${ }^{41}$, introductor y defensor de ésta técnica, nos describe este paso aislando el corte cerámico con una hoja de papel de aluminio.

Nuestra investigación en este tipo de metodología nos ha llevado a la conclusión, que uno de los mejores materiales aislantes y que mejor permiten a la masilla tomar la impronta, de la rotura de los bordes de la laguna, es el látex. Con una fina película, el látex, permite aislar totalmente la masilla de la cerámica sin que ésta penetre en ninguno de sus poros. Una vez realizadas y secas las reintegraciones, son desmontadas y adheridas al igual que los fragmentos situados a su alrededor.

Esta práctica es altamente indicada para efectuar reintegraciones con masillas que puedan contaminar por higroscopicidad la pasta cerámica original (escayola, polyfilla, etc).

En determinados casos las lagunas desmontables en ocasiones son inviables, ya que los cortes de los fragmentos adyacentes a las lagunas pueden ser en ocasiones muy irregulares, dificultando o imposibilitando la salida de este tipo de reintegraciones.

${ }^{41}$ Koob, S., "Detachable plaster restorations for Archaeological Ceramics" en Recents advances in the Conservation and Analysis of Artifacts. Jubilee consevation conference, London.1987. pp. 63-65 
Geschke, R., desarrolla otro método ${ }^{42}$, para eliminar la contracción de las lagunas reintegradas en arcilla cocida. primero realiza la reintegración de las lagunas en una pieza cerámica, con escayola. Con esta reintegración realiza un molde en silicona que tras su curado es sumergido en disolventes hidrocarbonados (8:1 acetona:white spirit) durante 20 horas, en la cual el molde aumenta en un 15\%, igual a lo que contrae la cerámica al cocer, a continuación moldea arcilla en los moldes obtenidos y cuando las reintegraciones están secas son cocidas. estos fragmentos son adheridos a la pieza original con resina epoxídica (adhesivo caracterizado por su alta irreversibilidad.), pero la contracción de la arcilla al cocer es muy difícil de controlar por lo que requiere estucar las zonas no cubiertas por esta reintegración con masilla.

En 1996 Hogan, L et alt ${ }^{43}$, nos describen el proceso, en opinión de la doctoranda, de reconstrucción más que de restauración de una pieza completa a partir de unos fragmentos originales, aproximadamente un $35 \%$ del original. Partiendo de la morfología de una pieza en la que sólo se conservan unos fragmentos, realizan una pieza completa en arcilla calculando el grado de contracción que ésta tiene al secar y al cocer. Antes de introducir la pieza en el horno, cuando la arcilla se encuentra en dureza cuero, se sitúan los fragmentos originales encima de la pieza de arcilla realizada, para señalar su posición por medio de

\footnotetext{
${ }^{42}$ Geschke, R., "Ceramic Gap-fills for Ceramic Restoration" En: The Conservator. $N^{o}$ 28, 2004. pp.74-83.

${ }^{43}$ Hogan, L et alt "Reconstructing major missing areas of ceramic vessels using clay" En: Triennial meeting (11 $\left.{ }^{\text {th }}\right)$. Edinburgh, 1-6 September 1996: preprints/ICOM. Committee for Conservation. Paris, France. London: James \& James, 1996. p.p.
} 
orificios en todo su perímetro, cortando a continuación la sección señalada. Cuando esta nueva pieza es cocida, se insertan en las lagunas originadas los fragmentos originales. La contracción experimentada por la nueva pieza hace que los fragmentos originales no coincidan en su posición correcta por lo que tienen que recurrir al empleo de masilla para adherirlos.

Es difícil justificar la reintegración formal de una pieza a partir de un porcentaje tan bajo de fragmentos originales. En el caso descrito anteriormente, en nuestra opinión, una reproducción moderna de cerámica, sin incluir en ella los fragmentos originales, sería mas apropiado. Si añadimos a todo esto, que hoy en día disponemos de otros materiales y métodos expositivos, esta técnica parece ser innecesaria y extremadamente larga en cuanto a tiempo.

En ocasiones nos encontramos ante piezas con un porcentaje bajo de original (40\%) formadas por un conjunto de fragmentos que nos ofrecen la información completa de su imagen.

La disposición de los fragmentos, en estos determinados casos, pueden obligarnos a realizar una reintegración parcial ya que tienen puntos de unión muy limitados para exponer la pieza en todo su conjunto solamente efectuando la adhesión.

Pero atendiendo a su bajo porcentaje podemos valorar, según la importancia de la pieza, a una exposición global y siempre reversible sobre un soporte inerte. 
Éste soporte inerte puede ser realizado tras un estudio minucioso de la forma interna del objeto, de manera que los conjuntos de fragmentos, se acoplen sobre dicho soporte, pudiendo contemplar la pieza en su globalidad. Los materiales de este soporte pueden ser variados (poliestireno extrusionado, metacrilato, etc.) siempre que sean inertes, con un acabado bien traslúcido o bien con una coloración acorde a la pieza original, como podemos apreciar en las siguientes fotografías.

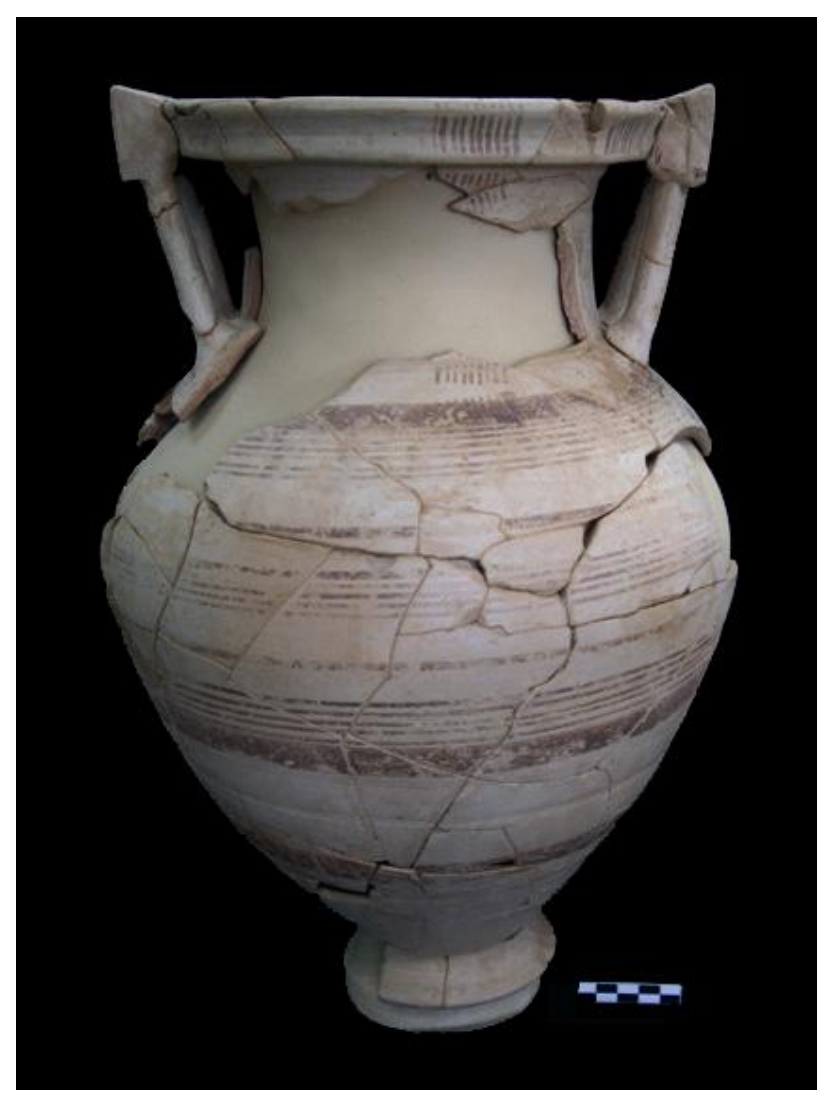

Fig. II.16. Crátera de época Ibérica. Museo Municipal de Enguera. Valencia. Vista frontal. 


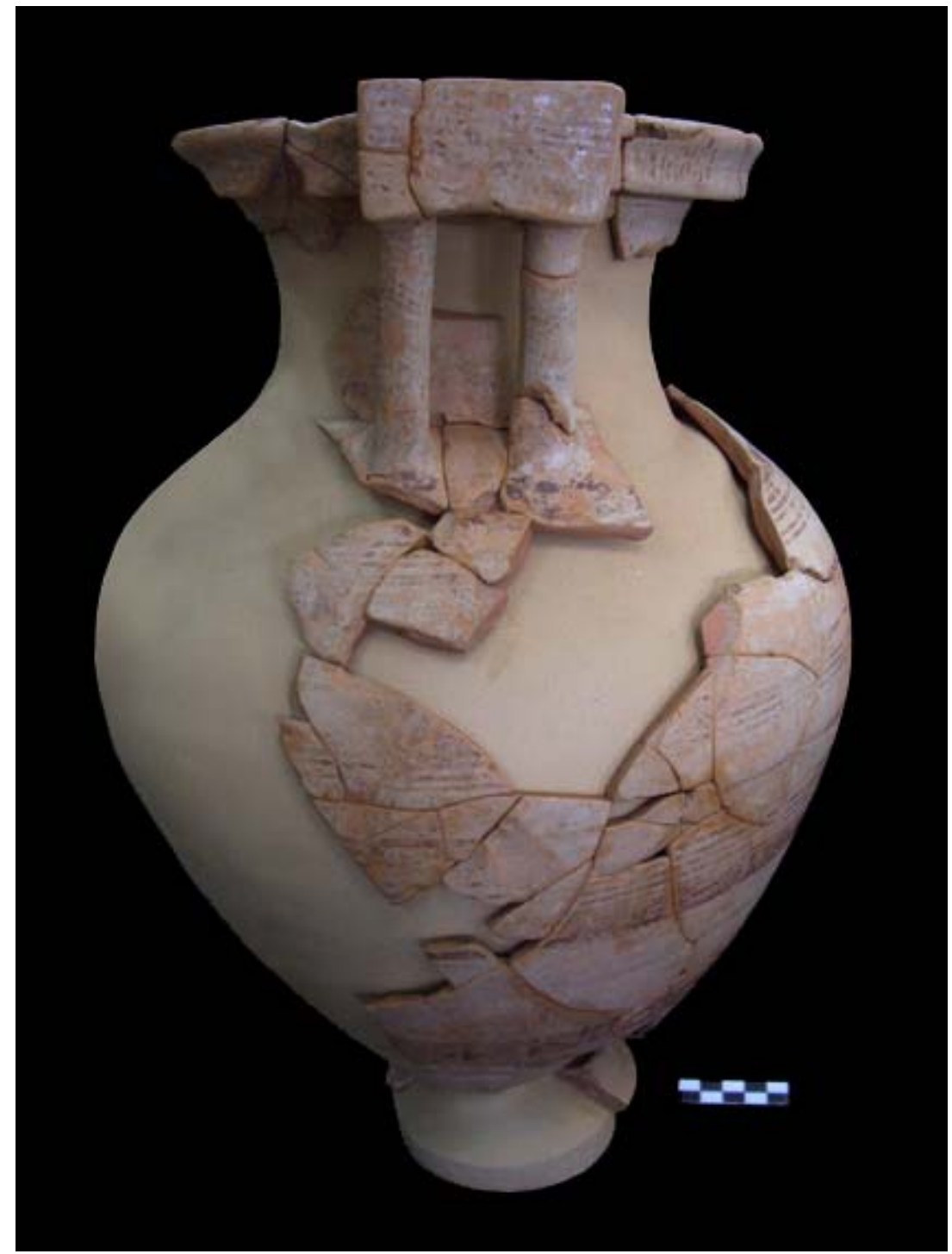

Figura II.17. Crátera de época Ibérica. Museo de Enguera. Valencia. Vista lateral. 



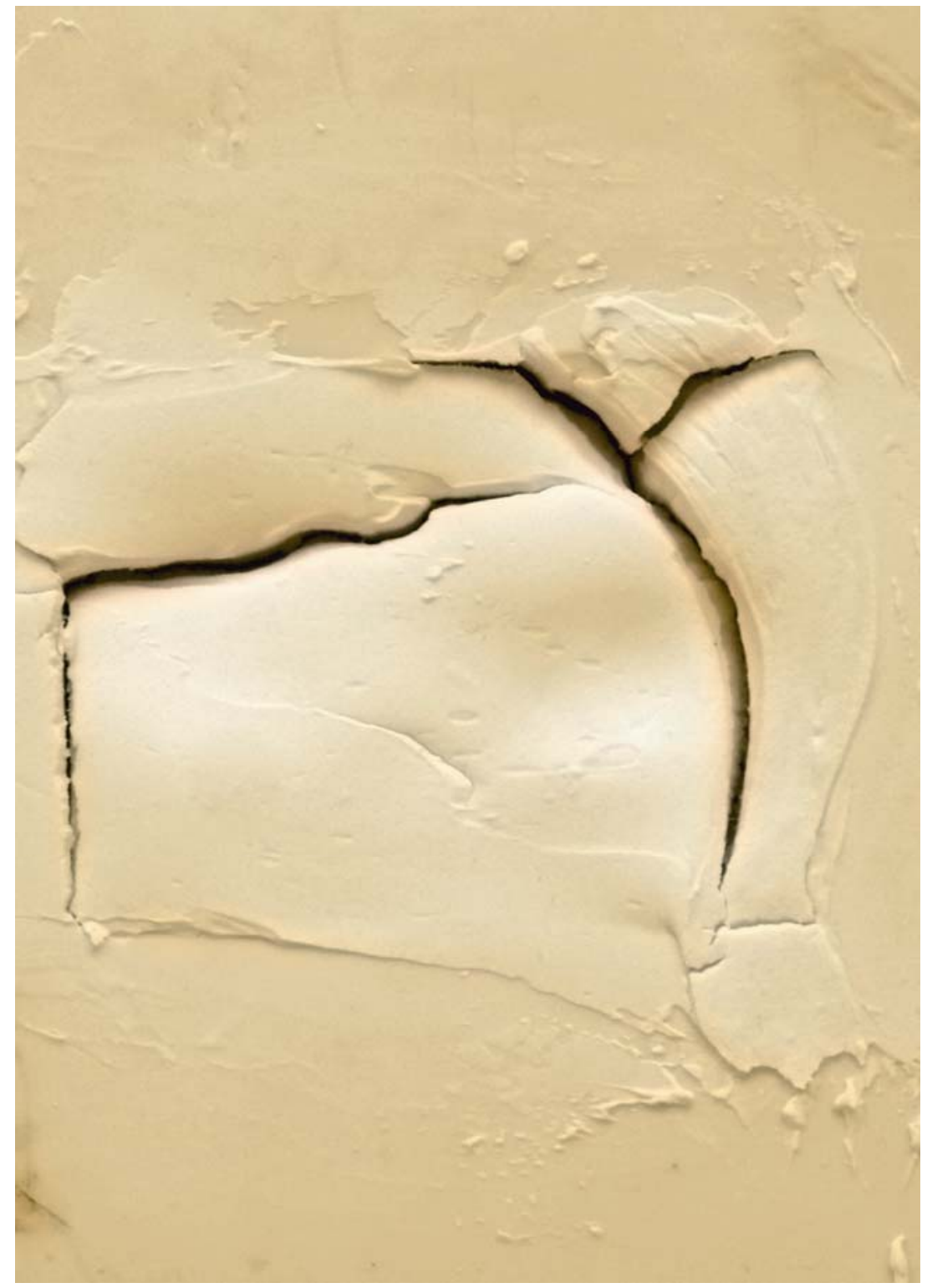

II.6.

REQUISITOS DE LAS MASILLAS DE RELLENO 



\section{II.6. REQUISITOS DE LAS MASILLAS DE RELLENO.}

Toda masilla de relleno o estuco, destinada a reintegrar lagunas en cerámicas arqueológicas debería cumplir una serie de requisitos para conseguir un óptimo comportamiento y estabilidad a largo plazo.

A continuación se muestran los parámetros que deberíamos tener en cuenta a la hora de seleccionar el material reintegrante:

\section{Estabilidad físico-química y biológica.}

Debería poseer una buena estabilidad frente al envejecimiento causado por la acción de los agentes de deterioro ambiental (humedad, temperatura y luz), así como ser indemne al asentamiento de bacterias y mohos.

\section{Reversibilidad.}

Se debería eliminar fácilmente sin dañar la cerámica original, esta reversibilidad puede ser dada a través del estrato intermedio.

\section{Compatibilidad.}

Con los materiales de la obra y los añadidos a ésta durante su restauración (tinción previa de la masilla consolidantes, adhesivos, retoques cromáticos, ect.).

4. Preparación rápida o capacidad de poder ser almacenada 0 conservada durante algún tiempo. 


\section{Facilidad de aplicación.}

Mediante inyección, vertido o espatulado.

\section{Que permita modelarse o moldearse.}

Que sea capaz de recoger la impronta de moldes o bien pueda ser moldeada mediante espátula.

7. Tiempo de fraguado rápido con el tiempo suficiente para poder aplicar la masilla y efectuar la nivelación.

\section{Capacidad de adhesión.}

Entre la masilla y la cerámica.

9. Que experimente una mínima variación de volumen o agrietamiento durante su fraguado o secado.

\section{Facilidad de nivelación y pulido.}

Mediante instrumental quirúrgico o papeles abrasivos.

\section{Dureza adecuada.}

La masilla seleccionada debería ser menos dura que la pasta cerámica original.

12. Que permita el retoque cromático.

Bien coloreándose la masilla previamente o retocando la reintegración una vez seca.

\section{Nula o baja toxicidad.}





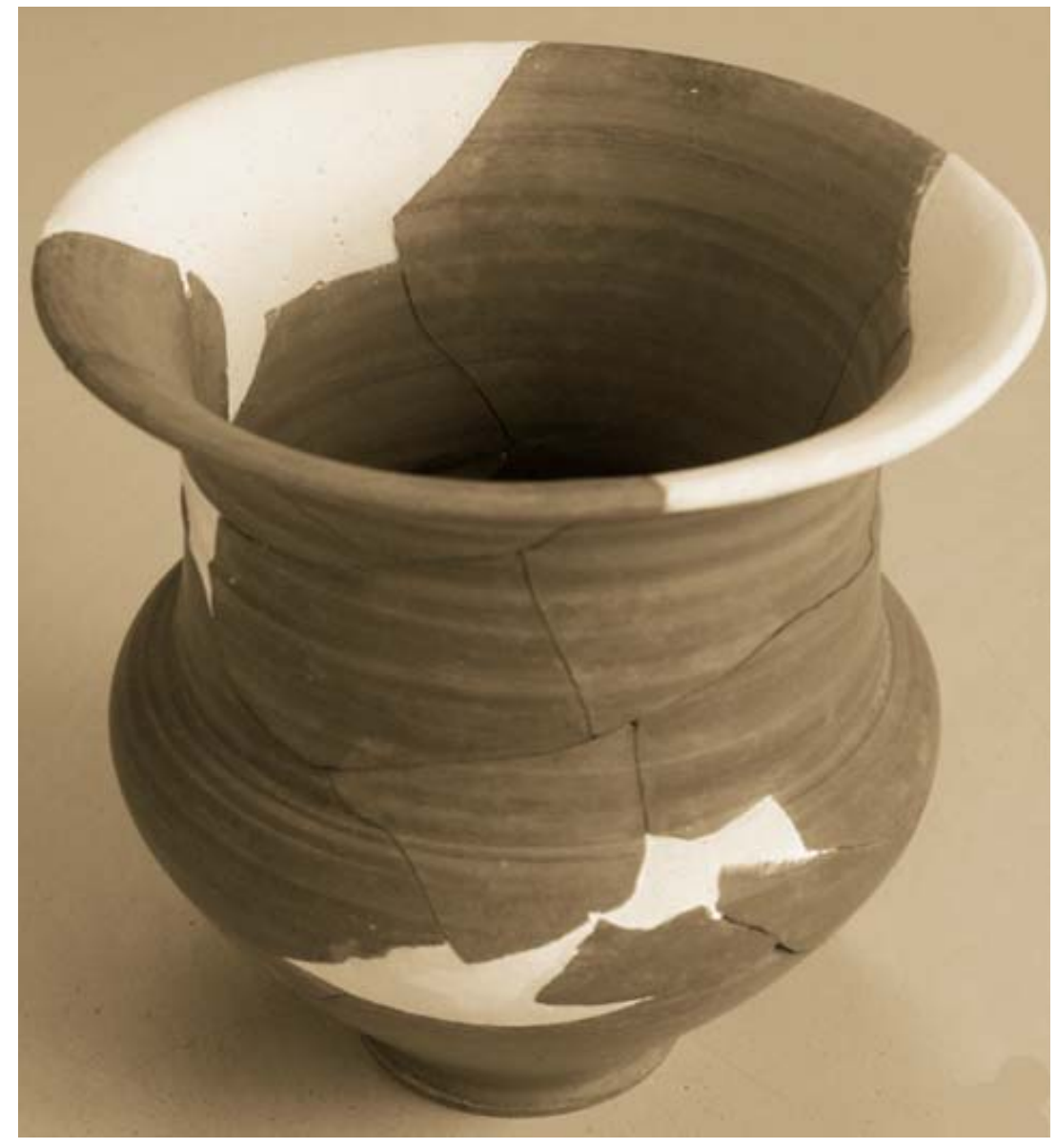

III.1. OBJETIVOS 



\section{OBJETIVOS.}

Hasta el momento hemos recopilado información referente a las distintas intervenciones que se realizan en la ConservaciónRestauración de cerámica arqueológica; la reintegración formal, desarrollada en la II parte de esta Tesis Doctoral ha expuesto el desarrollo de las metodologías y materiales utilizados hasta nuestros días, así como la descripción de un buen estuco o masilla.

El interés por encontrar nuevos productos alternativos a las escayolas y ceras ha dado lugar a una creciente investigación como hemos visto en capítulos anteriores. Por esta razón, el estudio llevado a cabo se ha centrado en la caracterización de las masillas que han venido utilizándose hasta el momento (tradicionales) y otras susceptibles de ser utilizadas como alternativas a las anteriores.

Los objetivos del trabajo de investigación desarrollados se concretan en:

A.- Elaboración de un "Catálogo de masillas para la Reintegración Volumétrica de Lagunas en Cerámicas Arqueológicas” para la caracterización de las masillas a corto - medio plazo. En dicho catálogo quedan expuestas y determinadas las propiedades cualitativas más importantes de cada una de ellas, incluyendo un diagnóstico de las mismas basado en sus ventajas e inconvenientes tras su utilización en la reintegración de lagunas de piezas cerámicas arqueológicas. Con ello, se pretende establecer la trabajabilidad y comportamiento de las 
masillas a corto y medio plazo, siendo capaces de poder realizar una primera elección de aquellas más idóneas.

B.- Estudio experimental de las masillas seleccionadas a largo plazo, el cual nos permita conocer o predecir el comportamiento de las mismas con el paso del tiempo, ante escenarios supuestos de degradación debida a la exposición de las piezas restauradas a los agentes atmosféricos (luz, humedad y contaminación atmosférica).

C. Identificar las masillas que mejor comportamiento ofrecen, tanto en cuanto a su aplicación en la laguna reintegrada, como en cuanto a su nivel de conservación con el paso del tiempo. Todo ello, sobre la base de los resultados obtenidos de:

- Trabajabilidad.

- Comportamiento.

- Estabilidad.

D. Evaluar las masillas alternativas a las tradicionales, y compararlas con éstas, en cada uno de los objetivos anteriores. 


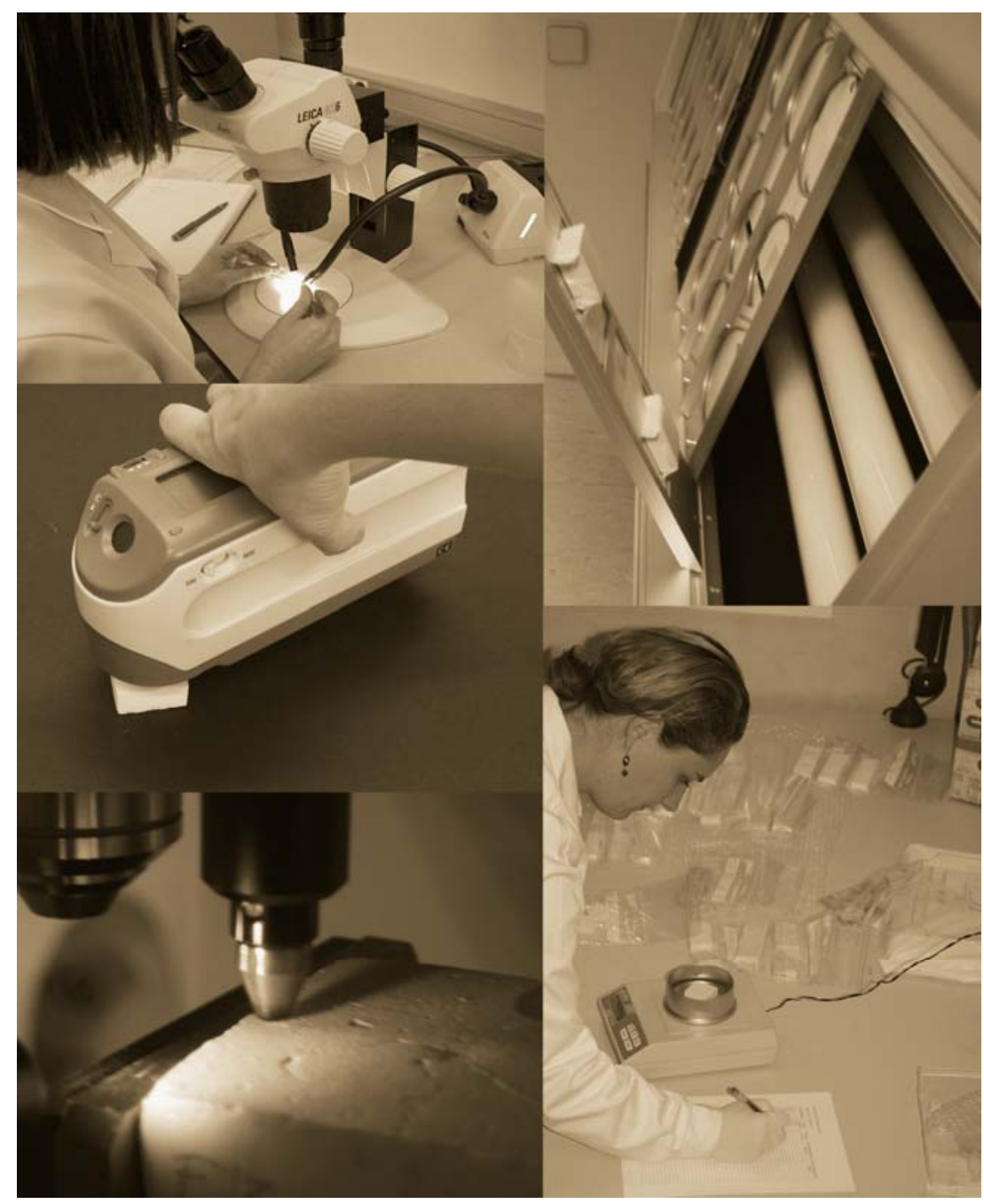

III.2.

FUNDAMENTO TEÓRICO DE LAS TÉCNICAS DE ANÁLISIS E INSTRUMENTACIÓN 



\section{III.2.1. INTRODUCCIÓN}

Consideramos los estudios científicos como una parte indisoluble a todo tratamiento de conservación y restauración de cualquier obra de arte, ya sea de tipo artístico, arqueológico o etnográfico; ya sea para la aplicación de una serie de análisis en la caracterización de los materiales presentes en la obra y en los procesos de degradación que ésta pueda sufrir, como en los materiales adicionados a las mismas en las distintas etapas que conforma la conservación y restauración de cualquier material.

Con el fin de lograr los objetivos establecidos, se han realizado diferentes técnicas analíticas para caracterizar las masillas ensayadas y reconocer los deterioros al ser expuestas a los distintos ensayos de envejecimiento artificial acelerado. Estos ensayos han sido realizados en distintos Laboratorios pertenecientes a la Universidad Politécnica de Valencia y a la Universidad Alfonso X el Sabio de Madrid:

Laboratorio físico-químico del Dpto. de Conservación y Restauración de Bienes Culturales e Instituto de Restauración del Patrimonio de la Universidad Politécnica de Valencia:

- Envejecimiento acelerado por irradiación con luz ultravioleta.

- Envejecimiento en atmósfera saturada de $\mathrm{SO}_{2}$.

- Espectroscopia infrarroja por transformada de Fourier (FT-IR). 
Taller de Conservación y Restauración de Materiales Arqueológicos y Etnográficos del Dpto. de Conservación y Restauración de Bienes Culturales e Instituto de Restauración del Patrimonio de la Universidad Politécnica de Valencia:

- Envejecimiento acelerado higrométrico.

- Determinación de densidades.

- Determinación de la trabajabilidad y comportamiento de las masillas

Taller de Óptica y Colorimetría del Dpto. de Conservación y Restauración de Bienes Culturales e Instituto de Restauración del Patrimonio de la Universidad Politécnica de Valencia:

- Espectrofotometría-Colorimetría.

Servicio de Microscopía Electrónica de la Universidad Politécnica de Valencia:

- Microscopía óptica (LM).

Laboratorio físico-Químico de la Universidad Alfonso X el Sabio de Madrid:

- Durometría. 


\section{III.2.2. MÉTODOS DE ANÁLISIS}

\section{III.2.2.1. Colorimetría}

\section{Principios generales}

La Colorimetría, como su propio nombre indica, es aquella parte de la Óptica que se ocupa del estudio de la medida del color, entendiendo por medir un color, el especificado de manera precisa y sin ambigüedades, de manera que pueda transmitirle a otra persona, la información necesaria para que un color sea interpretado de la misma forma con que nosotros lo percibimos.

Esta ciencia se ha convertido desde hace unas décadas, en una importante herramienta de análisis no destructivo de gran importancia en el campo de la Conservación y Restauración de obras de arte.

Una de sus aplicaciones más significativas en dicho campo es la realización de rigurosos ensayos de laboratorio sobre los posibles materiales a emplear en los procesos de restauración de un objeto, en nuestro caso las masillas, permitiendo advertir y valorar cuantitativamente los cambios cromáticos antes de ser percibidos por el ojo humano, posibilitando la elección del material más adecuado al fin deseado.

En el laboratorio de Colorimetría del Dpto. de Conservación y Restauración de Bienes Culturales se viene empleando desde hace 
años la espectrofotometría por reflexión, que, además de las coordenadas cromáticas, permite obtener el espectro de cada uno de los puntos medidos.

La toma de medidas se puede realizar por contacto y a distancia, en función de las características de la superficie a medir. En el caso de la presente investigación el estudio se ha efectuado por contacto, porque las características de las probetas lo permitían, pues la superficie a medir no estaba ni pulverulenta, ni mordiente, ni presentaba curvaturas de pequeño radio, ni deformaciones, condiciones estas que impedirían un contacto perfecto del instrumento, con los errores que esto conllevaría.

La ventaja del contacto es su fácil manejo, ya que al llevar la luz incorporada, podemos trabajar en ambientes iluminados, careciendo además de los problemas de posición que conlleva la técnica a distancia, donde, repetir las mismas condiciones de medida a veces es muy complicado, puesto que hay que referenciar meticulosamente, no solo la posición de los puntos, sino también la de todos y cada uno de los instrumentos empleados (medidor, fuentes de luz, etc.).

\section{Instrumentación}

Los datos espectrales y las coordenadas cromáticas realizadas para cuantificar los cambios cromáticos producidos en las probetas de las distintas masillas llevadas a estudio, tras ser sometidas a los distintos 
ensayos de envejecimiento acelerado, han sido obtenidos mediante un espectrofotómetro Minolta CM-2600d, eligiendo como condiciones de medidas el iluminante estándar CIE tipo D56 (luz día, temperatura de color $6500^{\circ} \mathrm{K}$ ) y el observador estandar $10^{\circ}$. Los datos se han tomado con componente especular incluida (SCI), que minimiza la influencia de las condiciones de la superficie de medida. En dicho medidor, se ha elegido el área de medida de $8 \mathrm{~mm} \varnothing$, ya que las dimensiones de las muestras lo permitían, pudiendo obtener de manera automática el valor medio de un área considerable de color.

La fuente de luz, incluida en dicho medidor, está formada por tres lámparas de xenón pulsante, estando su esfera integradora (de $52 \mathrm{~mm}$ de Ø) recubierta de $\mathrm{BaSO}_{4}$. El rango de longitud de onda del espectrofotómetro está comprendido entre 360 y 740 nm, cada 10nm, siendo su rango fotométrico de 0 al $175 \%$ de reflectancia, con resolución 0,01\%. En cuanto a su repetibilidad presenta una desviación estándar de 0,1\%, en reflectancia espectral, y, 0,04 para los valores colorimétricos de $\Delta \mathrm{E}^{*} \mathrm{ab}$ (CIE 76).

En cuanto a los espacios de color, utilizados en la presente investigación, comentar que se han utilizado los perceptivos CIELAB y CIELCH con los que se solventa el "problema", inherente al CIEYxy, de no-uniformidad en las diferencias de color, que hace muy costosa la comparación de los resultados.

El primero de los sistemas (idóneo para la medición de fuentes secundarias, que son las que nos ocupan) ha servido como base para 
calcular la diferencia cromática total entre dos estímulos, a partir de la siguiente ecuación (distancia euclidiana existente entre dichos puntos):

$$
\Delta \mathrm{E}^{*}=\sqrt{ }\left(\Delta \mathrm{L}^{*}\right)^{2}+\left(\Delta \mathrm{a}^{*}\right)^{2}+\left(\Delta \mathrm{b}^{*}\right)^{2}
$$

mientras el CIELCH, nos ha permitido hacer más asequible la información, al incluir las magnitudes psicofísicas Tono $\left(\mathrm{h}^{\circ}\right)$, Croma $\left(\mathrm{C}^{*}\right)$ y Claridad $\left(\mathrm{L}^{*}\right)$.

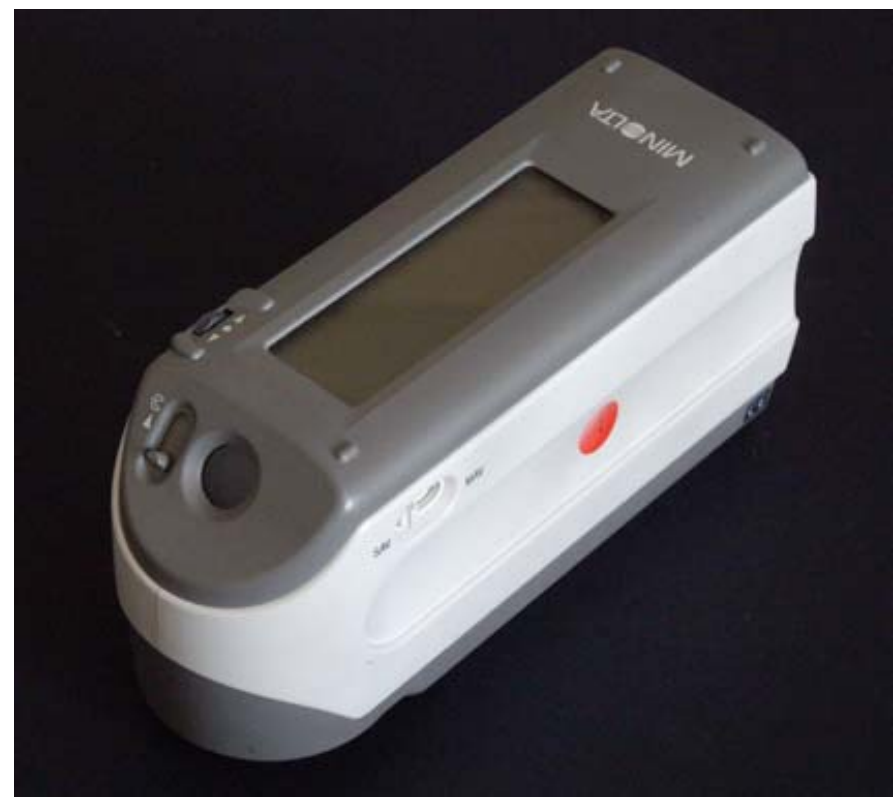

Figura III. 1. Espectrofotómetro Minolta CM-2600d utilizado en la toma de datos espectrales y coordenadas cromáticas. 


\section{III.2.2.2. Durometría}

\section{Principios generales}

El microdurómetro es una de las herramientas más empleadas para obtener medidas de dureza de un material a través de los distintos tipos de ensayos mecánicos. El ensayo de dureza es uno de los más empleados en la selección y control de calidad de los materiales, destacando entre ellos a los metales. La dureza es una condición de la superficie del material y no representa ninguna propiedad fundamental de la materia. Se evalúa convencionalmente midiendo la resistencia a la penetración de una herramienta de determinada geometría.

El ensayo de dureza es simple y de alto rendimiento y es particularmente útil para evaluar propiedades de los diferentes componentes microestructurales del material.

Los métodos existentes para la medición de la dureza se distinguen básicamente por la forma de la herramienta empleada (penetrador), por las condiciones de aplicación de la carga y por la propia forma de calcular (definir) la dureza. La elección del método de determinación de la dureza depende de factores tales como tipo, dimensiones de la muestra y espesor de la misma. En particular, el tipo de ensayo mecánico que hemos realizado en nuestro estudio es el tipo Vickers. 


\section{Instrumentación}

Las durezas obtenidas sobre la superficie de todas las muestras de masillas y cerámicas sin envejecer y envejecidas artificialmente han sido obtenidas mediante un Microdurómetro MICROHARDENESS TESTER FM de la marca Future-Tech, eligiendo como condiciones la dureza Vickers con penetrador de diamante con una carga de 300 gr.

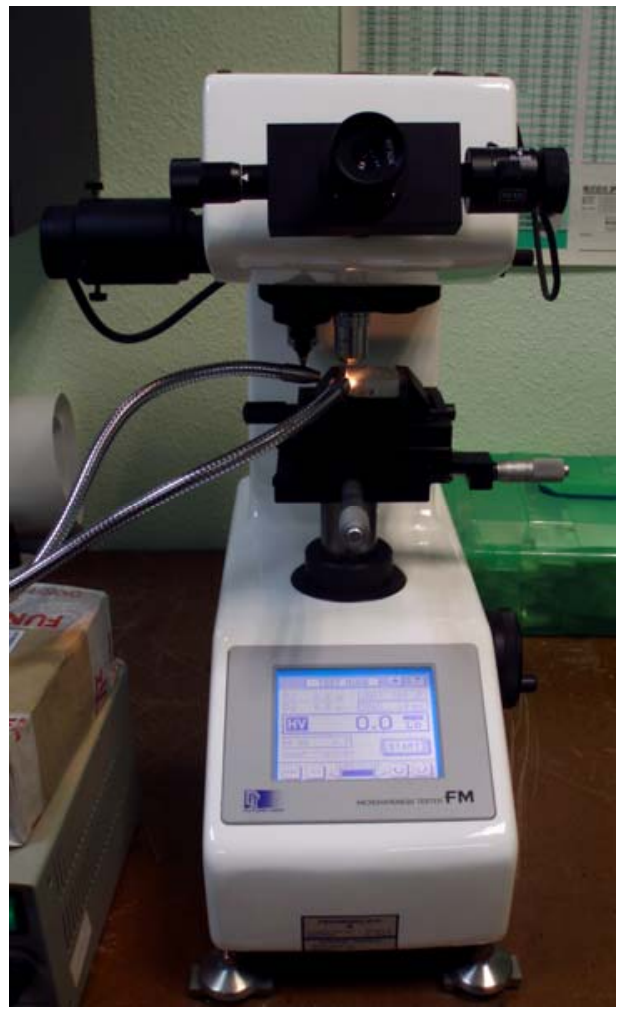

Figura III. 2. Microdurómetro utilizado en la toma de valores de dureza de las masillas tras los ensayos de envejecimiento acelerado. 


\section{III.2.2.3. Determinación de densidades}

\section{Principios generales}

La balanza electrónica de precisión es hoy en día indispensable en la toma de datos de cualquier tipo de ensayo que requiera un rigor de masa. En la presente investigación ha sido esencial el empleo de la balanza de precisión tanto para la elaboración de las masillas como para la obtención de los resultados de incremento/pérdida de masa tras someter las muestras a diferentes ensayos, como la determinación de la velocidad de evaporación y la determinación de masa tras el ensayo de envejecimiento acelerado en atmósfera saturada de $\mathrm{SO}_{2}$.

\section{Instrumentación}

Balanza de precisión electrónica modelo KERN con capacidad máxima de 40 gr y mínima de 0.001 gr

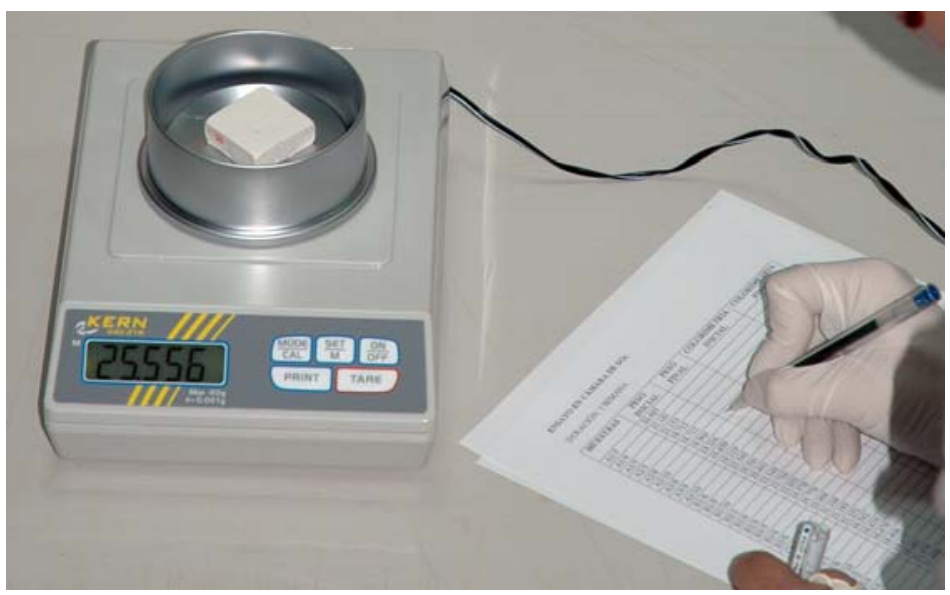

Figura III.3. Balanza utilizada en los ensayos. 


\section{III.2.2.4. Microscopía óptica (LM)}

\section{Principios generales}

La aplicación de la microscopía óptica al estudio de obras de arte y arqueología, permite desvelar la estructura interna de numerosos tipos de objetos, capas de pintura, pigmentos, etc.;morfología microscópica de materiales cerámicos, pétreos o metálicos como el tamaño de los poros, fisuras, identificación de microorganismos que atacan a las piezas $^{44}$, etc.

Con el empleo del Microscopio estereoscópico o Lupa binocular, pueden obtenerse niveles de resolución entre 8x y 80x., pudiéndose obtener imágenes al incorporar un adaptador de cámara fotográfica digital. En el presente estudio se han examinado bajo esta técnica los posibles cambios en las masillas ensayadas antes y después de someterlas a envejecimientos acelerados, así como la unión de la masilla a la cerámica.

\footnotetext{
${ }^{44}$ Gómez, M ${ }^{a}$ L., Examen científico aplicado a la conservación de obras de arte.Ed.Cuadernos Arte Cátedra. Instituto del Patrimonio Histórico Español. Madrid, 1998, p.186-188.
} 
Instrumentación.

Lupa binocular marca Leica, modelo MZ APO, con sistema fotográfico adaptable e iluminación por fibra óptica. Resolución/ aumentos entre $8 \mathrm{x}$ y $80 \mathrm{x}$.

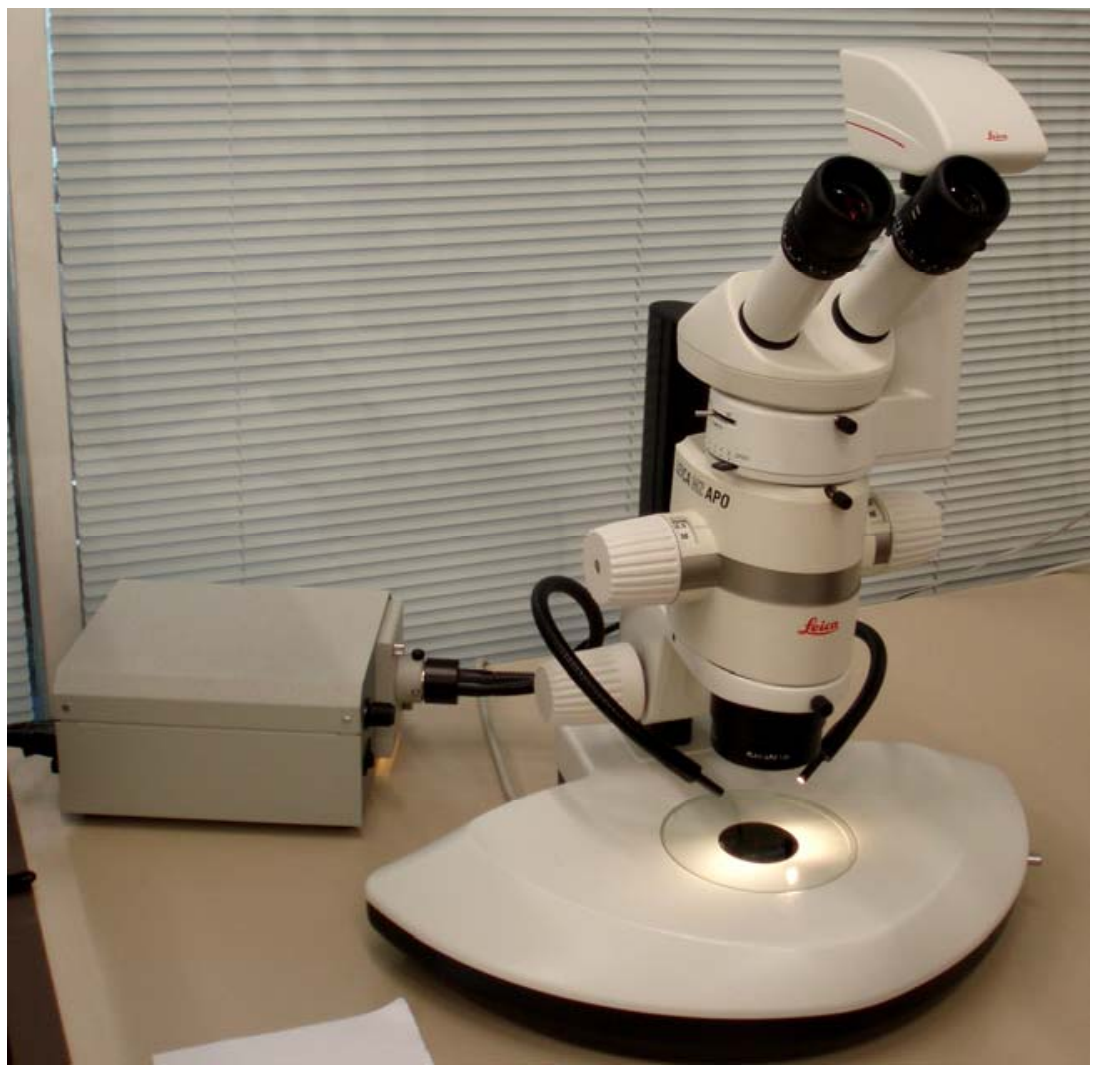

Figura III. 4. Lupa binocular utilizada en la observación y toma fotográfica de las masillas ensayadas tras los distintos envejecimientos acelerados y de la unión de las mismas con respecto a la cerámica. 


\section{2.2.5. Espectroscopía Infrarroja por Transformada de Fourier (FT-IR)}

\section{Principios generales}

La Espectroscopia Infrarroja por Transformada de Fourier (FTIR) es una técnica espectroscópica basada en la medida de la absorción de un haz de luz correspondiente a la región infrarroja proveniente de una fuente de excitación, producida al atravesar una muestra. Este haz luminoso no sufre dispersión y experimenta un cambio de fase con relación a otro haz de referencia. Una nueva combinación con el haz de referencia produce una interferencia de baja frecuencia que contiene toda la información relativa a la intensidad y frecuencia de la radiación. Este procedimiento matemático, denominado transformada de Fourier, se efectua a través de un programa informatizado.

La base teórica de esta técnica instrumental es la absorción de energía en la región infrarroja (2,5-25 $\mu \mathrm{m})$ del espectro electromagnético por las moléculas de la sustancia analizada. El espectro obtenido proporciona información relativa a los grupos funcionales de la molécula, y en general, a los enlaces químicos. La espectroscopia infrarroja tiene una gran aplicación en el análisis cualitativo y cuantitativo. Su principal utilización ha sido la identificación de compuestos orgánicos, que por lo general presentan espectros complejos en el infrarrojo medio con numerosos máximos y mínimos que resultan útiles al efectuar comparaciones ${ }^{45}$.

\footnotetext{
${ }^{45}$ Skoog, D., Leary, J., Análisis Instrumental,1994. Ed. McGraw-Hill. p.296
} 
En el presente estudio se han analizado mediante esta técnica todas las masillas ensayadas, antes y después de los distintos ensayos de envejecimiento acelerado, a continuación se comparan sus espectros y se detectan los posibles cambios sufridos en los componentes de la masillas.

\section{Instrumentación}

Espectrofotómetro Infrarrojo por Transformada de Fourier modelo VERTEX 70 BRUKER, equipado con el accesorio de ATR (Reflexión Total Atenuada) y un detector estabilizado de temperatura FR-DTGS (Sulfato Triglicina Deuterada).

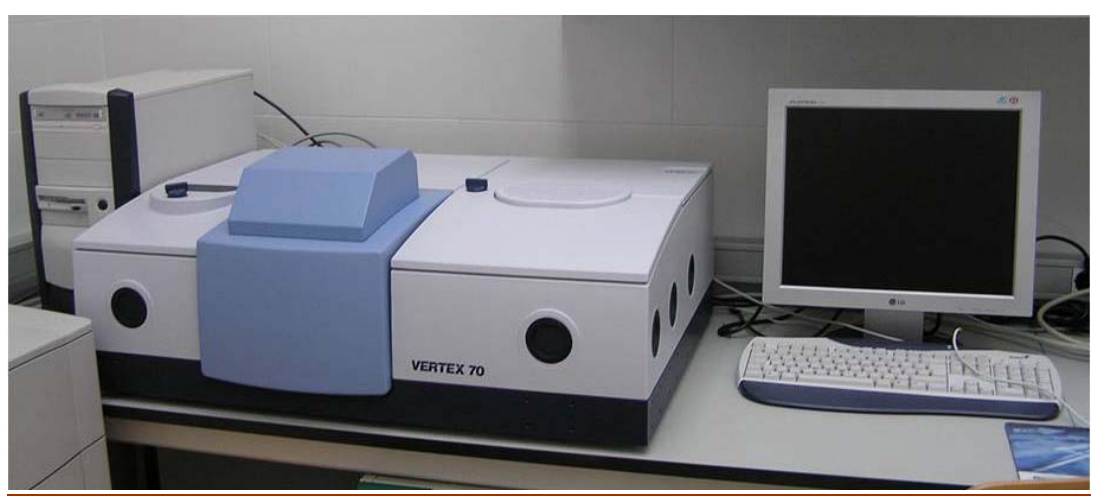

Figura III. 5. Espectrómetro Infrarrojo utilizado en el análisis de las masillas antes y después de ser ensayadas tras los envejecimientos acelerados. 


\section{III.2.3. ENSAYOS QUÍMICOS DE ENVEJECIMIENTO}

\section{III.2.3.1. Envejecimiento acelerado de humidificación y secado}

\section{Principios generales}

Esta experiencia pretende estudiar los efectos que las variaciones de humedad relativa y secado tienen en los materiales.

Las condiciones de humedad en las muestras se pueden lograr por exposición a una atmósfera con 100\% de humedad relativa, por inmersión, niebla o sobresaturación, manteniendo en este último caso las proximidades de la muestra. Lo más frecuente es establecer ciclos cuidando de que tengan la duración suficiente para permitir que la muestra alcance el equilibrio ${ }^{46}$.

\section{$\underline{\text { Instrumentación }}$}

La experiencia se ha llevado a cabo en dos campanas de vidrio de tipo desecación:

- Campana de vidrio tipo desecación en la que su base se llena de agua y sobre su rejilla cerámica se disponen las muestras sometidas a estudio, acompañadas de un termohigrómetro que captura los valores de H.R. y T. Esta cámara al cabo de 1 h. alcanza el 95-98\% H.R.

\footnotetext{
${ }^{46}$ Martín, A., Ensayos y experiencias de alteración en la conservación de obras de piedra de interés histórico artístico. Fundación Ramón Areces. 1990, p.516
} 
- Campana de vidrio de desecación, en la que su base se llena de gel de sílice y sobre la rejilla cerámica se disponen las muestras sometidas a estudio, acompañadas de un termohigrómetro que captura los valores de H.R. y T. Esta cámara al cabo de 1 h. alcanza entre el 10-15\% H.R.
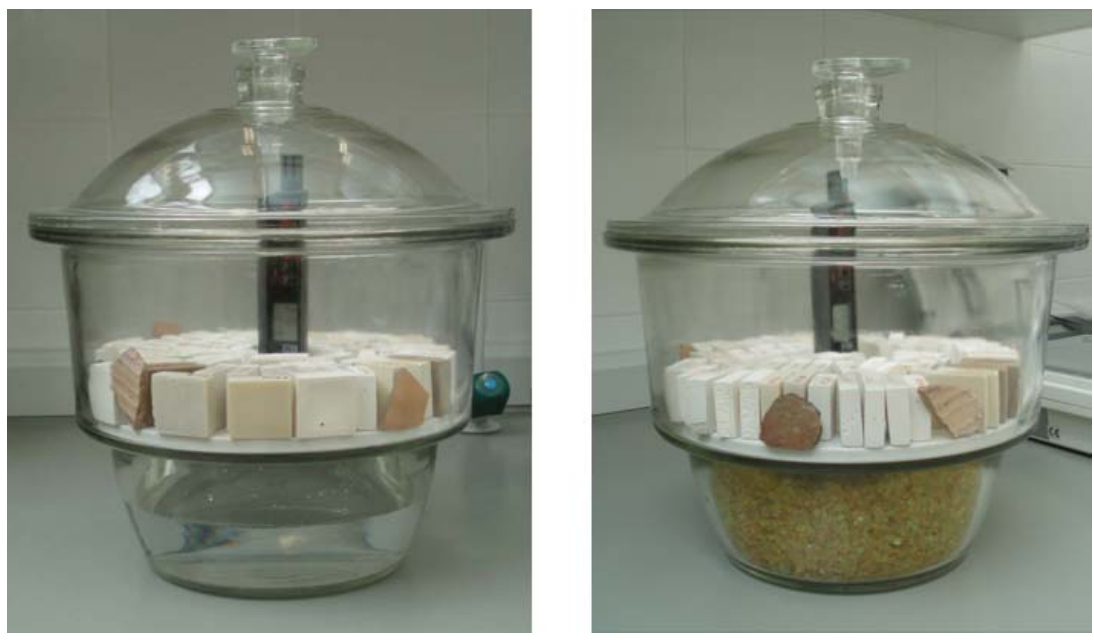

Figuras III. 6 y 7. Cámara de humedad y desecación creadas para el ensayo de envejecimiento acelerado de humidificación y secado. 


\section{2.3.2. Envejecimiento acelerado por irradiación con luz ultravioleta.}

\section{Principios generales}

Los ensayos de radiación están indicados para determinar el efecto de la radiación ultravioleta sobre distintos materiales. Estos ensayos acelerados se realizan en cámaras especiales de envejecimiento por luz ultravioleta., simulando los efectos nocivos del clima, con el objeto de predecir la duración relativa de los materiales expuestos a la intemperie. Los efectos nocivos de los rayos solares son simulados por lámparas UV fluorescentes. La temperatura de exposición se controla automáticamente, como también la secuencia diaria de los periodos de rayos UV y de condensación. En este ensayo se realizaron dos exposiciones de 5 horas.

\section{$\underline{\text { Instrumentación }}$}

Cámara QUV. La unidad contiene 8 lámparas fluorescentes dispuestas en 2 bancos de 4 lámparas cada uno. Una bancada irradia las probetas del frontal de la maquina, y la otra irradia las probetas de la parte posterior. Las luces fluorescentes ultravioleta son eléctricamente iguales a las luces fluorescentes F40 (40W) se usan reactancias para regular el flujo de corriente a los tubos. 


\section{2.3.3. Envejecimiento acelerado en atmósfera saturada de Dióxido de Azufre $\left(\mathrm{SO}_{2}\right)$}

\section{$\underline{\text { Principios generales }}$}

Estas experiencias son ensayos de laboratorio útiles para valorar la durabilidad de determinados materiales, permitiendo evaluar la resistencia a determinados agentes de alteración. Mediante estas experiencias se intenta reproducir fenómenos de alteración que son similares a aquellos que resultan de la alteración atmosférica, como la contaminación atmosférica que incrementa la velocidad de deterioro de los materiales. Las concentraciones de anhídrido sulfuroso utilizadas oscilan entre pocas partes por millón hasta 10.000 ppm, en función del grado de aceleración deseado ${ }^{47}$.

\section{Instrumentación}

Cámara de corrosión en atmósfera saturada con dióxido de azufre, modelo VCK-300 de DYCOMETAL

${ }^{47}$ Martín, A., op cit,. 1990, pp.517-518. 



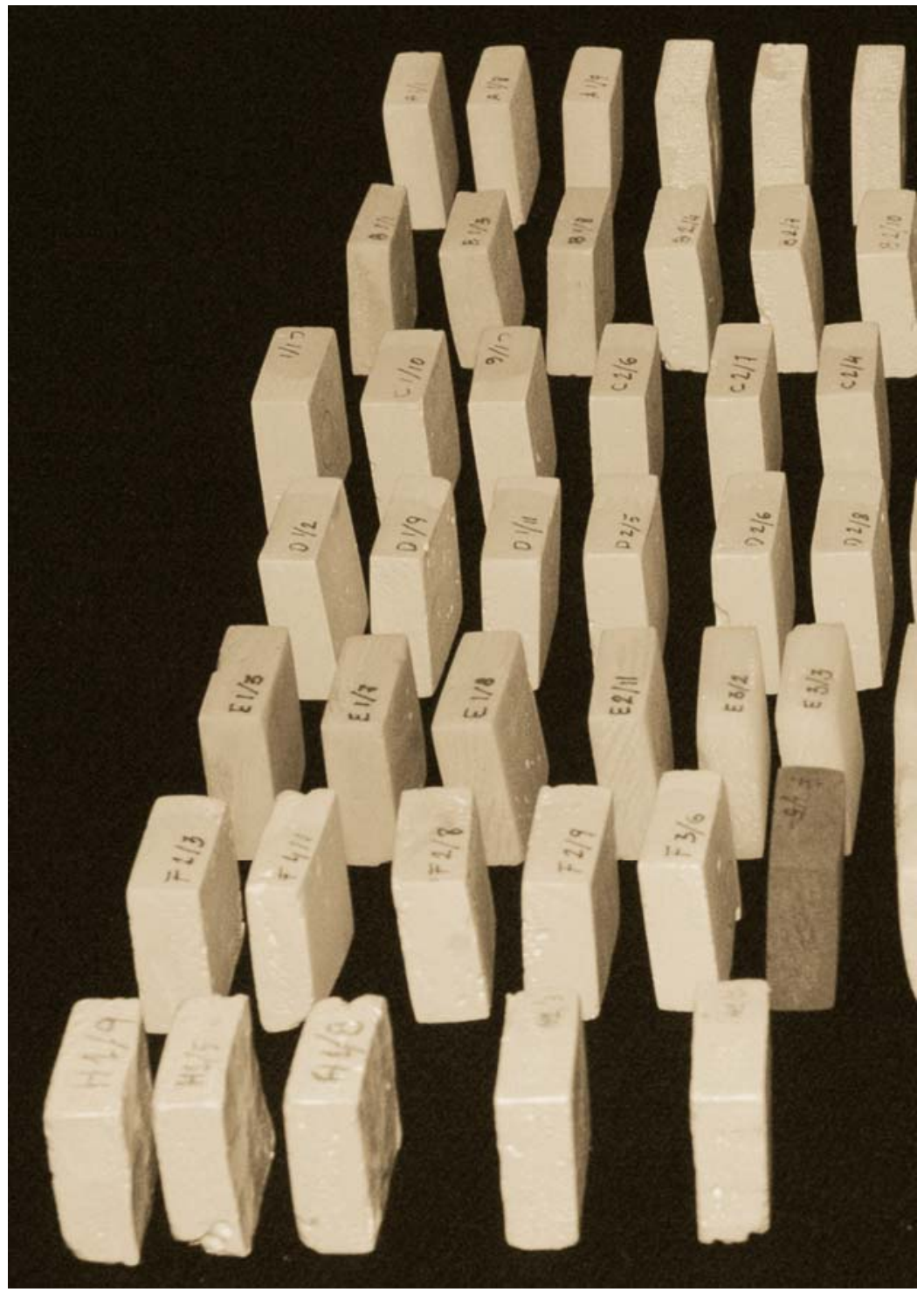

III. 3.

MASILLAS MATERIAS PRIMAS Y PREPARACIÓN 



\section{III.3.1. MATERIALES EMPLEADOS EN LA ELABORACIÓN DE LAS MASILLAS}

Con el fin de estudiar las masillas empleadas en la actualidad se realizó un estudio preliminar de las mismas y sus distintas dosificaciones, tanto sobre aquellas utilizadas habitualmente, como sobre las que pudieran ser susceptibles de ser usadas como reintegrantes en las lagunas de cerámicas arqueológicas.

Las distintas masillas preparadas inicialmente corresponden a formulaciones de origen inorgánico como la escayola en distintos grados de dureza, y de origen orgánico como, resinas sintéticas aglutinadas con cargas inertes, masillas comerciales y un estuco de cera (I 76) realizado a partir de la receta de la una receta de cera, I76, ideada por el Centro de Restauración de la Soprintendenza Archeologica per la Toscana en Florencia ${ }^{48}$.

En la Figura III.10. se muestran los materiales experimentados de modo esquemático, para a continuación describir cada material y su ficha técnica.

${ }^{48}$ Del Francia, P R., op cit., 1997. p.8. 


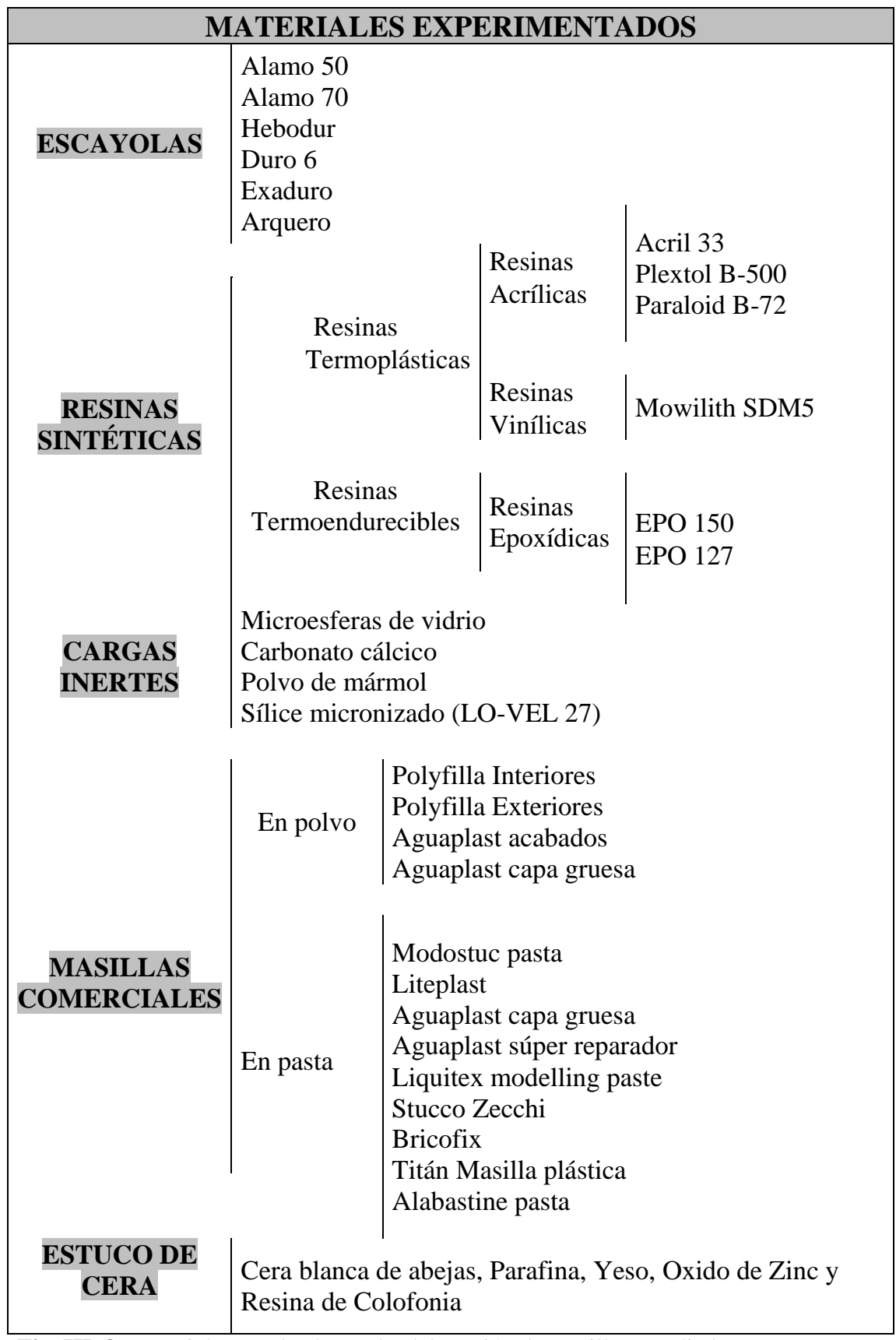

Fig. III. 8. Materiales empleados en la elaboración de masillas estudiadas. 


\section{III.3.1.1. ESCAYOLAS}

Las escayolas utilizadas en la presente investigación han sido proporcionadas por A.G.M. valenciana del fabricante Hebör Española, S.A.

A continuación se muestran las fichas técnicas de cada una de las escayolas utilizadas en los ensayos previos.

\begin{tabular}{|l|l|}
\hline \multicolumn{2}{|c|}{ ESCAYOLA ALAMO 50 } \\
\hline Color & Blanco \\
\hline $\begin{array}{l}\text { Dosificación recomendada por el fabricante } \\
\text { (yeso : agua) }\end{array}$ & $1,42-1,50: 1 \mathrm{Vol}$. \\
\hline Principio de fraguado & $10-12 \mathrm{~min}$. \\
\hline Expansión lineal & $0,19 \%$ \\
\hline Dureza Brinell & $320 \mathrm{Kg} / \mathrm{cm}^{2}$ \\
\hline
\end{tabular}

Tabla III.1. Propiedades de la escayola Alamo 50.

\begin{tabular}{|l|l|}
\hline \multicolumn{2}{|c|}{ ESCAYOLA ALAMO 70 } \\
\hline Color & Blanco \\
\hline $\begin{array}{l}\text { Dosificación recomendada por el fabricante } \\
\text { (yeso : agua) }\end{array}$ & $1,65-1,73: 1 \mathrm{Vol}$. \\
\hline Principio de fraguado & $10-12 \mathrm{~min}$. \\
\hline Expansión lineal & $0,20 \%$ \\
\hline Dureza Brinell & $480 \mathrm{Kg} / \mathrm{cm}^{2}$ \\
\hline
\end{tabular}

Tabla III.2. Propiedades de la escayola Alamo 70.

\begin{tabular}{|l|l|}
\hline \multicolumn{2}{|c|}{ ESCAYOLA HEBODUR } \\
\hline Color & Amarillo \\
\hline $\begin{array}{l}\text { Dosificación recomendada por el fabricante } \\
\text { (yeso : agua) }\end{array}$ & $30 \mathrm{gr} / 100 \mathrm{gr}$. \\
\hline Principio de fraguado & $4 / 15 \mathrm{~min}$. \\
\hline Expansión lineal & $0,1 \%$ \\
\hline Dureza Brinell & $3.200 \mathrm{Kg} / \mathrm{cm}^{2}$ \\
\hline
\end{tabular}

Tabla III.3. Propieades de la escayola Hebodur. 


\begin{tabular}{|l|l|}
\hline \multicolumn{2}{|c|}{ ESCAYOLA DURO 6 } \\
\hline Color & \\
\hline $\begin{array}{l}\text { Dosificación recomendada por el fabricante } \\
\text { (yeso : agua) }\end{array}$ & $2,00: 1 \mathrm{Vol}$. \\
\hline Principio de fraguado & $10-12 \mathrm{~min}$ \\
\hline Expansión lineal & $0,29 \%$ \\
\hline Dureza Brinell & $900 \mathrm{Kg} / \mathrm{cm}^{2}$ \\
\hline
\end{tabular}

Tabla III.4. Propiedades de la escayola Duro 6.

\begin{tabular}{|l|l|}
\hline \multicolumn{2}{|c|}{ ESCAYOLA EXADURO } \\
\hline Color & \\
\hline $\begin{array}{l}\text { Dosificación recomendada por el fabricante } \\
\text { (yeso : agua) }\end{array}$ & $2,50: 1 \mathrm{Vol}$. \\
\hline Principio de fraguado & $8-10 \mathrm{~min}$. \\
\hline Expansión lineal & $0,25 \%$ \\
\hline Dureza Brinell & $1.300 \mathrm{Kg} / \mathrm{cm}^{2}$ \\
\hline
\end{tabular}

Tabla III.5. Propiedades de la escayola Exaduro.

\begin{tabular}{|l|l|}
\hline \multicolumn{2}{|c|}{ ESCAYOLA ARQUERO } \\
\hline Color & \\
\hline $\begin{array}{l}\text { Dosificación recomendada por el fabricante } \\
\text { (yeso : agua) }\end{array}$ & $4,00-4,50: 1 \mathrm{Vol}$. \\
\hline Principio de fraguado & $14-15 \mathrm{~min}$. \\
\hline Expansión lineal & $0,12 \%$ \\
\hline Dureza Brinell & $5.000 \mathrm{Kg} / \mathrm{cm}^{2}$ \\
\hline
\end{tabular}

Tabla III.6. Propiedades de la escayola Arquero. 


\section{III.3.1.2. MASILLA DE CERA I76}

\begin{tabular}{|l|l|}
\hline \multicolumn{2}{|c|}{ ESTUCO DE CERA I76 } \\
\hline Yeso & 200 gr. \\
\hline Óxido de zinc & 150 gr. \\
\hline Cera blanca de abejas & 65 gr. \\
\hline Parafina & 65 gr. \\
\hline Resina de Colofonia & 10 gr. \\
\hline
\end{tabular}

Tabla III.7. Materiales utilizados en la composición del estuco de cera I76

\section{III.3.1.3. RESINAS SINTÉTICAS}

Las resinas sintéticas utilizadas en la presente investigación han sido proporcionadas por C.T.S. España S.L., así como sus especificaciones técnicas.

\section{$\underline{\text { Resinas Acrílicas }}$}

\section{Acril 33}

Dispersión acuosa de resina acrílica 100\% con óptimas características de resistencia y estabilidad tanto para interiores como para exteriores. Distribuida por CTS España S.L. como alternativo al Primal AC-33 de la Röhm \& Haas (gracias a la análoga formulación química). Su formulación se caracteriza por una óptima resistencia a los alcalinos y resulta particularmente indicada en combinación con ligantes hidráulicos 


\begin{tabular}{|l|l|}
\hline \multicolumn{2}{|c|}{ ACRIL 33 } \\
\hline Resina base & Copolímero acrílico \\
\hline Aspecto & Líquido lechoso blanco \\
\hline Olor & Amoniacal \\
\hline Residuo seco & $42-47 \%$ \\
\hline Viscosidad a 20 ${ }^{\circ}$ C & $2500+-5000 \mathrm{mPa}-\mathrm{s}$ \\
\hline pH & $9-10$ \\
\hline Diámetro medio de partículas & $0,15 \mu$ \\
\hline Temperatura transición vítrea (tg) & $6-8^{\circ} \mathrm{C}$ \\
\hline Temperatura mínima de película (mft) & $6^{\circ} \mathrm{C}$ \\
\hline
\end{tabular}

Tabla III.8. Propiedades físico-químicas del Acril 33

\section{Plextol B-500}

Dispersión acuosa de polímeros acrílicos termoplásticos a base de copolímero de Metacrilato (60\%) y Metilmetacrilato (40\%). Está caracterizada por una óptima resistencia a los agentes atmosféricos y estabilidad química. Fabricante: Rhom GMBH \& Co. Kg.

\begin{tabular}{|l|l|}
\hline \multicolumn{2}{|c|}{ PLEXTOL B-500 } \\
\hline Estado físico & Líquido \\
\hline Olor & Amoniacal. \\
\hline Color & Transparente. \\
\hline Residuo seco & $50 \pm 1 \%$ \\
\hline Viscosidad dinámica $\left(\mathbf{2 0}^{\mathbf{0}} \mathbf{C}\right)$ & $1100-4500 \mathrm{mPas}$ \\
\hline PH (20 $\mathbf{~}^{\circ}$ & $9,5-10$ \\
\hline Punto/intervalo de fusión & Aprox. $0^{\circ} \mathrm{C}$ \\
\hline Punto/intervalo de ebullición & Aprox. $100^{\circ} \mathrm{C}(1013 \mathrm{hPa})$ \\
\hline Punto de inflamabilidad & No aplicable \\
\hline Límite de explosión & -- \\
\hline Tensión de vapor $\left(\mathbf{2 0}^{\circ} \mathbf{C}\right)$ & Aprox. $23 \mathrm{hPa}$ \\
\hline Densidad $\left(\mathbf{2 0}^{\mathbf{}}\right)$ & $107 \mathrm{~g} / \mathrm{cm}^{3}$ \\
\hline Solubilidad en agua & Soluble. \\
\hline
\end{tabular}

Tabla III.9. Propiedades físico-químicas del Plextol B-500 


\section{Paraloid B-72}

Resina acrílica termoplástica, copolímero de etil metacrilato. Fabricada por Röhm \& Haas, España.

La resina necesita ser disuelta para su aplicación. Solubilidad: nbutanol, diacetona alcohol, cloruro de metileno, dicloruro de etileno, tricloroetileno, etil acetato, amil acetato, tolueno, xileno, acetona, metil etil cetona, dimetil formamida.

Forma una película transparente, incolora y flexible. Resistente a la decoloración, estabilidad química y durabilidad.

\begin{tabular}{|l|l|}
\hline \multicolumn{2}{|c|}{ PARALOID B-72 } \\
\hline Resina base & $\begin{array}{l}\text { Homopolímero de iso- } \\
\text { butilmetacrilato }\end{array}$ \\
\hline Aspecto & Incoloro \\
\hline Estado & Sólido en granos \\
\hline Olor carácterístico & Acrilato \\
\hline pH & No aplicable \\
\hline Viscosidad & No aplicable \\
\hline Peso específico (H2O=1) & $\begin{array}{l}0.66 \quad \text { g/cm } \\
\text { empaquetado densidad al }\end{array}$ \\
\hline Densidad de los vapores(aire=1) & No aplicable \\
\hline Tensión de vapor & No aplicable \\
\hline Punto de fusión & Ningún dato \\
\hline Punto de ebullición & No aplicable \\
\hline Solubilidad en agua & Prácticamente insoluble \\
\hline Porcentajes de volátiles & $1.15 \%$ Max. \\
\hline Toxicidad & $\begin{array}{l}\text { Puede resultar peligrosa su } \\
\text { ingestión, inhalación o absorción } \\
\text { a través de la piel. }\end{array}$ \\
\hline
\end{tabular}

Tabla III.10. Propiedades físico-químicas del Paraloid B-72 


\section{$\underline{\text { Resinas Vinílicas }}$}

\section{Mowilith SDM5}

Dispersión acuosa al 53\%. Copolímero en dispersión acuosa a base de acetato de vinilo y éster acrílico. Contiene derivados de la celulosa como coloide protector. con excelentes propiedades impregnantes y resistente a las bajas temperaturas, que se traduce en un material idóneo como ligante y aditivo de morteros. Es especialmente adecuado como ligante para pinturas de dispersión, y como adhesivo, sea para interiores como para exteriores.

\begin{tabular}{|l|l|}
\hline \multicolumn{2}{|c|}{ MOWILITH SDM5 } \\
\hline Aspecto & Líquido lechoso blanco \\
\hline Viscosidad & $2000-5000$ Mpa-s \\
\hline Residuo seco & $53+\_1 \%$ \\
\hline Densidad & $1.15 \mathrm{~g} / \mathrm{cm}^{3}$ aprox. \\
\hline PH (solución acuosa) & $4-5$ \\
\hline Temperatura mínima de película (mft) & $3^{\circ} \mathrm{C}$ aprox. \\
\hline $\begin{array}{l}\text { Absorción de agua después de } \mathbf{2 4 h} \text { de } \\
\text { inmersión }\end{array}$ & $10 \%$ aprox. \\
\hline Temperatura de transición vítrea (tg) & $5^{\circ}-11^{\circ} \mathrm{C}$ \\
\hline $\begin{array}{l}\text { Resistencia a tracción a } \mathbf{2 0}^{\circ} \mathrm{C} \text { y } \mathbf{6 5 \%} \\
\text { H.R. }\end{array}$ & $3 \mathrm{~N} / \mathrm{mm}^{2}$ aprox. \\
\hline $\begin{array}{l}\text { Alargamiento a rotura a } \mathbf{2 0}^{\circ} \mathbf{C} \text { y } \mathbf{6 5 \%} \\
\text { H.R. }\end{array}$ & $820 \%$ aprox. \\
\hline
\end{tabular}

Tabla III.11. Propiedades físico-químicas del Mowilith SDM5 


\section{$\underline{\text { Resinas Epoxídicas }}$}

\section{Resina epoxídica EPO 150}

Resina epoxídica bi-componente fluida reticulable en frío mediante un endurecedor a base de aminas cicloalifáticas. La mezcla de los dos componentes produce un sistema de elevada resistencia altamente adhesivo. Se puede cargar con varios inertes hasta obtener mezclas que se pueden utilizar para estucado y reintegración. Se suministra en presentación doble compuesta de Resina Epoxídica pura Epo-150 y endurecedor K-151. los componentes van unidos en la siguiente proporción Epo-150: K-151 (100:25 gr).

\begin{tabular}{|l|l|}
\hline \multicolumn{2}{|c|}{ EPO 150} \\
\hline Aspecto & Líquido \\
\hline Color & De amarillo a marrón \\
\hline Olor & Levemente epoxídico \\
\hline Peso específico & $1.11-1.16$ gr/cm \\
\hline Densidad relativa del vapor & No determinado \\
\hline Tensión de vapor & No determinado \\
\hline Punto/intervalo de ebullición & $\begin{array}{l}\text { Se descompone antes de la } \\
\text { ebullición }\end{array}$ \\
\hline Punto/intervalo de congelado & Puede solidificar a T<-15 ${ }^{\circ} \mathrm{C}$ \\
\hline Punto de inflamabilidad & $121^{\circ} \mathrm{C}$ \\
\hline Solubilidad en el agua & $<1 \%$ en peso (a $\left.25^{\circ} \mathrm{C}\right)$ \\
\hline pH & No aplicable \\
\hline Tiempo de laborabilidad de 200gr & $30-50 \mathrm{minutos}\left(25^{\circ} \mathrm{C}\right)$ \\
\hline Resistencia a la tracción & $400 \mathrm{Kg} / \mathrm{cm}^{2}$ \\
\hline Resistencia a la flexión & $1000 \mathrm{Kg} / \mathrm{cm}^{2}$ \\
\hline Resistencia a la compresión & $1220 \mathrm{Kg} / \mathrm{cm}^{2}$ \\
\hline Viscosidad del sistema (25 $\left.{ }^{\circ} \mathbf{C}\right)$ & $500-800 \mathrm{mPa}^{2}$ \\
\hline Equipamiento protector del personal & $\begin{array}{l}\text { Protección respiratoria, de la } \\
\text { piel, ojos y cara. }\end{array}$ \\
\hline
\end{tabular}

Tabla III.12. Propiedades físico-químicas de la resina epoxídica EPO 150 


\section{Resina epoxídica EPO 127}

Resina epoxídica formulada, catalizable a temperatura ambiente mediante el añadido de su endurecedor K 128 en rápor de peso 1:1.

El sistema bicomponente EPO 127 y K 128 ha sido estudiado para construcciones, integraciones y relleno de partes de madera, garantizando una óptima adhesión. Presenta la particularidad de ser fácilmente laborable, después del endurecimiento, para permitir al operador un perfecto acabado. El sistema garantiza una óptima resistencia mecánica y estabilidad dimensional. La mezcla resinaendurecedor debe ser aplicada dentro de $25-30$ minutos a $20^{\circ} \mathrm{C}$ aprox. después del endurecimiento el sistema se puede trabajar con los utensilios usados normalmente para la madera.

\begin{tabular}{|l|l|}
\hline \multicolumn{2}{|c|}{ EPO 127} \\
\hline Forma física & Pasta \\
\hline Color & Marrón oscuro \\
\hline Olor & Ligero \\
\hline Punto/intervalo de ebullición & $>200^{\circ} \mathrm{C}$ \\
\hline Temperatura de descomposición & $>200^{\circ} \mathrm{C}$ \\
\hline Punto de encendido & $>138^{\circ} \mathrm{C}$ \\
\hline Solubilidad en agua & $0.5 \%$ \\
\hline Presión de vapor & $<1 \mathrm{~Pa}$ \\
\hline Densidad relativa & $0.8-1.0$ g/ml $\left(25^{\circ} \mathrm{C}\right)$ \\
\hline Tiempo de trabajo & $20-30$ minutos aprox. $\left(20^{\circ} \mathrm{C}\right)$ \\
\hline Resistencia a la compresión & $22 \mathrm{~N} / \mathrm{mm} 2$ (a 24 horas) \\
\hline Pico térmico (masa 200 gr) & $55^{\circ} \mathrm{C}$ (después 48 minutos) \\
\hline Equipamiento protector del personal & $\begin{array}{l}\text { Protección respiratoria, de la } \\
\text { piel, ojos y cara. }\end{array}$ \\
\hline
\end{tabular}

Tabla III.13. Propiedades físico-químicas de la resina epoxídica EPO 1127 


\section{III.3.1.4. CARGAS INERTES}

Las cargas utilizadas en la presente investigación han sido proporcionadas por C.T.S. España S.L., así como sus especificaciones técnicas.

\section{Microesferas de vidrio}

Material obtenido por el óxido de silicio transformado en microesferas, utilizado como carga en distintos aglutinantes y como abrasivo para el microarenado de objetos de metal.

\begin{tabular}{|l|l|l|l|}
\hline \multicolumn{4}{|c|}{ MICROESFERAS DE VIDRIO } \\
\hline \multicolumn{2}{|l|}{ Composición (\%) } & \multicolumn{2}{l|}{ Características físico-químicas } \\
\hline $\mathrm{SiO} 2$ & 72,5 & Estado & Sólido \\
\hline $\mathbf{N a O}$ & 13,7 & color & Blanco \\
\hline $\mathbf{C a O}$ & 9,8 & Peso específico & $2,45-2,49 \mathrm{gr} / \mathrm{cm}^{3}$ \\
\hline $\mathbf{M g O}$ & 3,3 & Punto de fusión & $730^{\circ} \mathrm{C}$ \\
\hline $\mathbf{A l} 2 \mathrm{O} 3$ & 0,4 & densidad & $2,6 \mathrm{~g} / \mathrm{cm}^{3}\left(20^{\circ} \mathrm{C}\right)$ \\
\hline FeO/Fe2O3 & 0,2 & Dureza escala Mohs & 6,8 \\
\hline $\mathbf{K} 2 \mathrm{O}$ & 0,1 & Granulometría & $0-50 \mu$ \\
\hline
\end{tabular}

Tabla III.14. Componentes y propiedades físico-químicas de las Microesferas de vidrio

\section{Carbonato de calcio}

Según la proveniencia, la granulometría y el color, el calcio carbonato es conocido con diversos nombres como: Blanco de S.Giovanni, Blanco Meudon, Blanco de España y Blancón. El carbonato de calcio 
micronizado, por su granulometría finísima y seleccionada, se utiliza como carga en la preparación de estucos para superficies pintadas y materiales pétreos.

\begin{tabular}{|l|l|}
\hline \multicolumn{2}{|c|}{ CARBONATO DE CALCIO } \\
\hline Fórmula & $\mathrm{CaCO}_{3}$ \\
\hline Estado físico & Sólido en polvo \\
\hline Color & blanco \\
\hline Punto de inflamabilidad & Producto no inflamable \\
\hline Peso específico & 2,7 \\
\hline Peso aparente & 8,5 \\
\hline Densidad & $2730 \mathrm{Kg} / \mathrm{cm}^{3}$ \\
\hline Granulometría & $1-36 \mu$ \\
\hline Solubilidad & Soluble en ácidos \\
\hline pH & 9 \\
\hline Dureza escala Mohs & 3 \\
\hline Índice de refracción & 1,6 \\
\hline
\end{tabular}

Tabla III.15. Propiedades físico-químicas del Carbonato cálcico

\section{Polvo de mármol}

Agregado natural petrográficamente homogéneo constituido de fragmentos calcáreos microcristalinos.

\begin{tabular}{|l|l|}
\hline \multicolumn{2}{|c|}{ POLVO DE MÁRMOL BLANCO CARRARA } \\
\hline Estado físico & Sólido \\
\hline Aspecto & Granos finos \\
\hline Color & Blanco \\
\hline Olor & Ninguno \\
\hline Solubilidad & Insoluble \\
\hline pH & $8,2-8,5$ \\
\hline Temperatura de inflamabilidad & No inflamable \\
\hline
\end{tabular}




\begin{tabular}{|l|l|}
\hline Peso específico absoluto & $2,70 \mathrm{~g} / \mathrm{cm}^{3}$ \\
\hline Peso específico aparente & $1,50 \mathrm{~g} / \mathrm{cm}^{3}$ \\
\hline
\end{tabular}

Tabla III.16. Propiedades físico-químicas del Polvo de Mármol.

\section{Sílice Micronizado LO-VEL 27}

Bióxido de silicio puro obtenido por la pirohidrólisis de compuestos de silicio, amorfo a los rayos $\mathrm{X}$, con superficie de las partículas exentas de poros. Lo-Vel 27 es un sílice hidrófilo (humectable con agua) y fisiológicamente inerte; se añade en barnices, resinas, gomas silicónicas, etc., se usa como adesante y para mejorar el efecto tixotrópico.

\begin{tabular}{|l|l|}
\hline \multicolumn{2}{|c|}{ SÍLICE MICRONIZADO LO-VEL 27} \\
\hline Apariencia & Polvo muy fino blanco \\
\hline Olor & Ninguno \\
\hline Superficie & $150 \mathrm{~m}^{2} / \mathrm{g}$ \\
\hline Solubilidad en agua & Insoluble \\
\hline Tamaño de las partículas principales & $21 \mathrm{~nm}$ \\
\hline
\end{tabular}

Tabla III.17. Propiedades físico-químicas del Sílice micronizado LO-VEL . 


\section{III.3.1.5. MASILLAS COMERCIALES}

Las masillas comerciales "Polyfilla" utilizadas en la presente investigación han sido proporcionadas por C.T.S. España S.L., así como sus especificaciones técnicas. El resto de masillas han sido adquiridas en distintos establecimientos y las especificaciones técnicas de los productos han sido reportadas por los fabricantes de las mismas.

\section{Polyfilla Interior ${ }^{\circledR}$}

Fabricante: Unitecta Italiana Spa.

Estuco en polvo reforzado a la celulosa para el relleno de interiores.

Usado para estucar hendiduras, grietas, agujeros grandes y pequeños. Para igualar paredes y techos. Uso interno sobre: revoques, yeso, cemento, piedra, ladrillos, madera.

No se hincha ni parte. Tiene una óptima adherencia. Fácil aplicación. Preparación según el fabricante para trabajos de estucado: 2’5 partes de Polyfilla Interior en polvo con 1 parte de agua. Empastar de 3 a 5 minutos y dejar reposar unos minutos. Su composición no viene especificada por el fabricante.

\begin{tabular}{|l|l|}
\hline \multicolumn{2}{|c|}{ POLYFILLA INTERIOR ${ }^{\circledR}$} \\
\hline Aspecto & Polvo blanco \\
\hline Naturaleza del pegamento & Cemento \\
\hline Densidad & $\begin{array}{l}\text { Polvo }=1,1 \mathrm{~g} / \mathrm{cm}^{3} \\
\text { Emplaste }(\text { polvo }+ \text { agua })=1,7 \mathrm{~g} / \mathrm{cm}^{3}\end{array}$ \\
\hline Producto & $1-1,5 \mathrm{Kg} / \mathrm{m}^{2}$ por $\mathrm{mm}$. de espesor \\
\hline
\end{tabular}




\begin{tabular}{|l|l|}
\hline Tiempo de utilización & 45 min. una vez preparado \\
\hline Tiempo de endurecimiento & 1 hora. \\
\hline Tiempo de secado & 30 min. para un espesor de $1 \mathrm{~mm}$. \\
\hline
\end{tabular}

Tabla III.18. Propiedades de la Polyfilla Interior.

\section{Polyfilla Exterior ${ }^{\circledR}$}

Fabricante: Unitecta Italiana Spa.

Estuco en polvo reforzado al vinilo para el relleno de exteriores.

Es usado para estucar hendiduras, grietas, agujeros grandes y pequeños. Uso externo e interno sobre: cemento, hormigón, ladrillos, piedra y madera. No se aplica sobre el yeso. Resiste al agua y a la intemperie, no se hincha ni parte. Tiene una óptima adherencia. Resiste al calor, al hielo, a las vibraciones y a los choques. Puede tintarse. Unir dos partes y media de polyfilla exteriores en polvo con una parte de agua, mezclar bien hasta obtener una pasta homogénea.

Su composición no viene especificada por el fabricante. Aunque por los estudios realizados su composición mayoritaria es de yeso.

\begin{tabular}{|l|l|}
\hline \multicolumn{2}{|c|}{ POLYFILLA EXTERIOR ${ }^{\circledR}$} \\
\hline Aspecto & Polvo blanco \\
\hline Naturaleza del pegamento & Cemento \\
\hline Densidad & $\begin{array}{l}\text { Polvo }=1,6 \mathrm{~g} / \mathrm{cm}^{3} \\
\text { Emplaste }(\text { polvo }+ \text { agua })=1,7 \mathrm{~g} / \mathrm{cm}^{3}\end{array}$ \\
\hline pH & 12,4 \\
\hline Producto & $1,3 \mathrm{Kg} / \mathrm{m}^{2}$ por $\mathrm{mm}$. de espesor \\
\hline Tiempo de utilización & 1 hora una vez preparado \\
\hline Tiempo de endurecimiento & $1-5$ horas. \\
\hline
\end{tabular}

Tabla III.19. Propiedades de la Polyfilla Exterior. 


\section{Aguaplast Acabados Super Fine ${ }^{\circledR}$.}

Fabricante: Beissier, S.A. Plaste en polvo especial para enlucidos muy finos. Se puede aplicar sobre soportes interiores absorbentes, yeso, cemento, madera, etc. es idóneo para grandes superficies por su largo tiempo de trabajo. Proporciona un acabado muy fino y perfecto con una terminación excelente para decorar. Largo tiempo de trabajo (24 horas) y fácil lijado. Blanco y muy adherente. Fácil de preparar y cómodo de trabajar.

\begin{tabular}{|l|l|}
\hline \multicolumn{2}{|c|}{ AGUAPLAST ACABADOS SUPER FINE ${ }^{\circledR}$} \\
\hline Composición & $\begin{array}{l}\text { Polímeros hidrosolubles y cargas } \\
\text { minerales }\end{array}$ \\
\hline Diluyente & Agua \\
\hline Densidad aparente del polvo & $0.70 \pm 0.05 \mathrm{~g} / \mathrm{cc}$. \\
\hline Densidad aparente de la pasta & $1.6+0.05 \mathrm{~g} / \mathrm{cc}$. \\
\hline Apariencia & Polvo \\
\hline Color & Blanco \\
\hline Olor & Perfume lavanda \\
\hline Granulometría & $<100 \mu$ : fino \\
\hline pH & $7 \pm 0.5$ \\
\hline Resistencia al fuego & Incombustible \\
\hline Temperatura de aplicación & Entre $5^{\circ}$ y $30^{\circ} \mathrm{C}$ \\
\hline Mezcla & $0,5 \mathrm{l}$ de agua por $1 \mathrm{Kg}$ de polvo \\
\hline Espesor máximo por capa & 2 mm \\
\hline Tiempo de secado & \\
\hline Tiempo de trabajo & 24 horas a $20^{\circ} \mathrm{C}$ \\
\hline Consumo teórico & 1 Kg por $\mathrm{m}^{2}$ y mm de espesor \\
\hline Tiempo de secado & $\begin{array}{l}30 \text { min. En capa de } 2,2 \text { mm, } 24 \\
\text { horas en capa de } 2 \text { mm, variable } \\
\text { según condiciones ambientales. }\end{array}$ \\
\hline
\end{tabular}

Tabla III.20. Propiedades de Aguaplast Acabados Super Fine 


\section{Aguaplast Capa Gruesa ${ }^{\circledR}$}

Fabricante: Beissier, S.A. Plaste en polvo especial para nivelar y reparar irregularidades, rellenar grandes grietas, juntas, etc. Se puede aplicar sobre soportes interiores absorbentes de yeso, cemento, madera, placas de cartón yeso, pinturas plásticas, hormigón, poliestireno, etc. relleno rápido de grandes grietas, agujeros, rozas, juntas, etc hasta $50 \mathrm{~mm}$. tiene una gran capacidad de relleno sin merma ni fisuración. Gran rendimiento, muy rápido secado y endurecimiento. Lijado fácil y rápido. Excelente adherencia al soporte. proporciona un acabado fino y duro. Fácil de aplicar.

\begin{tabular}{|l|l|}
\hline \multicolumn{2}{|c|}{ AGUAPLAST CAPA GRUESA ${ }^{\circledR}$} \\
\hline Composición & $\begin{array}{l}\text { Polímeros hidrosolubles y cargas } \\
\text { minerales ligeras. }\end{array}$ \\
\hline Diluyente & Agua \\
\hline Densidad aparente del polvo & $0.70 \pm 0.05 \mathrm{~g} / \mathrm{cc}$. \\
\hline Densidad aparente de la pasta & $1.4 \pm 0.05 \mathrm{~g} / \mathrm{CC}$. \\
\hline Apariencia & Polvo \\
\hline Color & Blanco \\
\hline Olor & Perfume lavanda \\
\hline Granulometría & $<200 \mu$ : fino \\
\hline pH & $7 \pm 0.5$ \\
\hline Resistencia al fuego & Incombustible \\
\hline Dureza & Shore C: $80 \pm 5$ \\
\hline Temperatura de aplicación & Entre $5^{\circ}$ y $30^{\circ} \mathrm{C}$ \\
\hline Mezcla & $0,5 \mathrm{l}$ de agua por $1 \mathrm{Kg}$ de polvo \\
\hline Espesor máximo por capa & 50 mm \\
\hline Tiempo de trabajo & $30-60$ min. \\
\hline Consumo teórico & 0,9 Kg por $\mathrm{m}^{2}$ y mm de espesor \\
\hline Tiempo de secado & $\begin{array}{l}1-24 \text { horas,.. variable según } \\
\text { condiciones } \quad \text { (2 } \\
\text { espesores }<2 \text { mm). }\end{array}$ \\
\hline
\end{tabular}

Tabla III.21. Propiedades de Aguaplast Capa Gruesa . 


\section{Modostuc Pasta ${ }^{\circledR}$}

Fabricante: Plasveroi International, Srl. Masilla comercial preparada para su uso.

Especificaciones del distribuidor CTS:

Estuco profesional en pasta formulado con agua, aditivos celulósicos, resina en emulsión, plastificantes, carbonatos de calcio y sulfato de calcio natural. Se utiliza para eliminar irregularidades y defectos de todo tipo en soportes de madera y muros

\begin{tabular}{|l|l|}
\hline \multicolumn{2}{|c|}{ MODOSTUC PASTA ${ }^{\circledR}$} \\
\hline Resina vinilversatica & $1.5-3 \%$ en peso \\
\hline $\begin{array}{l}\text { Esteres poliglicolicos de ácidos } \\
\text { grasos }\end{array}$ & $0.5 \%$ en peso \\
\hline Biocida con isotiazolinoni & $0.08-0.11 \%$ en peso \\
\hline Inertes & $96-98 \%$ en peso \\
\hline Presentación & $\begin{array}{l}\text { Estuco preparado para su uso en } \\
\text { color blanco }\end{array}$ \\
\hline Peso específico & 1,92 aprox. \\
\hline
\end{tabular}

Tabla III.22. Propiedades de la masilla ya preparada Modostuc Pasta.

\section{Liteplast ${ }^{\circledR}$}

Fabricante: Quilosa.

Masilla comercial preparada para su uso.

Pasta ya preparada. Tapagrietas ligero. No merma ni se agrieta. Gran capacidad de relleno. Una vez seco se puede pintar, lijar e incluso taladrar. Uso en interiores y exteriores. Su composición no viene especificada por el fabricante. 


\section{Aguaplast Capa Gruesa ${ }^{\circledR}$}

Fabricante: Beissier, S.A

Masilla lista al uso para alisar y nivelar paredes irregulares en grandes espesores. Sobre materiales de obra interiores (hormigón, ladrillo, yeso, escayola, piedra, cartón-yeso, etc.). enlucidos y revocos en capa media y gruesa. Nivelación de superficies irregulares. Enlucidos sobre porexpan, reparación de fisuras y grietas hasta $5 \mathrm{~mm}$ de ancho. Buena capacidad de relleno. Mínima merma. Gran facilidad de lijado. Muy adherente sobre materiales de obra. Secado rápido. No descuelga. Ligero.

\begin{tabular}{|l|l|}
\hline \multicolumn{2}{|c|}{ AGUAPLAST CAPA GRUESA GROSS COAT ® } \\
\hline Composición & $\begin{array}{l}\text { Copolímeros acrílicos y cargas } \\
\text { ligeras. }\end{array}$ \\
\hline Diluyente & Agua \\
\hline Densidad & $1.35 \pm 0.05 \mathrm{~g} / \mathrm{cc}$. \\
\hline Apariencia & Pasta \\
\hline Color & Blanco \\
\hline Olor & Perfume lavanda \\
\hline Granulometría & $<200 \mu$ : fino \\
\hline pH & $8 \pm 1$ \\
\hline Temperatura de aplicación & Entre $5^{\circ}$ y $30^{\circ} \mathrm{C}$ \\
\hline Espesor máximo por capa & $50 \mathrm{~mm}$ \\
\hline Tiempo de trabajo & Sin límite. \\
\hline Consumo teórico & 1,4 Kg por ${ }^{2}$ y mm de espesor \\
\hline Tiempo de secado & $\begin{array}{l}12 \text { horas, por mm de capa, } \\
\text { variable según soporte y } \\
\text { condiciones ambientales. }\end{array}$ \\
\hline
\end{tabular}

Tabla III.23. Propiedades de la masilla lista para su uso Aguaplast Capa Gruesa . 


\section{Liquitex Modelling Paste ${ }^{\circledR}$}

Fabricante: Liquitex Artist Materials.

Masilla preparada al uso para rellenar soportes rígidos y crear formas tridimensionales. Cuando seca adquiere una gran dureza. Puede ser lijada o tallada. Se puede tintar antes de aplicar o una vez seca admite todo tipo de pinturas.

\begin{tabular}{|l|l|}
\hline \multicolumn{2}{|c|}{${ }^{49}$ LIQUITEX MODELLING PASTE ${ }^{\circledR}$} \\
\hline Composición & $\begin{array}{l}\text { Pigmento blanco, polvo de mármol, emulsión } \\
\text { acrílica, agua desionizada, 2-amino-2methyl-1- } \\
\text { propanol. }\end{array}$ \\
\hline pH & 9 \\
\hline Olor & Ligeramente acrílico \\
\hline $\begin{array}{l}\text { Gravedad } \\
\text { específica }\end{array}$ & 1.96 \\
\hline Solventes & Acetona, tolueno. \\
\hline Color & Blanco mate \\
\hline Textura & Dura \\
\hline
\end{tabular}

Tabla III.24. Propiedades de la masilla preparada para su uso Liquitex Modelling Paste.

\section{Stucco per Restauro Zecchi ${ }^{\circledR}$}

Fabricante: Zecchi Colori Belle Arti (Florencia).

Masilla lista para su uso. Masilla para restauración a base de yeso de dorador, cola de conejo y otras colas naturales.

Su composición no viene especificada por el fabricante.

${ }^{49}$ Loew, M., Solz, J., op. cit. 1998. p.27. 


\section{Bricofix ${ }^{\circledR}$}

Fabricante: Quilosa.

Pasta ya preparada. Masilla reparadora. Fácil de aplicar y extender. Secado rápido. Una vez seca, se puede pintar, lijar e incluso taladrar. Recomendada para la reparación de grietas, agujeros y fisuras. Nivelado de irregularidades en todo tipo de superficies porosas como madera, yeso, cemento, hormigón. Uso en interiores y exteriores. Color blanco.

Su composición no viene especificada por el fabricante.

\section{Titan Masilla Plástica ${ }^{\circledR}$}

Fabricante: Titanlux.

Masilla de relleno al agua preparada al uso, de aplicación interior.

Indicada para yeso, escayola, cemento, madera, mortero y cerámica. De fácil aplicación, no merma, no agrieta y de gran poder de relleno. Su composición no viene especificada por el fabricante.

\begin{tabular}{|l|l|}
\hline \multicolumn{2}{|c|}{ TITAN MASILLA PLÁSTICA ${ }^{\circledR}$} \\
\hline Acabado & Mate \\
\hline Color & Blanco \\
\hline Densidad & $1,9-2,0 \mathrm{Kgs} . / \mathrm{lt}$. \\
\hline Granulometría & $<200 \mu$ : fino \\
\hline Volumen sólido & $62-63 \%$ \\
\hline Secado $\left(\mathbf{2 0}^{\circ} \mathbf{C}\right)$ & 2 horas para $1 \mathrm{~mm}$. de espesor \\
\hline
\end{tabular}

Tabla III.25. Propiedades de la masilla lista para su uso Titan M. Plástica. 


\section{III.3.2. PREPARACIÓN DE MASILLAS. ESTUDIOS PREVIOS}

Uno de los objetivos de esta tesis es conseguir unas masillas idóneas alternativas a las tradicionales que sirvan como material de reintegración de lagunas en objetos cerámicos arqueológicos. Para ello se ha llevado a cabo un estudio previo en el que se han ensayado masillas con diferentes porcentajes de resinas e inertes, así como distintos productos comerciales preparados. Se han preparado un total de 103 formulaciones con las que se ha podido realizar una selección para llevar a cabo el estudio presentado en esta Tesis Doctoral.

\section{III.3.2.1. ELABORACIÓN DEL MOLDE PARA EL ESTUDIO PREVIO DE LAS MASILLAS}

Con el fin de observar detenidamente la trabajabilidad y el comportamiento de las masillas, se elaboraron muestras de distinto tamaño y grosor. Esto nos ha proporcionado información muy útil acerca de las propiedades físicas de las diferentes masillas como la trabajabilidad, el tiempo de trabajo y secado, la formación de burbujas, la contracción, el agrietamiento, la dureza, etc.

Las muestras se obtuvieron mediante un proceso de moldeo directo. Para ello se elaboraron unos moldes especiales empleando un elastómero RTV silicónico SILASTIC 3483 de la firma comercial Dow Corning. Se trata de un caucho de silicona de excelentes 
propiedades mecánicas, resistente y de elevada fluidez. Es un producto bicomponente, compuesto por una base fluida y un endurecedor, agente de curado SILASTIC 83, que al mezclarse cataliza a temperatura ambiente $\left(22-25^{\circ} \mathrm{C}\right)$, mediante una reacción de condensación, alcanzando unas propiedades mecánicas óptimas frente al desgarro y la flexión.

Las características de los moldes preparados son las siguientes:

- 2 moldes de $58 \mathrm{~mm}$ x $45 \mathrm{~mm}$ x $17 \mathrm{~mm}$

- $\quad 2$ moldes de $58 \mathrm{~mm}$ x $45 \mathrm{~mm}$ x $14 \mathrm{~mm}$

- $\quad 2$ moldes de $58 \mathrm{~mm}$ x $45 \mathrm{~mm}$ x $11 \mathrm{~mm}$

- 2 moldes de $58 \mathrm{~mm}$ x $45 \mathrm{~mm}$ x $8 \mathrm{~mm}$

- 2 moldes de $40 \mathrm{~mm}$ x $20 \mathrm{~mm}$ x $5 \mathrm{~mm}$

- 2 moldes de $40 \mathrm{~mm}$ x $20 \mathrm{~mm}$ x $3 \mathrm{~mm}$

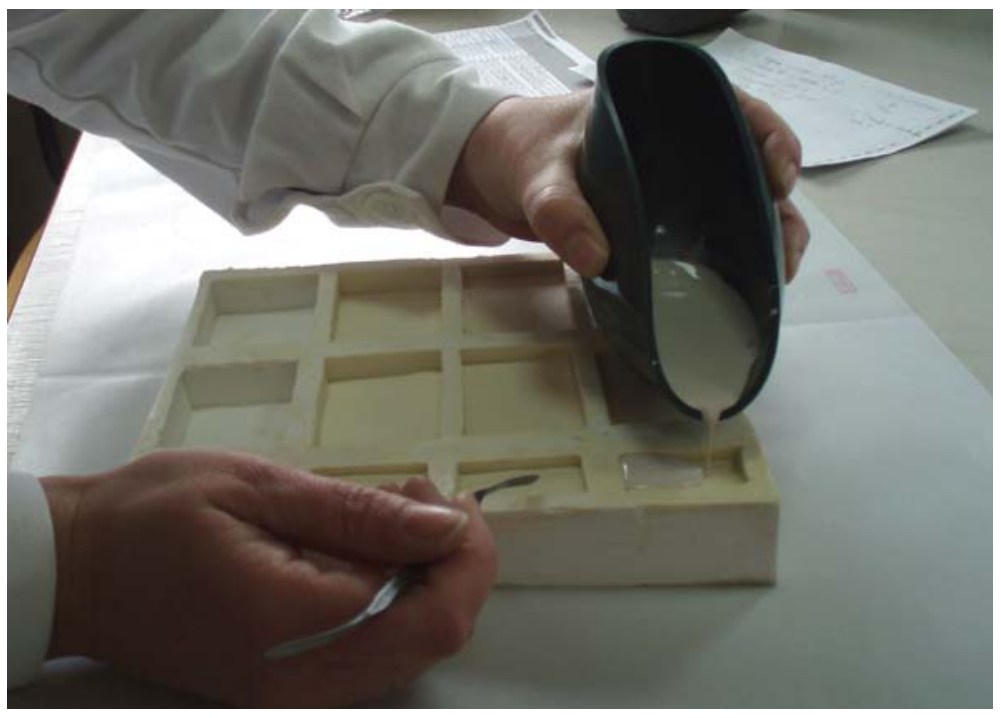

Figura 10. Molde realizado para los estudios previos de masillas 


\section{III.3.2.2. ELABORACIÓN DE LAS MASILLAS PREVIAS}

Las muestras se obtuvieron mediante un proceso de moldeo directo. Los diferentes componentes de las masillas se mezclaron homogéneamente, a continuación, se aplicaron mediante espátula flexible en el molde de silicona realizado.

Paralelamente al moldeo de las masillas se efectuó un ensayo de reintegración de lagunas en piezas de barro cocidas de época actual con una porosidad media, con el fin de poder observar y evaluar parámetros que las masillas por si mismas no aportan, como la adhesión al cuerpo cerámico y la reversibilidad.

Las masillas seleccionadas para el desarrollo de la investigación fueron:

- aquellas en las que se observó un comportamiento adecuado a las características de un buen estuco o masilla ${ }^{50}$.

- aquellas que tradicionalmente se siguen utilizando hoy en día en distintos centros de restauración, aún cuando su comportamiento en las pruebas realizadas no fuera óptimo.

El Anexo I recoge las fichas de cada una de las masillas ensayadas, indicando su dosificación, trabajabilidad y comportamiento. Todas ellas conforman el Catálogo de Masillas para la Reintegración

${ }^{50}$ II.6. Requisitos de las masillas de relleno 
Volumétrica de Lagunas en Cerámica Arqueológica, como uno de los objetivos de la presente Tesis Doctoral.

Cada una de las fichas de dicho Catálogo recoge las siguientes características y propiedades observadas para cada masilla, ante su elaboración, aplicación, trabajabilidad, comportamiento y reversibilidad, tal y como podemos ver en la Figura III. 12.

Composición: productos utilizados y su dosificación.

Las variedades de una misma masilla son infinitas, es por ello que no existen fórmulas únicas, de hecho el restaurador cuando prepara la masilla se guía más por la práctica y el empirismo que por unas dosificaciones exactas.

Preparación: pasos a seguir en la elaboración de la masilla.

Muchos de los materiales empleados (resinas sintéticas) en las masillas requieren una disolución previa antes de ser mezclados con cargas inertes.

Consistencia y Aplicación: dependiendo de la dosificación de la masilla, ésta será líquida, espesa o pastosa; pudiéndose aplicar mediante inyección, vertido y espátula. Este dato es fundamental ya que dependiendo de la consistencia de la masilla elegida podremos o no optar por un tipo de molde u otro, como ya vimos en capítulos anteriores. Señalamos en este punto que determinadas masillas como 


\begin{tabular}{|c|c|c|c|c|c|}
\hline REFERENCIA & \multicolumn{3}{|c|}{ MASILLA } & \multicolumn{2}{|c|}{$\mathbf{N}^{\mathbf{0}}$} \\
\hline \multicolumn{6}{|l|}{ COMPOSICIÓN } \\
\hline \multicolumn{6}{|l|}{ PREPARACIÓN } \\
\hline \multirow{2}{*}{$\begin{array}{l}\text { CONSISTENCIA Y } \\
\text { APLICACIÓN }\end{array}$} & Líquida & Espesa & \multicolumn{2}{|c|}{ Pastosa } & \\
\hline & Inyección & Vertido & \multicolumn{2}{|c|}{ Espátula } & \\
\hline \multicolumn{6}{|l|}{ T. DE TRABAJO } \\
\hline \multicolumn{6}{|l|}{ T. DE SECADO } \\
\hline CONTRACCIÓN & Alta & Media & \multicolumn{2}{|l|}{ Baja } & \\
\hline POROSIDAD & Alta & Media & \multicolumn{2}{|l|}{ Baja } & \\
\hline DUREZA & Alta & Media & \multicolumn{2}{|l|}{ Baja } & \\
\hline ADHESIÓN & Buena & Media & \multicolumn{2}{|l|}{ Mala } & \\
\hline \multirow{2}{*}{$\begin{array}{l}\text { NIVELACIÓN Y } \\
\text { PULIDO }\end{array}$} & Buena & Media & \multicolumn{2}{|l|}{ Mala } & \\
\hline & Bisturí & Lija & \multicolumn{2}{|l|}{ Otros } & \\
\hline \multicolumn{6}{|l|}{ RETOQUE } \\
\hline & \multicolumn{3}{|c|}{ VENTAJAS/INCONVENIENTES } & $\mathbf{V}$ & I \\
\hline \multicolumn{4}{|l|}{ ELABORACIÓN } & & \\
\hline \multicolumn{4}{|c|}{ SE CONOCEN LOS MATERIALES Y PROPORCIONES } & & \\
\hline \multicolumn{4}{|c|}{ APLICACIÓN } & & \\
\hline \multicolumn{4}{|c|}{ NIVELACIÓN Y PULIDO } & & \\
\hline \multicolumn{4}{|c|}{ TIEMPO DE TRABAJO } & & \\
\hline \multicolumn{4}{|c|}{ TIEMPO DE SECADO } & & \\
\hline \multicolumn{4}{|c|}{ CONTRACCIÓN/AGRIETAMIENTO } & & \\
\hline \multicolumn{4}{|l|}{ DUREZA } & & \\
\hline \multicolumn{4}{|l|}{ POROSIDAD } & & \\
\hline \multicolumn{4}{|c|}{ ADHESIÓN AL CUERPO CERÁMICO } & & \\
\hline \multicolumn{4}{|l|}{ RETOQUE } & & \\
\hline \multicolumn{4}{|l|}{ ALMACENAJE } & & \\
\hline \multicolumn{4}{|l|}{ REVERSIBILIDAD } & & \\
\hline OBSERVACIONES & & & & & \\
\hline VALORACIÓN & & & & & \\
\hline
\end{tabular}

Figura III.11. Modelo de ficha que compone el catálogo del Anexo I. 
los morteros de escayola varían su consistencia a medida que van fraguando, es por ello que en este parámetro se observe la indicación de líquida, espesa y pastosa al igual que en su aplicación, por inyección, vertido y espátula.

Tiempo de trabajo: desde su aplicación hasta el fraguado de la masilla. Dependiendo de la composición y dosificación de la masilla se obtendrán unos tiempos de trabajo totalmente distintos variando desde unos minutos (p. ej. las escayolas) hasta incluso horas.

Tiempo de secado: tiempo comprendido entre el fraguado de la masilla y su secado total. Algunas masillas (p. ej. preparados comerciales o masillas a base de resinas sintéticas) fraguan en películas superficiales en apenas unos minutos pero su secado completo no se produce hasta pasadas unas horas.

Contracción: algunas masillas experimentan contracción de volumen durante su secado, pudiendo derivar en la aparición de grietas, lo que hace necesaria una segunda aplicación para completar la laguna.

Porosidad: determinadas masillas durante su fraguado experimentan la aparición de pequeños poros o burbujas, que en muchas ocasiones deben ser rellenados en una segunda aplicación.

Dureza: determinada por la composición y características de las materias primas de la masilla. Una masilla extremadamente blanda 
puede sufrir cualquier deformación o rallado con un mínimo golpe o por el contrario una extremadamente dura dificultará su nivelación y pulido.

Adhesión: capacidad de adhesión entre el estuco y la cerámica. Esta adhesión viene determinada bien por la capacidad de la masilla de introducirse en el poro de la cerámica de manera que se genere una buena unión, bien porque la masilla se ajuste fielmente a los bordes irregulares de la laguna. Dependiendo de la masilla esta adherencia o adhesión ha sido evaluada como alta, media o baja.

Nivelación y Pulido: parámetro en el que se observa la resistencia a la nivelación o tallado de la masilla y su acabado final de superficie. El procedimiento de nivelación se realiza por lo general durante el fraguado de la masilla ya que ésta opone menor resistencia, o bien cuando ha secado completamente pudiendo en ocasiones reblandecer la misma con distintos solventes dependiendo de su composición; en ambos casos el bisturí es el instrumento más utilizado, pudiendo recurrir también al microtorno con revoluciones bajas, en el caso de que la masilla este completamente seca o bien no permita el reblandecimiento (p. ej. resinas epoxídicas).

La operación de pulido se realiza una vez esté completamente seco el estuco mediante papeles abrasivos de distinta granulometría.

Retoque: capacidad de la masilla una vez seca para recibir el retoque o reintegración cromática con distintos tipos de pinturas (al agua o sintéticas) y de protección de las mismas (barnices), así como su 
aplicación con distintas metodologías (pincel o aerógrafo). La capacidad de tinción no ha sido evaluada debido a que no ha sido un aspecto estudiado en este trabajo, aunque todas las masillas estudiadas pueden admitir tintes y pigmentos.

Como resultado de la observación en la utilización de cada masilla, cada una de las Fichas del Catalogo, incluye un resumen de las Ventajas e Inconvenientes de las mismas, con el fin de ofrecer una ayuda en la valoración cualitativa de cada masilla en caso de ser utilizada. Las ventajas e inconvenientes analizadas han sido las siguientes:

Elaboración: las masillas que ya vienen preparadas para su uso son ventajosas en cuanto a comodidad, en contra de las que han de ser elaboradas previamente a su utilización. Requisito $n^{\circ} 4$ de las masillas de relleno descritas en el pto. II.6.

Se conocen los materiales y proporciones: aún cuando una masilla comercial preparada es ventajosa en cuanto a su elaboración, es una desventaja en lo referente a que, por lo general, no hay ningún tipo de reseña de los materiales ni proporciones exactas empleadas en su composición. Mientras que en las masillas elaboradas por nosotros mismos con productos totalmente identificados se tiene el absoluto conocimiento de su composición y dosificación.

Aplicación: en ocasiones una masilla que puede ser ventajosa con respecto a otros parámetros puede tener una aplicación bastante 
incómoda dificultando su manipulación. Requisito $\mathrm{n}^{\circ} 5$ de las masillas de relleno descritas en el pto. II.6.

Nivelación y Pulido: una masilla será ventajosa en cuanto a su nivelación y pulido cuando no ofrezca demasiada resistencia, o bien, pueda realizarse el primero durante el fraguado. Requisito $\mathrm{n}^{0} 10$ de las masillas de relleno descritas en el pto. II.6.

Tiempo de trabajo: consideramos una ventaja al proceso de fraguado rápido, pero con el tiempo suficiente para poder nivelar la laguna. Desde nuestra experiencia, tiempos excesivamente largos ralentizan el trabajo, ya que en muchas ocasiones la pieza debe estar inmóvil hasta el fraguado de la masilla, por lo que es imposible intervenir en otra laguna. Somos conscientes de que este parámetro es un tanto subjetivo, en nuestra opinión, tiempos de aproximadamente 15 minutos son suficientes para la aplicación de la masilla, pasado este tiempo y fraguada la misma, se puede iniciar el proceso de nivelación. Éste proceso en masillas con un tiempo de trabajo excesivamente largo implica la inmovilización de la pieza, realizar el relleno de la laguna en horas muy tempranas para poder efectuar la nivelación sin excesivo trabajo mientras la masilla aún no ha secado. Requisito $\mathrm{n}^{0} 7$ de las masillas de relleno descritas en el pto. II.6.

Tiempo de secado: con la aplicación de determinadas masillas que no secan en horas la pieza ha de estar inmovilizada, además las tareas de nivelación y pulido deben esperar hasta su secado total. Todo ello representa un inconveniente en cuanto a la ralentización del trabajo. 
Por el contrario, determinadas masillas experimentan también un largo tiempo de secado pero no de fraguado por lo que pueden ser niveladas, pudiendo realizarse otras reintegraciones de lagunas en la misma pieza.

Contracción/Agrietamiento: aquellas masillas que no experimentan ninguna retracción significativa o agrietamiento se consideran ventajosas en contra de aquellas que si lo experimentan. Requisito $\mathrm{n}^{\circ} 9$ de las masillas de relleno descritas en el pto. II. 6 .

Dureza: son ventajosas aquellas masillas que tienen una dureza media entendiendo con ello que no ofrece demasiada resistencia a su pulido y nivelación una vez secas. Requisito $\mathrm{n}^{\circ} 11$ de las masillas de relleno descritas en el pto. II.6.

Porosidad: consideramos ventajosa una masilla que no experimenta durante su fraguado/secado una formación excesiva de poros y burbujas, que han de ser reparadas con posterioridad. Este parámetro es determinante en la eficiencia de procesos posteriores como el retoque o reintegración cromática

Adhesión al cuerpo cerámico: es un inconveniente que la masilla no se adhiera o tome la impronta del perímetro de la laguna ya que no ofrecerá ninguna garantía de adhesión a la misma. Requisito $n^{\circ} 8$ de las masillas de relleno. 
Retoque: se considera ventajosa aquella masilla que permita una reintegración cromática uniforme y pueda ser aplicada con diferentes metodologías. Requisito $\mathrm{n}^{0} 12$ de las masillas de relleno.

Almacenaje: consideramos ventajosas aquellas masillas que puedan ser almacenadas en recipientes estancos por un largo tiempo o que como mínimo ofrezca la posibilidad de reintegrar todas las lagunas de una misma pieza. Por lo general, las masillas comerciales ya preparadas para su uso y las ceras ofrecen esta posibilidad, aunque también las masillas a base de resinas termoplásticas pueden ser almacenadas por un tiempo, en contra de las masillas a base de resinas termoendurecibles o las masillas a base de sulfato cálcico. Requisito $\mathrm{n}^{\circ} 4$ de las masillas de relleno.

Reversibilidad: es la fácil eliminación de la masilla sin dañar la pieza original. Con el fin de valorar objetivamente la reversibilidad de cada masilla no se ha tenido en cuenta la aplicación de un estrato intermedio como vimos en el punto II.5.2. Requisito $\mathrm{n}^{0} 2$ de las masillas de relleno.

Toxicidad: se considera una ventaja la ausencia de efectos nocivos en los materiales que componen las masillas para el restaurador. Requisito $n^{\circ} 13$ de las masillas de relleno.

Finalmente, y como conclusión para cada una de las masillas, se ha incluido en su correspondiente Ficha un apartado de Observaciones y 
de Valoración en el que se resumen las características más relevantes en cada caso.

A modo de resumen del citado Catálogo, las siguientes tablas III.2633. recogen la totalidad de masillas que fueron ensayadas y su dosificación. Ésta ha sido calculada en volumen con el fin de poder elaborar en cualquier momento una masilla con las mismas proporciones.

\begin{tabular}{|l|l|l|}
\hline $\mathbf{N}^{\circ}$ & NOMBRE & COMPOSICIÓN/DOSIFICACIÓN \\
\hline
\end{tabular}

\begin{tabular}{|c|l|l|l|}
\hline \multicolumn{2}{|l|}{} & \multicolumn{2}{|c|}{ ESCAYOLAS } \\
\hline $\mathbf{1}$ & ALAMO 70/1 & Álamo 70 (1 Vol.) + agua ${ }^{51}$ (1 Vol.) \\
\hline $\mathbf{2}$ & ALAMO 70/2 & Álamo 70 (2 Vol.) + agua (1 Vol.) \\
\hline $\mathbf{3}$ & ALAMO 70/3 & Álamo 70 (3 Vol.) + agua (3 Vol.) \\
\hline $\mathbf{4}$ & ALAMO 70/4 & Álamo 70 (6 Vol.) + Mowilith SDM5 15\% en agua (5 Vol.) \\
\hline $\mathbf{5}$ & ALAMO 70/5 & Álamo 70 (3 Vol.) + Mowilith SDM5 20\% en agua (1 Vol.) \\
\hline $\mathbf{6}$ & ALAMO 70/6 & Álamo 70 (2 Vol.) + Mowilith SDM5 25\% en agua (1 Vol.) \\
\hline 7 & ALAMO 70/7 & Álamo 70 (3 Vol.) + Mowilith SDM5 25\% en agua (1 Vol.) \\
\hline $\mathbf{8}$ & ALAMO 70/8 & Álamo 70 (3 Vol.) + Mowilith SDM5 50\% en agua (1 Vol.) \\
\hline $\mathbf{9}$ & ALAMO 70/9 & Álamo 70 (2 Vol.) + ACRIL 33 15\% en agua (1 Vol.) \\
\hline $\mathbf{1 0}$ & ALAMO 70/10 & Álamo 70 (3 Vol.) + ACRIL 33 25\% en agua (1 Vol.) \\
\hline $\mathbf{1 1}$ & ALAMO 50/1 & Álamo 50 (3 Vol.) + agua (2 Vol.) \\
\hline $\mathbf{1 2}$ & ALAMO 50/2 & Álamo 50 (3 Vol.) + Mowilith SDM5 20\% en agua (1 Vol.) \\
\hline $\mathbf{1 3}$ & ALAMO 50/3 & Álamo 50 (3 Vol.) + Mowilith SDM5 20\% en agua (1 Vol.) \\
\hline
\end{tabular}

${ }^{51}$ En la presente Tesis siempre que mencionemos Agua nos referimos a agua desionizada. 


\section{\begin{tabular}{|l|l|l|}
\hline N $^{\circ}$ & NOMBRE & COMPOSICIÓN/DOSIFICACIÓN \\
\hline
\end{tabular}}

\begin{tabular}{|c|l|l|}
\hline $\mathbf{1 4}$ & ALAMO 50/4 & Álamo 50 (3 Vol.) + Mowilith SDM5 50\% en agua (1 Vol.) \\
\hline $\mathbf{1 5}$ & EXADURO & Exaduro (5 Vol.) + agua (2 Vol.) \\
\hline $\mathbf{1 6}$ & DURO 6/1 & Duro 6 (1 Vol.) + agua (1 Vol.) \\
\hline $\mathbf{1 7}$ & DURO 6/2 & Duro 6 (2 Vol.) + agua (1 Vol.) \\
\hline $\mathbf{1 8}$ & DURO 6/3 & Duro 6 (4 Vol.) + agua (1 Vol.) \\
\hline $\mathbf{1 9}$ & HEBODUR/1 & Hebodur (2 Vol.) + agua (1 Vol.) \\
\hline $\mathbf{2 0}$ & HEBODUR/2 & Hebodur (3 Vol.) + agua (1 Vol.) \\
\hline $\mathbf{2 1}$ & CERA & $\begin{array}{l}\text { Cera blanca de abejas (65 gr.) + parafina (65 gr.) + resina de } \\
\text { colofonia (10 gr.) + oxido de zinc (150 gr.) + yeso (200 gr.) }\end{array}$ \\
\hline
\end{tabular}

Tabla III.26. Estucos de escayola y cera ensayados.

\begin{tabular}{|c|l|l|}
\hline \multicolumn{3}{|c|}{ RESINA VINÍLICA “MOWILITH SDM5” } \\
\hline 22 & $\begin{array}{l}\text { MOWILITH } \\
\text { SDM5/1 }\end{array}$ & Mowilith SDM5 (1 Vol.) +Sílice coloidal (2 Vol.) \\
\hline 23 & $\begin{array}{l}\text { MOWILITH } \\
\text { SDM5/2 }\end{array}$ & Mowilith SDM5 (1 Vol.) +Polvo de mármol (2 Vol.) \\
\hline 24 & $\begin{array}{l}\text { MOWILITH } \\
\text { SDM5/3 }\end{array}$ & Mowilith SDM5 90\% en agua (1 Vol.) + Carbonato cálcico (1 Vol.) \\
\hline 25 & $\begin{array}{l}\text { MOWILITH } \\
\text { SDM5/4 }\end{array}$ & Mowilith SDM5 (1 Vol.) + Carbonato cálcico (3 Vol.) \\
\hline 26 & $\begin{array}{l}\text { MOWILITH } \\
\text { SDM5/5 }\end{array}$ & Mowilith SDM5 (2 Vol.) + Carbonato cálcico (7 Vol.) \\
\hline
\end{tabular}

Tabla III.27. Masillas de resina Vinílica “Mowilith SDM5”más cargas inertes.

\begin{tabular}{|l|l|l|}
\hline \multicolumn{3}{|c|}{ RESINA ACRILICA “ACRIL 33” } \\
\hline $\mathbf{2 7}$ & ACRIL 33/1 & Acril 33 (2 Vol.) + Sílice micronizado (3 Vol.) \\
\hline $\mathbf{2 8}$ & ACRIL 33/2 & Acril 33 (1 Vol.) + Carbonato cálcico (1 Vol.) \\
\hline $\mathbf{2 9}$ & ACRIL 33/3 & Acril 33 90\% en agua (1 Vol.) + Carbonato cálcico (1 Vol.) \\
\hline $\mathbf{3 0}$ & ACRIL 33/4 & Acril 33 (1 Vol.) + Carbonato cálcico (2 Vol.) \\
\hline $\mathbf{3 1}$ & ACRIL 33/5 & Acril 33 (1 Vol.) + Carbonato cálcico (3 Vol.) \\
\hline 32 & ACRIL 33/6 & Acril 33 (1 Vol.) + Carbonato cálcico (4 Vol.) \\
\hline
\end{tabular}




\begin{tabular}{|l|l|l|}
\hline $\mathbf{N}$ & \multicolumn{1}{|c|}{ NOMBRE } & \multicolumn{1}{c|}{ COMPOSICIÓN/DOSIFICACIÓN } \\
\hline 33 & ACRIL 33/7 & Acril 33 (4 Vol.) + Polvo de mármol (9 Vol.) \\
\hline $\mathbf{3 4}$ & ACRIL 33/8 & Acril 33 (4 Vol.) + Microesferas de vidrio (9 Vol.) \\
\hline
\end{tabular}

Tabla III.28. Masillas de resina acrílica en dispersión acuosa “Acril 33” aglutinadas con cargas inertes

\begin{tabular}{|l|l|l|}
\hline \multicolumn{3}{|c|}{ RESINA ACRÍLICA “PLEXTOL B-500” } \\
\hline 35 & PLEXTOL B-500/1 & Plextol B-500 (2 Vol.) + Microesferas de vidrio (3 Vol.) \\
\hline 36 & PLEXTOL B-500/2 & Plextol B-500 (1 Vol.) + Carbonato Cálcico (2 Vol.) \\
\hline 37 & PLEXTOL B-500/3 & Plextol B-500 al 66\% en agua (1 Vol.) + Carbonato Cálcico (2 Vol.) \\
\hline
\end{tabular}

Tabla III.29. Masillas de resina acrílica en dispersión acuosa "Plextol B-500” aglutinadas con cargas inertes.

\begin{tabular}{|c|c|c|}
\hline \multicolumn{3}{|c|}{ RESINA ACRÍLICA “PARALOID B-72” } \\
\hline 38 & PARALOID B-72/1 & Paraloid B-72 50\% en acetona (2 Vol.) + Polvo de mármol (3 Vol.) \\
\hline 39 & PARALOID B-72/2 & Paraloid B-72 50\% en acetona (2 Vol.) + Carbonato cálcico (3 Vol.) \\
\hline 40 & PARALOID B-72/3 & $\begin{array}{l}\text { Paraloid B-72 50\% en acetona }(1 \mathrm{Vol})+ \\
\text { Microesferas de vidrio }(1 \mathrm{Vol})\end{array}$ \\
\hline 41 & PARALOID B-72/4 & $\begin{array}{l}\text { Paraloid B-72 35\% en acetona (1 Vol.) + } \\
\text { Microesferas de vidrio (1 Vol.) + } 3 \text { gotas de alcohol etílico }\end{array}$ \\
\hline 42 & PARALOID B-72/5 & $\begin{array}{l}\text { Paraloid B-72 35\% en acetona (1 Vol.) + Microesferas de vidrio (2 } \\
\text { Vol.) + } 3 \text { gotas de alcohol etílico }\end{array}$ \\
\hline 43 & PARALOID B-72/6 & $\begin{array}{l}\text { Paraloid B-72 35\% en acetona:alcohol metílico(1:1) (1 Vol.) + } \\
\text { Microsferas de vidrio (3 Vol.) }\end{array}$ \\
\hline 44 & PARALOID B-72/7 & $\begin{array}{l}\text { Paraloid B-72 35\% en acetona (1 Vol.) + Carbonato cálcico (2 Vol.) } \\
+3 \text { gotas de alcohol etílico }\end{array}$ \\
\hline 45 & PARALOID B-72/8 & $\begin{array}{l}\text { Paraloid B-72 35\% en acetona:alcohol metílico(1:1) (1 Vol.) + } \\
\text { Carbonato cálcico (2 Vol.) }\end{array}$ \\
\hline 46 & PARALOID B-72/9 & Paraloid B-72 30\% en xileno (1 Vol.) + Carbonato cálcico (1 Vol.) \\
\hline 47 & PARALOID B-72/10 & Paraloid B-72 30\% en xileno ( 1 Vol.) + Polvo de mármol (2 Vol.) \\
\hline
\end{tabular}


Investigación y análisis de las masillas de relleno para la reintegración de lagunas cerámicas arqueológicas

\section{\begin{tabular}{|l|l|l}
\hline $\mathbf{N}^{\mathrm{o}}$ & NOMBRE & COMPOSICIÓN/DOSIFICACIÓN \\
\hline
\end{tabular}}

\begin{tabular}{|l|l|l|}
\hline $\mathbf{4 8}$ & PARALOID B-72/11 & $\begin{array}{l}\text { Paraloid B-72 25\% en acetona (1 Vol.) + } \\
\text { Microesferas de vidrio (1 Vol.) }\end{array}$ \\
\hline $\mathbf{4 9}$ & PARALOID B-72/12 & $\begin{array}{l}\text { Paraloid B-72 25\% en acetona (1 Vol.) + } \\
\text { Microesferas de vidrio (2 Vol.) }\end{array}$ \\
\hline $\mathbf{5 0}$ & PARALOID B-72/13 & $\begin{array}{l}\text { Paraloid B-72 25\% en acetona:alcohol metílico(1:1) (1 Vol.) + } \\
\text { Microesferas de vidrio (3 Vol.) }\end{array}$ \\
\hline $\mathbf{5 1}$ & PARALOID B-72/14 & Paraloid B-72 25\% en acetona (1 Vol.) + Carbonato cálcico (2 Vol.) \\
\hline $\mathbf{5 2}$ & PARALOID B-72/15 & Paraloid B-72 25\% en acetona (1 Vol.) + Carbonato cálcico (3 Vol.) \\
\hline $\mathbf{5 3}$ & PARALOID B-72/16 & $\begin{array}{l}\text { Paraloid B-72 25\% en Tolueno (1 Vol.) + Carbonato Cálcico (2 } \\
\text { Vol.) }\end{array}$ \\
\hline $\mathbf{5 4}$ & PARALOID B-72/17 & $\begin{array}{l}\text { Paraloid B-72 25\% en Tolueno (4 Vol.) + Carbonato Cálcico (8 } \\
\text { Vol.) + Silice coloidal (1 Vol.) }\end{array}$ \\
\hline $\mathbf{5 5}$ & PARALOID B-72/18 & $\begin{array}{l}\text { Paraloid B-72 25\% en acetona (2 Vol.)+ alcohol metílico (2 Vol.) } \\
\text { Carbonato cálcico (6 Vol.) }\end{array}$ \\
\hline $\mathbf{5 6}$ & PARALOID B-72/19 & $\begin{array}{l}\text { Paraloid B-72 25\% en acetona:alcohol metílico(1:1) (4 Vol.) + } \\
\text { Carbonato cálcico (7 Vol.) }\end{array}$ \\
\hline $\mathbf{5 7}$ & PARALOID B-72/20 & $\begin{array}{l}\text { Paraloid B-72 25\% en acetona:alcohol metílico(1:1) (1 Vol.) + } \\
\text { Polvo de mármol (1 Vol.) + Sílice coloidal (1 Vol.) }\end{array}$ \\
\hline
\end{tabular}

Tabla III.30. Masillas de resina acrílica “Paraloid B-72”más cargas inertes

\begin{tabular}{|l|l|l|}
\hline \multicolumn{2}{|c|}{ RESINAS EPOXÍDICAS } \\
\hline $\mathbf{5 8}$ & RESINA EPO 150/1 & EPO 150 (1 Vol.) \\
\hline $\mathbf{5 9}$ & RESINA EPO 150/2 & $\begin{array}{l}\text { EPO } 150 \text { (2 Vol.) + Microesferas de vidrio (7 Vol.) + Pigmento } \\
\text { Siena (0,10 Vol.) }\end{array}$ \\
\hline $\mathbf{6 0}$ & RESINA EPO 150/3 & EPO 150 (2 Vol.) + Microesferas de vidrio (5 Vol.) \\
\hline $\mathbf{6 1}$ & RESINA EPO 150/4 & EPO 150 (1 Vol.) + Polvo de mármol (4 Vol.) \\
\hline $\mathbf{6 2}$ & RESINA EPO 150/5 & EPO 150 (2 Vol.) + Carbonato de calcio (5 Vol.) \\
\hline $\mathbf{6 3}$ & RESINA EPO 150/6 & EPO 150 (1 Vol.) + Silice coloidad (3 Vol.) \\
\hline
\end{tabular}




\begin{tabular}{|l|l|l|}
\hline $\mathbf{N}^{\mathrm{o}}$ & NOMBRE & COMPOSICIÓN/DOSIFICACIÓN \\
\hline
\end{tabular}

\begin{tabular}{|l|l|l|}
\hline $\mathbf{6 4}$ & RESINA EPO 150/7 & EPO 150 (1 Vol.) + Silice coloidad (5 Vol.) \\
\hline $\mathbf{6 5}$ & RESINA EPO 127/1 & EPO 127:K 128 (1:1) \\
\hline
\end{tabular}

Tabla III.31.Masillas de resina Epoxídicas “Epo 127” y “Epo 150” más cargas inertes.

\begin{tabular}{|c|c|c|}
\hline \multicolumn{3}{|c|}{ MASILLAS COMERCIALES EN POLVO } \\
\hline 66 & $\begin{array}{l}\text { POLYFILLA } \\
\text { EXTERIORES/1 }\end{array}$ & Polyfilla Ext. (2 Vol.) + agua (1 Vol.) \\
\hline 67 & $\begin{array}{l}\text { POLYFILLA } \\
\text { EXTERIORES/2 }\end{array}$ & Polyfilla Ext. (2 Vol.) + Plextol B-500 al 75\% en agua (1 Vol.) \\
\hline 68 & $\begin{array}{l}\text { POLYFILLA } \\
\text { EXTERIORES/3 }\end{array}$ & Polyfilla Ext. (5 Vol.) + Acril 33 (4 Vol.) \\
\hline 69 & $\begin{array}{l}\text { POLYFILLA } \\
\text { INTERIORES/1 }\end{array}$ & Polyfilla Int. (2 Vol.) + Agua (1 Vol.) \\
\hline 70 & $\begin{array}{l}\text { POLYFILLA } \\
\text { INTERIORES/2 }\end{array}$ & Polyfilla Int. (3 Vol.) + Agua (1 Vol.) \\
\hline 71 & $\begin{array}{l}\text { POLYFILLA } \\
\text { INTERIORES/3 }\end{array}$ & Polyfilla Int. (3 Vol.) + Agua (2 Vol.) \\
\hline 72 & $\begin{array}{l}\text { POLYFILLA } \\
\text { INTERIORES/4 }\end{array}$ & Polyfilla Int. (2 Vol.) + Mowilith SDM5 en agua al 50\% (1 Vol.) \\
\hline 73 & $\begin{array}{l}\text { POLYFILLA } \\
\text { INTERIORES/5 }\end{array}$ & Polyfilla Int. (2 Vol.) + Mowilith SDM5 en agua al 25\% (1 Vol.) \\
\hline 74 & $\begin{array}{l}\text { POLYFILLA } \\
\text { INTERIORES/6 }\end{array}$ & Polyfilla Int. (2 Vol.) + Mowilith SDM5 en agua al 10\% (1 Vol.) \\
\hline 75 & $\begin{array}{l}\text { POLYFILLA } \\
\text { INTERIORES/7 }\end{array}$ & Polyfilla Int. (2 Vol.) + Mowilith SDM5 en agua al 5\% (1 Vol.) \\
\hline 76 & $\begin{array}{l}\text { POLYFILLA } \\
\text { INTERIORES/8 }\end{array}$ & Polyfilla Int. (2 Vol.) + Acril 33en agua al 10\% (1 Vol.) \\
\hline 77 & $\begin{array}{l}\text { POLYFILLA } \\
\text { INTERIORES/9 }\end{array}$ & $\begin{array}{l}\text { Polyfilla Int. (2 Vol.) + Acril } 33 \text { en agua al 10\% (2 Vol.) + Sílice } \\
\text { Coloidal (2 Vol.) }\end{array}$ \\
\hline
\end{tabular}




\section{$\mathbf{N}^{\circ}$ \\ NOMBRE \\ COMPOSICIÓN/DOSIFICACIÓN}

\begin{tabular}{|r|l|l|}
$\mathbf{7 8}$ & $\begin{array}{l}\text { POLYFILLA } \\
\text { INTERIORES/10 }\end{array}$ & $\begin{array}{l}\text { Polyfilla Int. (3 Vol.) + Agua (2 Vol.) + Microesferas de vidrio (3 } \\
\text { Vol.) }\end{array}$ \\
\hline $\mathbf{7 9}$ & $\begin{array}{l}\text { POLYFILLA } \\
\text { INTERIORES/11 }\end{array}$ & Polyfilla Int. (1 Vol.) + Agua (1 Vol.) + Sílice coloidal (2 Vol.) \\
\hline $\mathbf{8 0}$ & $\begin{array}{l}\text { AGUAPLAST } \\
\text { ACABADOS }\end{array}$ & Aguaplast acabados (2 Vol.) + Agua (1 Vol.) \\
\hline $\mathbf{8 1}$ & $\begin{array}{l}\text { AGUAPLAST CAPA } \\
\text { GRUESA }\end{array}$ & Aguaplast capa gruesa (2 Vol.) + Agua (1 Vol.) \\
\hline
\end{tabular}

Tabla III.32. Masillas comerciales en polvo.

\begin{tabular}{|l|l|l|}
\hline \multicolumn{2}{|c|}{ MASILLAS COMERCIALES PREPARADAS } \\
\hline $\mathbf{8 2}$ & MODOSTUC PASTA/1 & Modostuc pasta (50 gr.) + Liteplast pasta blanco (50 gr.) \\
\hline $\mathbf{8 3}$ & $\begin{array}{l}\text { MODOSTUC P.- } \\
\text { LITEPLAST / }\end{array}$ & Modostuc pasta (10 gr.) + Liteplast pasta blanco (1 gr.) \\
\hline $\mathbf{8 4}$ & $\begin{array}{l}\text { MODOSTUC- } \\
\text { LITEPLAST /2 }\end{array}$ & Modostuc pasta (10 gr.) + Liteplast pasta blanco (3 gr.) \\
\hline $\mathbf{8 5}$ & $\begin{array}{l}\text { MODOSTUC- } \\
\text { LITEPLAST /3 }\end{array}$ & $\begin{array}{l}\text { AGUAPLAST CAPA } \\
\text { GRUESA }\end{array}$ \\
\hline $\mathbf{8 7}$ & $\begin{array}{l}\text { LIQUITEX MODELLING } \\
\text { PASTE }\end{array}$ & Preparado comercial en pasta \\
\hline $\mathbf{8 8}$ & STUCCO ZECCHI & Preparado comercial en pasta \\
\hline $\mathbf{8 9}$ & $\begin{array}{l}\text { BRICOFIX TAPA } \\
\text { GRIETAS }\end{array}$ & Preparado comercial en pasta \\
\hline $\mathbf{9 0}$ & $\begin{array}{l}\text { TITAN. MASILLA } \\
\text { PLÁSTICA }\end{array}$ & \\
\hline
\end{tabular}

Tabla III.33. Masillas comerciales en pasta. 


\section{III.3.3. SELECCIÓN DE PROBETAS}

\section{III.3.3.1. INTRODUCCIÓN}

Como indicamos anteriormente, uno de los objetivos de esta Tesis Doctoral era establecer la trabajabilidad de las masillas utilizadas como material en la reintegración volumétrica de lagunas. Como se puede ver en el Anexo I, determinadas masillas seleccionadas para el estudio no presentan, desde nuestro criterio, buenos parámetros en este sentido, es decir, tienen un tiempo de secado excesivamente largo, son extremadamente duras, agrietan durante el secado y deben ser retocadas, etc. Pero son masillas, algunas de ellas; referenciadas bibliográficamente y que siguen utilizándose hoy en día en muchos talleres de restauración, tanto privados como pertenecientes a instituciones públicas, como vimos en capítulos anteriores.

Por ello, las masillas seleccionadas para el desarrollo de la investigación fueron tanto aquellas que presentaron un comportamiento adecuado a las características de un buen estuco o masilla $^{52}$, como las que tradicionalmente se siguen utilizando hoy en día en distintos centros de restauración, con el fin de valorar y comparar su comportamiento tras los distintos ensayos que veremos a continuación.

\footnotetext{
${ }^{52}$ II.6. Requisitos de las masillas de relleno.
} 
En la tabla III.34. se detallan las masillas sometidas a los distintos ensayos que se desarrollan en este capítulo, así como el número correspondiente ya aplicado en los ensayos previos de trabajabilidad (Tablas III 26 - 33). Con el fin de facilitar una rápida lectura de los resultados, en los distintos gráficos que acompañan los ensayos realizados, a cada masilla se le ha aplicado una referencia y un color

\begin{tabular}{|c|c|l|}
\hline REF. & $\mathbf{N}^{\mathbf{0}}$ & COMPOSICIÓN \\
\hline A1 & $\mathbf{5 0}$ & $\begin{array}{l}\text { Paraloid B-72 25\% en acetona:alcohol metílico(1:1) (2 Vol.) } \\
\text { +Microesferas de vidrio (6 Vol.) }\end{array}$ \\
\hline A2 & $\mathbf{5 6}$ & $\begin{array}{l}\text { Paraloid B-72 25\% en acetona:alcohol metílico(1:1) (2 Vol.) + } \\
\text { Carbonato cálcico (7 Vol.) }\end{array}$ \\
\hline A3 & $\mathbf{5 7}$ & $\begin{array}{l}\text { Paraloid B-72 25\% en acetona:alcohol metílico(1:1) (2 Vol.) }+ \\
\text { Polvo de mármol (2 Vol.) + Sílice coloidal (2 Vol.) }\end{array}$ \\
\hline B1 & $\mathbf{3 4}$ & Acril 33 (4 Vol.) + Microesferas de vidrio (9 Vol.) \\
\hline B2 & $\mathbf{3 0}$ & Acril 33 (1 Vol.) + Carbonato cálcico (2 Vol.) \\
\hline B3 & $\mathbf{3 3}$ & Acril 33 (4 Vol.) + Polvo de mármol (9 Vol.) \\
\hline C1 & $\mathbf{9}$ & Álamo 70 (2 vol.) + Acril 33 15\% en agua (1 Vol.) \\
\hline C2 & $\mathbf{4}$ & Álamo 70 (6 vol.) + Mowilith SDM5 15\% en agua (5 Vol.) \\
\hline C3 & $\mathbf{2}$ & Álamo 70 (2 vol.) + agua (1 Vol.) \\
\hline C4 & $\mathbf{1 9}$ & Hebodur (6 vol.) + agua (3 Vol.) \\
\hline D1 & $\mathbf{6 9}$ & Polyfilla Int. (2 vol.) + Agua (1 Vol.) \\
\hline D2 & $\mathbf{7 4}$ & Polyfilla Int. (2 vol.) + Mowilith SDM5 en agua al 10\% (1 Vol.) \\
\hline D3 & $\mathbf{7 6}$ & Polyfilla Int. (2 vol.) + Acril 33en agua al 10\% (1 Vol.) \\
\hline E1 & $\mathbf{6 0}$ & EPO 150 (2 Vol.) + Microesferas de vidrio (5 Vol.) \\
\hline E2 & $\mathbf{6 2}$ & EPO 150 (2 Vol.) + Carbonato de calcio (5 Vol.) \\
\hline E3 & $\mathbf{6 4}$ & EPO 150 (1 Vol.) + Silice coloidad (5 Vol.) \\
\hline E4 & $\mathbf{6 5}$ & EPO 127:K 128 (1:1) \\
\hline F1 & $\mathbf{8 7}$ & Liquitex Modelling Paste. \\
\hline F2 & $\mathbf{8 2}$ & Modostuc pasta. \\
\hline F3 & $\mathbf{8 5}$ & Modostuc pasta (10 gr.) + Liteplast (3 gr.) \\
\hline G & $\mathbf{2 1}$ & Estuco de cera I76 \\
\hline & & \\
\hline
\end{tabular}

Tabla III.34. Masillas seleccionadas. 


\section{III.3.3.2. Elaboración del molde para las probetas}

Los distintos ensayos fueron realizados con un número determinado de probetas de cada masilla con idénticas dimensiones. Para ello se prepararon nuevos moldes ${ }^{53}$ con los que poder elaborar al mismo tiempo y de una sola tirada las probetas necesarias de cada masilla. El tamaño elegido de molde fue de 3,5 x 3,5 x $1 \mathrm{~cm}$.

Del mismo modo, se prepararon unos moldes de $2 \times 1 \times 1 \mathrm{~cm}$. con la finalidad de realizar los ensayos de adhesión de las masillas con respecto a la cerámica, como veremos a continuación.

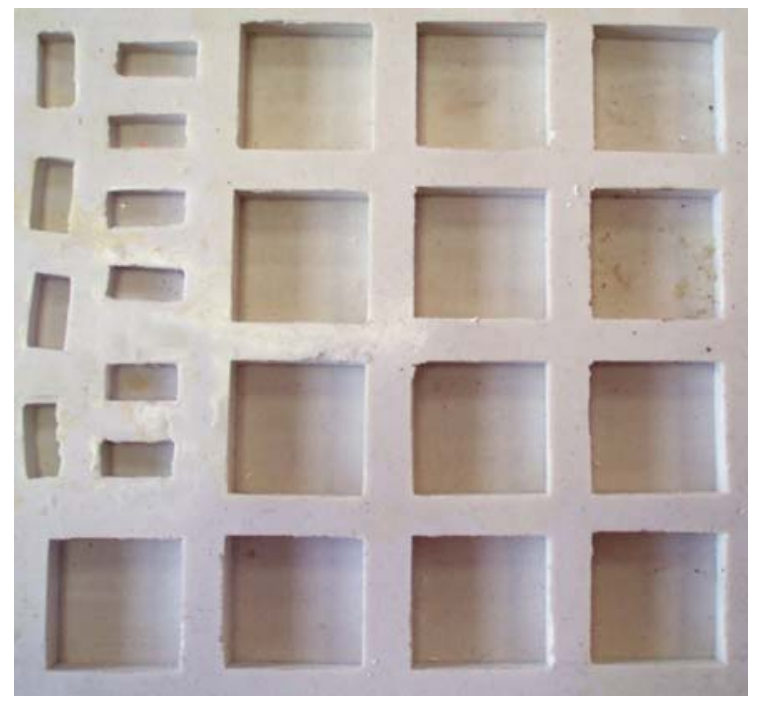

Figura III.12. Molde para las probetas ensayadas

\section{III.3.3.3. Elaboración de las probetas}

\footnotetext{
${ }^{53}$ ver moldes de los ensayos previos punto III.3.2.1. p.
} 
Las masillas seleccionadas fueron objeto de preparación de nuevas probetas, obteniendose un total de 12:

- 3 para envejecimiento acelerado por UV

- 3 para envejecimiento acelerado por HR

- 3 para envejecimiento acelerado por $\mathrm{SO}_{2}$

- 3 para posibles incidencias

Las probetas, al igual que las elaboradas en los ensayos previos, se obtuvieron mediante moldeo directo. Los diferentes componentes de las masillas se mezclaron homogéneamente $\mathrm{y}$ se vertieron $\mathrm{o}$ espatularon en los moldes.

Paralelamente al moldeo de las masillas se efectuó un moldeo de las mismas acompañado por fragmentos cerámicos originales. Éstos fueron cortados en medidas aproximadas de $1 \times 1 \mathrm{~cm}$., siendo las alturas determinadas por las propias cerámicas; seguidamente se aplicó un estrato intermedio, en el corte que iría en contacto con la masilla. Este estrato intermedio está compuesto por una resina acrílica “Paraloid B-72” diluida al 5\% en acetona. Estas muestras cerámicas fueron insertadas en los moldes mencionados anteriormente, de manera que ocuparan la mitad del molde mientras que en la otra mitad se disponía la masilla. De este modo se elaboraron 63 muestras combinadas con los tres tipos de cerámica seleccionadas por cada masilla. 
Las condiciones de trabajo en la realización de todas las probetas fue de una temperatura de $20^{\circ} \mathrm{C}$ y un $65 \%$ de H.R. Este dato es importante ya que temperaturas superiores pueden originar fraguados mucho más rápidos.

Transcurrido el tiempo suficiente para el fraguado de las probetas, distinto en cada masilla como se refleja en el Anexo 1, éstas se desmoldearon y secaron a la misma T y H.R. que cuando fueron elaboradas. Al igual que en el fraguado cada masilla ofreció unos tiempos distintos.

\section{III.3.3.4. Tratamiento de acabado}

Una vez secas las probetas y transcurrida una semana se trataron todas las caras de las mismas con papeles abrasivos de granulometría decreciente: $n^{\circ}$ 400, 800 y 1200. 


\section{III.3.4. SELECCIÓN DE CERÁMICA}

\section{III.3.4.1. Introducción}

Como parte de la investigación se han seleccionado fragmentos cerámicos informes de diferentes épocas históricas con objeto de comparar sus propiedades frente a las diferentes masillas sometidas a estudio.

La selección de diversos fragmentos cerámicos corresponden a piezas de barro cocido de la Edad del Bronce, Época Ibérica y Época Islámica pertenecientes al Museo Arqueológico de Requena (Valencia). La elección de estos fragmentos vino dada en primer lugar por ser las más comunes en lo referente a restauración, además de diferenciarse entre ellas por los distintos niveles de porosidad de sus pastas, derivados a su vez del tipo de material utilizado y de la técnica de fabricación empleada, la cual es, por otro lado, el resultado de una evolución histórico-cultural.

\section{III.3.4.2. Cerámica seleccionada.}

\section{Cerámica Edad del Bronce.}

El periodo protohistórico conocido como la Edad del Bronce tuvo lugar en la Península Ibérica a partir del III milenio a.C. con el inicio del trabajo de la metalurgia del cobre, y se extendió a lo largo del II milenio a.C., durante el cual se desarrolló el bronce en algunas zonas. 
En lo que respecta a la cerámica hay que mencionar que durante este período adquirió gran importancia, no ya como utensilio de uso doméstico, sino también como medio de enterramiento (en las zonas más representativas de este estadio arqueológico los restos humanos se introducían en urnas cerámicas posteriormente enterradas). Los fragmentos cerámicos seleccionados para la presente investigación pertenecen a yacimientos de la comarca Requena-Utiel y tuvieron presumiblemente un uso doméstico. Se trata de una cerámica tosca, pobre, de color pardo u oscuro y realizada a mano. Son producciones locales, autárquicas, elaboradas en los poblados por y para sus propios habitantes, naturalmente a mano y ligadas al trabajo de la mujer. El color oscuro nos da una idea de la técnica de fabricación en hornos u hogueras cerrados a temperaturas bajas (en atmósferas reductoras).

\section{Cerámica Época Ibérica.}

La Cultura Ibérica se desarrolló a lo largo de toda la franja mediterránea de la Península Ibérica, extendiéndose hasta amplias zonas de Andalucía, a partir del s. VI a.C., finalizando hacia el cambio de era, con la romanización. Es el producto de un conjunto de etnias autóctonas diferentes, configuradas además por un substrato anterior distinto en función del contacto con los pueblos que, desde fines del II milenio y durante todo el I, se establecieron en la península ibérica. En lo referente a la cerámica, la introducción del torno en el s. VIII a.C. por los fenicios cambió radicalmente su modo de fabricación, permitiendo el desarrollo de una de las manifestaciones más características de esta cultura. Se trata de una cerámica mucho más depurada, elaborada, torneada y decorada. Los fragmentos de 
cerámica ibérica disponibles para esta investigación provienen del yacimiento de Casillas del Cura. Casillas del Cura es un alfar cerámico cuyo inicio se fecha hacia el s. V a.C., y dos siglos constatados de actividad, ya que hacia el s. III a. C. durante el período Ibérico pleno se abandona. Son piezas de producción local, de pastas refinadas, color anaranjado y con una buena cocción en atmósfera reductora.

\section{Cerámica Época Islámica.}

El período islámico se engloba dentro de la Edad Medieval española, ya que la presencia musulmana en la Península Ibérica se extiende desde el 711 hasta 1492. No obstante, esta cultura, que en aquellos momentos conocía un período de esplendor y avance, contrastaba con el momento de decadencia material representada por la cultura medieval europea. En la Península Ibérica cohabitó en muchos casos con la cultura medieval cristiana debido al avance progresivo de la reconquista. Es por ello que en el terreno de la arqueología se plantea un problema de coexistencia, donde los límites entre una cultura y otra no están claros. No obstante, es innegable la importancia de la cultura islámica en la arqueología de la península durante más de ocho siglos. En lo que respecta a la cerámica, en los reinos musulmanes de España se desarrolló una potente actividad cerámica gracias a la expansión de las técnicas islámicas. Los fragmentos a analizar pertenecen a vasijas califales sin decoración de elaboración local, con pastas poco depuradas y sin ningún tratamiento especial, del alfar de Requena (s. $\mathrm{X}-\mathrm{XI})$. 


\section{III.2.4.2. PREPARACIÓN DE LAS MUESTRAS}

La cerámica proporcionada nos llegó sin ningún tratamiento previo, por lo que contenía aún concreciones de tipo terroso y calcáreo procedente de su enterramiento.

A los fragmentos se les efectuaron los tratamientos de limpieza mecánica con bisturí, sin utilizar ningún tratamiento químico que pudiera alterar su composición. Una vez eliminadas las concreciones los fragmentos cerámicos se sometieron a la eliminación de sales por inmersión en agua desmineralizada, cambiándose el agua cada 24 horas y controlando su conductividad hasta estabilizar la misma. El secado de las piezas se realizó en estufa a $60^{\circ} \mathrm{C}$ durante 2 horas.

Con el fin de obtener muestras con el mismo tamaño de las probetas de masilla, se efectuó el corte de la cerámica en unas dimensiones aproximadas de 3,5 x 3,5 cm. siendo su grosor determinado por la propia cerámica.

Del mismo modo y como mencionamos en puntos anteriores se realizaron cortes de cerámica de 1 x $1 \mathrm{~cm}$. para la elaboración de las probetas combinadas.

\begin{tabular}{|c|l|}
\hline REF. & TIPO DE CERÁMICA \\
\hline H1 & Cerámica Época Ibérica. \\
\hline H2 & Cerámica Época Islámica. \\
\hline H3 & Cerámica Edad del Bronce. \\
\hline
\end{tabular}

Tabla III.35. Cerámica seleccionada. 


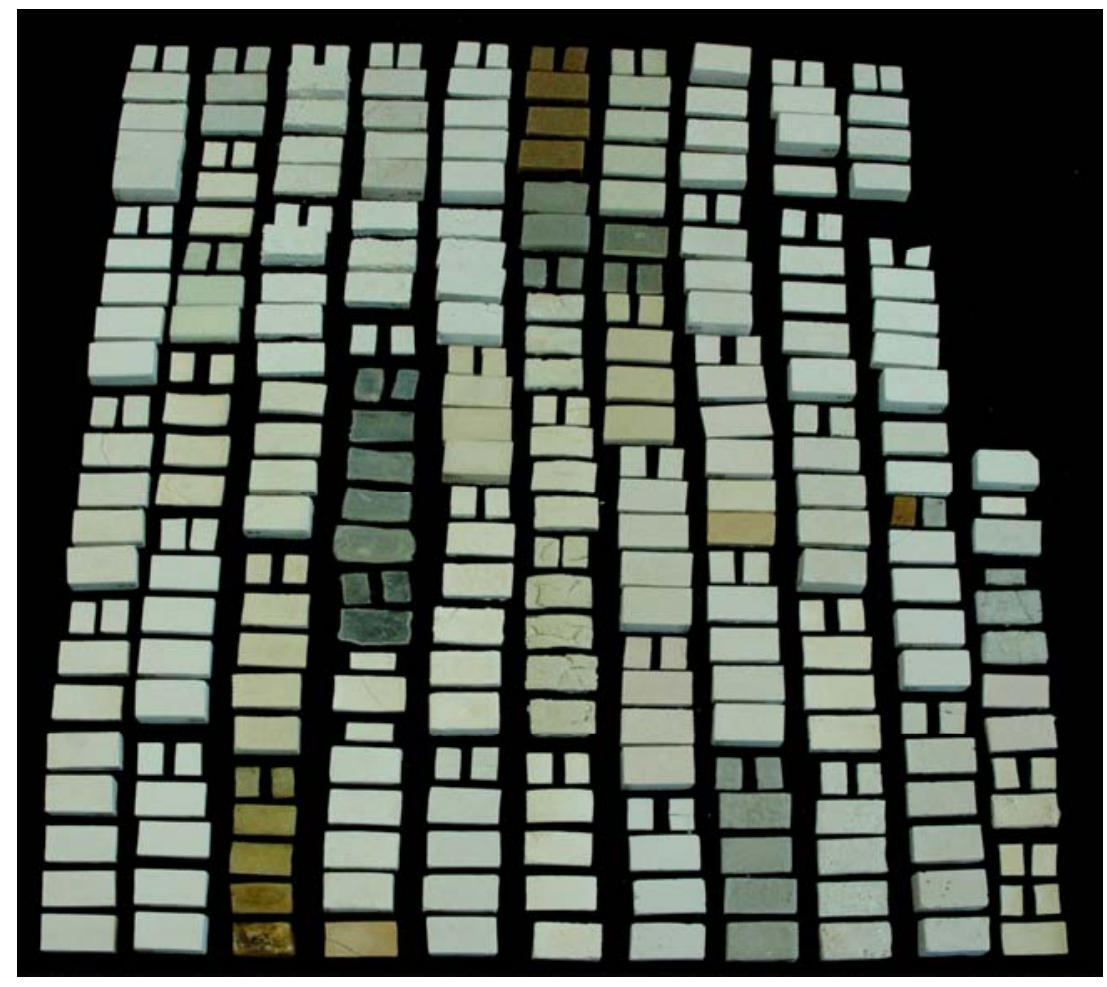

Figura III.13. Masillas previas elaboradas. 


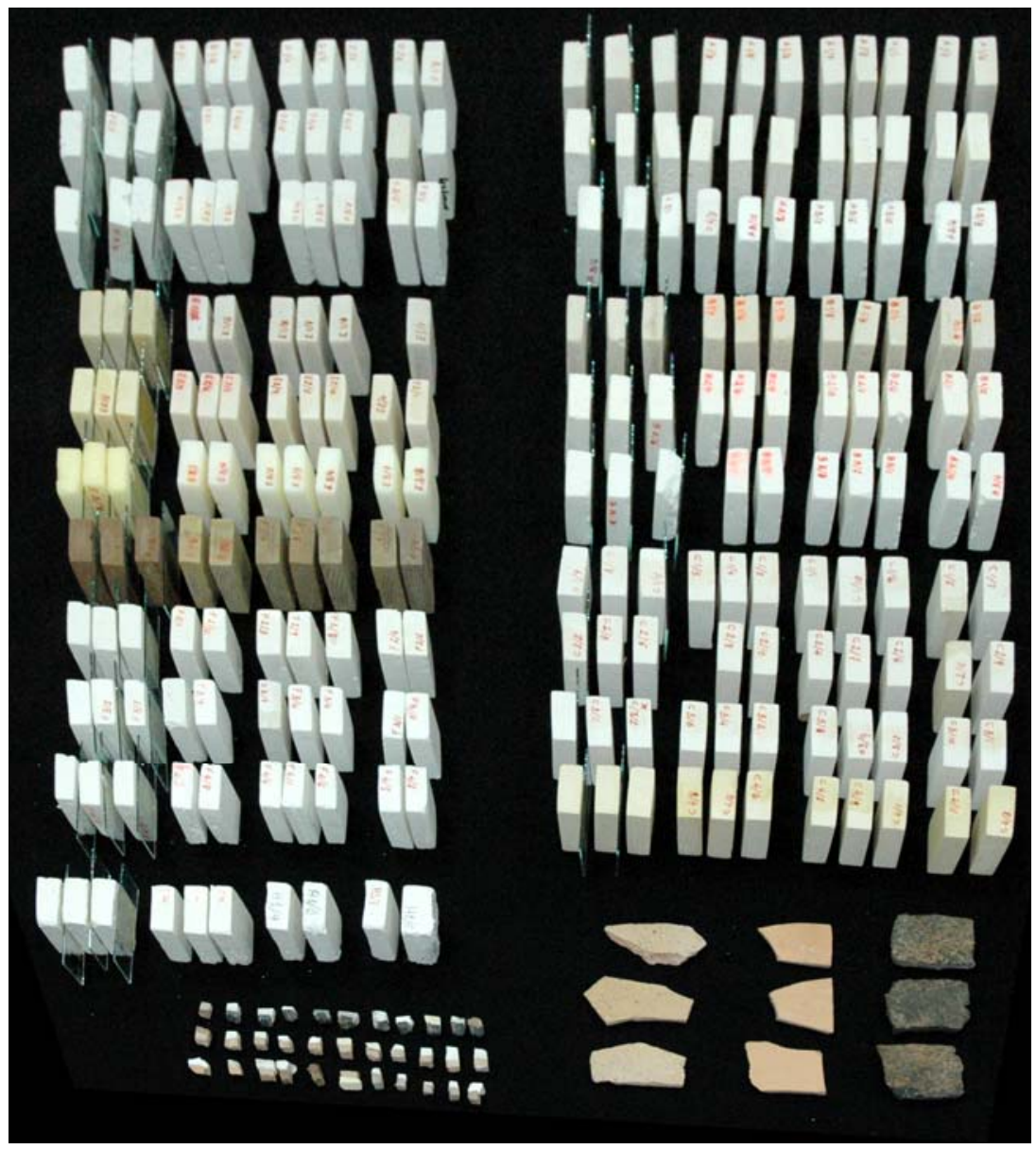

Figura III.14. Muestras de cerámica y masillas sometidas a estudio. 



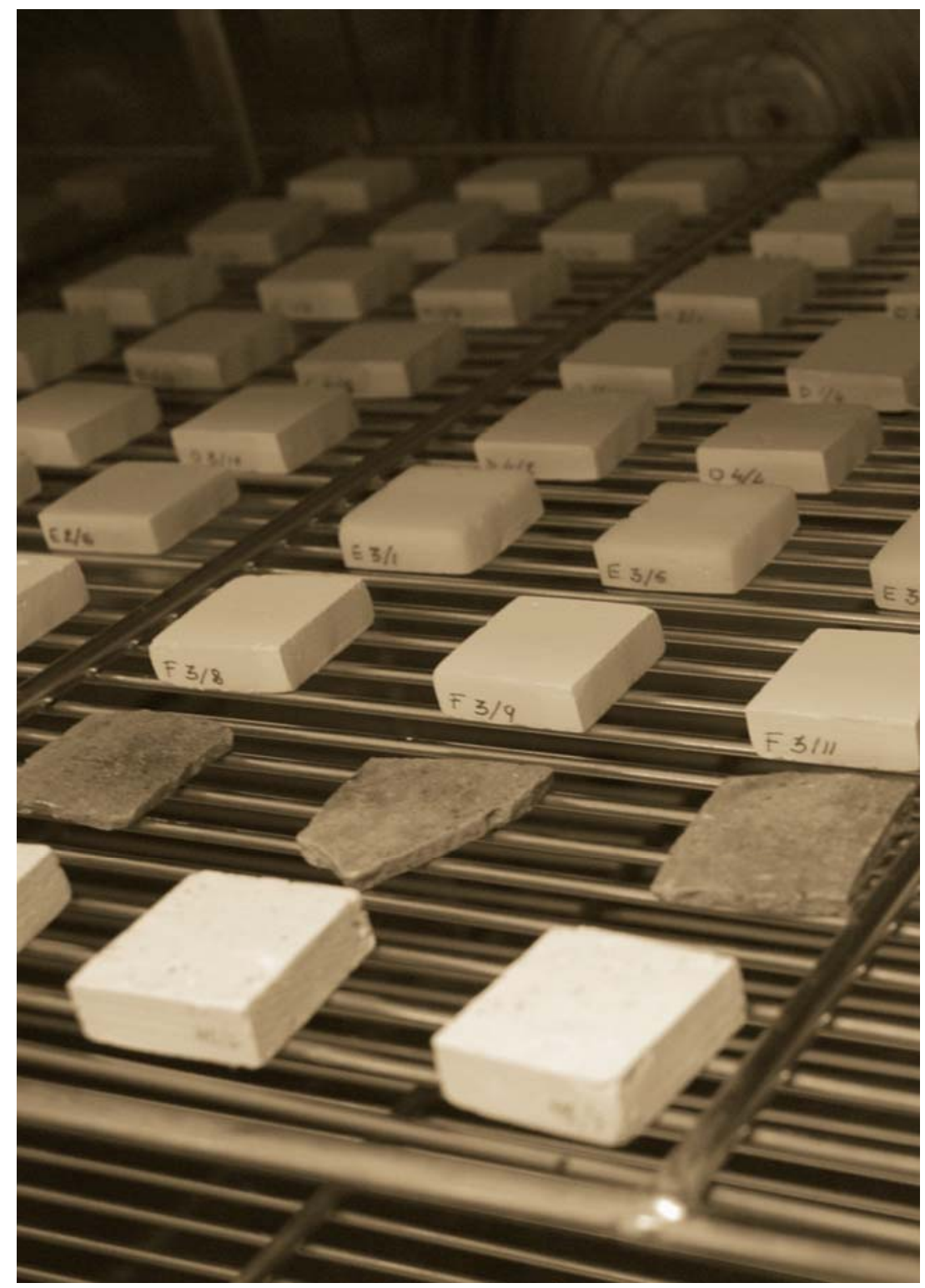

III.4.

RESULTADOS Y DISCUSIÓN 



\subsection{INTRODUCCIÓN}

En contra de los numerosos artículos publicados sobre masillas, que pueden ser aplicadas en la reconstrucción de lagunas en cerámicas arqueológicas, así como distintas metodologías de aplicación, como vimos en la segunda parte de la presente Tesis Doctoral, pocos son los estudios basados en ensayos físicos, mecánicos o químicos realizados a estucos o masillas.

Generalmente estos estudios están más bien dirigidos a la evaluación de la trabajabilidad, de modo empírico, y a los cambios colorimétricos que experimentan las pinturas aplicadas en la fase final de la restauración, cuando éstas son sometidas a ensayos de envejecimiento.

Entre varios artículos, podemos citar la aportación de Bradley y Green $(1987)^{54}$ donde estudiaron los cambios colorimétricos de una determinada masilla epoxídica en unión con una pintura sintética, ante exposiciones a la luz y al oscurecimiento.

También podemos destacar, en cuanto a estudios comparativos de barnices sintéticos utilizados en la restauración de cerámicas, la aportación de Caroca (2002) ${ }^{55}$, trabajo llevado a cabo en el laboratorio

\footnotetext{
${ }^{54}$ Bradley, S M., Green, L., “ Materials for filling and retouching ceramicsHidden dangers” ICOM $8^{\text {th }}$ Triennial Meeting, Sydney, 1987. pp.981-984 ${ }^{55}$ Caroca, A., "Barnices sintéticos: estudio comparativo de barnices sintéticos utilizados en la restauración de cerámicas” Conserva. Revista del Centro Nacional de Conservación y Restauración DIBAM. Nº6, Santiago de chile, 2002. pp.29-46.
} 
del Coatings Research Institute (CORI) en Bélgica. El estudio realizado consistió en la evaluación del comportamiento, al someter los barnices, a distintos ensayos: como la humedad, la inmersión en agua, la solubilidad, y al envejecimiento acelerado con luz ultravioleta. De los barnices ensayados destacan las resinas acrílicas como el Paraloid B-72, disueltas en xileno y tolueno, las resinas epoxídicas y distintas lacas comerciales.

Loew y Solz (1998) ${ }^{56}$ nos describen de un modo práctico, las ventajas y desventajas de los estucos comerciales, así como información específica de los productos.

Aportaciones más específicas en cuanto a ensayos físico-químicos realizados a distintas masillas son pocos. Podemos citar una importante aportación realizada por Barov y Lambert (1984) ${ }^{57}$. En su trabajo determinan el coeficiente de dilatación de distintos estucos, y el comportamiento de éstos en contacto con probetas cerámicas sometidas a procesos de envejecimiento muy drásticos. Éstos ensayos de envejecimiento consistieron en ciclos largos con variaciones intensas de temperatura y humedad relativa.

En 1996 Aura $^{58}$, desarrolla un estudio de estucos aplicados a la conservación de cerámica medieval, basado principalmente en

\footnotetext{
${ }^{56}$ Loew, M., Solz, J., op. cit. Vol.37, № 1, 1998. pp.23-34.

${ }^{57}$ Baroz, Z., Lambert, F., " Mechanical properties of some fill materials for ceramic conservation".ICOM $7^{\text {th }}$ Triennial Meeting, Copenhagen, 1984. pp. 84.20.1 - 84.20.4.

${ }^{58}$ Aura, E., op cit. 1996.
} 
escayolas pigmentadas, elaboradas con distintas dosificaciones, y masillas comerciales. En él, estudia la resistencia a la fuerza de tracción , la determinación de características cromáticas, la resistencia al pulido y el grado de estabilidad frente al envejecimiento acelerado termohigrométrico.

Van Lookeren ${ }^{59}$ en 1999, describe una investigación llevada a cabo en el Duth State Training School for Restorers con la colaboración del Netherlands Institute for Cultural Heritage. Éste estudio realiza ensayos de envejecimiento acelerado en cámara de luz y humedad relativa. También llevaron a estudio la expansión y retracción de dos tipos de masillas, una basada en escayola y otra en resina epoxídica, durante su secado.

Concluyendo que el cambio de volumen no fue un problema en la escayola, la alta humedad relativa tiene una leve influencia en contra de los que se esperaba. El envejecimiento de la escayola fue difícil de asegurar. Muchas investigaciones necesitan ser realizadas al igual que el proceso de migración de sales.

${ }^{59}$ Van Lookeren, "The training of ceramic and glass conservators/restores at The Netherlands Institute for Cultural Heritage” The Conservation of Glass and Ceramics Ed. Tennent, Norman H; James \& James, London, 1999, p.p.259-265. 


\subsection{CARACTERIZACIÓN FÍSICO-MECÁNICA}

\subsubsection{Introducción}

Los ensayos físicos y mecánicos se han realizado con el fin de determinar las propiedades hídricas y caracterizar la resistencia mecánica superficial de las masillas llevadas a estudio.

La humedad es una de las principales y más evidentes causas de alteración de los materiales, así como el origen de la disminución de las cualidades mecánicas, de la migración de sales, de la proliferación de microorganismos ${ }^{60}$, etc.

Un material seco absorbe humedad del aire húmedo, en forma de vapor, en función de la humedad relativa del mismo, y en cantidad superior a aquella que existe en el propio aire. Cuanto más alta sea la humedad relativa del aire, más alta es la cantidad de vapor de agua absorbida por el material. Esta humedad se llama humedad higroscópica. El comportamiento higroscópico puede ser causa de la dilatación y encogimiento de los materiales, y conducir a grietas y reventones. Es decir, que los cambios de la humedad relativa, especialmente en interiores, puede ser causa de importantes alteraciones de ciertos materiales ${ }^{61}$.

${ }^{60}$ Martín, A., Ensayos y experiencias de alteración en la conservación de obras de piedra de interés histórico artístico. Fundación Ramón Areces, 1990. p.439.

${ }^{61}$ Martín, A., op cit.,1990, p.440 
Durante el proceso de secado de un material pueden distinguirse dos fases: un periodo durante el cual la velocidad de secado permanece más o menos constante, y otro segundo, en el que disminuye la misma. Durante la primera fase, el agua pasa desde el interior del material, en nuestro estudio las masillas, a su superficie en forma líquida, y allí se evapora. A medida que desciende la cantidad de agua en la superficie, se transfiere agua desde los poros hasta la misma, pero cuando el contenido de agua de la probeta es inferior a un cierto valor, característico de cada material, los poros no son capaces de mantener dicho aporte, y entonces la evaporación, en vez de producirse en la superficie, tiene lugar en el interior del material, es decir, a partir de entonces se produce la salida del agua del material en forma de vapor. Naturalmente, el vapor de agua encuentra cierta resistencia a difundirse por parte de la muestra. De todo esto se deduce que el proceso de secado depende, además de las condiciones de temperatura, humedad relativa y velocidad del aire, de dos propiedades importantes de los materiales:

1.Contenido de agua crítico: contenido de agua mínimo que determina que el agua en vez de transferirse a la superficie en forma líquida lo haga en forma de vapor (un valor alto del contenido de agua crítico implica un secado lento)

2.Factor de resistencia a la difusión: la resistencia del material a la difusión del vapor de agua a su través (un valor elevado del mismo disminuye la velocidad de secado) ${ }^{62}$.

${ }^{62}$ Martín, A., op cit.,1990, p.440-441 
En la actualidad, disponemos de numerosos métodos de ensayo para valorar los diversos aspectos, antes citados, relacionados con el contenido de agua y su variación, pero debido a las características de las masillas ensayadas no ha sido posible determinarlos. La mayoría de estos métodos de ensayo requieren la inmersión en agua durante al menos 24 horas. Hemos comprobado que transcurrido este tiempo muchas de las masillas (a excepción de aquellas compuestas por resina epoxídica) experimentan pérdida de sus componentes por disolución.

Como consecuencia, se decidió aplicar el ensayo de desorción por higroscopicidad, dado que no requiere inmersión y que las masillas no experimentan pérdida de sus componentes. Con este ensayo se consiguió determinar la velocidad de evaporación de las masillas.

Así mismo, las características mecánicas de la superficie de los materiales, en nuestro caso las masillas y cerámicas, están ligadas a la dureza superficial o resistencia superficial a la deformación. La dureza por penetración es en sí la resistencia a la identación o penetración bajo cargas estáticas o dinámicas, estas durezas pueden medirse en durezas Brinell, Rockwell o Vickers ${ }^{63}$.

Para la valoración y comparación de la dureza de las masillas y cerámicas seleccionadas se ha realizado el ensayo mecánico de dureza por penetración.

${ }^{63}$ Martín, A., op cit.,1990, p.359-360. 


\subsubsection{Determinación de la velocidad de evaporación.}

El ensayo de velocidad de evaporación es de particular interés para valorar la medida en que un material determinado, en nuestro caso las masillas y cerámicas seleccionadas, permite salir el agua contenida por evaporación.

El ensayo ha consistido en la exposición de tres probetas de cada masilla y tres muestras de cada tipo de cerámica a dos ciclos de H.R. (98\% y 15\%) cada doce horas durante 10 semanas, con un total de 140 ciclos. Finalizados el último ciclo de H.R. alta las probetas, una a una, son sacadas de la cámara y pesadas cada 15 minutos en una balanza de precisión (0,001 gr) a una temperatura y humedad relativa controladas ( $20^{\circ} \mathrm{C}$ y $55-60 \% \mathrm{HR}$ ), hasta que la diferencia de tres pesos sucesivos resulte nulo.

El contenido de agua (\%) de cada probeta a partir de la retirada de la misma de la cámara de humedad, fue calculado en intervalos de 15 minutos mediante la siguiente fórmula:

$$
\mathrm{Wt}=\frac{\mathrm{M}_{\mathrm{t}}-\mathrm{M}_{\mathrm{s}}}{\mathrm{M}_{\mathrm{s}}} \times 100
$$

donde:

$\mathrm{Wt}=$ Contenido de agua en el intervalo de tiempo t (\%)

$\mathrm{Mt}=$ Peso de la muestra en el intervalo de tiempo $\mathrm{t}$ (gr)

Ms = Peso de la muestra seca antes del ensayo (gr) 
En nuestro caso, se realizaron estos cálculos de Wt para un total de 3 probetas por cada masilla y tipo de cerámica seleccionada (Tabla III. 36.).

En el caso de la masilla A1, los resultados medidos fueron los siguientes:

\begin{tabular}{|c|c|c|c|c|c|c|}
\cline { 2 - 7 } \multicolumn{1}{c|}{} & \multicolumn{2}{c|}{ A 1/1 } & \multicolumn{2}{c|}{ A 1/8 } & \multicolumn{2}{c|}{ A 1/9 } \\
\hline Ms (gr) & \multicolumn{2}{|c|}{$\mathbf{1 8 , 7 7}$} & \multicolumn{2}{c|}{$\mathbf{1 7 , 9 2}$} & \multicolumn{2}{c|}{$\mathbf{1 8 , 9 5}$} \\
\hline $\mathbf{t ~ ( m i n )}$ & $\mathbf{M t}$ & $\mathbf{W t}$ & $\mathbf{M t}$ & $\mathbf{W t}$ & $\mathbf{M t}$ & $\mathbf{W t}$ \\
\hline $\mathbf{0}$ & 18,98 & $1,13 \%$ & 18,06 & $0,82 \%$ & 19,17 & $1,18 \%$ \\
$\mathbf{1 5}$ & 18,96 & $0,98 \%$ & 18,04 & $0,68 \%$ & 19,14 & $1,02 \%$ \\
$\mathbf{3 0}$ & 18,96 & $0,98 \%$ & 18,04 & $0,68 \%$ & 19,14 & $1,02 \%$ \\
$\mathbf{4 5}$ & 18,93 & $0,82 \%$ & 18,01 & $0,52 \%$ & 19,11 & $0,84 \%$ \\
$\mathbf{6 0}$ & 18,9 & $0,71 \%$ & 18 & $0,48 \%$ & 19,09 & $0,73 \%$ \\
$\mathbf{7 5}$ & 18,89 & $0,63 \%$ & 17,98 & $0,36 \%$ & 19,07 & $0,65 \%$ \\
$\mathbf{9 0}$ & 18,88 & $0,60 \%$ & 17,97 & $0,31 \%$ & 19,06 & $0,60 \%$ \\
\hline
\end{tabular}

Tabla III.36. Resultados de Contenido de Agua durante la desorción

A partir de los resultados obtenidos para cada probeta, se obtuvo su recta de tendencia lineal como mejor aproximación, tal como se muestra a continuación para el caso de la masilla A1:

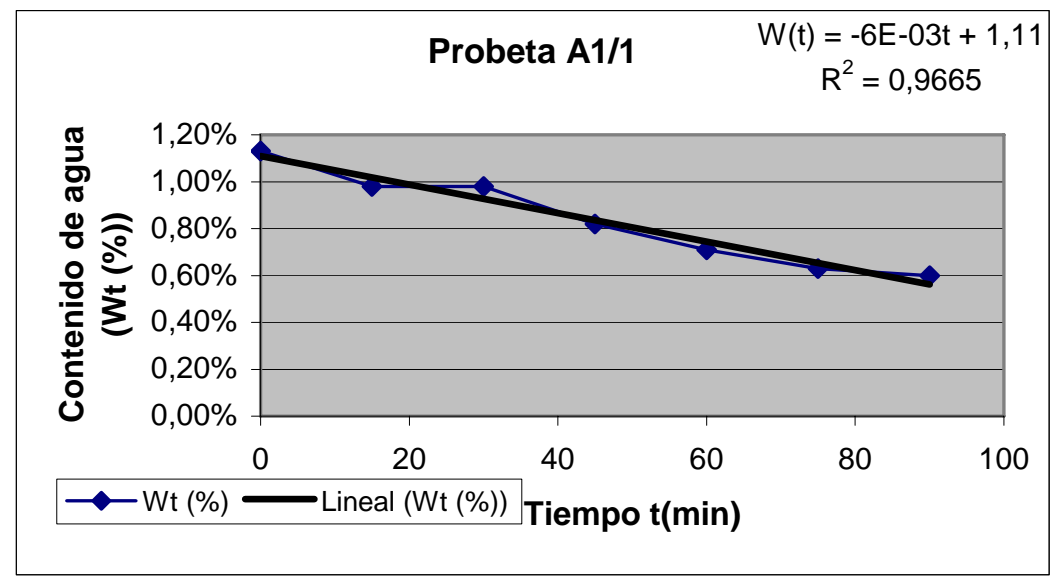

Gráfico III. 1: Representación gráfica del Contenido de Agua (Wt) de la Probeta A1/1 y de su Recta de Tendencia Lineal W(t) $=-6 \mathrm{E}-03 \mathrm{t}+1,11$ 


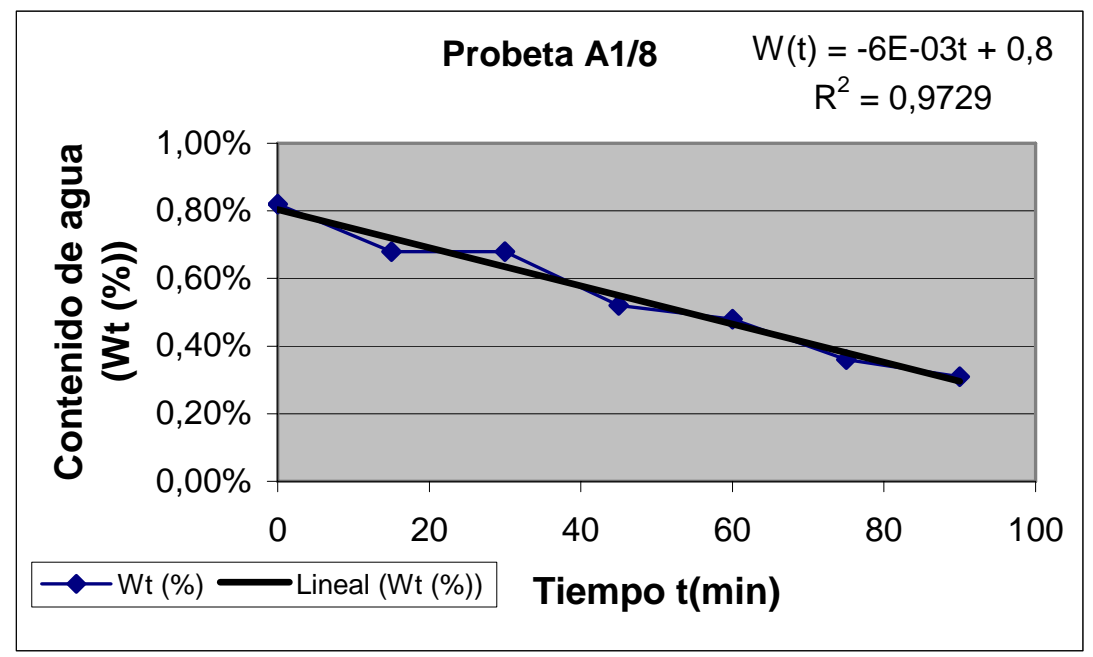

Gráfico III. 2.: Representación gráfica del Contenido de Agua (Wt) de la Probeta A1/8 y de su Recta de Tendencia Lineal $W(t)=-6 E-03 t+0,8$

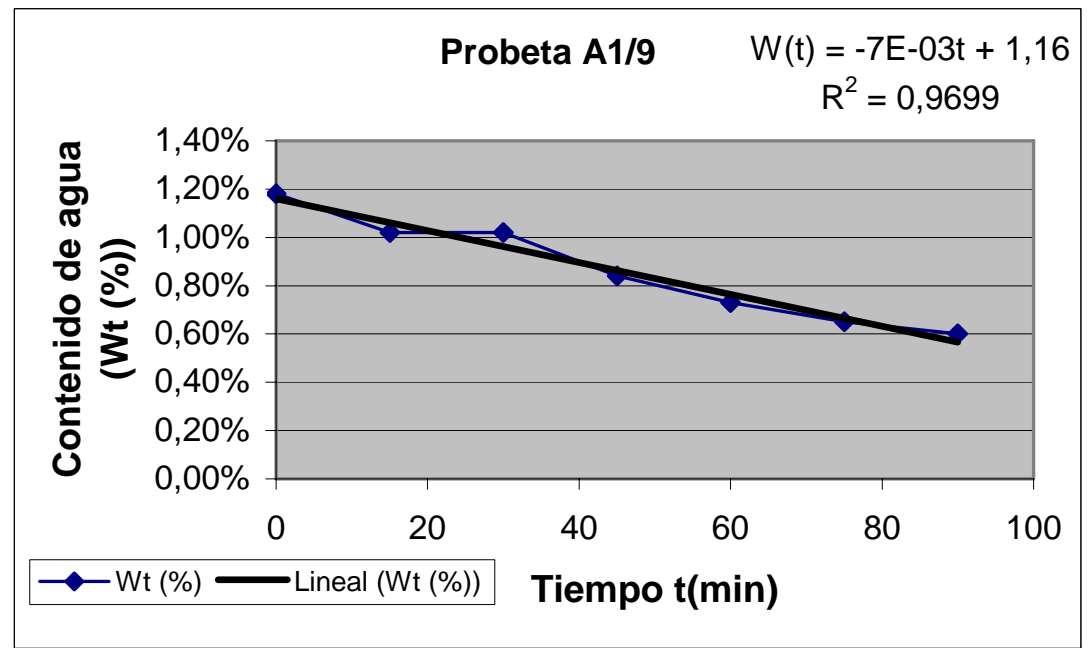

Gráfico III.3. Representación gráfica del Contenido de Agua (Wt) de la Probeta A1/9y de su Recta de Tendencia Lineal W(t) $=-7 \mathrm{E}-03 \mathrm{t}+1,16$ 
De estas 3 probetas A1/1, A1/8 y A1/9 de la masilla A1, y de sus correspondientes rectas de tendencia lineal del contenido de agua W(t), hemos podido obtener la Velocidad de Evaporación como el promedio de las pendientes de las rectas de tendencia lineal para cada probeta. Así, para la masilla A1, la velocidad de evaporación se obtuvo de la siguiente manera:

$$
\begin{aligned}
& \text { A1/1 } \rightarrow \mathrm{W}(\mathrm{t})=-6 \times 10^{-3} \mathrm{t}+1,11 \rightarrow \text { Pendiente }=-6 \times 10^{-3} \rightarrow \mathrm{Ve}=6 \times 10^{-3} \% \\
& \text { A1/8 } \rightarrow \mathrm{W}(\mathrm{t})=-6 \times 10^{-3} \mathrm{t}+0,8 \rightarrow \text { Pendiente }=-6 \times 10^{-3} \rightarrow \mathrm{Ve}=6 \times 10^{-3} \% \\
& \text { A1/9 } \rightarrow \mathrm{W}(\mathrm{t})=-7 \times 10^{-3} \mathrm{t}+1,16 \rightarrow \text { Pendiente }=-7 \times 10^{-3} \rightarrow \mathrm{Ve}=7 \times 10^{-3} \%
\end{aligned}
$$

Velocidad de Evaporación Masilla A1

$$
\begin{aligned}
& \rightarrow \text { Pendiente Promedio }=-6.3333 \times 10^{-3} \\
& \rightarrow \operatorname{Ve}(\% / \mathbf{m i n})=\mathbf{6 , 3 3} \times \mathbf{1 0}^{-3} \% / \mathbf{m i n}
\end{aligned}
$$

Esto significa que la masilla A1, en promedio, pierde contenido de agua como consecuencia de su evaporación a razón de un $6.33 \times 10^{-3} \%$ por cada minuto transcurrido tras su saturación de humedad por higroscopicidad.

\section{Resultados y discusión}

Los resultados obtenidos en el ensayo de velocidad de evaporación de agua se resumen en la Tabla III.37. conseguidos según lo explicado anteriormente para cada una de las masillas objeto de este estudio. En dicha tabla se recogen los valores de Velocidad de Evaporación así como la desviación estándar de estas. 


\begin{tabular}{|c|c|c|}
\hline MASILLAS & $\begin{array}{c}\text { Velocidad de evaporación } \\
\left(\mathbf{\%} / \mathbf{m i n} \mathbf{~ 1 0}^{-\mathbf{3}}\right)\end{array}$ & $\begin{array}{c}\text { Desviación estándar } \\
\left(\mathbf{S} \mathbf{~} \mathbf{~ 1 0}^{-\mathbf{3}}\right)\end{array}$ \\
\hline A1 & 6,33 & 0,58 \\
A2 & 1,00 & 0,00 \\
A3 & 3,00 & 0,00 \\
B1 & 3,33 & 0,58 \\
B2 & 3,00 & 0,00 \\
B3 & 3,33 & 0,58 \\
C1 & 3,00 & 0,00 \\
C2 & 10,00 & 0,00 \\
C3 & 2,33 & 0,58 \\
C4 & 5,33 & 0,58 \\
D1 & 6,67 & 1,15 \\
D2 & 7,33 & 0,58 \\
D3 & 9,67 & 0,58 \\
E1 & 1,33 & 0,58 \\
E2 & 0,20 & 0,10 \\
E3 & 0,30 & 0,10 \\
E4 & 4,67 & 0,58 \\
F1 & 8,33 & 0,58 \\
F2 & 10,00 & 0,00 \\
F3 & 20,00 & 0,00 \\
G & 0,17 & 0,12 \\
H1 & 6,67 & 0,58 \\
H2 & 30,00 & 0,00 \\
H3 & 20,00 & 0,00 \\
\hline
\end{tabular}

Tabla III.37. Valores promedio de Velocidad de Evaporación y desviación estándar de las masillas y cerámicas estudiadas.

El gráfico mostrado a continuación (Gráfico III.4) nos permite interpretar rápidamente la velocidad con la que los diferentes tipos de masillas y cerámicas ensayadas pierden agua tras su saturación de humedad por higroscopicidad, así como la comparación entre ellas. 


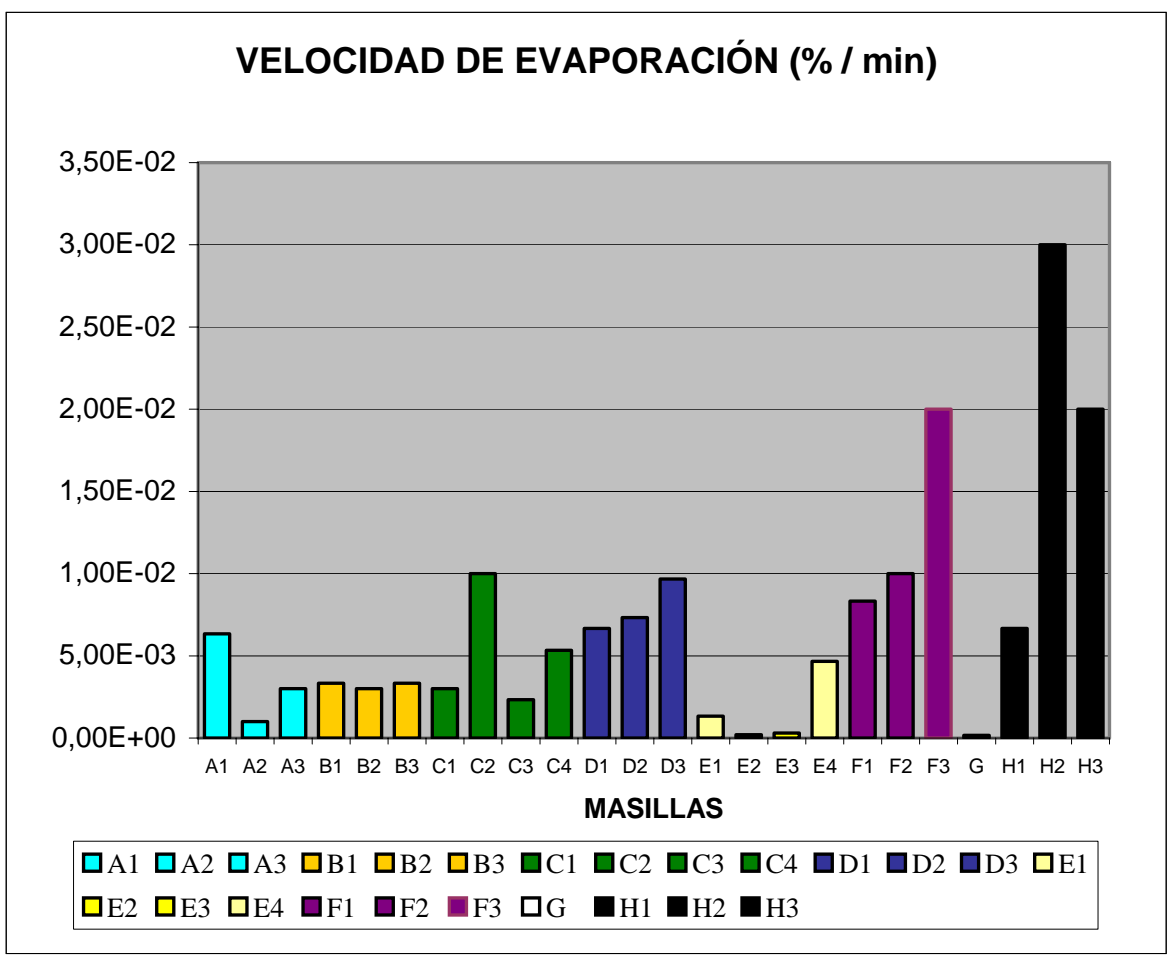

Gráfico III.4. Representación de la velocidad media de evaporación de las masillas y cerámicas estudiadas

Así, se observa que las cerámicas de tipo H2 y H3, junto con la masilla de tipo F3 (mezcla de masillas comerciales preparadas para su uso "Modostuc" y "Liteplast”) son las que pierden agua más rápidamente. Por el contrario, el estuco de cera $(\mathrm{H})$ y las masillas E2, E3, A2 y E1, son las masillas que menor velocidad de evaporación muestran, pudiendo deducir de ello(en lo que respecta a las masillas epoxídicas E y el estuco de cera G), que no han absorbido humedad, debido a las características de sus materiales, y por lo tanto no eliminan agua. 


\subsubsection{Durometría.}

El procedimiento ha sido llevado a cabo con un microdurómetro que aplica un penetrador de diamante en forma de pirámide de base cuadrada con un ángulo de $136^{\circ}$ entre las caras opuestas. El penetrador es aplicado perpendicularmente a la superficie de las probetas cuya dureza se desea medir, bajo la acción de una carga $\boldsymbol{P}$ (300 gr). Esta carga es mantenida durante un cierto tiempo, después del cual es retirada y medida la diagonal $\boldsymbol{d}$ de la impresión (rombo) que queda sobre la superficie de la muestra, gracias al microscopio óptico de tres lentes con diferentes aumentos (x10, x20, x40) que contiene el microdurómetro. Con este valor y utilizando tablas apropiadas se obtiene la dureza Vickers, que es caracterizada por $\boldsymbol{H} \boldsymbol{V}$ y definida como la relación entre la carga aplicada (expresada en Kgf) y el área de la superficie lateral de la impresión.:

$$
\mathrm{HV}=\frac{1,854 \cdot \mathrm{L}}{\mathrm{d}^{2}}
$$

Donde: $\quad$ L= carga aplicada $(\mathrm{Kg})$

$\mathrm{d}=$ longitud de la diagonal del cuadrado de la impresión (mm). 


\section{Resultados y discusión.}

Los valores obtenidos en el ensayo de dureza se muestran en la Tabla III.38. y representados en el Gráfico III.5. donde se indican los valores promedio y la desviación estándar correspondiente a tres probetas de cada masilla y a tres muestras de cada tipo de cerámica ensayada.

\begin{tabular}{|c|c|c|}
\hline $\begin{array}{r}\text { Probetas de masillas } \\
\text { y muestras cerámica }\end{array}$ & $\begin{array}{r}\text { Valor promedio } \\
\text { dureza (vickers) }\end{array}$ & $\begin{array}{r}\text { Desviación estándar } \\
\text { (S) }\end{array}$ \\
\hline A1 & 1,94 & 0,59 \\
A2 & 10,35 & 1,64 \\
\hline A3 & 17,80 & 2,78 \\
\hline B1 & 0,93 & 0,21 \\
B2 & 3,64 & 0,71 \\
B3 & 7,36 & 0,89 \\
C1 & 6,79 & 0,96 \\
\hline C2 & 1,91 & 0,45 \\
\hline C3 & 6,53 & 0,93 \\
\hline C4 & 10,16 & 1,45 \\
D1 & 4,44 & 1,22 \\
\hline D2 & 4,32 & 0,96 \\
\hline D3 & 4,57 & 1,19 \\
\hline E1 & 26,56 & 2,86 \\
\hline E2 & 24,50 & 1,31 \\
\hline E3 & 21,65 & 1,09 \\
F1 & 4,37 & 1,10 \\
\hline F2 & 2,48 & 0,30 \\
F3 & 1,94 & 0,36 \\
\hline F4 & 0,73 & 0,05 \\
H & 0,70 & 0,00 \\
\hline G1 & 21,17 & 2,45 \\
\hline G2 & 24,90 & 3,33 \\
\hline G4 & 28,47 & 2,58 \\
\hline & & \\
\hline & & 0 \\
\hline
\end{tabular}

Tabla III.38. Dureza (Vickers) de las masillas y cerámicas ensayadas, valores medios y desviación estándar. 


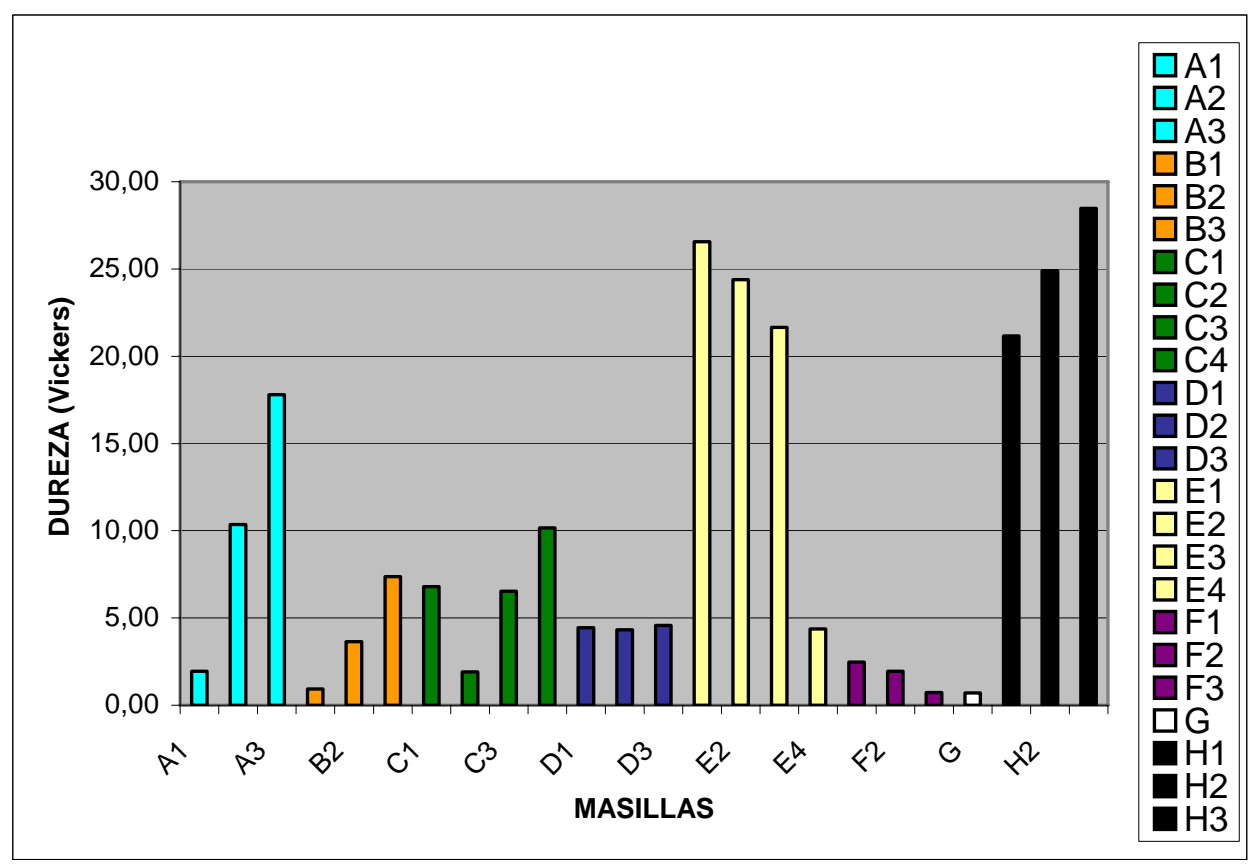

Gráfico III.5. Comparación de la dureza (Vickers) de las masillas y cerámicas ensayadas. 
Los valores obtenidos en este ensayo nos confirman unas durezas en las masillas de resina epoxídica (E1, E2, y E3) muy similares a la cerámica ensayada, a excepción de la masilla E4, ya que se trata de una resina epoxídica de distinta composición, e indicada para trabajos en madera.

El conjunto de masillas elaborado a partir de resina Paraloid B-72 (A) destaca en cuanto su dureza la A3, quizás, debido a que su carga está constituida por polvo de mármol.

De igual forma, el grupo constituido por resinas acrílicas en dispersión acuosa (B) es la masilla B3 la que destaca en dureza, con respecto a las otras dos, debido a que su carga es polvo de mármol

En cuanto a las escayolas ensayadas, destaca la dureza de la escayola Hebodur (C4), debido a su composición, con respecto a las elaboradas con “Alamo 70”, de menor dureza.

Los estucos realizados con la escayola Alamo 70 (C1, C2 y C3) han aportado dos datos importantes:

1. La dosificación de la escayola con respecto al vehículo influye de manera determinante en su dureza, aún cuando la escayola esté elaborada con una resina vinílica. Recordemos que el estuco C2 tiene un porcentaje de escayola inferior a los estucos C1 y C3. 
2. La adición de una resina acrílica al agua (al menos en un $15 \%)$ en la elaboración de una escayola no infiere mayor dureza. Podemos observar que los estucos C1 (con resina) y C3 (sin ella), con idéntica dosificación de escayola y vehículo, muestran unas durezas prácticamente iguales.

Estos datos, aportados por los estucos de escayola, se verifican al estudiar los valores del grupo de masillas (D), aún tratándose de masillas en polvo comerciales, donde un alto porcentaje de su composición se basa en sulfato de calcio. Todas estas masillas están elaboradas con idéntica dosificación (polvo:vehículo), pero adicionando una resina vinílica al $10 \%$ al agua en la masilla D2, una resina acrílica al 15\% en el caso de la masilla D3 o sin adicionar nada al agua en la masilla D1. Los valores de dureza de estas tres masillas, revelan que la adición o no de estas resinas (al menos en los porcentajes señalados) no incrementa o disminuye la dureza de las mismas.

En cuanto al grupo de masillas comerciales ya preparadas para su uso (F) son las que menor dureza muestran, a excepción del estuco de cera, de entre las tres ensayadas es la F1 la que tiene un valor más alto de dureza, debido a la naturaleza de la carga que contiene, polvo de mármol. 


\section{III.4.3. ESTABILIDAD FRENTE A AGENTES DEGRADANTES FÍSICO-QUÍMICOS.}

\subsubsection{Introducción.}

En algunas ocasiones es posible juzgar el comportamiento de un material a través de la experiencia personal o de un conocimiento científico, sin necesidad de recurrir a ensayos de alteración. El establecimiento de la durabilidad de un material pasa, sin embargo, en la mayoría de las ocasiones, por el sometimiento de los mismos a experiencias de alteración.

Las experiencias de alteración se pueden definir como la exposición sistemática de muestras, de características definidas, a un ambiente conocido, con el fin de estudiar las alteraciones que sufre un material dado. Estas experiencias se pueden clasificar en dos grandes grupos:

1. Experiencias a la intemperie o de exposición exterior.

Una serie de muestras son sometidas a determinadas condiciones ambientales, que son registradas durante todo el ensayo. Al final, o en diversos lapsos de tiempo, son analizadas las alteraciones sufridas por las muestras.

Dadas las características del material estudiado en la presente Tesis Doctoral esta experiencia no ha podido ser realizada. 
2. Experiencias en atmósferas controladas.

En las mismas se fijan la intensidad, frecuencia y secuencia de las variables del medio. En función del grado de aceleración se pueden distinguir:

a. Experiencias de imitación. En las que se intentan reproducir los valores de las variables del medio ambiente, eliminando así la aleatoriedad de los mismos.

b. Experiencias de alteración acelerada. En ellas se intensifican una o más variables, consiguiéndose así acortar la duración del ensayo. En nuestro estudio, esta ha sido la experiencia llevada a cabo.

Es difícil desarrollar experiencias de laboratorio para predecir el comportamiento de un material, ya que los mecanismos de alteración son complejos y rara vez bien comprendidos. Además, los factores externos que afectan al comportamiento de los materiales son numerosos y difíciles de cuantificar, de manera que muchas experiencias de laboratorio no incluyen todos los factores de importancia. También, hay que tener en cuenta que los materiales son ensayados frecuentemente en probetas de configuraciones diferentes a los elementos usados en la práctica.

Aún así, las experiencias de alteración acelerada, aunque no pueden considerarse como autosuficientes, son un elemento para juzgar el comportamiento de un material. Estas experiencias pueden definirse como una acción violenta y concentrada en el tiempo de los principales factores de alteración. Los resultados que se obtienen, de 
las propiedades medidas antes y después del envejecimiento, son ciertamente útiles para aceptar o rechazar un material o conocer el deterioro del mismo ${ }^{64}$.

Todo el conjunto de ensayos de envejecimiento acelerado frente a agentes degradantes físico-químicos se ha llevado a cabo con las masillas seleccionadas, según las formulaciones establecidas en la tabla III.34.

Como veremos a continuación, se han seleccionado tres ensayos que permiten obtener información acerca del comportamiento de las masillas elaboradas. Así como conocer los factores que pueden ocasionar cambios en las mismas.

${ }^{64}$ Martín, A., op Cit. pp.505-509 


\subsubsection{Ensayo de envejecimiento acelerado de humidificación y secado.}

El ensayo ha consistido en la exposición de tres probetas de cada masilla y tres muestras de cada tipo de cerámica a dos ciclos de H.R. (98\% y 15\%) cada doce horas durante 10 semanas, con un total de 140 ciclos.

Finalizado el ensayo, se han efectuado varias determinaciones:

- Colorimetría, sobre las probetas antes y después de ser sometidas a ensayo, eligiendo como condiciones de trabajo el iluminante estándar CIE tipo $\mathrm{D}_{65}$ (luz día, temperatura de color $6500^{\circ} \mathrm{K}$ ) y el observador estándar $10^{\circ}$.

- Dureza, sobre las probetas antes y después de ser sometidas a ensayo, eligiendo como condiciones la dureza Vickers con una carga de 300 gr y penetrador de diamante.

- Evaluación de ensayos de envejecimiento acelerado, sobre las probetas antes y después de ser sometidas a ensayo, mediante espectroscopia infrarroja por transformada de Fourier (FT-IR)

\section{$\underline{\text { Resultados y discusión }}$}

\section{Colorimetría}

Tras el ensayo de humidificación y secado podemos apreciar que los valores obtenidos, mostrados en la tabla III.39 y representados en el Gráfico III.6, en el conjunto de masillas ensayadas no experimentan 
grandes variaciones de color total $(\Delta \mathrm{E})$, a excepción de la masilla $\mathrm{E} 4$ (resina epoxídica “EPO 127” indicada para la restauración de objetos de madera) con respecto al resto de masillas.

VARIACIÓN DEL COLOR TOTAL (0E)

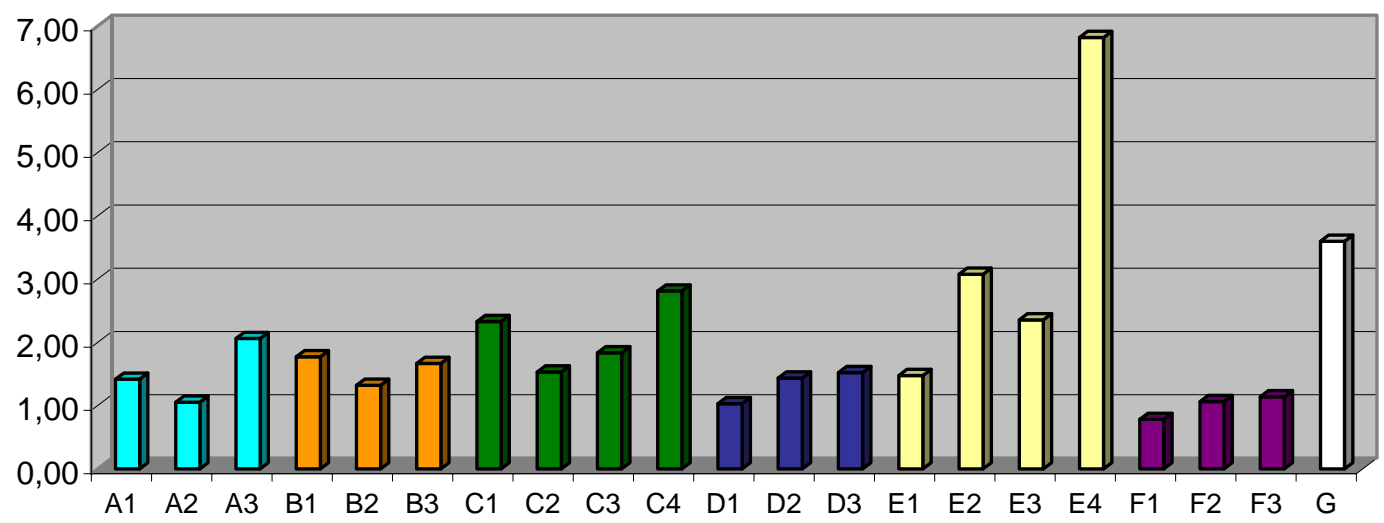

Gráfico III.6. Representación de la variación de color total $(\Delta \mathrm{E})$ experimentado en las masillas ensayadas ante envejecimiento acelerado de humidificación y secado. 


\begin{tabular}{|c|c|c|c|c|c|c|c|c|c|c|c|c|c|c|c|c|}
\hline Nombre & $\begin{array}{c}\mathbf{L}^{*} \\
\text { inicial }\end{array}$ & $\mathbf{S}$ & \begin{tabular}{|c|}
$L^{*}$ \\
final
\end{tabular} & S & $\Delta \mathbf{L}^{*}$ & $\begin{array}{c}\mathbf{a}^{*} \\
\text { inicial }\end{array}$ & S & \begin{tabular}{|c|}
$a^{*}$ \\
final
\end{tabular} & S & $\Delta \mathrm{a}^{*}$ & $\begin{array}{c}\mathbf{b}^{*} \\
\text { inicial }\end{array}$ & S & \begin{tabular}{|c|}
$b^{*}$ \\
final
\end{tabular} & S & $\Delta \mathbf{b}^{*}$ & $\Delta \mathbf{E}$ \\
\hline A1 & 88,81 & 0,27 & 87,53 & 0,05 & $-1,28$ & 1,28 & 0,07 & 1,49 & 0,00 & 0,21 & 7,58 & 0,34 & 8,16 & 0,01 & 0,58 & 1,42 \\
\hline A2 & 95,36 & 0,24 & 94,44 & 0,13 & $-0,91$ & 0,88 & 0,02 & 0,92 & 0,00 & 0,04 & 5,30 & 0,33 & 5,82 & 0,03 & 0,52 & 1,05 \\
\hline A3 & 95,53 & 0,41 & 93,53 & 0,08 & $-2,00$ & 0,09 & 0,04 & 0,22 & 0,01 & 0,14 & 2,87 & 0,81 & 3,36 & 0,06 & 0,49 & 2,06 \\
\hline B1 & 83,34 & 0,6 & 81,84 & 0,10 & $-1,50$ & 2,08 & 0,05 & 2,22 & 0,00 & 0,14 & 10,78 & 0,34 & 11,72 & 0,02 & 0,94 & 1,77 \\
\hline B2 & 94,27 & 0,11 & 93,07 & 0,06 & $-1,20$ & 1,08 & 0,04 & 1,20 & 0,01 & 0,12 & 7,41 & 0,15 & 7,95 & 0,10 & 0,54 & 1,32 \\
\hline B3 & 94,08 & 0,11 & 92,61 & 0,06 & $-1,48$ & 0,06 & 0 & 0,13 & 0,01 & 0,07 & 3,61 & 0,04 & 4,37 & 0,02 & 0,76 & 1,67 \\
\hline C1 & 89,71 & 0,09 & 88,19 & 0,07 & $-1,52$ & 1,17 & 0,09 & 1,60 & 0,01 & 0,43 & 4,84 & 0,47 & 6,55 & 0,03 & 1,71 & 2,33 \\
\hline C2 & 89,42 & 0,27 & 88,48 & 0,03 & $-0,95$ & 1,25 & 0,17 & 1,53 & 0,00 & 0,28 & 5,50 & 0,73 & 6,67 & 0,02 & 1,17 & 1,53 \\
\hline C3 & 92,30 & 0,03 & 90,79 & 0,09 & $-1,50$ & 1,03 & 0,04 & 1,29 & 0,00 & 0,26 & 4,02 & 0,21 & 5,04 & 0,04 & 1,02 & 1,84 \\
\hline C4 & 87,53 & 0,38 & 85,68 & 0,11 & $-1,85$ & 2,21 & 0 & 2,50 & 0,01 & 0,29 & 13,74 & 0,54 & 15,84 & 0,05 & 2,10 & 2,81 \\
\hline D1 & 91,98 & 0,27 & 91,00 & 0,08 & $-0,99$ & 0,35 & 0,02 & 0,47 & 0,01 & 0,11 & 3,08 & 0,05 & 3,36 & 0,05 & 0,27 & 1,03 \\
\hline D2 & 90,67 & 0,22 & 89,26 & 0,03 & $-1,41$ & 0,48 & 0,05 & 0,62 & 0,02 & 0,14 & 4,36 & 0,27 & 4,58 & 0,01 & 0,21 & 1,44 \\
\hline D3 & 92,02 & 0,16 & 90,61 & 0,05 & $-1,41$ & 0,37 & 0,02 & 0,52 & 0,01 & 0,15 & 3,30 & 0,16 & 3,86 & 0,02 & 0,56 & 1,52 \\
\hline E1 & 76,58 & 0,75 & 75,26 & 0,05 & $-1,32$ & 1,28 & 0,05 & 1,23 & 0,01 & $-0,05$ & 8,44 & 0,34 & 9,11 & 0,01 & 0,66 & 1,48 \\
\hline E2 & 83,38 & 0,15 & 81,48 & 0,03 & $-1,90$ & 1,67 & 0,12 & 1,74 & 0,00 & 0,07 & 13,57 & 0,04 & 15,99 & 0,07 & 2,42 & 3,08 \\
\hline E3 & 85,62 & 0,92 & 83,59 & 0,08 & $-2,03$ & $-5,41$ & 0,19 & $-5,87$ & 0,01 & $-0,46$ & 8,15 & 0,26 & 9,25 & 0,09 & 1,10 & 2,36 \\
\hline E4 & 48,43 & 0,74 & 48,06 & 0,67 & $-0,37$ & 7,67 & 0,28 & 7,86 & 0,24 & 0,19 & 11,84 & 0,36 & 18,65 & 0,33 & 6,81 & 6,82 \\
\hline F1 & 92,83 & 0,47 & 92,30 & 0,20 & $-0,53$ & 0,28 & 0,18 & 0,41 & 0,01 & 0,13 & 4,45 & 0,84 & 5,01 & 0,02 & 0,56 & 0,78 \\
\hline F2 & 95,59 & 0,12 & 94,98 & 0,02 & $-0,61$ & 0,24 & 0,02 & 0,20 & 0,00 & $-0,04$ & 2,50 & 0,06 & 3,37 & 0,01 & 0,87 & 1,06 \\
\hline F3 & 94,77 & 0,1 & 94,10 & 0,03 & $-0,67$ & 0,21 & 0,03 & 0,11 & 0,00 & $-0,11$ & 3,19 & 0,08 & 4,11 & 0,03 & 0,92 & 1,14 \\
\hline G & 92,39 & 0,17 & 91,08 & 0,04 & $-1,32$ & \begin{tabular}{|l}
$-0,25$ \\
\end{tabular} & 0,3 & $-0,50$ & 0,02 & $-0,26$ & 4,00 & 0,76 & 7,34 & 0,05 & 3,34 & 3,60 \\
\hline
\end{tabular}

Tabla III.39. Valores de variación de las coordenadas cromáticas $L^{*}, a^{*}, b^{*}$, desviación estándar y variación de color total $(\Delta \mathrm{E})$. Correspondientes a las masillas sometidas a envejecimiento por humidificación y secado.

De menor magnitud, podemos apreciar los valores de $\Delta \mathrm{E}$ en la masilla de cera y en la de resina epoxídica con carga de carbonato de calcio, G y E2, respectivamente. El resto de valores obtenidos, en cuanto a variación del color total $(\Delta \mathrm{E})$, en las masillas son imperceptibles al ojo humano. 
Analizando los valores de variación de la luminosidad $\left(\Delta \mathrm{L}^{*}\right)$ de todas las masillas ensayadas, se percibe en general un descenso, lo que explica un oscurecimiento de las mismas. Aunque, debemos resaltar que los valores son mínimos e inapreciables para todo el conjunto, como se puede ver en el Gráfico III.7. Podemos destacar que las mínimas variaciones en cuanto a la luminosidad corresponden a las masillas comerciales ya preparadas (F1, F2 y F3) y a la masilla de resina epoxy E4 (“EPO 127”).

\section{VARIACION DE LA LUMINOSIDAD $\left(-L^{*}\right)$}

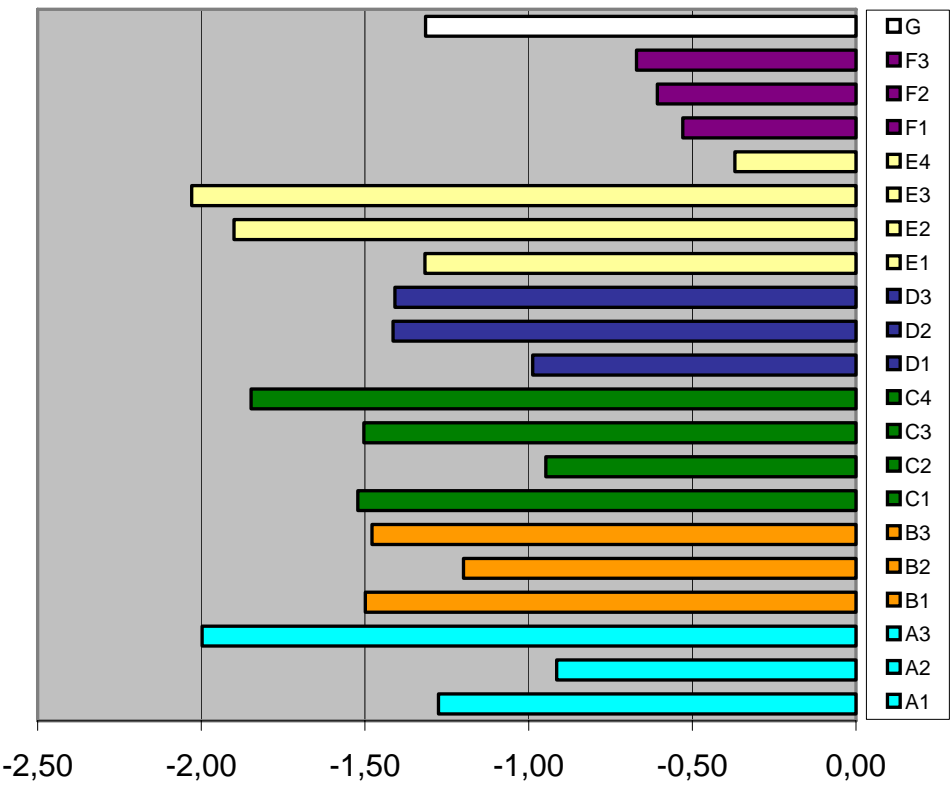

Grafico III.7. Representación de la variación de la luminosidad ( $\mathrm{L}^{*}$ ) de las masillas sometidas a envejecimiento por humidificación y secado. 
Estudiando los valores de Variación del Croma $\left(\Delta \mathrm{C}^{*}\right)$ y los valores del Tono $\left(\mathrm{h}^{*}\right)$ reflejados en la Tabla III.40., se obtienen unos resultados más amplios.

\begin{tabular}{|c|c|c|c|c|c|c|c|c|c|c|}
\hline Nombre & $\begin{array}{c}\text { C* } \\
\text { inicial }\end{array}$ & $\mathbf{S}$ & $\begin{array}{c}\text { C* } \\
\text { final }\end{array}$ & $\mathbf{S}$ & $\Delta \mathbf{C}^{*}$ & $\begin{array}{c}\mathbf{h} \\
\text { inicial }\end{array}$ & $\mathbf{S}$ & $\begin{array}{c}\mathbf{H} \\
\text { final }\end{array}$ & $\mathbf{S}$ & $\Delta \mathbf{h}$ \\
\hline A1 & 7,84 & 0,29 & 8,30 & 0,01 & $-8,29$ & 80,32 & 0,33 & 79,66 & 0,03 & $-0,66$ \\
A2 & 5,37 & 0,33 & 5,89 & 0,02 & $-5,87$ & 80,59 & 0,37 & 81,05 & 0,07 & 0,46 \\
A3 & 3,32 & 0,81 & 3,36 & 0,06 & $-3,30$ & 88,53 & 0,4 & 86,17 & 0,18 & $-2,36$ \\
B1 & 10,98 & 0,34 & 11,92 & 0,02 & $-11,91$ & 79,09 & 0,07 & 79,29 & 0,02 & 0,20 \\
B2 & 7,48 & 0,15 & 8,04 & 0,10 & $-7,94$ & 81,71 & 0,19 & 81,41 & 0,07 & $-0,30$ \\
B3 & 3,61 & 0,04 & 4,38 & 0,02 & $-4,36$ & 89,08 & 0,07 & 88,29 & 0,15 & $-0,79$ \\
C1 & 4,98 & 0,47 & 6,75 & 0,03 & $-6,72$ & 76,39 & 0,32 & 76,30 & 0,15 & $-0,09$ \\
C2 & 5,64 & 0,75 & 6,84 & 0,02 & $-6,82$ & 77,19 & 0,06 & 77,08 & 0,06 & $-0,11$ \\
C3 & 4,15 & 0,21 & 5,21 & 0,04 & $-5,16$ & 75,65 & 0,33 & 75,68 & 0,14 & 0,03 \\
C4 & 13,92 & 0,55 & 16,04 & 0,05 & $-15,99$ & 80,85 & 0,14 & 81,04 & 0,07 & 0,19 \\
D1 & 3,1 & 0,05 & 3,39 & 0,05 & $-3,35$ & 83,46 & 0,24 & 82,08 & 0,28 & $-1,38$ \\
D2 & 4,39 & 0,28 & 4,62 & 0,01 & $-4,61$ & 83,79 & 0,31 & 82,34 & 0,22 & $-1,45$ \\
D3 & 3,32 & 0,16 & 3,90 & 0,01 & $-3,88$ & 83,58 & 0,1 & 82,31 & 0,12 & $-1,27$ \\
E1 & 8,54 & 0,34 & 9,19 & 0,01 & $-9,18$ & 81,36 & 0,04 & 82,30 & 0,05 & 0,94 \\
E2 & 13,68 & 0,04 & 16,08 & 0,07 & $-16,01$ & 83,23 & 0,9 & 83,79 & 0,05 & 0,56 \\
E3 & 9,77 & 0,07 & 10,96 & 0,08 & $-10,88$ & 123,4 & 2,09 & 122,40 & 0,18 & $-1,02$ \\
E4 & 14,11 & 0,44 & 20,24 & 0,39 & $-19,85$ & 57,06 & 0,46 & 67,15 & 0,26 & 10,09 \\
F1 & 4,9 & 0,84 & 5,03 & 0,02 & $-5,01$ & 85,08 & 0,44 & 85,28 & 0,04 & 0,20 \\
F2 & 2,51 & 0,06 & 3,38 & 0,01 & $-3,37$ & 84,5 & 0,37 & 86,64 & 0,09 & 2,14 \\
F3 & 3,2 & 0,08 & 4,11 & 0,03 & $-4,08$ & 86,16 & 0,52 & 88,52 & 0,07 & 2,36 \\
G & 4,01 & 0,76 & 7,36 & 0,05 & $-7,31$ & 94,43 & 1,14 & 93,93 & 0,16 & $-0,50$ \\
\hline
\end{tabular}

Tabla III.40. Variación de las coordenadas cromáticas $\mathrm{C}^{*}$ y $\mathrm{h}^{*}$, su desviación estándar, variación del croma $\left(\Delta \mathrm{C}^{*}\right)$ y variación del tono $\left(\Delta \mathrm{h}^{*}\right)$ de las masillas sometidas a irradiación de luz ultravioleta.

Al igual que en los valores obtenidos en la diferencia de la Luminosidad $\left(\Delta \mathrm{L}^{*}\right)$, los valores derivados de la Variación del Croma 
$\left(\Delta \mathrm{C}^{*}\right)$, antes y después de ser sometidas las probetas al ensayo de humidificación y secado, son negativos. Por lo que se deduce que en todo el conjunto de masillas ensayadas el cromatismo ha disminuido.

Cierto es que, determinadas masillas han experimentado un gran cambio en el mismo $\left(\Delta \mathrm{C}^{*}\right)$, pudiendo destacar la masilla epoxídica “EPO 127”(E4) con un valor de $-19,85$, al igual que el resto de masillas de resina epoxídica (E1, E2 y E3).

Las masillas compuestas por resina acrílica en dispersión acuosa,(“Acril 33”) también destacan en su disminución del cromatismo (B1 y B2) cargadas con Microesferas de vidrio y carbonato cálcico, respectivamente.

En cuanto al conjunto de morteros de escayola, ha sido la escayola Hebodur (C4) la que más variación ha experimentado en su cromatismo.

La masilla A1 es la que destaca en cuanto a variación del cromatismo con respecto al resto de masillas elaboradas con la resina acrílica "Paraloid B-72"

El grupo de masillas afines en el que menos ha disminuido su cromatismo es el de las masillas comerciales, tanto las elaboradas con Polyfilla (D), como las preparadas para su uso (F). 
En cuanto a la variación de tono $\left(\Delta \mathrm{h}^{*}\right)$, y analizados los valores h*inicial y $\mathrm{h} *$ final, se determina con ayuda del diagrama cromático CIELAB la variación de las coordenadas cromáticas de las masillas, antes y después de someterlos al ensayo de envejecimiento. Éstas variaciones obtenidas son despreciables e inapreciables al ojo humano para todas las masillas ensayadas, a excepción de la masilla E4 cuya variación de tono $\left(\Delta \mathrm{C}^{*}\right)$, es de $10,09^{\circ}$, desplazándose hacia el amarillo.

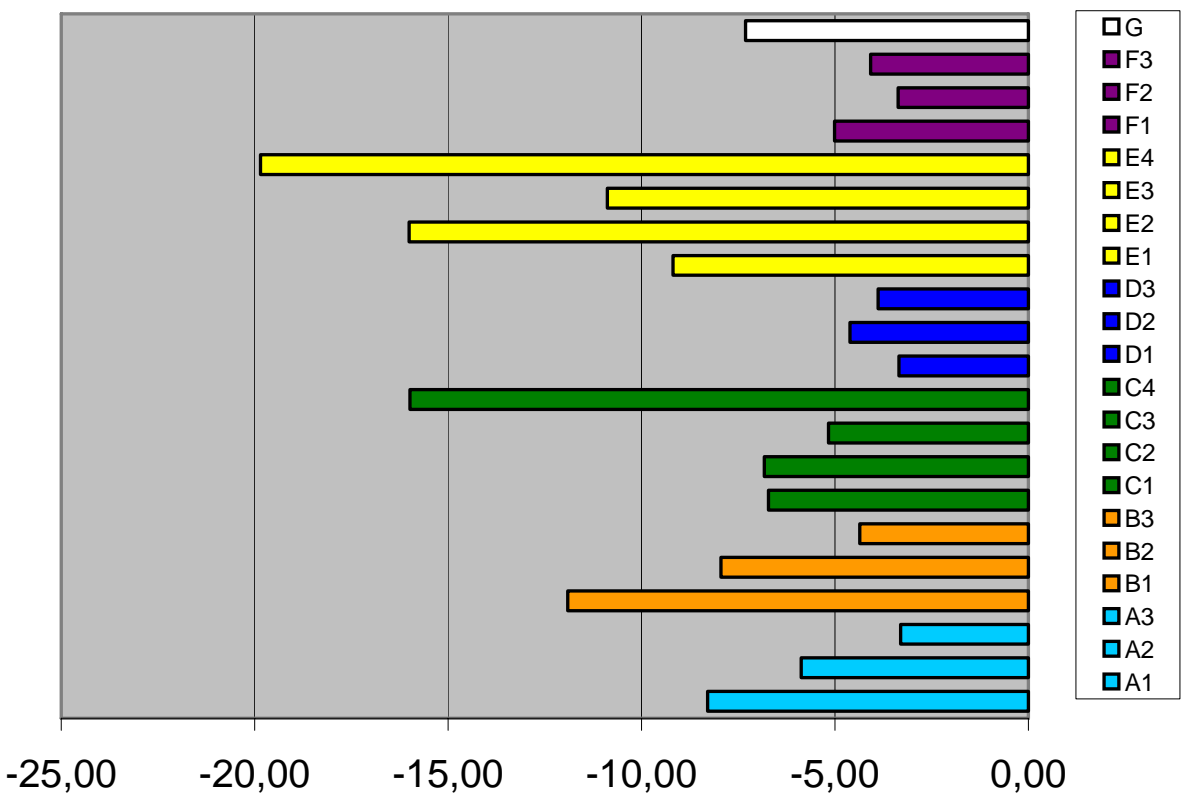

Gráfico III.8. Representación de la variación del Croma $\left(\Delta C^{*}\right)$ de las masillas sometidas a envejecimiento por humidificación y secado. 


\section{Durometría}

Los resultados obtenidos en el ensayo de dureza, de las probetas sometidas a envejecimiento acelerado de humidificación y secado, se encuentran reflejados en la Tabla III.41. y en el Gráfico III.9. donde se indican los valores promedio y la desviación estándar correspondiente a las tres probetas de cada masilla ensayada antes y después.

\begin{tabular}{|c|cc|cc|c|}
\hline Masillas & $\begin{array}{c}\text { Dureza } \\
\text { inicial }\end{array}$ & $\mathbf{S}$ & $\begin{array}{c}\text { Dureza } \\
\text { final }\end{array}$ & $\mathrm{S}$ & $\Delta$ Dureza \\
\hline A1 & 1,94 & 0,59 & 5,30 & 1,45 & 3,36 \\
A2 & 10,35 & 1,64 & 12,72 & 1,78 & 2,37 \\
A3 & 17,80 & 2,78 & 18,32 & 2,72 & 0,52 \\
B1 & 0,93 & 0,21 & 1,30 & 0,17 & 0,37 \\
B2 & 3,64 & 0,71 & 4,23 & 0,15 & 0,59 \\
B3 & 7,36 & 0,89 & 5,12 & 0,52 & $-2,24$ \\
C1 & 6,79 & 0,96 & 4,51 & 0,87 & $-2,28$ \\
C2 & 1,91 & 0,45 & 3,60 & 0,46 & 1,69 \\
C3 & 6,53 & 0,93 & 6,54 & 1,08 & 0,01 \\
C4 & 10,16 & 1,45 & 23,03 & 1,32 & 12,87 \\
D1 & 4,44 & 1,22 & 4,55 & 0,65 & 0,11 \\
D2 & 4,32 & 0,96 & 3,05 & 0,60 & $-1,27$ \\
D3 & 4,57 & 1,19 & 4,47 & 1,28 & $-0,10$ \\
E1 & 26,56 & 2,86 & 14,82 & 1,11 & $-11,74$ \\
E2 & 24,50 & 1,31 & 30,43 & 1,10 & 5,93 \\
E3 & 21,65 & 1,09 & 23,2 & 0,00 & 1,55 \\
E4 & 4,37 & 1,10 & 4,77 & 0,60 & 0,40 \\
F1 & 2,48 & 0,30 & 1,85 & 0,19 & $-0,63$ \\
F2 & 1,94 & 0,36 & 2,44 & 0,27 & 0,50 \\
F3 & 0,73 & 0,05 & 0,70 & 0,00 & $-0,03$ \\
G & 0,70 & 0,00 & 0,78 & 0,08 & 0,08 \\
\hline
\end{tabular}

Tabla III.41. Dureza (Vickers) de las masillas antes y después de ser sometidas a envejecimiento acelerado de humidificación y secado, valores medios, desviación estándar y diferencia total de dureza. 
En términos generales las masillas no han experimentado grandes cambios de dureza, a excepción de la escayola Hebodur (C4) que ha incrementado considerablemente su dureza al contrario que lo sucedido en la masilla E1 (resina epoxy mas microesferas de vidrio) que ha sufrido un descenso en su dureza.

\section{VARIACIÓN DE LA DUREZA}

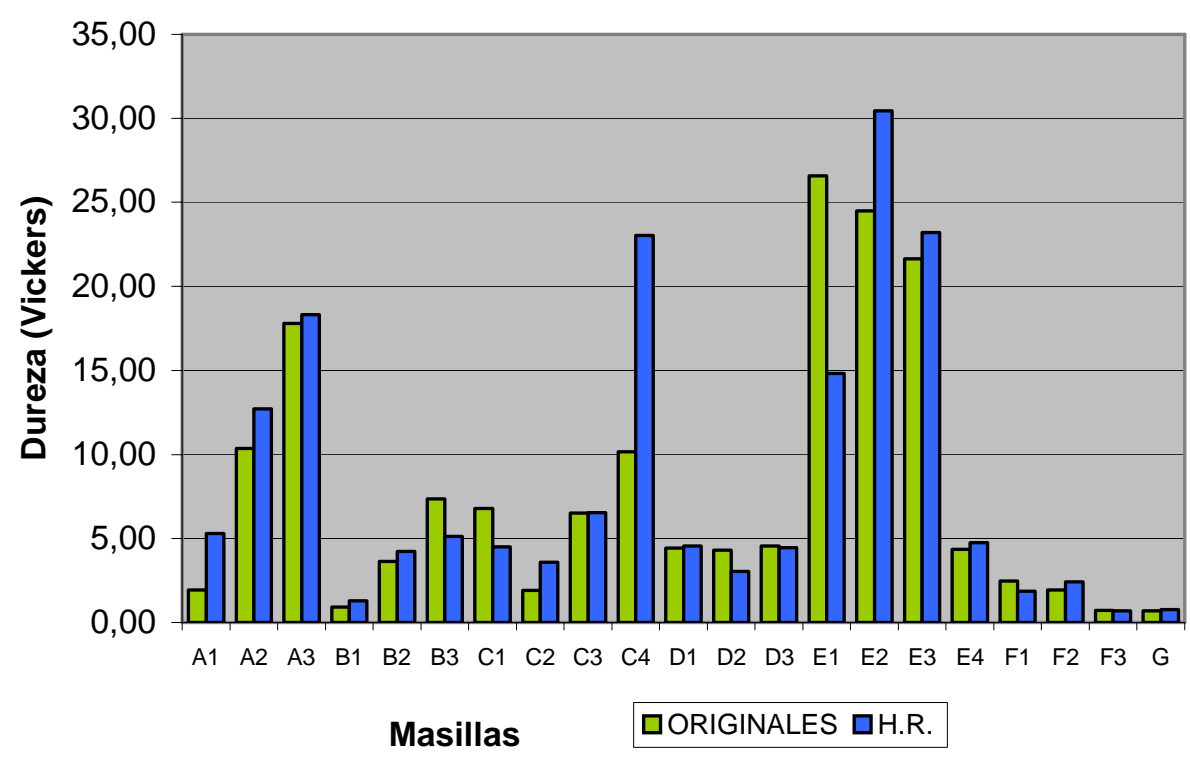

Gráfico III.9. Variación de la Dureza (Vickers) de las masillas antes y después de ser sometidas a envejecimiento acelerado de humidificación y secado. 
El resto de masillas muestran unos valores de incremento o aumento de dureza insignificativos, pudiendo destacar un ligero aumento de dureza en las masillas a base de resina acrílica Paraloid B-72 (A1 y A2) con cargas de Microesferas de vidrio y Carbonato cálcico, respectivamente.

Sin embargo, la dureza disminuye ligeramente en la escayola Alamo 70 aglutinada con una resina acrílica acuosa Acril 33 al 15\% (C1) y la masilla B3 (resina acrílica acuosa Acril 33 con carga de carbonato cálcico) 


\section{Espectrometría de infrarrojos}

De la información obtenida de los espectros de IR, una vez normalizados y comparados con el programa OPUS BRUKER se obtuvieron unos parámetros en \% de afinidad entre los espectros de las probetas sin tratar, respecto a las probetas envejecidas.

Dentro de este comportamiento el aumento de higroscopicidad es notable en las muestras E1 (resina epoxídica con microesferas de vidrio)y A1 (paraloid + microesferas de vidrio), las cuales muestran los peores resultados. La B1 (acril33 + microesferas) se comporta regular. El resto de probetas muestra variaciones inapreciables, por lo que su resultado podríamos decir que es óptimo. Todo esto queda representado en el siguiente gráfico:

\section{AFINIDAD ESPECTROS IR TRAS ENVEJECIMIENTO POR HUMIDIFICACION Y SECADO}

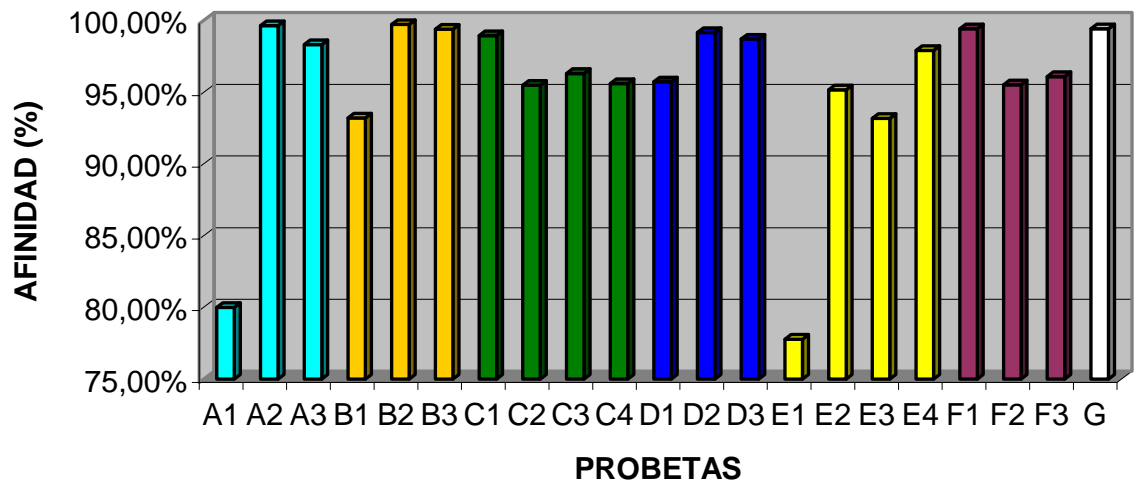

Gráfico III.10 . Afinidad de espectros IR tras el envejecimiento acelerado de humidificación y secado. 


\subsubsection{Ensayo de envejecimiento acelerado por irradiación con luz ultravioleta.}

Con este ensayo se pretende establecer unas condiciones experimentales de simulación de envejecimiento acelerado por irradiación con luz ultravioleta, empleándose tres probetas de cada masilla, con el fin de efectuar varias determinaciones:

- Colorimetría, sobre las probetas antes y después de ser sometidas a ensayo, eligiendo como condiciones de trabajo el iluminante estándar CIE tipo $\mathrm{D}_{65}$ (luz día, temperatura de color $6500^{\circ} \mathrm{K}$ ) y el observador estándar $10^{\circ}$.

- Dureza, sobre las probetas antes y después de ser sometidas a ensayo, eligiendo como condiciones de trabajo la dureza Vickers con una carga de 300 gr. y penetrador de diamante .

- Espectroscopia infrarroja por transformada de Fourier (FT-IR) para la evaluación de ensayos de envejecimiento artificial acelerado, sobre las probetas antes y después de ser sometidas a ensayo. 


\section{Resultados y discusión}

Colorimetría.

Tras el ensayo de envejecimiento acelerado por luz ultravioleta, podemos apreciar que los valores de variación total del color $(\Delta \mathrm{E})$ obtenidos, (Tabla III.42. y Gráfico III.10), en las masillas a base de resina epoxídica (E3, E2, E1 y E4) han experimentado un gran aumento, seguida por la masilla de cera (G).

En menor proporción, destacan en cuanto a variación de color total la masilla elaborada con Paraloid B-72 + Microesferas de vidrio (A1), las masillas comerciales preparadas como el Modostuc (F2) y el Modostuc + Liteplast (F3)y por último la masilla de Escayola Hebodur (C4).

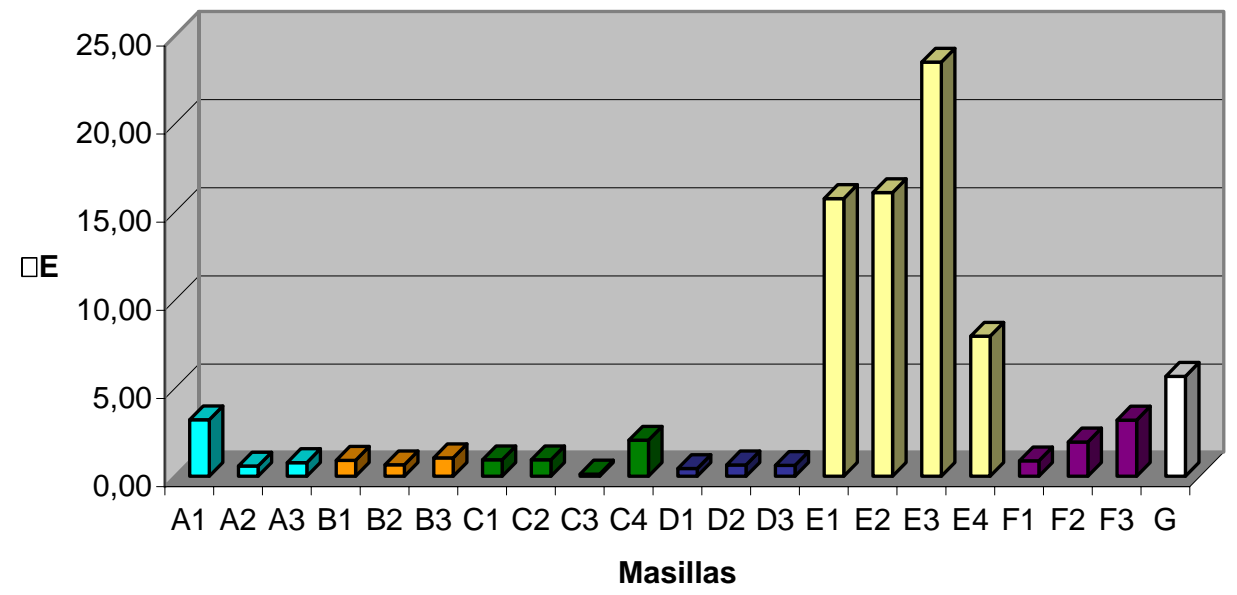

Gráfico III.11. Representación de la variación de color total $(\Delta \mathrm{E})$. 


\begin{tabular}{|c|c|c|c|c|c|c|c|c|c|c|c|c|c|c|c|c|}
\hline a & $\begin{array}{c}\mathbf{L}^{*} \\
\text { inicial } \\
\end{array}$ & S & $\begin{array}{c}L^{*} \\
\text { final }\end{array}$ & $\mathrm{S}$ & $\mathrm{L}^{*}$ & $\begin{array}{c}\mathrm{a}^{*} \\
\text { inicial }\end{array}$ & $\underline{s}$ & $\begin{array}{c}a^{*} \\
\text { final }\end{array}$ & $\underline{S}$ & * & \begin{tabular}{|c|}
$\mathbf{b}^{*}$ \\
inicial \\
\end{tabular} & $\underline{s}$ & $\begin{array}{c}\mathbf{b}^{*} \\
\text { final }\end{array}$ & $\underline{S}$ & * & $\Delta \mathrm{E}$ \\
\hline A1 & 88,81 & 0,27 & 87,15 & 0,64 & $-1,65$ & 1,28 & 0,07 & 1,20 & 0,41 & $-0,08$ & 7,58 & 0,34 & 10,33 & 4,05 & 2,75 & 3,21 \\
\hline A2 & 95,36 & 0,24 & 94,81 & 0,20 & $-0,55$ & 0,88 & 0,02 & 0,88 & 02 & 0,00 & 5,30 & 0,33 & 5,09 & 0,30 & $-0,21$ & 0,58 \\
\hline A3 & 95,53 & 0,41 & 94,79 & 0,29 & $-0,73$ & 0,09 & 0,04 & 0,06 & 03 & $-0,03$ & 3,32 & 0,81 & 3,07 & 0,39 & $-0,25$ & 0,78 \\
\hline B1 & 83,34 & 0,60 & 82,46 & 0,33 & $-0,88$ & 2,08 & 0,05 & 2,15 & 03 & 0,07 & 10,78 & 0,34 & 11,00 & 0,27 & 0,22 & 0,91 \\
\hline B2 & 94,27 & 0,11 & 93,69 & 0,23 & $-0,58$ & 1,08 & 0,04 & 1,07 & 0,05 & $-0,01$ & 7,41 & 0,15 & 7,12 & 0,15 & $-0,29$ & 0,65 \\
\hline B3 & 94,08 & 0,11 & 93,05 & 0,06 & $-1,03$ & 0,06 & 0,00 & 0,14 & 0,02 & 0,09 & 3,61 & 0,04 & 3,79 & 0,12 & 0,18 & 1,05 \\
\hline C1 & 89,71 & 0,09 & 90,51 & 0,28 & 0,80 & 1,17 & 0,09 & 0,99 & 0,04 & $-0,18$ & 4,84 & 0,47 & 4,38 & 0,44 & $-0,46$ & 0,94 \\
\hline C2 & 89,42 & 0,27 & 89,73 & 0,10 & 0,31 & 1,25 & 0,17 & 1,19 & 03 & $-0,06$ & 5,50 & 0,73 & 6,38 & 0,20 & 0,88 & 0,94 \\
\hline C3 & 92,30 & 0,03 & 92,40 & 0,57 & 0,11 & 1,03 & 0,04 & 0,96 & 08 & $-0,06$ & 4,02 & 0,21 & 4,04 & 0,72 & 0,02 & 0,13 \\
\hline C4 & 87,53 & 0,38 & 86,77 & 0,60 & $-0,76$ & 2,21 & 0,10 & 2,22 & 0,19 & 0,00 & 13,74 & 0,54 & 15,64 & 0,03 & 1,90 & 2,04 \\
\hline D1 & 91,98 & 0,27 & 91,55 & 0,19 & $-0,43$ & 0,35 & 0,02 & 0,40 & 0,02 & 0,05 & 3,08 & 0,05 & 3,07 & 0,07 & $-0,02$ & 0,44 \\
\hline D2 & 90,67 & 0,22 & 90,07 & 0,20 & $-0,61$ & 0,48 & 0,05 & 0,47 & 0,01 & $-0,01$ & 4,36 & 0,27 & 4,59 & 0,49 & 0,22 & 0,65 \\
\hline D3 & 92,02 & 0,16 & 91,41 & 0,24 & $-0,61$ & 0,37 & 0,02 & 0,40 & 03 & 0,02 & 3,30 & 0,16 & 3,41 & 0,29 & 0,10 & 0,62 \\
\hline E1 & 76,16 & 0,75 & 72,05 & & $-4,11$ & 1,28 & 0,05 & & & $\mid-0,00$ & & 0,34 & 23,65 & 0,65 & 15,20 & 15,76 \\
\hline E2 & 83,38 & 0,15 & 79,93 & 0,52 & $-3,45$ & 1,67 & 0,12 & 1,91 & 0,39 & 0,24 & 13,57 & 0,04 & 29,29 & 0,30 & 15,72 & 16,09 \\
\hline E3 & 85,62 & 0,92 & 79,51 & 0,76 & $-6,11$ & $-5,41$ & 0,19 & $-5,04$ & 0,52 & 0,38 & 8,15 & 0,26 & 30,84 & 0,91 & 22,69 & 23,50 \\
\hline E4 & 48,43 & 0,74 & 46,92 & 0,72 & $-1,51$ & 7,67 & 0,28 & 8,85 & 0,15 & 1,17 & 11,84 & 0,36 & 19,56 & 0,36 & 7,71 & 7,95 \\
\hline F1 & 92,83 & 0,47 & 92,51 & 0,41 & $-0,32$ & 0,28 & 0,18 & 0,11 & 0,09 & $-0,17$ & 4,89 & 0,84 & 5,69 & 0,71 & 0,80 & 0,88 \\
\hline F2 & 95,59 & 0,12 & 94,82 & 0,08 & $-0,77$ & 0,24 & 0,02 & 0,10 & 0,03 & $-0,14$ & 2,50 & 0,06 & 4,28 & 0,13 & 1,78 & 1,95 \\
\hline F3 & 94,77 & 0,10 & 94,06 & 0,07 & $-0,71$ & 0,21 & 0,03 & $-0,31$ & 0,05 & $-0,52$ & 3,19 & 0,08 & 6,25 & 0,07 & 3,07 & 3,19 \\
\hline G & 92,39 & 0,17 & 91,66 & 0,42 & $-0,73$ & $-0,25$ & 0,30 & $-0,92$ & 0,19 & $-0,68$ & 4,00 & 0,76 & 9,58 & 0,39 & 5,58 & 5,67 \\
\hline
\end{tabular}

Tabla III.42. Valores de variación de las coordenadas cromáticas L*, a*, b*, desviación estándar y variación de color total $(\Delta \mathrm{E})$. Correspondientes a las masillas sometidas a envejecimiento acelerado por luz UV.

El resto de las masillas han experimentado una Variación del Color total $(\Delta \mathrm{E})$ bajo, imperceptible al ojo humano.

En cuanto a los valores de Variación de la Luminosidad ( $L^{*}$ ) se observa (Tabla III. 42 y Gráfico III. 11) en general, un descenso, siendo perceptible de manera más acusada en las masillas epoxídicas (E1, E2, E3 y E4), lo cual justifica el oscurecimiento observado. 


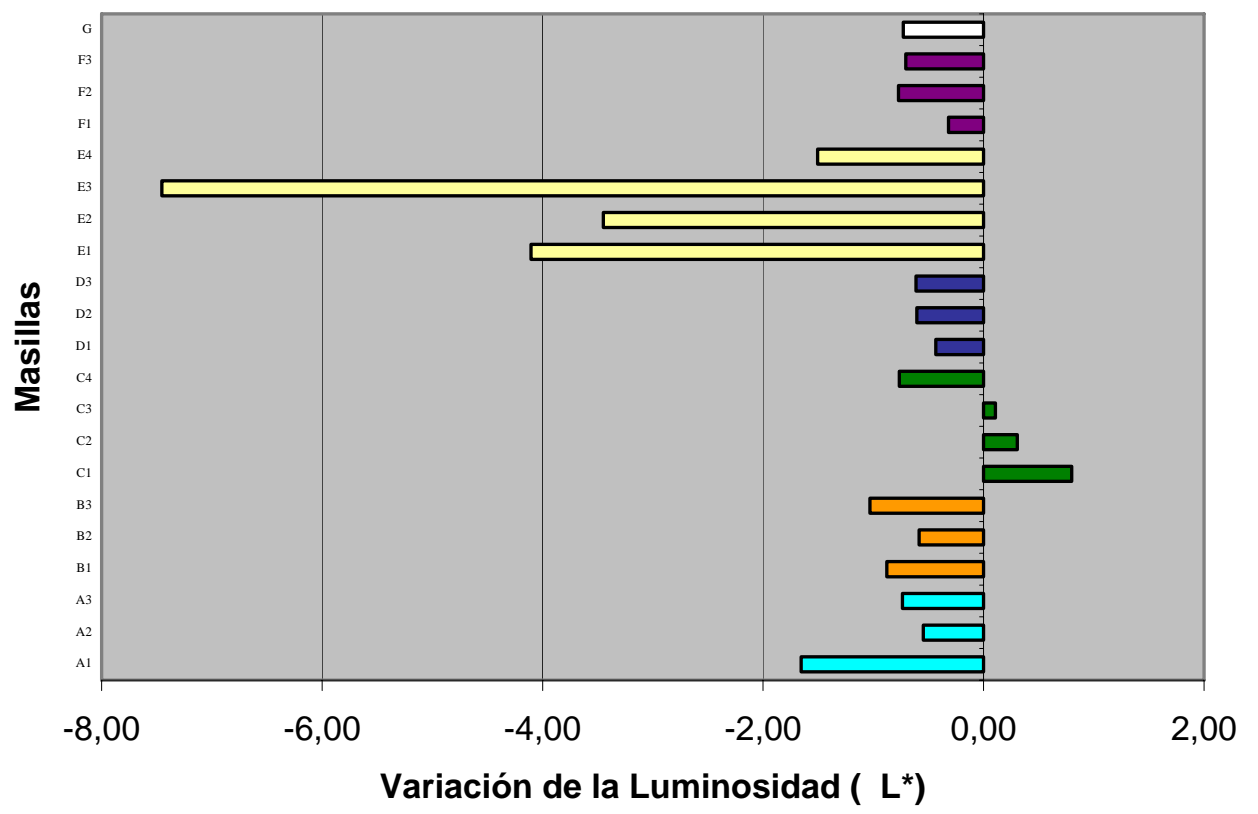

Grafico III.12. Representación de la variación de la luminosidad ( $\left.\Delta \mathrm{L}^{*}\right)$

Destacamos, que aunque imperceptible al ojo humano, en este apartado de la luminosidad, los datos aportados por los estucos de Escayola “Alamo 70” han experimentado un aumento en el valor de la luminosidad $(\Delta \mathrm{L})$, a excepción de la escayola Hebodur (C4).

El grupo formado por las masillas comerciales tanto en polvo (D) como ya preparadas (F) han sufrido un descenso de la luminosidad, apenas perceptible, destacando la variación de la masilla comercial preparada F1, como la más baja.

Analizando los valores de Croma $\left(\mathrm{C}^{*}\right)$ y Tono $\left(\mathrm{h}^{*}\right)$ se obtienen unos resultados más exhaustivos, todos ellos reflejados en la Tabla III.43. y 
representados en el Gráfico III.12.

Desde el punto de vista cromático, se observa que las masillas epoxídicas (E1, E2, E3 y F1) han experimentado un notable incremento en su croma lo que nos indica su ganancia en cromatismo, su color se hace más intenso.

\begin{tabular}{|c|cccc|c|cccc|c|}
\hline Nombre & $\mathbf{C}^{*}$ inicial & $\mathbf{S}$ & $\mathbf{C}^{*}$ final & $\mathbf{S}$ & $\boldsymbol{\Delta} \mathbf{C}^{*}$ & $\mathbf{h}^{*}$ inicial & $\mathbf{S}$ & $\mathbf{h}^{*}$ final & $\mathbf{S}$ & $\Delta \mathbf{h}^{*}$ \\
\hline A1 & 7,84 & 0,29 & 8,11 & 0,06 & 0,27 & 80,32 & 0,33 & 79,84 & 0,38 & $-0,48$ \\
\hline A2 & 5,37 & 0,33 & 5,17 & 0,30 & $-0,20$ & 80,59 & 0,37 & 80,23 & 0,44 & $-0,36$ \\
\hline A3 & 3,32 & 0,81 & 3,59 & 0,95 & 0,27 & 88,53 & 0,40 & 89,02 & 0,67 & 0,49 \\
B1 & 10,98 & 0,34 & 11,21 & 0,27 & 0,23 & 79,09 & 0,07 & 78,92 & 0,13 & $-0,16$ \\
B2 & 7,48 & 0,15 & 7,20 & 0,15 & $-0,29$ & 81,71 & 0,19 & 81,48 & 0,21 & $-0,23$ \\
B3 & 3,61 & 0,04 & 3,79 & 0,12 & 0,18 & 89,08 & 0,07 & 87,80 & 0,29 & $-1,28$ \\
C1 & 4,98 & 0,47 & 4,49 & 0,44 & $-0,49$ & 76,39 & 0,32 & 77,25 & 0,74 & 0,86 \\
C2 & 5,64 & 0,75 & 6,49 & 0,20 & 0,85 & 77,19 & 0,06 & 79,46 & 0,32 & 2,27 \\
C3 & 4,15 & 0,21 & 4,16 & 0,71 & 0,01 & 75,65 & 0,33 & 77,09 & 0,79 & 1,44 \\
C4 & 13,92 & 0,55 & 15,78 & 0,04 & 1,86 & 80,85 & 0,14 & 82,29 & 0,26 & 1,44 \\
D1 & 3,10 & 0,05 & 3,09 & 0,08 & $-0,01$ & 83,46 & 0,24 & 82,51 & 0,30 & $-0,95$ \\
D2 & 4,39 & 0,28 & 4,61 & 0,48 & 0,22 & 83,79 & 0,31 & 84,12 & 0,69 & 0,33 \\
\hline D3 & 3,32 & 0,16 & 3,43 & 0,29 & 0,11 & 83,58 & 0,10 & 83,36 & 0,20 & $-0,21$ \\
E1 & 8,54 & 0,34 & 23,66 & 0,65 & 15,12 & 81,36 & 0,04 & 88,24 & 0,03 & 6,88 \\
E2 & 13,68 & 0,04 & 29,33 & 0,30 & 15,66 & 83,23 & 0,90 & 86,44 & 0,48 & 3,22 \\
\hline E3 & 9,77 & 0,07 & 31,28 & 0,81 & 21,52 & 123,42 & 2,09 & 98,37 & 0,62 & $-25,04$ \\
\hline E4 & 14,11 & 0,44 & 21,47 & 0,28 & 7,35 & 57,06 & 0,46 & 65,65 & 0,75 & 8,59 \\
F1 & 4,90 & 0,84 & 5,69 & 0,71 & 0,79 & 85,08 & 0,44 & 89,42 & 0,58 & 4,34 \\
F2 & 2,51 & 0,06 & 4,29 & 0,13 & 1,77 & 84,50 & 0,37 & 88,71 & 0,41 & 4,21 \\
\hline F3 & 3,20 & 0,08 & 6,26 & 0,08 & 3,07 & 86,16 & 0,52 & 92,81 & 0,42 & 6,65 \\
G & 4,01 & 0,76 & 9,63 & 0,41 & 5,63 & 94,43 & 1,14 & 95,84 & 0,92 & 1,41 \\
\hline
\end{tabular}

Tabla III.43. Variación de las coordenadas cromáticas $\mathrm{C}^{*} \mathrm{y} \mathrm{h}$, su desviación estándar, variación del croma $\left(\Delta \mathrm{C}^{*}\right)$ y variación del tono $\left(\Delta \mathrm{h}^{*}\right)$ de las masillas sometidas a irradiación de luz ultravioleta. 
En este sentido también experimentan un aumento en su cromatismo, aunque a menor escala, la masilla de cera $(\mathrm{H})$, las masillas comerciales preparadas (F3 y F4) y la masilla Escayola Hebodur (C4). El resto de las masillas han obtenido unos valores inapreciables destacando la masilla de Escayola Alamo 70 (C3).

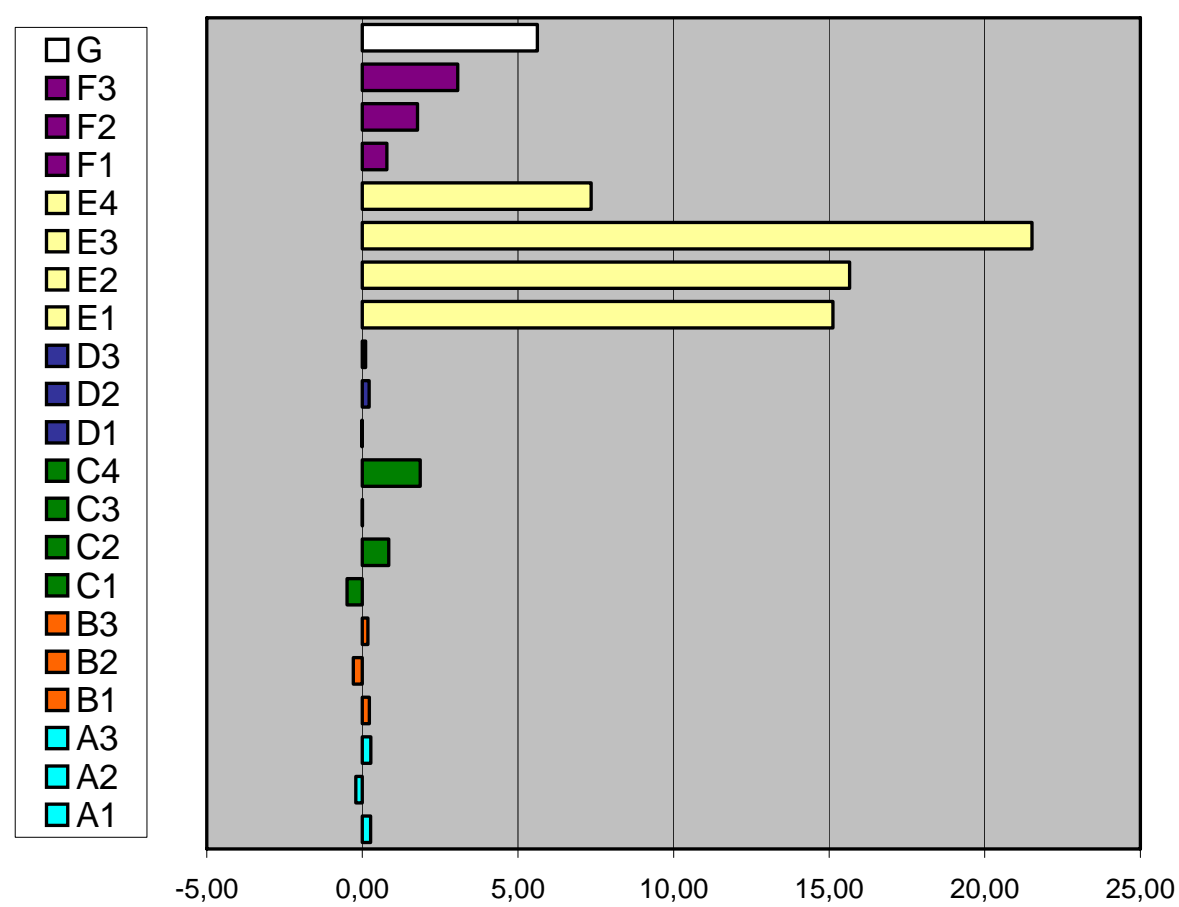

Gráfico III.13. Representación de la variación del Croma $\left(\Delta \mathrm{C}^{*}\right)$

En cuanto a la variación de tono $\left(\Delta \mathrm{h}^{*}\right)$, y analizados los valores $\mathrm{h}^{*}$ inicial y $\mathrm{h} *$ final se determina con ayuda del diagrama cromático CIELAB, la variación de las coordenadas cromáticas de las masillas antes y después de someterlos a ensayo de envejecimiento por irradiación de UV. Siendo las variaciones inapreciables al ojo humano 
a excepción de las masillas de resina epoxídica (E) que han virado hacia el amarillo siendo la masilla E3 (resina epoxídica y sílice coloidal) la que mayor variación ha sufrido con una diferencia de tono $\left(\mathrm{Dh}^{*}\right)$ de $-25,04^{\circ}$.

Otras masillas a destacar son las comerciales preparadas (F1, F2 y F3) con unas diferencias de tono $\left(\Delta \mathrm{h}^{*}\right)$ de $4,34^{\circ} ; 4,21^{\circ}$ y $6,65^{\circ}$ respectivamente. El resto de las masillas han experimentado un cambio de tono inapreciable o nulo.

\section{Durometría.}

En la Tabla III.44. y en el Gráfico III.13. se pueden advertir los valores obtenidos en el ensayo de dureza de las tres probetas de cada masilla ensayadas antes y después del envejecimiento acelerado por irradiación de luz ultravioleta (UV).

Analizados los valores de variación de la dureza podemos observar que las masillas no han experimentado grandes cambios, a excepción de la masilla E2 compuesta por resina epoxídica y carbonato cálcico en la cual su dureza ha aumentado en 10,40 Vickers. Con valores menos significativos en cuanto a incremento de dureza destacamos las masillas A1, D3 y E1. 
En cuanto al descenso o pérdida de dureza (no muy acusada) destacamos el conjunto de masillas elaboradas a partir de la resina acrílica en dispersión acuosa Acril 33 (B).

\begin{tabular}{|c|cc|cc|c|}
\hline Masillas & $\begin{array}{c}\text { Dureza } \\
\text { Inicial }\end{array}$ & $\mathrm{S}$ & $\begin{array}{c}\text { Dureza } \\
\text { final }\end{array}$ & $\mathrm{S}$ & $\Delta$ Dureza \\
\hline A1 & 1,94 & 0,59 & 5,00 & 1,55 & 3,06 \\
A2 & 10,35 & 1,64 & 10,18 & 1,29 & $-0,17$ \\
A3 & 17,80 & 2,78 & 19,67 & 0,91 & 1,87 \\
B1 & 0,93 & 0,21 & 0,70 & 0,13 & $-0,23$ \\
B2 & 3,64 & 0,71 & 1,58 & 0,00 & $-2,06$ \\
B3 & 7,36 & 0,89 & 1,38 & 0,15 & $-5,99$ \\
C1 & 6,79 & 0,96 & 2,80 & 0,72 & $-3,99$ \\
C2 & 1,91 & 0,45 & 3,83 & 0,68 & 1,91 \\
C3 & 6,53 & 0,93 & 4,86 & 1,07 & $-1,67$ \\
C4 & 10,16 & 1,45 & 12,33 & 1,22 & 2,17 \\
D1 & 4,44 & 1,22 & 6,31 & 0,97 & 1,87 \\
D2 & 4,32 & 0,96 & 4,60 & 0,37 & 0,28 \\
D3 & 4,57 & 1,19 & 7,88 & 0,45 & 3,31 \\
E1 & 26,56 & 2,86 & 30,70 & 2,34 & 4,14 \\
E2 & 24,50 & 1,31 & 34,90 & 1,59 & 10,40 \\
E3 & 21,65 & 1,09 & 22,03 & 1,06 & 0,38 \\
E4 & 4,37 & 1,10 & 3,13 & 0,25 & $-1,23$ \\
F1 & 2,48 & 0,30 & 2,82 & 0,23 & 0,34 \\
F2 & 1,94 & 0,36 & 2,90 & 0,17 & 0,96 \\
F3 & 0,73 & 0,05 & 1,30 & 0,32 & 0,58 \\
G & 0,70 & 0,00 & 0,97 & 0,06 & 0,27 \\
\hline
\end{tabular}

Tabla III.44. Variación de la Dureza (Vickers) de las masillas antes y después de ser sometidas a envejecimiento acelerado por irradiación de luz ultravioleta. 


\section{VARIACIÓN DE LA DUREZA}

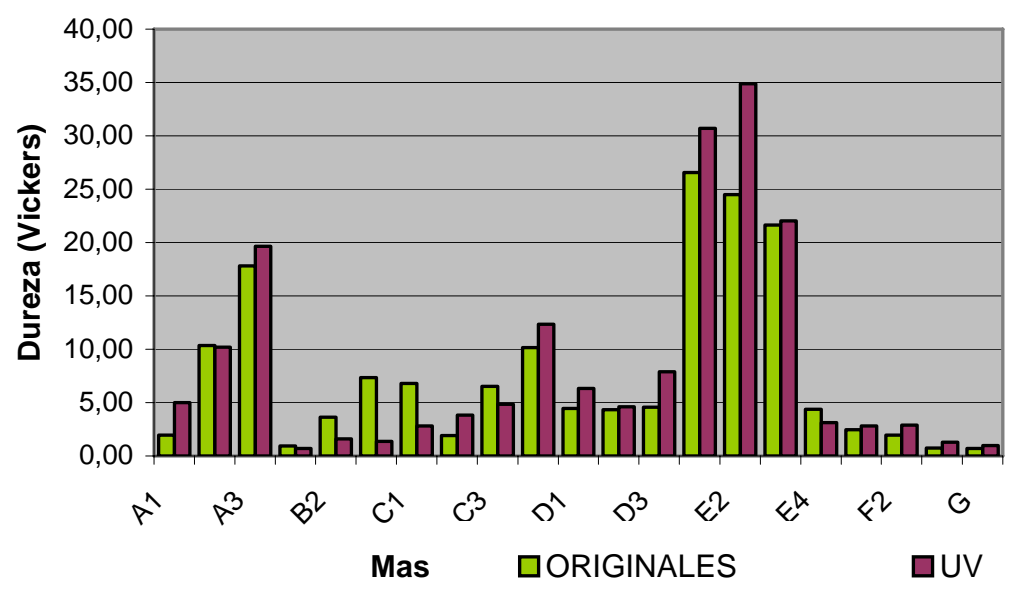

Gráfico III.14. Variación de la Dureza (Vickers) de las masillas antes y después de ser sometidas a envejecimiento acelerado por irradiación de luz ultravioleta.

\section{Espectrometría de Infrarrojos.}

De la información obtenida de los espectros de IR, una vez normalizados y comparados con el programa OPUS se obtuvieron unos parámetros en \% de afinidad entre los espectros de las probetas sin tratar, respecto a las probetas envejecidas.

El envejecimiento por UV produce oxidación en general, del polímero orgánico. Las probetas elaboradas con resina epoxídica, en particular la E1 (resina epoxídica más microesferas de vidrio) y la E3 (resina epoxídica más sílice coloidal) son las más sensibles de todas a este 
tipo de envejecimientos. La B3 (Acril 33 + polvo de mármol) muestra un comportamiento algo mejor que las anteriores, si bien para el resto de probetas los cambios son inapreciables.

Todo esto queda representado en el siguiente gráfico:

AFINIDAD ESPECTROS IR TRAS ENVEJECIMIENTO POR IRRADIACION UV

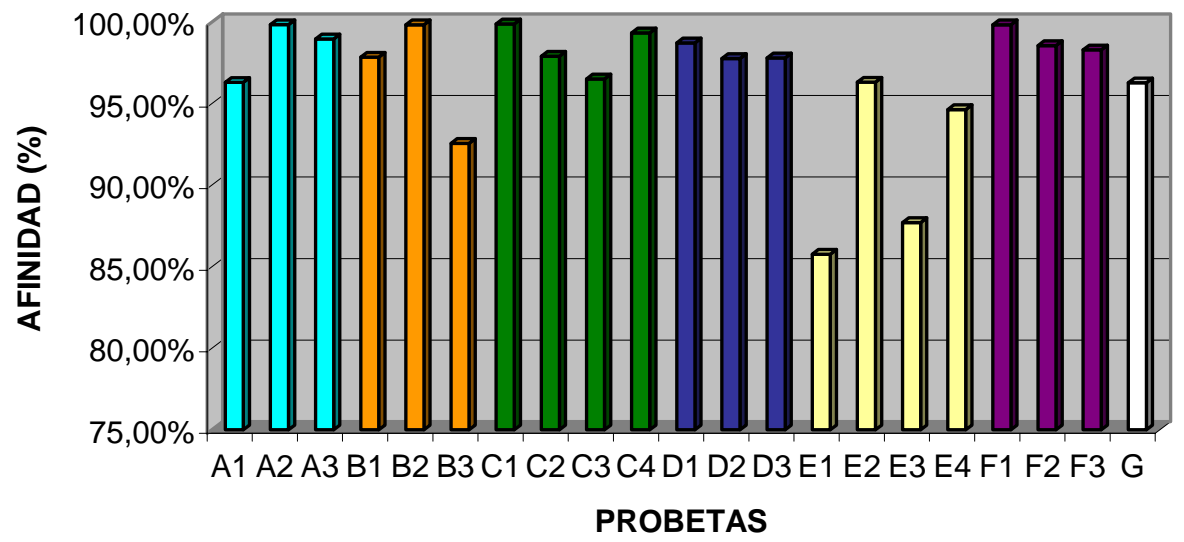

Gráfico III.15. Afinidad de espectros IR tras el envejecimiento acelerado de irradiación por UV. 


\subsubsection{Ensayo de envejecimiento acelerado en atmósfera saturada con $\mathrm{SO}_{2}$ con condensación general de la humedad.}

Con este ensayo se pretende establecer unas condiciones experimentales de simulación de estrés corrosivo bajo atmósferas urbanas e industriales, para ello se han empleado tres probetas de cada masilla estudiada.

La metodología experimental seguida en esta experiencia consistió en:

1. Pesada de las muestras en condiciones ambientales $\left(21^{\circ} \mathrm{C}\right.$ y H.R del 55\%).

2. La desecación previa de las muestras en estufa, no fue realizada debido a que un numeroso conjunto de las mismas está elaborado con resinas y cera y podrían verse afectadas por el calor, llegando incluso a la deformación.

3. Introducción de las muestras en el interior de la cámara de envejecimiento durante siete días a una temperatura de $40^{\circ} \mathrm{C}$ y una humedad relativa del 100\%, con una concentración de $\mathrm{SO}_{2}$ de 0,2-2 l/g. Pasado este tiempo, sigue una segunda etapa de 16 horas en la cual las probetas quedan expuestas al aire a temperatura ambiente. La duración del ensayo se estableció en 7 ciclos (168 h.). 
Tras el ensayo se han efectuado varias determinaciones:

- Densidad, tras el ensayo, las probetas se pesan cuando alcanzan estabilidad con el medio $\left(21^{\circ} \mathrm{C}\right.$ y H.R del $\left.55 \%\right)$, con la finalidad de analizar su pérdida o ganancia de masa.

- Colorimetría, sobre las probetas antes y después de ser sometidas a ensayo, eligiendo como condiciones de trabajo el iluminante estándar CIE tipo $\mathrm{D}_{65}$ (luz día, temperatura de color $6500^{\circ} \mathrm{K}$ ) y el observador estándar $10^{\circ}$.

- Dureza, sobre las probetas antes y después de ser sometidas a ensayo, realizando el ensayo con un microdurímetro MICROHARDENESS TESTER FM de la marca FutureTech, eligiendo como condiciones la dureza Vickers con penetrador de diamante con una carga de 300 gr.

- Evaluación de ensayos de envejecimiento artificial acelerado, sobre las probetas antes y después de ser sometidas a ensayo, mediante espectroscopia infrarroja por transformada de Fourier (FT-IR).

\section{Resultados y discusión}

\section{Densidad.}

Los valores medios de la densidad de las masillas seleccionadas antes y después de ser sometidas al ensayo de envejecimiento acelerado en 
atmósfera saturada de $\mathrm{SO}_{2}$ se muestran en la tabla III.45, siendo representados en el Grafico III.14.

\begin{tabular}{|c|c|c|c|c|c|c|}
\hline Masilla & $\begin{array}{c}\text { Peso } \\
\text { inicial }\end{array}$ & S & $\begin{array}{c}\text { Peso } \\
\text { final }\end{array}$ & S & $\begin{array}{c}\text { Pérdida/ } \\
\text { Ganancia } \\
\text { de masa(g) }\end{array}$ & $\begin{array}{c}\text { Pérdida/ } \\
\text { Ganancia } \\
\text { (\%) }\end{array}$ \\
\hline A1 & 20,940 & 0,39 & 20,968 & 0,39 & 0,029 & 0,14 \\
\hline A2 & 18,613 & 0,42 & 18,627 & 0,42 & 0,015 & 0,08 \\
\hline A3 & 19,278 & 0,20 & 19,242 & 0,20 & $-0,036$ & $-0,19$ \\
\hline B1 & 21,244 & 1,12 & 21,162 & 1,30 & $-0,082$ & $-0,39$ \\
\hline B2 & 22,737 & 0,10 & 22,199 & 0,16 & $-0,538$ & $-2,37$ \\
\hline B3 & 24,450 & 0,41 & 24,005 & 0,40 & $-0,445$ & $-1,82$ \\
\hline C1 & 21,258 & 0,08 & 21,273 & 0,08 & 0,015 & 0,07 \\
\hline C2 & 16,480 & 0,06 & 16,519 & 0,06 & 0,040 & 0,24 \\
\hline C3 & 18,522 & 0,14 & 18,565 & 0,14 & 0,043 & 0,23 \\
\hline C4 & 21,652 & 0,05 & 21,653 & 0,05 & 0,001 & 0,00 \\
\hline D1 & 16,606 & 0,05 & 16,603 & 0,05 & $-0,004$ & $-0,02$ \\
\hline D2 & 17,978 & 0,18 & 17,591 & 0,27 & $-0,387$ & $-2,15$ \\
\hline D3 & 17,966 & 0,37 & 17,754 & 0,37 & $-0,212$ & $-1,18$ \\
\hline E1 & 22,302 & 0,20 & 22,367 & 0,20 & 0,065 & 0,29 \\
\hline E2 & 22,637 & 0,17 & 22,682 & 0,17 & 0,045 & 0,20 \\
\hline E3 & 15,803 & 0,19 & 15,869 & 0,19 & 0,066 & 0,42 \\
\hline E4 & 9,743 & 0,06 & 9,950 & 0,06 & 0,207 & 2,12 \\
\hline F1 & 25,659 & 0,07 & 25,334 & 0,08 & $-0,326$ & $-1,27$ \\
\hline F2 & 24,115 & 0,06 & 23,872 & 0,07 & $-0,243$ & $-1,01$ \\
\hline F3 & 12,761 & 0,01 & 11,695 & 0,04 & $-1,067$ & $-8,36$ \\
\hline G & 26,083 & 0,54 & 26,039 & 0,54 & $-0,043$ & $-0,17$ \\
\hline & & & & & & \\
\hline
\end{tabular}

Tabla III.45. Valores medios de pérdida/ganancia de masa de las masillas sometidas a envejecimiento acelerado en atmósfera saturada en SO2, desviación estándar y diferencia en \%

Las masillas que mostraron un porcentaje de ganancia de peso/masa fueron las masillas epoxídicas (E), los estucos de escayola a excepción de la escayola Hebodur (C4) y las masillas a base de resina acrílica 
“Paraloid B-72” a excepción de la aglutinada con polvo de mármol y sílice coloidal. Los porcentajes obtenidos en estas ganancias de masa son bastante despreciables sin contar con los obtenidos por la masilla E4 con un 2'12 \%

En cuanto a pérdida de masa, la masilla compuesta por la mezcla de dos masillas comerciales preparadas (F), ha sido una de las que más ha destacado con un porcentaje de pérdida del 8,36\%

El resto de masillas han experimentado una pérdida de peso generalizada, con valores comprendidos entre $0,02 \%$ en la masilla comercial en polvo (D1) y un 2,37 \% para la masillas B2.

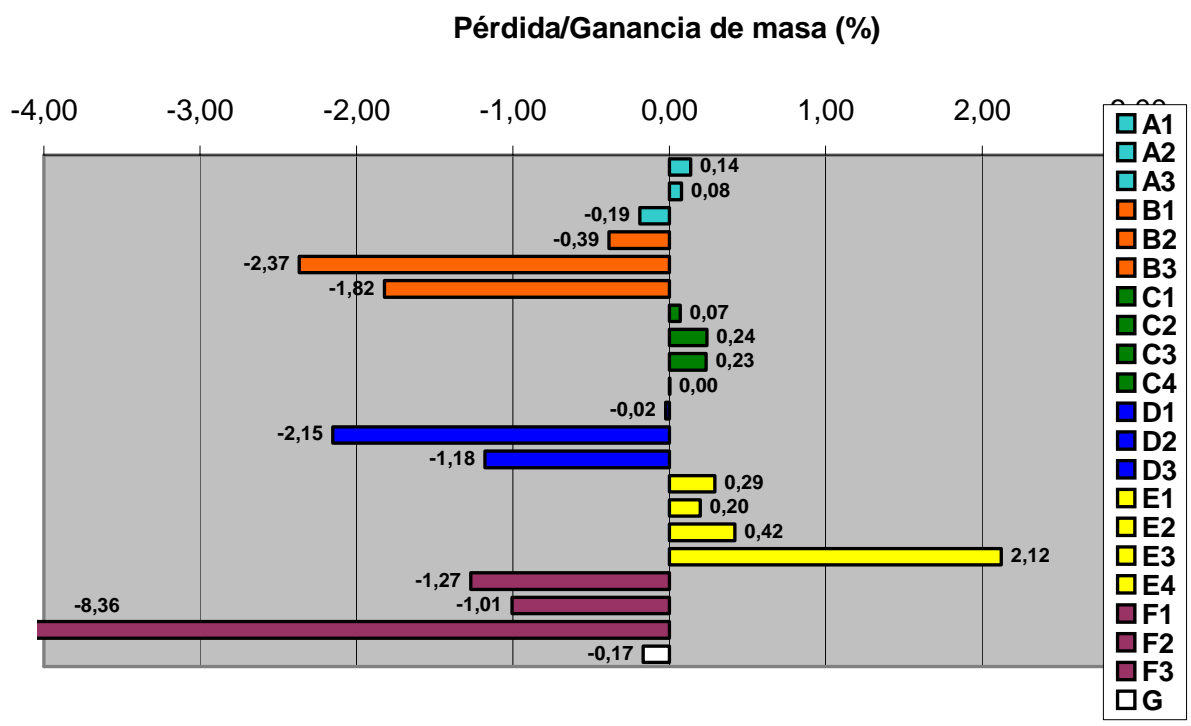

Gráfico III.16. Representación de los valores medios de pérdida o ganancia en \% de masa de las masillas sujetas al ensayo de envejecimiento acelerado en atmósfera saturada de $\mathrm{SO}_{2}$. 


\section{Colorimetría.}

Los resultados obtenidos en el ensayo de envejecimiento acelerado en atmósfera saturada de $\mathrm{SO}_{2}$ se muestran en la Tabla III.46 y Tabla III.47.

En general, se observa que las masilla E4 ( masilla epoxídica "EPO 127”) y la escayola Hebodur, han experimentado un gran aumento en la Variación del Color Total $(\Delta \mathrm{E})$.

\begin{tabular}{|c|c|c|c|c|c|c|c|c|c|c|c|c|c|c|c|c|}
\hline Masilla & $\begin{array}{c}\mathbf{L}^{*} \\
\text { inicial }\end{array}$ & S & $\begin{array}{c}L^{*} \\
\text { final }\end{array}$ & S & L* & $\begin{array}{c}\mathrm{a}^{*} \\
\text { inicial }\end{array}$ & $\mathrm{S}$ & $\begin{array}{l}a^{*} \\
\text { final }\end{array}$ & S & $\Delta \mathrm{a}^{*}$ & \begin{tabular}{|c|}
$\mathbf{b}^{*}$ \\
inicial \\
\end{tabular} & S & $\begin{array}{c}b^{*} \\
\text { final }\end{array}$ & S & $\Delta \mathbf{b}^{*}$ & $\Delta \mathbf{E}$ \\
\hline A1 & 8,81 & 0,27 & 88,41 & 0,03 & 39 & 8 & 0,07 & 1,27 & 0,00 & 1 & 58 & 0,34 & 61 & 0,01 &, 03 & 0,39 \\
\hline 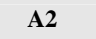 & ,36 & 0,24 & 94,33 & 0,06 & 02 & 0,88 & 02 & 0,86 & 01 & & 30 & 0,33 & ,32 & 11 & 02 & 45 \\
\hline A3 &, 53 & 0,41 & 96,24 & 0,15 & 1 & 0,09 & 0,04 & 0,06 & 0,00 & $-0,03$ & ,87 & 0,81 & 10 & 02 & 0,76 & 04 \\
\hline B1 & 34 & 0,6 & ,80 & 0,01 & -154 & 08 & 05 & 2,05 & 0,00 & $-0,03$ & 10,78 & 0,34 & 13,56 & 0,02 & ,78 & 18 \\
\hline 2 & 27 & 0,11 & 93,28 & 0,01 & 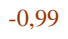 & 1,08 & 04 & 1,11 & 0,01 & 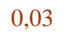 & 41 & 0,15 & 7,86 & 0,00 & ,46 & ,09 \\
\hline B3 & 08 & 0,11 & 92,83 & 0,15 & 26 & 0,06 & 0 & 0,11 & 0,02 & 0 , & 3,61 & 0,04 & 4,20 & 0,03 &, 59 & ,39 \\
\hline C1 & 71 & 0,09 & 87,81 & 0 & 00 & 7 & 09 & 1,76 & 0,00 & 0,59 & 84 & 0,47 &, 11 & ,03 &, 27 & 3,83 \\
\hline C2 & 89,42 & 27 & 87,73 & 0 & -169 & 1,25 & 7 & 1,62 & 0,01 & 0,37 & 0 & 0,73 & 87 & 04 & 38 & 79 \\
\hline C3 & 9230 & 0,03 & 90,54 & 0,03 & -176 & 1,03 & 0,04 & 1,37 & 0,00 & 0.3 & 4,02 & 0,21 & 5,82 & 0,02 & 1,80 & 2,54 \\
\hline C4 & ,53 & 0,38 & 78,39 & 0,01 & 14 & 2,21 & 0,1 & 4,77 & 0,02 & 2,3 & 13,74 & 0,54 & 26,12 & 0,09 & 12,38 & 15,60 \\
\hline D & 91,98 & 0,27 & 30 & 0 & $-1,00$ & 0,35 & 2 & 0,49 & 1 & 0,14 & 3,08 & 0,05 & 4 & 0,01 & 66 & 94 \\
\hline D & 90,67 & 0,22 & 89,03 & 0, & $-1,64$ & 0 , & 5 & 0,58 & 0,01 & 0, & 43 & 0,2 & 4,87 & 0,04 & 0.51 & 1,72 \\
\hline D3 & 92,02 & 0,16 & 90,15 & 0,10 & $-1,87$ & 0,37 & 0,02 & 0,55 & 0,01 & 0,18 & 3,30 & 0,16 & 3,90 & 0,02 & 0,60 & 1,97 \\
\hline & 76,58 & 0,75 & 77,22 & 0 & c1 & & 5 & 1,22 & 0 & 0 & 8,44 & 4 & 2 & 02 & ),62 & ,90 \\
\hline $\mathbf{E}_{2}$ & 38 & 0,15 & 80,56 & 0 , & $-2,82$ & 167 & 0,12 & 2,24 & 0,00 & 0,57 & 13,57 & 0,04 & 17,84 & 0,11 & 428 & 5,15 \\
\hline E3 & 5,62 & 0,92 & 82,81 & 0,47 & 81 & $-5,41$ & 0,19 & $-4,10$ & 0,05 & 13 & ,15 & 0,26 & 6,41 & 0,07 & $-1,74$ & 3,56 \\
\hline E4 & 48,43 & 0,74 & 57,08 & 0,12 & 65 & 7,67 & 0,28 & 5,64 & 0,02 & $-2,0$ & 11,84 & 0,36 & 26,33 & 0,25 & 14,49 & 17,00 \\
\hline F1 & 92,83 & 0,47 & 39 & 0 & $-1,44$ & 0,28 & 8 & 0,32 & 0 , & 0,04 & 4,45 & 0 , & 3 & 0,10 & 8 & 37 \\
\hline 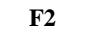 & 59 & 0,12 & 94,94 & 0,21 & $-0,65$ & 0,24 & 0,02 & 0,26 & 0,01 & 0,02 &, 50 & 0,06 & 3,04 & 0,04 &, 54 & 0,84 \\
\hline F3 & 77 & 0,1 & 94,48 & 0,01 & $-0,2$ & 0 , & 0,03 & 0,09 & 0,00 & & 3,19 & 0,08 & 3,79 & 0,01 & 0,60 & 0,68 \\
\hline G & 92,39 & 0,17 & 90,96 & 0,10 & $-1,43$ & 0,25 & 0,3 & $-0,41$ & 0,02 & $-0,16$ & 4,00 & 0,76 & 8,02 & 0,14 & 4,02 & 4,27 \\
\hline
\end{tabular}

La tabla III.46. Variación de las coordenadas cromáticas $L^{*}$, a* y b*, desviación estándar y Variación de color total $(\Delta \mathrm{E})$ de las masillas sometidas a ensayo de envejecimiento acelerado en atmósfera saturada de $\mathrm{SO}_{2}$. 
En menor proporción destacan en cuanto a $\Delta \mathrm{E}$ la masilla E2 elaborada con resina epoxídica y carbonato de calcio, así como el estuco de cera $\mathrm{H}$. El resto de masillas no experimentan grandes variaciones del color total destacando como inapreciables tanto el conjunto de masillas comerciales Polyfilla (D) como las ya preparadas para su uso a base de Modostuc (F2 y F3).

Los valores nulos e imperceptibles al ojo humano en la variación del color total están presentes en las masillas compuestas por Microesferas de vidrio tanto en resina acrílica (A1), como en resina epoxídica (E1).

\section{VARIACIÓN DEL COLOR ( E)}

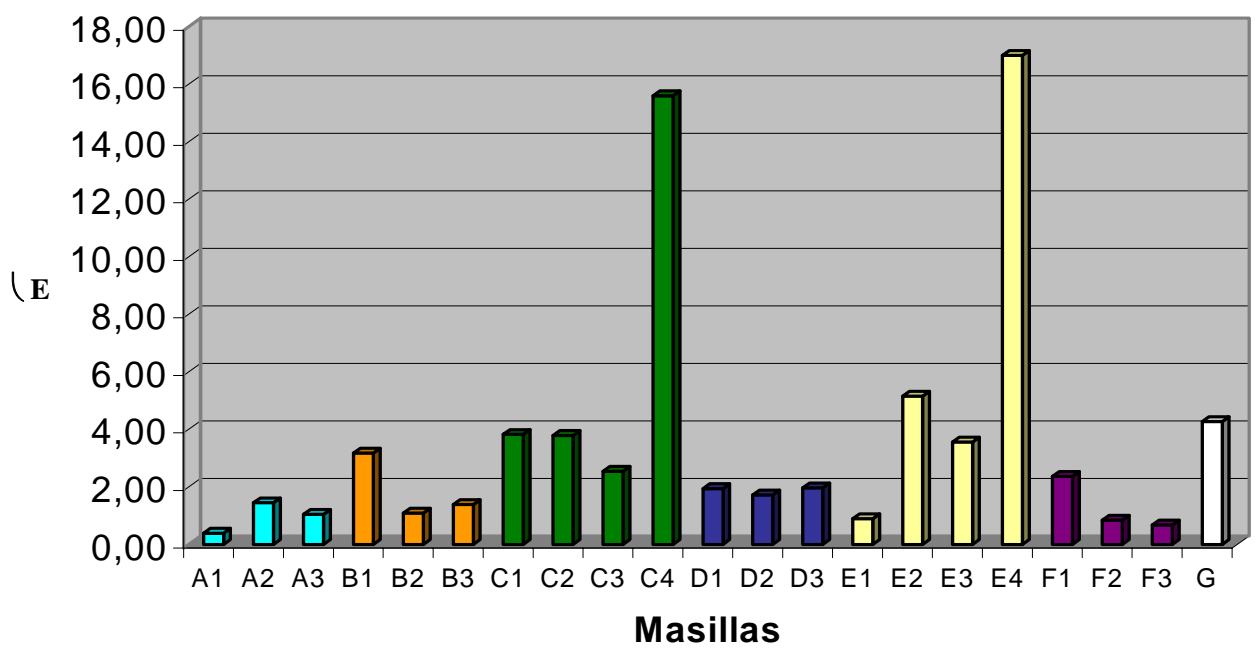

Gráfico III.17. Representación de la variación del color total $(\Delta \mathrm{E})$ de las masillas sometidas a ensayo de envejecimiento acelerado con luz UV. 
En cuanto a los valores de Variación de la Luminosidad $\left(\Delta \mathrm{L}^{*}\right)$, representados en el Gráfico III.16, se observan valores inapreciables a excepción de la masilla epoxídica E4, la cual aclara un poco y las masillas A3 y E1 que aclaran mínimamente.

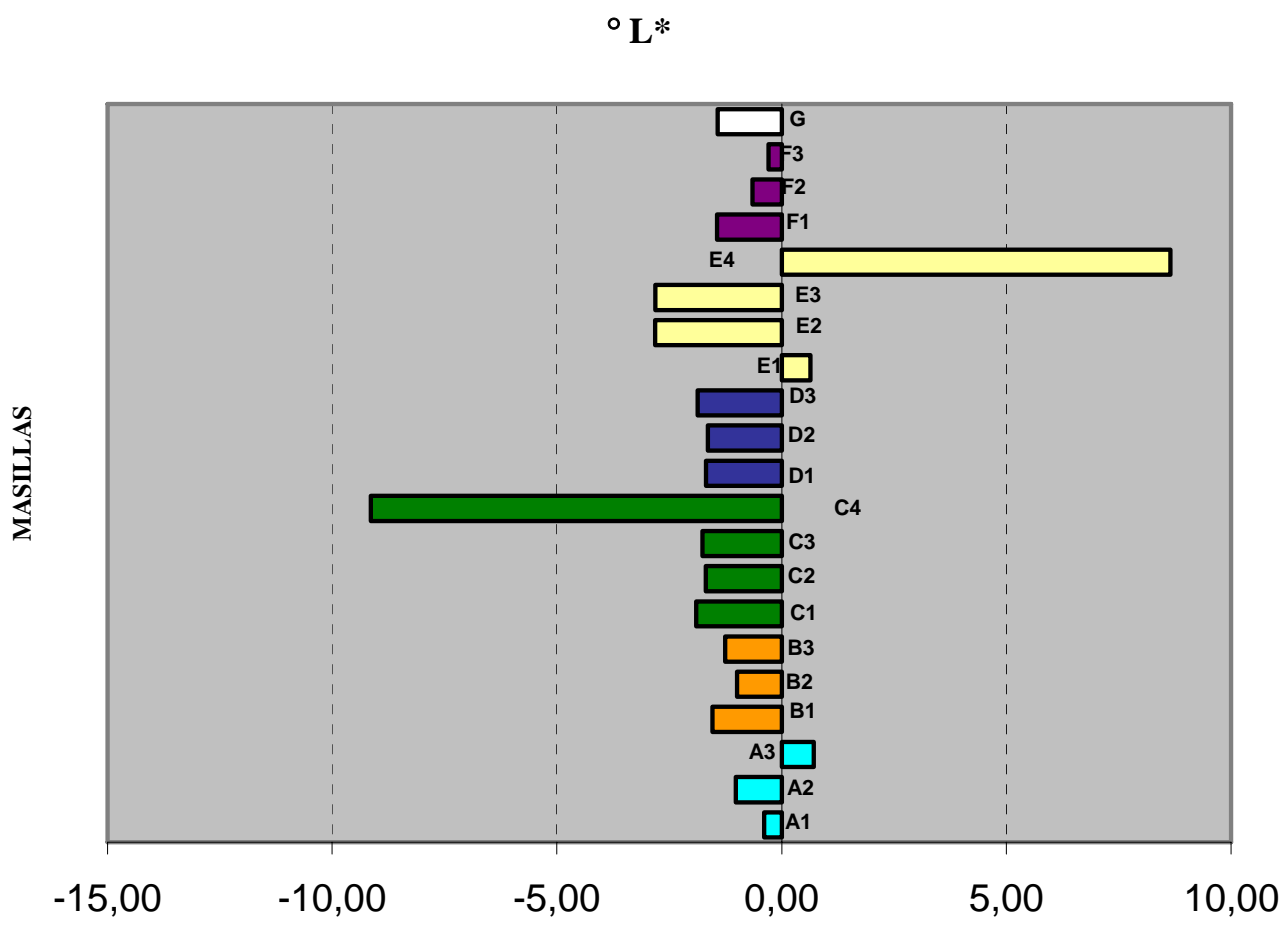

Gráfico III.18. Representación de la variación de la Luminosidad $\left(\Delta \mathrm{L}^{*}\right)$ de las masillas sometidas a ensayo de envejecimiento acelerado con luz UV.

Por el contrario, las masillas elaboradas con resina epoxídica y sílice coloidal (E3), al igual que la masilla E2 con carbonato cálcico, oscurecen levemente mientras que la escayola Hebodur (C4) presenta un oscurecimiento considerablemente. 
Analizando los valores de la Variación del Croma $\left(\Delta \mathrm{C}^{*}\right)$ se obtienen resultados más exhaustivos, todos ellos reflejados en la Tabla III.47 y representado en el Gráfico III.17.XX. Se observa que la masilla C4 ha experimentado un notable incremento en su Croma lo que nos indica que su color se hace más intenso. En este sentido también experimentan un ligero aumento en su cromatismo, las masillas E2, C2, C1, y B1. Mientras el cromatismo de la masilla E3 disminuye ligeramente. El resto de las masillas han obtenido unos valores inapreciables.

VARIACIÓN DEL CROMA ( $\left.\square C^{*}\right)$

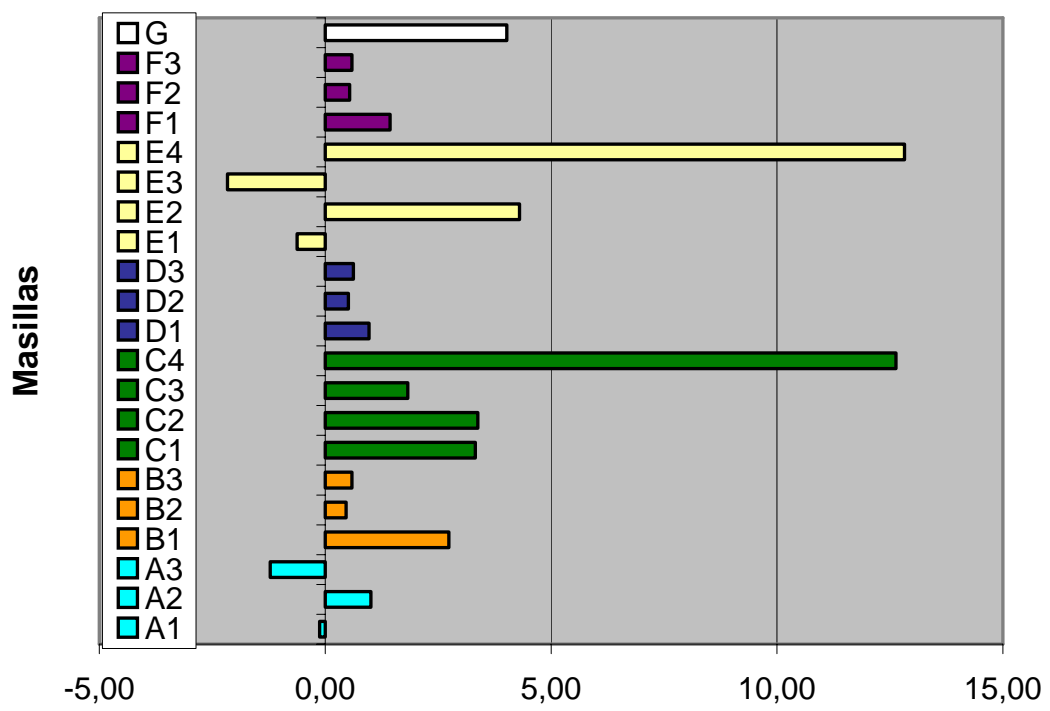

Gráfico III.19. Representación de la Variación del Croma ( $\Delta \mathrm{C}^{*}$ ) experimentado en las masillas sometidas a ensayo de envejecimiento en atmósfera saturada de $\mathrm{SO}_{2}$. 


\begin{tabular}{|c|ccccc|ccccc|}
\hline Masilla & $\begin{array}{c}\text { C* } \\
\text { inicial }\end{array}$ & $\mathbf{S}$ & $\begin{array}{c}\text { C* } \\
\text { final }\end{array}$ & $\mathbf{S}$ & $\mathbf{\Delta C}$ & $\begin{array}{c}\mathbf{h} \\
\text { inicial }\end{array}$ & $\mathrm{S}$ & $\begin{array}{c}\mathbf{h} \\
\text { final }\end{array}$ & $\mathrm{S}$ & $\Delta \mathbf{h}$ \\
\hline A1 & 7,84 & 0,29 & 7,72 & 0,01 & $-0,12$ & 80,32 & 0,33 & 80,54 & 0,02 & 0,22 \\
A2 & 5,37 & 0,33 & 6,38 & 0,11 & 1,01 & 80,59 & 0,37 & 82,22 & 0,07 & 1,63 \\
A3 & 3,32 & 0,81 & 2,10 & 0,02 & $-1,22$ & 88,53 & 0,4 & 88,44 & 0,10 & $-0,09$ \\
B1 & 10,98 & 0,34 & 13,72 & 0,02 & 2,74 & 79,09 & 0,07 & 81,41 & 0,02 & 2,32 \\
B2 & 7,48 & 0,15 & 7,94 & 0,00 & 0,46 & 81,71 & 0,19 & 81,97 & 0,06 & 0,26 \\
B3 & 3,61 & 0,04 & 4,20 & 0,03 & 0,59 & 89,08 & 0,07 & 88,45 & 0,25 & $-0,63$ \\
C1 & 4,98 & 0,47 & 8,30 & 0,03 & 3,32 & 76,39 & 0,32 & 77,79 & 0,08 & 1,40 \\
C2 & 5,64 & 0,75 & 9,02 & 0,04 & 3,38 & 77,19 & 0,06 & 79,66 & 0,06 & 2,47 \\
C3 & 4,15 & 0,21 & 5,98 & 0,02 & 1,83 & 75,65 & 0,33 & 76,72 & 0,04 & 1,07 \\
C4 & 13,92 & 0,55 & 26,55 & 0,08 & 12,63 & 80,85 & 0,14 & 79,66 & 0,07 & $-1,19$ \\
D1 & 3,1 & 0,05 & 4,07 & 0,01 & 0,97 & 83,46 & 0,24 & 83,06 & 0,13 & $-0,40$ \\
D2 & 4,39 & 0,28 & 4,91 & 0,04 & 0,52 & 83,79 & 0,31 & 83,21 & 0,11 & $-0,58$ \\
D3 & 3,32 & 0,16 & 3,94 & 0,02 & 0,62 & 83,58 & 0,1 & 81,92 & 0,19 & $-1,66$ \\
E1 & 8,54 & 0,34 & 7,92 & 0,02 & $-0,62$ & 81,36 & 0,04 & 81,16 & 0,02 & $-0,20$ \\
E2 & 13,68 & 0,04 & 17,98 & 0,11 & 4,30 & 83,23 & 0,9 & 82,84 & 0,03 & $-0,39$ \\
E3 & 9,77 & 0,07 & 7,61 & 0,08 & $-2,16$ & 123,4 & 2,09 & 122,59 & 0,07 & $-0,83$ \\
E4 & 14,11 & 0,44 & 26,93 & 0,24 & 12,82 & 57,06 & 0,46 & 77,91 & 0,14 & 20,85 \\
F1 & 4,9 & 0,84 & 6,34 & 0,10 & 1,44 & 85,08 & 0,44 & 87,12 & 0,10 & 2,04 \\
F2 & 2,51 & 0,06 & 3,05 & 0,04 & 0,54 & 84,5 & 0,37 & 85,05 & 0,25 & 0,55 \\
F3 & 3,2 & 0,08 & 3,79 & 0,01 & 0,59 & 86,16 & 0,52 & 88,59 & 0,07 & 2,43 \\
G & 4,01 & 0,76 & 8,03 & 0,14 & 4,02 & 94,43 & 1,14 & 92,93 & 0,19 & $-1,50$ \\
\hline & & & & & & & & & & \\
\hline
\end{tabular}

Tabla III.47. Variación de las coordenadas cromáticas $\mathrm{C}^{*} \mathrm{y}$ h*, desviación estándar, variación del croma $\left(\Delta \mathrm{C}^{*}\right)$ y variación del tono $\left(\Delta \mathrm{h}^{*}\right)$, de las masillas sometidas a ensayos de envejecimiento artificial en atmósfera de $\mathrm{SO}_{2}$

En cuanto a la variación de tono $(\Delta \mathrm{h} *)$, y analizados los valores $\mathrm{h}^{*}$ inicial y $\mathrm{h}^{*}$ final, se determina con ayuda del diagrama cromático CIELAB la variación de las coordenadas cromáticas de las masillas antes y después de someterlas a ensayo de envejecimiento en atmósfera saturada de $\mathrm{SO}_{2}$. Siendo las variaciones inapreciables al ojo humano a excepción de la masilla de resina epoxídica (E4) que ha virado hacia el amarillo. El resto de las masillas han experimentado un cambio de tono inapreciable o nulo. 


\section{Durometría}

En cuanto a los resultados obtenidos en el ensayo de dureza de las probetas sometidas a envejecimiento acelerado en atmósfera saturada de $\mathrm{SO}_{2}$, pueden verse en la Tabla III.48 y representados en la gráfica III.18.

\begin{tabular}{|c|cc|cc|c|}
\hline Masillas & $\begin{array}{c}\text { Dureza } \\
\text { inicial }\end{array}$ & $\mathrm{S}$ & $\begin{array}{c}\text { Dureza } \\
\text { final }\end{array}$ & $\mathrm{S}$ & $\Delta$ Dureza \\
\hline A1 & 1,94 & 0,59 & 5,6 & 0 & 3,66 \\
A2 & 10,35 & 1,64 & 15,35 & 0,49 & 5,00 \\
A3 & 17,80 & 2,78 & 20,51 & 0 & 2,71 \\
B1 & 0,93 & 0,21 & 1,20 & 0,18 & 0,27 \\
B2 & 3,64 & 0,71 & 2,5 & 0,84 & $-1,14$ \\
B3 & 7,36 & 0,89 & 5,50 & 0 & $-1,86$ \\
C1 & 6,79 & 0,96 & 4,58 & 0,57 & $-2,21$ \\
C2 & 1,91 & 0,45 & 2,70 & 0,47 & $-1,91$ \\
C3 & 6,53 & 0,93 & 7,95 & 1,57 & 1,42 \\
C4 & 10,16 & 1,45 & 13 & 0,4 & 2,84 \\
D1 & 4,44 & 1,22 & 4,78 & 0,54 & 0,34 \\
D2 & 4,32 & 0,96 & 4,91 & 0,26 & 0,59 \\
D3 & 4,57 & 1,19 & 4,8 & 0,71 & 0,23 \\
E1 & 26,56 & 2,86 & 21,55 & 1,24 & $-5,01$ \\
E2 & 24,50 & 1,31 & 31 & 1,41 & 6,50 \\
E3 & 21,65 & 1,09 & 25,74 & 1,56 & 4,09 \\
E4 & 4,37 & 1,10 & 10,64 & 1,10 & 6,27 \\
F1 & 2,48 & 0,30 & 3,73 & 0,35 & 1,26 \\
F2 & 1,94 & 0,36 & 1,63 & 0,21 & $-1,94$ \\
F3 & 0,73 & 0,05 & 1,57 & 0,22 & 0,85 \\
G & 0,70 & 0,00 & 0,7 & 0 & 0,00 \\
\hline
\end{tabular}

Tabla III.47. Dureza (Vickers) de las masillas antes y después de ser sometidas a envejecimiento acelerado en atmósfera saturada con $\mathrm{SO}_{2}$, valores medios, desviación estándar y diferencia total de dureza.

En términos generales las masillas no han experimentado grandes cambios de dureza, a excepción de las masillas compuestas por resina 
acrílica "Paraloid B-72" más carga de carbonato cálcico (A2) y de Microesferas de vidrio (A1) respectivamente, que han aumentado ligeramente su dureza, al igual que la masilla compuesta por resina epoxídica y carbonato de calcio (E2).

\section{VARIACIÓN DE LA DUREZA}

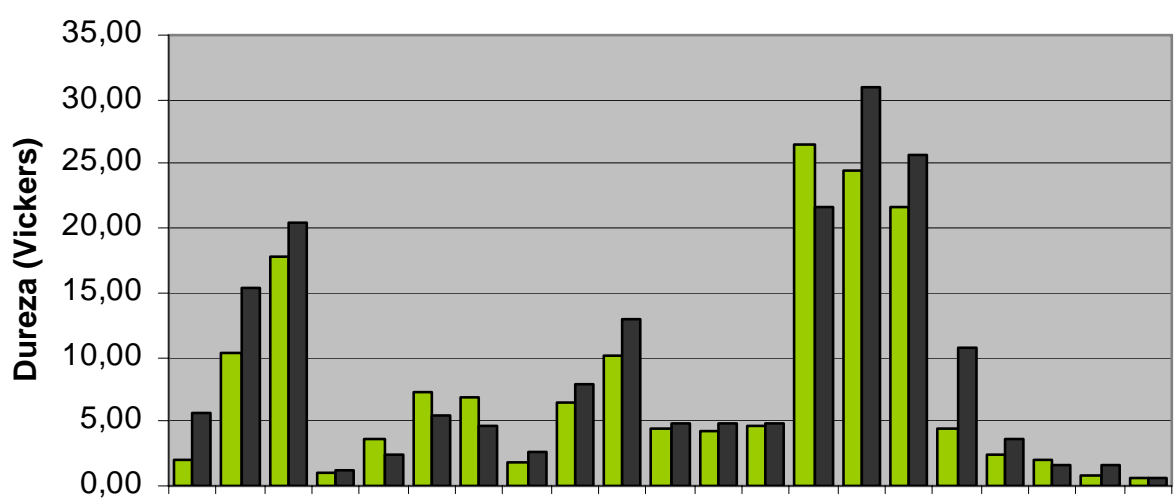

A1 A2 A3 B1 B2 B3 C1 C2 C3 C4 D1 D2 D3 E1 E2 E3 E4 F1 F2 F3 G Masillas 口ORIGINALES $\quad \square \mathrm{SO} 2$

Gráfico III.20. Variación de la Dureza (Vickers) de las masillas antes y después de ser sometidas a envejecimiento acelerado en atmósfera saturada de $\mathrm{SO}_{2}$ 


\section{Espectrometría de Infrarrojos.}

De la información obtenida de los espectros de IR, una vez normalizados y comparados con el programa OPUS se obtuvieron unos parámetros en \% de afinidad entre los espectros de las probetas sin tratar, respecto a las probetas envejecidas.

El envejecimiento acelerado en atmósfera saturada con SO2, produce sulfatación en masillas con $\mathrm{CaCO}_{3}$, polvo de mármol y microesferas de vidrio. Asimismo, produce oxidación en las resina epoxídicas, pero en pequeña cantidad.

En este envejecimiento destacan por su inercia las probetas con yeso o escayola. El estuco E1 (resina epoxídica más microesferas de vidrio) es especialmente sensible a este tipo de oxidación, tal y como se observa en los resultados obtenidos y mostrados en la gráfica siguiente. La E4 (resina epoxídica en pasta EPO 127:k128) ofrece también variaciones destacables aunque algo menores que la E1, mientras que el resto no muestran variaciones significativas.

Todo esto queda representado en el siguiente gráfico: 
AFINIDAD ESPECTROS IR TRAS ENVEJECIMIENTO POR $\mathrm{SO}_{2}$

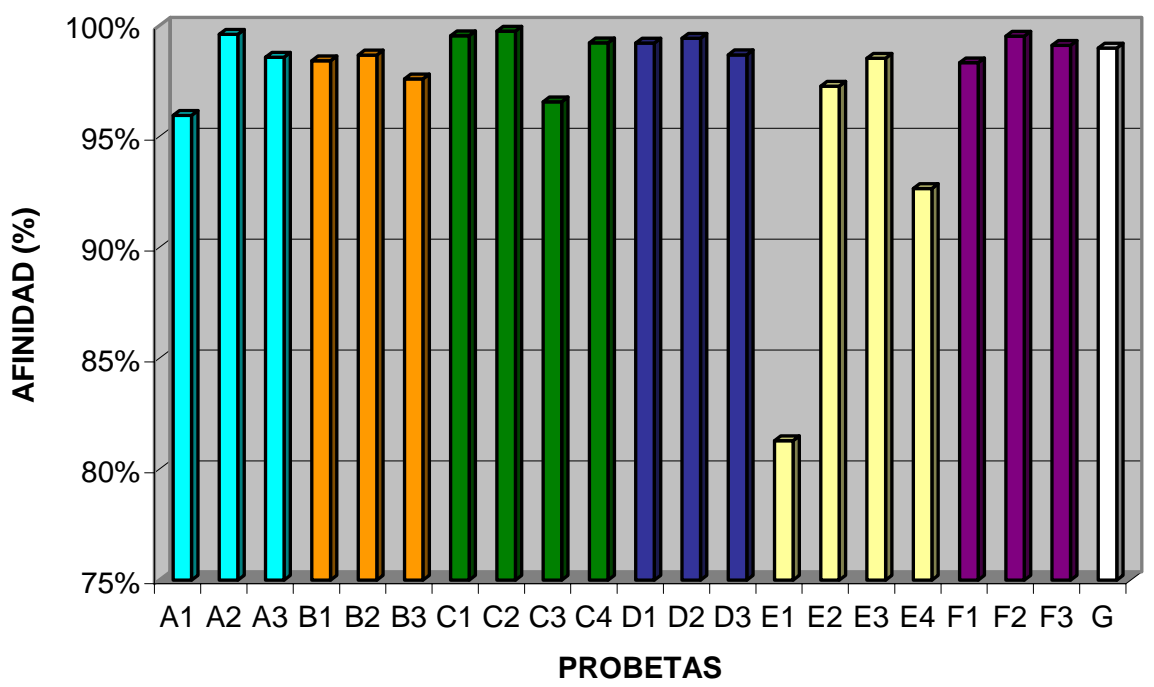

Gráfico III. 21. Afinidad de espectros IR tras el envejecimiento acelerado en atmósfera saturada con $\mathrm{SO}_{2}$ 


\section{III.4.5. CONCLUSIONES}

A continuación se exponen las conclusiones más importantes alcanzadas como resultado de la presente Tesis Doctoral.

\section{1.- De las características cualitativas de las masillas a corto $y$ medio plazo.}

Como hemos podido comprobar mediante la elaboración del Catálogo de Masillas adjunto en el Anexo I de la presente Tesis Doctoral, todas las masillas estudiadas han quedado perfectamente caracterizadas en cuanto a sus propiedades principales que pueden ser relevantes ante el uso de las mismas y su comportamiento a corto y medio plazo.

De todas las masillas estudiadas cabe destacar como óptimas las siguientes:

a) Las escayolas en general, pues todas ellas han demostrado un comportamiento destacado en cuanto a su consistencia, aplicación, tiempo de trabajo, retoque de color, buena adhesión y su baja toxicidad. En particular, de todas ellas, la más idónea ha resultado la escayola ALAMO 70, por su óptima trabajabilidad como consecuencia de su buena aplicación y nivelación. Así las cosas, hay que tener en cuenta que su aplicación indebida sin estrato intermedio en los bordes cerámicos de la laguna a reintegrar con una resina acrílica, puede dar como resultado problemas de reversibilidad y contaminación de sales, dada la propiedad de las 
escayolas de penetrar en los poros de la cerámica y transferirse por higroscopicidad. Salvada esta consideración como consecuencia de una buena práctica profesional en su aplicación, las escayolas se sitúan como una de las mejores opciones tradicionales como estuco en la reintegración de las lagunas cerámicas.

b) La resina acrílica Paraloid B-72 con cargas inertes (microesferas de vidrio, polvo de mármol o carbonato cálcico), la cual destaca por su alta reversibilidad, buena adhesión, buena nivelación tras su secado, consistencia, almacenamiento temporal para su aplicación tras su elaboración. Asimismo, es una masilla trabajable tanto mediante uso del bisturí como de la aplicación de disolventes orgánicos. Todas estas cualidades otorgan al Paraloid B-72 con carga inerte una de las mejores opciones como masilla alternativa. Además, en el caso particular de su aplicación con microesferas de vidrio, supone la solución ideal para la reintegración de lagunas en cerámicas de baja consistencia.

c) Masilla comercial en polvo POLYFILLA que contiene fundamentalmente yeso, la cual aplicada en forma de pasta, es destacable por su consistencia, tiempo de trabajo, buena adhesión, facilidad en la nivelación y pulido, retoque de color y baja toxicidad. De forma similar a lo citado en el caso de las escayolas, la Polyfilla puede dificultar su reversibilidad y transferencia de sales en caso de no aplicarse un estrato intermedio adecuadamente. Asimismo, el desconocimiento de los 
componentes de este estuco comercial, incorpora un cierto grado de incertidumbre a la hora de su aplicación debido a las posibles variaciones que se pueden llegar a presentar entre distintos lotes de fabricación y/o fabricantes de dicha masilla.

d) La resina acrílica en dispersión acuosa ACRIL-33, la cual, al igual que el Paraloid B-72, presenta óptimas propiedades de reversibilidad, buena adhesión, excelente nivelación tras su secado mediante bisturí y/o disolventes orgánicos, consistencia y almacenamiento temporal para su aplicación tras su elaboración. En contra, hay que tener en cuenta su largo tiempo de fraguado.

Por otro lado, es de destacar también de este Catálogo de Masillas, los resultados poco favorables obtenidos en el conjunto de masillas correspondientes a la familia de las masillas comerciales listas para su uso en pasta, las cuales han destacado negativamente en cuanto a su aplicación, ya que de no ser aplicadas de forma muy rigurosa, mediante capas finas, el resultado que ofrecen es un secado muy lento y la generación de grietas internas y superficiales que siempre requieren ser reparadas posteriormente.

Otras masillas cuyo diagnóstico ha resultado desfavorable han sido las de la familia de las Resinas Epoxídicas (E), ya que se presentan niveles de dureza excesivamente altos, son de difícil reversibilidad, su alta toxicidad, su difícil manejabilidad en la aplicación, su largo tiempo de fraguado y sobre todo su gran dificultad en la nivelación. 
Otra conclusión de interés fue el pésimo resultado obtenido con la resina acrílica PLEXTOL B-500 y la resina vinílica MOWILITH SDM5, con las cuales no se pudo conseguir una masilla apta como estuco para la reintegración de las lagunas cerámicas.

\section{2.- De las propiedades de las masillas y su comportamiento previsible a largo plazo}

a) En cuanto a la propiedad de evaporación o pérdida de agua ante escenarios de humedad relativa elevada (normalmente debido a exposiciones accidentales o inadecuadas) se ha observado que las cerámicas islámicas e ibéricas presentan mayores valores de velocidad de evaporación que la mayor parte de las masillas objeto de estudio. La masilla con mayor velocidad de evaporación ha resultado la F3 (mezcla de masillas comerciales preparadas para su uso MODOSTUC y LITEPLAST), lo cual nos indica por un lado un comportamiento higroscópico similar al de las cerámicas islámicas e ibéricas. Del resto de masillas podemos observar diferentes resultados en la velocidad de desorción, con valores medios y bajos, lo cual puede indicar que los materiales que constituyen las masillas o estucos, por permanecer húmedos durante más tiempo que el cuerpo cerámico, se hacen más higroscópicos y por tanto susceptibles de posterior degradación (por colonización de microorganismos o movimiento de sales)

b) Las masillas que se han presentado más inestables o variables en términos de propiedades mecánicas, como consecuencia de la 
aplicación de ensayos de envejecimiento acelerado han sido sin duda alguna las Resinas Epoxídicas, las cuales han visto incrementada su dureza tras su exposición a condiciones ambientales aceleradas de humedad relativa y desecación, irradiación de luz ultravioleta y $\mathrm{SO}_{2}$, Dicha variabilidad en términos de dureza, sugiere como conclusión la inestabilidad de dichas masillas a largo plazo desde un punto de vista de cohesión estructural de la materia.

Por otro lado, las masillas más estables en cuanto a su variación de dureza tras su envejecimiento acelerado por las diferentes técnicas aplicadas han sido las de la familia "D” de la Polyfilla, lo que les confiere una propiedad destacable de estabilidad a largo plazo desde el punto de vista mecánico.

Respecto al resto de masillas, las variaciones observadas de dureza tras los ensayos de envejecimiento acelerado son menores, por lo que no se consideran concluyentes.

c) Desde un punto de vista colorimétrico, las masillas sometidas a envejecimiento acelerado tienden en general a perder su cromatismo original, siendo las más destacables las masillas de la familia E (resinas epoxídicas), por su mayor variación del color total en todas las técnicas de envejecimiento aplicadas. Asimismo, la masilla C4 (escayola HEBODUR) y la G (Cera) destacan también por su variación del color total. 
El resto de las masillas ensayadas presentaron variaciones cromáticas inapreciables ante los ensayos de envejecimiento acelerado, lo cual les confiere en general una buena estabilidad cromática.

d) Por último, los resultados de espectrometría de infrarrojos por transformada de Fourier (FTIR), se muestran a continuación agrupados (Gráfico IV.I) para los tres ensayos de envejecimiento empleados.

Todas las probetas objeto de este estudio, fueron ensayadas para obtener su espectro de IR, el cual se representó gráficamente para su comparativa antes y después del envejecimiento acelerado por los diferentes métodos empleados.

En el anexo 2 de la presente Tesis Doctoral, se muestran los espectros de IR de cada probeta, en los cuales se pueden observar las diferencias entre la probeta original y la envejecida por cada método empleado.

De la información obtenida de los citados espectros de IR, una vez normalizados y comparados con el programa .OPUS se obtuvieron unos parámetros en \% de afinidad entre los espectros de las probetas sin tratar, respecto a las probetas envejecidas mediante los tres métodos empleados: con cambios cíclicos de HR; con atmósfera de $\mathrm{SO}_{2}$; y mediante irradiación UV. 


\section{AFINIDAD ESPECTROS IR ANTES Y DESPUES DE SU ENVEJECIMIENTO}

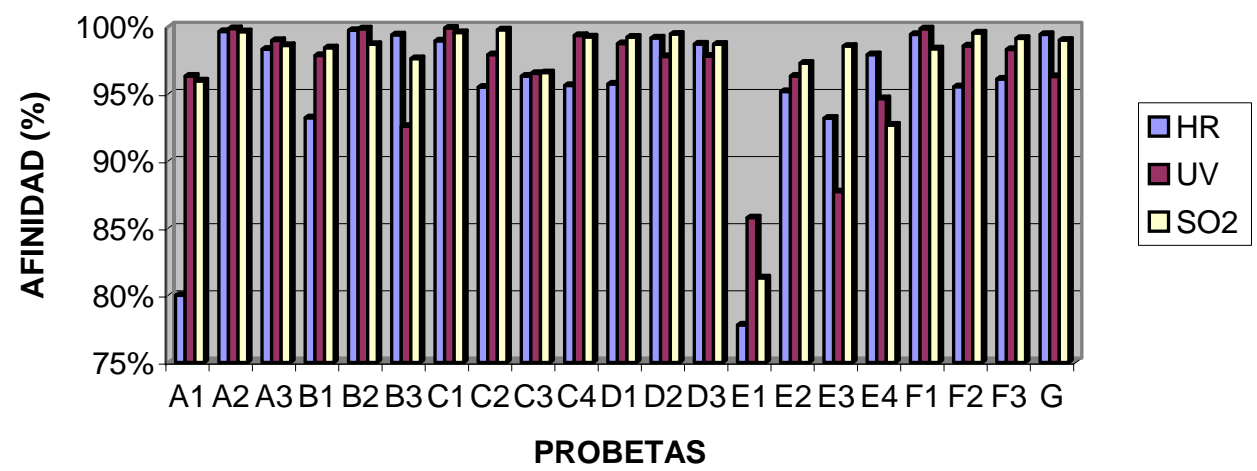

\section{Gráfico IV.I.}

De forma general, y haciendo uso sólo del parámetro de similitud de espectros está claro que la probeta que mayores variaciones globales muestra en lo que se refiere a los tres tipos de envejecimiento es la probeta E1 (Resina epoxídica más microesferas de vidrio). El resto de las probetas elaboradas con resina epoxídica (E2, E3 y E4) se mantienen más o menos estables ante los diferentes parámetros de envejecimiento, aunque alguna otra como la E3 (resina epoxídica más sílice coloidal) sufre bastante ante la irradiación UV. Esto es lógico si consideramos que las resinas epoxídicas suelen mostrar un mal comportamiento a largo plazo en lo que se refiere a estabilidad cromática, lo que también es evidencia de degradación química y fotoquímica. Por otro lado, la resina acrílica A1 (Paraloid B-72 más microesferas de vidrio) también destaca negativamente por su inestabilidad ante el envejecimiento acelerado por HR. 
El efecto más importante cuantitativamente de los tres envejecimientos ensayados es el de los cambios de humedad relativa. Consiste en un aumento casi generalizado en todas las probetas del contenido en agua de humectación. Esto puede indicar que los materiales que constituyen las probetas se hacen más higroscópicos y por tanto susceptibles de posterior degradación (por colonización de microorganismos o movimiento de sales).

El envejecimiento por UV ha resultado el que menos ha afectado al conjunto de probetas, si exceptuamos las masillas con resinas epoxídicas que por lo general cambian química y cromáticamente.

\section{3.- De la evaluación y diagnóstico sobre la idoneidad de las masillas. Las mejores y las peores.}

Como consecuencia de las conclusiones comentadas en los dos puntos anteriores, los estucos más idóneos a todos los efectos (corto, medio y largo plazo), usando los criterios de selección aquí expuestos, serían: la Polyfilla (D), las Escayolas Alamo 70 (C) y las resinas acrílicas (B y A), excepto la A1, debido a su inestabilidad química ante el envejecimiento acelerado por HR (observado en ensayo FTIR)

Por el contrario, las masillas más desfavorables a todos los efectos han resultado ser: las Resinas Epoxídicas, la Escayola Hebodur (C4), y la Cera $(G)$, 


\section{4.- De la comparación entre las masillas tradicionales y sus alternativas actuales.}

Las masillas tradicionales ensayadas han sido las escayolas, las cuales han ofrecido en general un buen resultado como masillas para la reintegración de lagunas en restauración cerámica de tipo arqueológico, tanto desde el punto de vista de su aplicación (trabajabilidad y comportamiento a corto y medio plazo) como desde el punto de vista de estabilidad mecánica, física y química (largo plazo). Como única excepción encontrada, cabe destacar la escayola HEBODUR (C4), en la cual se ha experimentado resultados desfavorables a largo plazo, sobre todo en cuanto a inestabilidad cromática, lo cual junto a su condición de la menos favorable de las escayolas en términos de trabajabilidad y comportamiento a corto y medio plazo, nos hace concluir su catalogación como no recomendable para el uso como reintegrante volumétrico en el tipo de cerámica objeto de este estudio.

Las masillas alternativas ensayadas más recomendables en opinión de la Doctoranda, a tenor de los resultados obtenidos, son sin duda las de la familia de la Polyfilla, por su buena estabilidad mecánica. No obstante, las masillas alternativas de la familia de las resinas acrílicas, dado que no han presentado resultados de inestabilidad relevante a largo plazo, salvo en el caso de la A1 (Paraloid B-72 más microesferas de vidrio), son también consideradas como óptimas para la restauración de piezas de cerámica arqueológica. 
Por otro lado, las masillas comerciales preparadas para su uso en pasta, si bien han sido catalogadas como poco favorables en términos de trabajabilidad, los resultados de estabilidad ante los ensayos de envejecimiento acelerado no han presentado resultados desfavorables.

Como conclusión final, cabe destacar los óptimos y satisfactorios resultados de las escayolas, los cuales confieren a estas masillas tradicionales unas propiedades para la restauración, tan aptas o más como las de las masillas alternativas más extendidas en la práctica actual de la Restauración Cerámica arqueológica (Polyfilla y Paraloid). 





\section{BIBLIOGRAFÍA}

AAVV., La conservación en excavaciones arqueológicas. Ministerio de Cultura. ICCROM.1984.

Arqueología, restauración y conservación. Hondarribia: Nerea, D.L. 2002.

"Actuaciones y Servicios para la conservación del Patrimonio Artístico (IAPH 1999-2001)” En: Boletín del Instituto Andaluz del Patrimonio Histórico, No 39, Sevilla, Junio 2002.

., Science for conservators: Adhesives and coatings. Conservation Science Teaching Series. Museums \& Galleries Commission. Londres, 1999.

., Rehabilitación de la azulejería en la Arquitectura. Ponencias del Seminario celebrado en Valencia del 25-27 de noviembre de 1993. Asociación de ceramología, 1995.

ACTON, L., MCAULEY, P., Restauración de loza y porcelana. Ed. Gustabo Gil. Barcelona, 1997.

ALEJANDRE, F.; VILLEGAS, R.; JURADO,M., “Evaluación del comportamiento de materiales empleados en la reintegración 
de materiales cerámicos de la Plaza de España” (Sevilla). Materiales de construcción (Madrid). 2005.

ANDREEVA, T., "On the possibility of using burnt ceramic masses for making up damage ceramics". En: The ceramics cultural heritage: proceedings of the international symposium...,. Florence, Italy, June 28-July2, 1994. Vincenzini, P (ed.); Faenza: TECHNA, 1995, P. 739-746.

ANGELLOTTO, D., FRANCOLINI, S., KUMAR, F., MORADEI, R., VACCARI, MG; “L'uso delle resine per l'integrazione delle lacune della terracota invetriata e il montaggio meccanico: due esperienza recenti” En: OPD restauro, N.14, 2002,

ARNOLD, A., "Determination of mineral salts from monuments” En: Studies in Conservation, n 29, 1984.

ASHURST,J., ASHURST, N., Brick, terracotta and earth. Aldershot. Gower, 1989.

AURA, E., Desarrollo de procedimientos metodológicos para la caracterización, restauración y conservación de piezas cerámicas medievales (siglos XVIII-XV) de Paterna y Manises. Tesis Doctoral. Universidad Politécnica de Valencia, 1996.

Aura, E., Domenech, $\mathrm{M}^{\mathrm{a}}$ T., "Evaluación de adhesivos cerámicos ensayados, estudio comparativo de sus características" En: XII Congreso de Conservación y Restauración de Bienes Culturales. Alicante, 1998, pp.211-219.

BALCAR, N., BOURGEOIS, B., DENOYELLE, M., MERLIN, C., «Les vases grecs de Gustave Moreau: ètude et restauration.= the Greek vases of Gustave Moreau : study and restauration ». En: La revue des musées de France: revue du Louvre $n^{\circ} 5$. Diciembre 2005, pp.35-45. 
BALDINI, U., Teoría de la restauración y unidad metodológica. Vol I y II, Ed. Nerea. Madrid, 1997.

BANDINI, G., "Intorno al restauro di un bucchero etrusco". En: Kermes. Arte e técnica del restauro, Anno 5,N 14, 1992, pp.3240.

BAROZ, Z., LAMBERT, F., "Mechanical properties of some fill materials for ceramic conservation". En: Preprints ICOM $7^{\text {th }}$ Triennial Meeting, Copenhagen, 10-14 September, ICOM, 1984.

BAROZ, Z., “ The reconstruction of a Greek vase: the Kyknos Kraker”. En: Studies in Conservation, no 33, 1988 , pp. 165-177

BARRIO, J., “ Proceso de conservación y restauración de cerámicas arqueológicas” En: Estudios de Prehistoria y Arqueología Madrileñas. 1987, pp. 53-68.

BEJÍN, P., KAMINSKA, E., “Termal accelerated ageing test method development”. En: Restaurator. $n^{\circ}$ 23, 2002, p. 89-105. BERDUCOU, M.C., La conservation en archéologie. Ed. Masson, Paris, 1990.

BONETTI, S;LANTERNA, G., MICHELUCCI, M., TOSINI, I; «Il restauro dei bacini ceramici del Duomo di San Miniato in Pisa: tecniche e metodi di integrazione per la cerámica” En: OPD restauro, N.12, 2000.

BRADLEY, S., GREEN, L., "Materials for filling and retouching ceramics". En: Preprints ICOM $7^{\text {th }}$ Triennial Meeting, Copenhagen, September, 1984.

BRANDI, C., Teoría de la Restauración. Ed. Alianza. Madrid 1993. 
BUYS, S., OAKLEY, V., Conservation and Restoration of Ceramics. Ed. Butterworth Heinemann, Oxford, 1996.

CARRASCOSA, B., Investigación sobre tratamientos de Conservación y Restauración de piezas cerámicas y arqueológicas. Tesis Doctoral. Universidad Politécnica de Valencia, 1995.

CARRASCOSA, B., Iniciación a la conservación y restauración de objetos cerámicos. Ed. Universidad Politécnica de Valencia. 2006.

CARRASCOSA, B., LASTRAS, M., La Conservación y Restauración de la Azulejería. Ed. Universidad Politécnica de Valencia. 2006.

CAROCA, R, A., "Barnices sintéticos: estudio comparativo de barnices sintéticos utilizados en la restauración de cerámicas”. En: Conserva, $\mathrm{n}^{\circ}$ 2, 2002, pp.29-46

CASADIO, R., "Alcuni interventi di restauro: da problematiche specifiche a considerazioni generali sul restauro della ceramica" En: Il Restauro all'Istituto Statale d'Arte per la cerámica di Faenza. Banca del Monte e Cassa di Risparmio di Faenza. Faenza, 1993.

CAVALLI, G., EMILIANI, G., "La decorazione e la formatura nella riesecuzione e nell'integrazione dei reperti ceramici”. En: Il Restauro all'Istituto Statale d'Arte per la cerámica di Faenza. Banca del Monte e Cassa di Risparmio di Faenza. Faenza, 1993.

CHOI, J; Consolidation and infilling materials for stabilizing fragile stoneware figure. Queen's University. Department of art. Dingston, Canada, Kingston: Queen’s University, 2002. 
COLL, C. J., "Museo Nacional de Cerámica: criterios de restauración” En: Restauración \& Rehabilitación. N ${ }^{\circ}$ 89, julio 2004, pp. 50-55.

Museo Nacional de Cerámica: criterios de restauración. Restauración \& Rehabilitación, N.89. 2004. pp.5055.

CRAFT, ML., SOLZ, J, A., "Comercial vinyl and acrylic fill materials" En: Journal of the Americn Institute for Conservation, $\mathrm{n}^{\circ}$ 37, 1998, pp. 23-34.

CRUZ, A., GUEVARA, Ma . E., CYPHERS, A., “La restauración de la cerámica olmeca de San Lorenzo Tenochtitlan, Veracruz, México: teoría y práctica”. En: 13th trienal meeting Rio de Janeiro, 22-27 September 2002. Ed. James \&James.2002, pp.829-834.

CRUZ, L., MAGAR, V., "Algunos aspectos de la historia de la restauración de los objetos cerámicos en México: materiales, procesos y criterios”. En: El Correo del Restaurador $n^{\circ} 5$. Instituto Nacional de Antropología e Historia.

DAVISON, S., "Reversible fills for transparent and translucent materials" En: Journal of the American Institute for Conservation, $\mathrm{n}^{\circ}$ 37, 1998, pp.35-47

DAVIDSON, S., SMOLDERS, H. F., "Restoring Japanese porcelain vases”. En: Conservation News, $n^{0}$ 91. Julio 2004, pp. 24-26.

DEL FRANCIA, P R., "Centro di restauro, Soprintendenza archeologica per la Toscana, Florence, Italy” En: Glass \& ceramics conservation, $\mathrm{n}^{\circ} 2,1997, \mathrm{pp} .8-11$. 
DOWN, J.L., "The yellowing of epoxy resin adhesives; report on natural dark aging”. En: Studies in Conservation, n 29, 1984, pp. 63-76.

"The yellowing of epoxy resin adhesives; report on high-intensity light aging”. En: Studies in Conservation, $\mathrm{n}^{\circ}$ 31, 1986, pp. 159-170.

DOUGHTY, D.H., "Applications of light cured composite resins as fill material" En: Newsletter (Western Association for Art Conservation). № 8, Septiembre 1986.

ELSTON, M., "Technical and aesthetic considetations in the conservation of ancient ceramic and terracotta objects in the L. Paul Getty Museum: Five case studies" En: Studies in Conservation, $\mathrm{n}^{0}$ 35, 1990, pp. 69-80.

ELSTON, M., “A corrective treatment on a $6^{\text {th }}$ centuryBc Attic Krater” En: Interim Meeting of the ICOM-CC Working Group” September 13-16, 1998 Vantad, Finland, pp. 106-114.

FABBRI, B., RAVANELLI, C., Il Restauro della Ceramica. Ed. Nardini, Firenze, 1993.

FLORES-ALÉS, V., HERRERA, A., VÁZQUEZ, A I., “ Propuestas de conservación de azulejos a partir de su caracterización físico-química” En: Boletín del Instituto Andaluz del Patrimonio Histórico. № 37, Sevilla, 2001. p.79 - 83.

FLOS, N., Memoria d'activitats del centre de conservació $i$ restauració de béns mobles de la Generalitat de Catalunya (1982-1988). Ed. Generalitat de Catalunya, Barcelona, 1988.

FRAGIADAKI, I., “ Research on tinted epoxy resins (epoxi putties) used as fillers on porcelain artefacts: preparation testing 
of their to porcelain, artificial aging”. En: Glass and ceramics conservation, N.4, 1998, p.5-7,

GÄNSICKE, S., HIRX, J., “A translucent was-resin fill material for the compensation of losses in objects” En: Objects Specialty Group postprints (American Institute for Conservation of Historic and Artistic Works).Washintong 1995, pp. 94-116.

GERONAZZO, D., GERMAIN-BONNE, D., “ Porurquoi coller et retoucher? Actualité, réflexions méthodologiques, déontologiques.(Why adhere and retouch? Current techonologies, methodologicl and ethical reflections". En: Conservation et retauration du patrimoine culturel, $\mathrm{n}^{0} 15,2005$, pp.34-37.

GESCHKE, R., “Ceramic gap-fills for ceramic restoration”. En: The conservator, $\mathrm{n}^{\circ}$ 28, 2004, pp. 74-83.

GÓMEZ, M. L., La restauración. Examen científico aplicado a la conservación de obras de arte. Ed. Catedra (Cuadernos de arte) e IPHE. Madrid, 1998.

GOODOY, L., "Investigation into core fills and crackle barniz for use within ceramic conservation" En: Conservation news: UKIC, $\mathrm{N}^{\circ} 61,1996$, pp. 44-47.

HATCHFIELD, P., "Note on a fill material for water sensitive objects”. En: JAID vol. 25, 1986, pp. 93-96.

HOGAN, L., BUTLER, L., COOPER, J.,ELLIOTT, K., "Reconstructing major missing areas of ceramic vessels using clay" Triennial meeting $\left(11^{\text {th }}\right)$. Edinburgh, 1-6 September 1996: En: preprints/ICOM. Committee for Conservation. Paris, France. London: James \& James, 1996 p. 
HORIE, C.V., Materials for conservation. Organic consolidants, adhesives and coatings. Ed. Butterworthheinemann, Oxford, 1999.

ILLANES, K. M., ALVAREZ, P \& R. V., "Restauración de alfarería prehispánica: intervenciones en vasijas del cementerio Metro Estación Quinta Normal”. En: Conserva: revista del Centro Nacional de Conservación y Restauración, $n^{0}$ 7. 2003, pp. 65-84.

JIANG, D., "Restoration of ancient ceramics". En: Sciences of Conservation and Archaeology, $\mathrm{n}^{\mathrm{0}}$ 16, 2004, pp.56-59.

JORDAN, Fi., "The practical application of tinted epoxy resins for filling, casting and retouching porcelain". En: The conservation News, nº 59, 1996.

"The practical application of tinted epoxy resins for filling, casting and retouching porcelain". En: The conservation of glass and ceramics: research, practice and training. Ed: Tennent, Norman H; London: James \& James, 1999, p.138-145.

KOOB, S. P., "Instability of cellulose nitrate adhesives". En: The Conservator, $\mathrm{n}^{\circ}$ 6, 1982, pp.6:31-3.

"The use of Paraloid B-72 as an adhesive: it is application for archaeological ceramics and other materials". En: Studies in Conservation, nº31, 1986. pp. 7-14.

«Detachable plaster restorations for archaeological ceramics» En: Recents advances in the Conservation and Analysis of Artifacts. Jubilee consevation conference, London 6-10 July 1987. Ed. J.W.B. Black. Institute 
of archaeology Summer Schools Press. London, 1987, pp. 6365.

“ Obsolete fill materials found on ceramics” En:

Journal of the American Institute for Conservation, $\mathrm{n}^{0}$ 37, 1998, pp.49-67.

"Four beakers or two beakers? Only your conservator knows for sure..." En: Objets Specialty Group postprints (American Institute for conservation of Historic and Artistic Works. 2002, pp. 114-130.

LARNEY, J., Restoring ceramics. British Museum Publications, London, 1975.

"Ceramic Restoration in the Victorian and Albert Museum”. En: Studies in Conservation, n 16, 1971.

LEGORBURU, $\mathrm{M}^{\mathrm{a}}$. P., Criterios sobre la reintegración de lagunas en obras de arte y transcendencia del estuco en el resultado final según su composición y aplicación. Servicio Editorial Universidad del País Vasco. Serie Tesis Doctorales. 1992.

LOEW, M., SOLZ, J., "Comercial vinyl and acryl fill materials”. En: JAIC, No 37, 1998, PP. 23-.

MACARRÓN, A.M., Historia de la conservación y la restauración desde la antigüedad hasta finales del siglo XIX. Ed. Tecnos, Madrid, 1995

Historia de la conservación y la restauración desde la antigüedad hasta el siglo XX. Ed. Tecnos, Madrid, 2002. 
MARTÍN, A., Ensayos y experiencias de alteración en la conservación de obras de piedra de interés histórico artístico. Fundación Ramón Areces, Madrid, 1990.

MARTÍNEZ, A. "Los hornos ibéricos de Las Casillas del Cura (Venta del Moro), Alcoi: Recerques del Museo 6, 1997, pp.6169.

MARTÍNEZ, A, et al. "La producción de ánforas en el alfar ibérico de Casillas del Cura”. En: III Reuniò sobre economía en el món ibèric, Saguntum-PLAV, Extra 3, Valencia. 2000.

MELUCCO, A., PRUNAS, E., SOMON, M., NUGARI, M.P., "La reintegrazione della cerámica da scavo". En: Bolletino del Museo Internacionales delle ceramica di Faenza, no 1-3, Faenza editrice, 1989.

MORENO, M". ${ }^{\mathrm{a}}$ DAVILA., "Estudio de antiguas intervenciones de restauración en los distintos objetos, llevadas a cabo en el Museo Arqueológico Nacional desde su fundación. Evolución de los criterios y productos empleados”. En: X Congreso de Conservación y Restauración de Bienes Culturales. Cuenca, 1994, pp.337-348.

NAGY, E.; "A reversible structural fill of decreasing compressive strength for a large, decayed wooden sculpture". En: Journal of the Canadian Association for Conservation, Vol. 23, 1998, p.20-25.

"Fill for white marble: properties of seven fillers and two thermosetting resins". En: Journal of the American Institute for Conservation, Vol. 37, n.1, 1998, p.68-87. 
NEWTON, R., DAVISON, S., Conservation of glass. Butterworths, London, 1989.

OAKLEY, V. L., JAIN, K. K., Essentials in the Care and Conservation of Historical Ceramic Objects. Ed. Archetype publications. London, 2002.

OMNÈS, O., "Du raccommodeur au conservateur-restaurateur: une approche de l'histoire de la restauration de la céramique". En: Techne: la science au service de l'histoire de l'art et des civilisations, N. 16, 2002, p. 109-112.

PANTELLI, K., “A comparative study testing various media used for gap filling glazed ceramics” En Conservation news, $\mathrm{N}^{\circ}$ 70, 1999, p. 21-25

PASCUAL, E., PATIÑO, M., Cerámica y porcelana. Ed: Parramón. Barcelona, 2004.

PEDELI, C., "Pulitura con ablatore ad ultrasuoni di ceramiche archeologiche: calibrazione dello strumento e medda a punto della técnica”. En Lo stato dell'arte 2: conservazione e restauro confronto di esperienze. Palazzo Reale, Genova, 27-29 Septiembre 2004. Grupo Italiano IIC. pp. 136-149.

PLENDERLEITH, H. J., WERNER, A.E.A., The conservation of antiquities and works of art. Ed. University Press. Oxford, 1971.

PYE, E., Caring for the Past: issues in conservation for archaeology and museums. Ed. James \& James, London, 2001.

SIMPSON, M.T., Restauración y conservación de antigüedades. Ed. Celeste. Madrid, 1996. 
SMITH, S., "Filling and painting of ceramics for exhibition in the British Museum: is it aceptable?” En: Restoration: is it acceptable?" (British Museum Occasional Paper, 99) Ed. Oddy, A., British Museum Press, 1994, p. 159-169.

"British Bronze Age pottery: an overview of deterioration and current techniques of conservation at the British Museum” En The conservator, n 22, 1989, p.p. 3-11.

SMOLDERS, H., "Restoring Japanese porcelain vases" En: Conservation news: UKIC, No 91, 2004, P. 24-26.

SOHEIL, M., "Criteria and intervention in tiled surfaces: the case of Iran”. En: El estudio y la conservación de la cerámica decorada en arquitectura: un compendio de colaboraciones, Roma, Enero 2001- Junio 2002.ICCROM conservation studies, Rome, 2003, p. 79-85.

VAN LOOKEREN CHAMPAGNE, K., “ The training of ceramic and glass conservators/restorers at the Netherlands Institute for Cultural Heritage" En: The conservation of glass and ceramics: research, practice and training. Ed. James \& James, London, 1999, p. 259-265,

WILLIANS, N., "Pottery restoration: an account of spinnig technique used in the British Museum” En: The conservator, $\mathrm{n}^{\circ}$ 4, London, 1980, pp.34-37. 



\begin{tabular}{|c|c|c|c|c|c|c|c|}
\hline REFERENCIA & \multicolumn{5}{|c|}{ MASILLA } & \multicolumn{2}{|c|}{$\mathbf{N}^{0}$} \\
\hline & \multicolumn{5}{|c|}{ ALAMO 70/1 } & \multicolumn{2}{|c|}{1} \\
\hline COMPOSICIÓN & \multicolumn{7}{|c|}{$\begin{array}{l}\text { Escayola “Alamo 70” (1 Vol.) } \\
\text { Agua (1 Vol.) }\end{array}$} \\
\hline PREPARACIÓN & \multicolumn{7}{|c|}{$\begin{array}{l}\text { Sobre el agua se tamiza la escayola, transcurridos } 15 \text { "' } \\
\text { se agita otros } 15 \text { "' }\end{array}$} \\
\hline \multirow{2}{*}{$\begin{array}{l}\text { CONSISTENCIA Y } \\
\text { APLICACIÓN }\end{array}$} & Líquida & $\mathbf{X}$ & Espesa & $\mathbf{X}$ & Pastosa & & $\mathbf{X}$ \\
\hline & Inyección & $\mathbf{X}$ & Vertido & $\mathbf{X}$ & Espátula & & $\mathbf{X}$ \\
\hline T. DE TRABAJO & \multicolumn{7}{|l|}{$17^{\prime}$} \\
\hline T. DE SECADO & \multicolumn{7}{|l|}{8 horas } \\
\hline CONTRACCIÓN & Alta & $\mathbf{X}$ & Media & & \multicolumn{3}{|l|}{ Baja } \\
\hline POROSIDAD & Alta & & Media & $\mathbf{X}$ & \multicolumn{2}{|l|}{ Baja } & \\
\hline DUREZA & Alta & & Media & & \multicolumn{2}{|l|}{ Baja } & $\mathbf{X}$ \\
\hline ADHESIÓN & Buena & & Media & $\mathbf{X}$ & \multicolumn{2}{|l|}{ Mala } & \\
\hline NIVELACIÓN Y & Buena & $\mathbf{X}$ & Media & & \multicolumn{2}{|l|}{ Mala } & \\
\hline PULIDO & Bisturí & $\mathbf{X}$ & Lija & $\mathbf{X}$ & \multicolumn{2}{|l|}{ Otros } & \\
\hline RETOQUE & \multicolumn{7}{|c|}{ Pinturas de todo tipo. } \\
\hline & \multicolumn{5}{|c|}{ VENTAJAS/INCONVENIENTES } & $\mathbf{V}$ & I \\
\hline \multicolumn{7}{|l|}{ ELABORACIÓN } & $\mathbf{X}$ \\
\hline \multicolumn{6}{|c|}{ SE CONOCEN LOS MATERIALES Y PROPORCIONES } & $\mathbf{X}$ & \\
\hline \multicolumn{6}{|c|}{ APLICACIÓN } & $\mathbf{X}$ & \\
\hline \multicolumn{6}{|c|}{ NIVELACIÓN Y PULIDO } & $\mathbf{X}$ & \\
\hline \multicolumn{6}{|c|}{ TIEMPO DE TRABAJO } & $\mathbf{X}$ & \\
\hline \multicolumn{6}{|c|}{ TIEMPO DE SECADO } & $\mathbf{X}$ & \\
\hline \multicolumn{6}{|c|}{ CONTRACCIÓN/AGRIETAMIENTO } & & $\mathbf{X}$ \\
\hline \multicolumn{6}{|l|}{ DUREZA } & & $\mathbf{X}$ \\
\hline \multicolumn{6}{|l|}{ POROSIDAD } & & $\mathbf{X}$ \\
\hline \multicolumn{6}{|c|}{ ADHESIÓN AL CUERPO CERÁMICO } & & $\mathbf{X}$ \\
\hline \multicolumn{6}{|l|}{ RETOQUE } & $\mathbf{X}$ & \\
\hline \multicolumn{6}{|l|}{ ALMACENAJE } & & $\mathbf{X}$ \\
\hline \multicolumn{6}{|l|}{ REVERSIBILIDAD } & & $\mathbf{X}$ \\
\hline OBSERVACIONES & $\begin{array}{ll}\text { Secado } 1 \\
\text { consistenci }\end{array}$ & $\begin{array}{l}\text { go. } \\
\text { Pulv }\end{array}$ & $\begin{array}{l}\text { Retracci } \\
\text { arulencia. }\end{array}$ & & perficial. & & aja \\
\hline VALORACIÓN & & NO & PTA $/ / \mathbf{R E}$ & IAZ & DA & & \\
\hline
\end{tabular}




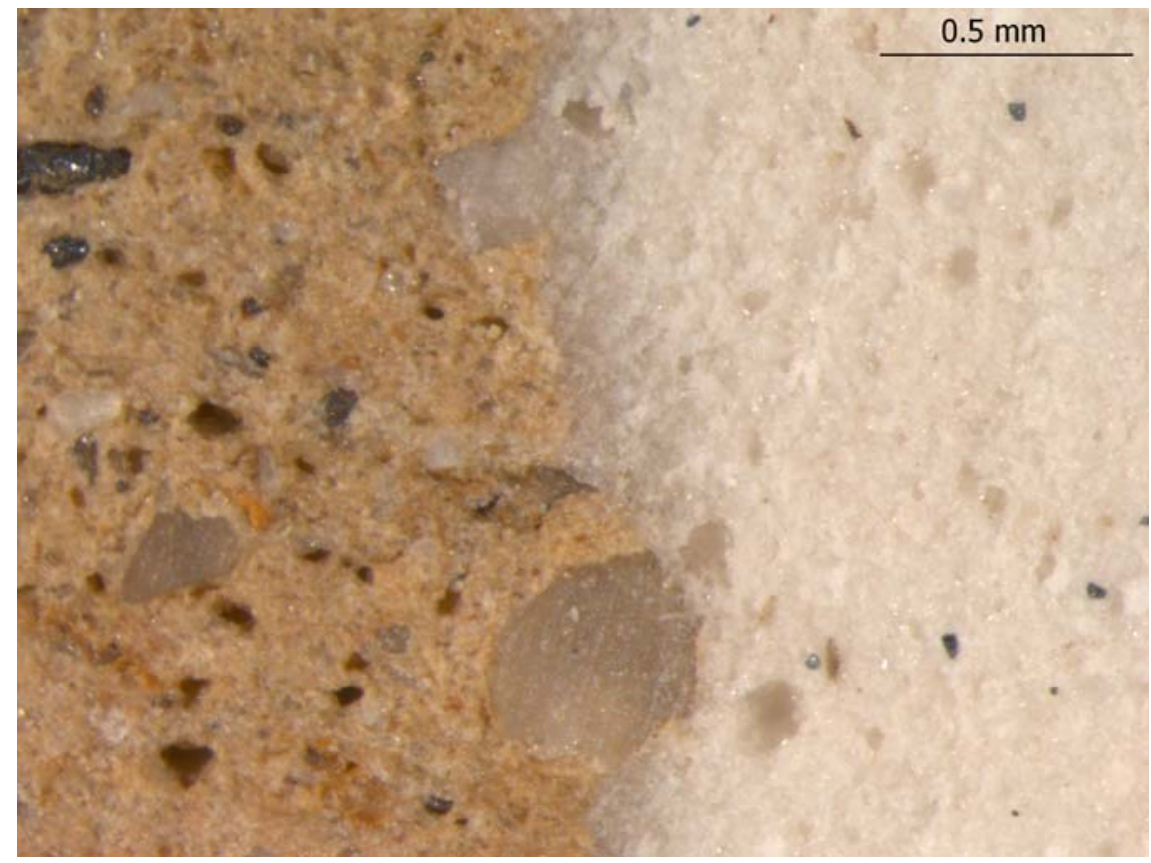

Figura 1. Escayola C3 y cerámica época Islámica. 


\begin{tabular}{|c|c|c|c|c|c|c|c|}
\hline REFERENCIA & \multicolumn{5}{|c|}{ MASILLA } & \multicolumn{2}{|c|}{$\mathrm{N}^{\circ}$} \\
\hline C3 & \multicolumn{5}{|c|}{ ALAMO 70/2 } & \multicolumn{2}{|c|}{2} \\
\hline COMPOSICIÓN & \multicolumn{7}{|c|}{$\begin{array}{l}\text { Escayola “Alamo 70” (2 Vol.) } \\
\text { Agua (1 Vol.) }\end{array}$} \\
\hline PREPARACIÓN & \multicolumn{7}{|c|}{$\begin{array}{l}\text { Sobre el agua se tamiza la escayola, transcurridos } 15 \text { "' } \\
\text { se agita otros } 15 \text { ", }\end{array}$} \\
\hline \multirow{2}{*}{$\begin{array}{l}\text { CONSISTENCIA Y } \\
\text { APLICACIÓN }\end{array}$} & Líquida & $\mathbf{X}$ & Espesa & $\mathbf{X}$ & Pastosa & & $\mathbf{X}$ \\
\hline & Inyección & $\mathbf{X}$ & Vertido & $\mathbf{X}$ & Espátula & & $\mathbf{X}$ \\
\hline T. DE TRABAJO & \multicolumn{7}{|l|}{$8-10^{\prime}$} \\
\hline T. DE SECADO & \multicolumn{7}{|l|}{4 horas } \\
\hline CONTRACCIÓN & Alta & & Media & & \multicolumn{2}{|l|}{ Baja } & $\mathbf{X}$ \\
\hline POROSIDAD & Alta & & Media & $\mathbf{X}$ & \multicolumn{2}{|l|}{ Baja } & \\
\hline DUREZA & Alta & & Media & $\mathbf{X}$ & \multicolumn{2}{|l|}{ Baja } & \\
\hline ADHESIÓN & Buena & $\mathbf{X}$ & Media & & \multicolumn{2}{|l|}{ Mala } & \\
\hline NIVELACIÓN Y & Buena & $\mathbf{X}$ & Media & & \multicolumn{2}{|l|}{ Mala } & \\
\hline PULIDO & Bisturí & $\mathbf{X}$ & Lija & $\mathbf{X}$ & \multicolumn{2}{|l|}{ Otros } & $\mathbf{X}$ \\
\hline \multirow[t]{2}{*}{ RETOQUE } & \multicolumn{7}{|c|}{ Pinturas de todo tipo. } \\
\hline & \multicolumn{5}{|c|}{ VENTAJAS/INCONVENIENTES } & $\mathrm{V}$ & I \\
\hline \multicolumn{6}{|l|}{ ELABORACIÓN } & & $\mathbf{X}$ \\
\hline \multicolumn{6}{|c|}{ SE CONOCEN LOS MATERIALES Y PROPORCIONES } & $\mathbf{X}$ & \\
\hline \multicolumn{6}{|l|}{ APLICACIÓN } & $\mathbf{X}$ & \\
\hline \multicolumn{6}{|c|}{ NIVELACIÓN Y PULIDO } & $\mathbf{X}$ & \\
\hline \multicolumn{6}{|c|}{ TIEMPO DE TRABAJO } & $\mathbf{X}$ & \\
\hline \multicolumn{6}{|c|}{ TIEMPO DE SECADO } & $\mathbf{X}$ & \\
\hline \multicolumn{6}{|c|}{ CONTRACCIÓN/AGRIETAMIENTO } & $\mathbf{X}$ & \\
\hline \multicolumn{6}{|l|}{ DUREZA } & $\mathbf{X}$ & \\
\hline \multicolumn{6}{|l|}{ POROSIDAD } & $\mathbf{X}$ & \\
\hline \multicolumn{6}{|c|}{ ADHESIÓN AL CUERPO CERÁMICO } & $\mathbf{X}$ & \\
\hline \multicolumn{6}{|l|}{ RETOQUE } & $\mathbf{X}$ & \\
\hline \multicolumn{6}{|l|}{ ALMACENAJE } & & $\mathbf{X}$ \\
\hline REVERSIBILIDAD & & & & & & & $\mathbf{X}$ \\
\hline OBSERVACIONES & $\begin{array}{l}\text { La nivelac } \\
\text { su rápido s }\end{array}$ & & ejecut & & amente & & \\
\hline VALORACIÓN & & & TAA/ENs & $\mathbf{A D}$ & & & \\
\hline
\end{tabular}




\begin{tabular}{|c|c|c|c|c|c|c|c|}
\hline REFEREN & \multicolumn{5}{|c|}{ MASILLA } & \multicolumn{2}{|c|}{$\mathbf{N}^{\circ}$} \\
\hline & \multicolumn{5}{|c|}{ ALAMO 70/3 } & \multicolumn{2}{|l|}{3} \\
\hline COMPOSICIÓN & \multicolumn{7}{|c|}{$\begin{array}{l}\text { Escayola “Alamo 70” (3 Vol.) } \\
\text { Agua (2 Vol.) }\end{array}$} \\
\hline PREPARACIÓN & \multicolumn{7}{|c|}{$\begin{array}{l}\text { Sobre el agua se tamiza la escayola, transcurridos } 15 \text { "' } \\
\text { se agita otros } 15,\end{array}$} \\
\hline \multirow{2}{*}{$\begin{array}{l}\text { CONSISTENCIA Y } \\
\text { APLICACIÓN }\end{array}$} & Líquida & $\mathbf{X}$ & Espesa & $\mathbf{X}$ & Pastosa & & $\mathbf{X}$ \\
\hline & Inyección & $\mathbf{X}$ & Vertido & $\mathrm{X}$ & Espátula & & $\mathbf{X}$ \\
\hline T. DE TRABAJO & \multicolumn{7}{|l|}{5} \\
\hline T. DE SECADO & \multicolumn{7}{|l|}{3 horas } \\
\hline CONTRACCIÓN & Alta & & Media & & \multicolumn{2}{|l|}{ Baja } & $\mathbf{X}$ \\
\hline POROSIDAD & Alta & & Media & & \multicolumn{2}{|l|}{ Baja } & $\mathbf{X}$ \\
\hline DUREZA & Alta & & Media & $\mathbf{X}$ & \multicolumn{2}{|l|}{ Baja } & $\mathbf{X}$ \\
\hline ADHESIÓN & Buena & $\mathbf{X}$ & Media & & \multicolumn{2}{|l|}{ Mala } & \\
\hline NIVELACIÓN Y & Buena & & Media & $\mathbf{X}$ & \multicolumn{2}{|l|}{ Mala } & \\
\hline PULIDO & Bisturí & $\mathbf{X}$ & Lija & $\mathbf{X}$ & \multicolumn{2}{|l|}{ Otros } & $\mathbf{X}$ \\
\hline \multirow[t]{2}{*}{ RETOQUE } & \multicolumn{7}{|c|}{ Pinturas de todo tipo. } \\
\hline & & V & $\mathbf{I}$ \\
\hline ELABORACIÓN & \multicolumn{5}{|c|}{ VEIV I AJAS/IIVCUIN VEIVIEIV IES } & & $\mathbf{X}$ \\
\hline \multicolumn{6}{|c|}{ SE CONOCEN LOS MATERIALES Y PROPORCIONES } & $\mathbf{X}$ & \\
\hline \multicolumn{6}{|l|}{ APLICACIÓN } & $\mathbf{X}$ & \\
\hline \multicolumn{6}{|c|}{ NIVELACIÓN Y PULIDO } & $\mathbf{X}$ & \\
\hline \multicolumn{6}{|c|}{ TIEMPO DE TRABAJO } & & $\mathbf{X}$ \\
\hline \multicolumn{6}{|c|}{ TIEMPO DE SECADO } & $\mathbf{X}$ & \\
\hline \multicolumn{6}{|c|}{ CONTRACCIÓN/AGRIETAMIENTO } & $\mathbf{X}$ & \\
\hline \multicolumn{6}{|l|}{ DUREZA } & & $\mathbf{X}$ \\
\hline \multicolumn{6}{|l|}{ POROSIDAD } & $\mathbf{X}$ & \\
\hline \multicolumn{6}{|c|}{ ADHESIÓN AL CUERPO CERÁMICO } & $\mathbf{X}$ & \\
\hline \multicolumn{6}{|l|}{ RETOQUE } & $\mathbf{X}$ & \\
\hline ALMACENAJE & & & & & & & $\mathbf{X}$ \\
\hline REVERSIBILIDAD & & & & & & & $\mathbf{X}$ \\
\hline OBSERVACIONES & Tiempo de & IDdjo & corto. & & & & \\
\hline VALORACIÓN & & NO & PTA//RE & IAZ & ADA & & \\
\hline
\end{tabular}




\begin{tabular}{|c|c|c|c|c|c|c|c|}
\hline REFERENCIA & \multicolumn{5}{|c|}{ MASILLA } & \multicolumn{2}{|c|}{$\mathbf{N}^{0}$} \\
\hline $\mathrm{C} 2$ & \multicolumn{5}{|c|}{ ALAMO 70/4 } & \multicolumn{2}{|c|}{4} \\
\hline COMPOSICIÓN & \multicolumn{7}{|c|}{$\begin{array}{l}\text { Escayola “Alamo 70" (6 Vol.) } \\
\text { Mowilith SDM5 15\% en agua (5 Vol.) }\end{array}$} \\
\hline PREPARACIÓN & \multicolumn{7}{|c|}{$\begin{array}{l}\text { Sobre el agua se tamiza la escayola, transcurridos } 15 \text { "' } \\
\text { se agita otros } 15 \text { "' }\end{array}$} \\
\hline \multirow{2}{*}{$\begin{array}{l}\text { CONSISTENCIA Y } \\
\text { APLICACIÓN }\end{array}$} & Líquida & $\mathbf{X}$ & Espesa & $X$ & Pastosa & & $\mathbf{X}$ \\
\hline & Inyección & $\mathbf{X}$ & Vertido & $\mathrm{X}$ & Espátula & & $\mathbf{X}$ \\
\hline T. DE TRABAJO & \multicolumn{7}{|l|}{$15^{\prime}$} \\
\hline T. DE SECADO & \multicolumn{7}{|l|}{4 horas } \\
\hline CONTRACCIÓN & Alta & & Media & $\mathbf{X}$ & \multicolumn{2}{|l|}{ Baja } & \\
\hline POROSIDAD & Alta & & Media & $\mathbf{X}$ & \multicolumn{2}{|l|}{ Baja } & \\
\hline DUREZA & Alta & & Media & $\mathbf{X}$ & \multicolumn{2}{|l|}{ Baja } & \\
\hline ADHESIÓN & Buena & & Media & $\mathrm{X}$ & \multicolumn{2}{|l|}{ Mala } & \\
\hline \multirow{2}{*}{$\begin{array}{l}\text { NIVELACIÓN Y } \\
\text { PULIDO }\end{array}$} & Buena & $\mathbf{X}$ & Media & & \multicolumn{2}{|l|}{ Mala } & \\
\hline & Bisturí & $\mathbf{X}$ & Lija & $\mathbf{X}$ & Otros & & $\mathbf{X}$ \\
\hline \multirow[t]{2}{*}{ RETOQUE } & \multicolumn{7}{|c|}{ Pinturas de todo tipo. } \\
\hline & \multicolumn{5}{|c|}{ VENTAJAS/INCONVENIENTES } & V & $\mathrm{I}$ \\
\hline \multicolumn{6}{|l|}{ ELABORACIÓN } & & $\mathbf{X}$ \\
\hline \multicolumn{6}{|c|}{ SE CONOCEN LOS MATERIALES Y PROPORCIONES } & $\mathbf{X}$ & \\
\hline \multicolumn{6}{|l|}{ APLICACIÓN } & $\mathbf{X}$ & \\
\hline \multicolumn{6}{|c|}{ NIVELACIÓN Y PULIDO } & $\mathbf{X}$ & \\
\hline \multicolumn{6}{|c|}{ TIEMPO DE TRABAJO } & $\mathbf{X}$ & \\
\hline \multicolumn{6}{|c|}{ TIEMPO DE SECADO } & $\mathbf{X}$ & \\
\hline \multicolumn{6}{|c|}{ CONTRACCIÓN/AGRIETAMIENTO } & & $\mathbf{X}$ \\
\hline \multicolumn{6}{|l|}{ DUREZA } & $\mathbf{X}$ & \\
\hline \multicolumn{6}{|l|}{ POROSIDAD } & $\mathbf{X}$ & \\
\hline \multicolumn{6}{|c|}{ ADHESIÓN AL CUERPO CERÁMICO } & $\mathbf{X}$ & \\
\hline \multicolumn{6}{|l|}{ RETOQUE } & $\mathbf{X}$ & \\
\hline \multicolumn{6}{|l|}{ ALMACENAJE } & & $\mathbf{X}$ \\
\hline REVERSIBILIDAD & & & & & & & $\mathbf{X}$ \\
\hline OBSERVACIONES & Ligera retr & 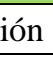 & uperficial & reza & decuada. & & \\
\hline VALORACIÓN & & & TAA/ENs & AD & & & \\
\hline
\end{tabular}




\begin{tabular}{|c|c|c|c|c|c|c|c|}
\hline REFERENCIA & \multicolumn{5}{|c|}{ MASILLA } & \multicolumn{2}{|c|}{$\mathbf{N}^{0}$} \\
\hline & \multicolumn{5}{|c|}{ ALAMO 70/5 } & \multicolumn{2}{|l|}{5} \\
\hline COMPOSICIÓN & \multicolumn{7}{|c|}{$\begin{array}{l}\text { Escayola “Alamo 70" (3 Vol.) } \\
\text { Mowilith SDM5 20\% en agua (1 Vol.) }\end{array}$} \\
\hline PREPARACIÓN & \multicolumn{7}{|c|}{$\begin{array}{l}\text { Sobre el agua se tamiza la escayola, transcurridos } 15 \text { ”, } \\
\text { se agita otros } 15,\end{array}$} \\
\hline \multirow{2}{*}{$\begin{array}{l}\text { CONSISTENCIA Y } \\
\text { APLICACIÓN }\end{array}$} & Líquida & $\mathbf{X}$ & Espesa & $\mathrm{X}$ & \begin{tabular}{|l|} 
Pastosa \\
\end{tabular} & & $\mathbf{X}$ \\
\hline & Inyección & $\mathbf{X}$ & Vertido & $\mathrm{X}$ & Espátulé & & $\mathbf{X}$ \\
\hline T. DE TRABAJO & \multicolumn{7}{|l|}{2} \\
\hline T. DE SECADO & \multicolumn{7}{|l|}{3 horas. } \\
\hline CONTRACCIÓN & Alta & & Media & & \multicolumn{2}{|l|}{ Baja } & $\mathbf{X}$ \\
\hline POROSIDAD & Alta & & Media & & \multicolumn{2}{|l|}{ Baja } & $\mathbf{X}$ \\
\hline DUREZA & Alta & $\mathbf{X}$ & Media & & \multicolumn{2}{|l|}{ Baja } & \\
\hline ADHESIÓN & Buena & $\mathbf{X}$ & Media & & \multicolumn{2}{|l|}{ Mala } & \\
\hline \multirow{2}{*}{$\begin{array}{l}\text { NIVELACIÓN Y } \\
\text { PULIDO }\end{array}$} & Buena & & Media & $\mathbf{X}$ & \multicolumn{2}{|l|}{ Mala } & \\
\hline & Bisturí & $\mathbf{X}$ & Lija & $\mathbf{X}$ & Otros & & $\mathbf{X}$ \\
\hline \multirow[t]{2}{*}{ RETOQUE } & \multicolumn{7}{|c|}{ Pinturas de todo tipo. } \\
\hline & \multicolumn{5}{|c|}{ VENTAJAS/INCONVENIENTES } & V & $\mathbf{I}$ \\
\hline \multicolumn{6}{|l|}{ ELABORACIÓN } & & $\mathbf{X}$ \\
\hline \multicolumn{6}{|c|}{ SE CONOCEN LOS MATERIALES Y PROPORCIONES } & $\mathbf{X}$ & \\
\hline \multicolumn{6}{|l|}{ APLICACIÓN } & & $\mathbf{X}$ \\
\hline \multicolumn{6}{|c|}{ NIVELACIÓN Y PULIDO } & & $\mathbf{X}$ \\
\hline \multicolumn{6}{|c|}{ TIEMPO DE TRABAJO } & & $\mathbf{X}$ \\
\hline \multicolumn{6}{|c|}{ TIEMPO DE SECADO } & $\mathbf{X}$ & \\
\hline \multicolumn{6}{|c|}{ CONTRACCIÓN/AGRIETAMIENTO } & $\mathbf{X}$ & \\
\hline \multicolumn{6}{|l|}{ DUREZA } & & $\mathbf{X}$ \\
\hline \multicolumn{6}{|l|}{ POROSIDAD } & $\mathbf{X}$ & \\
\hline \multicolumn{6}{|c|}{ ADHESIÓN AL CUERPO CERÁMICO } & $\mathbf{X}$ & \\
\hline \multicolumn{6}{|l|}{ RETOQUE } & $\mathbf{X}$ & \\
\hline \multicolumn{6}{|l|}{ ALMACENAJE } & & $\mathbf{X}$ \\
\hline REVERSIBILIDAD & & & & & & & $\mathbf{X}$ \\
\hline OBSERVACIONES & Fragua rápi & men & & & & & \\
\hline VALORACIÓN & & NO & PTA//RE & IAZ & ADA & & \\
\hline
\end{tabular}




\begin{tabular}{|c|c|c|c|c|c|c|c|}
\hline REFERENCIA & \multicolumn{5}{|c|}{ MASILLA } & \multicolumn{2}{|c|}{$\mathbf{N}^{0}$} \\
\hline & \multicolumn{5}{|c|}{ ALAMO 70/6 } & \multicolumn{2}{|c|}{6} \\
\hline COMPOSICIÓN & \multicolumn{7}{|c|}{$\begin{array}{l}\text { Escayola “Alamo 70” (2 Vol.) } \\
\text { Mowilith SDM5 25\% en agua (1 Vol.) }\end{array}$} \\
\hline PREPARACIÓN & \multicolumn{7}{|c|}{$\begin{array}{l}\text { Sobre el agua se tamiza la escayola, transcurridos 15" } \\
\text { se agita otros } 15 \text { ", }\end{array}$} \\
\hline \multirow{2}{*}{$\begin{array}{l}\text { CONSISTENCIA Y } \\
\text { APLICACIÓN }\end{array}$} & Líquida & $\mathbf{X}$ & Espesa & $X$ & Pastosa & & $\mathrm{X}$ \\
\hline & Inyección & $\mathbf{X}$ & Vertido & $\mathrm{X}$ & Espátula & & $\mathbf{X}$ \\
\hline T. DE TRABAJO & \multicolumn{7}{|l|}{$10-12^{\prime}$} \\
\hline T. DE SECADO & \multicolumn{7}{|l|}{5 horas } \\
\hline CONTRACCIÓN & Alta & & Media & & \multicolumn{2}{|l|}{ Baja } & $\mathbf{X}$ \\
\hline POROSIDAD & Alta & & Media & $\mathbf{X}$ & \multicolumn{2}{|l|}{ Baja } & \\
\hline DUREZA & Alta & & Media & $\mathbf{X}$ & \multicolumn{2}{|l|}{ Baja } & \\
\hline ADHESIÓN & Buena & & Media & $\mathrm{X}$ & \multicolumn{2}{|l|}{ Mala } & \\
\hline NIVELACIÓN Y & Buena & $\mathbf{X}$ & Media & & \multicolumn{2}{|l|}{ Mala } & \\
\hline PULIDO & Bisturí & $\mathbf{X}$ & Lija & $\mathbf{X}$ & \multicolumn{2}{|l|}{ Otros } & $\mathbf{X}$ \\
\hline RETOQUE & \multicolumn{7}{|c|}{ Pinturas de todo tipo. } \\
\hline & \multicolumn{5}{|c|}{ VENTAJAS/INCONVENIENTES } & $\mathrm{V}$ & $\mathrm{I}$ \\
\hline \multicolumn{6}{|l|}{ ELABORACIÓN } & & $\mathbf{X}$ \\
\hline \multicolumn{6}{|c|}{ SE CONOCEN LOS MATERIALES Y PROPORCIONES } & $\mathbf{X}$ & \\
\hline \multicolumn{6}{|l|}{ APLICACIÓN } & $\mathbf{X}$ & \\
\hline \multicolumn{6}{|c|}{ NIVELACIÓN Y PULIDO } & $\mathbf{X}$ & \\
\hline \multicolumn{6}{|c|}{ TIEMPO DE TRABAJO } & $\mathbf{X}$ & \\
\hline \multicolumn{6}{|c|}{ TIEMPO DE SECADO } & $\mathbf{X}$ & \\
\hline \multicolumn{6}{|c|}{ CONTRACCIÓN/AGRIETAMIENTO } & $\mathbf{X}$ & \\
\hline \multicolumn{6}{|l|}{ DUREZA } & $\mathbf{X}$ & \\
\hline \multicolumn{6}{|l|}{ POROSIDAD } & & $\mathbf{X}$ \\
\hline \multicolumn{6}{|c|}{ ADHESIÓN AL CUERPO CERÁMICO } & $\mathbf{X}$ & \\
\hline \multicolumn{6}{|l|}{ RETOQUE } & $\mathbf{X}$ & \\
\hline \multicolumn{6}{|l|}{ ALMACENAJE } & & $\mathbf{X}$ \\
\hline \multicolumn{6}{|l|}{ REVERSIBILIDAD } & & $\mathbf{X}$ \\
\hline OBSERVACIONES & & & & & & & \\
\hline VALORACIÓN & & $\mathbf{A P}$ & A//NO E & AYA & & & \\
\hline
\end{tabular}




\begin{tabular}{|c|c|c|c|c|c|c|c|}
\hline REFERENC & \multicolumn{5}{|c|}{ MASILLA } & \multicolumn{2}{|c|}{$\mathbf{N}^{0}$} \\
\hline & \multicolumn{5}{|c|}{ ALAMO 70/7 } & \multicolumn{2}{|l|}{7} \\
\hline COMPOSICIÓN & \multicolumn{7}{|c|}{$\begin{array}{l}\text { Escayola “Alamo 70" ( } 3 \text { Vol.) } \\
\text { Mowilith SDM5 25\% en agua (1 Vol.) }\end{array}$} \\
\hline PREPARACIÓN & \multicolumn{7}{|c|}{$\begin{array}{l}\text { Sobre el agua se tamiza la escayola, transcurridos } 15 \text { ”, } \\
\text { se agita otros } 15,\end{array}$} \\
\hline \multirow{2}{*}{$\begin{array}{l}\text { CONSISTENCIA Y } \\
\text { APLICACIÓN }\end{array}$} & Líquida & & Espesa & $\mathrm{X}$ & Pastosa & & $\mathbf{X}$ \\
\hline & Inyección & & \begin{tabular}{|l|} 
Vertido \\
\end{tabular} & $\mathrm{X}$ & Espátulé & & $\mathbf{X}$ \\
\hline T. DE TRABAJO & \multicolumn{7}{|l|}{$3-4$} \\
\hline T. DE SECADO & \multicolumn{7}{|l|}{4 horas. } \\
\hline CONTRACCIÓN & Alta & & Media & & \multicolumn{2}{|l|}{ Baja } & $\mathbf{X}$ \\
\hline POROSIDAD & Alta & & Media & & \multicolumn{2}{|l|}{ Baja } & $\mathbf{X}$ \\
\hline DUREZA & Alta & $\mathbf{X}$ & Media & & \multicolumn{2}{|l|}{ Baja } & \\
\hline ADHESIÓN & Buena & $\mathbf{X}$ & Media & & \multicolumn{2}{|l|}{ Mala } & \\
\hline \multirow{2}{*}{$\begin{array}{l}\text { NIVELACIÓN Y } \\
\text { PULIDO }\end{array}$} & Buena & & Media & $\mathbf{X}$ & \multicolumn{2}{|l|}{ Mala } & \\
\hline & Bisturí & $\mathbf{X}$ & Lija & $\mathbf{X}$ & Otros & & $\mathbf{X}$ \\
\hline \multirow[t]{2}{*}{ RETOQUE } & \multicolumn{7}{|c|}{ Pinturas de todo tipo. } \\
\hline & \multicolumn{5}{|c|}{ VENTAJAS/INCONVENIENTES } & $\mathrm{V}$ & $\mathbf{I}$ \\
\hline \multicolumn{6}{|l|}{ ELABORACIÓN } & & $\mathbf{X}$ \\
\hline \multicolumn{6}{|c|}{ SE CONOCEN LOS MATERIALES Y PROPORCIONES } & $\mathbf{X}$ & \\
\hline \multicolumn{6}{|l|}{ APLICACIÓN } & & $\mathbf{X}$ \\
\hline \multicolumn{6}{|c|}{ NIVELACIÓN Y PULIDO } & & $\mathbf{X}$ \\
\hline \multicolumn{6}{|c|}{ TIEMPO DE TRABAJO } & & $\mathbf{X}$ \\
\hline \multicolumn{6}{|c|}{ TIEMPO DE SECADO } & $\mathbf{X}$ & \\
\hline \multicolumn{6}{|c|}{ CONTRACCIÓN/AGRIETAMIENTO } & $\mathbf{X}$ & \\
\hline \multicolumn{6}{|c|}{ DUREZA } & & $\mathbf{X}$ \\
\hline \multicolumn{6}{|l|}{ POROSIDAD } & $\mathbf{X}$ & \\
\hline \multicolumn{6}{|c|}{ ADHESIÓN AL CUERPO CERÁMICO } & $\mathbf{X}$ & \\
\hline \multicolumn{6}{|l|}{ RETOQUE } & $\mathbf{X}$ & \\
\hline \multicolumn{6}{|l|}{ ALMACENAJE } & & $\mathbf{X}$ \\
\hline REVERSIBILIDAD & & & & & & & $\mathbf{X}$ \\
\hline OBSERVACIONES & Fragua rápi & nen & & & & & \\
\hline VALORACIÓN & & $\mathrm{JO}$ & APTA//RE & IAZ & ADA & & \\
\hline
\end{tabular}




\begin{tabular}{|c|c|c|c|c|c|c|c|}
\hline REFERENCIA & \multicolumn{5}{|c|}{ MASILLA } & \multicolumn{2}{|c|}{$\mathbf{N}^{0}$} \\
\hline & \multicolumn{5}{|c|}{ ALAMO 70/8 } & \multicolumn{2}{|c|}{8} \\
\hline COMPOSICIÓN & \multicolumn{7}{|c|}{$\begin{array}{l}\text { Escayola “Alamo 70” (3 Vol.) } \\
\text { Mowilith SDM5 50\% en agua (1 Vol.) }\end{array}$} \\
\hline PREPARACIÓN & \multicolumn{7}{|c|}{$\begin{array}{l}\text { Sobre el agua se tamiza la escayola, transcurridos 15" } \\
\text { se agita otros } 15 \text { ", }\end{array}$} \\
\hline \multirow{2}{*}{$\begin{array}{l}\text { CONSISTENCIA Y } \\
\text { APLICACIÓN }\end{array}$} & Líquida & & Espesa & $X$ & Pastosa & & $\mathrm{X}$ \\
\hline & Inyección & & Vertido & $\mathrm{X}$ & Espátul & & $\mathbf{X}$ \\
\hline T. DE TRABAJO & \multicolumn{7}{|c|}{4 ' } \\
\hline T. DE SECADO & \multicolumn{7}{|l|}{5 horas } \\
\hline CONTRACCIÓN & Alta & & Media & & \multicolumn{2}{|l|}{ Baja } & $\mathbf{X}$ \\
\hline POROSIDAD & Alta & & Media & & \multicolumn{2}{|l|}{ Baja } & $\mathbf{X}$ \\
\hline DUREZA & Alta & & Media & $\mathbf{X}$ & \multicolumn{2}{|l|}{ Baja } & \\
\hline ADHESIÓN & Buena & & Media & $\mathrm{X}$ & \multicolumn{2}{|l|}{ Mala } & \\
\hline NIVELACIÓN Y & Buena & & Media & $\mathbf{X}$ & \multicolumn{2}{|l|}{ Mala } & \\
\hline PULIDO & Bisturí & $\mathbf{X}$ & Lija & $\mathbf{X}$ & \multicolumn{2}{|l|}{ Otros } & $\mathbf{X}$ \\
\hline RETOQUE & \multicolumn{7}{|c|}{ Pinturas de todo tipo. } \\
\hline & \multicolumn{5}{|c|}{ VENTAJAS/INCONVENIENTES } & $\mathrm{V}$ & $\mathrm{I}$ \\
\hline \multicolumn{6}{|l|}{ ELABORACIÓN } & & $\mathbf{X}$ \\
\hline \multicolumn{6}{|c|}{ SE CONOCEN LOS MATERIALES Y PROPORCIONES } & $\mathbf{X}$ & \\
\hline \multicolumn{6}{|l|}{ APLICACIÓN } & & $\mathbf{X}$ \\
\hline \multicolumn{6}{|c|}{ NIVELACIÓN Y PULIDO } & $\mathbf{X}$ & \\
\hline \multicolumn{6}{|c|}{ TIEMPO DE TRABAJO } & & $\mathbf{X}$ \\
\hline \multicolumn{6}{|c|}{ TIEMPO DE SECADO } & $\mathbf{X}$ & \\
\hline \multicolumn{6}{|c|}{ CONTRACCIÓN/AGRIETAMIENTO } & $\mathbf{X}$ & \\
\hline \multicolumn{6}{|l|}{ DUREZA } & $\mathbf{X}$ & \\
\hline \multicolumn{6}{|l|}{ POROSIDAD } & $\mathbf{X}$ & \\
\hline \multicolumn{6}{|c|}{ ADHESIÓN AL CUERPO CERÁMICO } & $\mathbf{X}$ & \\
\hline \multicolumn{6}{|l|}{ RETOQUE } & $\mathbf{X}$ & \\
\hline \multicolumn{6}{|l|}{ ALMACENAJE } & & $\mathbf{X}$ \\
\hline \multicolumn{6}{|l|}{ REVERSIBILIDAD } & & $\mathbf{X}$ \\
\hline OBSERVACIONES & & & & & & & \\
\hline VALORACIÓN & & $\mathbf{A P}^{\prime}$ & A//NO E & AYA & & & \\
\hline
\end{tabular}




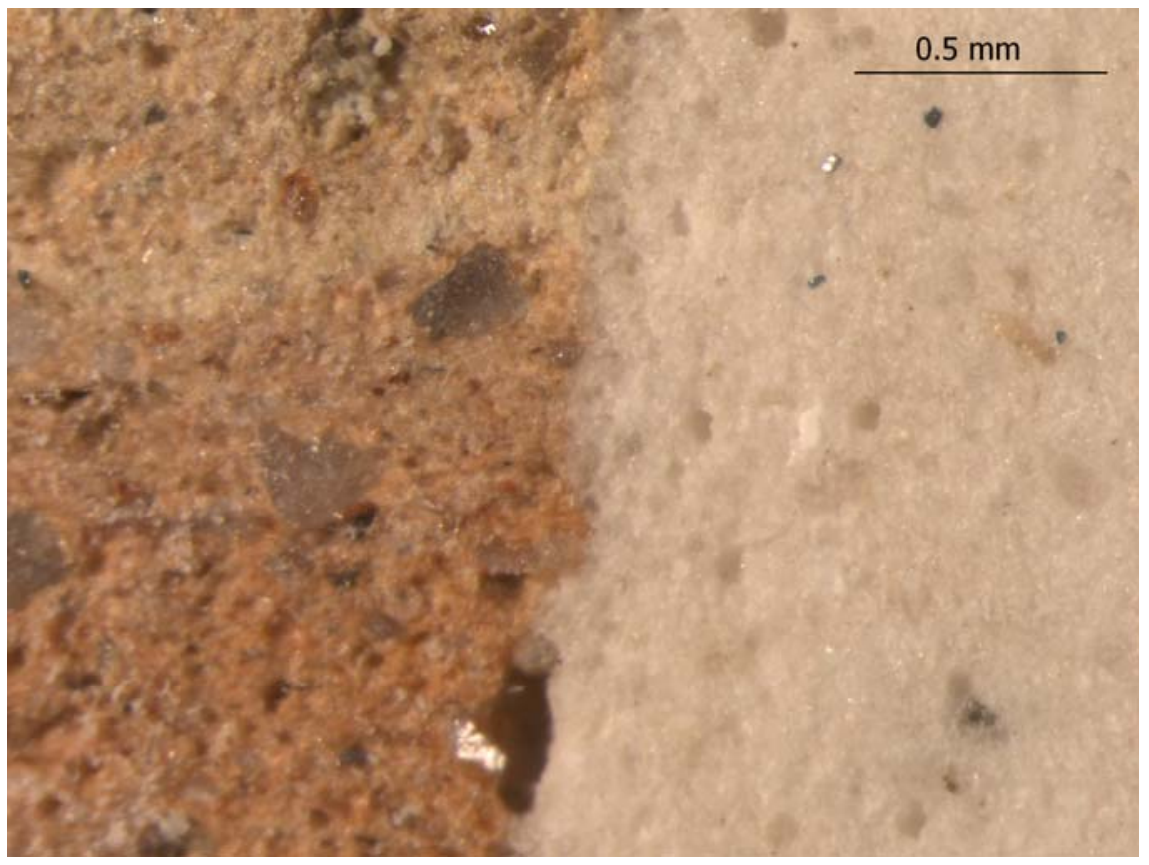

Figura 2. Escayola C1 y cerámica época islámica. 


\begin{tabular}{|c|c|c|c|c|c|c|c|}
\hline REFERENCIA & \multicolumn{5}{|c|}{ MASILLA } & \multirow{2}{*}{\multicolumn{2}{|c|}{$\frac{N^{\circ}}{9}$}} \\
\hline C1 & \multicolumn{5}{|c|}{ ALAMO 70/9 } & & \\
\hline COMPOSICIÓN & \multicolumn{7}{|c|}{$\begin{array}{l}\text { Escayola “Alamo } 70 " \text { ( } 2 \text { Vol.) } \\
\text { ACRIL } 33 \text { al } 15 \% \text { en agua ( } 1 \text { Vol.) }\end{array}$} \\
\hline PREPARACIÓN & \multicolumn{7}{|c|}{$\begin{array}{l}\text { Sobre el agua se tamiza la escayola, transcurridos } 15 \text { "' } \\
\text { se agita otros } 15 \text { ", }\end{array}$} \\
\hline \multirow{2}{*}{$\begin{array}{l}\text { CONSISTENCIA Y } \\
\text { APLICACIÓN }\end{array}$} & Líquida & $\mathbf{X}$ & Espesa & $X$ & Pastosa & & $\mathbf{X}$ \\
\hline & Inyección & $\mathbf{X}$ & Vertido & $\mathrm{X}$ & Espátul & & $\mathbf{X}$ \\
\hline T. DE TRABAJO & \multicolumn{7}{|l|}{$12^{\prime}$} \\
\hline T. DE SECADO & \multicolumn{7}{|l|}{4 horas } \\
\hline CONTRACCIÓN & Alta & & Media & & \multicolumn{2}{|l|}{ Baja } & $\mathbf{X}$ \\
\hline POROSIDAD & Alta & & Media & & \multicolumn{2}{|l|}{ Baja } & $\mathbf{X}$ \\
\hline DUREZA & Alta & & Media & $\mathbf{X}$ & \multicolumn{2}{|l|}{ Baja } & \\
\hline ADHESIÓN & Buena & & Media & $\mathrm{X}$ & \multicolumn{2}{|l|}{ Mala } & \\
\hline NIVELACIÓN Y & Buena & $\mathbf{X}$ & Media & & \multicolumn{2}{|l|}{ Mala } & \\
\hline PULIDO & Bisturí & $\mathbf{X}$ & Lija & $\mathbf{X}$ & \multicolumn{2}{|l|}{ Otros } & $\mathbf{X}$ \\
\hline RETOQUE & \multicolumn{7}{|c|}{ Pinturas de todo tipo. } \\
\hline & \multicolumn{5}{|c|}{ VENTAJAS/INCONVENIENTES } & $\mathrm{V}$ & $\mathrm{I}$ \\
\hline \multicolumn{6}{|l|}{ ELABORACIÓN } & & $\mathbf{X}$ \\
\hline \multicolumn{6}{|c|}{ SE CONOCEN LOS MATERIALES Y PROPORCIONES } & $\mathbf{X}$ & \\
\hline \multicolumn{6}{|l|}{ APLICACIÓN } & $\mathbf{X}$ & \\
\hline \multicolumn{6}{|c|}{ NIVELACIÓN Y PULIDO } & $\mathbf{X}$ & \\
\hline \multicolumn{6}{|c|}{ TIEMPO DE TRABAJO } & $\mathbf{X}$ & \\
\hline \multicolumn{6}{|c|}{ TIEMPO DE SECADO } & $\mathbf{X}$ & \\
\hline \multicolumn{6}{|c|}{ CONTRACCIÓN/AGRIETAMIENTO } & $\mathbf{X}$ & \\
\hline \multicolumn{6}{|l|}{ DUREZA } & $\mathbf{X}$ & \\
\hline \multicolumn{6}{|l|}{ POROSIDAD } & $\mathbf{X}$ & \\
\hline \multicolumn{6}{|c|}{ ADHESIÓN AL CUERPO CERÁMICO } & $\mathbf{X}$ & \\
\hline \multicolumn{6}{|l|}{ RETOQUE } & $\mathbf{X}$ & \\
\hline \multicolumn{6}{|l|}{ ALMACENAJE } & & $\mathbf{X}$ \\
\hline \multicolumn{6}{|l|}{ REVERSIBILIDAD } & & $\mathbf{X}$ \\
\hline \multicolumn{8}{|l|}{ OBSERVACIONES } \\
\hline VALORACIÓN & & & TA // EN & YAD & & & \\
\hline
\end{tabular}




\begin{tabular}{|c|c|c|c|c|c|c|c|}
\hline REFERENCIA & \multicolumn{5}{|c|}{ MASILLA } & \multicolumn{2}{|c|}{$\mathbf{N}^{0}$} \\
\hline & \multicolumn{5}{|c|}{ ALAMO 70/10 } & \multicolumn{2}{|c|}{10} \\
\hline COMPOSICIÓN & \multicolumn{7}{|c|}{$\begin{array}{l}\text { Escayola "Alamo } 70 \text { " ( } 3 \text { Vol.) } \\
\text { ACRIL } 33 \text { al } 25 \% \text { en agua (1 Vol.) }\end{array}$} \\
\hline PREPARACIÓN & \multicolumn{7}{|c|}{$\begin{array}{l}\text { Sobre el agua se tamiza la escayola, transcurridos } 15 \text { " } \\
\text { se agita otros } 15 \text { ", }\end{array}$} \\
\hline \multirow{2}{*}{$\begin{array}{l}\text { CONSISTENCIA Y } \\
\text { APLICACIÓN }\end{array}$} & Líquida & & Espesa & $\mathbf{X}$ & Pastosa & & $\mathbf{X}$ \\
\hline & Inyección & & Vertido & $\mathrm{X}$ & Espátul & & $\mathbf{X}$ \\
\hline T. DE TRABAJO & \multicolumn{7}{|l|}{2} \\
\hline T. DE SECADO & \multicolumn{7}{|l|}{4 horas } \\
\hline CONTRACCIÓN & Alta & & Media & & \multicolumn{2}{|l|}{ Baja } & $\mathbf{X}$ \\
\hline POROSIDAD & Alta & & Media & & \multicolumn{2}{|l|}{ Baja } & $\mathbf{X}$ \\
\hline DUREZA & Alta & $\mathbf{X}$ & Media & & \multicolumn{2}{|l|}{ Baja } & \\
\hline ADHESIÓN & Buena & $\mathbf{X}$ & Media & & \multicolumn{2}{|l|}{ Mala } & \\
\hline \multirow{2}{*}{$\begin{array}{l}\text { NIVELACIÓN Y } \\
\text { PULIDO }\end{array}$} & Buena & & Media & $\mathbf{X}$ & \multicolumn{2}{|l|}{ Mala } & \\
\hline & Bisturí & $\mathbf{X}$ & Lija & $\mathbf{X}$ & Otros & & $\mathbf{X}$ \\
\hline \multirow[t]{2}{*}{ RETOQUE } & \multicolumn{7}{|c|}{ Pinturas de todo tipo. } \\
\hline & \multicolumn{5}{|c|}{ VENTAJAS/INCONVENIENTES } & $\mathbf{V}$ & I \\
\hline \multicolumn{6}{|l|}{ ELABORACIÓN } & & $\mathbf{X}$ \\
\hline \multicolumn{6}{|c|}{ SE CONOCEN LOS MATERIALES Y PROPORCIONES } & $\mathbf{X}$ & \\
\hline \multicolumn{6}{|c|}{ APLICACIÓN } & & $\mathbf{X}$ \\
\hline \multicolumn{6}{|c|}{ NIVELACIÓN Y PULIDO } & & $\mathbf{X}$ \\
\hline \multicolumn{6}{|c|}{ TIEMPO DE TRABAJO } & & $\mathbf{X}$ \\
\hline \multicolumn{6}{|c|}{ TIEMPO DE SECADO } & $\mathbf{X}$ & \\
\hline \multicolumn{6}{|c|}{ CONTRACCIÓN/AGRIETAMIENTO } & $\mathbf{X}$ & \\
\hline \multicolumn{6}{|l|}{ DUREZA } & $\mathbf{X}$ & \\
\hline \multicolumn{6}{|l|}{ POROSIDAD } & $\mathbf{X}$ & \\
\hline \multicolumn{6}{|c|}{ ADHESIÓN AL CUERPO CERÁMICO } & $\mathbf{X}$ & \\
\hline \multicolumn{6}{|c|}{ RETOQUE } & $\mathbf{X}$ & \\
\hline \multicolumn{6}{|l|}{ ALMACENAJE } & & $\mathbf{X}$ \\
\hline REVERSIBILIDAD & & & & & & & $\mathbf{X}$ \\
\hline OBSERVACIONES & $\begin{array}{l}\text { La nivelaci } \\
\text { su rápido se }\end{array}$ & & ee ejecutar & & amente & & \\
\hline VALORACIÓN & & AP? & ГA//NO EI & AYA & & & \\
\hline
\end{tabular}




\begin{tabular}{|c|c|c|c|c|c|c|c|}
\hline REFERENCIA & \multicolumn{5}{|c|}{ MASILLA } & \multicolumn{2}{|c|}{$\mathbf{N}^{0}$} \\
\hline & \multicolumn{5}{|c|}{ ALAMO 50/1 } & \multicolumn{2}{|c|}{11} \\
\hline COMPOSICIÓN & \multicolumn{7}{|c|}{$\begin{array}{l}\text { Escayola “Alamo 50” (3 Vol.) } \\
\text { Agua (2 Vol.) }\end{array}$} \\
\hline PREPARACIÓN & \multicolumn{7}{|c|}{$\begin{array}{l}\text { Sobre el agua se tamiza la escayola, transcurridos } 15 \text { "' } \\
\text { se agita otros } 15 \text { ", }\end{array}$} \\
\hline \multirow{2}{*}{$\begin{array}{l}\text { CONSISTENCIA Y } \\
\text { APLICACIÓN }\end{array}$} & Líquida & $\mathrm{X}$ & Espesa & $X$ & Pastosa & & $\mathbf{X}$ \\
\hline & Inyección & $\mathbf{X}$ & Vertido & $\mathrm{X}$ & Espátula & & $\mathbf{X}$ \\
\hline T. DE TRABAJO & \multicolumn{7}{|l|}{ 3' } \\
\hline T. DE SECADO & \multicolumn{7}{|l|}{3 horas } \\
\hline CONTRACCIÓN & Alta & & Media & \multicolumn{3}{|c|}{ Baja } & $\mathbf{X}$ \\
\hline POROSIDAD & Alta & $\mathbf{X}$ & Media & \multicolumn{3}{|c|}{ Baja } & \\
\hline DUREZA & Alta & & Media & $\mathbf{X}$ & \multicolumn{2}{|l|}{ Baja } & \\
\hline ADHESIÓN & Buena & & Media & $\mathbf{X}$ & \multicolumn{2}{|l|}{ Mala } & \\
\hline NIVELACIÓN Y & Buena & $\mathbf{X}$ & Media & & \multicolumn{2}{|l|}{ Mala } & \\
\hline PULIDO & Bisturí & $\mathbf{X}$ & Lija & $\mathbf{X}$ & Otros & & $\bar{X}$ \\
\hline RETOQUE & \multicolumn{7}{|c|}{ Pinturas de todo tipo. } \\
\hline & \multicolumn{5}{|c|}{ VENTAJAS/INCONVENIENTES } & V & I \\
\hline \multicolumn{6}{|l|}{ ELABORACIÓN } & & $\mathbf{X}$ \\
\hline \multicolumn{6}{|c|}{ SE CONOCEN LOS MATERIALES Y PROPORCIONES } & $\mathbf{X}$ & \\
\hline \multicolumn{6}{|l|}{ APLICACIÓN } & & $\mathbf{X}$ \\
\hline \multicolumn{6}{|c|}{ NIVELACIÓN Y PULIDO } & $\overline{\mathbf{X}}$ & \\
\hline \multicolumn{6}{|c|}{ TIEMPO DE TRABAJO } & & $\mathrm{X}$ \\
\hline \multicolumn{6}{|c|}{ TIEMPO DE SECADO } & $\bar{X}$ & \\
\hline \multicolumn{6}{|c|}{ CONTRACCIÓN/AGRIETAMIENTO } & & $\mathbf{X}$ \\
\hline \multicolumn{6}{|l|}{ DUREZA } & & $\mathbf{X}$ \\
\hline \multicolumn{6}{|l|}{ POROSIDAD } & $\mathbf{X}$ & \\
\hline \multicolumn{6}{|c|}{ ADHESIÓN AL CUERPO CERÁMICO } & $\mathbf{X}$ & \\
\hline \multicolumn{6}{|l|}{ RETOQUE } & $\mathbf{X}$ & \\
\hline \multicolumn{6}{|l|}{ ALMACENAJE } & & $\mathbf{X}$ \\
\hline \multicolumn{6}{|l|}{ REVERSIBILIDAD } & & $\mathbf{X}$ \\
\hline OBSERVACIONES & $\begin{array}{l}\text { Dosificació } \\
\text { retracción } \\
\text { Pulverulenc }\end{array}$ & & $\begin{array}{l}\text { nendada } \\
\text { erficial. }\end{array}$ & & $\begin{array}{r}\text { bricante. } \\
\text { consis }\end{array}$ & & \\
\hline VALORACIÓN & & & $\begin{array}{l}\mathbf{P T A} / / \mathbf{R F} \\
\end{array}$ & 178 & $\mathbf{D A}$ & & \\
\hline
\end{tabular}




\begin{tabular}{|c|c|c|c|c|c|c|c|}
\hline REFERENCIA & \multicolumn{5}{|c|}{ MASILLA } & \multicolumn{2}{|c|}{$\mathbf{N}^{0}$} \\
\hline & \multicolumn{5}{|c|}{ ALAMO 50/2 } & \multicolumn{2}{|c|}{12} \\
\hline COMPOSICIÓN & \multicolumn{7}{|c|}{$\begin{array}{l}\text { Escayola “Alamo 50" (3 Vol.) } \\
\text { Mowilith SDM5 al 25\% en agua (2 Vol.) }\end{array}$} \\
\hline PREPARACIÓN & \multicolumn{7}{|c|}{$\begin{array}{l}\text { Sobre el agua se tamiza la escayola, transcurridos } 15 \text { ", } \\
\text { se agita otros } 15,\end{array}$} \\
\hline \multirow{2}{*}{$\begin{array}{l}\text { CONSISTENCIA Y } \\
\text { APLICACIÓN }\end{array}$} & Líquida & $X$ & Espesa & $\mathrm{X}$ & Pastosa & & $\mathbf{X}$ \\
\hline & Inyección & $\mathbf{X}$ & Vertido & $\mathrm{X}$ & Espátul & & $\mathbf{X}$ \\
\hline T. DE TRABAJO & \multicolumn{7}{|l|}{4} \\
\hline T. DE SECADO & \multicolumn{7}{|l|}{4 horas } \\
\hline CONTRACCIÓN & Alta & & Media & $\mathbf{X}$ & \multicolumn{2}{|l|}{ Baja } & \\
\hline POROSIDAD & Alta & & Media & & \multicolumn{2}{|l|}{ Baja } & $\mathbf{X}$ \\
\hline DUREZA & Alta & & Media & $\mathbf{X}$ & \multicolumn{2}{|l|}{ Baja } & \\
\hline ADHESIÓN & Buena & & Media & $\mathbf{X}$ & \multicolumn{2}{|l|}{ Mala } & \\
\hline \multirow{2}{*}{$\begin{array}{l}\text { NIVELACIÓN Y } \\
\text { PULIDO }\end{array}$} & Buena & $\mathbf{X}$ & Media & & \multicolumn{2}{|l|}{ Mala } & \\
\hline & Bisturí & $\mathbf{X}$ & Lija & $\mathbf{X}$ & Otros & & $\mathbf{X}$ \\
\hline \multirow[t]{2}{*}{ RETOQUE } & \multicolumn{7}{|c|}{ Pinturas de todo tipo. } \\
\hline & \multicolumn{5}{|c|}{ VENTAJAS/INCONVENIENTES } & $\mathbf{V}$ & I \\
\hline \multicolumn{6}{|l|}{ ELABORACIÓN } & & $\mathbf{X}$ \\
\hline \multicolumn{6}{|c|}{ SE CONOCEN LOS MATERIALES Y PROPORCIONES } & $\mathbf{X}$ & \\
\hline \multicolumn{6}{|l|}{ APLICACIÓN } & & $\mathbf{X}$ \\
\hline \multicolumn{6}{|c|}{ NIVELACIÓN Y PULIDO } & $\mathbf{X}$ & \\
\hline \multicolumn{6}{|c|}{ TIEMPO DE TRABAJO } & & $\mathbf{X}$ \\
\hline \multicolumn{6}{|c|}{ TIEMPO DE SECADO } & $\mathbf{X}$ & \\
\hline \multicolumn{6}{|c|}{ CONTRACCIÓN/AGRIETAMIENTO } & $\mathbf{X}$ & \\
\hline \multicolumn{6}{|c|}{ DUREZA } & $\mathbf{X}$ & \\
\hline \multicolumn{6}{|l|}{ POROSIDAD } & $\mathbf{X}$ & \\
\hline \multicolumn{6}{|c|}{ ADHESIÓN AL CUERPO CERÁMICO } & $\mathbf{X}$ & \\
\hline \multicolumn{6}{|l|}{ RETOQUE } & $\mathbf{X}$ & \\
\hline \multicolumn{6}{|l|}{ ALMACENAJE } & & $\mathbf{X}$ \\
\hline REVERSIBILIDAD & & & & & & & $\mathbf{X}$ \\
\hline OBSERVACIONES & $\begin{array}{l}\text { Ligera re } \\
\text { mayor du }\end{array}$ & & iperf & & resina & & \\
\hline VALORACIÓN & & APT & $/ / / \mathrm{NOH}$ & AY & ADA & & \\
\hline
\end{tabular}




\begin{tabular}{|c|c|c|c|c|c|c|c|}
\hline REFERENCIA & \multicolumn{5}{|c|}{ MASILLA } & \multicolumn{2}{|c|}{$\mathbf{N}^{0}$} \\
\hline & \multicolumn{5}{|c|}{ ALAMO 50/3 } & \multicolumn{2}{|c|}{13} \\
\hline COMPOSICIÓN & \multicolumn{7}{|c|}{$\begin{array}{l}\text { Escayola "Alamo 50" (3 Vol.) } \\
\text { Mowilith SDM5 al 20\% en agua (1 Vol.) }\end{array}$} \\
\hline PREPARACIÓN & \multicolumn{7}{|c|}{$\begin{array}{l}\text { Sobre el agua se tamiza la escayola, transcurridos } 15 \text { " } \\
\text { se agita otros } 15 \text { "' }\end{array}$} \\
\hline \multirow{2}{*}{$\begin{array}{l}\text { CONSISTENCIA Y } \\
\text { APLICACIÓN }\end{array}$} & Líquida & & Espesa & $X$ & Pastosa & & $\mathbf{X}$ \\
\hline & Inyección & & Vertido & $\mathrm{X}$ & Espátula & & $\mathbf{X}$ \\
\hline T. DE TRABAJO & \multicolumn{7}{|l|}{$2^{\prime}$} \\
\hline T. DE SECADO & \multicolumn{7}{|l|}{3 horas } \\
\hline CONTRACCIÓN & Alta & & Media & $\mathbf{X}$ & \multicolumn{2}{|l|}{ Baja } & \\
\hline POROSIDAD & Alta & & Media & & \multicolumn{2}{|l|}{ Baja } & $\mathbf{X}$ \\
\hline DUREZA & Alta & $\mathbf{X}$ & Media & & \multicolumn{2}{|l|}{ Baja } & \\
\hline ADHESIÓN & Buena & $\mathbf{X}$ & Media & & \multicolumn{2}{|l|}{ Mala } & \\
\hline \multirow{2}{*}{$\begin{array}{l}\text { NIVELACIÓN Y } \\
\text { PULIDO }\end{array}$} & Buena & & Media & $\mathbf{X}$ & Mala & & \\
\hline & Bisturí & $\mathbf{X}$ & Lija & $\mathbf{X}$ & Otros & & $\mathbf{X}$ \\
\hline \multirow[t]{2}{*}{ RETOQUE } & \multicolumn{7}{|c|}{ Pinturas de todo tipo. } \\
\hline & \multicolumn{5}{|c|}{ VENTAJAS/INCONVENIENTES } & V & I \\
\hline \multicolumn{6}{|l|}{ ELABORACIÓN } & & $\mathbf{X}$ \\
\hline \multicolumn{6}{|c|}{ SE CONOCEN LOS MATERIALES Y PROPORCIONES } & $\mathbf{X}$ & \\
\hline \multicolumn{6}{|l|}{ APLICACIÓN } & & $\mathbf{X}$ \\
\hline \multicolumn{6}{|c|}{ NIVELACIÓN Y PULIDO } & & $\mathbf{X}$ \\
\hline \multicolumn{6}{|c|}{ TIEMPO DE TRABAJO } & & $\mathbf{X}$ \\
\hline \multicolumn{6}{|c|}{ TIEMPO DE SECADO } & $\bar{X}$ & \\
\hline \multicolumn{6}{|c|}{ CONTRACCIÓN/AGRIETAMIENTO } & & $\mathbf{X}$ \\
\hline \multicolumn{6}{|c|}{ DUREZA } & $\bar{X}$ & \\
\hline \multicolumn{6}{|l|}{ POROSIDAD } & $\mathbf{X}$ & \\
\hline \multicolumn{6}{|c|}{ ADHESIÓN AL CUERPO CERÁMICO } & $\bar{X}$ & \\
\hline \multicolumn{6}{|l|}{ RETOQUE } & $\mathbf{X}$ & \\
\hline \multicolumn{6}{|l|}{ ALMACENAJE } & & $\mathbf{X}$ \\
\hline \multicolumn{6}{|l|}{ REVERSIBILIDAD } & & $\mathbf{X}$ \\
\hline OBSERVACIONES & $\begin{array}{l}\text { Ligera retr } \\
\text { ejecutarse } \mathrm{r}\end{array}$ & & $\begin{aligned} \text { superfici } \\
\text { ente debic }\end{aligned}$ & & $\begin{array}{l}\text { nivelación } \\
\text { ipido secad }\end{array}$ & & \\
\hline VALORACIÓN & & $\mathbf{A P T}$ & // NOF & AY & IDA & & \\
\hline
\end{tabular}




\begin{tabular}{|c|c|c|c|c|c|c|c|}
\hline REFERENCIA & \multicolumn{5}{|c|}{ MASILLA } & \multicolumn{2}{|c|}{$\mathbf{N}^{0}$} \\
\hline & \multicolumn{5}{|c|}{ ALAMO 50/4 } & \multicolumn{2}{|c|}{14} \\
\hline COMPOSICIÓN & \multicolumn{7}{|c|}{$\begin{array}{l}\text { Escayola “Alamo 50” (3 Vol.) } \\
\text { Mowilith SDM5 al 50\% en agua (1 Vol.) }\end{array}$} \\
\hline PREPARACIÓN & \multicolumn{7}{|c|}{$\begin{array}{l}\text { Sobre el agua se vierte la escayola tamizada, } \\
\text { transcurridos } 15 \text { "' se agita otros } 15 \text { ", }\end{array}$} \\
\hline \multirow{2}{*}{$\begin{array}{l}\text { CONSISTENCIA Y } \\
\text { APLICACIÓN }\end{array}$} & Líquida & & Espesa & $\mathrm{X}$ & Pastosa & & $\mathbf{X}$ \\
\hline & Inyección & & Vertido & $\mathrm{X}$ & Espátul & & $\mathbf{X}$ \\
\hline T. DE TRABAJO & \multicolumn{7}{|l|}{ 3' } \\
\hline T. DE SECADO & \multicolumn{7}{|l|}{5 horas } \\
\hline CONTRACCIÓN & Alta & & Media & & \multicolumn{2}{|l|}{ Baja } & $\mathbf{X}$ \\
\hline POROSIDAD & Alta & & Media & & \multicolumn{2}{|l|}{ Baja } & $\mathbf{X}$ \\
\hline DUREZA & Alta & $\mathbf{X}$ & Media & & \multicolumn{2}{|l|}{ Baja } & \\
\hline ADHESIÓN & Buena & & Media & $\mathbf{X}$ & \multicolumn{2}{|l|}{ Mala } & \\
\hline \multirow{2}{*}{$\begin{array}{l}\text { NIVELACIÓN Y } \\
\text { PULIDO }\end{array}$} & Buena & $\mathbf{X}$ & Media & & \multicolumn{2}{|l|}{ Mala } & \\
\hline & Bisturí & $\mathbf{X}$ & Lija & $\mathbf{X}$ & Otros & & $\mathbf{X}$ \\
\hline \multirow[t]{2}{*}{ RETOQUE } & \multicolumn{7}{|c|}{ Pinturas de todo tipo. } \\
\hline & \multicolumn{5}{|c|}{ VENTAJAS/INCONVENIENTES } & V & $\mathbf{I}$ \\
\hline \multicolumn{6}{|l|}{ ELABORACIÓN } & & $\mathbf{X}$ \\
\hline \multicolumn{6}{|c|}{ SE CONOCEN LOS MATERIALES Y PROPORCIONES } & $\mathbf{X}$ & \\
\hline \multicolumn{6}{|l|}{ APLICACIÓN } & & $\mathbf{X}$ \\
\hline \multicolumn{6}{|c|}{ NIVELACIÓN Y PULIDO } & $\mathbf{X}$ & \\
\hline \multicolumn{6}{|c|}{ TIEMPO DE TRABAJO } & & $\mathbf{X}$ \\
\hline \multicolumn{6}{|c|}{ TIEMPO DE SECADO } & $\mathbf{X}$ & \\
\hline \multicolumn{6}{|c|}{ CONTRACCIÓN/AGRIETAMIENTO } & $\mathbf{X}$ & \\
\hline \multicolumn{6}{|c|}{ DUREZA } & $\mathbf{X}$ & \\
\hline \multicolumn{6}{|l|}{ POROSIDAD } & $\mathbf{X}$ & \\
\hline \multicolumn{6}{|c|}{ ADHESIÓN AL CUERPO CERÁMICO } & $\mathbf{X}$ & \\
\hline \multicolumn{6}{|c|}{ RETOQUE } & $\mathbf{X}$ & \\
\hline \multicolumn{6}{|l|}{ ALMACENAJE } & & $\mathbf{X}$ \\
\hline REVERSIBILIDAD & & & & & & & $\mathbf{X}$ \\
\hline OBSERVACIONES & $\begin{array}{l}\text { La nivelaci } \\
\text { su rápido se }\end{array}$ & & ee ejecutar & & amente & & \\
\hline VALORACIÓN & & PT & A // NOE & AY & ADA & & \\
\hline
\end{tabular}




\begin{tabular}{|c|c|c|c|c|c|c|c|}
\hline REFERENCIA & \multicolumn{5}{|c|}{ MASILLA } & \multicolumn{2}{|c|}{$\mathbf{N}^{0}$} \\
\hline & \multicolumn{5}{|c|}{ EXADURO } & \multicolumn{2}{|c|}{15} \\
\hline COMPOSICIÓN & \multicolumn{7}{|c|}{$\begin{array}{l}\text { Escayola “Exaduro” (5 Vol.) } \\
\text { Agua ( } 2 \text { Vol.) }\end{array}$} \\
\hline PREPARACIÓN & \multicolumn{7}{|c|}{$\begin{array}{l}\text { Sobre el agua se tamiza la escayola, transcurridos } 15 \text { "' } \\
\text { se agita otros } 15 \text { "' }\end{array}$} \\
\hline \multirow{2}{*}{$\begin{array}{c}\text { CONSISTENCIA Y } \\
\text { APLICACIÓN } \\
\end{array}$} & Líquida & & Espesa & $\mathbf{X}$ & Pastosa & & $\mathbf{X}$ \\
\hline & Inyección & & Vertido & $\mathbf{X}$ & Espátula & & $\mathbf{X}$ \\
\hline T. DE TRABAJO & \multicolumn{7}{|c|}{$6^{\prime}$} \\
\hline T. DE SECADO & \multicolumn{7}{|l|}{5 horas } \\
\hline CONTRACCIÓN & Alta & $\mathbf{X}$ & Media & & \multicolumn{2}{|l|}{ Baja } & \\
\hline POROSIDAD & Alta & & Media & & \multicolumn{2}{|l|}{ Baja } & $\mathbf{X}$ \\
\hline DUREZA & Alta & $\mathbf{X}$ & Media & & \multicolumn{2}{|l|}{ Baja } & \\
\hline ADHESIÓN & Buena & $\mathbf{X}$ & Media & & \multicolumn{2}{|l|}{ Mala } & \\
\hline \multirow{2}{*}{$\begin{array}{l}\text { NIVELACIÓN Y } \\
\text { PULIDO }\end{array}$} & Buena & & Media & $\mathbf{X}$ & Mala & & \\
\hline & Bisturí & $\mathbf{X}$ & Lija & $\mathbf{X}$ & Otros & & $\mathbf{X}$ \\
\hline \multirow[t]{2}{*}{ RETOQUE } & \multicolumn{7}{|c|}{ Pinturas de todo tipo. } \\
\hline & \multicolumn{5}{|c|}{ VENTAJAS/INCONVENIENTES } & V & I \\
\hline \multicolumn{6}{|l|}{ ELABORACIÓN } & & $\mathbf{X}$ \\
\hline \multicolumn{6}{|c|}{ SE CONOCEN LOS MATERIALES Y PROPORCIONES } & $\mathbf{X}$ & \\
\hline \multicolumn{6}{|l|}{ APLICACIÓN } & $\mathbf{X}$ & \\
\hline \multicolumn{6}{|c|}{ NIVELACIÓN Y PULIDO } & & $\mathbf{X}$ \\
\hline \multicolumn{6}{|c|}{ TIEMPO DE TRABAJO } & & $\mathbf{X}$ \\
\hline \multicolumn{6}{|c|}{ TIEMPO DE SECADO } & $\mathbf{X}$ & \\
\hline \multicolumn{6}{|c|}{ CONTRACCIÓN/AGRIETAMIENTO } & $\mathbf{X}$ & \\
\hline \multicolumn{6}{|l|}{ DUREZA } & & $\mathbf{X}$ \\
\hline \multicolumn{6}{|l|}{ POROSIDAD } & $\mathbf{X}$ & \\
\hline \multicolumn{6}{|c|}{ ADHESIÓN AL CUERPO CERÁMICO } & $\bar{X}$ & \\
\hline \multicolumn{6}{|l|}{ RETOQUE } & $\mathbf{X}$ & \\
\hline \multicolumn{6}{|l|}{ ALMACENAJE } & & $\mathbf{X}$ \\
\hline \multicolumn{6}{|l|}{ REVERSIBILIDAD } & & $\mathbf{X}$ \\
\hline OBSERVACIONES & $\begin{array}{l}\text { Dosificación } \\
\text { nivelación d } \\
\text { rápido secad }\end{array}$ & $\begin{array}{l}\text { reco } \\
\text { ebe ej } \\
\text { La I }\end{array}$ & $\begin{array}{l}\text { mendada } \\
\text { ecutarse rá } \\
\text { ivelación } €\end{array}$ & & $\begin{array}{r}\text { fabricant } \\
\text { nte debid } \\
\text { es costosa } \\
\end{array}$ & & \\
\hline VALORACIÓN & & APTA & // NO EI & AYA & DA & & \\
\hline
\end{tabular}




\begin{tabular}{|c|c|c|c|c|c|c|c|}
\hline REFERENCIA & \multicolumn{5}{|c|}{ MASILLA } & \multicolumn{2}{|c|}{$\mathbf{N}^{\mathbf{0}}$} \\
\hline & \multicolumn{5}{|c|}{ DURO 6/1 } & \multicolumn{2}{|c|}{16} \\
\hline COMPOSICIÓN & \multicolumn{7}{|c|}{$\begin{array}{l}\text { Escayola “Duro 6” (1 Vol.) } \\
\text { Agua (1 Vol.) }\end{array}$} \\
\hline PREPARACIÓN & \multicolumn{7}{|c|}{$\begin{array}{l}\text { Sobre el agua se tamiza la escayola, transcurridos } 15 \text { "' } \\
\text { se agita otros } 15,\end{array}$} \\
\hline \multirow{2}{*}{$\begin{array}{l}\text { CONSISTENCIA Y } \\
\text { APLICACIÓN } \\
\end{array}$} & Líquida & $\mathbf{X}$ & Espesa & $\mathrm{X}$ & Pastos & & \\
\hline & Inyección & $\mathbf{X}$ & Vertido & $\mathrm{X}$ & Espát & & \\
\hline T. DE TRABAJO & \multicolumn{7}{|l|}{$15^{\prime}$} \\
\hline T. DE SECADO & \multicolumn{7}{|c|}{ Más de 12 horas. } \\
\hline CONTRACCIÓN & Alta & $\mathbf{X}$ & Media & \multicolumn{3}{|c|}{ Baja } & \\
\hline POROSIDAD & Alta & & Media & $\mathbf{X}$ & \multicolumn{2}{|l|}{ Baja } & \\
\hline DUREZA & Alta & & Media & & \multicolumn{2}{|l|}{ Baja } & $\mathbf{X}$ \\
\hline ADHESIÓN & Buena & & Media & $\mathbf{X}$ & \multicolumn{2}{|l|}{ Mala } & \\
\hline NIVELACIÓN Y & Buena & $\mathbf{X}$ & Media & & \multicolumn{2}{|l|}{ Mala } & \\
\hline PULIDO & Bisturí & $\mathbf{X}$ & Lija & $\mathbf{X}$ & \multicolumn{2}{|l|}{ Otros } & \\
\hline RETOQUE & \multicolumn{7}{|c|}{ Pinturas de todo tipo. } \\
\hline & \multicolumn{5}{|c|}{ VENTAJAS/INCONVENIENTES } & $\mathbf{V}$ & I \\
\hline \multicolumn{6}{|l|}{ ELABORACIÓN } & & $\mathbf{X}$ \\
\hline \multicolumn{6}{|c|}{ SE CONOCEN LOS MATERIALES Y PROPORCIONES } & $\mathbf{X}$ & \\
\hline \multicolumn{6}{|l|}{ APLICACIÓN } & $\mathbf{X}$ & \\
\hline \multicolumn{6}{|c|}{ NIVELACIÓN Y PULIDO } & $\mathbf{X}$ & \\
\hline \multicolumn{6}{|c|}{ TIEMPO DE TRABAJO } & $\mathbf{X}$ & \\
\hline \multicolumn{6}{|c|}{ TIEMPO DE SECADO } & & \\
\hline \multicolumn{6}{|c|}{ CONTRACCIÓN/AGRIETAMIENTO } & & $\mathbf{X}$ \\
\hline \multicolumn{6}{|l|}{ DUREZA } & & $\mathbf{X}$ \\
\hline \multicolumn{6}{|l|}{ POROSIDAD } & $\mathbf{X}$ & \\
\hline \multicolumn{6}{|c|}{ ADHESIÓN AL CUERPO CERÁMICO } & $\mathbf{X}$ & \\
\hline \multicolumn{6}{|l|}{ RETOQUE } & $\mathbf{X}$ & \\
\hline \multicolumn{6}{|l|}{ ALMACENAJE } & & $\mathbf{X}$ \\
\hline \multicolumn{6}{|l|}{ REVERSIBILIDAD } & & $\mathbf{X}$ \\
\hline OBSERVACIONES & $\begin{array}{l}\text { Color rosad } \\
\text { aun excesc } \\
\text { Demasiado }\end{array}$ & & $\begin{array}{l}\text { acción su } \\
\text { agua. Ta }\end{array}$ & & $\begin{array}{l}(5 \mathrm{~mm} \\
\text { tante }\end{array}$ & & \\
\hline VALORACIÓN & & $U_{\mathrm{A}}$ & TA // R & HA2 & ADA & & \\
\hline
\end{tabular}




\begin{tabular}{|c|c|c|c|c|c|c|c|}
\hline REFERENCIA & \multicolumn{5}{|c|}{ MASILLA } & \multicolumn{2}{|c|}{$\mathbf{N}^{0}$} \\
\hline & \multicolumn{5}{|c|}{ DURO 6/2 } & \multicolumn{2}{|c|}{17} \\
\hline COMPOSICIÓN & \multicolumn{7}{|c|}{$\begin{array}{l}\text { Escayola “Duro 6” (2 Vol.) } \\
\text { Agua (1 Vol.) }\end{array}$} \\
\hline PREPARACIÓN & \multicolumn{7}{|c|}{$\begin{array}{l}\text { Sobre el agua se tamiza la escayola, transcurridos } 15 \text { "' } \\
\text { se agita otros } 15 \text { "' }\end{array}$} \\
\hline \multirow{2}{*}{$\begin{array}{l}\text { CONSISTENCIA Y } \\
\text { APLICACIÓN }\end{array}$} & Líquida & & Espesa & $\mathbf{X}$ & Pastosa & & $\mathbf{X}$ \\
\hline & Inyección & & Vertido & $\mathrm{X}$ & Espátula & & $\mathbf{X}$ \\
\hline T. DE TRABAJO & \multicolumn{7}{|l|}{$12^{\prime}$} \\
\hline T. DE SECADO & \multicolumn{7}{|l|}{6 horas. } \\
\hline CONTRACCIÓN & Alta & & Media & & \multicolumn{2}{|l|}{ Baja } & $\mathbf{X}$ \\
\hline POROSIDAD & Alta & & Media & & \multicolumn{2}{|l|}{ Baja } & $\mathbf{X}$ \\
\hline DUREZA & Alta & $\mathbf{X}$ & Media & & \multicolumn{2}{|l|}{ Baja } & \\
\hline ADHESIÓN & Buena & $\mathbf{X}$ & Media & & \multicolumn{2}{|l|}{ Mala } & \\
\hline \multirow{2}{*}{$\begin{array}{l}\text { NIVELACIÓN Y } \\
\text { PULIDO }\end{array}$} & Buena & $\mathbf{X}$ & Media & $\mathbf{X}$ & \multicolumn{2}{|l|}{ Mala } & \\
\hline & Bisturí & $\mathbf{X}$ & Lija & $\mathbf{X}$ & \multicolumn{2}{|l|}{ Otros } & $\mathbf{X}$ \\
\hline \multirow[t]{2}{*}{ RETOQUE } & \multicolumn{7}{|c|}{ Pinturas de todo tipo. } \\
\hline & \multicolumn{5}{|c|}{ VENTAJAS/INCONVENIENTES } & $\mathbf{V}$ & I \\
\hline \multicolumn{6}{|l|}{ ELABORACIÓN } & & $\mathbf{X}$ \\
\hline \multicolumn{6}{|c|}{ SE CONOCEN LOS MATERIALES Y PROPORCIONES } & $\mathbf{X}$ & \\
\hline \multicolumn{6}{|l|}{ APLICACIÓN } & X & \\
\hline \multicolumn{6}{|c|}{ NIVELACIÓN Y PULIDO } & $\mathbf{X}$ & $\mathbf{X}$ \\
\hline \multicolumn{6}{|c|}{ TIEMPO DE TRABAJO } & $\mathbf{X}$ & \\
\hline \multicolumn{6}{|c|}{ TIEMPO DE SECADO } & $\mathbf{X}$ & \\
\hline \multicolumn{6}{|c|}{ CONTRACCIÓN/AGRIETAMIENTO } & $\mathbf{X}$ & \\
\hline \multicolumn{6}{|l|}{ DUREZA } & & $\mathbf{X}$ \\
\hline \multicolumn{6}{|l|}{ POROSIDAD } & $\mathbf{X}$ & \\
\hline \multicolumn{6}{|c|}{ ADHESIÓN AL CUERPO CERÁMICO } & $\mathbf{X}$ & \\
\hline \multicolumn{6}{|l|}{ RETOQUE } & $\mathbf{X}$ & \\
\hline ALMACENAJE & & & & & & & $\mathbf{X}$ \\
\hline REVERSIBILIDAD & & & & & & & $\mathbf{X}$ \\
\hline OBSERVACIONES & $\begin{array}{l}\text { Color rosa } \\
\text { fraguado-se } \\
\text { dura. }\end{array}$ & & $\begin{array}{l}\text { debe nive } \\
\text { Una vez }\end{array}$ & & $\begin{array}{l}\text { rante el } p \\
\text { excesivc }\end{array}$ & & \\
\hline VALORACIÓN & & & // NOE & AY & DA & & \\
\hline
\end{tabular}




\begin{tabular}{|c|c|c|c|c|c|c|c|}
\hline REFERENCIA & \multicolumn{5}{|c|}{ MASILLA } & \multicolumn{2}{|c|}{$\mathbf{N}^{0}$} \\
\hline & \multicolumn{5}{|c|}{ DURO 6/3 } & \multicolumn{2}{|c|}{18} \\
\hline COMPOSICIÓN & \multicolumn{7}{|c|}{ Escayola "Duro 6" (4 Vol.) $\quad$ Agua (1 Vol.) } \\
\hline PREPARACIÓN & \multicolumn{7}{|c|}{$\begin{array}{l}\text { Sobre el agua se tamiza la escayola, transcurridos } 15 \text { "' } \\
\text { se agita otros } 15 \text { "' }\end{array}$} \\
\hline \multirow{2}{*}{$\begin{array}{l}\text { CONSISTENCIA Y } \\
\text { APLICACIÓN }\end{array}$} & Líquida & & Espesa & & Pastosa & & $\mathbf{X}$ \\
\hline & Inyección & & Vertido & & Espátul & & $\mathbf{X}$ \\
\hline T. DE TRABAJO & \multicolumn{7}{|l|}{$15^{\prime}$} \\
\hline T. DE SECADO & \multicolumn{7}{|l|}{6 horas } \\
\hline CONTRACCIÓN & Alta & & Media & \multicolumn{3}{|c|}{ Baja } & $\mathbf{X}$ \\
\hline POROSIDAD & Alta & & Media & \multicolumn{3}{|c|}{ Baja } & $\mathbf{X}$ \\
\hline DUREZA & Alta & $\mathbf{X}$ & Media & \multicolumn{3}{|c|}{ Baja } & \\
\hline ADHESIÓN & Buena & $\mathbf{X}$ & Media & \multicolumn{3}{|c|}{ Mala } & \\
\hline \multirow{2}{*}{$\begin{array}{l}\text { NIVELACIÓN Y } \\
\text { PULIDO }\end{array}$} & Buena & $\mathbf{X}$ & Media & $\mathbf{X}$ & \multicolumn{2}{|l|}{ Mala } & \\
\hline & Bisturí & $\mathbf{X}$ & Lija & $\mathbf{X}$ & Otros & & $\mathbf{X}$ \\
\hline \multirow[t]{2}{*}{ RETOQUE } & \multicolumn{7}{|c|}{ Pinturas de todo tipo. } \\
\hline & \multicolumn{5}{|c|}{ VENTAJAS/INCONVENIENTES } & V & I \\
\hline \multicolumn{6}{|l|}{ ELABORACIÓN } & & $\mathbf{X}$ \\
\hline \multicolumn{6}{|c|}{ SE CONOCEN LOS MATERIALES Y PROPORCIONES } & $\mathbf{X}$ & \\
\hline \multicolumn{6}{|c|}{ APLICACIÓN } & $\mathbf{X}$ & \\
\hline \multicolumn{6}{|c|}{ NIVELACIÓN Y PULIDO } & $\mathbf{X}$ & \\
\hline \multicolumn{6}{|c|}{ TIEMPO DE TRABAJO } & $\mathbf{X}$ & \\
\hline \multicolumn{6}{|c|}{ TIEMPO DE SECADO } & $\mathbf{X}$ & \\
\hline \multicolumn{6}{|c|}{ CONTRACCIÓN/AGRIETAMIENTO } & $\mathbf{X}$ & \\
\hline \multicolumn{6}{|l|}{ DUREZA } & & $\mathbf{X}$ \\
\hline \multicolumn{6}{|l|}{ POROSIDAD } & $\mathbf{X}$ & \\
\hline \multicolumn{6}{|c|}{ ADHESIÓN AL CUERPO CERÁMICO } & $\mathbf{X}$ & \\
\hline \multicolumn{6}{|l|}{ RETOQUE } & $\mathbf{X}$ & \\
\hline \multicolumn{6}{|l|}{ ALMACENAJE } & & $\mathbf{X}$ \\
\hline REVERSIBILIDAD & & & & & & & $\mathbf{X}$ \\
\hline OBSERVACIONES & $\begin{array}{l}\text { Se debe ap } \\
\text { fraguado. L } \\
\text { fraguado-sec } \\
\text { recurrir a mi }\end{array}$ & & $\begin{array}{l}\text { rápidamen } \\
\text { elación de } \\
\text { En la nive } \\
\text { nos. }\end{array}$ & $\begin{array}{l}\text { debi } \\
\text { reali } \\
\text { ción } \\
\end{array}$ & $\begin{array}{l}\text { do a su } \\
\text { zarse dur } \\
\text { en seco }\end{array}$ & & \\
\hline VALORACI & & & A / NO & - & & & \\
\hline
\end{tabular}




\begin{tabular}{|c|c|c|c|c|c|c|c|}
\hline REFERENCIA & \multicolumn{5}{|c|}{ MASILLA } & \multirow{2}{*}{\multicolumn{2}{|c|}{$\frac{N^{0}}{19}$}} \\
\hline C4 & \multicolumn{5}{|c|}{ HEBODUR/1 } & & \\
\hline COMPOSICIÓN & \multicolumn{7}{|c|}{$\begin{array}{l}\text { Escayola “Hebodur” (2 Vol.) } \\
\text { Agua (1 Vol.) }\end{array}$} \\
\hline PREPARACIÓN & \multicolumn{7}{|c|}{$\begin{array}{l}\text { Sobre el agua se vierte la escayola tamizada, } \\
\text { transcurridos } 15 \text { "' se agita otros } 15 \text { ", }\end{array}$} \\
\hline \multirow{2}{*}{$\begin{array}{l}\text { CONSISTENCIA Y } \\
\text { APLICACIÓN }\end{array}$} & Líquida & $\mathbf{X}$ & Espesa & $\mathrm{X}$ & Pastosa & & $\mathbf{X}$ \\
\hline & Inyección & $\mathrm{X}$ & Vertido & $\mathrm{X}$ & Espátula & & $\mathbf{X}$ \\
\hline T. DE TRABAJO & \multicolumn{7}{|l|}{$15^{\prime}$} \\
\hline T. DE SECADO & \multicolumn{7}{|l|}{4 horas } \\
\hline CONTRACCIÓN & Alta & & Media & & \multicolumn{2}{|l|}{ Baja } & $\mathbf{X}$ \\
\hline POROSIDAD & Alta & & Media & & \multicolumn{2}{|l|}{ Baja } & $\mathbf{X}$ \\
\hline DUREZA & Alta & $\mathbf{X}$ & Media & & \multicolumn{2}{|l|}{ Baja } & \\
\hline ADHESIÓN & Buena & $\mathrm{X}$ & Media & & \multicolumn{2}{|l|}{ Mala } & \\
\hline NIVELACIÓN Y & Buena & & Media & $\mathbf{X}$ & \multicolumn{2}{|l|}{ Mala } & \\
\hline PULIDO & Bisturí & $\mathbf{X}$ & Lija & $\mathbf{X}$ & \multicolumn{2}{|l|}{ Otros } & $\mathbf{X}$ \\
\hline RETOQUE & \multicolumn{7}{|c|}{ Pinturas de todo tipo. } \\
\hline & \multicolumn{5}{|c|}{ VENTAJAS/INCONVENIENTES } & V & I \\
\hline \multicolumn{6}{|l|}{ ELABORACIÓN } & & $\mathbf{X}$ \\
\hline \multicolumn{6}{|c|}{ SE CONOCEN LOS MATERIALES Y PROPORCIONES } & $\mathbf{X}$ & \\
\hline \multicolumn{6}{|l|}{ APLICACIÓN } & $\mathbf{X}$ & \\
\hline \multicolumn{6}{|c|}{ NIVELACIÓN Y PULIDO } & $\overline{\mathbf{X}}$ & $\mathbf{X}$ \\
\hline \multicolumn{6}{|c|}{ TIEMPO DE TRABAJO } & $\mathbf{X}$ & \\
\hline \multicolumn{6}{|c|}{ TIEMPO DE SECADO } & $\mathbf{X}$ & \\
\hline \multicolumn{6}{|c|}{ CONTRACCIÓN/AGRIETAMIENTO } & $\mathbf{X}$ & \\
\hline \multicolumn{6}{|l|}{ DUREZA } & & $\mathbf{X}$ \\
\hline \multicolumn{6}{|l|}{ POROSIDAD } & $\mathbf{X}$ & \\
\hline \multicolumn{6}{|c|}{ ADHESIÓN AL CUERPO CERÁMICO } & $\mathbf{X}$ & \\
\hline \multicolumn{6}{|l|}{ RETOQUE } & $\mathbf{X}$ & \\
\hline \multicolumn{6}{|l|}{ ALMACENAJE } & & $\mathbf{X}$ \\
\hline \multicolumn{6}{|l|}{ REVERSIBILIDAD } & & $\mathbf{X}$ \\
\hline \multicolumn{8}{|l|}{ OBSERVACIONES } \\
\hline VALORACIÓN & & & TA//ENS & AD & & & \\
\hline
\end{tabular}




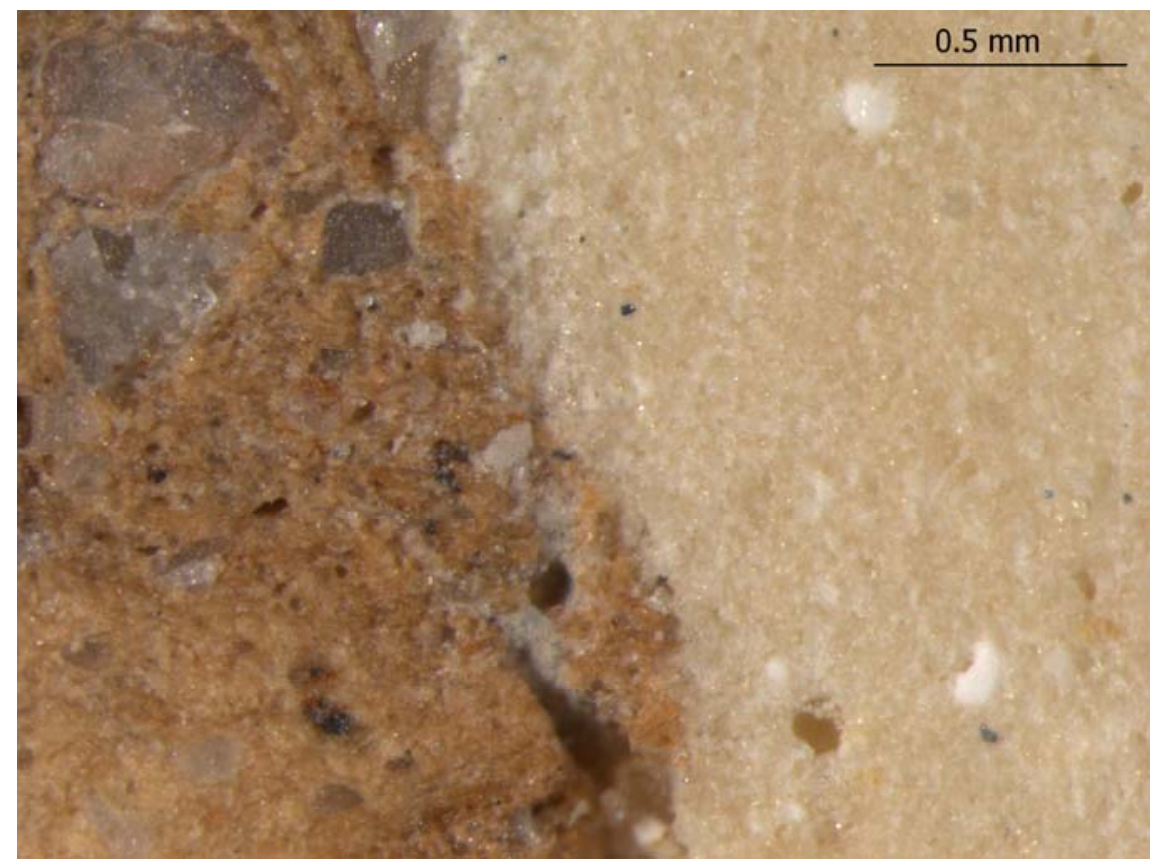

Figura 3. Escayola C4 y cerámica época Islámica. 


\begin{tabular}{|c|c|c|c|c|c|c|}
\hline REFERENCIA & \multicolumn{5}{|c|}{ MASILLA } & $\mathbf{N}^{0}$ \\
\hline & \multicolumn{5}{|c|}{ HEBODUR/2 } & 20 \\
\hline COMPOSICIÓN & \multicolumn{6}{|c|}{$\begin{array}{l}\text { Escayola “Hebodur” (3 Vol.) } \\
\text { Agua (1 Vol.) }\end{array}$} \\
\hline PREPARACIÓN & \multicolumn{6}{|c|}{$\begin{array}{l}\text { Sobre el agua se tamiza la escayola, transcurridos } 15 \text { ", } \\
\text { se agita otros } 15 \text { ", }\end{array}$} \\
\hline \multirow{2}{*}{$\begin{array}{l}\text { CONSISTENCIA Y } \\
\text { APLICACIÓN }\end{array}$} & Líquida & $\mathbf{X}$ & Espesa & $\mathrm{X}$ & Pastosa & $\bar{X}$ \\
\hline & Inyección & $\mathrm{X}$ & Vertido & $\mathbf{X}$ & Espátula & $\bar{X}$ \\
\hline T. DE TRABAJO & \multicolumn{6}{|l|}{$10^{\prime}$} \\
\hline T. DE SECADO & \multicolumn{6}{|l|}{3 horas } \\
\hline CONTRACCIÓN & Alta & & Media & & Baja & $\mathbf{X}$ \\
\hline POROSIDAD & Alta & & Media & & Baja & $\mathrm{X}$ \\
\hline DUREZA & Alta & $\mathbf{X}$ & Media & & Baja & \\
\hline ADHESIÓN & Buena & $\mathbf{X}$ & Media & & Mala & \\
\hline \multirow{2}{*}{$\begin{array}{l}\text { NIVELACIÓN Y } \\
\text { PULIDO }\end{array}$} & Buena & & Media & $\mathbf{X}$ & Mala & \\
\hline & Bisturí & $\mathbf{X}$ & Lija & & Otros & $\mathrm{X}$ \\
\hline \multirow[t]{2}{*}{ RETOQUE } & \multicolumn{6}{|c|}{ Pinturas de todo tipo. } \\
\hline & \multicolumn{5}{|c|}{ VENTAJAS/INCONVENIENTES } & \begin{tabular}{l|l} 
V & I \\
\end{tabular} \\
\hline \multicolumn{6}{|l|}{ ELABORACIÓN } & $\mathbf{X}$ \\
\hline \multicolumn{6}{|c|}{ SE CONOCEN LOS MATERIALES Y PROPORCIONES } & $\mathbf{X}$ \\
\hline \multicolumn{6}{|l|}{ APLICACIÓN } & $\mathbf{X}$ \\
\hline \multicolumn{6}{|c|}{ NIVELACIÓN Y PULIDO } & $\mathbf{X}$ \\
\hline \multicolumn{6}{|c|}{ TIEMPO DE TRABAJO } & $\mathbf{X}$ \\
\hline \multicolumn{6}{|c|}{ TIEMPO DE SECADO } & $\bar{X}$ \\
\hline \multicolumn{6}{|c|}{ CONTRACCIÓN/AGRIETAMIENTO } & $\mathbf{X}$ \\
\hline \multicolumn{6}{|l|}{ DUREZA } & $\mathbf{X}$ \\
\hline \multicolumn{6}{|l|}{ POROSIDAD } & $\mathbf{X}$ \\
\hline \multicolumn{6}{|c|}{ ADHESIÓN AL CUERPO CERÁMICO } & $\mathbf{X}$ \\
\hline \multicolumn{6}{|l|}{ RETOQUE } & $\mathbf{X}$ \\
\hline ALMACENAJE & & & & & & $\mathbf{X}$ \\
\hline REVERSIBILIDAD & & & & & & $\mathbf{X}$ \\
\hline OBSERVACIONES & $\begin{array}{l}\text { Color ama } \\
\text { rápidamente } \\
\text { cuando seca }\end{array}$ & & $\begin{array}{l}\text { La nive } \\
\text { su fragt }\end{array}$ & & $\begin{array}{l}\text { debe ejec } \\
\text { bido a su }\end{array}$ & $\begin{array}{l}\text { cutarse } \\
\text { dureza }\end{array}$ \\
\hline VALORACIÓN & & $\mathrm{AB}$ & NO SEL & 4101 & NADA & \\
\hline
\end{tabular}




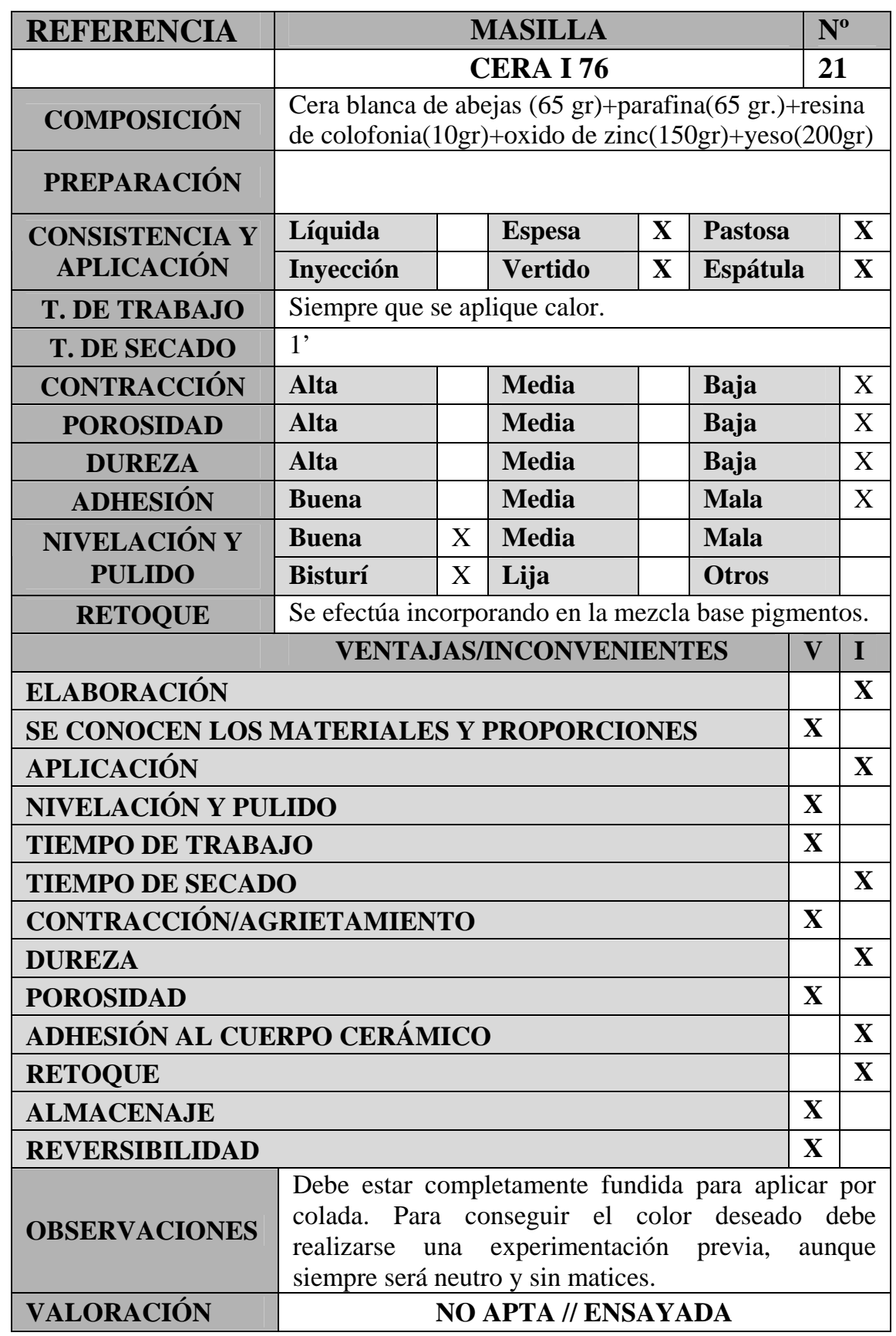




\begin{tabular}{|c|c|c|c|c|c|c|c|}
\hline REFERENCIA & \multicolumn{5}{|c|}{ MASILLA } & \multicolumn{2}{|c|}{$\mathbf{N}^{0}$} \\
\hline & \multicolumn{5}{|c|}{ MOWILITH SDM5/1 } & \multicolumn{2}{|c|}{22} \\
\hline COMPOSICIÓN & \multicolumn{7}{|c|}{$\begin{array}{l}\text { Mowilith SDM5 (1 Vol.) } \\
\text { Sílice coloidal (2 Vol.) }\end{array}$} \\
\hline PREPARACIÓN & \multicolumn{7}{|c|}{ Mezclar los dos componentes homogéneamente. } \\
\hline \multirow{2}{*}{$\begin{array}{l}\text { CONSISTENCIA Y } \\
\text { APLICACIÓN }\end{array}$} & Líquida & & Espesa & & Pastosa & & $\mathbf{X}$ \\
\hline & Inyección & & Vertido & & Espátul & & $\mathbf{X}$ \\
\hline T. DE TRABAJO & \multicolumn{7}{|l|}{2 horas } \\
\hline T. DE SECADO & \multicolumn{7}{|l|}{+24 horas } \\
\hline CONTRACCIÓN & Alta & & Media & & \multicolumn{2}{|l|}{ Baja } & $\mathrm{X}$ \\
\hline POROSIDAD & Alta & & Media & $\mathrm{X}$ & \multicolumn{2}{|l|}{ Baja } & \\
\hline DUREZA & Alta & & Media & & \multicolumn{2}{|l|}{ Baja } & $\mathrm{X}$ \\
\hline ADHESIÓN & Buena & & Media & $\mathrm{X}$ & \multicolumn{2}{|l|}{ Mala } & \\
\hline NIVELACIÓN Y & Buena & $\mathrm{X}$ & Media & & \multicolumn{2}{|l|}{ Mala } & \\
\hline PULIDO & Bisturí & $\mathrm{X}$ & Lija & & \multicolumn{2}{|l|}{ Otros } & $\mathrm{X}$ \\
\hline \multicolumn{8}{|l|}{ RETOQUE } \\
\hline & \multicolumn{5}{|c|}{ VENTAJAS/INCONVENIENTES } & $\mathbf{V}$ & I \\
\hline \multicolumn{7}{|l|}{ ELABORACIÓN } & $\mathbf{X}$ \\
\hline \multicolumn{6}{|c|}{ SE CONOCEN LOS MATERIALES Y PROPORCIONES } & $\mathbf{X}$ & \\
\hline \multicolumn{6}{|l|}{ APLICACIÓN } & & $\mathbf{X}$ \\
\hline \multicolumn{6}{|c|}{ NIVELACIÓN Y PULIDO } & $\mathbf{X}$ & \\
\hline \multicolumn{6}{|c|}{ TIEMPO DE TRABAJO } & $\mathbf{X}$ & \\
\hline \multicolumn{6}{|c|}{ TIEMPO DE SECADO } & & $\mathbf{X}$ \\
\hline \multicolumn{6}{|c|}{ CONTRACCIÓN/AGRIETAMIENTO } & $\mathbf{X}$ & \\
\hline \multicolumn{6}{|l|}{ DUREZA } & & $\mathbf{X}$ \\
\hline \multicolumn{6}{|l|}{ POROSIDAD } & & \\
\hline \multicolumn{6}{|c|}{ ADHESIÓN AL CUERPO CERÁMICO } & $\mathbf{X}$ & \\
\hline \multicolumn{6}{|l|}{ RETOQUE } & & \\
\hline \multicolumn{6}{|l|}{ ALMACENAJE } & $\mathbf{X}$ & \\
\hline \multicolumn{6}{|l|}{ REVERSIBILIDAD } & $\mathbf{X}$ & \\
\hline OBSERVACIONES & Muy flexib & & & & & & \\
\hline VALORACIÓN & & 20 & PTA//RE & $18 \mathrm{H}$ & DA & & \\
\hline
\end{tabular}




\begin{tabular}{|c|c|c|c|c|c|c|c|}
\hline REFERENCIA & \multicolumn{5}{|c|}{ MASILLA } & \multicolumn{2}{|c|}{$\mathbf{N}^{0}$} \\
\hline & \multicolumn{5}{|c|}{ MOWILITH SDM5/2 } & \multicolumn{2}{|c|}{23} \\
\hline COMPOSICIÓN & \multicolumn{7}{|c|}{$\begin{array}{l}\text { Mowilith SDM5 (1 Vol.) } \\
\text { Polvo de Mármol (2 Vol.) }\end{array}$} \\
\hline PREPARACIÓN & \multicolumn{7}{|c|}{ Mezclar los dos componentes homogéneamente. } \\
\hline \multirow{2}{*}{$\begin{array}{l}\text { CONSISTENCIA Y } \\
\text { APLICACIÓN }\end{array}$} & Líquida & & Espesa & & Pastosa & & $\mathbf{X}$ \\
\hline & Inyección & & Vertido & & Espátul & & $\mathbf{X}$ \\
\hline T. DE TRABAJO & \multicolumn{7}{|c|}{ 30’ seca superficialmente. } \\
\hline T. DE SECADO & \multicolumn{7}{|c|}{+24 horas } \\
\hline CONTRACCIÓN & Alta & & Media & & \multicolumn{2}{|l|}{ Baja } & $\mathrm{X}$ \\
\hline POROSIDAD & Alta & & Media & $\mathrm{X}$ & \multicolumn{2}{|l|}{ Baja } & \\
\hline DUREZA & Alta & & Media & & \multicolumn{2}{|l|}{ Baja } & $\mathrm{X}$ \\
\hline ADHESIÓN & Buena & & Media & $\mathrm{X}$ & \multicolumn{2}{|l|}{ Mala } & \\
\hline NIVELACIÓN Y & Buena & $\mathrm{X}$ & Media & & \multicolumn{2}{|l|}{ Mala } & \\
\hline PULIDO & Bisturí & $\mathrm{X}$ & Lija & & \multicolumn{2}{|l|}{ Otros } & $\mathrm{X}$ \\
\hline \multicolumn{8}{|l|}{ RETOQUE } \\
\hline & \multicolumn{5}{|c|}{ VENTAJAS/INCONVENIENTES } & V & I \\
\hline \multicolumn{6}{|l|}{ ELABORACIÓN } & & $\mathbf{X}$ \\
\hline \multicolumn{6}{|c|}{ SE CONOCEN LOS MATERIALES Y PROPORCIONES } & $\mathbf{X}$ & \\
\hline \multicolumn{6}{|l|}{ APLICACIÓN } & & $\mathbf{X}$ \\
\hline \multicolumn{6}{|c|}{ NIVELACIÓN Y PULIDO } & $\mathbf{X}$ & \\
\hline \multicolumn{6}{|c|}{ TIEMPO DE TRABAJO } & $\mathbf{X}$ & \\
\hline \multicolumn{6}{|c|}{ TIEMPO DE SECADO } & & $\mathbf{X}$ \\
\hline \multicolumn{6}{|c|}{ CONTRACCIÓN/AGRIETAMIENTO } & $\mathbf{X}$ & \\
\hline \multicolumn{6}{|l|}{ DUREZA } & & $\mathbf{X}$ \\
\hline \multicolumn{6}{|l|}{ POROSIDAD } & $\mathbf{X}$ & \\
\hline \multicolumn{6}{|c|}{ ADHESIÓN AL CUERPO CERÁMICO } & $\mathbf{X}$ & \\
\hline \multicolumn{6}{|l|}{ RETOQUE } & & \\
\hline \multicolumn{6}{|l|}{ ALMACENAJE } & $\mathbf{X}$ & \\
\hline \multicolumn{6}{|l|}{ REVERSIBILIDAD } & $\mathbf{X}$ & \\
\hline OBSERVACIONES & Flexible y a & so pe & ada. & & & & \\
\hline VALORACIÓN & & NO & PTA//RE & 178 & ADA & & \\
\hline
\end{tabular}




\begin{tabular}{|c|c|c|c|c|c|c|c|}
\hline REFERENCIA & \multicolumn{5}{|c|}{ MASILLA } & \multicolumn{2}{|c|}{$\mathbf{N}^{0}$} \\
\hline & \multicolumn{5}{|c|}{ MOWILITH SDM5/3 } & \multicolumn{2}{|c|}{24} \\
\hline COMPOSICIÓN & \multicolumn{7}{|c|}{$\begin{array}{l}\text { Mowilith SDM5 al 90\% en agua (1 Vol.) } \\
\text { Carbonato cálcico ( } 1 \text { Vol.) }\end{array}$} \\
\hline PREPARACIÓN & \multicolumn{7}{|c|}{ Mezclar los dos componentes homogéneamente. } \\
\hline \multirow{2}{*}{$\begin{array}{l}\text { CONSISTENCIA Y } \\
\text { APLICACIÓN }\end{array}$} & Líquida & & Espesa & $\mathbf{X}$ & Pastosi & & \\
\hline & Inyección & & Vertido & $\mathbf{X}$ & Espátu & & \\
\hline T. DE TRABAJO & \multicolumn{7}{|c|}{ En tres horas se crea una película superficial seca } \\
\hline T. DE SECADO & \multicolumn{7}{|c|}{ + de 48 horas } \\
\hline CONTRACCIÓN & Alta & & Media & & \multicolumn{2}{|l|}{ Baja } & $\mathrm{X}$ \\
\hline POROSIDAD & Alta & & Media & $\mathrm{X}$ & \multicolumn{2}{|l|}{ Baja } & \\
\hline DUREZA & Alta & & Media & & \multicolumn{2}{|l|}{ Baja } & $\mathrm{X}$ \\
\hline ADHESIÓN & Buena & & Media & $\mathrm{X}$ & \multicolumn{2}{|l|}{ Mala } & \\
\hline NIVELACIÓN Y & Buena & $\mathrm{X}$ & Media & & \multicolumn{2}{|l|}{ Mala } & \\
\hline PULIDO & Bisturí & $\mathrm{X}$ & Lija & & \multicolumn{2}{|l|}{ Otros } & $\mathrm{X}$ \\
\hline \multicolumn{8}{|l|}{ RETOQUE } \\
\hline & \multicolumn{5}{|c|}{ VENTAJAS/INCONVENIENTES } & V & I \\
\hline \multicolumn{6}{|l|}{ ELABORACIÓN } & & $\mathbf{X}$ \\
\hline \multicolumn{6}{|c|}{ SE CONOCEN LOS MATERIALES Y PROPORCIONES } & $\mathbf{X}$ & \\
\hline \multicolumn{6}{|c|}{ APLICACIÓN } & $\mathbf{X}$ & \\
\hline \multicolumn{6}{|c|}{ NIVELACIÓN Y PULIDO } & $\mathbf{X}$ & \\
\hline \multicolumn{6}{|c|}{ TIEMPO DE TRABAJO } & $\mathbf{X}$ & \\
\hline \multicolumn{6}{|c|}{ TIEMPO DE SECADO } & & $\mathbf{X}$ \\
\hline \multicolumn{6}{|c|}{ CONTRACCIÓN/AGRIETAMIENTO } & & $\mathrm{X}$ \\
\hline \multicolumn{6}{|l|}{ DUREZA } & & $\mathbf{X}$ \\
\hline \multicolumn{6}{|l|}{ POROSIDAD } & & $\mathbf{X}$ \\
\hline \multicolumn{6}{|c|}{ ADHESIÓN AL CUERPO CERÁMICO } & $\mathbf{X}$ & \\
\hline \multicolumn{8}{|l|}{ RETOQUE } \\
\hline \multicolumn{6}{|l|}{ ALMACENAJE } & $\mathbf{X}$ & \\
\hline \multicolumn{6}{|l|}{ REVERSIBILIDAD } & $\mathbf{X}$ & \\
\hline OBSERVACIONES & Agrieta en & eca & lo. Flexibl & & & & \\
\hline VALORACIÓN & & 8 & PTA//RE & $18 \mathrm{H}$ & DA & & \\
\hline
\end{tabular}




\begin{tabular}{|c|c|c|c|c|c|c|c|}
\hline REFERENCIA & \multicolumn{5}{|c|}{ MASILLA } & \multicolumn{2}{|c|}{$\mathbf{N}^{0}$} \\
\hline & \multicolumn{5}{|c|}{ MOWILITH SDM5/4 } & \multicolumn{2}{|c|}{25} \\
\hline COMPOSICIÓN & \multicolumn{7}{|c|}{$\begin{array}{l}\text { Mowilith SDM5 (1 Vol.) } \\
\text { Carbonato cálcico (3 Vol.) }\end{array}$} \\
\hline PREPARACIÓN & \multicolumn{7}{|c|}{ Mezclar los dos componentes homogéneamente. } \\
\hline \multirow{2}{*}{$\begin{array}{l}\text { CONSISTENCIA Y } \\
\text { APLICACIÓN }\end{array}$} & Líquida & & Espesa & $\mathbf{X}$ & Pastos & & \\
\hline & Inyección & & Vertido & $\mathbf{X}$ & Espátı & & \\
\hline T. DE TRABAJO & \multicolumn{7}{|c|}{ En una hora se crea una película superficial seca } \\
\hline T. DE SECADO & \multicolumn{7}{|c|}{ + de 24 horas } \\
\hline CONTRACCIÓN & Alta & & Media & & \multicolumn{2}{|l|}{ Baja } & $\mathrm{X}$ \\
\hline POROSIDAD & Alta & & Media & $\mathrm{X}$ & \multicolumn{2}{|l|}{ Baja } & \\
\hline DUREZA & Alta & & Media & & \multicolumn{2}{|l|}{ Baja } & $\mathrm{X}$ \\
\hline ADHESIÓN & Buena & & Media & $\mathrm{X}$ & \multicolumn{2}{|l|}{ Mala } & \\
\hline NIVELACIÓN Y & Buena & $\mathrm{X}$ & Media & & \multicolumn{2}{|l|}{ Mala } & \\
\hline PULIDO & Bisturí & $\mathrm{X}$ & Lija & & \multicolumn{2}{|l|}{ Otros } & $\mathrm{X}$ \\
\hline \multicolumn{8}{|l|}{ RETOQUE } \\
\hline & \multicolumn{5}{|c|}{ VENTAJAS/INCONVENIENTES } & $\mathbf{V}$ & I \\
\hline \multicolumn{6}{|l|}{ ELABORACIÓN } & & $\mathbf{X}$ \\
\hline \multicolumn{6}{|c|}{ SE CONOCEN LOS MATERIALES Y PROPORCIONES } & $\mathbf{X}$ & \\
\hline \multicolumn{6}{|l|}{ APLICACIÓN } & $\mathbf{X}$ & \\
\hline \multicolumn{6}{|c|}{ NIVELACIÓN Y PULIDO } & $\mathbf{X}$ & \\
\hline \multicolumn{6}{|c|}{ TIEMPO DE TRABAJO } & $\mathbf{X}$ & \\
\hline \multicolumn{6}{|c|}{ TIEMPO DE SECADO } & & $\mathbf{X}$ \\
\hline \multicolumn{6}{|c|}{ CONTRACCIÓN/AGRIETAMIENTO } & & $\mathbf{X}$ \\
\hline \multicolumn{6}{|l|}{ DUREZA } & & $\mathbf{X}$ \\
\hline \multicolumn{6}{|l|}{ POROSIDAD } & & $\mathbf{X}$ \\
\hline \multicolumn{6}{|c|}{ ADHESIÓN AL CUERPO CERÁMICO } & $\mathbf{X}$ & \\
\hline \multicolumn{6}{|l|}{ RETOQUE } & & \\
\hline \multicolumn{6}{|l|}{ ALMACENAJE } & $\mathbf{X}$ & \\
\hline \multicolumn{6}{|l|}{ REVERSIBILIDAD } & $\mathbf{X}$ & \\
\hline OBSERVACIONES & Flexible. A & & & & & & \\
\hline VALORACIÓN & & NO & IPTA//RE & 178 & ADA & & \\
\hline
\end{tabular}




\begin{tabular}{|c|c|c|c|c|c|c|c|}
\hline REFERENCIA & \multicolumn{5}{|c|}{ MASILLA } & \multicolumn{2}{|c|}{$\mathbf{N}^{\circ}$} \\
\hline & \multicolumn{5}{|c|}{ MOWILITH SDM5/5 } & \multicolumn{2}{|c|}{26} \\
\hline COMPOSICIÓN & \multicolumn{7}{|c|}{$\begin{array}{l}\text { Mowilith SDM5 (2 Vol.) } \\
\text { Carbonato cálcico (7 Vol.) }\end{array}$} \\
\hline PREPARACIÓN & \multicolumn{7}{|c|}{ Mezclar los dos componentes homogéneamente. } \\
\hline \multirow{2}{*}{$\begin{array}{l}\text { CONSISTENCIA Y } \\
\text { APLICACIÓN }\end{array}$} & Líquida & & Espesa & & Pastosa & & $\mathbf{X}$ \\
\hline & Inyección & & Vertido & & Espátu & & $\mathbf{X}$ \\
\hline T. DE TRABAJO & \multicolumn{7}{|l|}{$30^{\prime}$} \\
\hline T. DE SECADO & \multicolumn{7}{|l|}{12 horas } \\
\hline CONTRACCIÓN & Alta & & Media & & \multicolumn{2}{|l|}{ Baja } & $\mathrm{X}$ \\
\hline POROSIDAD & Alta & & Media & $\mathrm{X}$ & \multicolumn{2}{|l|}{ Baja } & \\
\hline DUREZA & Alta & & Media & & \multicolumn{2}{|l|}{ Baja } & $\mathrm{X}$ \\
\hline ADHESIÓN & Buena & & Media & $\mathrm{X}$ & \multicolumn{2}{|l|}{ Mala } & \\
\hline NIVELACIÓN Y & Buena & $\mathrm{X}$ & Media & & \multicolumn{2}{|l|}{ Mala } & \\
\hline PULIDO & Bisturí & $\mathrm{X}$ & Lija & & \multicolumn{2}{|l|}{ Otros } & $\mathrm{X}$ \\
\hline \multicolumn{8}{|l|}{ RETOQUE } \\
\hline & \multicolumn{5}{|c|}{ VENTAJAS/INCONVENIENTES } & $\mathbf{V}$ & I \\
\hline \multicolumn{6}{|l|}{ ELABORACIÓN } & & $\mathbf{X}$ \\
\hline \multicolumn{6}{|c|}{ SE CONOCEN LOS MATERIALES Y PROPORCIONES } & $\mathbf{X}$ & \\
\hline \multicolumn{6}{|c|}{ APLICACIÓN } & & $\mathbf{X}$ \\
\hline \multicolumn{6}{|c|}{ NIVELACIÓN Y PULIDO } & $\mathbf{X}$ & \\
\hline \multicolumn{6}{|c|}{ TIEMPO DE TRABAJO } & $\mathbf{X}$ & \\
\hline \multicolumn{6}{|c|}{ TIEMPO DE SECADO } & & $\mathbf{X}$ \\
\hline \multicolumn{6}{|c|}{ CONTRACCIÓN/AGRIETAMIENTO } & & $\mathbf{X}$ \\
\hline \multicolumn{6}{|l|}{ DUREZA } & & $\mathbf{X}$ \\
\hline \multicolumn{6}{|l|}{ POROSIDAD } & $\mathbf{X}$ & \\
\hline \multicolumn{6}{|c|}{ ADHESIÓN AL CUERPO CERÁMICO } & $\mathbf{X}$ & \\
\hline \multicolumn{8}{|l|}{ RETOQUE } \\
\hline \multicolumn{6}{|l|}{ ALMACENAJE } & $\mathbf{X}$ & \\
\hline \multicolumn{6}{|l|}{ REVERSIBILIDAD } & $\mathbf{X}$ & \\
\hline OBSERVACIONES & $\begin{array}{l}\text { Cuesta apli } \\
\text { es algo flex }\end{array}$ & & recoje bie & & ronta. A & grie & \\
\hline VALORACIÓN & & NO & PTA//RE & [AZZ & IDA & & \\
\hline
\end{tabular}




\begin{tabular}{|c|c|c|c|c|c|c|c|}
\hline REFERENCIA & \multicolumn{5}{|c|}{ MASILLA } & \multicolumn{2}{|c|}{$\mathbf{N}^{\mathbf{o}}$} \\
\hline & \multicolumn{5}{|c|}{ ACRIL 33/1 } & \multicolumn{2}{|c|}{27} \\
\hline COMPOSICIÓN & \multicolumn{7}{|c|}{$\begin{array}{l}\text { Acril } 33 \text { (2 Vol.) } \\
\text { Sílice micronizado (3 Vol.) }\end{array}$} \\
\hline PREPARACIÓN & \multicolumn{7}{|c|}{$\begin{array}{l}\text { Mezcla de los dos componentes con espátula flexible } \\
\text { hasta conseguir una mezcla homogénea. }\end{array}$} \\
\hline \multirow{2}{*}{$\begin{array}{l}\text { CONSISTENCIA Y } \\
\text { APLICACIÓN }\end{array}$} & Líquida & & Espesa & & Pastosa & & $\mathbf{X}$ \\
\hline & Inyección & & Vertido & & Espátul & & $\mathbf{X}$ \\
\hline T. DE TRABAJO & \multicolumn{7}{|l|}{3 horas } \\
\hline T. DE SECADO & \multicolumn{7}{|l|}{24 horas } \\
\hline CONTRACCIÓN & Alta & $\mathbf{X}$ & Media & & \multicolumn{3}{|l|}{ Baja } \\
\hline POROSIDAD & Alta & & Media & $\mathbf{X}$ & \multicolumn{2}{|l|}{ Baja } & \\
\hline DUREZA & Alta & & Media & & \multicolumn{2}{|l|}{ Baja } & $\mathbf{X}$ \\
\hline ADHESIÓN & Buena & & Media & $\mathbf{X}$ & \multicolumn{2}{|l|}{ Mala } & \\
\hline NIVELACIÓN Y & Buena & & Media & $\mathbf{X}$ & \multicolumn{2}{|l|}{ Mala } & \\
\hline PULIDO & Bisturí & $\mathbf{X}$ & Lija & & \multicolumn{2}{|l|}{ Otros } & $\mathbf{X}$ \\
\hline \multicolumn{3}{|l|}{ RETOQUE } & & & & & \\
\hline \multirow{2}{*}{\multicolumn{7}{|c|}{ VENTAJAS/INCONVENIENTES }} & I \\
\hline & & & & & & & $\mathbf{X}$ \\
\hline \multicolumn{6}{|c|}{ SE CONOCEN LOS MATERIALES Y PROPORCIONES } & $\mathbf{X}$ & \\
\hline \multicolumn{6}{|l|}{ APLICACIÓN } & & $\mathbf{X}$ \\
\hline \multicolumn{6}{|c|}{ NIVELACIÓN Y PULIDO } & & $\mathbf{X}$ \\
\hline \multicolumn{6}{|c|}{ TIEMPO DE TRABAJO } & & $\mathbf{X}$ \\
\hline \multicolumn{6}{|c|}{ TIEMPO DE SECADO } & & $\mathbf{X}$ \\
\hline \multicolumn{6}{|c|}{ CONTRACCIÓN/AGRIETAMIENTO } & & $\mathbf{X}$ \\
\hline \multicolumn{6}{|l|}{ DUREZA } & & $\mathbf{X}$ \\
\hline \multicolumn{6}{|l|}{ POROSIDAD } & $\mathbf{X}$ & \\
\hline \multicolumn{6}{|c|}{ ADHESIÓN AL CUERPO CERÁMICO } & $\mathbf{x}$ & \\
\hline \multicolumn{6}{|l|}{ RETOQUE } & & \\
\hline \multicolumn{6}{|l|}{ ALMACENAJE } & $\mathbf{X}$ & \\
\hline \multicolumn{6}{|l|}{ REVERSIBILIDAD } & $\mathbf{X}$ & \\
\hline OBSERVACIONES & Presenta $\mathrm{m}$ & cha & exibilida & & & & \\
\hline VALORACIÓN & & JOA & $\overline{\text { PTA / RE }}$ & $1 \mathrm{AL}$ & $\overline{\text { ADA }}$ & & \\
\hline
\end{tabular}




\begin{tabular}{|c|c|c|c|c|c|c|c|}
\hline REFERENCIA & \multicolumn{5}{|c|}{ MASILLA } & $\mathbf{N}$ & \\
\hline & \multicolumn{5}{|c|}{ ACRIL 33/2 } & 28 & \\
\hline COMPOSICIÓN & \multicolumn{5}{|c|}{$\begin{array}{l}\text { Acril } 33 \text { (1 Vol.) } \\
\text { Carbonato cálcico (1 Vol.) }\end{array}$} & & \\
\hline PREPARACIÓN & \multicolumn{7}{|c|}{$\begin{array}{l}\text { Mezcla de los dos componentes con espátula flexible } \\
\text { hasta conseguir una mezcla homogéne. }\end{array}$} \\
\hline \multirow{2}{*}{$\begin{array}{l}\text { CONSISTENCIA Y } \\
\text { APLICACIÓN }\end{array}$} & Líquida & & Espesa & & Pastosa & & $\mathbf{X}$ \\
\hline & Inyección & & Vertido & & Espátula & & $\mathbf{X}$ \\
\hline T. DE TRABAJO & \multicolumn{7}{|l|}{3 horas } \\
\hline T. DE SECADO & \multicolumn{7}{|l|}{24 horas } \\
\hline CONTRACCIÓN & Alta & $\mathbf{X}$ & Media & & \multicolumn{2}{|l|}{ Baja } & \\
\hline POROSIDAD & Alta & & Media & $\mathbf{X}$ & \multicolumn{2}{|l|}{ Baja } & \\
\hline DUREZA & Alta & & Media & $\mathbf{X}$ & \multicolumn{2}{|l|}{ Baja } & \\
\hline ADHESIÓN & Buena & & Media & $\mathbf{X}$ & \multicolumn{2}{|l|}{ Mala } & \\
\hline \multirow{2}{*}{$\begin{array}{l}\text { NIVELACIÓN Y } \\
\text { PULIDO }\end{array}$} & Buena & & Media & $\mathbf{X}$ & Mala & & \\
\hline & Bisturí & $\mathbf{X}$ & Lija & & Otros & & $\mathbf{X}$ \\
\hline \multirow[t]{2}{*}{ RETOQUE } & \multicolumn{7}{|c|}{ Toda clase de pinturas } \\
\hline & \multicolumn{5}{|c|}{ VENTAJAS/INCONVENIENTES } & $\mathbf{V}$ & I \\
\hline \multicolumn{6}{|l|}{ ELABORACIÓN } & & $\mathbf{X}$ \\
\hline \multicolumn{6}{|c|}{ SE CONOCEN LOS MATERIALES Y PROPORCIONES } & $\mathbf{X}$ & \\
\hline \multicolumn{6}{|l|}{ APLICACIÓN } & & $\mathbf{X}$ \\
\hline \multicolumn{6}{|c|}{ NIVELACIÓN Y PULIDO } & & $\mathbf{X}$ \\
\hline \multicolumn{6}{|c|}{ TIEMPO DE TRABAJO } & & $\mathbf{X}$ \\
\hline \multicolumn{6}{|c|}{ TIEMPO DE SECADO } & & $\mathbf{X}$ \\
\hline \multicolumn{6}{|c|}{ CONTRACCIÓN/AGRIETAMIENTO } & & $\mathbf{X}$ \\
\hline \multicolumn{6}{|l|}{ DUREZA } & & $\mathbf{X}$ \\
\hline \multicolumn{6}{|l|}{ POROSIDAD } & $\mathbf{X}$ & \\
\hline \multicolumn{6}{|c|}{ ADHESIÓN AL CUERPO CERÁMICO } & $\mathbf{X}$ & \\
\hline \multicolumn{7}{|l|}{ RETOQUE } & \\
\hline \multicolumn{6}{|l|}{ ALMACENAJE } & $\mathbf{X}$ & \\
\hline \multicolumn{6}{|l|}{ REVERSIBILIDAD } & $\mathbf{X}$ & \\
\hline OBSERVACIONES & \multicolumn{7}{|c|}{ Masilla muy flexible . Agrieta durante el secado } \\
\hline VALORACIÓN & \multicolumn{7}{|c|}{ NO APTA / RECHAZADA } \\
\hline
\end{tabular}




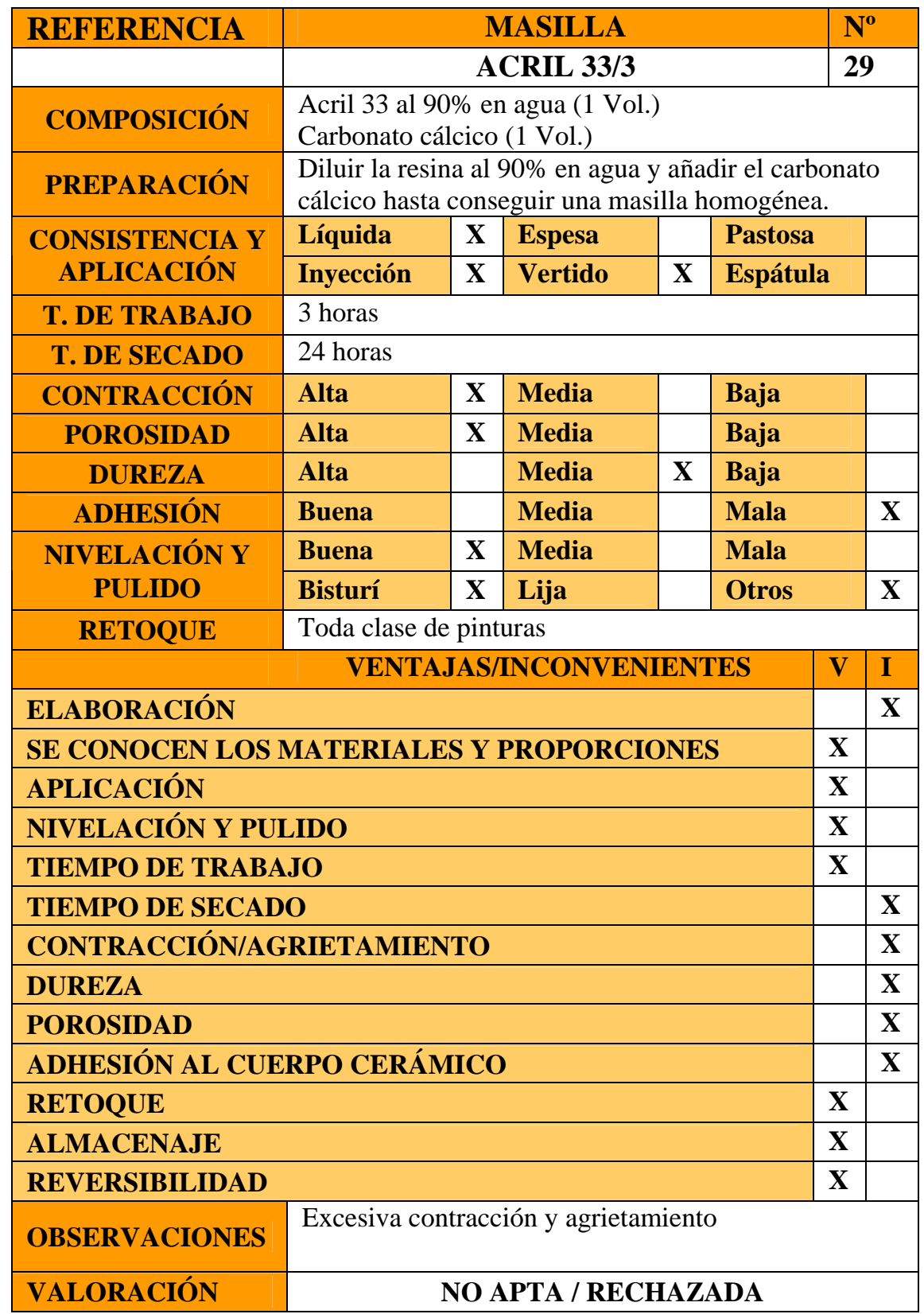




\begin{tabular}{|c|c|c|c|c|c|c|c|}
\hline REFERENCIA & \multicolumn{5}{|c|}{ MASILLA } & $\mathbf{N}$ & \\
\hline B2 & \multicolumn{5}{|c|}{ ACRIL 33/4 } & 30 & \\
\hline COMPOSICIÓN & \multicolumn{6}{|c|}{$\begin{array}{l}\text { Acril } 33 \text { (1 Vol.) } \\
\text { Carbonato cálcico (2 Vol.) }\end{array}$} & \\
\hline PREPARACIÓN & \multicolumn{7}{|c|}{$\begin{array}{l}\text { Mezcla de los dos componentes hasta conseguir una } \\
\text { masilla homogénea. }\end{array}$} \\
\hline \multirow{2}{*}{$\begin{array}{l}\text { CONSISTENCIA Y } \\
\text { APLICACIÓN }\end{array}$} & Líquida & & Espesa & $\mathbf{X}$ & Pastosa & & \\
\hline & Inyección & & Vertido & $\mathbf{X}$ & Espátule & & \\
\hline T. DE TRABAJO & \multicolumn{7}{|l|}{1 hora } \\
\hline T. DE SECADO & \multicolumn{7}{|c|}{ + de 24 horas } \\
\hline CONTRACCIÓN & Alta & & Media & $\mathrm{X}$ & \multicolumn{2}{|l|}{ Baja } & \\
\hline POROSIDAD & Alta & & Media & $\mathrm{X}$ & \multicolumn{2}{|l|}{ Baja } & \\
\hline DUREZA & Alta & & Media & $\mathrm{X}$ & \multicolumn{2}{|l|}{ Baja } & \\
\hline ADHESIÓN & Buena & $\mathrm{X}$ & Media & & \multicolumn{2}{|l|}{ Mala } & \\
\hline \multirow{2}{*}{$\begin{array}{l}\text { NIVELACIÓN Y } \\
\text { PULIDO }\end{array}$} & Buena & $\mathrm{X}$ & Media & & Mala & & \\
\hline & Bisturí & $\mathrm{X}$ & Lija & $\mathrm{X}$ & Otros & & $\mathrm{X}$ \\
\hline \multirow[t]{2}{*}{ RETOQUE } & \multicolumn{7}{|c|}{ Toda clase de pinturas } \\
\hline & \multicolumn{5}{|c|}{ VENTAJAS/INCONVENIENTES } & $\mathbf{V}$ & I \\
\hline \multicolumn{6}{|l|}{ ELABORACIÓN } & & $\mathbf{X}$ \\
\hline \multicolumn{6}{|c|}{ SE CONOCEN LOS MATERIALES Y PROPORCIONES } & $\mathbf{X}$ & \\
\hline \multicolumn{6}{|c|}{ APLICACIÓN } & $\mathbf{X}$ & \\
\hline \multicolumn{6}{|c|}{ NIVELACIÓN Y PULIDO } & $\mathbf{X}$ & \\
\hline \multicolumn{6}{|c|}{ TIEMPO DE TRABAJO } & $\mathbf{X}$ & \\
\hline \multicolumn{6}{|c|}{ TIEMPO DE SECADO } & & $\mathbf{X}$ \\
\hline \multicolumn{6}{|c|}{ CONTRACCIÓN/AGRIETAMIENTO } & & $\mathbf{X}$ \\
\hline \multicolumn{6}{|l|}{ DUREZA } & $\mathbf{X}$ & \\
\hline \multicolumn{6}{|l|}{ POROSIDAD } & & $\mathbf{X}$ \\
\hline \multicolumn{6}{|c|}{ ADHESIÓN AL CUERPO CERÁMICO } & $\mathbf{X}$ & \\
\hline \multicolumn{6}{|l|}{ RETOQUE } & $\mathbf{X}$ & \\
\hline \multicolumn{6}{|l|}{ ALMACENAJE } & $\mathbf{X}$ & \\
\hline \multicolumn{6}{|l|}{ REVERSIBILIDAD } & $\mathbf{X}$ & \\
\hline OBSERVACIONES & \multicolumn{7}{|c|}{ Nivelación en seco. } \\
\hline VALORACIÓN & \multicolumn{7}{|c|}{ APTA / ENSAYADA } \\
\hline
\end{tabular}




\begin{tabular}{|c|c|c|c|c|c|c|c|}
\hline REFERENCIA & \multicolumn{5}{|c|}{ MASILLA } & \multicolumn{2}{|c|}{$\mathbf{N}^{\circ}$} \\
\hline & \multicolumn{5}{|c|}{ ACRIL 33/5 } & 31 & \\
\hline COMPOSICIÓN & \multicolumn{5}{|c|}{$\begin{array}{l}\text { Acril } 33 \text { (1 Vol.) } \\
\text { Carbonato cálcico (3 Vol.) }\end{array}$} & & \\
\hline PREPARACIÓN & \multicolumn{7}{|c|}{$\begin{array}{l}\text { Mezcla de los dos componentes hasta conseguir una } \\
\text { masilla homogénea. }\end{array}$} \\
\hline \multirow{2}{*}{$\begin{array}{l}\text { CONSISTENCIA Y } \\
\text { APLICACIÓN }\end{array}$} & Líquida & & Espesa & $\mathbf{X}$ & Pastosa & & \\
\hline & Inyección & & Vertido & $\mathbf{X}$ & Espátula & & \\
\hline T. DE TRABAJO & \multicolumn{7}{|l|}{1 hora } \\
\hline T. DE SECADO & \multicolumn{7}{|c|}{ + de 24 horas } \\
\hline CONTRACCIÓN & Alta & & Media & $\mathrm{X}$ & \multicolumn{2}{|l|}{ Baja } & \\
\hline POROSIDAD & Alta & & Media & $\mathrm{X}$ & \multicolumn{2}{|l|}{ Baja } & \\
\hline DUREZA & Alta & $\mathrm{X}$ & Media & & \multicolumn{2}{|l|}{ Baja } & \\
\hline ADHESIÓN & Buena & $\mathrm{X}$ & Media & & \multicolumn{2}{|l|}{ Mala } & \\
\hline \multirow{2}{*}{$\begin{array}{l}\text { NIVELACIÓN Y } \\
\text { PULIDO }\end{array}$} & Buena & $\mathrm{X}$ & Media & & Mala & & \\
\hline & Bisturí & $\begin{array}{l}\mathrm{X} \\
\mathrm{X}\end{array}$ & Lija & $\mathrm{X}$ & Otros & & $\mathrm{X}$ \\
\hline RETOQUE & \multicolumn{7}{|c|}{ Toda clase de pinturas } \\
\hline & \multicolumn{5}{|c|}{ VENTAJAS/INCONVENIENTES } & $\overline{\mathbf{V}}$ & $\mathbf{I}$ \\
\hline \multicolumn{6}{|l|}{ ELABORACIÓN } & & $\mathbf{X}$ \\
\hline \multicolumn{6}{|c|}{ SE CONOCEN LOS MATERIALES Y PROPORCIONES } & $\mathbf{X}$ & \\
\hline \multicolumn{6}{|l|}{ APLICACIÓN } & $\mathbf{X}$ & \\
\hline \multicolumn{6}{|c|}{ NIVELACIÓN Y PULIDO } & $\mathbf{X}$ & \\
\hline \multicolumn{6}{|c|}{ TIEMPO DE TRABAJO } & $\mathbf{X}$ & \\
\hline \multicolumn{6}{|c|}{ TIEMPO DE SECADO } & & $\mathbf{X}$ \\
\hline \multicolumn{6}{|c|}{ CONTRACCIÓN/AGRIETAMIENTO } & & $\mathbf{X}$ \\
\hline \multicolumn{6}{|l|}{ DUREZA } & & $\mathbf{X}$ \\
\hline \multicolumn{6}{|l|}{ POROSIDAD } & & $\mathbf{X}$ \\
\hline \multicolumn{6}{|c|}{ ADHESIÓN AL CUERPO CERÁMICO } & $\mathbf{X}$ & \\
\hline \multicolumn{6}{|l|}{ RETOQUE } & $\mathbf{X}$ & \\
\hline \multicolumn{6}{|l|}{ ALMACENAJE } & $\mathbf{X}$ & \\
\hline \multicolumn{6}{|l|}{ REVERSIBILIDAD } & $\mathbf{X}$ & \\
\hline OBSERVACIONES & \multicolumn{7}{|c|}{$\begin{array}{l}\text { Agrietamiento que debe ser reparado. Nivelación en } \\
\text { seco }\end{array}$} \\
\hline VALORACIÓN & \multicolumn{7}{|c|}{ APATA/RECHAZADA } \\
\hline
\end{tabular}




\begin{tabular}{|c|c|c|c|c|c|c|c|}
\hline REFERENCIA & \multicolumn{5}{|c|}{ MASILLA } & $\mathbf{N}$ & \\
\hline & \multicolumn{5}{|c|}{ ACRIL 33/6 } & 3 & \\
\hline COMPOSICIÓN & \multicolumn{5}{|c|}{$\begin{array}{l}\text { Acril } 33 \text { (1 Vol.) } \\
\text { Carbonato cálcico (4 Vol.) }\end{array}$} & & \\
\hline PREPARACIÓN & \multicolumn{7}{|c|}{$\begin{array}{l}\text { Mezcla de los dos componentes hasta conseguir una } \\
\text { masilla homogénea. }\end{array}$} \\
\hline \multirow{2}{*}{$\begin{array}{l}\text { CONSISTENCIA Y } \\
\text { APLICACIÓN }\end{array}$} & Líquida & & Espesa & $\mathbf{X}$ & Pastosa & & $\mathbf{X}$ \\
\hline & Inyección & & Vertido & & Espátula & & $\mathbf{X}$ \\
\hline T. DE TRABAJO & \multicolumn{7}{|l|}{30 ' } \\
\hline T. DE SECADO & \multicolumn{7}{|l|}{+24 horas } \\
\hline CONTRACCIÓN & Alta & & Media & $\mathrm{X}$ & \multicolumn{2}{|l|}{ Baja } & \\
\hline POROSIDAD & Alta & & Media & & \multicolumn{2}{|l|}{ Baja } & $\mathrm{X}$ \\
\hline DUREZA & Alta & & Media & $\mathrm{X}$ & \multicolumn{2}{|l|}{ Baja } & \\
\hline ADHESIÓN & Buena & $\mathrm{X}$ & Media & & \multicolumn{2}{|l|}{ Mala } & \\
\hline \multirow{2}{*}{$\begin{array}{l}\text { NIVELACIÓN Y } \\
\text { PULIDO }\end{array}$} & Buena & $\mathrm{X}$ & Media & & Mala & & \\
\hline & Bisturí & $\mathrm{X}$ & Lija & $\mathrm{X}$ & Otros & & $\mathrm{X}$ \\
\hline \multirow[t]{2}{*}{ RETOQUE } & \multicolumn{7}{|c|}{ Toda clase de pinturas } \\
\hline & \multicolumn{5}{|c|}{ VENTAJAS/INCONVENIENTES } & $\mathbf{V}$ & I \\
\hline \multicolumn{6}{|l|}{ ELABORACIÓN } & & $\mathbf{X}$ \\
\hline \multicolumn{6}{|c|}{ SE CONOCEN LOS MATERIALES Y PROPORCIONES } & $\mathbf{X}$ & \\
\hline \multicolumn{6}{|c|}{ APLICACIÓN } & & $\mathbf{X}$ \\
\hline \multicolumn{6}{|c|}{ NIVELACIÓN Y PULIDO } & $\mathbf{X}$ & \\
\hline \multicolumn{6}{|c|}{ TIEMPO DE TRABAJO } & $\mathbf{X}$ & \\
\hline \multicolumn{6}{|c|}{ TIEMPO DE SECADO } & & $\mathbf{X}$ \\
\hline \multicolumn{6}{|c|}{ CONTRACCIÓN/AGRIETAMIENTO } & & $\mathbf{X}$ \\
\hline \multicolumn{6}{|l|}{ DUREZA } & $\mathbf{X}$ & \\
\hline \multicolumn{6}{|l|}{ POROSIDAD } & $\mathbf{X}$ & \\
\hline \multicolumn{6}{|c|}{ ADHESIÓN AL CUERPO CERÁMICO } & $\mathbf{X}$ & \\
\hline \multicolumn{6}{|l|}{ RETOQUE } & $\mathbf{X}$ & \\
\hline \multicolumn{6}{|l|}{ ALMACENAJE } & & $\mathbf{X}$ \\
\hline \multicolumn{6}{|l|}{ REVERSIBILIDAD } & $\mathbf{X}$ & \\
\hline NES & \multicolumn{7}{|c|}{$\begin{array}{l}\text { Flexible en capa fina. Agrieta en capa gruesa. Tinene } \\
\text { un buen acabado,. }\end{array}$} \\
\hline VALORACIÓN & \multicolumn{7}{|c|}{ APTA//RECHAZADA } \\
\hline
\end{tabular}


Investigación y análisis de las masillas de relleno para la reintegración de lagunas cerámicas arqueológicas

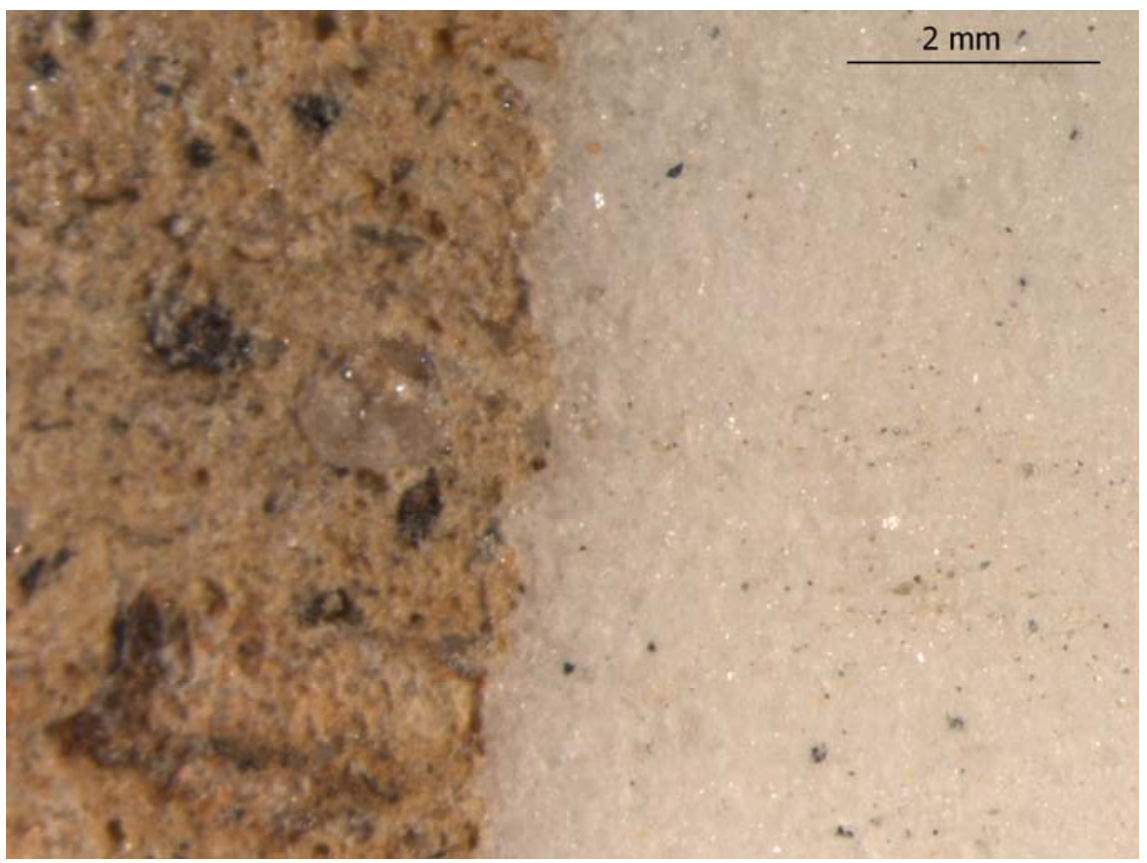

Figura 4. Masilla B3 y cerámica época islámica. 


\begin{tabular}{|c|c|c|c|c|c|c|c|}
\hline REFERENCIA & \multicolumn{5}{|c|}{ MASILLA } & \multirow{2}{*}{\multicolumn{2}{|c|}{$\begin{array}{l}\mathbf{N}^{\circ} \\
33\end{array}$}} \\
\hline B3 & \multicolumn{5}{|c|}{ ACRIL 33/7 } & & \\
\hline COMPOSICIÓN & \multicolumn{7}{|c|}{$\begin{array}{l}\text { Acril } 33 \text { (4 Vol.) } \\
\text { Polvo de mármol (9 Vol.) }\end{array}$} \\
\hline PREPARACIÓN & \multicolumn{7}{|c|}{$\begin{array}{l}\text { Mezcla de los dos componentes hasta conseguir una } \\
\text { masilla homogénea. }\end{array}$} \\
\hline \multirow{2}{*}{$\begin{array}{l}\text { CONSISTENCIA Y } \\
\text { APLICACIÓN }\end{array}$} & Líquida & $\mathbf{X}$ & Espesa & & Pastosa & & \\
\hline & Inyección & $\mathbf{X}$ & Vertido & $\mathbf{X}$ & Espátul & & \\
\hline T. DE TRABAJO & \multicolumn{7}{|l|}{1 hora } \\
\hline T. DE SECADO & \multicolumn{7}{|l|}{+24 horas } \\
\hline CONTRACCIÓN & Alta & & Media & & \multicolumn{2}{|l|}{ Baja } & $\mathrm{X}$ \\
\hline POROSIDAD & Alta & & Media & & \multicolumn{2}{|l|}{ Baja } & $\mathrm{X}$ \\
\hline DUREZA & Alta & $\mathrm{X}$ & Media & & \multicolumn{2}{|l|}{ Baja } & \\
\hline ADHESIÓN & Buena & $\mathrm{X}$ & Media & & \multicolumn{2}{|l|}{ Mala } & \\
\hline \multirow{2}{*}{$\begin{array}{l}\text { NIVELACIÓN Y } \\
\text { PULIDO }\end{array}$} & Buena & $\mathrm{X}$ & Media & & \multicolumn{2}{|l|}{ Mala } & \\
\hline & Bisturí & $\mathrm{X}$ & Lija & $\mathrm{X}$ & Otros & & $\mathrm{X}$ \\
\hline RETOQUE & \multicolumn{7}{|c|}{ Toda clase de pinturas } \\
\hline & \multicolumn{5}{|c|}{ VENTAJAS/INCONVENIENTES } & $\mathbf{V}$ & I \\
\hline \multicolumn{6}{|l|}{ ELABORACIÓN } & & $\mathbf{X}$ \\
\hline \multicolumn{6}{|c|}{ SE CONOCEN LOS MATERIALES Y PROPORCIONES } & $\mathbf{X}$ & \\
\hline \multicolumn{6}{|c|}{ APLICACIÓN } & $\mathbf{X}$ & \\
\hline \multicolumn{6}{|c|}{ NIVELACIÓN Y PULIDO } & $\mathbf{X}$ & \\
\hline \multicolumn{6}{|c|}{ TIEMPO DE TRABAJO } & $\mathbf{X}$ & \\
\hline \multicolumn{6}{|c|}{ TIEMPO DE SECADO } & & $\mathbf{X}$ \\
\hline \multicolumn{6}{|c|}{ CONTRACCIÓN/AGRIETAMIENTO } & $\mathbf{X}$ & \\
\hline \multicolumn{6}{|l|}{ DUREZA } & $\mathbf{X}$ & \\
\hline \multicolumn{6}{|l|}{ POROSIDAD } & $\mathbf{X}$ & \\
\hline \multicolumn{6}{|c|}{ ADHESIÓN AL CUERPO CERÁMICO } & $\mathbf{X}$ & \\
\hline \multicolumn{6}{|l|}{ RETOQUE } & $\mathbf{X}$ & \\
\hline \multicolumn{6}{|l|}{ ALMACENAJE } & $\mathbf{X}$ & \\
\hline \multicolumn{6}{|l|}{ REVERSIBILIDAD } & $\mathbf{X}$ & \\
\hline OBSERVACIONES & \multicolumn{7}{|c|}{$\begin{array}{l}\text { Muy cómoda de nivelar, siempre en seco, con } \\
\text { cualquier medio, no produce polvo. }\end{array}$} \\
\hline VALORACIÓN & & APT & / / SELEC & $\overline{\mathbf{O N}}$ & DA & & \\
\hline
\end{tabular}




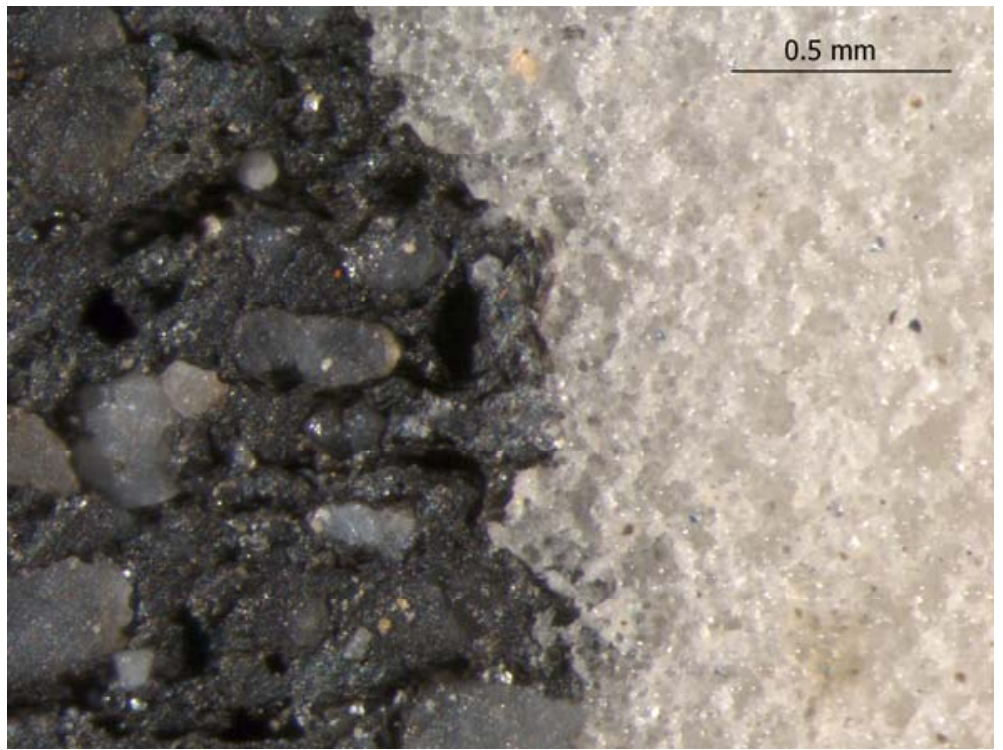

Figura 5. Masilla B1 y cerámica Edad del Bronce.

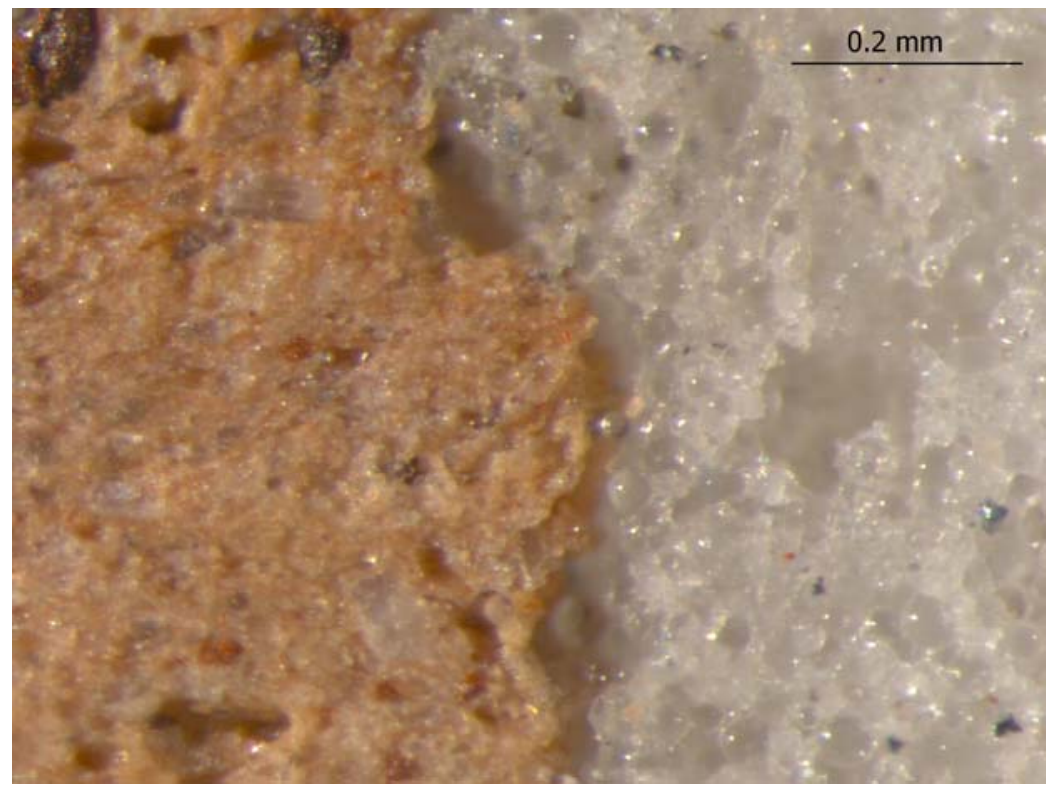

Figura 6. Masilla B1 y cerámica época islámica. 


\begin{tabular}{|c|c|c|c|c|c|c|c|}
\hline REFERENCIA & \multicolumn{5}{|c|}{ MASILLA } & $\mathbf{N}$ & \\
\hline B1 & \multicolumn{5}{|c|}{ ACRIL 33/8 } & 3 & \\
\hline COMPOSICIÓN & \multicolumn{7}{|c|}{$\begin{array}{l}\text { Acril } 33 \text { (4 Vol.) } \\
\text { Microesferas de vidrio (9 Vol.) }\end{array}$} \\
\hline PREPARACIÓN & \multicolumn{7}{|c|}{$\begin{array}{l}\text { Mezcla de los dos componentes hasta conseguir una } \\
\text { masilla homogénea. }\end{array}$} \\
\hline \multirow{2}{*}{$\begin{array}{l}\text { CONSISTENCIA Y } \\
\text { APLICACIÓN }\end{array}$} & Líquida & $\mathbf{X}$ & Espesa & $\mathbf{X}$ & Pasto & & \\
\hline & Inyección & $\mathbf{X}$ & Vertido & $\mathbf{X}$ & Espát & & \\
\hline T. DE TRABAJO & \multicolumn{7}{|l|}{1 hora } \\
\hline T. DE SECADO & \multicolumn{7}{|c|}{+ de 24 horas } \\
\hline CONTRACCIÓN & Alta & & Media & $\mathrm{X}$ & \multicolumn{2}{|l|}{ Baja } & \\
\hline POROSIDAD & Alta & & Media & $\mathrm{X}$ & \multicolumn{2}{|l|}{ Baja } & \\
\hline DUREZA & Alta & & Media & $\mathrm{X}$ & \multicolumn{2}{|l|}{ Baja } & \\
\hline ADHESIÓN & Buena & $\mathrm{X}$ & Media & & \multicolumn{2}{|l|}{ Mala } & \\
\hline \multirow{2}{*}{$\begin{array}{l}\text { NIVELACIÓN Y } \\
\text { PULIDO }\end{array}$} & Buena & $\mathrm{X}$ & Media & & Mala & & \\
\hline & Bisturí & $\mathrm{X}$ & Lija & $\mathrm{X}$ & Otros & & $\mathrm{X}$ \\
\hline \multirow[t]{2}{*}{ RETOQUE } & \multicolumn{7}{|c|}{ Toda clase de pinturas } \\
\hline & \multicolumn{5}{|c|}{ VENTAJAS/INCONVENIENTES } & $\mathbf{V}$ & I \\
\hline \multicolumn{6}{|l|}{ ELABORACIÓN } & & $\mathbf{X}$ \\
\hline \multicolumn{6}{|c|}{ SE CONOCEN LOS MATERIALES Y PROPORCIONES } & $\mathbf{X}$ & \\
\hline \multicolumn{6}{|c|}{ APLICACIÓN } & $\mathbf{X}$ & \\
\hline \multicolumn{6}{|c|}{ NIVELACIÓN Y PULIDO } & $\mathbf{X}$ & \\
\hline \multicolumn{6}{|c|}{ TIEMPO DE TRABAJO } & $\mathbf{X}$ & \\
\hline \multicolumn{6}{|c|}{ TIEMPO DE SECADO } & & $\mathbf{X}$ \\
\hline \multicolumn{6}{|c|}{ CONTRACCIÓN/AGRIETAMIENTO } & $\mathbf{X}$ & \\
\hline \multicolumn{6}{|l|}{ DUREZA } & $\mathbf{X}$ & \\
\hline \multicolumn{6}{|l|}{ POROSIDAD } & $\mathbf{X}$ & \\
\hline \multicolumn{6}{|c|}{ ADHESIÓN AL CUERPO CERÁMICO } & $\mathbf{X}$ & \\
\hline \multicolumn{6}{|l|}{ RETOQUE } & $\mathbf{X}$ & \\
\hline \multicolumn{6}{|l|}{ ALMACENAJE } & $\mathbf{X}$ & \\
\hline \multicolumn{6}{|l|}{ REVERSIBILIDAD } & $\mathbf{X}$ & \\
\hline OBSERVACIONES & \multicolumn{7}{|c|}{$\begin{array}{l}\text { Muy cómoda de nivelar, siempre en seco, con bisturí } \\
\text { y acetona, no produce polvo. Se puede preparar y } \\
\text { almacenar. }\end{array}$} \\
\hline VALORACIÓN & \multicolumn{7}{|c|}{ APTA / SELECCIONADA } \\
\hline
\end{tabular}




\begin{tabular}{|c|c|c|c|c|c|c|c|}
\hline REFERENCIA & \multicolumn{5}{|c|}{ MASILLA } & \multicolumn{2}{|c|}{$\mathbf{N}^{\mathbf{0}}$} \\
\hline & \multicolumn{5}{|c|}{ PLEXTOL B-500/1 } & 3 & \\
\hline COMPOSICIÓN & \multicolumn{7}{|c|}{$\begin{array}{l}\text { Plextol B-500 (2 Vol.) } \\
\text { Microesferas de vidrio (3 Vol.) }\end{array}$} \\
\hline PREPARACIÓN & \multicolumn{7}{|c|}{$\begin{array}{l}\text { Mezcla de los dos componentes con espátula flexible } \\
\text { hasta conseguir una mezcla homogénea. }\end{array}$} \\
\hline \multirow{2}{*}{$\begin{array}{l}\text { CONSISTENCIA Y } \\
\text { APLICACIÓN }\end{array}$} & Líquida & & Espesa & & Pastosa & & $\mathbf{X}$ \\
\hline & Inyección & & Vertido & & Espátul & & $\mathbf{X}$ \\
\hline T. DE TRABAJO & \multicolumn{7}{|l|}{1 hora } \\
\hline T. DE SECADO & \multicolumn{7}{|l|}{12 horas } \\
\hline CONTRACCIÓN & Alta & & Media & & \multicolumn{2}{|l|}{ Baja } & $\mathrm{X}$ \\
\hline POROSIDAD & Alta & & Media & $\mathrm{X}$ & \multicolumn{2}{|l|}{ Baja } & \\
\hline DUREZA & Alta & & Media & & \multicolumn{2}{|l|}{ Baja } & $\mathrm{X}$ \\
\hline ADHESIÓN & Buena & & Media & & \multicolumn{2}{|l|}{ Mala } & $\mathrm{X}$ \\
\hline \multirow{2}{*}{$\begin{array}{l}\text { NIVELACIÓN Y } \\
\text { PULIDO }\end{array}$} & Buena & $\mathrm{X}$ & Media & & \multicolumn{2}{|l|}{ Mala } & \\
\hline & Bisturí & $\mathrm{X}$ & Lija & & \multicolumn{2}{|l|}{ Otros } & $\mathrm{X}$ \\
\hline \multicolumn{8}{|l|}{ RETOQUE } \\
\hline & \multicolumn{5}{|c|}{ VENTAJAS/INCONVENIENTES } & V & I \\
\hline \multicolumn{6}{|l|}{ ELABORACIÓN } & & $\mathbf{X}$ \\
\hline \multicolumn{6}{|c|}{ SE CONOCEN LOS MATERIALES Y PROPORCIONES } & $\mathbf{X}$ & \\
\hline \multicolumn{6}{|l|}{ APLICACIÓN } & & $\mathbf{X}$ \\
\hline \multicolumn{6}{|c|}{ NIVELACIÓN Y PULIDO } & $\mathbf{X}$ & \\
\hline \multicolumn{6}{|c|}{ TIEMPO DE TRABAJO } & $\mathbf{X}$ & \\
\hline \multicolumn{6}{|c|}{ TIEMPO DE SECADO } & & $\mathbf{X}$ \\
\hline \multicolumn{6}{|c|}{ CONTRACCIÓN/AGRIETAMIENTO } & & $\mathbf{X}$ \\
\hline \multicolumn{6}{|l|}{ DUREZA } & & $\mathbf{X}$ \\
\hline \multicolumn{6}{|l|}{ POROSIDAD } & $\mathbf{X}$ & \\
\hline \multicolumn{6}{|c|}{ ADHESIÓN AL CUERPO CERÁMICO } & & $\mathbf{X}$ \\
\hline \multicolumn{6}{|l|}{ RETOQUE } & & \\
\hline \multicolumn{6}{|l|}{ ALMACENAJE } & $\mathbf{X}$ & \\
\hline \multicolumn{6}{|l|}{ REVERSIBILIDAD } & $\mathbf{X}$ & \\
\hline OBSERVACIONES & Flexible. & & & & & & \\
\hline VALORACIÓN & & NO & PTA//R & 16 & ADA & & \\
\hline
\end{tabular}




\begin{tabular}{|c|c|c|c|c|c|c|c|}
\hline REFERENCIA & \multicolumn{5}{|c|}{ MASILLA } & \multicolumn{2}{|c|}{$\mathbf{N}^{\mathbf{0}}$} \\
\hline & \multicolumn{5}{|c|}{ PLEXTOL B-500/2 } & \multicolumn{2}{|c|}{36} \\
\hline COMPOSICIÓN & \multicolumn{7}{|c|}{$\begin{array}{l}\text { Plextol B-500 (1 Vol.) } \\
\text { Carbonato cálcico (2 Vol.) }\end{array}$} \\
\hline PREPARACIÓN & \multicolumn{7}{|c|}{$\begin{array}{l}\text { Mezcla de los dos componentes con espátula flexible } \\
\text { hasta conseguir una mezcla homogénea. }\end{array}$} \\
\hline \multirow{2}{*}{$\begin{array}{l}\text { CONSISTENCIA Y } \\
\text { APLICACIÓN }\end{array}$} & Líquida & & Espesa & & Pastosa & & $\mathbf{X}$ \\
\hline & Inyección & & Vertido & & Espátula & & $\mathbf{X}$ \\
\hline T. DE TRABAJO & \multicolumn{7}{|l|}{1 hora } \\
\hline T. DE SECADO & \multicolumn{7}{|c|}{ + de 12 horas } \\
\hline CONTRACCIÓN & Alta & $\mathrm{X}$ & Media & & \multicolumn{2}{|l|}{ Baja } & \\
\hline POROSIDAD & Alta & & Media & $\mathrm{X}$ & \multicolumn{2}{|l|}{ Baja } & \\
\hline DUREZA & Alta & & Media & $\mathrm{X}$ & \multicolumn{2}{|l|}{ Baja } & \\
\hline ADHESIÓN & Buena & & Media & $\mathrm{X}$ & \multicolumn{2}{|l|}{ Mala } & \\
\hline \multirow{2}{*}{$\begin{array}{l}\text { NIVELACIÓN Y } \\
\text { PULIDO }\end{array}$} & Buena & $\mathrm{X}$ & Media & & \multicolumn{2}{|l|}{ Mala } & \\
\hline & Bisturí & $\mathrm{X}$ & Lija & & \multicolumn{2}{|l|}{ Otros } & $\mathrm{X}$ \\
\hline \multicolumn{8}{|l|}{ RETOQUE } \\
\hline & \multicolumn{5}{|c|}{ VENTAJAS/INCONVENIENTES } & $\mathbf{V}$ & I \\
\hline \multicolumn{6}{|l|}{ ELABORACIÓN } & & $\mathbf{X}$ \\
\hline \multicolumn{6}{|c|}{ SE CONOCEN LOS MATERIALES Y PROPORCIONES } & $\mathbf{X}$ & \\
\hline \multicolumn{6}{|l|}{ APLICACIÓN } & & $\mathbf{X}$ \\
\hline \multicolumn{6}{|c|}{ NIVELACIÓN Y PULIDO } & $\mathbf{X}$ & \\
\hline \multicolumn{6}{|c|}{ TIEMPO DE TRABAJO } & $\mathbf{X}$ & \\
\hline \multicolumn{6}{|c|}{ TIEMPO DE SECADO } & & $\mathbf{X}$ \\
\hline \multicolumn{6}{|c|}{ CONTRACCIÓN/AGRIETAMIENTO } & & $\mathbf{X}$ \\
\hline \multicolumn{6}{|l|}{ DUREZA } & & $\mathbf{X}$ \\
\hline \multicolumn{6}{|l|}{ POROSIDAD } & $\mathbf{X}$ & \\
\hline \multicolumn{6}{|c|}{ ADHESIÓN AL CUERPO CERÁMICO } & $\mathbf{X}$ & \\
\hline \multicolumn{6}{|l|}{ RETOQUE } & $\mathbf{X}$ & \\
\hline \multicolumn{6}{|l|}{ ALMACENAJE } & $\mathbf{X}$ & \\
\hline REVERSIBILIDAD & & & & & & $\mathbf{X}$ & \\
\hline OBSERVACIONES & Excesivame & e & xible & & & & \\
\hline VALORACIÓN & & SO & PTA/RE & IAZ & $\mathbf{D A}$ & & \\
\hline
\end{tabular}




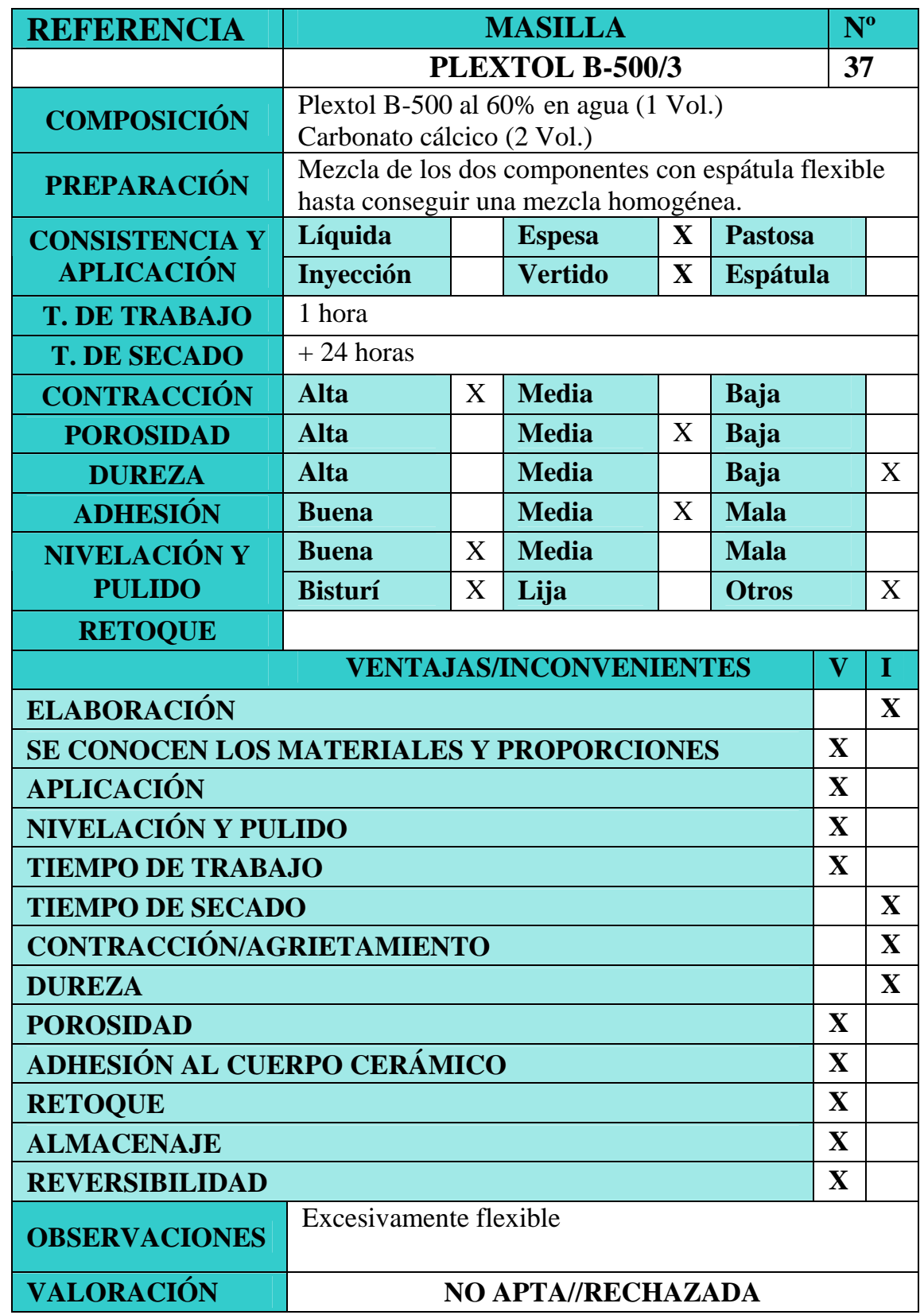




\begin{tabular}{|c|c|c|c|c|c|c|c|}
\hline REFERENCIA & \multicolumn{5}{|c|}{ MASILLA } & \multicolumn{2}{|c|}{$\mathbf{N}^{\mathbf{0}}$} \\
\hline & \multicolumn{5}{|c|}{ PARALOID B-72/1 } & & 8 \\
\hline COMPOSICIÓN & \multicolumn{7}{|c|}{$\begin{array}{l}\text { Paraloid B-72 al 50\% en acetona (2 Vol.) } \\
\text { Polvo de Mármol (3 Vol.) }\end{array}$} \\
\hline PREPARACIÓN & \multicolumn{7}{|c|}{$\begin{array}{l}\text { Sobre la resina previamente preparada ( } 48 \mathrm{~h} \text {.) se vierte } \\
\text { el polvo de mármol y se mezcla homogéneamente. }\end{array}$} \\
\hline \multirow{2}{*}{$\begin{array}{l}\text { CONSISTENCIA Y } \\
\text { APLICACIÓN }\end{array}$} & Líquida & & Espesa & $\mathbf{X}$ & Pastosa & & \\
\hline & Inyección & & Vertido & & Espátula & & $\mathbf{X}$ \\
\hline T. DE TRABAJO & \multicolumn{7}{|c|}{ En 5’, seca en superficie. } \\
\hline T. DE SECADO & \multicolumn{7}{|l|}{24 horas } \\
\hline CONTRACCIÓN & Alta & & Media & $\mathrm{X}$ & \multicolumn{2}{|l|}{ Baja } & \\
\hline POROSIDAD & Alta & $\mathrm{X}$ & Media & & \multicolumn{2}{|l|}{ Baja } & \\
\hline DUREZA & Alta & & Media & & \multicolumn{2}{|l|}{ Baja } & $\mathrm{X}$ \\
\hline ADHESIÓN & Buena & $\mathrm{X}$ & Media & & \multicolumn{2}{|l|}{ Mala } & \\
\hline \multirow{2}{*}{$\begin{array}{l}\text { NIVELACIÓN Y } \\
\text { PULIDO }\end{array}$} & Buena & $\mathrm{X}$ & Media & & Mala & & \\
\hline & Bisturí & $\mathrm{X}$ & Lija & $\mathrm{X}$ & Otros & & $\mathrm{X}$ \\
\hline RETOQUE & \multicolumn{7}{|l|}{ SI } \\
\hline & \multicolumn{5}{|c|}{ VENTAJAS/INCONVENIENTES } & $\mathbf{V}$ & I \\
\hline \multicolumn{6}{|l|}{ ELABORACIÓN } & & $\mathbf{X}$ \\
\hline \multicolumn{6}{|c|}{ SE CONOCEN LOS MATERIALES Y PROPORCIONES } & $\mathbf{X}$ & \\
\hline \multicolumn{6}{|l|}{ APLICACIÓN } & & $\mathbf{X}$ \\
\hline \multicolumn{6}{|c|}{ NIVELACIÓN Y PULIDO } & $\mathbf{X}$ & \\
\hline \multicolumn{6}{|c|}{ TIEMPO DE TRABAJO } & & $\mathbf{X}$ \\
\hline \multicolumn{6}{|c|}{ TIEMPO DE SECADO } & & $\mathbf{X}$ \\
\hline \multicolumn{6}{|c|}{ CONTRACCIÓN/AGRIETAMIENTO } & $\mathbf{X}$ & \\
\hline \multicolumn{6}{|l|}{ DUREZA } & & $\mathbf{X}$ \\
\hline \multicolumn{6}{|l|}{ POROSIDAD } & & $\mathbf{X}$ \\
\hline \multicolumn{6}{|c|}{ ADHESIÓN AL CUERPO CERÁMICO } & $\mathbf{X}$ & \\
\hline \multicolumn{6}{|l|}{ RETOQUE } & $\mathbf{X}$ & \\
\hline \multicolumn{6}{|l|}{ ALMACENAJE } & $\mathbf{X}$ & \\
\hline \multicolumn{6}{|l|}{ REVERSIBILIDAD } & $\mathbf{X}$ & \\
\hline OBSERVACIONES & \multicolumn{7}{|c|}{ Muy poroso. Flexible en grosor de $5 \mathrm{~mm}$. } \\
\hline VALORACIÓN & \multicolumn{7}{|c|}{ NO APTA// NO ENSAYADA } \\
\hline
\end{tabular}




\begin{tabular}{|c|c|c|c|c|c|c|c|}
\hline REFERENCIA & \multicolumn{5}{|c|}{ MASILLA } & \multicolumn{2}{|c|}{$\mathbf{N}^{\mathbf{0}}$} \\
\hline & \multicolumn{5}{|c|}{ PARALOID B-72/2 } & \multicolumn{2}{|c|}{39} \\
\hline COMPOSICIÓN & \multicolumn{7}{|c|}{$\begin{array}{l}\text { Paraloid B-72 al 50\% en acetona (2 Vol.) } \\
\text { Carbonato de calcio (3 Vol.) }\end{array}$} \\
\hline PREPARACIÓN & \multicolumn{7}{|c|}{$\begin{array}{l}\text { Sobre la resina previamente preparada ( } 48 \mathrm{~h} \text {.) se vierte } \\
\text { el Carbonato de calcio y se mezcla homogéneamente. }\end{array}$} \\
\hline \multirow{2}{*}{$\begin{array}{l}\text { CONSISTENCIA Y } \\
\text { APLICACIÓN }\end{array}$} & Líquida & & Espesa & $\mathbf{X}$ & Pastosa & & \\
\hline & Inyección & & Vertido & & Espátula & & $\mathrm{X}$ \\
\hline T. DE TRABAJO & \multicolumn{7}{|c|}{ En 10 ', seca en superficie. } \\
\hline T. DE SECADO & \multicolumn{7}{|l|}{24 horas } \\
\hline CONTRACCIÓN & Alta & & Media & & \multicolumn{2}{|l|}{ Baja } & $\mathrm{X}$ \\
\hline POROSIDAD & Alta & $\mathrm{X}$ & Media & & \multicolumn{2}{|l|}{ Baja } & \\
\hline DUREZA & Alta & & Media & $\mathrm{X}$ & \multicolumn{2}{|l|}{ Baja } & \\
\hline ADHESIÓN & Buena & $\mathrm{X}$ & Media & & \multicolumn{2}{|l|}{ Mala } & \\
\hline \multirow{2}{*}{$\begin{array}{l}\text { NIVELACIÓN Y } \\
\text { PULIDO }\end{array}$} & Buena & $\mathrm{X}$ & Media & & \multicolumn{2}{|l|}{ Mala } & \\
\hline & Bisturí & $\mathrm{X}$ & Lija & $\mathrm{X}$ & Otros & & $\mathrm{X}$ \\
\hline RETOQUE & \multicolumn{7}{|l|}{ SI } \\
\hline & \multicolumn{5}{|c|}{ VENTAJAS/INCONVENIENTES } & $\mathbf{V}$ & $\mathbf{I}$ \\
\hline \multicolumn{6}{|l|}{ ELABORACIÓN } & & $\mathbf{X}$ \\
\hline \multicolumn{6}{|c|}{ SE CONOCEN LOS MATERIALES Y PROPORCIONES } & $\mathbf{X}$ & \\
\hline \multicolumn{6}{|l|}{ APLICACIÓN } & & $\mathbf{X}$ \\
\hline \multicolumn{6}{|c|}{ NIVELACIÓN Y PULIDO } & $\mathbf{X}$ & \\
\hline \multicolumn{6}{|c|}{ TIEMPO DE TRABAJO } & $\mathbf{X}$ & \\
\hline \multicolumn{6}{|c|}{ TIEMPO DE SECADO } & & $\mathrm{X}$ \\
\hline \multicolumn{6}{|c|}{ CONTRACCIÓN/AGRIETAMIENTO } & $\mathbf{X}$ & \\
\hline \multicolumn{6}{|l|}{ DUREZA } & $\mathbf{X}$ & \\
\hline \multicolumn{6}{|l|}{ POROSIDAD } & & $\mathrm{X}$ \\
\hline \multicolumn{6}{|c|}{ ADHESIÓN AL CUERPO CERÁMICO } & $\mathbf{X}$ & \\
\hline \multicolumn{6}{|l|}{ RETOQUE } & $\mathbf{X}$ & \\
\hline \multicolumn{6}{|l|}{ ALMACENAJE } & $\mathbf{X}$ & \\
\hline \multicolumn{6}{|l|}{ REVERSIBILIDAD } & $\mathbf{X}$ & \\
\hline OBSERVACIC & $\begin{array}{l}\text { Porosa. As! } \\
\text { dada su vis } \\
\end{array}$ & $\begin{array}{ll}\text { cto } \mathrm{p} \\
\text { sidac }\end{array}$ & $\begin{array}{l}\text { ástico. Su } \\
\text {. Flexible }\end{array}$ & & $\begin{array}{l}\text { ón es comp } \\
\text { r de } 5 \mathrm{~mm}\end{array}$ & & \\
\hline VALORACIÓN & & $\mathbf{O A}$ & TA// NO & SA & ADA & & \\
\hline
\end{tabular}




\begin{tabular}{|c|c|c|c|c|c|c|c|}
\hline REFERENCIA & \multicolumn{5}{|c|}{ MASILLA } & \multicolumn{2}{|c|}{$\mathbf{N}^{\mathbf{0}}$} \\
\hline & \multicolumn{5}{|c|}{ PARALOID B-72/3 } & & 10 \\
\hline COMPOSICIÓN & \multicolumn{7}{|c|}{$\begin{array}{l}\text { Paraloid B-72 al 50\% en acetona (1 Vol.) } \\
\text { Microesferas de vidrio ( } 1 \text { Vol.) }\end{array}$} \\
\hline PREPARACIÓN & \multicolumn{7}{|c|}{$\begin{array}{l}\text { Sobre la resina previamente preparada ( } 48 \mathrm{~h} \text {.) se vierte } \\
\text { las microesferas y se mezcla homogéneamente. }\end{array}$} \\
\hline \multirow{2}{*}{$\begin{array}{l}\text { CONSISTENCIA Y } \\
\text { APLICACIÓN }\end{array}$} & Líquida & & Espesa & $\mathbf{X}$ & Pastosa & & \\
\hline & Inyección & & Vertido & & Espátul & & $\mathbf{X}$ \\
\hline T. DE TRABAJO & \multicolumn{7}{|c|}{ En 10’, seca en superficie. } \\
\hline T. DE SECADO & \multicolumn{7}{|l|}{24 horas } \\
\hline CONTRACCIÓN & Alta & & Media & & \multicolumn{2}{|l|}{ Baja } & $\mathrm{X}$ \\
\hline POROSIDAD & Alta & $\mathrm{X}$ & Media & & \multicolumn{2}{|l|}{ Baja } & \\
\hline DUREZA & Alta & & Media & $\mathrm{X}$ & \multicolumn{2}{|l|}{ Baja } & \\
\hline ADHESIÓN & Buena & $\mathrm{X}$ & Media & & \multicolumn{2}{|l|}{ Mala } & \\
\hline \multirow{2}{*}{$\begin{array}{l}\text { NIVELACIÓN Y } \\
\text { PULIDO }\end{array}$} & Buena & $\mathrm{X}$ & Media & & Mala & & \\
\hline & Bisturí & $\mathrm{X}$ & Lija & $\mathrm{X}$ & Otros & & $\mathrm{X}$ \\
\hline RETOQUE & \multicolumn{7}{|l|}{ SI } \\
\hline & \multicolumn{5}{|c|}{ VENTAJAS/INCONVENIENTES } & $\mathbf{V}$ & I \\
\hline \multicolumn{6}{|l|}{ ELABORACIÓN } & & $\mathbf{X}$ \\
\hline \multicolumn{6}{|c|}{ SE CONOCEN LOS MATERIALES Y PROPORCIONES } & $\mathbf{X}$ & \\
\hline \multicolumn{6}{|l|}{ APLICACIÓN } & & $\mathbf{X}$ \\
\hline \multicolumn{6}{|c|}{ NIVELACIÓN Y PULIDO } & $\mathbf{X}$ & \\
\hline \multicolumn{6}{|c|}{ TIEMPO DE TRABAJO } & $\mathbf{X}$ & \\
\hline \multicolumn{6}{|c|}{ TIEMPO DE SECADO } & & $\mathbf{X}$ \\
\hline \multicolumn{6}{|c|}{ CONTRACCIÓN/AGRIETAMIENTO } & $\mathbf{X}$ & \\
\hline \multicolumn{6}{|l|}{ DUREZA } & $\mathbf{X}$ & \\
\hline \multicolumn{6}{|l|}{ POROSIDAD } & & $\mathbf{X}$ \\
\hline \multicolumn{6}{|c|}{ ADHESIÓN AL CUERPO CERÁMICO } & $\mathbf{X}$ & \\
\hline \multicolumn{6}{|l|}{ RETOQUE } & $\mathbf{X}$ & \\
\hline \multicolumn{6}{|l|}{ ALMACENAJE } & $\mathbf{X}$ & \\
\hline \multicolumn{6}{|l|}{ REVERSIBILIDAD } & $\mathbf{X}$ & \\
\hline NES & \multicolumn{7}{|c|}{$\begin{array}{l}\text { Poroso. Bastante rígido una vez seca. Aplicación } \\
\text { complicada. }\end{array}$} \\
\hline VALORACIÓN & \multicolumn{7}{|c|}{ NO APTA// NO ENSAYADA } \\
\hline
\end{tabular}




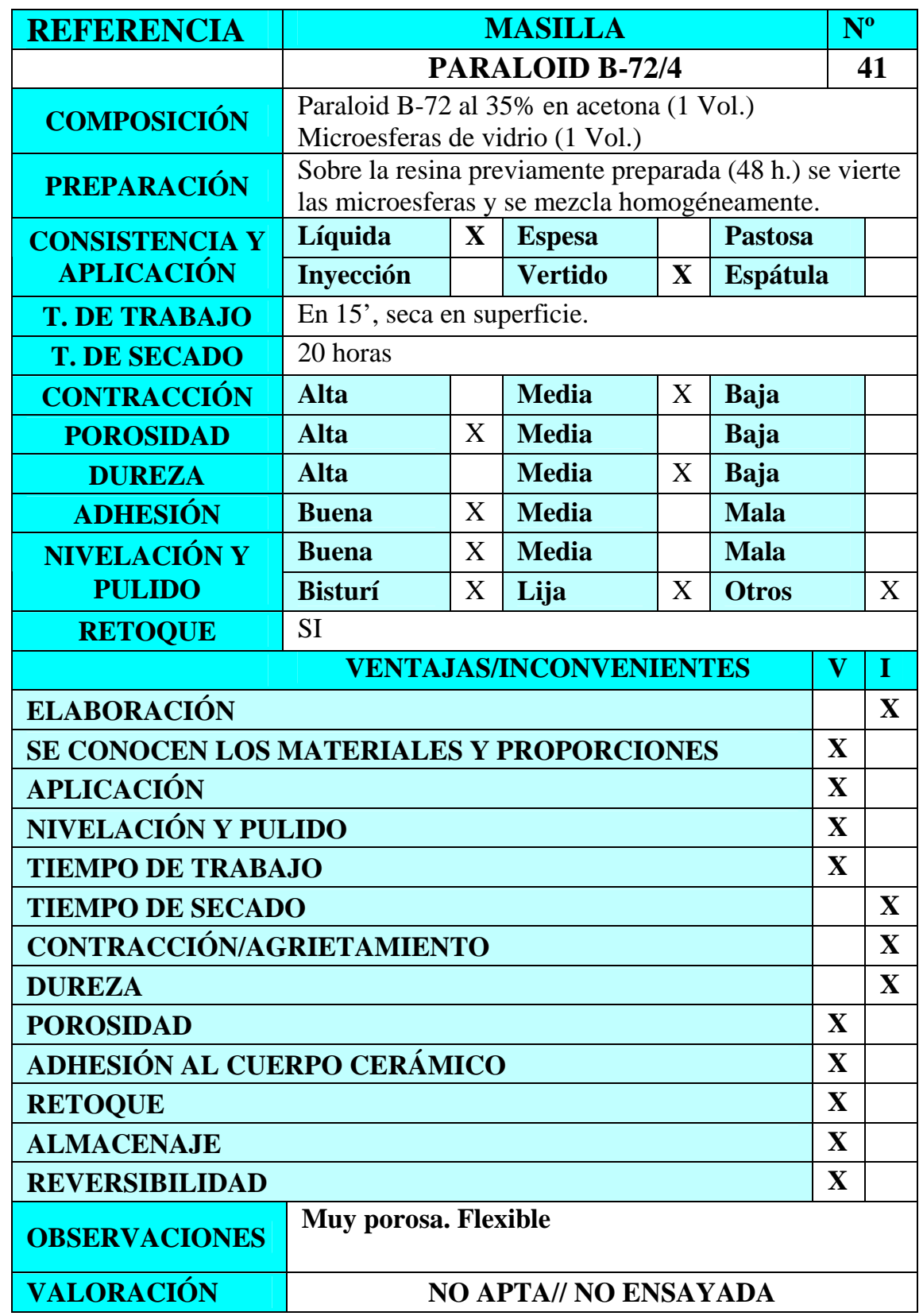




\begin{tabular}{|c|c|c|c|c|c|c|c|}
\hline REFERENCIA & \multicolumn{5}{|c|}{ MASILLA } & \multicolumn{2}{|c|}{$\mathbf{N}^{\mathbf{0}}$} \\
\hline & \multicolumn{5}{|c|}{ PARALOID B-72/5 } & & 2 \\
\hline COMPOSICIÓN & \multicolumn{7}{|c|}{$\begin{array}{l}\text { Paraloid B-72 al 35\% en acetona (1 Vol.) } \\
\text { Microesferas de vidrio (2 Vol.) }\end{array}$} \\
\hline PREPARACIÓN & \multicolumn{7}{|c|}{$\begin{array}{l}\text { Sobre la resina previamente preparada ( } 48 \mathrm{~h} \text {.) se vierte } \\
\text { las microesferas y se mezcla homogéneamente. }\end{array}$} \\
\hline \multirow{2}{*}{$\begin{array}{l}\text { CONSISTENCIA Y } \\
\text { APLICACIÓN }\end{array}$} & Líquida & & Espesa & $\mathbf{X}$ & Pastosa & & \\
\hline & Inyección & & Vertido & & Espátula & & $\mathbf{X}$ \\
\hline T. DE TRABAJO & \multicolumn{7}{|c|}{ En 10’, seca en superficie. } \\
\hline T. DE SECADO & \multicolumn{7}{|l|}{20 horas } \\
\hline CONTRACCIÓN & Alta & & Media & & \multicolumn{2}{|l|}{ Baja } & $\mathrm{X}$ \\
\hline POROSIDAD & Alta & & Media & $\mathrm{X}$ & \multicolumn{2}{|l|}{ Baja } & \\
\hline DUREZA & Alta & $\mathrm{X}$ & Media & & \multicolumn{2}{|l|}{ Baja } & \\
\hline ADHESIÓN & Buena & $\mathrm{X}$ & Media & & \multicolumn{2}{|l|}{ Mala } & \\
\hline \multirow{2}{*}{$\begin{array}{l}\text { NIVELACIÓN Y } \\
\text { PULIDO }\end{array}$} & Buena & $\mathrm{X}$ & Media & & Mala & & \\
\hline & Bisturí & $\mathrm{X}$ & Lija & $\mathrm{X}$ & Otros & & $\mathrm{X}$ \\
\hline RETOQUE & \multicolumn{7}{|l|}{ SI } \\
\hline & \multicolumn{5}{|c|}{ VENTAJAS/INCONVENIENTES } & $\mathbf{V}$ & I \\
\hline \multicolumn{6}{|l|}{ ELABORACIÓN } & & $\mathbf{X}$ \\
\hline \multicolumn{6}{|c|}{ SE CONOCEN LOS MATERIALES Y PROPORCIONES } & $\mathbf{X}$ & \\
\hline \multicolumn{6}{|c|}{ APLICACIÓN } & & $\mathbf{X}$ \\
\hline \multicolumn{6}{|c|}{ NIVELACIÓN Y PULIDO } & $\mathbf{X}$ & \\
\hline \multicolumn{6}{|c|}{ TIEMPO DE TRABAJO } & & $\mathbf{X}$ \\
\hline \multicolumn{6}{|c|}{ TIEMPO DE SECADO } & & $\mathbf{X}$ \\
\hline \multicolumn{6}{|c|}{ CONTRACCIÓN/AGRIETAMIENTO } & $\mathbf{X}$ & \\
\hline \multicolumn{6}{|l|}{ DUREZA } & $\mathbf{X}$ & \\
\hline \multicolumn{6}{|l|}{ POROSIDAD } & $\mathbf{X}$ & \\
\hline \multicolumn{6}{|c|}{ ADHESIÓN AL CUERPO CERÁMICO } & $\mathbf{X}$ & \\
\hline \multicolumn{6}{|l|}{ RETOQUE } & $\mathbf{X}$ & \\
\hline \multicolumn{6}{|l|}{ ALMACENAJE } & $\mathbf{X}$ & \\
\hline \multicolumn{6}{|l|}{ REVERSIBILIDAD } & $\mathbf{X}$ & \\
\hline NES & \multicolumn{7}{|c|}{$\begin{array}{l}\text { Cuesta aplicarla ya que al evaporara rápidamente } \\
\text { el disolvente se vuelve pegajosa. }\end{array}$} \\
\hline VALORACIÓN & \multicolumn{7}{|c|}{ NO APTA// NO ENSAYADA } \\
\hline
\end{tabular}




\begin{tabular}{|c|c|c|c|c|c|c|c|}
\hline REFERENCIA & \multicolumn{5}{|c|}{ MASILLA } & \multicolumn{2}{|c|}{$\mathbf{N}^{\mathbf{o}}$} \\
\hline & \multicolumn{5}{|c|}{ PARALOID B-72/6 } & & 43 \\
\hline COMPOSICIÓN & \multicolumn{7}{|c|}{$\begin{array}{l}\text { Paraloid B-72 al 35\% en acetona:alcohol metílico 1:1 (1 Vol.) } \\
\text { Microesferas de vidrio (3 Vol.) }\end{array}$} \\
\hline PREPARACIÓN & \multicolumn{7}{|c|}{$\begin{array}{l}\text { Sobre la resina previamente preparada ( } 48 \mathrm{~h} .) \text { se vierte } \\
\text { las microesferas y se mezcla homogéneamente. }\end{array}$} \\
\hline \multirow{2}{*}{$\begin{array}{l}\text { CONSISTENCIA Y } \\
\text { APLICACIÓN }\end{array}$} & Líquida & & Espesa & $\mathbf{X}$ & Pasto & & \\
\hline & Inyección & & Vertido & $\mathbf{X}$ & Espát & & \\
\hline T. DE TRABAJO & \multicolumn{7}{|c|}{ En 15', seca en superficie. } \\
\hline T. DE SECADO & \multicolumn{7}{|l|}{20 horas } \\
\hline CONTRACCIÓN & Alta & & Media & & \multicolumn{2}{|l|}{ Baja } & $\mathrm{X}$ \\
\hline POROSIDAD & Alta & & Media & & \multicolumn{2}{|l|}{ Baja } & $\mathrm{X}$ \\
\hline DUREZA & Alta & & Media & $\mathrm{X}$ & \multicolumn{2}{|l|}{ Baja } & \\
\hline ADHESIÓN & Buena & $\mathrm{X}$ & Media & & \multicolumn{2}{|l|}{ Mala } & \\
\hline NIVELACIÓN Y & Buena & $\mathrm{X}$ & Media & & \multicolumn{2}{|l|}{ Mala } & \\
\hline PULIDO & Bisturí & $\mathrm{X}$ & Lija & $\mathrm{X}$ & \multicolumn{2}{|l|}{ Otros } & $\mathrm{X}$ \\
\hline RETOQUE & SI & & & & & & \\
\hline & \multicolumn{6}{|c|}{ VENTAJAS/INCONVENIENTES } & I \\
\hline \multicolumn{6}{|l|}{ ELABORACIÓN } & & $\mathbf{X}$ \\
\hline \multicolumn{6}{|c|}{ SE CONOCEN LOS MATERIALES Y PROPORCIONES } & $\mathbf{X}$ & \\
\hline \multicolumn{6}{|l|}{ APLICACIÓN } & $\mathbf{X}$ & \\
\hline \multicolumn{6}{|c|}{ NIVELACIÓN Y PULIDO } & $\mathbf{X}$ & \\
\hline \multicolumn{6}{|c|}{ TIEMPO DE TRABAJO } & $\mathbf{X}$ & \\
\hline \multicolumn{6}{|c|}{ TIEMPO DE SECADO } & & $\mathbf{X}$ \\
\hline \multicolumn{6}{|c|}{ CONTRACCIÓN/AGRIETAMIENTO } & $\mathbf{X}$ & \\
\hline \multicolumn{6}{|l|}{ DUREZA } & $\mathbf{X}$ & \\
\hline \multicolumn{6}{|l|}{ POROSIDAD } & $\mathbf{X}$ & \\
\hline \multicolumn{6}{|c|}{ ADHESIÓN AL CUERPO CERÁMICO } & $\mathbf{X}$ & \\
\hline \multicolumn{6}{|l|}{ RETOQUE } & $\mathbf{X}$ & \\
\hline \multicolumn{6}{|l|}{ ALMACENAJE } & $\mathbf{X}$ & \\
\hline \multicolumn{6}{|l|}{ REVERSIBILIDAD } & $\mathbf{X}$ & \\
\hline \multicolumn{8}{|l|}{ OBSERVACIONES } \\
\hline VALORACIÓN & & & NO & $Y$ Y & & & \\
\hline
\end{tabular}




\begin{tabular}{|c|c|c|c|c|c|c|c|}
\hline REFERENCIA & \multicolumn{5}{|c|}{ MASILLA } & \multicolumn{2}{|c|}{$\mathbf{N}^{\mathbf{0}}$} \\
\hline & \multicolumn{5}{|c|}{ PARALOID B-72/7 } & & 4 \\
\hline COMPOSICIÓN & \multicolumn{7}{|c|}{$\begin{array}{l}\text { Paraloid B-72 al 35\% en acetona (1 Vol.) } \\
\text { Carbonato de calcio (2 Vol.) } 3 \text { gotas alcohol }\end{array}$} \\
\hline PREPARACIÓN & \multicolumn{7}{|c|}{$\begin{array}{l}\text { Sobre la resina previamente preparada }(48 \mathrm{~h} \text {.) se vierte } \\
\text { carbonato de calcio y se deja reposar durante } 15 \text { '. }\end{array}$} \\
\hline \multirow{2}{*}{$\begin{array}{l}\text { CONSISTENCIA Y } \\
\text { APLICACIÓN }\end{array}$} & Líquida & & Espesa & $\mathbf{X}$ & Pastosa & & \\
\hline & Inyección & & Vertido & $\mathbf{X}$ & Espátula & & \\
\hline T. DE TRABAJO & \multicolumn{7}{|c|}{ En 10’, seca en superficie. } \\
\hline T. DE SECADO & \multicolumn{7}{|l|}{24 horas } \\
\hline CONTRACCIÓN & Alta & & Media & & \multicolumn{2}{|l|}{ Baja } & $\mathrm{X}$ \\
\hline POROSIDAD & Alta & $\mathrm{X}$ & Media & & \multicolumn{2}{|l|}{ Baja } & \\
\hline DUREZA & Alta & & Media & $\mathrm{X}$ & \multicolumn{2}{|l|}{ Baja } & \\
\hline ADHESIÓN & Buena & & Media & $\mathrm{X}$ & \multicolumn{2}{|l|}{ Mala } & \\
\hline \multirow{2}{*}{$\begin{array}{l}\text { NIVELACIÓN Y } \\
\text { PULIDO }\end{array}$} & Buena & $\mathrm{X}$ & Media & & Mala & & \\
\hline & Bisturí & $\mathrm{X}$ & Lija & $\mathrm{X}$ & Otros & & $\mathrm{X}$ \\
\hline RETOQUE & \multicolumn{7}{|l|}{ SI } \\
\hline & \multicolumn{5}{|c|}{ VENTAJAS/INCONVENIENTES } & $\mathbf{V}$ & $\mathbf{I}$ \\
\hline \multicolumn{6}{|l|}{ ELABORACIÓN } & & $\mathbf{X}$ \\
\hline \multicolumn{6}{|c|}{ SE CONOCEN LOS MATERIALES Y PROPORCIONES } & $\mathbf{X}$ & \\
\hline \multicolumn{6}{|c|}{ APLICACIÓN } & $\mathbf{X}$ & \\
\hline \multicolumn{6}{|c|}{ NIVELACIÓN Y PULIDO } & $\mathbf{X}$ & \\
\hline \multicolumn{6}{|c|}{ TIEMPO DE TRABAJO } & & $\mathbf{X}$ \\
\hline \multicolumn{6}{|c|}{ TIEMPO DE SECADO } & & $\mathbf{X}$ \\
\hline \multicolumn{6}{|c|}{ CONTRACCIÓN/AGRIETAMIENTO } & $\mathbf{X}$ & \\
\hline \multicolumn{6}{|l|}{ DUREZA } & & $\mathbf{X}$ \\
\hline \multicolumn{6}{|l|}{ POROSIDAD } & & $\mathbf{X}$ \\
\hline \multicolumn{6}{|c|}{ ADHESIÓN AL CUERPO CERÁMICO } & & $\mathbf{X}$ \\
\hline \multicolumn{6}{|l|}{ RETOQUE } & $\mathbf{X}$ & \\
\hline \multicolumn{6}{|l|}{ ALMACENAJE } & $\mathbf{X}$ & \\
\hline \multicolumn{6}{|l|}{ REVERSIBILIDAD } & $\mathbf{X}$ & \\
\hline OBSERVACIONES & \multicolumn{7}{|c|}{ Muy porosa. Flexible } \\
\hline VALORACIÓN & \multicolumn{7}{|c|}{ NO APTA// NO ENSAYADA } \\
\hline
\end{tabular}




\begin{tabular}{|c|c|c|c|c|c|c|c|}
\hline REFERENCIA & \multicolumn{5}{|c|}{ MASILLA } & \multicolumn{2}{|c|}{$\mathbf{N}^{\mathbf{o}}$} \\
\hline & \multicolumn{5}{|c|}{ PARALOID B-72/8 } & & 45 \\
\hline COMPOSICIÓN & \multicolumn{7}{|c|}{$\begin{array}{l}\text { Paraloid B-72 al 35\% en acetona:alcohol metílico 1:1 (1 Vol.) } \\
\text { Carbonato cálcico (2 Vol.) }\end{array}$} \\
\hline PREPARACIÓN & \multicolumn{7}{|c|}{$\begin{array}{l}\text { Sobre la resina previamente preparada ( } 48 \text { h.) se vierte } \\
\text { carbonato de calcio y se deja reposar durante } 15 \text { '. }\end{array}$} \\
\hline \multirow{2}{*}{$\begin{array}{l}\text { CONSISTENCIA Y } \\
\text { APLICACIÓN }\end{array}$} & Líquida & $\mathbf{X}$ & Espesa & $\mathbf{X}$ & Pastc & & \\
\hline & Inyección & & Vertido & $\mathbf{X}$ & Espá & & \\
\hline T. DE TRABAJO & \multicolumn{7}{|c|}{ En 10', seca en superficie. } \\
\hline T. DE SECADO & \multicolumn{7}{|l|}{20 horas } \\
\hline CONTRACCIÓN & Alta & & Media & & \multicolumn{2}{|l|}{ Baja } & $\mathrm{X}$ \\
\hline POROSIDAD & Alta & $\mathrm{X}$ & Media & & \multicolumn{2}{|l|}{ Baja } & \\
\hline DUREZA & Alta & & Media & $\mathrm{X}$ & \multicolumn{2}{|l|}{ Baja } & \\
\hline ADHESIÓN & Buena & $\mathrm{X}$ & Media & & \multicolumn{2}{|l|}{ Mala } & \\
\hline NIVELACIÓN Y & Buena & $\mathrm{X}$ & Media & & \multicolumn{2}{|l|}{ Mala } & \\
\hline PULIDO & Bisturí & $\mathrm{X}$ & Lija & $\mathrm{X}$ & \multicolumn{2}{|c|}{ Otros } & $\mathrm{X}$ \\
\hline RETOQUE & \multicolumn{7}{|l|}{ SI } \\
\hline & \multicolumn{5}{|c|}{ VENTAJAS/INCONVENIENTES } & $\mathbf{V}$ & I \\
\hline \multicolumn{6}{|l|}{ ELABORACIÓN } & & $\mathbf{X}$ \\
\hline \multicolumn{6}{|c|}{ SE CONOCEN LOS MATERIALES Y PROPORCIONES } & $\mathbf{X}$ & \\
\hline \multicolumn{6}{|l|}{ APLICACIÓN } & & $\mathbf{X}$ \\
\hline \multicolumn{6}{|c|}{ NIVELACIÓN Y PULIDO } & $\mathbf{X}$ & \\
\hline \multicolumn{6}{|c|}{ TIEMPO DE TRABAJO } & & $\mathbf{X}$ \\
\hline \multicolumn{6}{|c|}{ TIEMPO DE SECADO } & & $\mathbf{X}$ \\
\hline \multicolumn{6}{|c|}{ CONTRACCIÓN/AGRIETAMIENTO } & $\mathbf{X}$ & \\
\hline \multicolumn{6}{|l|}{ DUREZA } & $\mathbf{X}$ & \\
\hline \multicolumn{6}{|l|}{ POROSIDAD } & & $\mathbf{X}$ \\
\hline \multicolumn{6}{|c|}{ ADHESIÓN AL CUERPO CERÁMICO } & $\mathbf{X}$ & \\
\hline \multicolumn{6}{|l|}{ RETOQUE } & $\mathbf{X}$ & \\
\hline \multicolumn{6}{|l|}{ ALMACENAJE } & $\mathbf{X}$ & \\
\hline \multicolumn{6}{|l|}{ REVERSIBILIDAD } & $\mathbf{X}$ & \\
\hline OBSERVACIONES & \multicolumn{7}{|c|}{ Muy poroso } \\
\hline VALORACIÓN & & $\overline{\text { APT }}$ & $\mathbf{A} / /$ NO E & $\overline{\mathrm{AYA}}$ & & & \\
\hline
\end{tabular}




\begin{tabular}{|c|c|c|c|c|c|c|c|}
\hline REFERENCIA & \multicolumn{5}{|c|}{ MASILLA } & \multicolumn{2}{|c|}{$\mathbf{N}^{\mathbf{0}}$} \\
\hline & \multicolumn{5}{|c|}{ PARALOID B-72/9 } & & 16 \\
\hline COMPOSICIÓN & \multicolumn{7}{|c|}{$\begin{array}{l}\text { Paraloid B-72 al 30\% en xileno 1:1 (1 Vol.) } \\
\text { Carbonato cálcico (1 Vol.) }\end{array}$} \\
\hline PREPARACIÓN & \multicolumn{7}{|c|}{$\begin{array}{l}\text { Sobre la resina previamente preparada ( } 48 \mathrm{~h} \text {.) se vierte } \\
\text { carbonato de calcio y se deja reposar durante } 15 \text { '. }\end{array}$} \\
\hline \multirow{2}{*}{$\begin{array}{l}\text { CONSISTENCIA Y } \\
\text { APLICACIÓN }\end{array}$} & Líquida & & Espesa & $\mathbf{x}$ & Pastosa & & \\
\hline & Inyección & & Vertido & $\mathbf{x}$ & Espátula & & \\
\hline T. DE TRABAJO & \multicolumn{7}{|c|}{ En 15-20', seca en superficie. } \\
\hline T. DE SECADO & \multicolumn{7}{|l|}{24 horas } \\
\hline CONTRACCIÓN & Alta & & Media & & \multicolumn{2}{|l|}{ Baja } & $\mathrm{X}$ \\
\hline POROSIDAD & Alta & $\mathrm{X}$ & Media & & \multicolumn{2}{|l|}{ Baja } & \\
\hline DUREZA & Alta & & Media & $\mathrm{X}$ & \multicolumn{2}{|l|}{ Baja } & \\
\hline ADHESIÓN & Buena & $\mathrm{X}$ & Media & & \multicolumn{2}{|l|}{ Mala } & \\
\hline \multirow{2}{*}{$\begin{array}{l}\text { NIVELACIÓN Y } \\
\text { PULIDO }\end{array}$} & Buena & $\mathrm{X}$ & Media & & Mala & & \\
\hline & Bisturí & $\mathrm{X}$ & Lija & $\mathrm{X}$ & Otros & & $\mathrm{X}$ \\
\hline \multirow[t]{2}{*}{ RETOQUE } & \multicolumn{7}{|l|}{ SI } \\
\hline & \multicolumn{5}{|c|}{ VENTAJAS/INCONVENIENTES } & $\mathbf{V}$ & I \\
\hline \multicolumn{6}{|l|}{ ELABORACIÓN } & & $\mathbf{X}$ \\
\hline \multicolumn{6}{|c|}{ SE CONOCEN LOS MATERIALES Y PROPORCIONES } & $\mathbf{X}$ & \\
\hline \multicolumn{6}{|l|}{ APLICACIÓN } & $\mathbf{X}$ & \\
\hline \multicolumn{6}{|c|}{ NIVELACIÓN Y PULIDO } & $\mathbf{X}$ & \\
\hline \multicolumn{6}{|c|}{ TIEMPO DE TRABAJO } & $\mathbf{X}$ & \\
\hline \multicolumn{6}{|c|}{ TIEMPO DE SECADO } & & $\mathbf{X}$ \\
\hline \multicolumn{6}{|c|}{ CONTRACCIÓN/AGRIETAMIENTO } & $\mathbf{X}$ & \\
\hline \multicolumn{6}{|l|}{ DUREZA } & & $\mathbf{X}$ \\
\hline \multicolumn{6}{|l|}{ POROSIDAD } & & $\mathbf{X}$ \\
\hline \multicolumn{6}{|c|}{ ADHESIÓN AL CUERPO CERÁMICO } & $\mathbf{X}$ & \\
\hline \multicolumn{6}{|l|}{ RETOQUE } & $\mathbf{X}$ & \\
\hline \multicolumn{6}{|l|}{ ALMACENAJE } & $\mathbf{X}$ & \\
\hline \multicolumn{6}{|l|}{ REVERSIBILIDAD } & $\mathbf{X}$ & \\
\hline OBSERVACIONES & \multicolumn{7}{|l|}{ Tóxico. } \\
\hline VALORACIÓN & & AP? & $\mathrm{A} / / \mathrm{NO} \mathbf{E}$ & $A Y A$ & & & \\
\hline
\end{tabular}




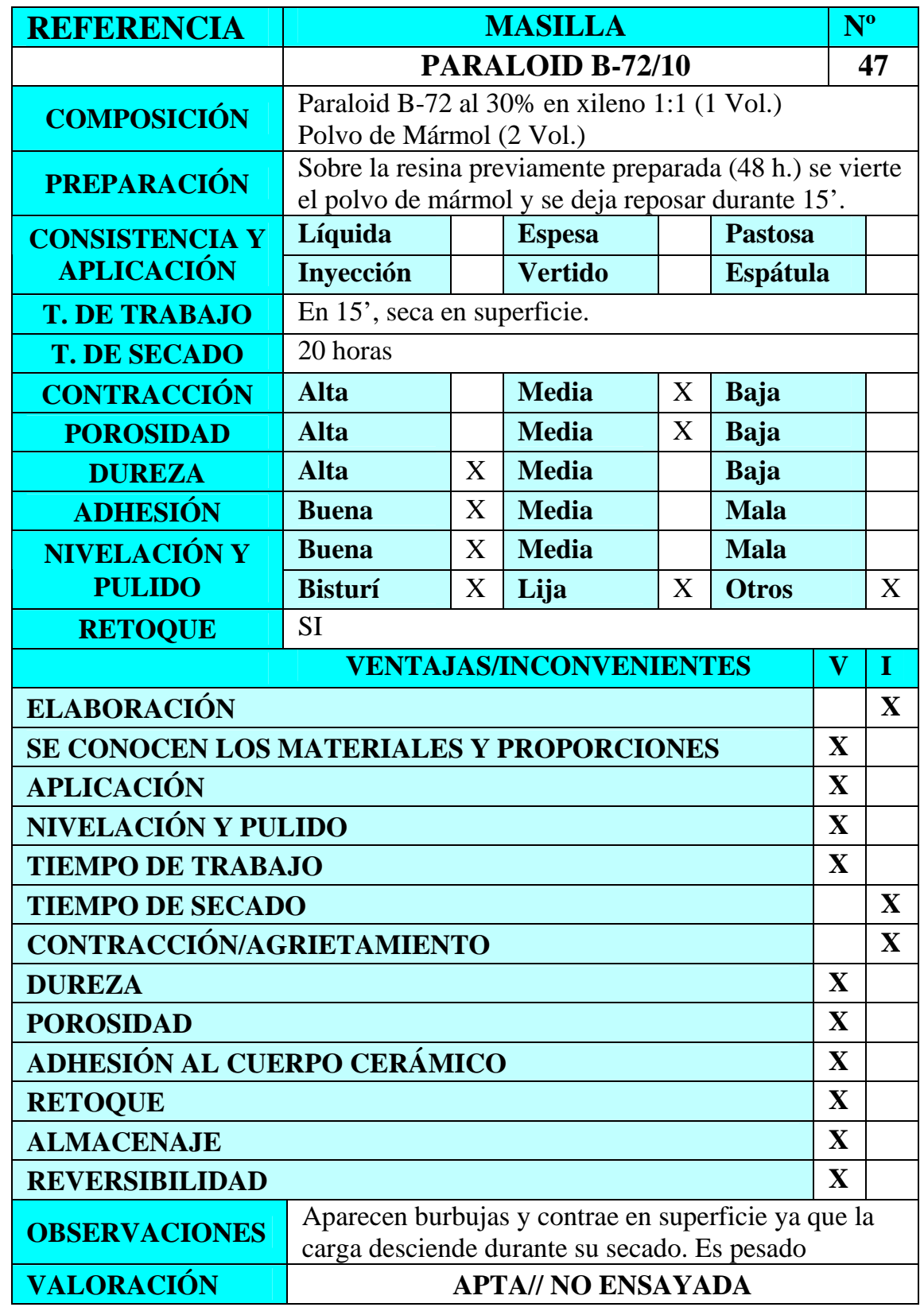




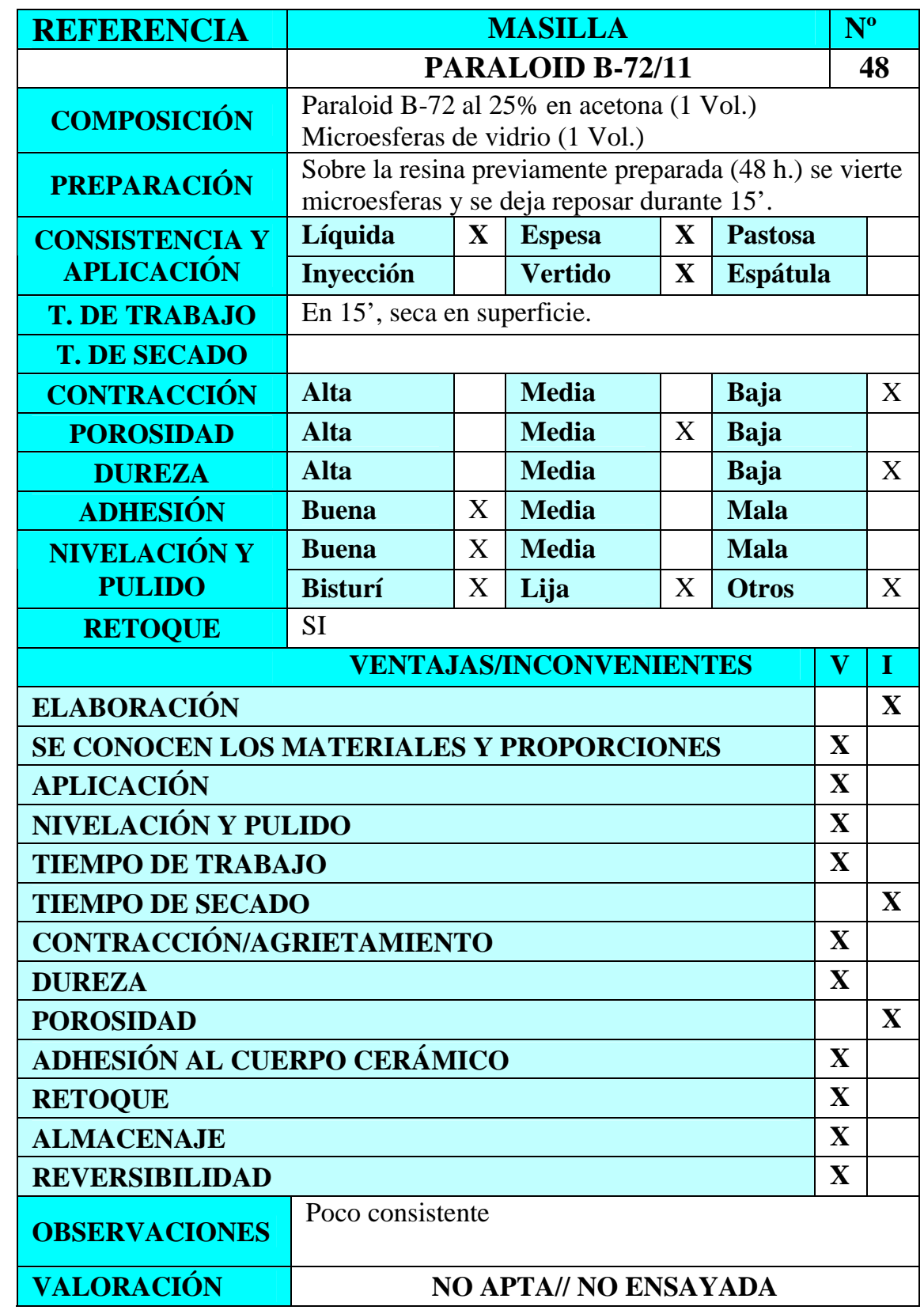




\begin{tabular}{|c|c|c|c|c|c|c|c|}
\hline REFERENCIA & \multicolumn{5}{|c|}{ MASILLA } & \multicolumn{2}{|c|}{$\mathbf{N}^{\mathbf{0}}$} \\
\hline & \multicolumn{5}{|c|}{ PARALOID B-72/12 } & \multicolumn{2}{|c|}{49} \\
\hline COMPOSICIÓN & \multicolumn{7}{|c|}{$\begin{array}{l}\text { Paraloid B-72 al 25\% en acetona (1 Vol.) } \\
\text { Microesferas de vidrio (2 Vol.) }\end{array}$} \\
\hline PREPARACIÓN & \multicolumn{7}{|c|}{$\begin{array}{l}\text { Sobre la resina previamente preparada ( } 48 \text { h.) se vierte } \\
\text { microesferas y se deja reposar durante } 15 \text {. }\end{array}$} \\
\hline \multirow{2}{*}{$\begin{array}{l}\text { CONSISTENCIA Y } \\
\text { APLICACIÓN }\end{array}$} & Líquida & & Espesa & $\mathbf{X}$ & Pastosa & & \\
\hline & Inyección & & Vertido & & Espátula & & $\mathbf{X}$ \\
\hline T. DE TRABAJO & \multicolumn{7}{|l|}{$10^{\prime}$} \\
\hline T. DE SECADO & \multicolumn{7}{|l|}{24 horas } \\
\hline CONTRACCIÓN & Alta & & Media & & \multicolumn{2}{|l|}{ Baja } & $\mathrm{X}$ \\
\hline POROSIDAD & Alta & & Media & $\mathrm{X}$ & \multicolumn{2}{|l|}{ Baja } & \\
\hline DUREZA & Alta & & Media & $\mathrm{X}$ & \multicolumn{2}{|l|}{ Baja } & \\
\hline ADHESIÓN & Buena & $\mathrm{X}$ & Media & & \multicolumn{2}{|l|}{ Mala } & \\
\hline NIVELACIÓN Y & Buena & $\mathrm{X}$ & Media & & \multicolumn{2}{|l|}{ Mala } & \\
\hline PULIDO & Bisturí & $\mathrm{X}$ & Lija & $\mathrm{X}$ & Otros & & $\mathrm{X}$ \\
\hline RETOQUE & \multicolumn{7}{|l|}{ SI } \\
\hline & \multicolumn{5}{|c|}{ VENTAJAS/INCONVENIENTES } & $\mathbf{V}$ & I \\
\hline \multicolumn{6}{|l|}{ ELABORACIÓN } & & $\mathbf{X}$ \\
\hline \multicolumn{6}{|c|}{ SE CONOCEN LOS MATERIALES Y PROPORCIONES } & $\mathbf{X}$ & \\
\hline \multicolumn{6}{|l|}{ APLICACIÓN } & & $\mathbf{X}$ \\
\hline \multicolumn{6}{|c|}{ NIVELACIÓN Y PULIDO } & $\mathbf{X}$ & \\
\hline \multicolumn{6}{|c|}{ TIEMPO DE TRABAJO } & & $\mathbf{X}$ \\
\hline \multicolumn{6}{|c|}{ TIEMPO DE SECADO } & & $\mathbf{X}$ \\
\hline \multicolumn{6}{|c|}{ CONTRACCIÓN/AGRIETAMIENTO } & $\mathbf{X}$ & \\
\hline \multicolumn{6}{|l|}{ DUREZA } & $\mathbf{X}$ & \\
\hline \multicolumn{6}{|l|}{ POROSIDAD } & & $\mathbf{X}$ \\
\hline \multicolumn{6}{|c|}{ ADHESIÓN AL CUERPO CERÁMICO } & $\mathbf{X}$ & \\
\hline \multicolumn{6}{|l|}{ RETOQUE } & $\mathbf{X}$ & \\
\hline \multicolumn{6}{|l|}{ ALMACENAJE } & $\mathbf{X}$ & \\
\hline \multicolumn{6}{|l|}{ REVERSIBILIDAD } & $\mathbf{X}$ & \\
\hline OBSERVACIONES & \multicolumn{7}{|c|}{$\begin{array}{l}\text { Debe estar seca para nivelarla. Cuesta aplicarla ya que } \\
\text { el disolvente evapora rápidamente. }\end{array}$} \\
\hline VALORACIÓN & & & A// NOE & A & & & \\
\hline
\end{tabular}




\begin{tabular}{|c|c|c|c|c|c|c|c|}
\hline REFERENCIA & \multicolumn{5}{|c|}{ MASILLA } & \multicolumn{2}{|c|}{$\mathbf{N}^{\mathbf{0}}$} \\
\hline A1 & \multicolumn{5}{|c|}{ PARALOID B-72/13 } & & 0 \\
\hline COMPOSICIÓN & \multicolumn{7}{|c|}{$\begin{array}{l}\text { Paraloid B-72 al 25\% en acetona:alcohol metílico 1:1 (1 Vol.) } \\
\text { Microesferas de vidrio ( } 3 \text { Vol.) }\end{array}$} \\
\hline PREPARACIÓN & \multicolumn{7}{|c|}{$\begin{array}{l}\text { Sobre la resina previamente preparada ( } 48 \text { h.) se vierte } \\
\text { microesferas y se deja reposar durante } 15 \text { '. }\end{array}$} \\
\hline \multirow{2}{*}{$\begin{array}{l}\text { CONSISTENCIA Y } \\
\text { APLICACIÓN }\end{array}$} & Líquida & & Espesa & $\mathbf{X}$ & Pastosa & & \\
\hline & Inyección & & Vertido & & Espátul & & $\mathbf{X}$ \\
\hline T. DE TRABAJO & \multicolumn{7}{|l|}{15 ' } \\
\hline T. DE SECADO & \multicolumn{7}{|l|}{24 horas } \\
\hline CONTRACCIÓN & Alta & & Media & & \multicolumn{2}{|l|}{ Baja } & $\mathrm{X}$ \\
\hline POROSIDAD & Alta & & Media & $\mathrm{X}$ & \multicolumn{2}{|l|}{ Baja } & \\
\hline DUREZA & Alta & & Media & $\mathrm{X}$ & \multicolumn{2}{|l|}{ Baja } & \\
\hline ADHESIÓN & Buena & $\mathrm{X}$ & Media & & \multicolumn{2}{|l|}{ Mala } & \\
\hline NIVELACIÓN Y & Buena & $\mathrm{X}$ & Media & & \multicolumn{2}{|l|}{ Mala } & \\
\hline PULIDO & Bisturí & $\mathrm{X}$ & Lija & $\mathrm{X}$ & \multicolumn{2}{|l|}{ Otros } & $\mathrm{X}$ \\
\hline RETOQUE & \multicolumn{7}{|l|}{ SI } \\
\hline & \multicolumn{5}{|c|}{ VENTAJAS/INCONVENIENTES } & $\mathbf{V}$ & I \\
\hline \multicolumn{6}{|l|}{ ELABORACIÓN } & & $\mathbf{X}$ \\
\hline \multicolumn{6}{|c|}{ SE CONOCEN LOS MATERIALES Y PROPORCIONES } & $\mathbf{X}$ & \\
\hline \multicolumn{6}{|l|}{ APLICACIÓN } & $\mathbf{X}$ & \\
\hline \multicolumn{6}{|c|}{ NIVELACIÓN Y PULIDO } & $\mathbf{X}$ & \\
\hline \multicolumn{6}{|c|}{ TIEMPO DE TRABAJO } & $\mathbf{X}$ & \\
\hline \multicolumn{6}{|c|}{ TIEMPO DE SECADO } & & $\mathbf{X}$ \\
\hline \multicolumn{6}{|c|}{ CONTRACCIÓN/AGRIETAMIENTO } & $\mathbf{X}$ & \\
\hline \multicolumn{6}{|l|}{ DUREZA } & $\mathbf{X}$ & \\
\hline \multicolumn{6}{|l|}{ POROSIDAD } & & $\mathbf{X}$ \\
\hline \multicolumn{6}{|c|}{ ADHESIÓN AL CUERPO CERÁMICO } & $\mathbf{X}$ & \\
\hline \multicolumn{6}{|l|}{ RETOQUE } & $\mathbf{X}$ & \\
\hline \multicolumn{6}{|l|}{ ALMACENAJE } & $\mathbf{X}$ & \\
\hline \multicolumn{6}{|l|}{ REVERSIBILIDAD } & $\mathbf{X}$ & \\
\hline \multicolumn{8}{|l|}{ OBSERVACIONES } \\
\hline VALORACIÓN & & & TA// EN & $\overline{Y A D}$ & & & \\
\hline
\end{tabular}


Investigación y análisis de las masillas de relleno para la reintegración de lagunas cerámicas arqueológicas

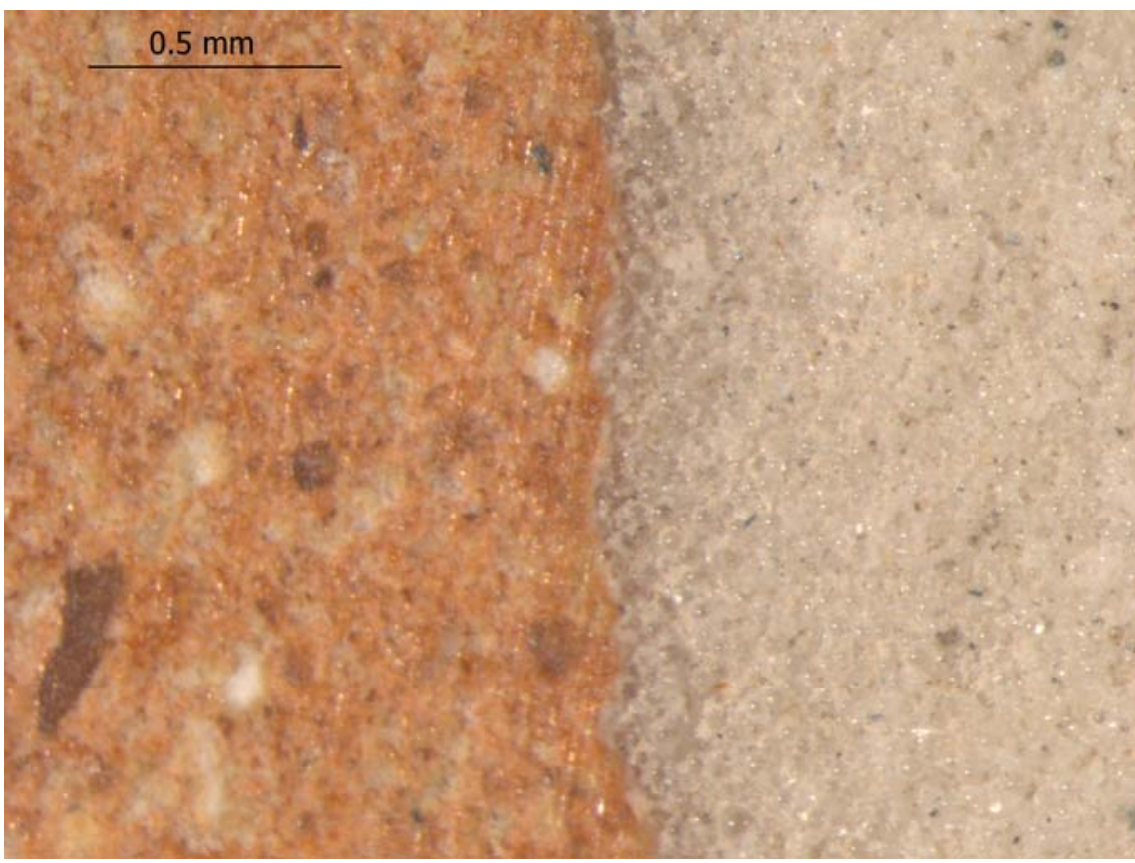

Figura 7 . Masilla A1. 


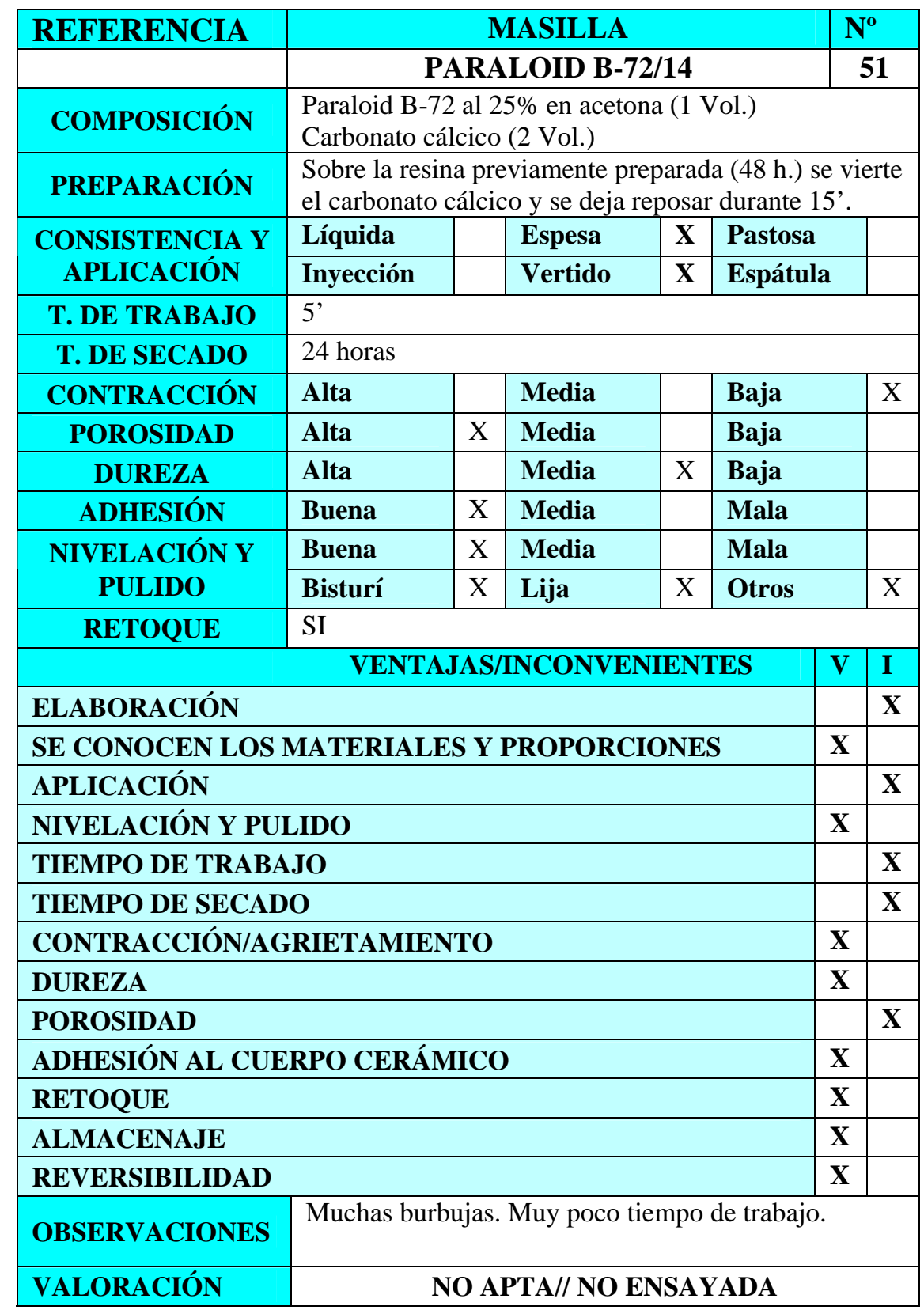




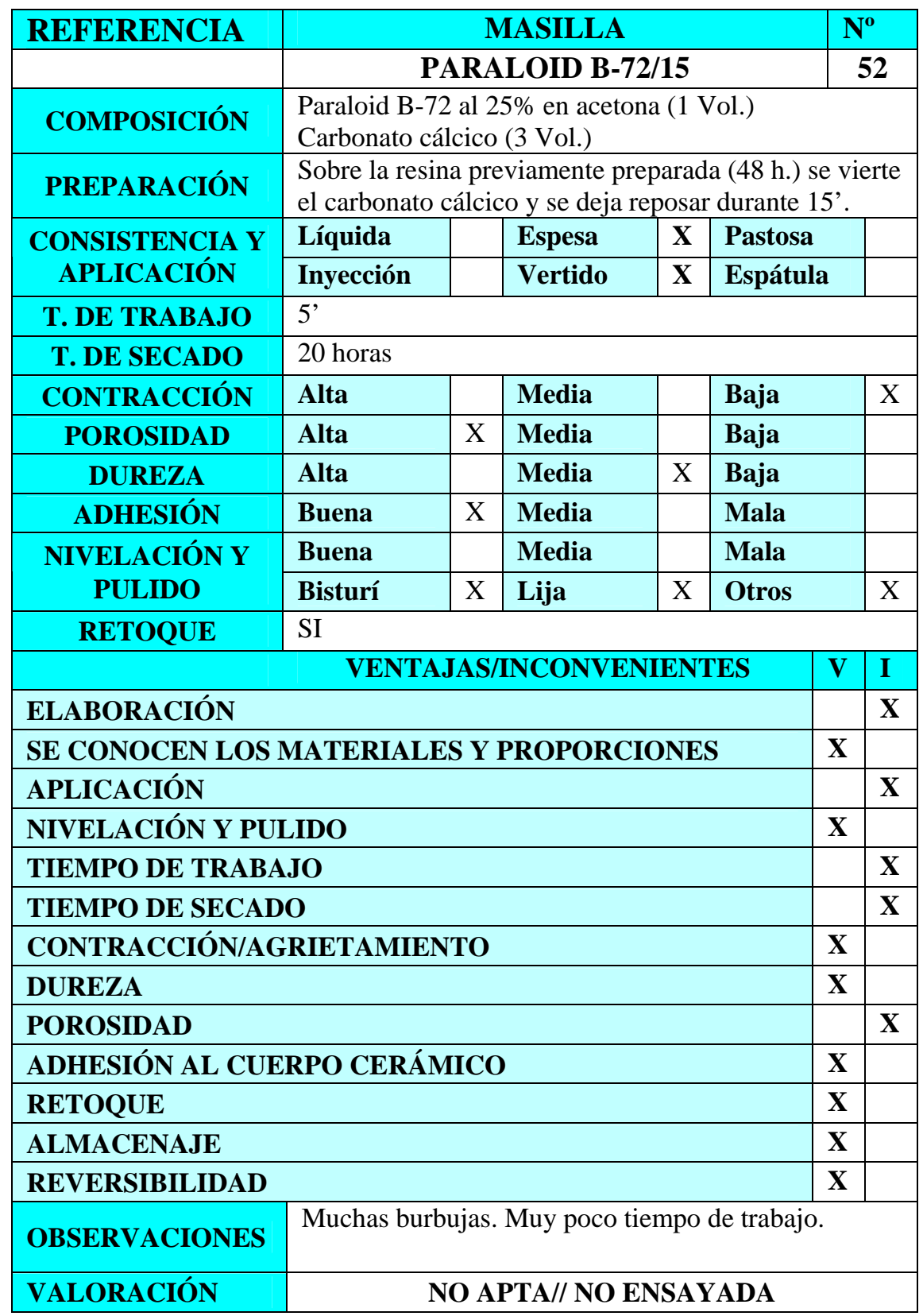




\begin{tabular}{|c|c|c|c|c|c|c|c|}
\hline REFERENCIA & \multicolumn{5}{|c|}{ MASILLA } & \multicolumn{2}{|c|}{$\mathbf{N}^{\circ}$} \\
\hline & \multicolumn{5}{|c|}{ PARALOID B-72/16 } & \multicolumn{2}{|c|}{53} \\
\hline COMPOSICIÓN & \multicolumn{7}{|c|}{$\begin{array}{l}\text { Paraloid B-72 al 25\% en Tolueno(1 Vol.) } \\
\text { Carbonato cálcico (2 Vol.) }\end{array}$} \\
\hline PREPARACIÓN & \multicolumn{7}{|c|}{$\begin{array}{l}\text { Sobre la resina previamente preparada ( } 48 \text { h.) se vierte } \\
\text { el carbonato cálcico y se deja reposar durante } 15 \text { '. }\end{array}$} \\
\hline \multirow{2}{*}{$\begin{array}{l}\text { CONSISTENCIA Y } \\
\text { APLICACIÓN }\end{array}$} & Líquida & & Espesa & $\mathbf{X}$ & Pastosa & & \\
\hline & Inyección & & Vertido & $\mathbf{X}$ & Espátula & & \\
\hline T. DE TRABAJO & \multicolumn{7}{|l|}{$10-15^{\prime}$} \\
\hline T. DE SECADO & \multicolumn{7}{|l|}{24 horas } \\
\hline CONTRACCIÓN & Alta & & Media & $\mathrm{X}$ & \multicolumn{2}{|l|}{ Baja } & \\
\hline POROSIDAD & Alta & & Media & $\mathrm{X}$ & \multicolumn{2}{|l|}{ Baja } & \\
\hline DUREZA & Alta & & Media & $\mathrm{X}$ & \multicolumn{2}{|l|}{ Baja } & \\
\hline ADHESIÓN & Buena & $\mathrm{X}$ & Media & & \multicolumn{2}{|l|}{ Mala } & \\
\hline \multirow{2}{*}{$\begin{array}{l}\text { NIVELACIÓN Y } \\
\text { PULIDO }\end{array}$} & Buena & $\mathrm{X}$ & Media & & Mala & & \\
\hline & Bisturí & $\mathrm{X}$ & Lija & $\mathrm{X}$ & Otros & & $\mathrm{X}$ \\
\hline RETOQUE & \multicolumn{7}{|l|}{ SI } \\
\hline & \multicolumn{5}{|c|}{ VENTAJAS/INCONVENIENTES } & $\mathbf{V}$ & I \\
\hline \multicolumn{6}{|l|}{ ELABORACIÓN } & & $\mathbf{X}$ \\
\hline \multicolumn{6}{|c|}{ SE CONOCEN LOS MATERIALES Y PROPORCIONES } & $\mathbf{X}$ & \\
\hline \multicolumn{6}{|l|}{ APLICACIÓN } & $\mathbf{X}$ & \\
\hline \multicolumn{6}{|c|}{ NIVELACIÓN Y PULIDO } & $\mathbf{X}$ & \\
\hline \multicolumn{6}{|c|}{ TIEMPO DE TRABAJO } & $\mathbf{X}$ & \\
\hline \multicolumn{6}{|c|}{ TIEMPO DE SECADO } & & $\mathbf{X}$ \\
\hline \multicolumn{6}{|c|}{ CONTRACCIÓN/AGRIETAMIENTO } & & $\mathbf{X}$ \\
\hline \multicolumn{6}{|l|}{ DUREZA } & $\mathbf{X}$ & \\
\hline \multicolumn{6}{|l|}{ POROSIDAD } & $\mathbf{X}$ & \\
\hline \multicolumn{6}{|c|}{ ADHESIÓN AL CUERPO CERÁMICO } & $\mathbf{X}$ & \\
\hline \multicolumn{6}{|l|}{ RETOQUE } & $\mathbf{X}$ & \\
\hline \multicolumn{6}{|l|}{ ALMACENAJE } & $\mathbf{X}$ & \\
\hline \multicolumn{6}{|l|}{ REVERSIBILIDAD } & $\mathbf{X}$ & \\
\hline OBSERVACIONES & \multicolumn{7}{|c|}{$\begin{array}{l}\text { Tarda en secar y la pieza debe estar inmóvil, ya qu no } \\
\text { es una masilla tixotrópica. Se adapta bien al molde. } \\
\text { Tóxico }\end{array}$} \\
\hline VALORACIÓN & & & $\mathrm{A} / /$ NO E & $\overline{\mathrm{AYA}}$ & & & \\
\hline
\end{tabular}




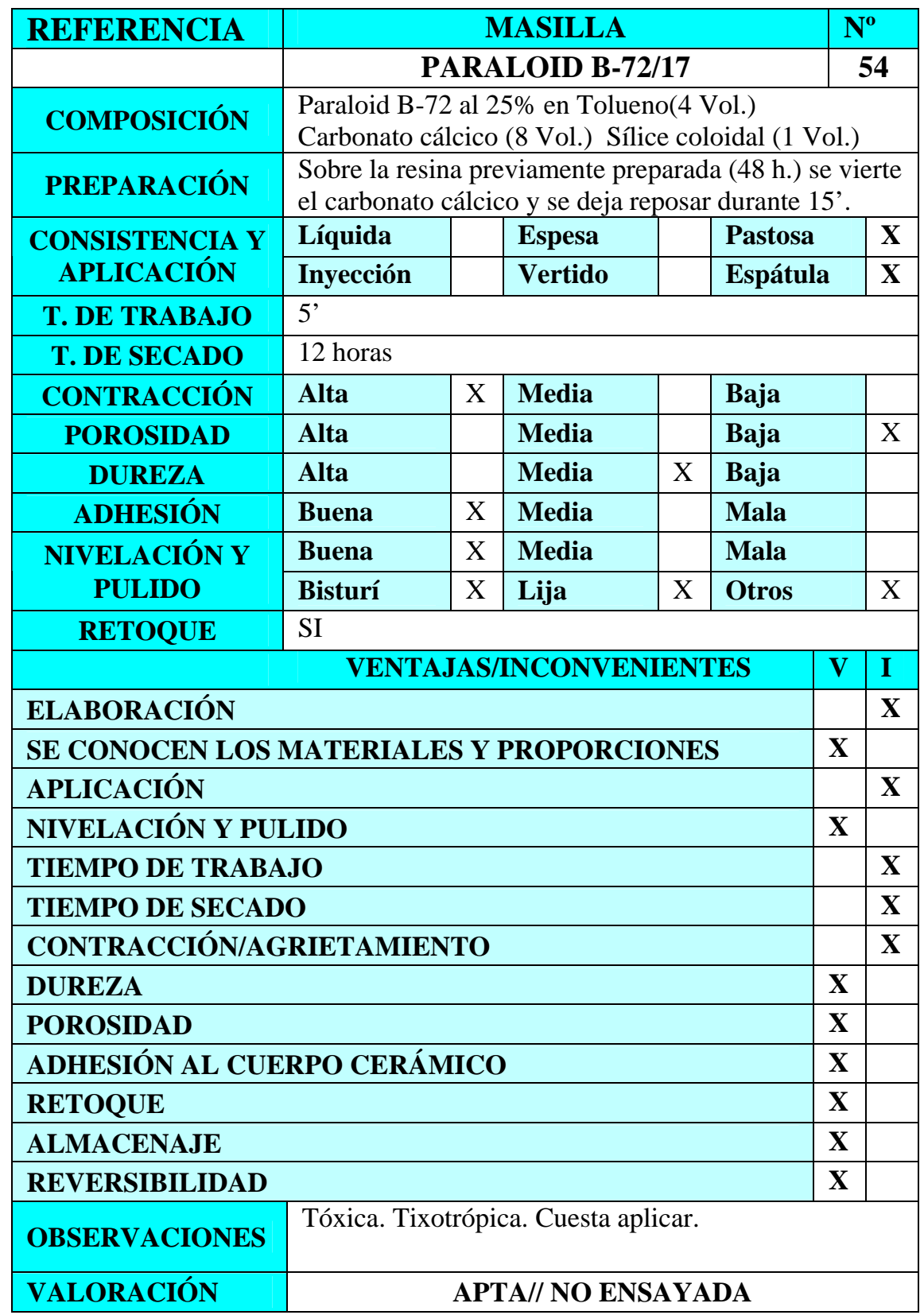




\begin{tabular}{|c|c|c|c|c|c|c|c|}
\hline REFERENCIA & \multicolumn{5}{|c|}{ MASILLA } & \multicolumn{2}{|c|}{$\mathbf{N}^{\mathbf{0}}$} \\
\hline & \multicolumn{5}{|c|}{ PARALOID B-72/18 } & & 5 \\
\hline COMPOSICIÓN & \multicolumn{7}{|c|}{ Paraloid B-72 al 25\% en acetona (2 Vol.) } \\
\hline PREPARACIÓN & \multicolumn{7}{|c|}{$\begin{array}{l}\text { Sobre la resina previamente preparada ( } 48 \mathrm{~h} \text {.) se vierte } \\
\text { el carbonato cálcico y se deja reposar durante } 15 \text { '. }\end{array}$} \\
\hline \multirow{2}{*}{$\begin{array}{l}\text { CONSISTENCIA Y } \\
\text { APLICACIÓN }\end{array}$} & Líquida & & Espesa & $\mathrm{X}$ & Pastosa & & \\
\hline & Inyección & & Vertido & $\mathbf{X}$ & Espátula & & \\
\hline T. DE TRABAJO & \multicolumn{7}{|l|}{$15^{\prime}$} \\
\hline T. DE SECADO & \multicolumn{7}{|l|}{20 horas } \\
\hline CONTRACCIÓN & Alta & & Media & & \multicolumn{2}{|l|}{ Baja } & $\mathrm{X}$ \\
\hline POROSIDAD & Alta & & Media & $\mathrm{X}$ & \multicolumn{2}{|l|}{ Baja } & \\
\hline DUREZA & Alta & & Media & $\mathrm{X}$ & \multicolumn{2}{|l|}{ Baja } & \\
\hline ADHESIÓN & Buena & $\mathrm{X}$ & Media & & \multicolumn{2}{|l|}{ Mala } & \\
\hline \multirow{2}{*}{$\begin{array}{l}\text { NIVELACIÓN Y } \\
\text { PULIDO }\end{array}$} & Buena & $\mathrm{X}$ & Media & & Mala & & \\
\hline & Bisturí & & Lija & $\mathrm{X}$ & Otros & & $\mathrm{X}$ \\
\hline RETOQUE & \multicolumn{7}{|l|}{ SI } \\
\hline & \multicolumn{5}{|c|}{ VENTAJAS/INCONVENIENTES } & $\mathbf{V}$ & I \\
\hline \multicolumn{6}{|l|}{ ELABORACIÓN } & & $\mathbf{X}$ \\
\hline \multicolumn{6}{|c|}{ SE CONOCEN LOS MATERIALES Y PROPORCIONES } & $\mathbf{X}$ & \\
\hline \multicolumn{6}{|l|}{ APLICACIÓN } & $\mathbf{X}$ & \\
\hline \multicolumn{6}{|c|}{ NIVELACIÓN Y PULIDO } & $\mathbf{X}$ & \\
\hline \multicolumn{6}{|c|}{ TIEMPO DE TRABAJO } & $\mathbf{X}$ & \\
\hline \multicolumn{6}{|c|}{ TIEMPO DE SECADO } & & $\mathbf{X}$ \\
\hline \multicolumn{6}{|c|}{ CONTRACCIÓN/AGRIETAMIENTO } & $\mathbf{X}$ & \\
\hline \multicolumn{6}{|l|}{ DUREZA } & $\mathbf{X}$ & \\
\hline \multicolumn{6}{|l|}{ POROSIDAD } & & $\mathbf{X}$ \\
\hline \multicolumn{6}{|c|}{ ADHESIÓN AL CUERPO CERÁMICO } & $\mathbf{X}$ & \\
\hline \multicolumn{6}{|l|}{ RETOQUE } & $\mathbf{X}$ & \\
\hline \multicolumn{6}{|l|}{ ALMACENAJE } & $\mathbf{X}$ & \\
\hline \multicolumn{6}{|l|}{ REVERSIBILIDAD } & $\mathbf{X}$ & \\
\hline OI & \multicolumn{7}{|c|}{$\begin{array}{l}\text { Permite un tiempo más largo de aplicación. algo } \\
\text { porosa }\end{array}$} \\
\hline VALORACIÓN & & $\overline{\mathbf{A P T}}$ & $\mathrm{A} / /$ NO E & $\overline{\mathrm{AYA}}$ & & & \\
\hline
\end{tabular}




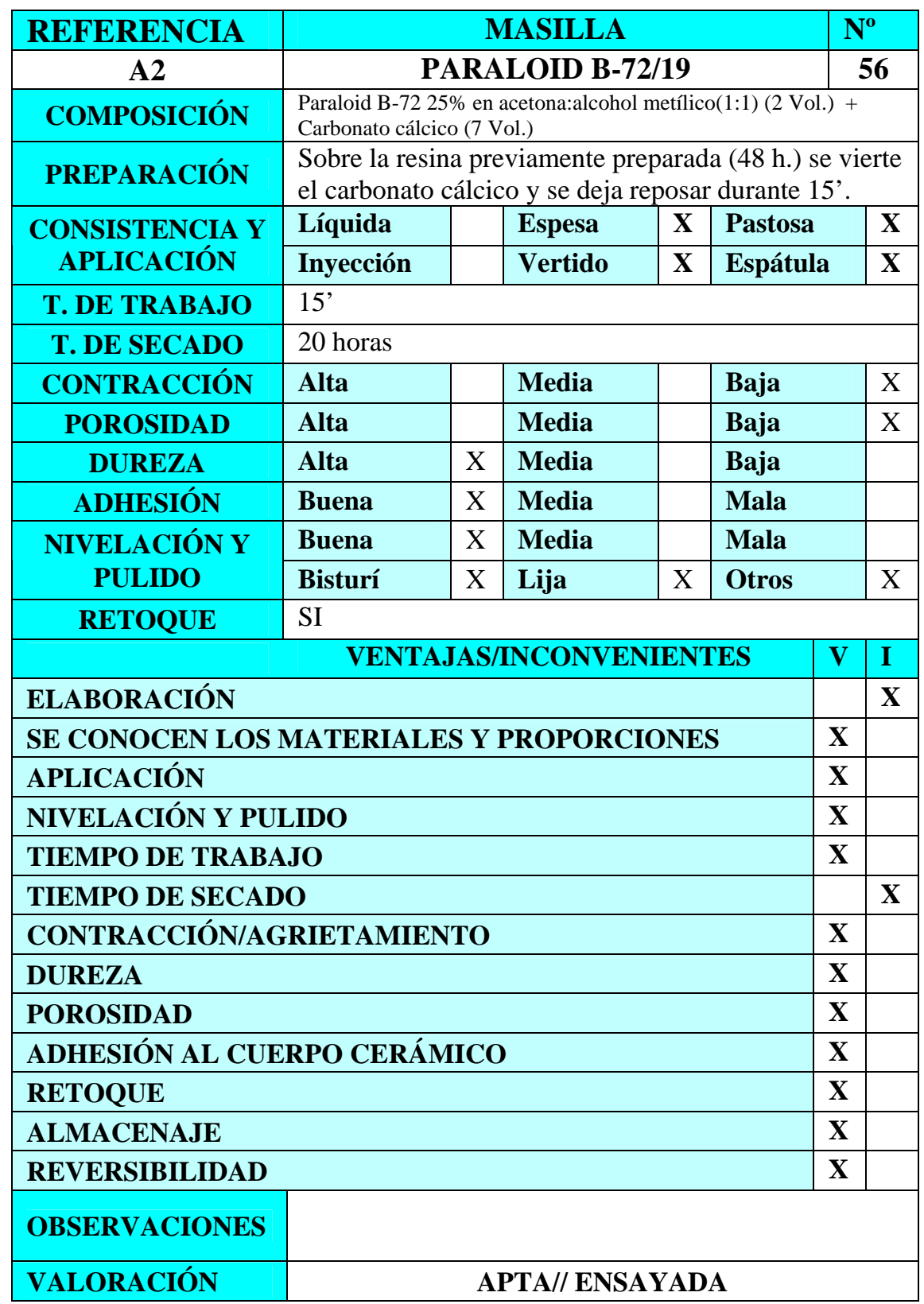




\begin{tabular}{|c|c|c|c|c|c|c|c|}
\hline REFERENCIA & \multicolumn{5}{|c|}{ MASILLA } & \multicolumn{2}{|c|}{$\mathbf{N}^{\mathbf{0}}$} \\
\hline A3 & \multicolumn{5}{|c|}{ PARALOID B-72/20 } & & 57 \\
\hline COMPOSICIÓN & \multicolumn{7}{|c|}{$\begin{array}{l}\text { Paraloid B-72 al 25\% en acetona: alcohol metílico 1:1 (1 Vol.) } \\
\text { Polvo de mármol (1 Vol.) Sílice coloidal (1 Vol.) }\end{array}$} \\
\hline PREPARACIÓN & \multicolumn{7}{|c|}{$\begin{array}{l}\text { Sobre la resina previamente preparada ( } 48 \text { h.) se vierte } \\
\text { el sílice y el polvo de mármol y se deja reposar } \\
\text { durante } 15 \text { '. }\end{array}$} \\
\hline \multirow{2}{*}{$\begin{array}{l}\text { CONSISTENCIA Y } \\
\text { APLICACIÓN }\end{array}$} & Líquida & & Espesa & $\mathbf{X}$ & Pastosa & & $\mathbf{X}$ \\
\hline & Inyección & & Vertido & & Espátula & & $\mathbf{X}$ \\
\hline T. DE TRABAJO & \multicolumn{7}{|l|}{$15-20^{\prime}$} \\
\hline T. DE SECADO & \multicolumn{7}{|l|}{20 horas } \\
\hline CONTRACCIÓN & Alta & & Media & & \multicolumn{2}{|l|}{ Baja } & $\mathrm{X}$ \\
\hline POROSIDAD & Alta & & Media & & \multicolumn{2}{|l|}{ Baja } & $\mathrm{X}$ \\
\hline DUREZA & Alta & $\mathrm{X}$ & Media & & \multicolumn{2}{|l|}{ Baja } & \\
\hline ADHESIÓN & Buena & $\mathrm{X}$ & Media & & \multicolumn{2}{|l|}{ Mala } & \\
\hline \multirow{2}{*}{$\begin{array}{l}\text { NIVELACIÓN Y } \\
\text { PULIDO }\end{array}$} & Buena & $\mathrm{X}$ & Media & & Mala & & \\
\hline & Bisturí & & Lija & $\mathrm{X}$ & Otros & & $\mathrm{X}$ \\
\hline \multirow[t]{2}{*}{ RETOQUE } & \multicolumn{7}{|l|}{ SI } \\
\hline & \multicolumn{5}{|c|}{ VENTAJAS/INCONVENIENTES } & $\mathbf{V}$ & I \\
\hline \multicolumn{6}{|l|}{ ELABORACIÓN } & & $\mathbf{X}$ \\
\hline \multicolumn{6}{|c|}{ SE CONOCEN LOS MATERIALES Y PROPORCIONES } & $\mathbf{X}$ & \\
\hline \multicolumn{6}{|l|}{ APLICACIÓN } & $\mathbf{X}$ & \\
\hline \multicolumn{6}{|c|}{ NIVELACIÓN Y PULIDO } & $\mathbf{X}$ & \\
\hline \multicolumn{6}{|c|}{ TIEMPO DE TRABAJO } & $\mathbf{X}$ & \\
\hline \multicolumn{6}{|c|}{ TIEMPO DE SECADO } & & $\mathbf{X}$ \\
\hline \multicolumn{6}{|c|}{ CONTRACCIÓN/AGRIETAMIENTO } & $\mathbf{X}$ & \\
\hline \multicolumn{6}{|l|}{ DUREZA } & & $\mathbf{X}$ \\
\hline \multicolumn{6}{|l|}{ POROSIDAD } & $\mathbf{X}$ & \\
\hline \multicolumn{6}{|c|}{ ADHESIÓN AL CUERPO CERÁMICO } & $\mathbf{X}$ & \\
\hline \multicolumn{6}{|c|}{ RETOQUE } & $\mathbf{X}$ & \\
\hline \multicolumn{6}{|l|}{ ALMACENAJE } & $\mathbf{X}$ & \\
\hline \multicolumn{6}{|l|}{ REVERSIBILIDAD } & $\mathbf{X}$ & \\
\hline OBSERVACIONES & \multicolumn{7}{|c|}{$\begin{array}{l}\text { Cuando seca es una masilla pesada y dura pero de } \\
\text { fácil reversibilidad con acetona. }\end{array}$} \\
\hline VALORACIÓN & & & TA// EN & YAD & & & \\
\hline
\end{tabular}




\begin{tabular}{|c|c|c|c|c|c|c|}
\hline REFERENCIA & \multicolumn{4}{|c|}{ MASILLA } & \multicolumn{2}{|c|}{$\mathbf{N}^{\mathbf{0}}$} \\
\hline & \multicolumn{4}{|c|}{ RESINA EPO 150/1 } & \multicolumn{2}{|c|}{58} \\
\hline COMPOSICIÓN & \multicolumn{6}{|c|}{ EPO 150 : K 151 (100:25 gr) } \\
\hline PREPARACIÓN & \multicolumn{6}{|c|}{$\begin{array}{l}\text { Preparar según lo indicado en la composición } \\
\text { removiendo la mezcla uniformemente. }\end{array}$} \\
\hline \multirow{2}{*}{$\begin{array}{l}\text { CONSISTENCIA Y } \\
\text { APLICACIÓN }\end{array}$} & Líquida & $\mathbf{X}$ & Espesa & \multicolumn{2}{|c|}{ Pastosa } & \\
\hline & Inyección & $\mathbf{X}$ & Vertido & \multicolumn{2}{|c|}{ Espátula } & \\
\hline \multicolumn{7}{|l|}{ T. DE TRABAJO } \\
\hline \multicolumn{7}{|l|}{ T. DE SECADO } \\
\hline CONTRACCIÓN & Alta & & Media & \multicolumn{2}{|l|}{ Baja } & $\mathrm{X}$ \\
\hline POROSIDAD & Alta & & Media & \multicolumn{2}{|c|}{ Baja } & $\mathrm{X}$ \\
\hline DUREZA & Alta & $\mathrm{X}$ & Media & \multicolumn{2}{|c|}{ Baja } & \\
\hline ADHESIÓN & Buena & $\mathrm{X}$ & Media & \multicolumn{2}{|c|}{ Mala } & \\
\hline \multirow{2}{*}{$\begin{array}{l}\text { NIVELACIÓN Y } \\
\text { PULIDO }\end{array}$} & Buena & & Media & Mal & & $\mathrm{X}$ \\
\hline & Bisturí & & Lija & Otro & & $\mathrm{X}$ \\
\hline RETOQUE & \multicolumn{6}{|c|}{ Pinturas sintéticas o epoxídicas } \\
\hline \multicolumn{5}{|c|}{ VENTAJAS/INCONVENIENTES } & $\mathbf{V}$ & $\mathbf{I}$ \\
\hline \multicolumn{5}{|l|}{ ELABORACIÓN } & & $\mathbf{X}$ \\
\hline \multicolumn{5}{|c|}{ SE CONOCEN LOS MATERIALES Y PROPORCIONES } & $\mathbf{X}$ & \\
\hline \multicolumn{5}{|l|}{ APLICACIÓN } & & $\mathbf{X}$ \\
\hline \multicolumn{5}{|c|}{ NIVELACIÓN Y PULIDO } & & $\mathbf{X}$ \\
\hline \multicolumn{7}{|c|}{ TIEMPO DE TRABAJO } \\
\hline \multicolumn{5}{|c|}{ TIEMPO DE SECADO } & & \\
\hline \multicolumn{5}{|c|}{ CONTRACCIÓN/AGRIETAMIENTO } & $\mathbf{X}$ & \\
\hline \multicolumn{5}{|l|}{ DUREZA } & & $\mathbf{X}$ \\
\hline \multicolumn{5}{|l|}{ POROSIDAD } & $\mathbf{X}$ & \\
\hline \multicolumn{5}{|c|}{ ADHESIÓN AL CUERPO CERÁMICO } & $\mathbf{X}$ & \\
\hline \multicolumn{5}{|l|}{ RETOQUE } & & $\mathbf{X}$ \\
\hline \multicolumn{5}{|l|}{ ALMACENAJE } & & $\mathbf{X}$ \\
\hline REVERSIBILIDAD & & & & & & $\mathbf{X}$ \\
\hline OBSERVACIONES & Se debe niv & ar en & seco con & micre & & \\
\hline VALORACIÓN & & $\mathbf{O}$ & TA//NO & ADA & & \\
\hline
\end{tabular}




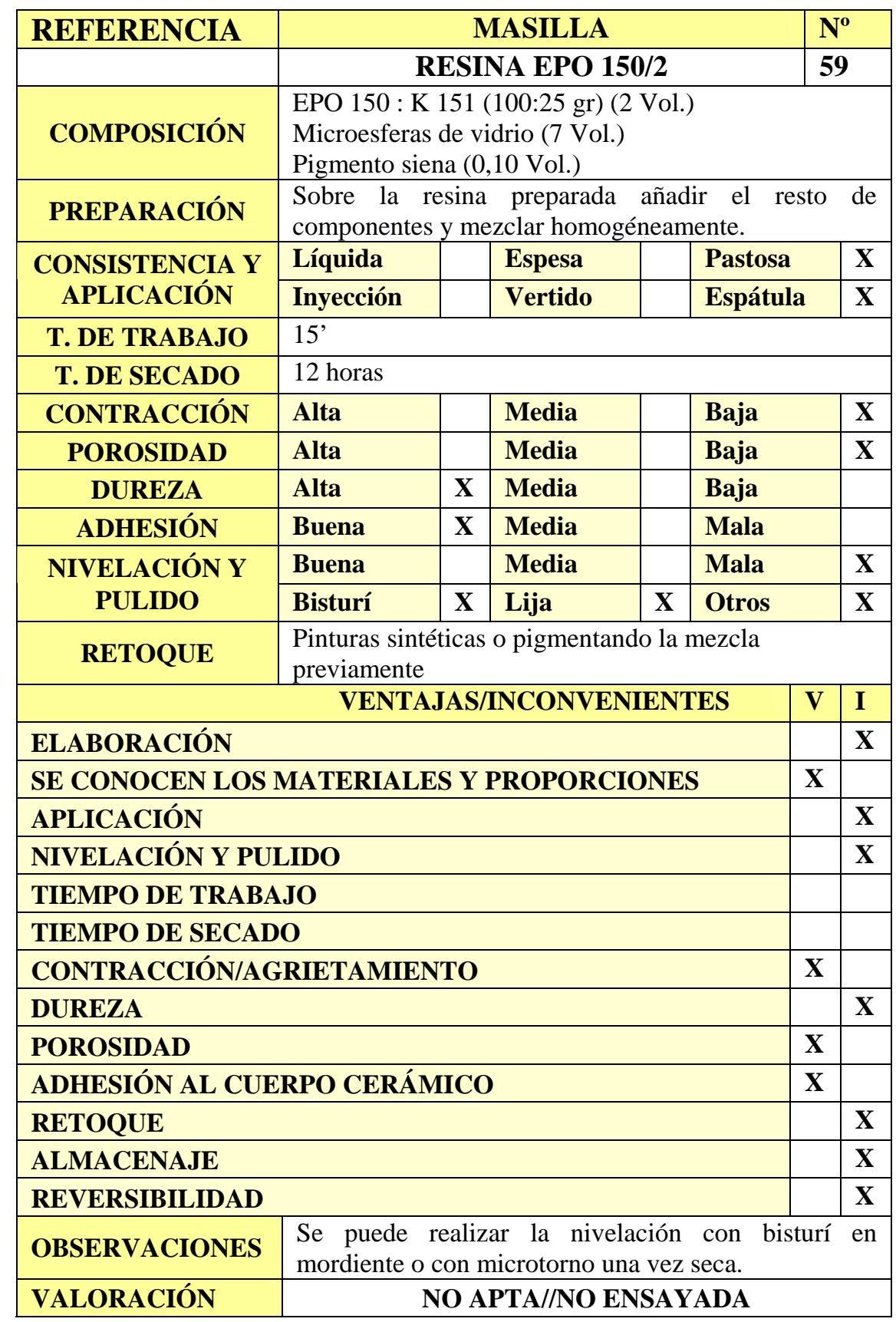




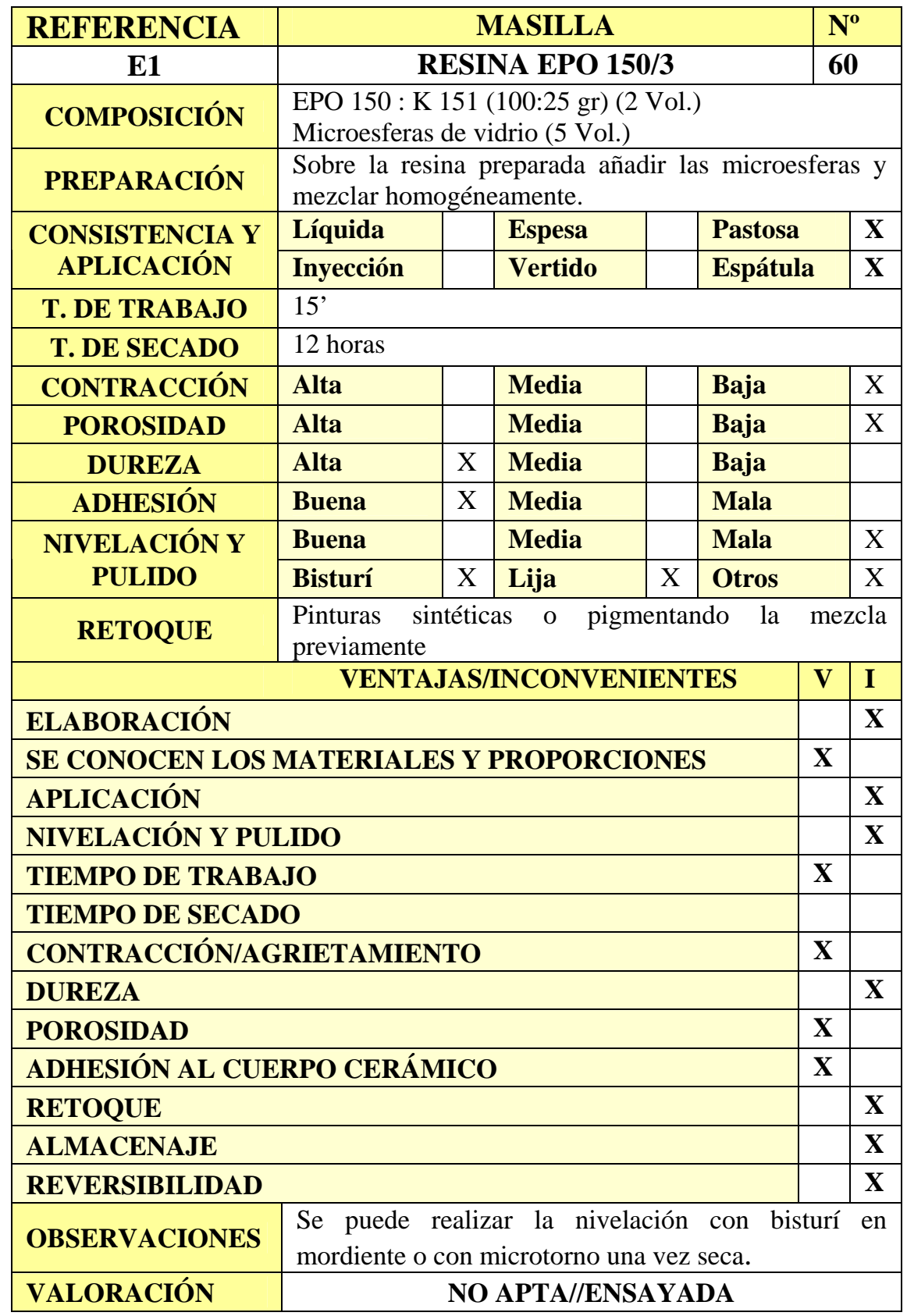




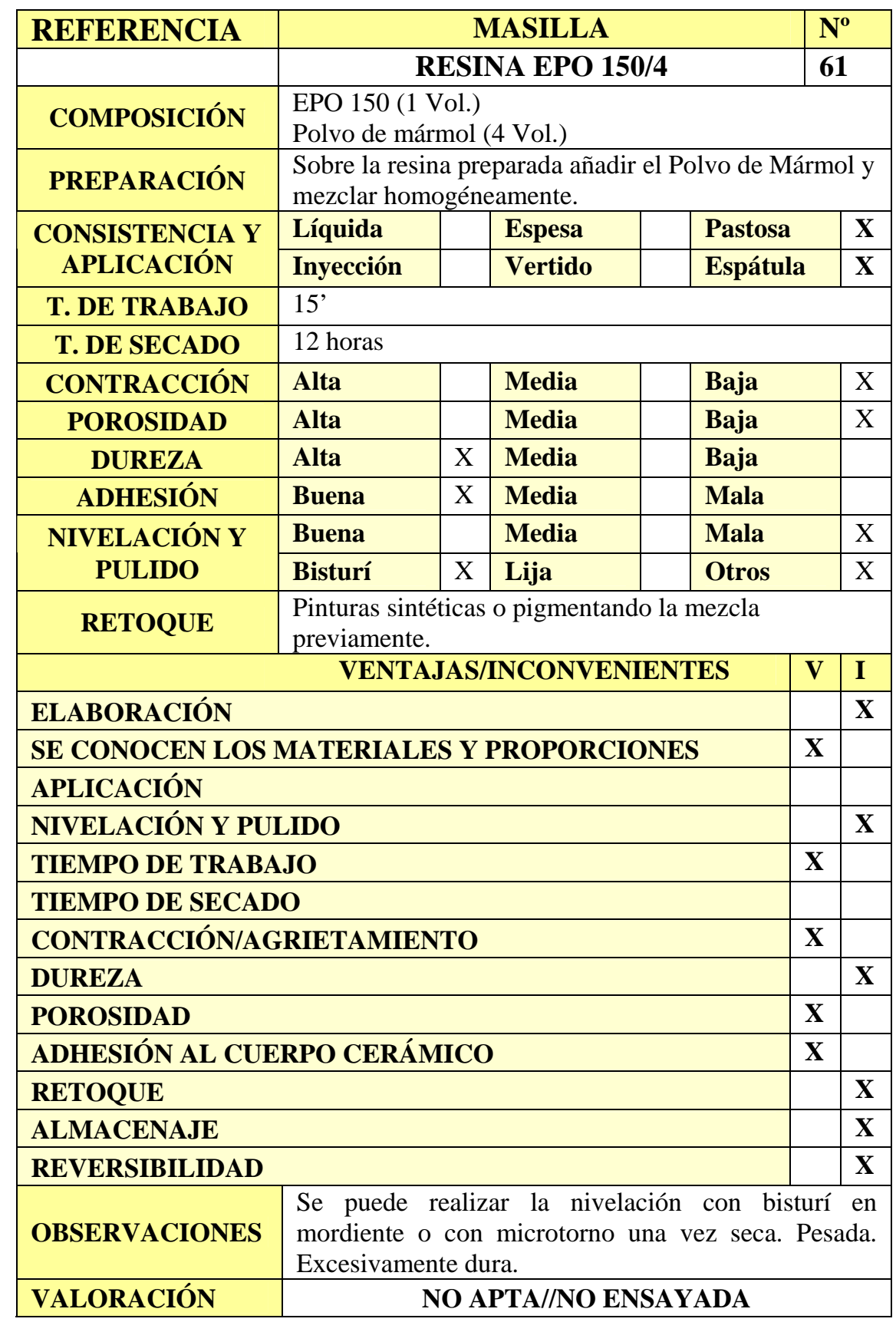




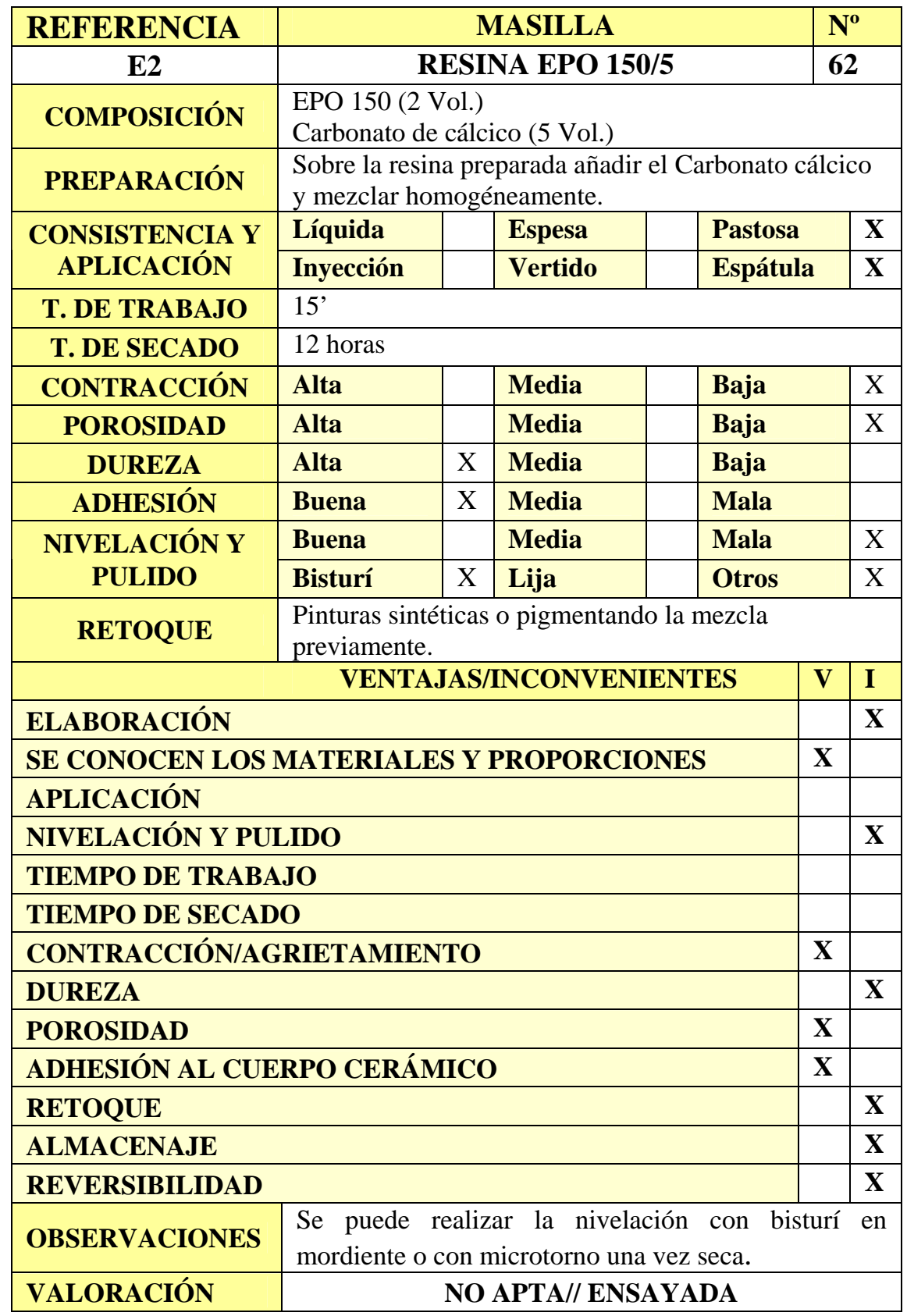




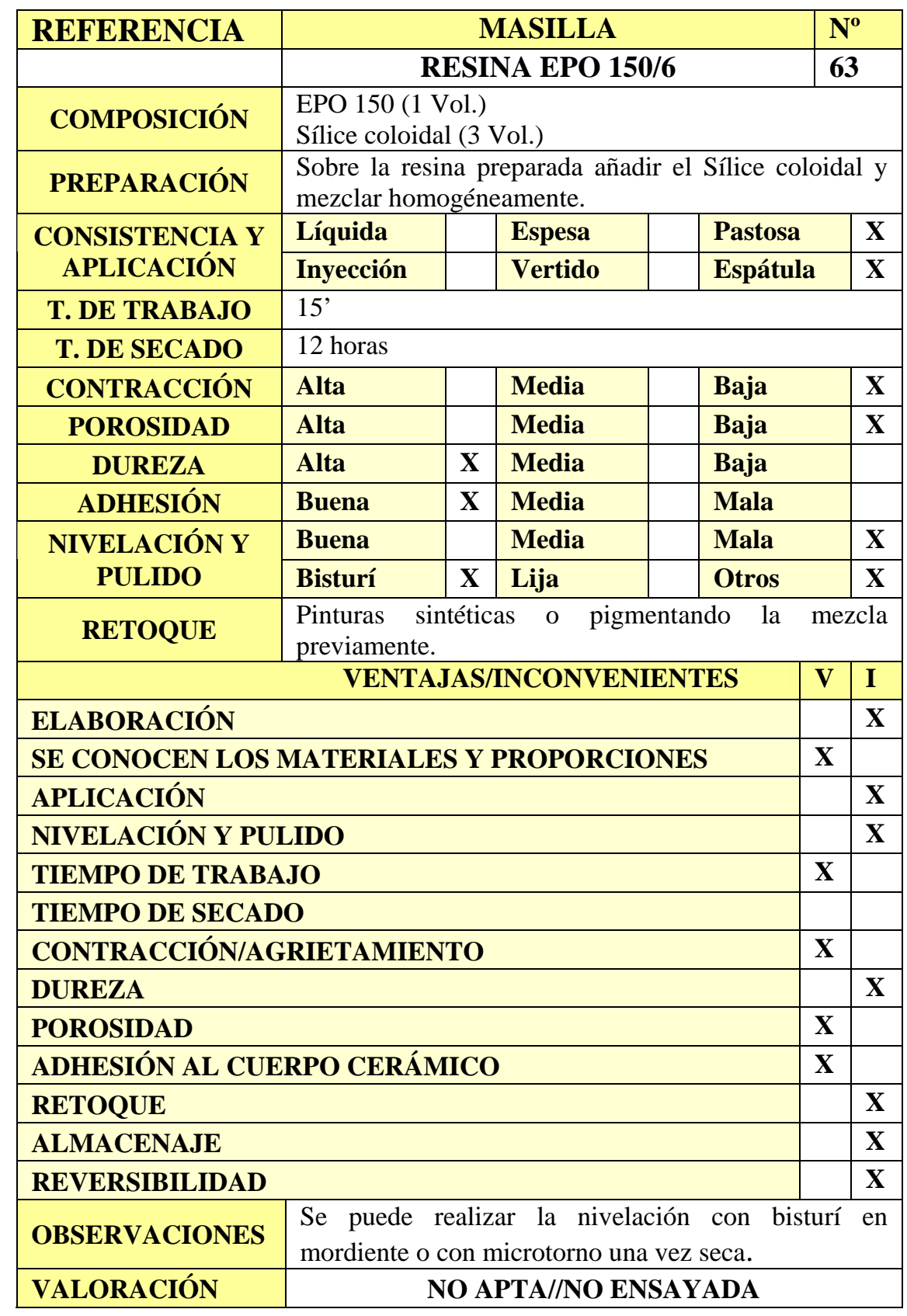




\begin{tabular}{|c|c|c|c|c|c|c|}
\hline REFERENCIA & \multicolumn{4}{|c|}{ MASILLA } & \multicolumn{2}{|c|}{$\mathbf{N}^{\circ}$} \\
\hline E3 & \multicolumn{4}{|c|}{ RESINA EPO 150/7 } & \multicolumn{2}{|c|}{64} \\
\hline COMPOSICIÓN & \multicolumn{6}{|c|}{$\begin{array}{l}\text { EPO } 150 \text { (1 Vol.) } \\
\text { Sílice coloidal (5 Vol.) }\end{array}$} \\
\hline PREPARACIÓN & \multicolumn{6}{|c|}{$\begin{array}{l}\text { Sobre la resina preparada añadir el Sílice coloidal y } \\
\text { mezclar homogéneamente. }\end{array}$} \\
\hline \multirow{2}{*}{$\begin{array}{l}\text { CONSISTENCIA Y } \\
\text { APLICACIÓN }\end{array}$} & Líquida & & Espesa & $\mathbf{P a}$ & & $\mathbf{X}$ \\
\hline & Inyección & & Vertido & & & $\mathbf{X}$ \\
\hline T. DE TRABAJO & \multicolumn{6}{|l|}{$15^{\prime}$} \\
\hline T. DE SECADO & \multicolumn{6}{|l|}{12 horas } \\
\hline CONTRACCIÓN & Alta & & Media & \multicolumn{2}{|c|}{ Baja } & $\mathrm{X}$ \\
\hline POROSIDAD & Alta & & Media & \multicolumn{2}{|c|}{ Baja } & $\mathrm{X}$ \\
\hline DUREZA & Alta & $\mathrm{X}$ & Media & \multicolumn{2}{|c|}{ Baja } & \\
\hline ADHESIÓN & Buena & $\mathrm{X}$ & Media & \multicolumn{2}{|c|}{ Mala } & \\
\hline \multirow{2}{*}{$\begin{array}{l}\text { NIVELACIÓN Y } \\
\text { PULIDO }\end{array}$} & Buena & & Media & $\mathbf{M}$ & & $\mathrm{X}$ \\
\hline & Bisturí & $\mathrm{X}$ & Lija & Ot & & $\mathrm{X}$ \\
\hline RETOQUE & \multicolumn{6}{|c|}{$\begin{array}{llllll}\begin{array}{l}\text { Pinturas sintéticas } \\
\text { previamente. }\end{array} & \text { o pigmentando la } & \text { mezcla } \\
\end{array}$} \\
\hline & \multicolumn{4}{|c|}{ VENTAJAS/INCONVENIENTES } & $\mathbf{V}$ & $\mathbf{I}$ \\
\hline \multicolumn{5}{|l|}{ ELABORACIÓN } & & $\mathbf{X}$ \\
\hline \multicolumn{5}{|c|}{ SE CONOCEN LOS MATERIALES Y PROPORCIONES } & $\mathbf{X}$ & \\
\hline \multicolumn{5}{|l|}{ APLICACIÓN } & & $\mathbf{X}$ \\
\hline \multicolumn{5}{|c|}{ NIVELACIÓN Y PULIDO } & & $\mathbf{X}$ \\
\hline \multicolumn{5}{|c|}{ TIEMPO DE TRABAJO } & $\underline{\mathbf{X}}$ & \\
\hline \multicolumn{5}{|c|}{ TIEMPO DE SECADO } & & \\
\hline \multicolumn{5}{|c|}{ CONTRACCIÓN/AGRIETAMIENTO } & $\mathbf{X}$ & \\
\hline \multicolumn{5}{|l|}{ DUREZA } & & $\mathbf{X}$ \\
\hline \multicolumn{5}{|l|}{ POROSIDAD } & $\bar{X}$ & \\
\hline \multicolumn{5}{|c|}{ ADHESIÓN AL CUERPO CERÁMICO } & $\mathbf{X}$ & \\
\hline \multicolumn{5}{|l|}{ RETOQUE } & & $\mathbf{X}$ \\
\hline \multicolumn{5}{|l|}{ ALMACENAJE } & & $\mathbf{X}$ \\
\hline \multicolumn{5}{|l|}{ REVERSIBILIDAD } & & $\mathbf{X}$ \\
\hline OBSERVACIONES & \multicolumn{6}{|c|}{$\begin{array}{l}\text { Se puede realizar la nivelación con bisturí en } \\
\text { mordiente o con poxídica una vez seca. Masilla } \\
\text { poxídica más ligera. }\end{array}$} \\
\hline VALORACIÓN & & NO & APTA/ E & $\mathbf{D A}$ & & \\
\hline
\end{tabular}




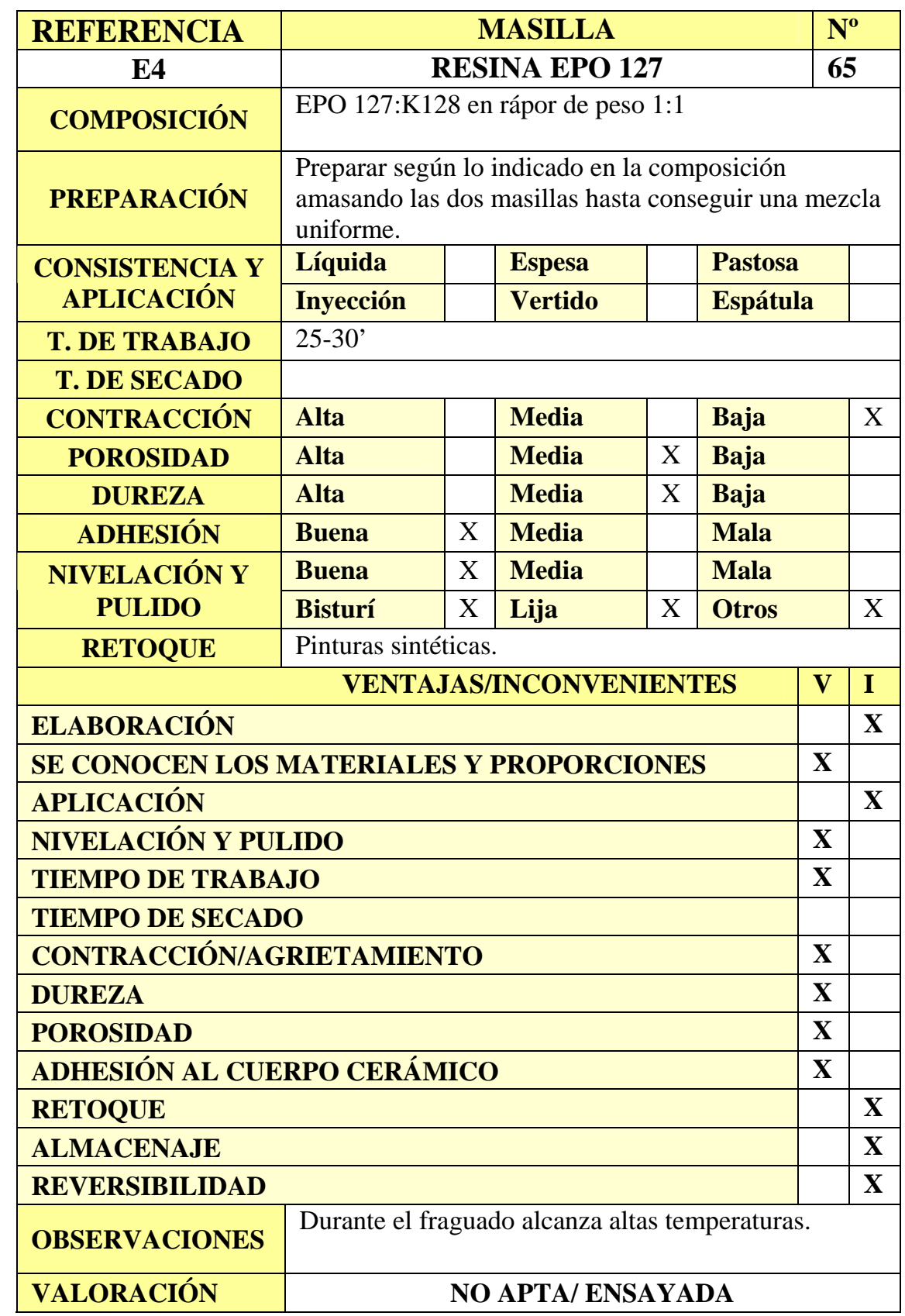




\begin{tabular}{|c|c|c|c|c|c|c|c|}
\hline REFERENCIA & \multicolumn{5}{|c|}{ MASILLA } & \multicolumn{2}{|c|}{$\mathbf{N}^{\mathbf{0}}$} \\
\hline & \multicolumn{5}{|c|}{ POLYFILLA EXTERIORES/1 } & \multicolumn{2}{|c|}{66} \\
\hline COMPOSICIÓN & \multicolumn{7}{|c|}{$\begin{array}{l}\text { Polyfila exteriores (2 Vol.) } \\
\text { Agua (1 Vol.) }\end{array}$} \\
\hline PREPARACIÓN & \multicolumn{7}{|c|}{$\begin{array}{l}\text { Sobre el agua se espolvorea la Polyfilla tamizada, se } \\
\text { amasa con ayuda de espátula flexible hasta conseguir } \\
\text { una mezcla homogénea. }\end{array}$} \\
\hline CONSISTENCIA Y & Líquida & & Espesa & $\mathbf{X}$ & \multicolumn{2}{|c|}{ Pastosa } & $\mathbf{X}$ \\
\hline APLICACIÓN & Inyección & & Vertido & $\mathbf{X}$ & \multicolumn{2}{|c|}{ Espátula } & $\mathbf{X}$ \\
\hline T. DE TRABAJO & \multicolumn{7}{|l|}{1 hora } \\
\hline T. DE SECADO & \multicolumn{7}{|l|}{12 horas } \\
\hline CONTRACCIÓN & Alta & & Media & & \multicolumn{2}{|l|}{ Baja } & $\mathrm{X}$ \\
\hline POROSIDAD & Alta & $\mathrm{X}$ & Media & & \multicolumn{2}{|l|}{ Baja } & \\
\hline DUREZA & Alta & & Media & & \multicolumn{2}{|l|}{ Baja } & $\mathrm{X}$ \\
\hline ADHESIÓN & Buena & & Media & & \multicolumn{2}{|l|}{ Mala } & $\mathrm{X}$ \\
\hline NIVELACIÓN Y & Buena & $\mathrm{X}$ & Media & & \multicolumn{2}{|l|}{ Mala } & \\
\hline PULIDO & Bisturí & $\mathrm{X}$ & Lija & $\mathrm{X}$ & \multicolumn{2}{|l|}{ Otros } & \\
\hline \multirow[t]{2}{*}{ RETOQUE } & \multicolumn{7}{|c|}{ Toda clase de pinturas } \\
\hline & \multicolumn{6}{|c|}{ VENTAJAS/INCONVENIENTES } & $\mathbf{I}$ \\
\hline \multicolumn{7}{|l|}{ ELABORACIÓN } & $\mathbf{X}$ \\
\hline \multicolumn{6}{|c|}{ SE CONOCEN LOS MATERIALES Y PROPORCIONES } & & $\mathbf{X}$ \\
\hline \multicolumn{6}{|l|}{ APLICACIÓN } & $\mathbf{X}$ & \\
\hline \multicolumn{6}{|c|}{ NIVELACIÓN Y PULIDO } & $\mathbf{X}$ & \\
\hline \multicolumn{6}{|c|}{ TIEMPO DE TRABAJO } & $\mathbf{X}$ & \\
\hline \multicolumn{6}{|c|}{ TIEMPO DE SECADO } & & \\
\hline \multicolumn{6}{|c|}{ CONTRACCIÓN/AGRIETAMIENTO } & $\mathbf{X}$ & \\
\hline \multicolumn{6}{|l|}{ DUREZA } & & $\mathbf{X}$ \\
\hline \multicolumn{6}{|l|}{ POROSIDAD } & & $\mathbf{X}$ \\
\hline \multicolumn{6}{|c|}{ ADHESIÓN AL CUERPO CERÁMICO } & & $\mathbf{X}$ \\
\hline \multicolumn{6}{|l|}{ RETOQUE } & $\mathbf{X}$ & \\
\hline ALMACENAJE & & & & & & & $\mathbf{X}$ \\
\hline REVERSIBILIDAD & & & & & & $\mathbf{X}$ & \\
\hline OBSERVACIONES & $\begin{array}{l}\text { Presenta m } \\
\text { capa. }\end{array}$ & & Irbujas, e & & aplica & & \\
\hline VALORACIÓN & & 120 & PTA $/ / \mathbf{R}$ & & & & \\
\hline
\end{tabular}




\begin{tabular}{|c|c|c|c|c|c|c|c|}
\hline REFERENCIA & \multicolumn{5}{|c|}{ MASILLA } & \multicolumn{2}{|c|}{$\mathbf{N}^{\mathbf{0}}$} \\
\hline & \multicolumn{5}{|c|}{ POLYFILLA EXTERIORES/2 } & \multicolumn{2}{|c|}{67} \\
\hline COMPOSICIÓN & \multicolumn{7}{|c|}{$\begin{array}{l}\text { Polyfila exteriores (2 Vol.) } \\
\text { Plextol B-500 al 75\% en agua (1 Vol.) }\end{array}$} \\
\hline PREPARACIÓN & \multicolumn{7}{|c|}{$\begin{array}{l}\text { Sobre el Plextol ya preparado se espolvorea la } \\
\text { Polyfilla tamizada. Se amasa con ayuda de espátula } \\
\text { flexible hasta conseguir una mezcla homogénea. }\end{array}$} \\
\hline CONSISTENCIA Y & Líquida & & Espesa & $\mathbf{X}$ & \multicolumn{2}{|l|}{ Pastosa } & $\mathbf{X}$ \\
\hline APLICACIÓN & Inyección & & Vertido & $\mathbf{X}$ & \multicolumn{2}{|c|}{ Espátula } & $\mathbf{X}$ \\
\hline T. DE TRABAJO & \multicolumn{7}{|l|}{$30^{\prime}$} \\
\hline T. DE SECADO & \multicolumn{7}{|l|}{4 horas } \\
\hline CONTRACCIÓN & Alta & & Media & & \multicolumn{2}{|l|}{ Baja } & $\mathrm{X}$ \\
\hline POROSIDAD & Alta & & Media & $\mathrm{X}$ & \multicolumn{2}{|l|}{ Baja } & \\
\hline DUREZA & Alta & & Media & $\mathrm{X}$ & \multicolumn{2}{|l|}{ Baja } & \\
\hline ADHESIÓN & Buena & & Media & $\mathrm{X}$ & \multicolumn{2}{|l|}{ Mala } & \\
\hline NIVELACIÓN Y & Buena & $\mathrm{X}$ & Media & & \multicolumn{2}{|l|}{ Mala } & \\
\hline PULIDO & Bisturí & $\mathrm{X}$ & Lija & $\mathrm{X}$ & \multicolumn{2}{|l|}{ Otros } & \\
\hline \multirow[t]{2}{*}{ RETOQUE } & \multicolumn{7}{|c|}{ Toda clase de pintura } \\
\hline & \multicolumn{5}{|c|}{ VENTAJAS/INCONVENIENTES } & $\mathbf{V}$ & $\mathbf{I}$ \\
\hline \multicolumn{6}{|l|}{ ELABORACIÓN } & & $\mathbf{X}$ \\
\hline \multicolumn{6}{|c|}{ SE CONOCEN LOS MATERIALES Y PROPORCIONES } & & $\mathbf{X}$ \\
\hline \multicolumn{6}{|l|}{ APLICACIÓN } & $\mathbf{X}$ & \\
\hline \multicolumn{6}{|c|}{ NIVELACIÓN Y PULIDO } & $\mathbf{X}$ & \\
\hline \multicolumn{6}{|c|}{ TIEMPO DE TRABAJO } & $\mathbf{X}$ & \\
\hline \multicolumn{6}{|c|}{ TIEMPO DE SECADO } & $\mathbf{X}$ & \\
\hline \multicolumn{6}{|c|}{ CONTRACCIÓN/AGRIETAMIENTO } & $\mathbf{X}$ & \\
\hline \multicolumn{6}{|l|}{ DUREZA } & $\mathbf{X}$ & \\
\hline \multicolumn{6}{|l|}{ POROSIDAD } & & $\mathbf{X}$ \\
\hline \multicolumn{6}{|c|}{ ADHESIÓN AL CUERPO CERÁMICO } & $\mathbf{X}$ & \\
\hline \multicolumn{6}{|l|}{ RETOQUE } & $\mathbf{X}$ & \\
\hline ALMACENAJE & & & & & & & $\mathbf{X}$ \\
\hline REVERSIBILIDAD & & & & & & & $\mathbf{X}$ \\
\hline OBSERVACIONES & Muy porosa & & & & & & \\
\hline VALORACIÓN & & & A & & & & \\
\hline
\end{tabular}




\begin{tabular}{|c|c|c|c|c|c|c|c|}
\hline REFERENCIA & \multicolumn{5}{|c|}{ MASILLA } & \multicolumn{2}{|c|}{$\mathbf{N}^{\mathbf{0}}$} \\
\hline & \multicolumn{5}{|c|}{ POLYFILLA EXTERIORES/3 } & 68 & \\
\hline COMPOSICIÓN & \multicolumn{7}{|c|}{$\begin{array}{l}\text { PolyfilLa exteriores (5 Vol.) } \\
\text { Acril } 33 \text { (4 Vol.) }\end{array}$} \\
\hline PREPARACIÓN & \multicolumn{7}{|c|}{$\begin{array}{l}\text { Sobre el Acril se espolvorea la Polyfilla tamizada. Se } \\
\text { amasa con ayuda de espátula flexible hasta conseguir } \\
\text { una mezcla homogénea. }\end{array}$} \\
\hline CONSISTENCIA Y & Líquida & & Espesa & & \multicolumn{2}{|l|}{ Pastosa } & $\mathbf{X}$ \\
\hline APLICACIÓN & Inyección & & Vertido & & \multicolumn{2}{|c|}{ Espátula } & $\mathbf{X}$ \\
\hline T. DE TRABAJO & \multicolumn{7}{|l|}{$30^{\prime}$} \\
\hline T. DE SECADO & \multicolumn{7}{|l|}{3 horas } \\
\hline CONTRACCIÓN & Alta & & Media & & \multicolumn{2}{|l|}{ Baja } & $\mathrm{X}$ \\
\hline POROSIDAD & Alta & $\mathrm{X}$ & Media & & \multicolumn{2}{|l|}{ Baja } & \\
\hline DUREZA & Alta & & Media & $\mathrm{X}$ & \multicolumn{2}{|l|}{ Baja } & \\
\hline ADHESIÓN & Buena & $\mathrm{X}$ & Media & & \multicolumn{2}{|l|}{ Mala } & \\
\hline NIVELACIÓN Y & Buena & $\mathrm{X}$ & Media & & \multicolumn{2}{|l|}{ Mala } & \\
\hline PULIDO & Bisturí & $\mathrm{X}$ & Lija & $\mathrm{X}$ & \multicolumn{2}{|l|}{ Otros } & $\mathrm{X}$ \\
\hline \multirow[t]{2}{*}{ RETOQUE } & \multicolumn{7}{|c|}{ SI } \\
\hline & \multicolumn{6}{|c|}{$\begin{array}{ll}\text { VENTAJAS/INCONVENIENTES } & \text { V }\end{array}$} & $\mathbf{I}$ \\
\hline \multicolumn{6}{|l|}{ ELABORACIÓN } & & $\mathbf{X}$ \\
\hline \multicolumn{6}{|c|}{ SE CONOCEN LOS MATERIALES Y PROPORCIONES } & & $\mathbf{X}$ \\
\hline \multicolumn{6}{|l|}{ APLICACIÓN } & $\mathbf{X}$ & \\
\hline \multicolumn{6}{|c|}{ NIVELACIÓN Y PULIDO } & $\mathbf{X}$ & \\
\hline \multicolumn{6}{|c|}{ TIEMPO DE TRABAJO } & $\mathbf{X}$ & \\
\hline \multicolumn{6}{|c|}{ TIEMPO DE SECADO } & $\mathbf{X}$ & \\
\hline \multicolumn{6}{|c|}{ CONTRACCIÓN/AGRIETAMIENTO } & $\mathbf{X}$ & \\
\hline \multicolumn{6}{|l|}{ DUREZA } & $\mathbf{X}$ & \\
\hline \multicolumn{6}{|l|}{ POROSIDAD } & $\mathbf{X}$ & \\
\hline \multicolumn{6}{|c|}{ ADHESIÓN AL CUERPO CERÁMICO } & $\mathbf{X}$ & \\
\hline \multicolumn{6}{|l|}{ RETOQUE } & $\mathbf{X}$ & \\
\hline \multicolumn{6}{|l|}{ ALMACENAJE } & & $\mathbf{X}$ \\
\hline REVERSIBILIDAD & & & & & & & $\mathbf{X}$ \\
\hline OBSERVACIONES & Es necesar & aplic & Ir una $2^{\mathrm{a}} \mathrm{c}$ & parc & cerrar los & por & \\
\hline VALORACIÓN & & & A//NO E & 4 & & & \\
\hline
\end{tabular}




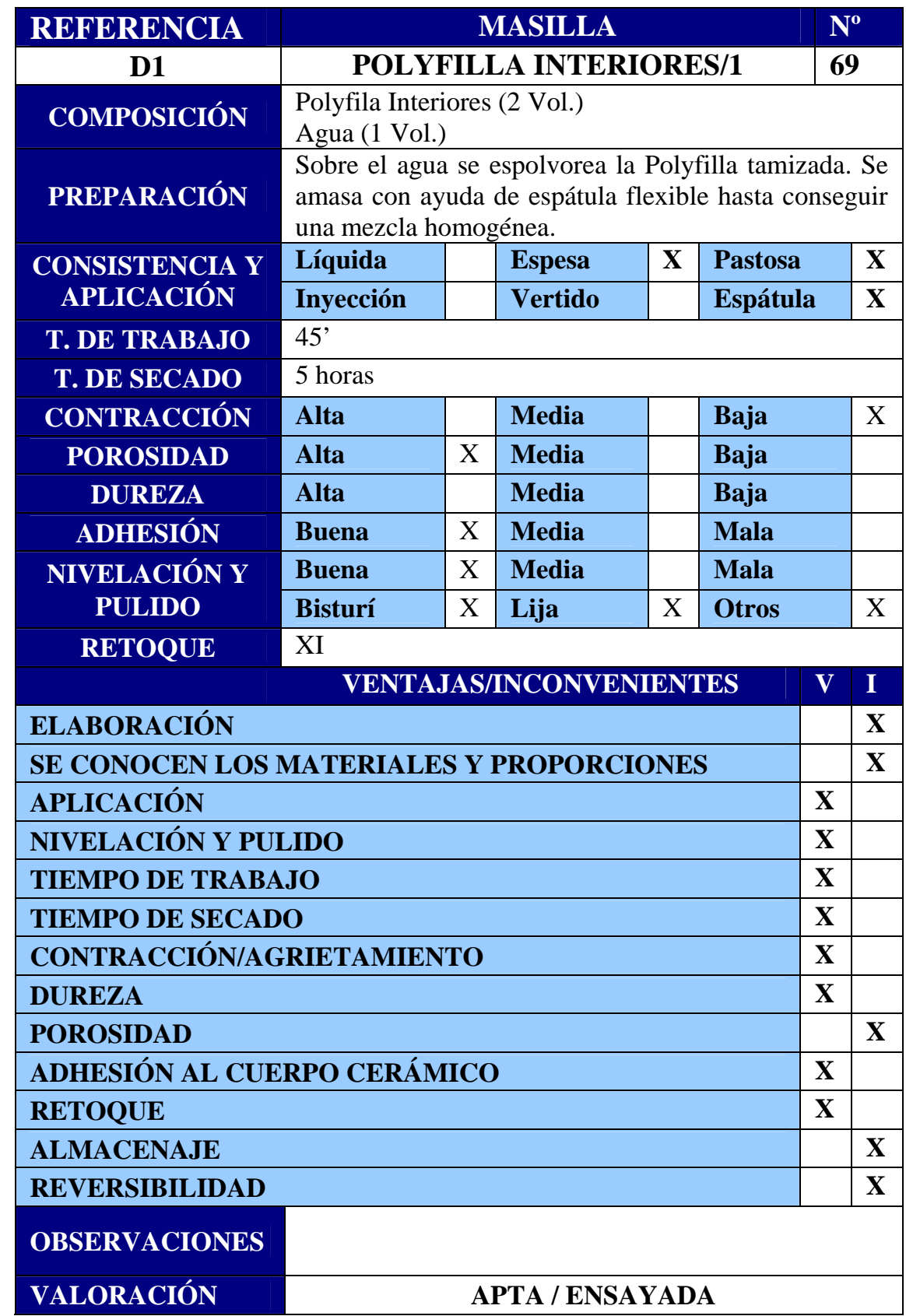




\begin{tabular}{|c|c|c|c|c|c|c|c|}
\hline REFERENCIA & \multicolumn{5}{|c|}{ MASILLA } & \multicolumn{2}{|c|}{$\mathbf{N}^{\mathbf{0}}$} \\
\hline & \multicolumn{5}{|c|}{ POLYFILLA INTERIORES/2 } & 7 & \\
\hline COMPOSICIÓN & \multicolumn{7}{|c|}{$\begin{array}{l}\text { Polyfila Interiores (3 Vol.) } \\
\text { Agua (1 Vol.) }\end{array}$} \\
\hline PREPARACIÓN & \multicolumn{7}{|c|}{$\begin{array}{l}\text { Sobre el agua se espolvorea la Polyfilla tamizada. Se } \\
\text { amasa con ayuda de espátula flexible hasta conseguir } \\
\text { una mezcla homogénea. }\end{array}$} \\
\hline CONSISTENCIA Y & Líquida & & Espesa & & \multicolumn{2}{|l|}{ Pastosa } & $\mathbf{X}$ \\
\hline APLICACIÓN & Inyección & & Vertido & & \multicolumn{2}{|c|}{ Espátula } & $\mathbf{X}$ \\
\hline T. DE TRABAJO & \multicolumn{7}{|l|}{$30^{\prime}$} \\
\hline T. DE SECADO & \multicolumn{7}{|l|}{ 2'5 horas } \\
\hline CONTRACCIÓN & Alta & & Media & & \multicolumn{2}{|l|}{ Baja } & $\mathrm{x}$ \\
\hline POROSIDAD & Alta & & Media & $\mathrm{X}$ & \multicolumn{2}{|l|}{ Baja } & \\
\hline DUREZA & Alta & & Media & $\mathrm{X}$ & \multicolumn{2}{|l|}{ Baja } & \\
\hline ADHESIÓN & Buena & $\mathrm{X}$ & Media & & \multicolumn{2}{|l|}{ Mala } & \\
\hline NIVELACIÓN Y & Buena & $\mathrm{X}$ & Media & & \multicolumn{2}{|l|}{ Mala } & \\
\hline PULIDO & Bisturí & $\mathrm{X}$ & Lija & $\mathrm{X}$ & \multicolumn{2}{|l|}{ Otros } & $\mathrm{X}$ \\
\hline \multirow[t]{2}{*}{ RETOQUE } & \multicolumn{7}{|l|}{ SI } \\
\hline & \multicolumn{6}{|c|}{$\begin{array}{ll}\text { VENTAJAS/INCONVENIENTES } & \text { V }\end{array}$} & $\mathbf{I}$ \\
\hline \multicolumn{6}{|l|}{ ELABORACIÓN } & & $\mathbf{X}$ \\
\hline \multicolumn{6}{|c|}{ SE CONOCEN LOS MATERIALES Y PROPORCIONES } & & $\mathbf{X}$ \\
\hline \multicolumn{6}{|l|}{ APLICACIÓN } & & $\mathbf{X}$ \\
\hline \multicolumn{6}{|c|}{ NIVELACIÓN Y PULIDO } & $\mathbf{X}$ & \\
\hline \multicolumn{6}{|c|}{ TIEMPO DE TRABAJO } & $\mathbf{X}$ & \\
\hline \multicolumn{6}{|c|}{ TIEMPO DE SECADO } & $\mathbf{X}$ & \\
\hline \multicolumn{6}{|c|}{ CONTRACCIÓN/AGRIETAMIENTO } & $\mathbf{X}$ & \\
\hline \multicolumn{6}{|l|}{ DUREZA } & $\mathbf{X}$ & \\
\hline \multicolumn{6}{|l|}{ POROSIDAD } & $\mathbf{X}$ & \\
\hline \multicolumn{6}{|c|}{ ADHESIÓN AL CUERPO CERÁMICO } & $\mathbf{X}$ & \\
\hline \multicolumn{6}{|l|}{ RETOQUE } & $\mathbf{X}$ & \\
\hline \multicolumn{6}{|l|}{ ALMACENAJE } & & $\mathbf{X}$ \\
\hline REVERSIBILIDAD & & & & & & & $\mathbf{X}$ \\
\hline OBSERVACIONES & Excesivam & te de & sa, cuesta & icar & & & \\
\hline VALORACIÓN & & & A / NO & $M$ & & & \\
\hline
\end{tabular}




\begin{tabular}{|c|c|c|c|c|c|c|c|}
\hline REFERENCIA & \multicolumn{5}{|c|}{ MASILLA } & \multicolumn{2}{|c|}{$\mathbf{N}^{\mathbf{0}}$} \\
\hline & \multicolumn{5}{|c|}{ POLYFILLA INTERIORES/3 } & \multicolumn{2}{|c|}{71} \\
\hline COMPOSICIÓN & \multicolumn{7}{|c|}{$\begin{array}{l}\text { Polyfila Interiores (3 Vol.) } \\
\text { Agua (2 Vol.) }\end{array}$} \\
\hline PREPARACIÓN & \multicolumn{7}{|c|}{$\begin{array}{l}\text { Sobre el agua se espolvorea la Polyfilla tamizada. Se } \\
\text { amasa con ayuda de espátula flexible hasta conseguir } \\
\text { una mezcla homogénea. }\end{array}$} \\
\hline \multirow{2}{*}{$\begin{array}{l}\text { CONSISTENCIA Y } \\
\text { APLICACIÓN }\end{array}$} & Líquida & & Espesa & & Pastosa & & $\mathbf{X}$ \\
\hline & Inyección & & Vertido & & Espátul & & $\mathbf{X}$ \\
\hline T. DE TRABAJO & \multicolumn{7}{|l|}{$40^{\prime}$} \\
\hline T. DE SECADO & \multicolumn{7}{|l|}{4 horas } \\
\hline CONTRACCIÓN & Alta & & Media & \multicolumn{3}{|c|}{ Baja } & $\mathrm{X}$ \\
\hline POROSIDAD & Alta & & Media & $\mathrm{X}$ & \multicolumn{2}{|l|}{ Baja } & \\
\hline DUREZA & Alta & & Media & $\mathrm{X}$ & \multicolumn{2}{|l|}{ Baja } & \\
\hline ADHESIÓN & Buena & $\mathrm{X}$ & Media & & \multicolumn{2}{|l|}{ Mala } & \\
\hline NIVELACIÓN Y & Buena & $\mathrm{X}$ & Media & & \multicolumn{2}{|l|}{ Mala } & \\
\hline PULIDO & Bisturí & $\mathrm{X}$ & Lija & $\mathrm{X}$ & \multicolumn{2}{|l|}{ Otros } & $\mathrm{X}$ \\
\hline \multirow[t]{2}{*}{ RETOQUE } & \\
\hline & \multicolumn{5}{|c|}{ VENTAJAS/INCONVENIENTES } & $\mathbf{V}$ & $\mathbf{I}$ \\
\hline \multicolumn{6}{|l|}{ ELABORACIÓN } & & $\mathbf{X}$ \\
\hline \multicolumn{6}{|c|}{ SE CONOCEN LOS MATERIALES Y PROPORCIONES } & & $\mathbf{X}$ \\
\hline \multicolumn{6}{|l|}{ APLICACIÓN } & $\mathbf{X}$ & \\
\hline \multicolumn{6}{|c|}{ NIVELACIÓN Y PULIDO } & $\mathbf{X}$ & \\
\hline \multicolumn{6}{|c|}{ TIEMPO DE TRABAJO } & $\mathbf{X}$ & \\
\hline \multicolumn{6}{|c|}{ TIEMPO DE SECADO } & $\mathbf{X}$ & \\
\hline \multicolumn{6}{|c|}{ CONTRACCIÓN/AGRIETAMIENTO } & $\mathbf{X}$ & \\
\hline \multicolumn{6}{|l|}{ DUREZA } & $\mathbf{X}$ & \\
\hline \multicolumn{6}{|l|}{ POROSIDAD } & $\mathbf{X}$ & \\
\hline \multicolumn{6}{|c|}{ ADHESIÓN AL CUERPO CERÁMICO } & $\mathbf{X}$ & \\
\hline \multicolumn{6}{|l|}{ RETOQUE } & $\mathbf{X}$ & \\
\hline \multicolumn{6}{|l|}{ ALMACENAJE } & & $\mathbf{X}$ \\
\hline REVERSIBILIDAD & & & & & & & $\mathbf{X}$ \\
\hline OBSERVACIONES & & & & & & & \\
\hline VALORACIÓN & & & $\mathrm{A} / \mathrm{NO}$ & & & & \\
\hline
\end{tabular}




\begin{tabular}{|c|c|c|c|c|c|c|c|}
\hline REFERENCIA & \multicolumn{5}{|c|}{ MASILLA } & \multicolumn{2}{|c|}{$\mathbf{N}^{\mathbf{0}}$} \\
\hline & \multicolumn{5}{|c|}{ POLYFILLA INTERIORES/4 } & \multicolumn{2}{|c|}{72} \\
\hline COMPOSICIÓN & \multicolumn{7}{|c|}{$\begin{array}{l}\text { Polyfila Interiores (2 Vol.) } \\
\text { Mowilith SDM5 al 50\% en agua (1 Vol.) }\end{array}$} \\
\hline PREPARACIÓN & \multicolumn{7}{|c|}{$\begin{array}{l}\text { Sobre la resina preparada se espolvorea la Polyfilla } \\
\text { tamizada. Se amasa con ayuda de espátula flexible } \\
\text { hasta conseguir una mezcla homogénea. }\end{array}$} \\
\hline CONSISTENCIA Y & Líquida & & Espesa & & \multicolumn{2}{|c|}{ Pastosa } & $\mathbf{X}$ \\
\hline APLICACIÓN & Inyección & & Vertido & & \multicolumn{2}{|c|}{ Espátula } & $\mathbf{X}$ \\
\hline T. DE TRABAJO & \multicolumn{7}{|l|}{$20^{\prime}$} \\
\hline T. DE SECADO & \multicolumn{7}{|l|}{ 2'5 horas } \\
\hline CONTRACCIÓN & Alta & & Media & & \multicolumn{2}{|l|}{ Baja } & $\mathrm{X}$ \\
\hline POROSIDAD & Alta & $\mathrm{X}$ & Media & & \multicolumn{2}{|l|}{ Baja } & \\
\hline DUREZA & Alta & & Media & $\mathrm{X}$ & \multicolumn{2}{|l|}{ Baja } & \\
\hline ADHESIÓN & Buena & $\mathrm{X}$ & Media & & \multicolumn{2}{|l|}{ Mala } & \\
\hline NIVELACIÓN Y & Buena & $\mathrm{X}$ & Media & & \multicolumn{2}{|l|}{ Mala } & \\
\hline PULIDO & Bisturí & $\mathrm{X}$ & Lija & $\mathrm{X}$ & \multicolumn{2}{|l|}{ Otros } & $\mathrm{X}$ \\
\hline \multirow[t]{2}{*}{ RETOQUE } & \multicolumn{7}{|l|}{ SI } \\
\hline & \multicolumn{6}{|c|}{$\begin{array}{ll}\text { VENTAJAS/INCONVENIENTES } & \text { V }\end{array}$} & $\mathbf{I}$ \\
\hline \multicolumn{6}{|l|}{ ELABORACIÓN } & & $\mathbf{X}$ \\
\hline \multicolumn{6}{|c|}{ SE CONOCEN LOS MATERIALES Y PROPORCIONES } & & $\mathbf{X}$ \\
\hline \multicolumn{6}{|l|}{ APLICACIÓN } & $\mathbf{X}$ & \\
\hline \multicolumn{6}{|c|}{ NIVELACIÓN Y PULIDO } & $\mathbf{X}$ & \\
\hline \multicolumn{6}{|c|}{ TIEMPO DE TRABAJO } & $\mathbf{X}$ & \\
\hline \multicolumn{6}{|c|}{ TIEMPO DE SECADO } & $\mathbf{X}$ & \\
\hline \multicolumn{6}{|c|}{ CONTRACCIÓN/AGRIETAMIENTO } & $\mathbf{X}$ & \\
\hline \multicolumn{6}{|l|}{ DUREZA } & $\mathbf{X}$ & \\
\hline \multicolumn{6}{|l|}{ POROSIDAD } & & $\mathbf{X}$ \\
\hline \multicolumn{6}{|c|}{ ADHESIÓN AL CUERPO CERÁMICO } & $\mathbf{X}$ & \\
\hline \multicolumn{6}{|l|}{ RETOQUE } & $\mathbf{X}$ & \\
\hline ALMACENAJE & & & & & & & $\mathbf{X}$ \\
\hline REVERSIBILIDAD & & & & & & & $\mathbf{X}$ \\
\hline OBSERVACIONES & Superficie i & dy $\mathrm{pl}$ & stica. Po & & & & \\
\hline VALORACIÓN & & AP & $\mathrm{A} / / \mathrm{NO} \mathbf{E}$ & & & & \\
\hline
\end{tabular}




\begin{tabular}{|c|c|c|c|c|c|c|c|}
\hline REFERENCIA & \multicolumn{5}{|c|}{ MASILLA } & \multicolumn{2}{|c|}{$\mathbf{N}^{\mathbf{0}}$} \\
\hline & \multicolumn{5}{|c|}{ POLYFILLA INTERIORES/5 } & \multicolumn{2}{|c|}{73} \\
\hline COMPOSICIÓN & \multicolumn{7}{|c|}{$\begin{array}{l}\text { Polyfila Interiores (2 Vol.) } \\
\text { Mowilith SDM5 al 25\% en agua (1 Vol.) }\end{array}$} \\
\hline PREPARACIÓN & \multicolumn{7}{|c|}{$\begin{array}{l}\text { Sobre la resina preparada se espolvorea la Polyfilla } \\
\text { tamizada. Se amasa con ayuda de espátula flexible } \\
\text { hasta conseguir una mezcla homogénea. }\end{array}$} \\
\hline \multirow{2}{*}{$\begin{array}{l}\text { CONSISTENCIA Y } \\
\text { APLICACIÓN }\end{array}$} & Líquida & & Espesa & & Pastosa & & $\mathbf{X}$ \\
\hline & Inyección & & Vertido & & Espátule & & $\mathbf{X}$ \\
\hline T. DE TRABAJO & \multicolumn{7}{|l|}{$30^{\prime}$} \\
\hline T. DE SECADO & \multicolumn{7}{|l|}{ 3’5 horas } \\
\hline CONTRACCIÓN & Alta & & Media & & \multicolumn{2}{|l|}{ Baja } & $\mathrm{x}$ \\
\hline POROSIDAD & Alta & & Media & $\mathrm{x}$ & \multicolumn{2}{|l|}{ Baja } & \\
\hline DUREZA & Alta & & Media & $\mathrm{x}$ & \multicolumn{2}{|l|}{ Baja } & \\
\hline ADHESIÓN & Buena & $\mathrm{X}$ & Media & & \multicolumn{2}{|l|}{ Mala } & \\
\hline NIVELACIÓN Y & Buena & $\mathrm{X}$ & Media & & \multicolumn{2}{|l|}{ Mala } & \\
\hline PULIDO & Bisturí & $\mathrm{X}$ & Lija & $\mathrm{X}$ & \multicolumn{2}{|l|}{ Otros } & $\mathrm{X}$ \\
\hline \multirow[t]{2}{*}{ RETOQUE } & \\
\hline & \multicolumn{5}{|c|}{ VENTAJAS/INCONVENIENTES } & $\mathbf{V}$ & $\mathbf{I}$ \\
\hline \multicolumn{6}{|l|}{ ELABORACIÓN } & & $\mathbf{X}$ \\
\hline \multicolumn{6}{|c|}{ SE CONOCEN LOS MATERIALES Y PROPORCIONES } & & $\mathbf{X}$ \\
\hline \multicolumn{6}{|l|}{ APLICACIÓN } & $\mathbf{X}$ & \\
\hline \multicolumn{6}{|c|}{ NIVELACIÓN Y PULIDO } & $\mathbf{X}$ & \\
\hline \multicolumn{6}{|c|}{ TIEMPO DE TRABAJO } & $\mathbf{X}$ & \\
\hline \multicolumn{6}{|c|}{ TIEMPO DE SECADO } & $\mathbf{X}$ & \\
\hline \multicolumn{6}{|c|}{ CONTRACCIÓN/AGRIETAMIENTO } & $\mathbf{X}$ & \\
\hline \multicolumn{6}{|l|}{ DUREZA } & $\mathbf{X}$ & \\
\hline \multicolumn{6}{|l|}{ POROSIDAD } & $\mathbf{X}$ & \\
\hline \multicolumn{6}{|c|}{ ADHESIÓN AL CUERPO CERÁMICO } & $\mathbf{X}$ & \\
\hline \multicolumn{6}{|l|}{ RETOQUE } & $\mathbf{X}$ & \\
\hline \multicolumn{6}{|l|}{ ALMACENAJE } & & $\mathbf{X}$ \\
\hline REVERSIBILIDAD & & & & & & & $\mathbf{X}$ \\
\hline OBSERVACIONES & & & & & & & \\
\hline VALORACIÓN & & & $\mathbf{A} / \mathbf{N O}$ & & & & \\
\hline
\end{tabular}




\begin{tabular}{|c|c|c|c|c|c|c|c|}
\hline REFERENCIA & \multicolumn{5}{|c|}{ MASILLA } & \multicolumn{2}{|c|}{$\mathbf{N}^{0}$} \\
\hline D2 & \multicolumn{5}{|c|}{ POLYFILLA INTERIORES/6 } & \multicolumn{2}{|c|}{74} \\
\hline COMPOSICIÓN & \multicolumn{7}{|c|}{$\begin{array}{l}\text { Polyfila Interiores (2 Vol.) } \\
\text { Mowilith SDM5 al 10\% en agua (1 Vol.) }\end{array}$} \\
\hline PREPARACIÓN & \multicolumn{7}{|c|}{$\begin{array}{l}\text { Sobre la resina preparada se espolvorea la Polyfilla } \\
\text { tamizada. Se amasa con ayuda de espátula flexible } \\
\text { hasta conseguir una mezcla homogénea. }\end{array}$} \\
\hline CONSISTENCIA Y & Líquida & & Espesa & $\mathbf{X}$ & \multicolumn{2}{|l|}{ Pastosa } & $\mathbf{X}$ \\
\hline APLICACIÓN & Inyección & & Vertido & $\mathbf{X}$ & \multicolumn{2}{|c|}{ Espátula } & $\mathbf{X}$ \\
\hline T. DE TRABAJO & \multicolumn{7}{|l|}{$45^{\prime}$} \\
\hline T. DE SECADO & \multicolumn{7}{|l|}{4 horas } \\
\hline CONTRACCIÓN & Alta & & Media & & \multicolumn{2}{|l|}{ Baja } & $\mathrm{X}$ \\
\hline POROSIDAD & Alta & & Media & $\mathrm{X}$ & \multicolumn{2}{|l|}{ Baja } & \\
\hline DUREZA & Alta & & Media & $\mathrm{X}$ & \multicolumn{2}{|l|}{ Baja } & \\
\hline ADHESIÓN & Buena & $\mathrm{X}$ & Media & & \multicolumn{2}{|l|}{ Mala } & \\
\hline NIVELACIÓN Y & Buena & $\mathrm{X}$ & Media & & \multicolumn{2}{|l|}{ Mala } & \\
\hline PULIDO & Bisturí & $\mathrm{X}$ & Lija & $\mathrm{X}$ & \multicolumn{2}{|l|}{ Otros } & $\mathrm{X}$ \\
\hline \multirow[t]{2}{*}{ RETOQUE } & \\
\hline & \multicolumn{6}{|c|}{$\begin{array}{ll}\text { VENTAJAS/INCONVENIENTES } & \text { V }\end{array}$} & $\mathbf{I}$ \\
\hline \multicolumn{6}{|l|}{ ELABORACIÓN } & & $\mathbf{X}$ \\
\hline \multicolumn{6}{|c|}{ SE CONOCEN LOS MATERIALES Y PROPORCIONES } & & $\mathbf{X}$ \\
\hline \multicolumn{6}{|l|}{ APLICACIÓN } & $\mathbf{X}$ & \\
\hline \multicolumn{6}{|c|}{ NIVELACIÓN Y PULIDO } & $\mathbf{X}$ & \\
\hline \multicolumn{6}{|c|}{ TIEMPO DE TRABAJO } & $\mathbf{X}$ & \\
\hline \multicolumn{6}{|c|}{ TIEMPO DE SECADO } & $\mathbf{X}$ & \\
\hline \multicolumn{6}{|c|}{ CONTRACCIÓN/AGRIETAMIENTO } & $\mathbf{X}$ & \\
\hline \multicolumn{6}{|l|}{ DUREZA } & $\mathbf{X}$ & \\
\hline \multicolumn{6}{|l|}{ POROSIDAD } & $\mathbf{X}$ & \\
\hline \multicolumn{6}{|c|}{ ADHESIÓN AL CUERPO CERÁMICO } & $\mathbf{X}$ & \\
\hline \multicolumn{6}{|l|}{ RETOQUE } & $\mathbf{X}$ & \\
\hline ALMACENAJE & & & & & & & $\mathbf{X}$ \\
\hline REVERSIBILIDAD & & & & & & & $\mathbf{X}$ \\
\hline OBSERVACIONES & & & & & & & \\
\hline VALORACIÓN & & & TA / E & IAl & & & \\
\hline
\end{tabular}




\begin{tabular}{|c|c|c|c|c|c|c|c|}
\hline REFERENCIA & \multicolumn{5}{|c|}{ MASILLA } & \multicolumn{2}{|c|}{$\mathbf{N}^{\mathbf{0}}$} \\
\hline & \multicolumn{5}{|c|}{ POLYFILLA INTERIORES/7 } & 75 & \\
\hline COMPOSICIÓN & \multicolumn{7}{|c|}{$\begin{array}{l}\text { Polyfila Interiores (2 Vol.) } \\
\text { Mowilith SDM5 al 5\% en agua (1 Vol.) }\end{array}$} \\
\hline PREPARACIÓN & \multicolumn{7}{|c|}{$\begin{array}{l}\text { Sobre la resina preparada se espolvorea la Polyfilla } \\
\text { tamizada. Se amasa con ayuda de espátula flexible } \\
\text { hasta conseguir una mezcla homogénea. }\end{array}$} \\
\hline \multirow{2}{*}{$\begin{array}{l}\text { CONSISTENCIA Y } \\
\text { APLICACIÓN }\end{array}$} & Líquida & & Espesa & $\mathbf{X}$ & Pastosa & & $\mathbf{X}$ \\
\hline & Inyección & & Vertido & $\mathbf{X}$ & Espátule & & $\mathbf{X}$ \\
\hline T. DE TRABAJO & \multicolumn{7}{|l|}{$45-60$} \\
\hline T. DE SECADO & \multicolumn{7}{|l|}{4 horas } \\
\hline CONTRACCIÓN & Alta & & Media & & \multicolumn{2}{|l|}{ Baja } & $\mathrm{X}$ \\
\hline POROSIDAD & Alta & & Media & $\mathrm{X}$ & \multicolumn{2}{|l|}{ Baja } & \\
\hline DUREZA & Alta & & Media & $\mathrm{X}$ & \multicolumn{2}{|l|}{ Baja } & \\
\hline ADHESIÓN & Buena & & Media & $\mathrm{X}$ & \multicolumn{2}{|l|}{ Mala } & \\
\hline NIVELACIÓN Y & Buena & $\mathrm{X}$ & Media & & \multicolumn{2}{|l|}{ Mala } & \\
\hline PULIDO & Bisturí & $\mathrm{X}$ & Lija & $\mathrm{X}$ & \multicolumn{2}{|l|}{ Otros } & $\mathrm{X}$ \\
\hline \multirow[t]{2}{*}{ RETOQUE } & \\
\hline & \multicolumn{5}{|c|}{ VENTAJAS/INCONVENIENTES } & $\mathbf{V}$ & I \\
\hline \multicolumn{6}{|l|}{ ELABORACIÓN } & & $\mathbf{X}$ \\
\hline \multicolumn{6}{|c|}{ SE CONOCEN LOS MATERIALES Y PROPORCIONES } & & $\mathbf{X}$ \\
\hline \multicolumn{6}{|l|}{ APLICACIÓN } & $\mathbf{X}$ & \\
\hline \multicolumn{6}{|c|}{ NIVELACIÓN Y PULIDO } & $\mathbf{X}$ & \\
\hline \multicolumn{6}{|c|}{ TIEMPO DE TRABAJO } & $\mathbf{X}$ & \\
\hline \multicolumn{6}{|c|}{ TIEMPO DE SECADO } & $\mathbf{X}$ & \\
\hline \multicolumn{6}{|c|}{ CONTRACCIÓN/AGRIETAMIENTO } & $\mathbf{X}$ & \\
\hline \multicolumn{6}{|l|}{ DUREZA } & $\mathbf{X}$ & \\
\hline \multicolumn{6}{|l|}{ POROSIDAD } & $\mathbf{X}$ & \\
\hline \multicolumn{6}{|c|}{ ADHESIÓN AL CUERPO CERÁMICO } & $\mathbf{X}$ & \\
\hline \multicolumn{6}{|l|}{ RETOQUE } & $\mathbf{X}$ & \\
\hline \multicolumn{6}{|l|}{ ALMACENAJE } & & $\mathbf{X}$ \\
\hline \multicolumn{6}{|l|}{ REVERSIBILIDAD } & & $\mathbf{X}$ \\
\hline OBSERVACIOI & & & & & & & \\
\hline VALORACIÓN & & & TA / E & AD & & & \\
\hline
\end{tabular}




\begin{tabular}{|c|c|c|c|c|c|c|c|}
\hline REFERENCIA & \multicolumn{5}{|c|}{ MASILLA } & \multicolumn{2}{|c|}{$\mathbf{N}^{\mathbf{0}}$} \\
\hline D3 & \multicolumn{5}{|c|}{ POLYFILLA INTERIORES/8 } & \multicolumn{2}{|c|}{76} \\
\hline COMPOSICIÓN & \multicolumn{7}{|c|}{$\begin{array}{l}\text { Polyfila Interiores ( } 2 \text { Vol.) } \\
\text { Acril } 33 \text { al } 10 \% \text { en agua (1 Vol.) }\end{array}$} \\
\hline PREPARACIÓN & \multicolumn{7}{|c|}{$\begin{array}{l}\text { Sobre la resina preparada se espolvorea la Polyfilla } \\
\text { tamizada. Se amasa con ayuda de espátula flexible } \\
\text { hasta conseguir una mezcla homogénea. }\end{array}$} \\
\hline CONSISTENCIA Y & Líquida & & Espesa & $\mathbf{X}$ & \multicolumn{2}{|c|}{ Pastosa } & $\mathbf{X}$ \\
\hline APLICACIÓN & Inyección & & Vertido & $\mathbf{X}$ & \multicolumn{2}{|c|}{ Espátula } & $\mathbf{X}$ \\
\hline T. DE TRABAJO & \multicolumn{6}{|l|}{$45-60$ ' } & \\
\hline T. DE SECADO & \multicolumn{7}{|l|}{4 horas } \\
\hline CONTRACCIÓN & Alta & & Media & & \multicolumn{2}{|l|}{ Baja } & $\mathrm{X}$ \\
\hline POROSIDAD & Alta & & Media & $\mathrm{X}$ & \multicolumn{2}{|l|}{ Baja } & \\
\hline DUREZA & Alta & & Media & $\mathrm{X}$ & \multicolumn{2}{|l|}{ Baja } & \\
\hline ADHESIÓN & Buena & $\mathrm{X}$ & Media & & \multicolumn{2}{|l|}{ Mala } & \\
\hline NIVELACIÓN Y & Buena & $\mathrm{X}$ & Media & & \multicolumn{2}{|l|}{ Mala } & \\
\hline PULIDO & Bisturí & $\mathrm{X}$ & Lija & $\mathrm{X}$ & \multicolumn{2}{|l|}{ Otros } & $\mathrm{X}$ \\
\hline \multirow[t]{2}{*}{ RETOQUE } & \multicolumn{7}{|l|}{ SI } \\
\hline & \multicolumn{6}{|c|}{$\begin{array}{ll}\text { VENTAJAS/INCONVENIENTES } & \text { V }\end{array}$} & $\mathbf{I}$ \\
\hline \multicolumn{6}{|l|}{ ELABORACIÓN } & & $\mathbf{X}$ \\
\hline \multicolumn{6}{|c|}{ SE CONOCEN LOS MATERIALES Y PROPORCIONES } & & $\mathbf{X}$ \\
\hline \multicolumn{6}{|l|}{ APLICACIÓN } & $\mathbf{X}$ & \\
\hline \multicolumn{6}{|c|}{ NIVELACIÓN Y PULIDO } & $\mathbf{X}$ & \\
\hline \multicolumn{6}{|c|}{ TIEMPO DE TRABAJO } & $\mathbf{X}$ & \\
\hline \multicolumn{6}{|c|}{ TIEMPO DE SECADO } & $\mathbf{X}$ & \\
\hline \multicolumn{6}{|c|}{ CONTRACCIÓN/AGRIETAMIENTO } & $\mathbf{X}$ & \\
\hline \multicolumn{6}{|l|}{ DUREZA } & $\mathbf{X}$ & \\
\hline \multicolumn{6}{|l|}{ POROSIDAD } & $\mathbf{X}$ & \\
\hline \multicolumn{6}{|c|}{ ADHESIÓN AL CUERPO CERÁMICO } & $\mathbf{X}$ & \\
\hline \multicolumn{6}{|l|}{ RETOQUE } & $\mathbf{X}$ & \\
\hline ALMACENAJE & & & & & & & $\mathbf{X}$ \\
\hline REVERSIBILIDAD & & & & & & & $\mathbf{X}$ \\
\hline OBSERVACI & & & & & & & \\
\hline VALORACIÓN & & & TA / EI & $1 \mathrm{ND}$ & & & \\
\hline
\end{tabular}




\begin{tabular}{|c|c|c|c|c|c|c|c|}
\hline REFERENCIA & \multicolumn{5}{|c|}{ MASILLA } & \multicolumn{2}{|c|}{$\mathbf{N}^{\mathbf{0}}$} \\
\hline & \multicolumn{5}{|c|}{ POLYFILLA INTERIORES/9 } & 7 & \\
\hline COMPOSICIÓN & \multicolumn{7}{|c|}{$\begin{array}{l}\text { Polyfila Interiores ( } 3 \text { Vol.) Sílice coloidal (2 Vol.) } \\
\text { Acril } 33 \text { al } 10 \% \text { en agua (2 Vol.) }\end{array}$} \\
\hline PREPARACIÓN & \multicolumn{7}{|c|}{$\begin{array}{l}\text { Sobre la resina preparada se espolvorea la Polyfilla } \\
\text { tamizada. Se amasa con ayuda de espátula flexible } \\
\text { hasta conseguir una mezcla homogénea, por último se } \\
\text { añade el sílice. }\end{array}$} \\
\hline CONSISTENCIA Y & Líquida & & Espesa & & \multicolumn{2}{|c|}{ Pastosa } & $\mathbf{X}$ \\
\hline APLICACIÓN & Inyección & & Vertido & & \multicolumn{2}{|c|}{ Espátula } & $\mathbf{X}$ \\
\hline T. DE TRABAJO & \multicolumn{7}{|l|}{$15^{\prime}$} \\
\hline T. DE SECADO & \multicolumn{7}{|l|}{2 horas } \\
\hline CONTRACCIÓN & Alta & & Media & & \multicolumn{2}{|l|}{ Baja } & $\mathrm{X}$ \\
\hline POROSIDAD & Alta & $\mathrm{X}$ & Media & & \multicolumn{2}{|l|}{ Baja } & \\
\hline DUREZA & Alta & & Media & & \multicolumn{2}{|l|}{ Baja } & $\mathrm{X}$ \\
\hline ADHESIÓN & Buena & & Media & $\mathrm{X}$ & \multicolumn{2}{|l|}{ Mala } & \\
\hline NIVELACIÓN Y & Buena & $\mathrm{X}$ & Media & & \multicolumn{2}{|l|}{ Mala } & \\
\hline PULIDO & Bisturí & $\mathrm{X}$ & Lija & $\mathrm{X}$ & \multicolumn{2}{|l|}{ Otros } & $\mathrm{X}$ \\
\hline \multirow[t]{2}{*}{ RETOQUE } & \multicolumn{7}{|c|}{ SI } \\
\hline & \multicolumn{5}{|c|}{ VENTAJAS/INCONVENIENTES } & $\mathbf{V}$ & $\mathbf{I}$ \\
\hline \multicolumn{6}{|l|}{ ELABORACIÓN } & & $\mathbf{X}$ \\
\hline \multicolumn{6}{|c|}{ SE CONOCEN LOS MATERIALES Y PROPORCIONES } & & $\mathbf{X}$ \\
\hline \multicolumn{6}{|l|}{ APLICACIÓN } & & $\mathbf{X}$ \\
\hline \multicolumn{6}{|c|}{ NIVELACIÓN Y PULIDO } & $\mathbf{X}$ & \\
\hline \multicolumn{6}{|c|}{ TIEMPO DE TRABAJO } & $\mathbf{X}$ & \\
\hline \multicolumn{6}{|c|}{ TIEMPO DE SECADO } & $\mathbf{X}$ & \\
\hline \multicolumn{6}{|c|}{ CONTRACCIÓN/AGRIETAMIENTO } & $\mathbf{X}$ & \\
\hline \multicolumn{6}{|l|}{ DUREZA } & & $\mathbf{X}$ \\
\hline \multicolumn{6}{|l|}{ POROSIDAD } & & $\mathbf{X}$ \\
\hline \multicolumn{6}{|c|}{ ADHESIÓN AL CUERPO CERÁMICO } & & $\mathbf{X}$ \\
\hline \multicolumn{6}{|l|}{ RETOQUE } & $\mathbf{X}$ & \\
\hline \multicolumn{6}{|l|}{ ALMACENAJE } & & $\mathbf{X}$ \\
\hline REVERSIBILIDAD & & & & & & & $\mathbf{X}$ \\
\hline OBSERVACIONES & $\begin{array}{l}\text { Cuesta ap } \\
\text { cuando se }\end{array}$ & & consis & & eruler & & \\
\hline VALORACIÓN & & $\mathbf{O}$ & TA $/ / N O$ & SAY & ADA & & \\
\hline
\end{tabular}




\begin{tabular}{|c|c|c|c|c|c|c|c|}
\hline REFERENCIA & \multicolumn{5}{|c|}{ MASILLA } & \multicolumn{2}{|c|}{$\mathbf{N}^{\mathbf{o}}$} \\
\hline & \multicolumn{5}{|c|}{ POLYFILLA INTERIORES/10 } & \multicolumn{2}{|c|}{78} \\
\hline COMPOSICIÓN & \multicolumn{7}{|c|}{$\begin{array}{l}\text { Polyfila Interiores (3 Vol.) } \\
\text { Microesferas de vidrio (3 Vol.) Agua (2 Vol.) }\end{array}$} \\
\hline PREPARACIÓN & \multicolumn{7}{|c|}{$\begin{array}{l}\text { Sobre el agua se espolvorea la Polyfilla tamizada. Se } \\
\text { amasa con ayuda de espátula flexible hasta conseguir } \\
\text { una mezcla homogénea, por último se añade las } \\
\text { microesferas. }\end{array}$} \\
\hline CONSISTENCIA Y & Líquida & & Espesa & & \multicolumn{2}{|l|}{ Pastosa } & $\mathbf{X}$ \\
\hline APLICACIÓN & Inyección & & Vertido & & \multicolumn{2}{|c|}{ Espátula } & $\mathbf{X}$ \\
\hline T. DE TRABAJO & \multicolumn{7}{|l|}{$15^{\prime}$} \\
\hline T. DE SECADO & \multicolumn{7}{|l|}{2 horas } \\
\hline CONTRACCIÓN & Alta & & Media & & \multicolumn{2}{|l|}{ Baja } & $\mathrm{X}$ \\
\hline POROSIDAD & Alta & & Media & $\mathrm{X}$ & \multicolumn{2}{|l|}{ Baja } & \\
\hline DUREZA & Alta & & Media & $\mathrm{X}$ & \multicolumn{2}{|l|}{ Baja } & \\
\hline ADHESIÓN & Buena & $\mathrm{X}$ & Media & & \multicolumn{2}{|l|}{ Mala } & \\
\hline NIVELACIÓN Y & Buena & $\mathrm{X}$ & Media & & \multicolumn{2}{|l|}{ Mala } & \\
\hline PULIDO & Bisturí & $\mathrm{X}$ & Lija & $\mathrm{X}$ & \multicolumn{2}{|l|}{ Otros } & $\mathrm{X}$ \\
\hline RETOQUE & \multicolumn{7}{|l|}{ SI } \\
\hline & \multicolumn{6}{|c|}{ VENTAJAS/INCONVENIENTES } & $\mathbf{I}$ \\
\hline \multicolumn{6}{|l|}{ ELABORACIÓN } & & $\mathbf{X}$ \\
\hline \multicolumn{6}{|c|}{ SE CONOCEN LOS MATERIALES Y PROPORCIONES } & & $\mathbf{X}$ \\
\hline \multicolumn{6}{|l|}{ APLICACIÓN } & & $\mathbf{X}$ \\
\hline \multicolumn{6}{|c|}{ NIVELACIÓN Y PULIDO } & $\mathbf{X}$ & \\
\hline \multicolumn{6}{|c|}{ TIEMPO DE TRABAJO } & $\mathbf{X}$ & \\
\hline \multicolumn{6}{|c|}{ TIEMPO DE SECADO } & $\mathbf{X}$ & \\
\hline \multicolumn{6}{|c|}{ CONTRACCIÓN/AGRIETAMIENTO } & $\mathbf{X}$ & \\
\hline \multicolumn{6}{|l|}{ DUREZA } & $\mathbf{X}$ & \\
\hline \multicolumn{6}{|l|}{ POROSIDAD } & $\mathbf{X}$ & \\
\hline \multicolumn{6}{|c|}{ ADHESIÓN AL CUERPO CERÁMICO } & $\mathbf{X}$ & \\
\hline \multicolumn{6}{|l|}{ RETOQUE } & $\mathbf{X}$ & \\
\hline \multicolumn{6}{|l|}{ ALMACENAJE } & & $\mathbf{X}$ \\
\hline REVERSIBILIDAD & & & & & & & $\mathbf{X}$ \\
\hline OBSERVACIONES & Pesada. & & & & & & \\
\hline VALORACIÓN & & & A/ NO EI & & & & \\
\hline
\end{tabular}




\begin{tabular}{|c|c|c|c|c|c|c|c|}
\hline REFERENCIA & \multicolumn{5}{|c|}{ MASILLA } & \multicolumn{2}{|c|}{$\mathbf{N}^{\mathbf{0}}$} \\
\hline & \multicolumn{5}{|c|}{ POLYFILLA INTERIORES/11 } & \multicolumn{2}{|c|}{79} \\
\hline COMPOSICIÓN & \multicolumn{7}{|c|}{$\begin{array}{l}\text { Polyfila Interiores (1 Vol.) } \\
\text { Sílice coloidal (2 Vol.) Agua (1 Vol.) }\end{array}$} \\
\hline PREPARACIÓN & \multicolumn{7}{|c|}{$\begin{array}{l}\text { Sobre el agua se espolvorea la Polyfilla tamizada. Se } \\
\text { amasa con ayuda de espátula flexible hasta conseguir } \\
\text { una mezcla homogénea. A continuación se añade } \\
\text { sílice y se amasa. }\end{array}$} \\
\hline \multirow{2}{*}{$\begin{array}{l}\text { CONSISTENCIA Y } \\
\text { APLICACIÓN }\end{array}$} & Líquida & & Espesa & $\mathbf{x}$ & Pastosa & & $\mathbf{X}$ \\
\hline & Inyección & & Vertido & $\mathbf{x}$ & Espátule & & $\mathbf{X}$ \\
\hline T. DE TRABAJO & \multicolumn{7}{|c|}{$40^{\prime}$} \\
\hline T. DE SECADO & \multicolumn{7}{|l|}{4 horas } \\
\hline CONTRACCIÓN & Alta & & Media & $\mathrm{X}$ & \multicolumn{2}{|l|}{ Baja } & \\
\hline POROSIDAD & Alta & $\mathrm{X}$ & Media & & \multicolumn{2}{|l|}{ Baja } & \\
\hline DUREZA & Alta & & Media & & \multicolumn{2}{|l|}{ Baja } & $\mathrm{X}$ \\
\hline ADHESIÓN & Buena & & Media & $\mathrm{X}$ & \multicolumn{2}{|l|}{ Mala } & \\
\hline NIVELACIÓN Y & Buena & $\mathrm{X}$ & Media & & \multicolumn{2}{|l|}{ Mala } & \\
\hline PULIDO & Bisturí & $\mathrm{X}$ & Lija & $\mathrm{X}$ & \multicolumn{2}{|l|}{ Otros } & $\mathrm{X}$ \\
\hline RETOQUE & \multicolumn{7}{|c|}{ SI } \\
\hline & \multicolumn{5}{|c|}{ VENTAJAS/INCONVENIENTES } & $\mathbf{V}$ & $\mathbf{I}$ \\
\hline \multicolumn{6}{|l|}{ ELABORACIÓN } & & $\mathbf{X}$ \\
\hline \multicolumn{6}{|c|}{ SE CONOCEN LOS MATERIALES Y PROPORCIONES } & & $\mathbf{X}$ \\
\hline \multicolumn{6}{|l|}{ APLICACIÓN } & $\mathbf{X}$ & \\
\hline \multicolumn{6}{|c|}{ NIVELACIÓN Y PULIDO } & $\mathbf{X}$ & \\
\hline \multicolumn{6}{|c|}{ TIEMPO DE TRABAJO } & $\mathbf{X}$ & \\
\hline \multicolumn{6}{|c|}{ TIEMPO DE SECADO } & $\mathbf{X}$ & \\
\hline \multicolumn{6}{|c|}{ CONTRACCIÓN/AGRIETAMIENTO } & & $\mathbf{X}$ \\
\hline \multicolumn{6}{|l|}{ DUREZA } & & $\mathbf{X}$ \\
\hline \multicolumn{6}{|l|}{ POROSIDAD } & & $\mathbf{X}$ \\
\hline \multicolumn{6}{|c|}{ ADHESIÓN AL CUERPO CERÁMICO } & & $\mathbf{X}$ \\
\hline \multicolumn{6}{|l|}{ RETOQUE } & $\mathbf{X}$ & \\
\hline \multicolumn{6}{|l|}{ ALMACENAJE } & & $\mathbf{X}$ \\
\hline \multicolumn{6}{|l|}{ REVERSIBILIDAD } & & $\mathbf{X}$ \\
\hline OBSERVACIONES & Muy lige & & lenta. & & & & \\
\hline VALORACIÓN & & $0 \mathrm{~A}$ & TTA//NO & זע & ADA & & \\
\hline
\end{tabular}




\begin{tabular}{|c|c|c|c|c|c|c|c|}
\hline REFERENCIA & \multicolumn{5}{|c|}{ MASILLA } & \multicolumn{2}{|c|}{$\mathbf{N}^{\circ}$} \\
\hline & \multicolumn{5}{|c|}{ AGUAPLAST ACABADOS } & \multicolumn{2}{|c|}{80} \\
\hline COMPOSICIÓN & \multicolumn{7}{|c|}{$\begin{array}{l}\text { Aguaplast Acabados (2 Vol.) } \\
\text { Agua (1 Vol.) }\end{array}$} \\
\hline PREPARACIÓN & \multicolumn{7}{|c|}{$\begin{array}{l}\text { Sobre el agua se espolvorea el producto tamizado. Se } \\
\text { amasa con ayuda de espátula flexible hasta conseguir } \\
\text { una mezcla homogénea. }\end{array}$} \\
\hline CONSISTENCIA Y & Líquida & & Espesa & $\mathbf{X}$ & \multicolumn{2}{|c|}{ Pastosa } & $\mathbf{X}$ \\
\hline APLICACIÓN & Inyección & & Vertido & $\mathbf{X}$ & \multicolumn{2}{|c|}{ Espátula } & $\mathbf{x}$ \\
\hline T. DE TRABAJO & \multicolumn{7}{|l|}{$45^{\prime}$} \\
\hline T. DE SECADO & \multicolumn{7}{|l|}{4 horas } \\
\hline CONTRACCIÓN & Alta & & Media & & \multicolumn{2}{|l|}{ Baja } & $\mathrm{X}$ \\
\hline POROSIDAD & Alta & & Media & $\mathrm{X}$ & \multicolumn{2}{|l|}{ Baja } & \\
\hline DUREZA & Alta & & Media & $\mathrm{X}$ & \multicolumn{2}{|l|}{ Baja } & \\
\hline ADHESIÓN & Buena & $\mathrm{X}$ & Media & & \multicolumn{2}{|l|}{ Mala } & \\
\hline NIVELACIÓN Y & Buena & $\mathrm{X}$ & Media & & \multicolumn{2}{|l|}{ Mala } & \\
\hline PULIDO & Bisturí & $\mathrm{X}$ & Lija & $\mathrm{X}$ & \multicolumn{2}{|l|}{ Otros } & $\mathrm{X}$ \\
\hline \multicolumn{8}{|l|}{ RETOQUE } \\
\hline & \multicolumn{6}{|c|}{$\begin{array}{ll}\text { VENTAJAS/INCONVENIENTES } & \text { V }\end{array}$} & $\mathbf{I}$ \\
\hline \multicolumn{6}{|l|}{ ELABORACIÓN } & & $\mathbf{X}$ \\
\hline \multicolumn{6}{|c|}{ SE CONOCEN LOS MATERIALES Y PROPORCIONES } & & $\mathbf{X}$ \\
\hline \multicolumn{6}{|l|}{ APLICACIÓN } & $\mathbf{X}$ & \\
\hline \multicolumn{6}{|c|}{ NIVELACIÓN Y PULIDO } & $\mathbf{X}$ & \\
\hline \multicolumn{6}{|c|}{ TIEMPO DE TRABAJO } & $\mathbf{X}$ & \\
\hline \multicolumn{6}{|c|}{ TIEMPO DE SECADO } & $\mathbf{X}$ & \\
\hline \multicolumn{6}{|c|}{ CONTRACCIÓN/AGRIETAMIENTO } & $\mathbf{X}$ & \\
\hline \multicolumn{6}{|l|}{ DUREZA } & $\mathbf{X}$ & \\
\hline \multicolumn{6}{|l|}{ POROSIDAD } & $\mathbf{X}$ & \\
\hline \multicolumn{6}{|c|}{ ADHESIÓN AL CUERPO CERÁMICO } & $\mathbf{X}$ & \\
\hline \multicolumn{6}{|l|}{ RETOQUE } & $\mathbf{X}$ & \\
\hline \multicolumn{6}{|l|}{ ALMACENAJE } & & $\mathbf{X}$ \\
\hline REVERSIBILIDAD & & & & & & & $\mathbf{X}$ \\
\hline OBSERVACIONES & Masilla lig & & & & & & \\
\hline VALORACIÓN & & & A/NO I & & & & \\
\hline
\end{tabular}




\begin{tabular}{|c|c|c|c|c|c|c|c|}
\hline REFERENCIA & \multicolumn{5}{|c|}{ MASILLA } & \multicolumn{2}{|c|}{$\mathbf{N}^{\mathbf{0}}$} \\
\hline & \multicolumn{5}{|c|}{ AGUAPLAST CAPA GRUESA } & \multicolumn{2}{|c|}{81} \\
\hline COMPOSICIÓN & \multicolumn{7}{|c|}{$\begin{array}{l}\text { Aguaplast Capa Gruesa (2 Vol.) } \\
\text { Agua (1 Vol.) }\end{array}$} \\
\hline PREPARACIÓN & \multicolumn{7}{|c|}{$\begin{array}{l}\text { Sobre el agua se espolvorea la Polyfilla tamizada. Se } \\
\text { amasa con ayuda de espátula flexible hasta conseguir } \\
\text { una mezcla homogénea. }\end{array}$} \\
\hline CONSISTENCIA Y & Líquida & & Espesa & $\mathbf{X}$ & \multicolumn{2}{|l|}{ Pastosa } & $\mathbf{X}$ \\
\hline APLICACIÓN & Inyección & & Vertido & $\mathbf{X}$ & \multicolumn{2}{|c|}{ Espátula } & $\mathbf{X}$ \\
\hline T. DE TRABAJO & \multicolumn{7}{|l|}{$60^{\prime}$} \\
\hline T. DE SECADO & \multicolumn{7}{|l|}{4 horas } \\
\hline CONTRACCIÓN & Alta & & Media & & \multicolumn{2}{|l|}{ Baja } & $\mathrm{X}$ \\
\hline POROSIDAD & Alta & & Media & $\mathrm{X}$ & \multicolumn{2}{|l|}{ Baja } & \\
\hline DUREZA & Alta & & Media & & \multicolumn{2}{|l|}{ Baja } & $\mathrm{X}$ \\
\hline ADHESIÓN & Buena & $\mathrm{X}$ & Media & & \multicolumn{2}{|l|}{ Mala } & \\
\hline NIVELACIÓN Y & Buena & $\mathrm{X}$ & Media & & \multicolumn{2}{|l|}{ Mala } & \\
\hline PULIDO & Bisturí & $\mathrm{X}$ & Lija & $\mathrm{X}$ & \multicolumn{2}{|l|}{ Otros } & $\mathrm{X}$ \\
\hline \multirow[t]{2}{*}{ RETOQUE } & \multicolumn{7}{|l|}{ SI } \\
\hline & \multicolumn{5}{|c|}{ VENTAJAS/INCONVENIENTES } & $\mathbf{V}$ & $\mathbf{I}$ \\
\hline \multicolumn{6}{|l|}{ ELABORACIÓN } & & $\mathbf{X}$ \\
\hline \multicolumn{6}{|c|}{ SE CONOCEN LOS MATERIALES Y PROPORCIONES } & & $\mathbf{X}$ \\
\hline \multicolumn{6}{|l|}{ APLICACIÓN } & $\mathbf{X}$ & \\
\hline \multicolumn{6}{|c|}{ NIVELACIÓN Y PULIDO } & $\mathbf{X}$ & \\
\hline \multicolumn{6}{|c|}{ TIEMPO DE TRABAJO } & $\mathbf{X}$ & \\
\hline \multicolumn{6}{|c|}{ TIEMPO DE SECADO } & $\mathbf{X}$ & \\
\hline \multicolumn{6}{|c|}{ CONTRACCIÓN/AGRIETAMIENTO } & $\mathbf{X}$ & \\
\hline \multicolumn{6}{|l|}{ DUREZA } & & $\mathbf{X}$ \\
\hline \multicolumn{6}{|l|}{ POROSIDAD } & $\mathbf{X}$ & \\
\hline \multicolumn{6}{|c|}{ ADHESIÓN AL CUERPO CERÁMICO } & $\mathbf{X}$ & \\
\hline \multicolumn{6}{|l|}{ RETOQUE } & $\mathbf{X}$ & \\
\hline ALMACENAJE & & & & & & & $\mathbf{X}$ \\
\hline REVERSIBILIDAD & & & & & & & $\mathbf{X}$ \\
\hline OBSERVACIONES & muy ligera & blanc & & & & & \\
\hline VALORACIÓN & & JO A & PTA/NO & & ADA & & \\
\hline
\end{tabular}




\begin{tabular}{|c|c|c|c|c|c|c|c|}
\hline REFERENCIA & \multicolumn{5}{|c|}{ MASILLA } & \multicolumn{2}{|c|}{$\mathbf{N}^{\mathbf{0}}$} \\
\hline F2 & \multicolumn{5}{|c|}{ MODOSTUC PASTA/1 } & \multicolumn{2}{|c|}{82} \\
\hline \multicolumn{8}{|l|}{ COMPOSICIÓN } \\
\hline PREPARACIÓN & \multicolumn{7}{|c|}{ Preparada para su uso } \\
\hline \multirow{2}{*}{$\begin{array}{l}\text { CONSISTENCIA Y } \\
\text { APLICACIÓN }\end{array}$} & Líquida & & Espesa & & Pastosa & & $\mathbf{X}$ \\
\hline & Inyección & & Vertido & & Espátul & & $\mathbf{X}$ \\
\hline T. DE TRABAJO & \multicolumn{7}{|l|}{$20^{\prime}$} \\
\hline T. DE SECADO & \multicolumn{7}{|c|}{1 hora en capa fina// + de 24 horas capa gruesa } \\
\hline CONTRACCIÓN & Alta & $\mathrm{X}$ & Media & & \multicolumn{2}{|l|}{ Baja } & \\
\hline POROSIDAD & Alta & & Media & $\mathrm{X}$ & \multicolumn{2}{|l|}{ Baja } & \\
\hline DUREZA & Alta & & Media & & \multicolumn{2}{|l|}{ Baja } & $\mathrm{X}$ \\
\hline ADHESIÓN & Alta & & Media & $\mathrm{X}$ & \multicolumn{2}{|l|}{ Baja } & \\
\hline \multirow{2}{*}{$\begin{array}{l}\text { NIVELACIÓN Y } \\
\text { PULIDO }\end{array}$} & Alta & $\mathrm{X}$ & Media & & \multicolumn{2}{|l|}{ Baja } & \\
\hline & Bisturí & $\mathrm{X}$ & Lija & $\mathrm{X}$ & \multicolumn{2}{|l|}{ Otros } & $\mathrm{X}$ \\
\hline \multirow[t]{2}{*}{ RETOQUE } & \multicolumn{7}{|c|}{ SI } \\
\hline & \multicolumn{5}{|c|}{ VENTAJAS/INCONVENIENTES } & $\mathbf{V}$ & $\mathbf{I}$ \\
\hline \multicolumn{6}{|l|}{ ELABORACIÓN } & $\mathbf{X}$ & \\
\hline \multicolumn{6}{|c|}{ SE CONOCEN LOS MATERIALES Y PROPORCIONES } & & $\mathbf{X}$ \\
\hline \multicolumn{6}{|l|}{ APLICACIÓN } & & $\mathbf{X}$ \\
\hline \multicolumn{6}{|c|}{ NIVELACIÓN Y PULIDO } & $\mathbf{X}$ & \\
\hline \multicolumn{6}{|c|}{ TIEMPO DE TRABAJO } & & $\mathbf{X}$ \\
\hline \multicolumn{6}{|c|}{ TIEMPO DE SECADO } & & $\mathbf{X}$ \\
\hline \multicolumn{6}{|c|}{ CONTRACCIÓN/AGRIETAMIENTO } & & $\mathbf{X}$ \\
\hline \multicolumn{6}{|l|}{ DUREZA } & & $\mathbf{X}$ \\
\hline \multicolumn{6}{|l|}{ POROSIDAD } & $\mathbf{X}$ & \\
\hline \multicolumn{6}{|c|}{ ADHESIÓN AL CUERPO CERÁMICO } & $\mathbf{X}$ & \\
\hline \multicolumn{6}{|l|}{ RETOQUE } & $\mathbf{X}$ & \\
\hline ALMACENAJE & & & & & & & $\mathbf{X}$ \\
\hline REVERSIBILIDAD & & & & & & & $\mathbf{X}$ \\
\hline OBSERVACIONES & Agrieta en & apa $g$ & uesa. Tard & $\mathrm{isec}$ & & & \\
\hline VALORACIÓN & & & APTA//E & YA & & & \\
\hline
\end{tabular}




\begin{tabular}{|c|c|c|c|c|c|c|c|}
\hline REFERENCIA & \multicolumn{5}{|c|}{ MASILLA } & \multicolumn{2}{|c|}{$\mathbf{N}^{\mathbf{0}}$} \\
\hline & \multicolumn{5}{|c|}{ MODOSTUC P.-LITEPLAST /1 } & \multicolumn{2}{|c|}{83} \\
\hline COMPOSICIÓN & \multicolumn{7}{|c|}{ Modostuc pasta (50 gr.) + Liteplast pasta blanco (50 gr.) } \\
\hline PREPARACIÓN & \multicolumn{7}{|c|}{ Mezclar con espátula flexible } \\
\hline CONSISTENCIA Y & Líquida & & Espesa & & \multicolumn{2}{|l|}{ Pastosa } & $\mathbf{X}$ \\
\hline APLICACIÓN & Inyección & & Vertido & & \multicolumn{2}{|c|}{ Espátula } & $\mathbf{X}$ \\
\hline T. DE TRABAJO & \multicolumn{7}{|l|}{$20^{\prime}$} \\
\hline T. DE SECADO & \multicolumn{7}{|c|}{1 hora es capa fina, + de 24 en capa gruesa } \\
\hline CONTRACCIÓN & Alta & $\mathrm{X}$ & Media & & \multicolumn{2}{|l|}{ Baja } & \\
\hline POROSIDAD & Alta & & Media & $\mathrm{X}$ & \multicolumn{2}{|l|}{ Baja } & \\
\hline DUREZA & Alta & & Media & & \multicolumn{2}{|l|}{ Baja } & $\mathrm{X}$ \\
\hline ADHESIÓN & Alta & & Media & $\mathrm{X}$ & \multicolumn{2}{|l|}{ Baja } & \\
\hline NIVELACIÓN Y & Alta & & Media & $\mathrm{X}$ & \multicolumn{2}{|l|}{ Baja } & \\
\hline PULIDO & Bisturí & $\mathrm{X}$ & Lija & $\mathrm{X}$ & \multicolumn{2}{|l|}{ Otros } & $\mathrm{X}$ \\
\hline RETOQUE & \multicolumn{7}{|l|}{ SI } \\
\hline & \multicolumn{5}{|c|}{ VENTAJAS/INCONVENIENTES } & $\mathbf{V}$ & I \\
\hline \multicolumn{7}{|l|}{ ELABORACIÓN } & $\mathbf{X}$ \\
\hline \multicolumn{6}{|c|}{ SE CONOCEN LOS MATERIALES Y PROPORCIONES } & & $\mathbf{X}$ \\
\hline \multicolumn{6}{|l|}{ APLICACIÓN } & & $\mathbf{X}$ \\
\hline \multicolumn{6}{|c|}{ NIVELACIÓN Y PULIDO } & $\mathbf{X}$ & \\
\hline \multicolumn{6}{|c|}{ TIEMPO DE TRABAJO } & & $\mathbf{X}$ \\
\hline \multicolumn{6}{|c|}{ TIEMPO DE SECADO } & & $\mathbf{X}$ \\
\hline \multicolumn{6}{|c|}{ CONTRACCIÓN/AGRIETAMIENTO } & & $\mathbf{X}$ \\
\hline \multicolumn{6}{|l|}{ DUREZA } & & $\mathbf{X}$ \\
\hline \multicolumn{6}{|l|}{ POROSIDAD } & $\mathbf{X}$ & \\
\hline \multicolumn{6}{|c|}{ ADHESIÓN AL CUERPO CERÁMICO } & $\mathbf{X}$ & \\
\hline \multicolumn{6}{|l|}{ RETOQUE } & $\mathbf{X}$ & \\
\hline \multicolumn{6}{|l|}{ ALMACENAJE } & $\mathbf{X}$ & \\
\hline REVERSIBILIDAD & & & & & & & $\mathbf{X}$ \\
\hline OBSERVACIONES & Muy ligera & nan & lo. Retrae & griet & Es flex & & \\
\hline VALORACIÓN & & UA & TAA/NO & SAY & $\overline{\text { ADA }}$ & & \\
\hline
\end{tabular}




\begin{tabular}{|c|c|c|c|c|c|c|c|}
\hline REFERENCIA & \multicolumn{5}{|c|}{ MASILLA } & \multicolumn{2}{|c|}{$\mathbf{N}^{0}$} \\
\hline & \multicolumn{5}{|c|}{ MODOSTUC-LITEPLAST /2 } & \multicolumn{2}{|c|}{84} \\
\hline COMPOSICIÓN & \multicolumn{7}{|c|}{ Modostuc pasta (10 gr.) + Liteplast pasta blanco (1 gr.) } \\
\hline PREPARACIÓN & \multicolumn{7}{|c|}{ Mezclar con espátula flexible } \\
\hline \multirow{2}{*}{$\begin{array}{l}\text { CONSISTENCIA Y } \\
\text { APLICACIÓN }\end{array}$} & Líquida & & Espesa & & Pastosa & & $\mathbf{X}$ \\
\hline & Inyección & & Vertido & & Espátul & & $\mathbf{X}$ \\
\hline T. DE TRABAJO & \multicolumn{7}{|l|}{$20^{\prime}$} \\
\hline T. DE SECADO & \multicolumn{7}{|c|}{1 hora es capa fina, + de 24 en capa gruesa } \\
\hline CONTRACCIÓN & Alta & $\mathrm{X}$ & Media & & \multicolumn{2}{|l|}{ Baja } & \\
\hline POROSIDAD & Alta & & Media & $\mathrm{X}$ & \multicolumn{2}{|l|}{ Baja } & \\
\hline DUREZA & Alta & & Media & & \multicolumn{2}{|l|}{ Baja } & $\mathrm{X}$ \\
\hline ADHESIÓN & Alta & & Media & $\mathrm{X}$ & \multicolumn{2}{|l|}{ Baja } & \\
\hline NIVELACIÓN Y & Alta & $\mathrm{X}$ & Media & & \multicolumn{2}{|l|}{ Baja } & \\
\hline PULIDO & Bisturí & $\mathrm{X}$ & Lija & $\mathrm{X}$ & \multicolumn{2}{|l|}{ Otros } & \\
\hline RETOQUE & \multicolumn{7}{|l|}{ SI } \\
\hline & \multicolumn{5}{|c|}{ VENTAJAS/INCONVENIENTES } & V & I \\
\hline \multicolumn{6}{|l|}{ ELABORACIÓN } & & $\mathbf{X}$ \\
\hline \multicolumn{6}{|c|}{ SE CONOCEN LOS MATERIALES Y PROPORCIONES } & & $\mathbf{X}$ \\
\hline \multicolumn{6}{|l|}{ APLICACIÓN } & & $\mathbf{X}$ \\
\hline \multicolumn{6}{|c|}{ NIVELACIÓN Y PULIDO } & $\mathbf{X}$ & \\
\hline \multicolumn{6}{|c|}{ TIEMPO DE TRABAJO } & & $\mathbf{X}$ \\
\hline \multicolumn{6}{|c|}{ TIEMPO DE SECADO } & & $\mathbf{X}$ \\
\hline \multicolumn{6}{|c|}{ CONTRACCIÓN/AGRIETAMIENTO } & & $\mathbf{X}$ \\
\hline \multicolumn{6}{|l|}{ DUREZA } & & $\mathbf{X}$ \\
\hline \multicolumn{6}{|l|}{ POROSIDAD } & $\mathbf{X}$ & \\
\hline \multicolumn{6}{|c|}{ ADHESIÓN AL CUERPO CERÁMICO } & $\mathbf{X}$ & \\
\hline \multicolumn{6}{|l|}{ RETOQUE } & $\mathbf{X}$ & \\
\hline \multicolumn{6}{|l|}{ ALMACENAJE } & $\mathbf{X}$ & \\
\hline \multicolumn{6}{|l|}{ REVERSIBILIDAD } & & $\mathbf{X}$ \\
\hline OBSERVACIONES & Muy ligera & blan & o. Retrae & grie & a. Es flexi & & \\
\hline VALORACIÓN & & $\mathbf{O A}$ & TA//NO & SAI & ADA & & \\
\hline
\end{tabular}




\begin{tabular}{|c|c|c|c|c|c|c|c|}
\hline REFERENCIA & \multicolumn{5}{|c|}{ MASILLA } & \multicolumn{2}{|c|}{$\mathbf{N}^{0}$} \\
\hline F3 & \multicolumn{5}{|c|}{ MODOSTUC-LITEPLAST /3 } & \multicolumn{2}{|c|}{85} \\
\hline COMPOSICIÓN & \multicolumn{7}{|c|}{ Modostuc pasta (10 gr.) + Liteplast pasta blanco (3 gr.) } \\
\hline PREPARACIÓN & \multicolumn{7}{|c|}{ Mezclar con espátula flexible } \\
\hline \multirow{2}{*}{$\begin{array}{l}\text { CONSISTENCIA Y } \\
\text { APLICACIÓN }\end{array}$} & Líquida & & Espesa & & Pastosa & & $\mathbf{X}$ \\
\hline & Inyección & & Vertido & & Espátula & & $\mathbf{X}$ \\
\hline T. DE TRABAJO & \multicolumn{7}{|l|}{$20^{\prime}$} \\
\hline T. DE SECADO & \multicolumn{7}{|c|}{1 hora es capa fina, + de 24 en capa gruesa } \\
\hline CONTRACCIÓN & Alta & $\mathrm{X}$ & Media & & \multicolumn{2}{|l|}{ Baja } & \\
\hline POROSIDAD & Alta & & Media & $\mathrm{X}$ & \multicolumn{2}{|l|}{ Baja } & \\
\hline DUREZA & Alta & & Media & & \multicolumn{2}{|l|}{ Baja } & $\mathrm{X}$ \\
\hline ADHESIÓN & Alta & & Media & $\mathrm{X}$ & \multicolumn{2}{|l|}{ Baja } & \\
\hline NIVELACIÓN Y & Alta & $\mathrm{X}$ & Media & & \multicolumn{2}{|l|}{ Baja } & \\
\hline PULIDO & Bisturí & $\mathrm{X}$ & Lija & $\mathrm{X}$ & \multicolumn{2}{|l|}{ Otros } & \\
\hline RETOQUE & \multicolumn{7}{|l|}{ SI } \\
\hline & \multicolumn{5}{|c|}{ VENTAJAS/INCONVENIENTES } & $\mathbf{V}$ & $\mathbf{I}$ \\
\hline \multicolumn{6}{|l|}{ ELABORACIÓN } & & $\mathbf{X}$ \\
\hline \multicolumn{6}{|c|}{ SE CONOCEN LOS MATERIALES Y PROPORCIONES } & & $\mathbf{X}$ \\
\hline \multicolumn{6}{|l|}{ APLICACIÓN } & & $\mathbf{X}$ \\
\hline \multicolumn{6}{|c|}{ NIVELACIÓN Y PULIDO } & $\mathbf{X}$ & \\
\hline \multicolumn{6}{|c|}{ TIEMPO DE TRABAJO } & & $\mathbf{X}$ \\
\hline \multicolumn{6}{|c|}{ TIEMPO DE SECADO } & & $\mathbf{X}$ \\
\hline \multicolumn{6}{|c|}{ CONTRACCIÓN/AGRIETAMIENTO } & & $\mathbf{X}$ \\
\hline \multicolumn{6}{|l|}{ DUREZA } & & $\mathbf{X}$ \\
\hline \multicolumn{6}{|l|}{ POROSIDAD } & $\mathbf{X}$ & \\
\hline \multicolumn{6}{|c|}{ ADHESIÓN AL CUERPO CERÁMICO } & $\mathbf{X}$ & \\
\hline \multicolumn{6}{|l|}{ RETOQUE } & $\mathbf{X}$ & \\
\hline \multicolumn{6}{|l|}{ ALMACENAJE } & $\mathbf{X}$ & \\
\hline \multicolumn{6}{|l|}{ REVERSIBILIDAD } & & $\mathbf{X}$ \\
\hline OBSERVACIONES & Muy ligera & blan & lo. Retrae & grie & a. Es flexi & & \\
\hline VALORACIÓN & & & APTA $/ / \mathbf{E}$ & AYA & & & \\
\hline
\end{tabular}




\begin{tabular}{|c|c|c|c|c|c|c|c|}
\hline REFERENCIA & \multicolumn{5}{|c|}{ MASILLA } & \multicolumn{2}{|c|}{$\mathbf{N}^{0}$} \\
\hline & \multicolumn{5}{|c|}{ AGUAPLAST CAPA GRUESA } & \multicolumn{2}{|c|}{86} \\
\hline \multicolumn{8}{|l|}{ COMPOSICIÓN } \\
\hline PREPARACIÓN & \multicolumn{7}{|c|}{ Preparada para su uso } \\
\hline \multirow{2}{*}{$\begin{array}{l}\text { CONSISTENCIA Y } \\
\text { APLICACIÓN }\end{array}$} & Líquida & & Espesa & & Pastosa & & $\mathbf{X}$ \\
\hline & Inyección & & Vertido & & Espátul & & $\mathrm{X}$ \\
\hline T. DE TRABAJO & \multicolumn{7}{|l|}{20 ' } \\
\hline T. DE SECADO & \multicolumn{7}{|c|}{1 hora es capa fina, + de 24 en capa gruesa } \\
\hline CONTRACCIÓN & Alta & $\mathrm{X}$ & Media & & \multicolumn{2}{|l|}{ Baja } & \\
\hline POROSIDAD & Alta & & Media & & \multicolumn{2}{|l|}{ Baja } & $\mathrm{X}$ \\
\hline DUREZA & Alta & & Media & & \multicolumn{2}{|l|}{ Baja } & $\mathrm{X}$ \\
\hline ADHESIÓN & Alta & & Media & $\mathrm{X}$ & \multicolumn{2}{|l|}{ Baja } & \\
\hline NIVELACIÓN Y & Alta & $\mathrm{X}$ & Media & & \multicolumn{2}{|l|}{ Baja } & \\
\hline PULIDO & Bisturí & $\mathrm{X}$ & Lija & $\mathrm{X}$ & \multicolumn{2}{|l|}{ Otros } & \\
\hline \multirow[t]{2}{*}{ RETOQUE } & \multicolumn{7}{|l|}{ SI } \\
\hline & \multicolumn{5}{|c|}{ VENTAJAS/INCONVENIENTES } & $\mathbf{V}$ & $\mathbf{I}$ \\
\hline \multicolumn{6}{|l|}{ ELABORACIÓN } & $\mathbf{X}$ & \\
\hline \multicolumn{6}{|c|}{ SE CONOCEN LOS MATERIALES Y PROPORCIONES } & & $\mathbf{X}$ \\
\hline \multicolumn{6}{|l|}{ APLICACIÓN } & & $\mathbf{X}$ \\
\hline \multicolumn{6}{|c|}{ NIVELACIÓN Y PULIDO } & $\mathbf{X}$ & \\
\hline \multicolumn{6}{|c|}{ TIEMPO DE TRABAJO } & & $\mathbf{X}$ \\
\hline \multicolumn{6}{|c|}{ TIEMPO DE SECADO } & $\mathbf{X}$ & \\
\hline \multicolumn{6}{|c|}{ CONTRACCIÓN/AGRIETAMIENTO } & & $\mathbf{X}$ \\
\hline \multicolumn{6}{|l|}{ DUREZA } & & $\mathbf{X}$ \\
\hline \multicolumn{6}{|l|}{ POROSIDAD } & $\mathbf{X}$ & \\
\hline \multicolumn{6}{|c|}{ ADHESIÓN AL CUERPO CERÁMICO } & $\mathbf{X}$ & \\
\hline \multicolumn{6}{|l|}{ RETOQUE } & $\mathbf{X}$ & \\
\hline \multicolumn{6}{|l|}{ ALMACENAJE } & $\mathbf{X}$ & \\
\hline REVERSIBILIDAD & & & & & & & $\mathbf{X}$ \\
\hline OBSERVACIONES & Agrieta en c & $\mathrm{ga} \mathrm{gr}$ & lesa y tarc & ías $\mathrm{e}$ & n secar. & & \\
\hline VALORACIÓN & & O A & TA//NO & SA & ADA & & \\
\hline
\end{tabular}




\begin{tabular}{|c|c|c|c|c|c|c|c|}
\hline REFERENCIA & \multicolumn{5}{|c|}{ MASILLA } & \multicolumn{2}{|c|}{$\mathbf{N}^{0}$} \\
\hline $\mathbf{F 1}$ & \multicolumn{5}{|c|}{ LIQUITEX MODELLING PASTE } & \multicolumn{2}{|c|}{87} \\
\hline \multicolumn{8}{|l|}{ COMPOSICIÓN } \\
\hline PREPARACIÓN & \multicolumn{7}{|c|}{ Preparada para su uso } \\
\hline \multirow{2}{*}{$\begin{array}{l}\text { CONSISTENCIA Y } \\
\text { APLICACIÓN }\end{array}$} & Líquida & & Espesa & & \multicolumn{2}{|l|}{ Pastosa } & $\mathbf{X}$ \\
\hline & Inyección & & Vertido & & Espátul & & $\mathrm{X}$ \\
\hline T. DE TRABAJO & \multicolumn{7}{|l|}{$20^{\prime}$} \\
\hline T. DE SECADO & \multicolumn{7}{|c|}{1 hora es capa fina, + de 24 en capa gruesa } \\
\hline CONTRACCIÓN & Alta & $\mathrm{X}$ & Media & & \multicolumn{2}{|l|}{ Baja } & \\
\hline POROSIDAD & Alta & & Media & & \multicolumn{2}{|l|}{ Baja } & $\mathrm{X}$ \\
\hline DUREZA & Alta & $\mathrm{X}$ & Media & & \multicolumn{2}{|l|}{ Baja } & \\
\hline ADHESIÓN & Alta & $\mathrm{X}$ & Media & & \multicolumn{2}{|l|}{ Baja } & \\
\hline \multirow{2}{*}{$\begin{array}{l}\text { NIVELACIÓN Y } \\
\text { PULIDO }\end{array}$} & Alta & $\mathrm{X}$ & Media & & \multicolumn{2}{|l|}{ Baja } & \\
\hline & Bisturí & $\mathrm{X}$ & Lija & $\mathrm{X}$ & Otros & & $\mathrm{X}$ \\
\hline \multirow[t]{2}{*}{ RETOQUE } & \multicolumn{7}{|c|}{ SI } \\
\hline & \multicolumn{5}{|c|}{ VENTAJAS/INCONVENIENTES } & $\mathbf{V}$ & $\mathbf{I}$ \\
\hline \multicolumn{6}{|l|}{ ELABORACIÓN } & $\mathbf{X}$ & \\
\hline \multicolumn{6}{|c|}{ SE CONOCEN LOS MATERIALES Y PROPORCIONES } & & $\mathbf{X}$ \\
\hline \multicolumn{6}{|l|}{ APLICACIÓN } & & $\mathrm{X}$ \\
\hline \multicolumn{6}{|c|}{ NIVELACIÓN Y PULIDO } & $\mathbf{X}$ & \\
\hline \multicolumn{6}{|c|}{ TIEMPO DE TRABAJO } & & $\mathbf{X}$ \\
\hline \multicolumn{6}{|c|}{ TIEMPO DE SECADO } & & $\mathbf{X}$ \\
\hline \multicolumn{6}{|c|}{ CONTRACCIÓN/AGRIETAMIENTO } & & $\mathbf{X}$ \\
\hline \multicolumn{6}{|l|}{ DUREZA } & & $\mathbf{X}$ \\
\hline \multicolumn{6}{|l|}{ POROSIDAD } & $\mathbf{X}$ & \\
\hline \multicolumn{6}{|c|}{ ADHESIÓN AL CUERPO CERÁMICO } & $\mathbf{X}$ & \\
\hline \multicolumn{6}{|l|}{ RETOQUE } & $\mathbf{X}$ & \\
\hline ALMACENAJE & & & & & & $\mathbf{X}$ & \\
\hline REVERSIBILIDAD & & & & & & & $\mathbf{X}$ \\
\hline OBSERVACIONES & $\begin{array}{l}\text { Agrieta en c } \\
\text { de aplicar. }\end{array}$ & pa gr & uesa y tarc & & secar. & & \\
\hline VALORACIÓN & & & APTA $/ / \mathbf{E}$ & $11 \mathrm{~A}$ & & & \\
\hline
\end{tabular}




\begin{tabular}{|c|c|c|c|c|c|c|c|}
\hline REFERENCIA & \multicolumn{5}{|c|}{ MASILLA } & \multicolumn{2}{|c|}{$\mathbf{N}^{\circ}$} \\
\hline & \multicolumn{5}{|c|}{ STUCCO ZECCHI } & \multicolumn{2}{|c|}{88} \\
\hline \multicolumn{8}{|l|}{ COMPOSICIÓN } \\
\hline PREPARACIÓN & \multicolumn{7}{|c|}{ Preparada para su uso } \\
\hline \multirow{2}{*}{$\begin{array}{l}\text { CONSISTENCIA Y } \\
\text { APLICACIÓN }\end{array}$} & Líquida & & Espesa & & Pastosa & & $\mathbf{X}$ \\
\hline & Inyección & & Vertido & & Espátul & & $\mathrm{X}$ \\
\hline T. DE TRABAJO & \multicolumn{7}{|l|}{30 ' } \\
\hline T. DE SECADO & \multicolumn{7}{|c|}{12 horas en capas gruesas } \\
\hline CONTRACCIÓN & Alta & $\mathrm{X}$ & Media & & \multicolumn{2}{|l|}{ Baja } & \\
\hline POROSIDAD & Alta & & Media & $\mathrm{X}$ & \multicolumn{2}{|l|}{ Baja } & \\
\hline DUREZA & Alta & $\mathrm{X}$ & Media & & \multicolumn{2}{|l|}{ Baja } & \\
\hline ADHESIÓN & Alta & $\mathrm{X}$ & Media & & \multicolumn{2}{|l|}{ Baja } & \\
\hline \multirow{2}{*}{$\begin{array}{l}\text { NIVELACIÓN Y } \\
\text { PULIDO }\end{array}$} & Alta & $\mathrm{X}$ & Media & & \multicolumn{2}{|l|}{ Baja } & \\
\hline & Bisturí & $\mathrm{X}$ & Lija & $\mathrm{X}$ & Otros & & $\mathrm{X}$ \\
\hline \multirow[t]{2}{*}{ RETOQUE } & \multicolumn{7}{|l|}{ SI } \\
\hline & \multicolumn{5}{|c|}{ VENTAJAS/INCONVENIENTES } & $\mathbf{V}$ & $\mathbf{I}$ \\
\hline \multicolumn{6}{|l|}{ ELABORACIÓN } & $\mathbf{X}$ & \\
\hline \multicolumn{6}{|c|}{ SE CONOCEN LOS MATERIALES Y PROPORCIONES } & & $\mathbf{X}$ \\
\hline \multicolumn{6}{|l|}{ APLICACIÓN } & $\mathbf{X}$ & \\
\hline \multicolumn{6}{|c|}{ NIVELACIÓN Y PULIDO } & $\mathbf{X}$ & \\
\hline \multicolumn{6}{|c|}{ TIEMPO DE TRABAJO } & & $\mathbf{X}$ \\
\hline \multicolumn{6}{|c|}{ TIEMPO DE SECADO } & & $\mathbf{X}$ \\
\hline \multicolumn{6}{|c|}{ CONTRACCIÓN/AGRIETAMIENTO } & & $\mathbf{X}$ \\
\hline \multicolumn{6}{|l|}{ DUREZA } & & $\mathbf{X}$ \\
\hline \multicolumn{6}{|l|}{ POROSIDAD } & $\mathbf{X}$ & \\
\hline \multicolumn{6}{|c|}{ ADHESIÓN AL CUERPO CERÁMICO } & $\mathbf{X}$ & \\
\hline \multicolumn{6}{|l|}{ RETOQUE } & $\mathbf{X}$ & \\
\hline \multicolumn{6}{|l|}{ ALMACENAJE } & & $\mathbf{X}$ \\
\hline REVERSIBILIDAD & & & & & & & $\mathbf{X}$ \\
\hline OBSERVACIONES & Agrieta En & pa g & uesa. Cua & $\mathrm{sec}$ & es muy f & ierte & \\
\hline VALORACIÓN & & O A & TA//NO & SA & ADA & & \\
\hline
\end{tabular}




\begin{tabular}{|c|c|c|c|c|c|c|c|}
\hline REFERENCIA & \multicolumn{5}{|c|}{ MASILLA } & \multicolumn{2}{|c|}{$\mathbf{N}^{0}$} \\
\hline & \multicolumn{5}{|c|}{ BRICOFIX TAPA GRIETAS } & \multicolumn{2}{|c|}{89} \\
\hline \multicolumn{8}{|l|}{ COMPOSICIÓN } \\
\hline PREPARACIÓN & \multicolumn{7}{|c|}{ Viene preparado para su uso } \\
\hline \multirow{2}{*}{$\begin{array}{l}\text { CONSISTENCIA Y } \\
\text { APLICACIÓN }\end{array}$} & Líquida & & Espesa & & \multicolumn{2}{|l|}{ Pastosa } & $\mathbf{X}$ \\
\hline & Inyección & & Vertido & & \multicolumn{2}{|c|}{ Espátula } & $\mathbf{X}$ \\
\hline T. DE TRABAJO & \multicolumn{6}{|l|}{$20^{\prime}$} & \\
\hline T. DE SECADO & \multicolumn{7}{|c|}{1 hora en capa fina, + de 24 en capa gruesa } \\
\hline CONTRACCIÓN & Alta & $\mathrm{X}$ & Media & & \multicolumn{2}{|l|}{ Baja } & \\
\hline POROSIDAD & Alta & $\mathrm{X}$ & Media & & \multicolumn{2}{|l|}{ Baja } & \\
\hline DUREZA & Alta & & Media & & \multicolumn{2}{|l|}{ Baja } & $\mathrm{X}$ \\
\hline ADHESIÓN & Alta & & Media & $\mathrm{X}$ & \multicolumn{2}{|l|}{ Baja } & \\
\hline NIVELACIÓN Y & Alta & $\mathrm{X}$ & Media & & \multicolumn{2}{|l|}{ Baja } & \\
\hline PULIDO & Bisturí & $\mathrm{X}$ & Lija & $\mathrm{X}$ & \multicolumn{2}{|l|}{ Otros } & $\mathrm{X}$ \\
\hline \multicolumn{8}{|l|}{ RETOQUE } \\
\hline & \multicolumn{5}{|c|}{ VENTAJAS/INCONVENIENTES } & $\mathbf{V}$ & $\mathbf{I}$ \\
\hline \multicolumn{6}{|l|}{ ELABORACIÓN } & $\mathbf{X}$ & \\
\hline \multicolumn{6}{|c|}{ SE CONOCEN LOS MATERIALES Y PROPORCIONES } & & $\mathbf{X}$ \\
\hline \multicolumn{6}{|l|}{ APLICACIÓN } & & $\mathbf{X}$ \\
\hline \multicolumn{6}{|c|}{ NIVELACIÓN Y PULIDO } & $\mathbf{X}$ & \\
\hline \multicolumn{6}{|c|}{ TIEMPO DE TRABAJO } & & $\mathbf{X}$ \\
\hline \multicolumn{6}{|c|}{ TIEMPO DE SECADO } & & $\mathbf{X}$ \\
\hline \multicolumn{6}{|c|}{ CONTRACCIÓN/AGRIETAMIENTO } & & $\mathbf{X}$ \\
\hline \multicolumn{6}{|l|}{ DUREZA } & & $\mathbf{X}$ \\
\hline \multicolumn{6}{|l|}{ POROSIDAD } & & $\mathbf{X}$ \\
\hline \multicolumn{6}{|c|}{ ADHESIÓN AL CUERPO CERÁMICO } & $\mathbf{X}$ & \\
\hline \multicolumn{6}{|l|}{ RETOQUE } & $\mathbf{X}$ & \\
\hline ALMACENAJE & & & & & & $\mathbf{X}$ & \\
\hline REVERSIBILIDAD & & & & & & & $\mathbf{X}$ \\
\hline OBSERVACIONES & Demasiado & and & & & & & \\
\hline VALORACIÓN & & $8 \pi$ & PTA//NO I & SAY & ADA & & \\
\hline
\end{tabular}




\begin{tabular}{|c|c|c|c|c|c|c|c|}
\hline REFERENCIA & \multicolumn{5}{|c|}{ MASILLA } & \multicolumn{2}{|c|}{$\mathbf{N}^{0}$} \\
\hline & \multicolumn{5}{|c|}{ TITAN. MASILLA PLÁSTICA } & \multicolumn{2}{|c|}{90} \\
\hline \multicolumn{8}{|l|}{ COMPOSICIÓN } \\
\hline PREPARACIÓN & \multicolumn{7}{|c|}{ Viene preparada para su uso } \\
\hline \multirow{2}{*}{$\begin{array}{l}\text { CONSISTENCIA Y } \\
\text { APLICACIÓN }\end{array}$} & Líquida & & Espesa & & \multicolumn{2}{|l|}{ Pastosa } & $\mathbf{X}$ \\
\hline & Inyección & & Vertido & & \multicolumn{2}{|l|}{ Espátula } & $\mathbf{X}$ \\
\hline T. DE TRABAJO & \multicolumn{6}{|l|}{$20^{\prime}$} & \\
\hline T. DE SECADO & \multicolumn{7}{|c|}{1 hora eN capa fina, + de 24 en capa gruesa } \\
\hline CONTRACCIÓN & Alta & $\mathrm{X}$ & Media & & \multicolumn{2}{|l|}{ Baja } & \\
\hline POROSIDAD & Alta & & Media & $\mathrm{X}$ & \multicolumn{2}{|l|}{ Baja } & \\
\hline DUREZA & Alta & & Media & & \multicolumn{2}{|l|}{ Baja } & $\mathrm{X}$ \\
\hline ADHESIÓN & Alta & & Media & $\mathrm{X}$ & \multicolumn{2}{|l|}{ Baja } & \\
\hline NIVELACIÓN Y & Alta & $\mathrm{X}$ & Media & & \multicolumn{2}{|l|}{ Baja } & \\
\hline PULIDO & Bisturí & $\mathrm{X}$ & Lija & $\mathrm{X}$ & \multicolumn{2}{|l|}{ Otros } & \\
\hline RETOQUE & \multicolumn{7}{|l|}{ SI } \\
\hline & \multicolumn{5}{|c|}{ VENTAJAS/INCONVENIENTES } & V & I \\
\hline \multicolumn{6}{|l|}{ ELABORACIÓN } & $\mathbf{X}$ & \\
\hline \multicolumn{6}{|c|}{ SE CONOCEN LOS MATERIALES Y PROPORCIONES } & & $\mathbf{X}$ \\
\hline \multicolumn{6}{|l|}{ APLICACIÓN } & & $\mathbf{X}$ \\
\hline \multicolumn{6}{|c|}{ NIVELACIÓN Y PULIDO } & $\mathbf{X}$ & \\
\hline \multicolumn{6}{|c|}{ TIEMPO DE TRABAJO } & & $\mathbf{X}$ \\
\hline \multicolumn{6}{|c|}{ TIEMPO DE SECADO } & & $\mathbf{X}$ \\
\hline \multicolumn{6}{|c|}{ CONTRACCIÓN/AGRIETAMIENTO } & & $\mathbf{X}$ \\
\hline \multicolumn{6}{|l|}{ DUREZA } & & $\mathbf{X}$ \\
\hline \multicolumn{6}{|l|}{ POROSIDAD } & & $\mathbf{X}$ \\
\hline \multicolumn{6}{|c|}{ ADHESIÓN AL CUERPO CERÁMICO } & $\mathbf{X}$ & \\
\hline \multicolumn{6}{|l|}{ RETOQUE } & $\mathbf{X}$ & \\
\hline ALMACENAJE & & & & & & $\mathbf{X}$ & \\
\hline REVERSIBILIDAD & & & & & & & $\mathbf{X}$ \\
\hline OBSERVACIONES & Alto agriet & ient & incluso e & $\mathrm{pat}$ & & & \\
\hline VALORACIÓN & & 8 & TA//NO & 61 & ADA & & \\
\hline
\end{tabular}




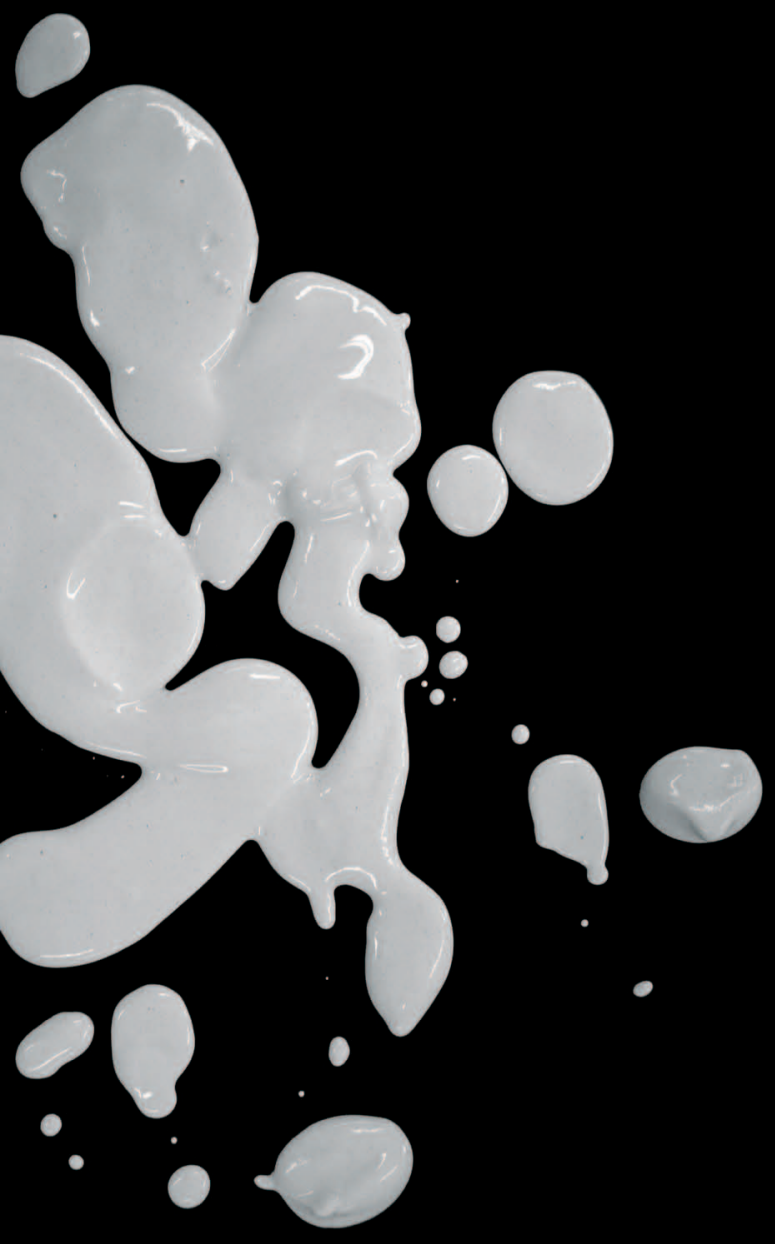

ANEXO II 



\section{PARALOID B-72 + MICROESFERAS DE VIDRIO}

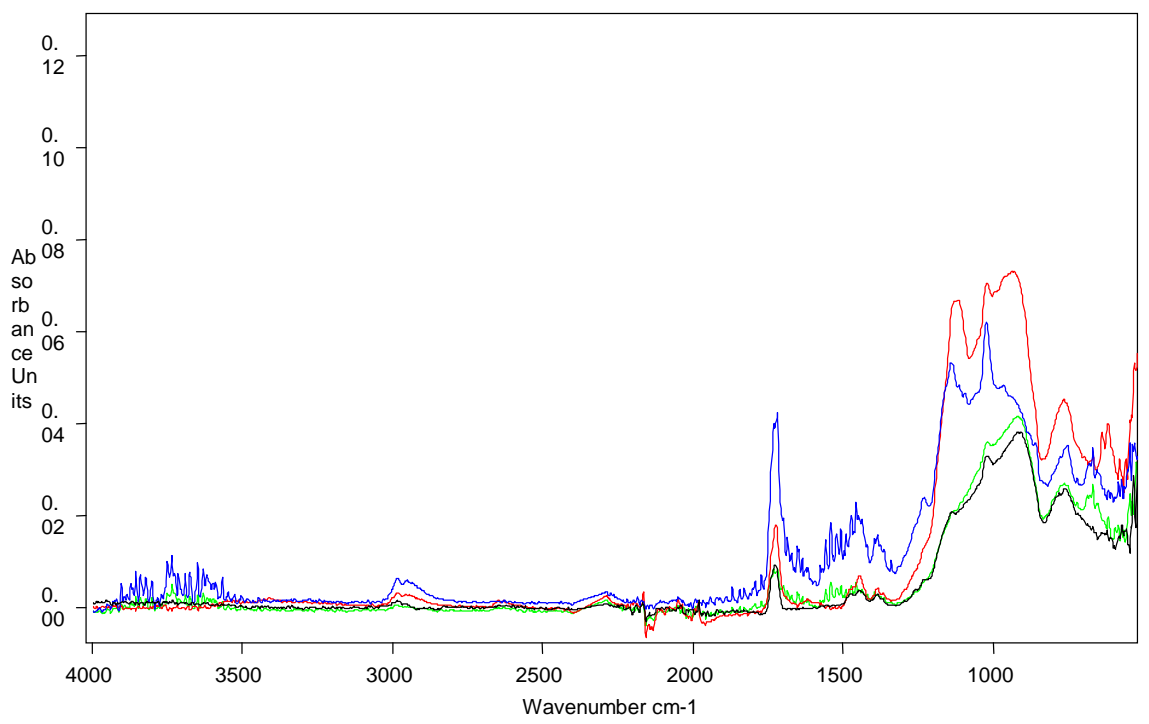

\begin{tabular}{|l|l|l|}
\hline Probetas sin envejecer & \\
\hline & Probetas sometidas a envejecimiento acelerado por $\mathrm{HR}$ & Sube la cantidad de agua \\
\hline & Probetas sometidas a envejecimiento acelerado por $\mathrm{SO}_{2}$ & Suben los sulfatos \\
\hline & Probetas sometidas a envejecimiento acelerado por UV & Sube el agua \\
\hline
\end{tabular}




\section{A2}

PARALOID B-72 + CARBONATO DE CALCIO

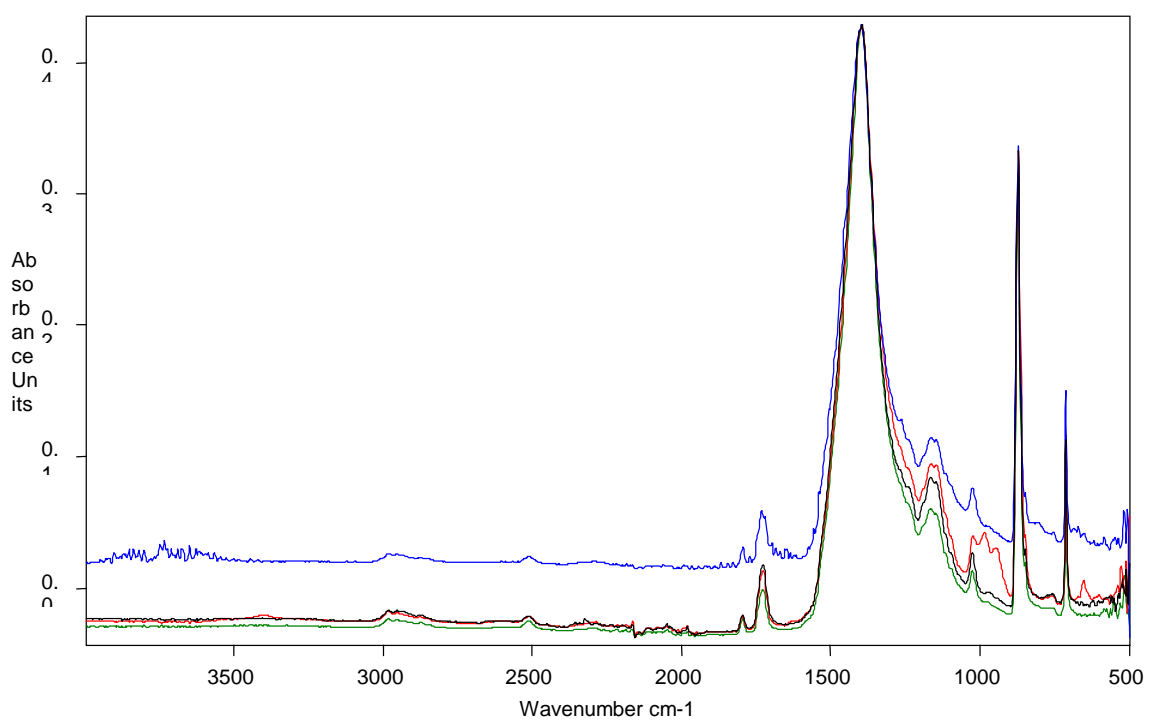

\begin{tabular}{|l|l|c|}
\hline Probetas sin envejecer & \\
\hline Probetas sometidas a envejecimiento acelerado por $\mathrm{HR}$ & Sube la cantidad de agua \\
\hline Probetas sometidas a envejecimiento acelerado por $\mathrm{SO}_{2}$ & Suben sulfatos \\
\hline Probetas sometidas a envejecimiento acelerado por UV & - \\
\hline
\end{tabular}


A3

PARALOID B-72 + POLVO DE MÁRMOL

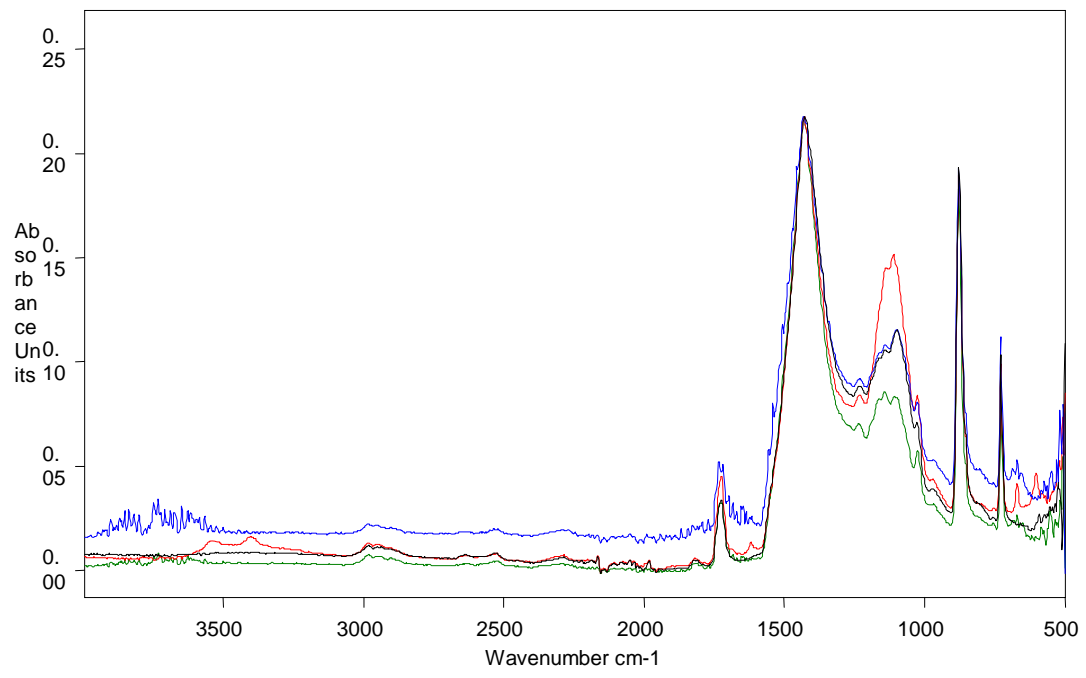

Probetas sin envejecer

Probetas sometidas a envejecimiento acelerado por HR

Sube la cantidad de agua

\begin{tabular}{|l|l|}
\hline Probetas sometidas a envejecimiento acelerado por $\mathrm{SO}_{2}$ & Suben los sulfatos
\end{tabular}

Probetas sometidas a envejecimiento acelerado por UV

$-$ 


\section{B1}

ACRIL 33 + MICROESFERAS DE VIDRIO

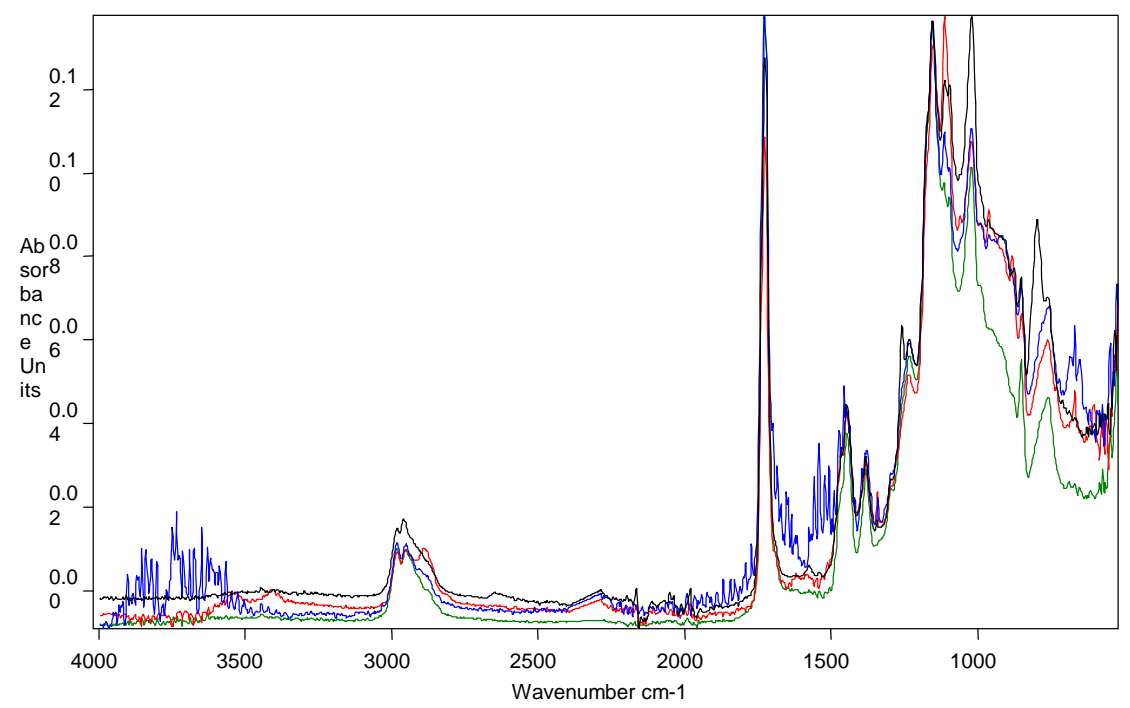

\begin{tabular}{|l|l|l|}
\hline Probetas sin envejecer & \\
\hline Probetas sometidas a envejecimiento acelerado por HR & Sube la cantidad de agua \\
\hline Probetas sometidas a envejecimiento acelerado por $\mathrm{SO}_{2}$ & Suben los sulfatos \\
\hline Probetas sometidas a envejecimiento acelerado por UV & Oxidación polímero \\
\hline
\end{tabular}

B2 


\section{ACRIL 33 + CARBONATO DE CALCIO}

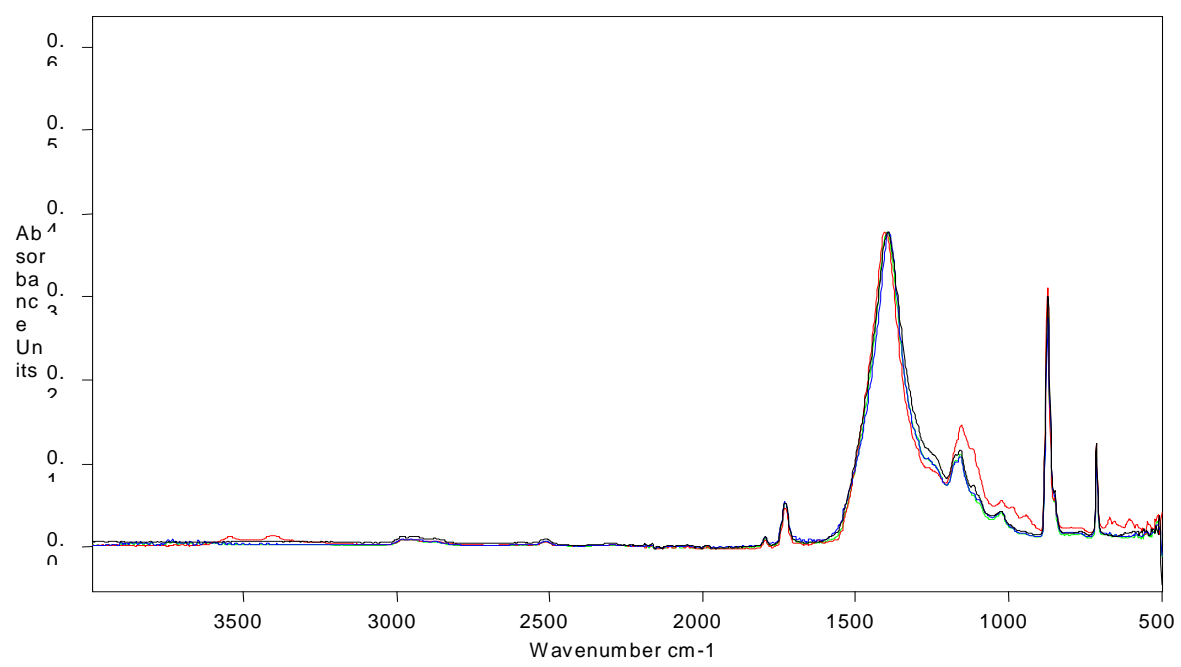

\begin{tabular}{|l|c|}
\hline Probetas sin envejecer & \\
\hline Probetas sometidas a envejecimiento acelerado por HR & - \\
\hline Probetas sometidas a envejecimiento acelerado por $\mathrm{SO}_{2}$ & Suben los sulfatos \\
\hline Probetas sometidas a envejecimiento acelerado por UV & - \\
\hline
\end{tabular}




\section{B3}

\section{ACRIL 33 +POLVO DE MÁRMOL}

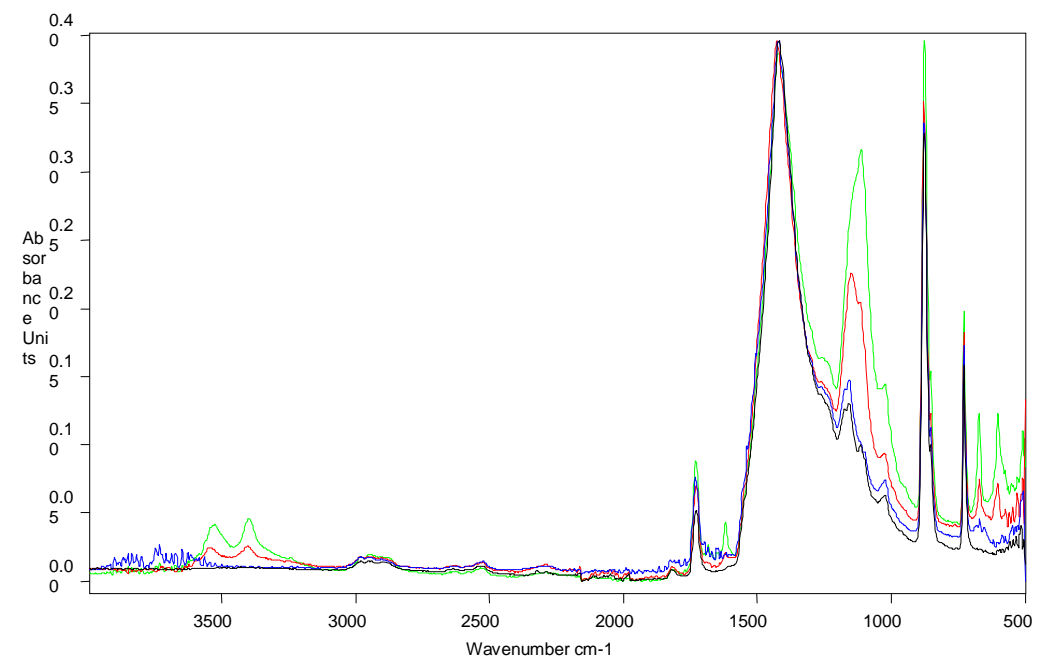

Probetas sin envejecer

Probetas sometidas a envejecimiento acelerado por HR

Sube la cantidad de agua

Probetas sometidas a envejecimiento acelerado por $\mathrm{SO}_{2}$

Suben los sulfatos

Probetas sometidas a envejecimiento acelerado por UV

Oxidación polímero 
C1

ESCAYOLA “ALAMO 70” + ACRIL 33

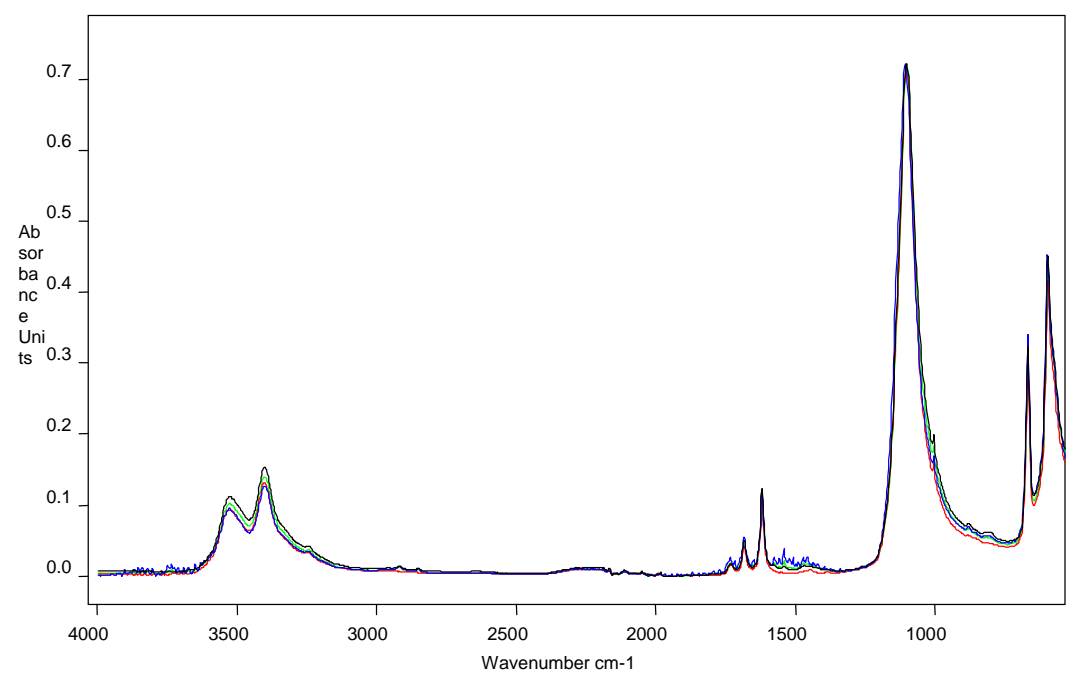

Probetas sin envejecer

Probetas sometidas a envejecimiento acelerado por HR $\quad$ Sube la cantidad de agua

Probetas sometidas a envejecimiento acelerado por $\mathrm{SO}_{2}$ $-$

Probetas sometidas a envejecimiento acelerado por UV 


\section{C2}

\section{ESCAYOLA “ALAMO 70” + MOWILITH SDM5}

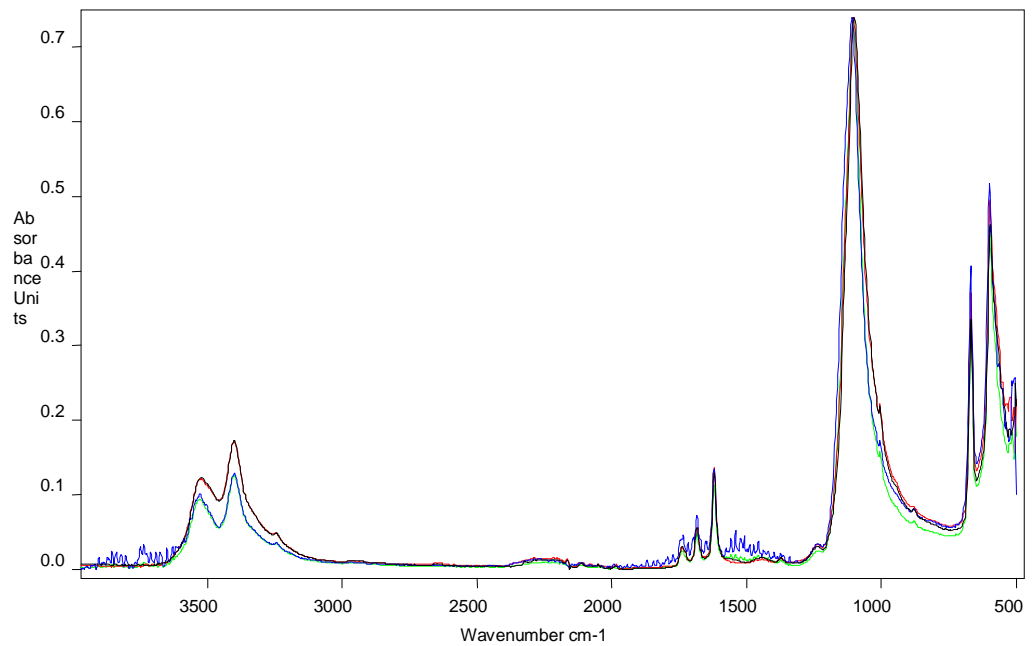

Probetas sin envejecer

Probetas sometidas a envejecimiento acelerado por HR

Sube la cantidad de agua

Probetas sometidas a envejecimiento acelerado por $\mathrm{SO}_{2}$

Probetas sometidas a envejecimiento acelerado por UV 


\section{C3}

ESCAYOLA “ALAMO 70”

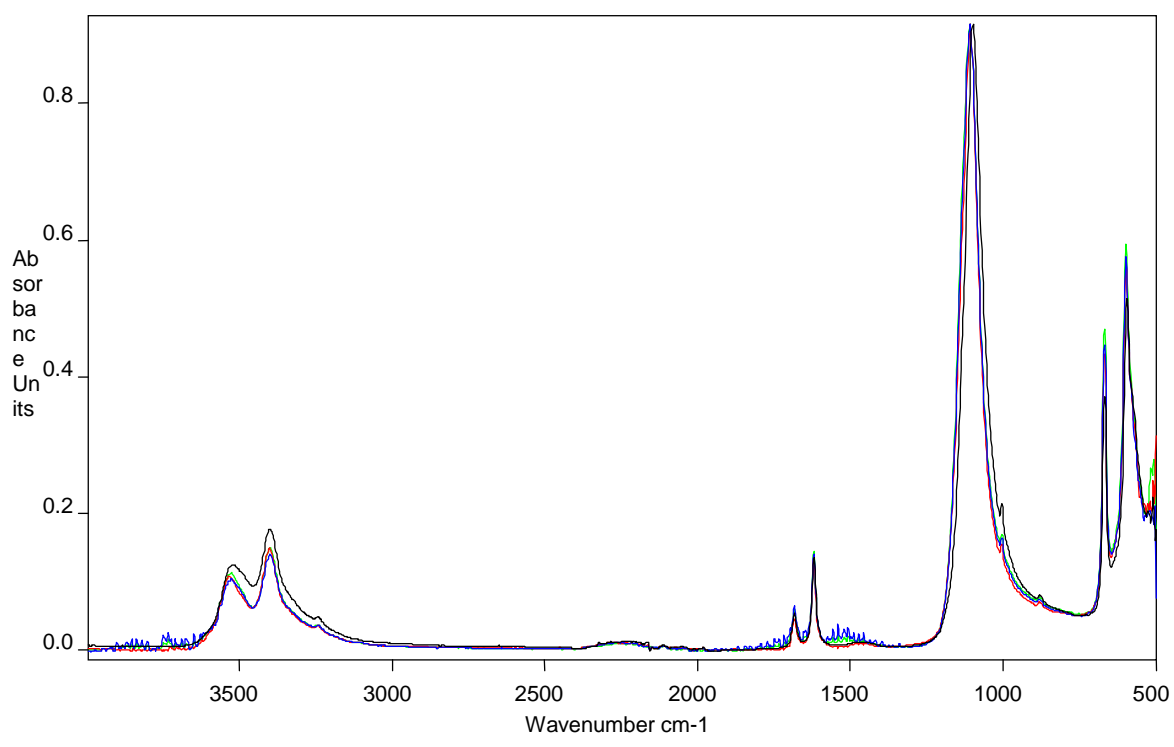

Probetas sin envejecer

Probetas sometidas a envejecimiento acelerado por HR

Sube la cantidad de agua

Probetas sometidas a envejecimiento acelerado por $\mathrm{SO}_{2}$ $-$

Probetas sometidas a envejecimiento acelerado por UV $-$ 
C4

ESCAYOLA “HEBODUR”

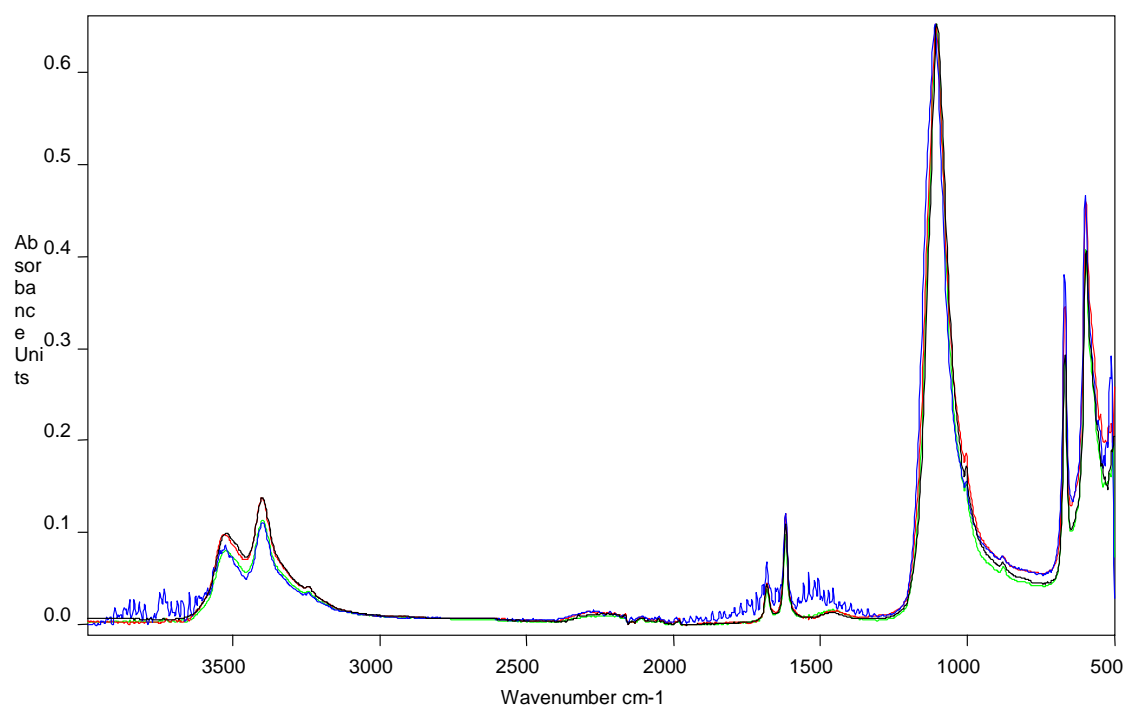

Probetas sin envejecer

Probetas sometidas a envejecimiento acelerado por HR

Sube la cantidad de agua

Probetas sometidas a envejecimiento acelerado por $\mathrm{SO}_{2}$

Probetas sometidas a envejecimiento acelerado por UV 


\section{D1}

\section{POLYFILLA INTERIORES}

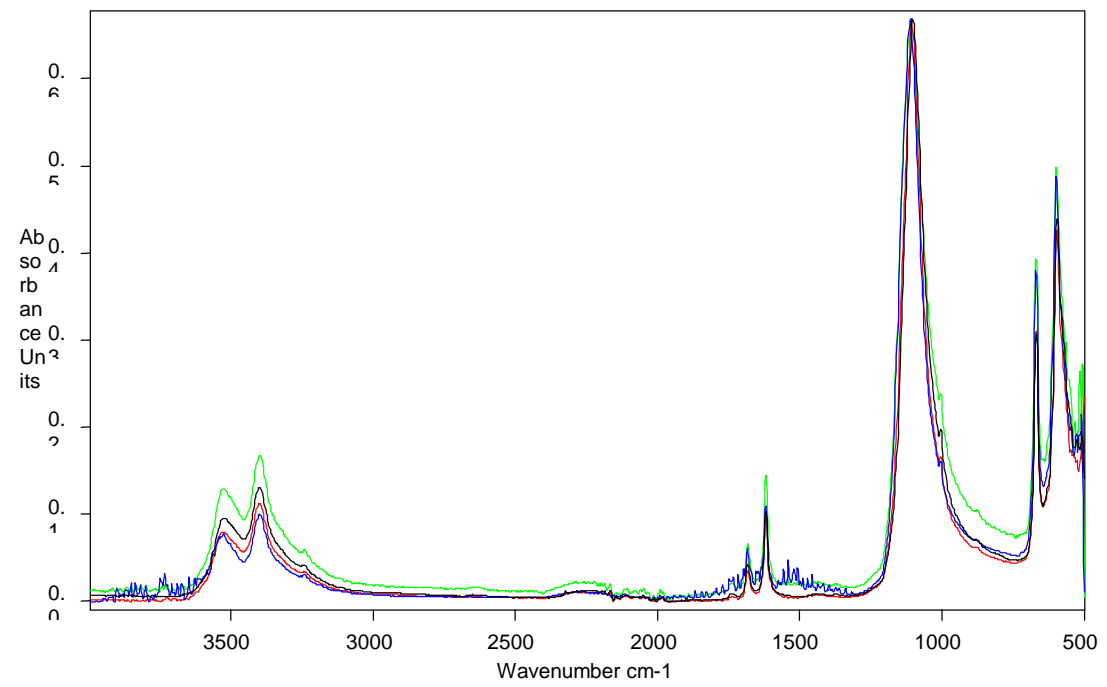

Probetas sin envejecer

Probetas sometidas a envejecimiento acelerado por HR Sube la cantidad de agua

Probetas sometidas a envejecimiento acelerado por $\mathrm{SO}_{2}$ Probetas sometidas a envejecimiento acelerado por UV 


\section{D2}

\section{POLYFILLA INTERIORES + MOWILITH SDM5}

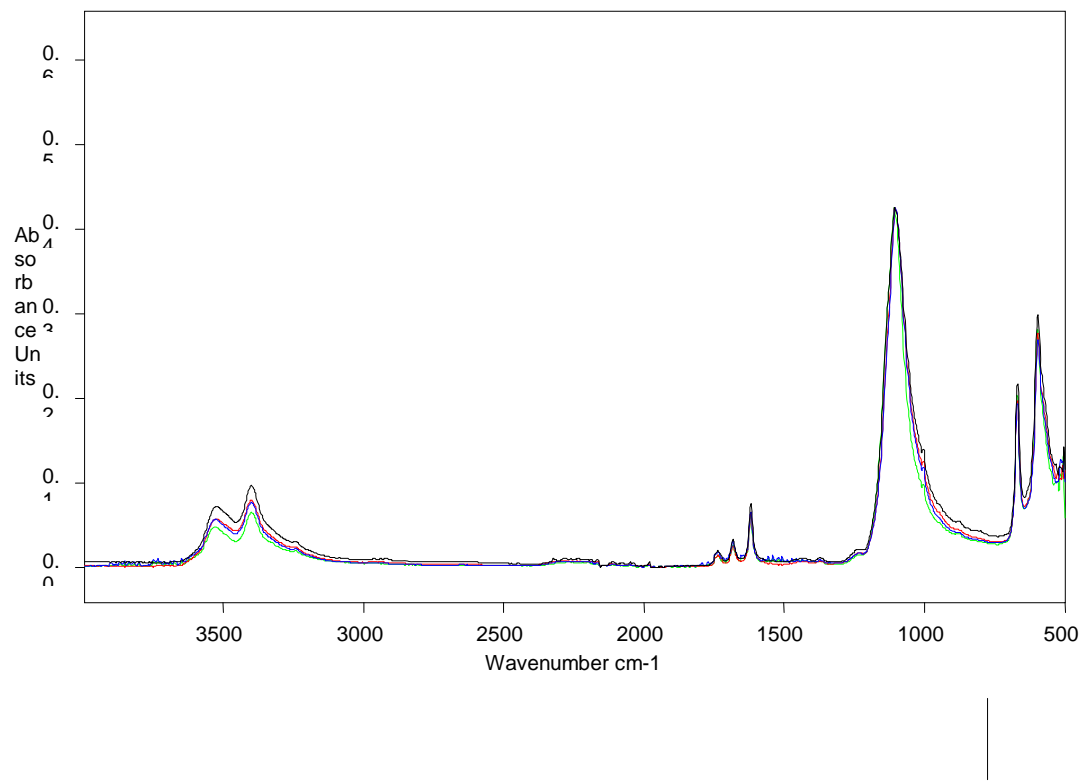

Probetas sin envejecer

Probetas sometidas a envejecimiento acelerado por HR

Sube la cantidad de agua

Probetas sometidas a envejecimiento acelerado por $\mathrm{SO}_{2}$

Probetas sometidas a envejecimiento acelerado por UV 
D3

POLYFILLA INTERIORES + ACRIL 33

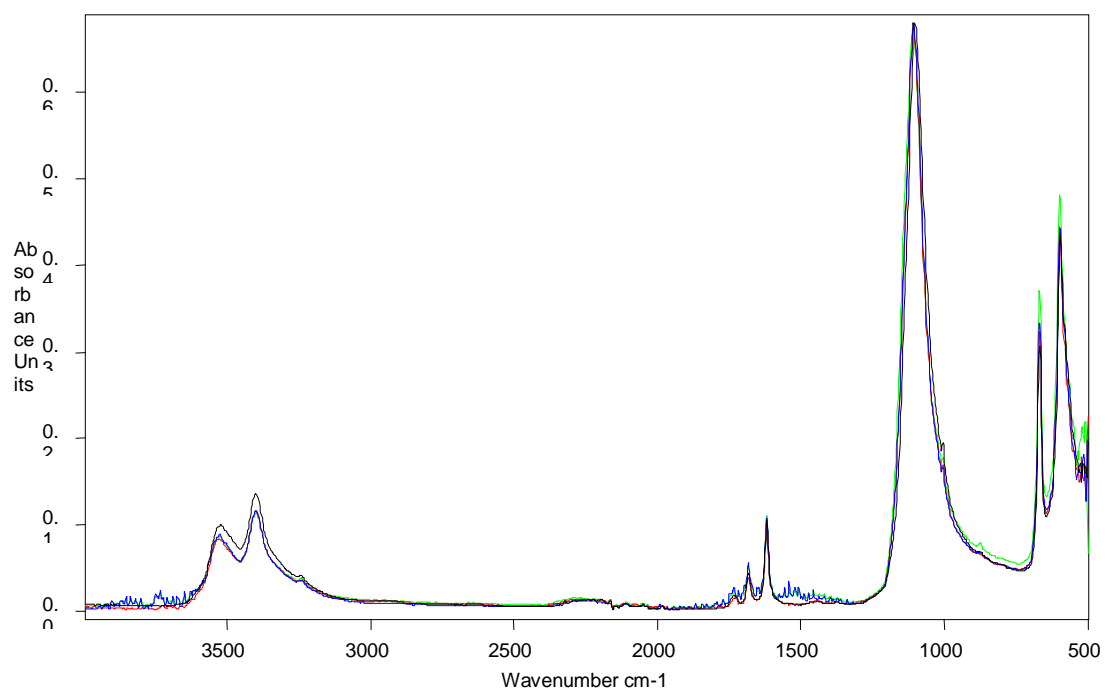

Probetas sin envejecer

\begin{tabular}{l|l} 
Probetas sometidas a envejecimiento acelerado por HR & Sube la cantidad de agua
\end{tabular}

Probetas sometidas a envejecimiento acelerado por $\mathrm{SO}_{2}$ $-$

Probetas sometidas a envejecimiento acelerado por UV 


\section{E1}

\section{RESINA EPOXÍDICA “EPO 150” + MICROESFERAS DE VIDRIO}

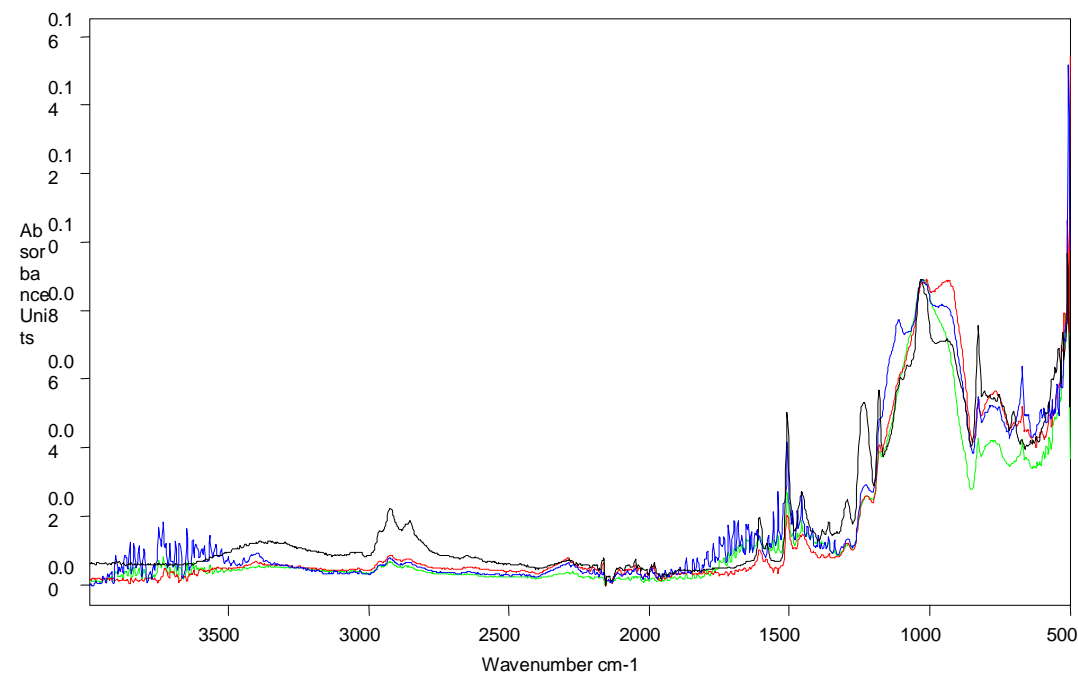

\begin{tabular}{|l|l|l|}
\hline Probetas sin envejecer & \\
\hline Probetas sometidas a envejecimiento acelerado por $\mathrm{HR}$ & Sube la cantidad de agua \\
\hline Probetas sometidas a envejecimiento acelerado por $\mathrm{SO}_{2}$ & $\begin{array}{l}\text { oxidación polímero } \\
\text { (aumentan enlaces C-O) }\end{array}$ \\
\hline Probetas sometidas a envejecimiento acelerado por UV & \\
\hline
\end{tabular}


E2

RESINA EPOXÍDICA “EPO 150” + CARBONATO DE CALCIO

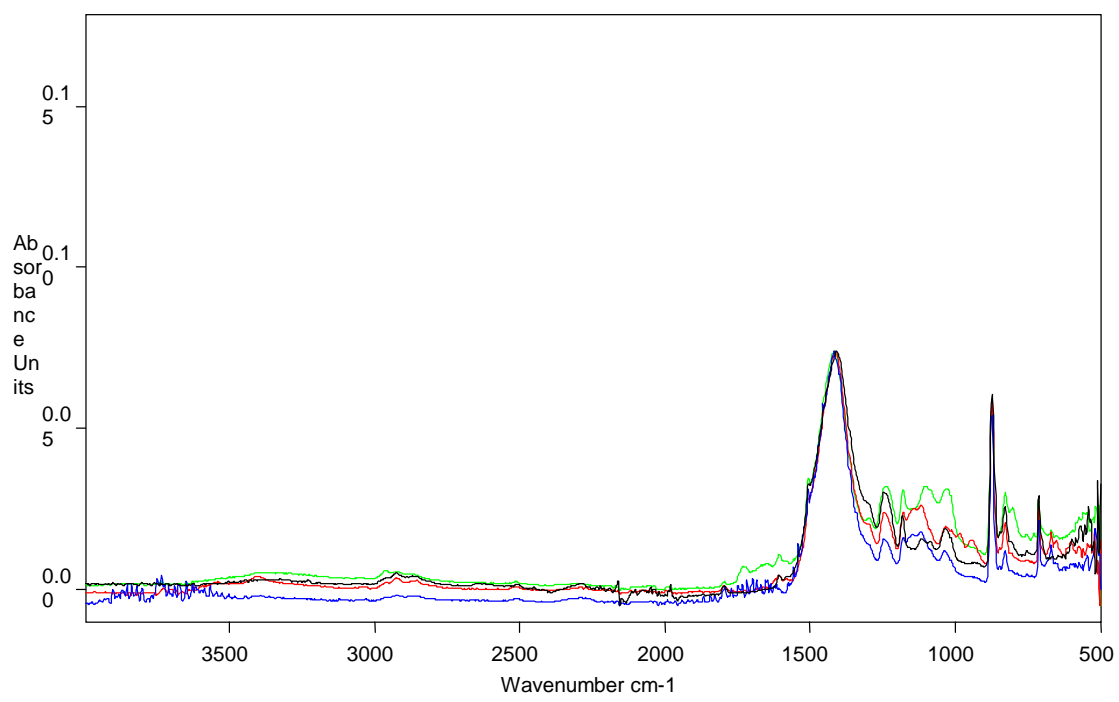

\begin{tabular}{|l|l|l|}
\hline Probetas sin envejecer & \\
\hline Probetas sometidas a envejecimiento acelerado por $\mathrm{HR}$ & Sube la cantidad de agua \\
\hline Probetas sometidas a envejecimiento acelerado por $\mathrm{SO}_{2}$ & $\begin{array}{l}\text { Sube sulfato, oxidación } \\
\text { polímero (aumentan } \\
\text { enlaces C-O) }\end{array}$ \\
\hline & Probetas sometidas a envejecimiento acelerado por UV & Oxidación polímero \\
\hline
\end{tabular}




\section{E3}

\section{RESINA EPOXÍDICA “EPO 150” + SÍLICE COLOIDAL}

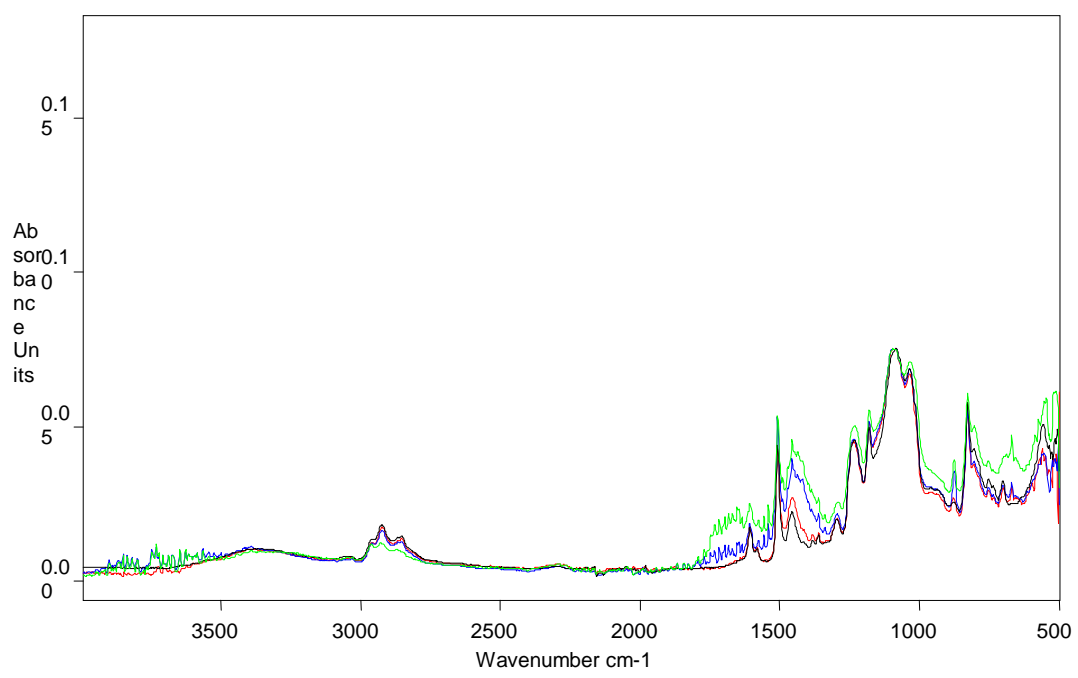

\begin{tabular}{|l|l|}
\hline Probetas sin envejecer & \\
\hline Probetas sometidas a envejecimiento acelerado por $\mathrm{HR}$ & Sube la cantidad de agua \\
\hline Probetas sometidas a envejecimiento acelerado por $\mathrm{SO}_{2}$ & \\
\hline Probetas sometidas a envejecimiento acelerado por UV & Sube la cantidad de agua \\
\hline
\end{tabular}


E4

RESINA EPOXÍDICA “EPO 127”

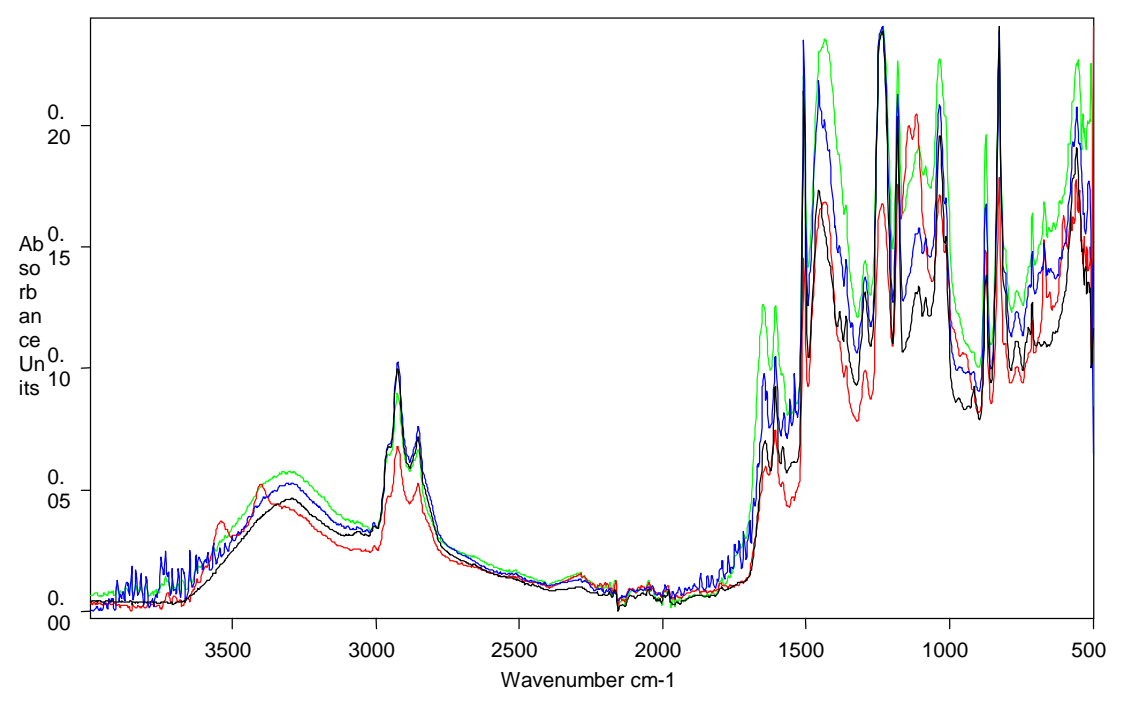

Probetas sin envejecer

\begin{tabular}{|l|l}
\hline Probetas sometidas a envejecimiento acelerado por HR & Sube la cantidad de agua
\end{tabular}

Probetas sometidas a envejecimiento acelerado por $\mathrm{SO}_{2} \quad$ Oxidación polímero

\begin{tabular}{ll|l} 
Probetas sometidas a envejecimiento acelerado por UV & Oxidación polímero
\end{tabular} 
Investigación y análisis de las masillas de relleno para la reintegración de lagunas cerámicas arqueológicas

\section{F1}

\section{LIQUITEX MODELLING PASTE}

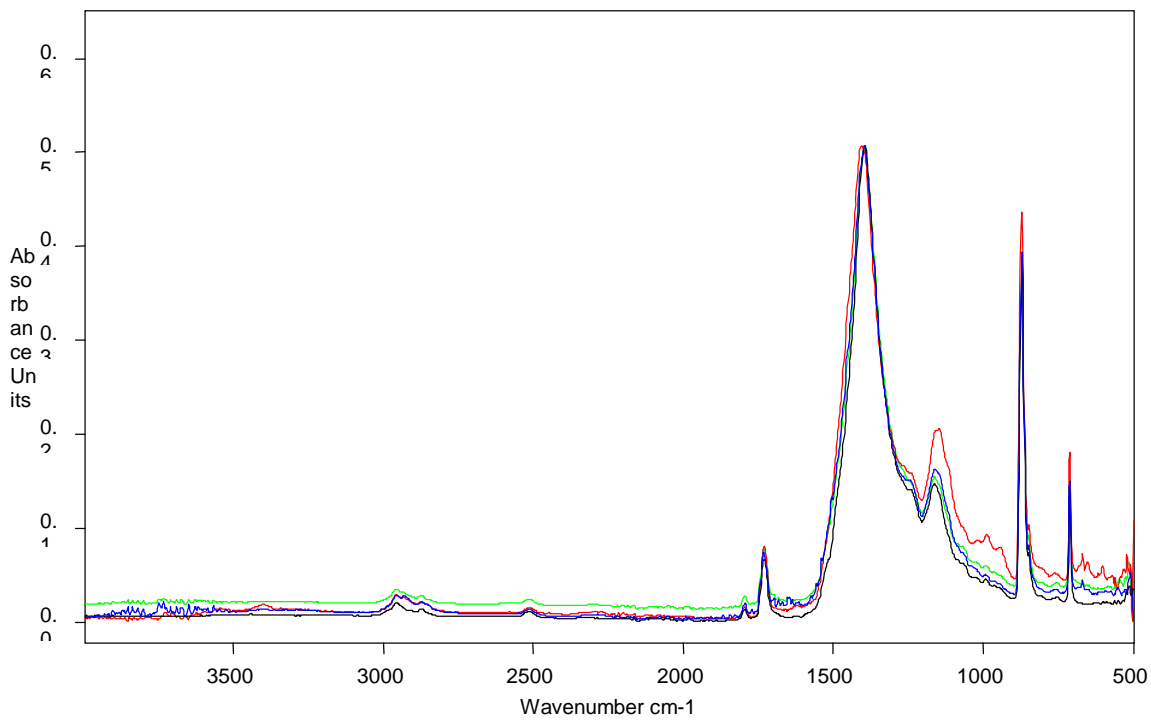

\begin{tabular}{|l|l|l|}
\hline \multicolumn{2}{|l|}{ Probetas sin envejecer } & \\
\hline & Probetas sometidas a envejecimiento acelerado por HR & \\
\hline & Probetas sometidas a envejecimiento acelerado por $\mathrm{SO}_{2}$ & Sube sulfato \\
\hline & Probetas sometidas a envejecimiento acelerado por UV & Oxidación polímero \\
\hline
\end{tabular}


F2

\section{MODOSTUC PASTA}

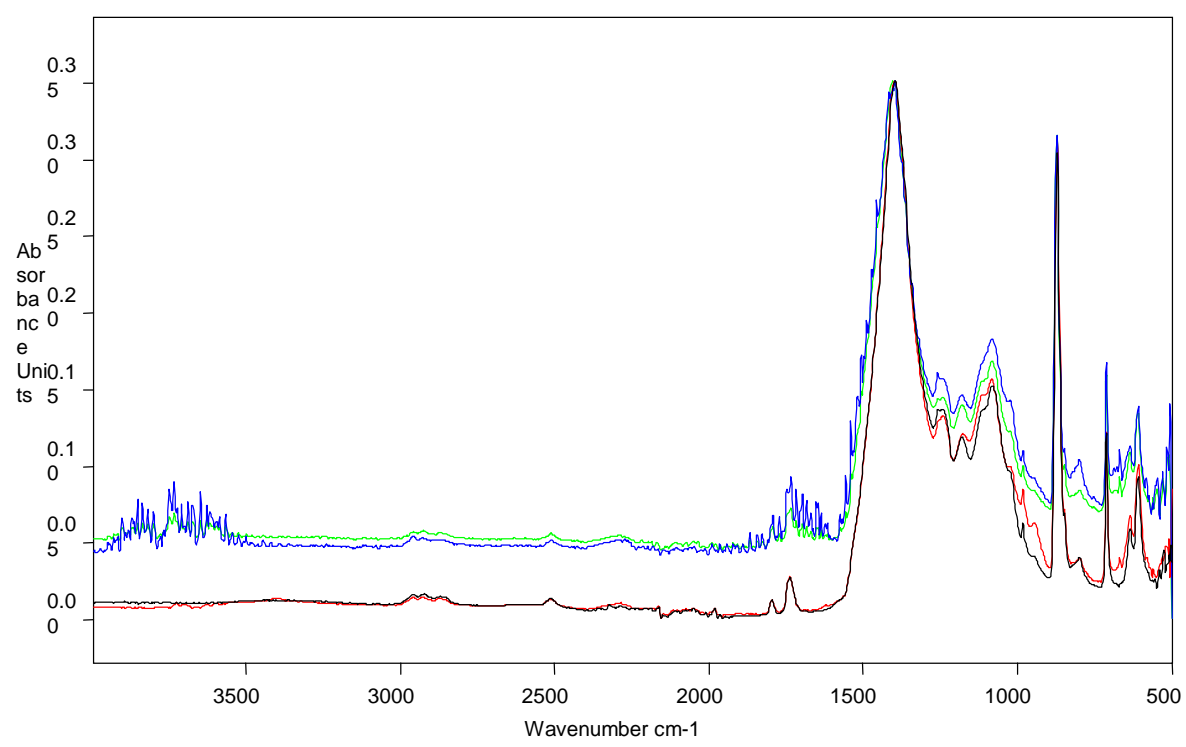

\begin{tabular}{|l|l|}
\hline Probetas sin envejecer & \\
\hline Probetas sometidas a envejecimiento acelerado por HR & Sube la cantidad de agua \\
\hline Probetas sometidas a envejecimiento acelerado por $\mathrm{SO}_{2}$ & \\
\hline Probetas sometidas a envejecimiento acelerado por UV & Sube la cantidad de agua \\
\hline
\end{tabular}


F3

MODOSTUC PASTA + LITEPLAST PASTA

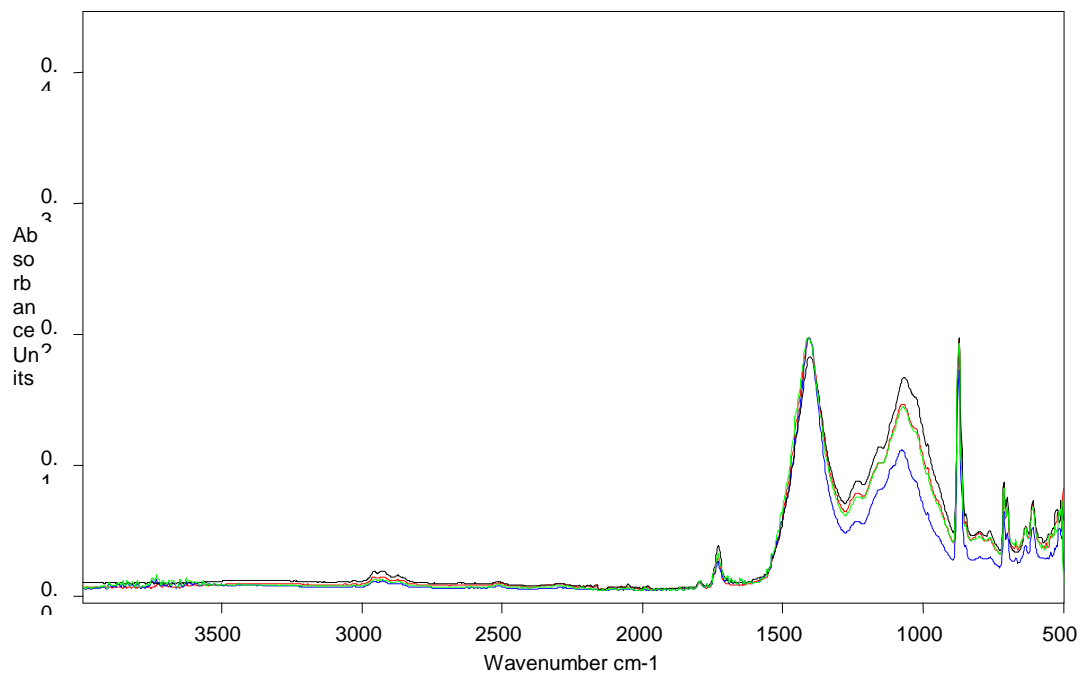

Probetas sin envejecer

Probetas sometidas a envejecimiento acelerado por HR

Probetas sometidas a envejecimiento acelerado por $\mathrm{SO}_{2}$

Probetas sometidas a envejecimiento acelerado por UV

Sube la cantidad de agua 
G

ESTUCO DE CERA I 76

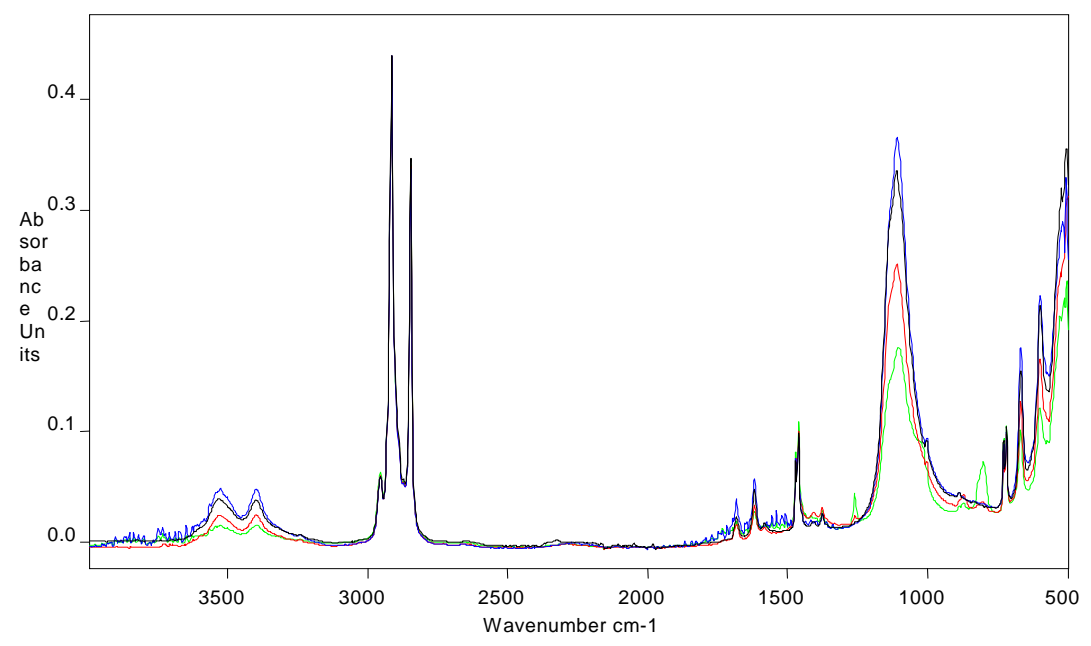

Probetas sin envejecer

Probetas sometidas a envejecimiento acelerado por HR

Sube la cantidad de agua

Probetas sometidas a envejecimiento acelerado por $\mathrm{SO}_{2}$

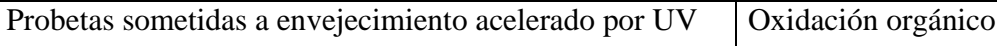


